ANDRE VINICIUS PION DE CARVALHO

PROPOSIÇÃO DE MODIFICAÇÕES NO PROCESSO UCT PARA O TRATAMENTO DE ESGOTO SANITÁRIO VISANDO À REMOÇÃO DE NITROGÊNIO E FÓSFORO

SÃO PAULO

2016 


\title{
PROPOSIÇÃO DE MODIFICAÇÕES NO PROCESSO UCT PARA O TRATAMENTO DE ESGOTO SANITÁRIO VISANDO À REMOÇÃO DE NITROGÊNIO E FÓSFORO
}

\author{
Dissertação de mestrado apresentada ao \\ Programa de Pós-Graduação em \\ Engenharia Civil da Escola Politécnica \\ da Universidade de São Paulo, em \\ cumprimento às exigências para \\ obtenção do título de Mestre em \\ Ciências.
}

Área de Concentração: Engenharia Hidráulica e Sanitária

Linha de Pesquisa: Tratamento de esgotos - Processos de remoção de nutrientes

Orientador:

Professor Roque Passos Piveli

SÃO PAULO 
Este exemplar foi revisado e corrigido em relação à versão original, sob responsabilidade única do autor e com a anuência de seu orientador.

São Paulo, de de

Assinatura do autor:

Assinatura do orientador:

Catalogação-na-publicação

CARVALHO, ANDRE VINICIUS PION

PROPOSIÇÃO DE MODIFICAÇÕES NO PROCESSO UCT PARA O

TRATAMENTO DE ESGOTO SANITÁRIO VISANDO À REMOÇÃO DE

NITROGÊNIO E FÓSFORO / A. V. P. CARVALHO -- versão corr. -- São Paulo, 2016.

$161 \mathrm{p}$.

Dissertação (Mestrado) - Escola Politécnica da Universidade de São Paulo. Departamento de Engenharia de Hidráulica e Ambiental.

1.REMOÇÃO DE NUTRIENTES 2.ESGOTOS SANITÁRIOS 3.PROCESSO

UCT I.Universidade de São Paulo. Escola Politécnica. Departamento de Engenharia de Hidráulica e Ambiental Il.t. 


\section{AGRADECIMENTOS}

Aos meus pais e familiares, pelo apoio incondicional em todos os momentos da minha vida, especialmente nos momentos de dificuldade.

Ao Prof. Dr. Roque Passos Piveli, por ter me ajudado a conduzir todos os experimentos, assim como ter me orientado em todas as etapas de aprendizado.

Aos Professores do Departamento de Hidráulica da Poli-USP que me ajudaram e apoiaram em minha vida, especialmente ao Prof. Dr. Sidney Seckler.

Aos técnicos do laboratório de saneamento Fábio e Laerte por toda a ajuda e paciência na condução dos experimentos.

Aos meus amigos, por possibilitarem tornar a minha vida acadêmica mais prazerosa. 


\section{RESUMO}

PION DE CARVALHO, A. V. Proposição de modificações no processo UCT para o tratamento de esgoto sanitário visando à remoção biológica de nitrogênio e Fósforo. 2016. 177p. Dissertação [Mestrado] - Escola Politécnica da Universidade de São Paulo, São Paulo, 2016.

Atualmente, os processos de remoção biológica de nitrogênio e fósforo tem especial importância no âmbito brasileiro e mundial. Dentre os processos existentes, o Processo UCT Modificado é um dos principais processos capazes de realizar estas atividades. Este processo tem por característica básica possuir uma câmara anaeróbia para formação de ácidos orgânicos voláteis e duas câmaras anóxicas para a etapa de desnitrificação. Com o intuito de avaliar possíveis melhorias neste processo, operou-se uma planta piloto nos moldes de um UCT modificado porém com a câmara anaeróbia chicaneada e em uma segunda etapa introduziu-se microaeração nas câmaras anóxicas. Foi mantida idade do lodo em 10 dias e relação Alimento/microrganismos (A/M) entre 0,18 e $0,40 \mathrm{~kg}$ DBO5,20/kgSSV d. De acordo com os resultados obtidos não foi possível observar gerações de AOVs (ácido orgânico voláteis) na câmara anaeróbia. Com relação à atividade de microaeração das câmaras anóxicas foram observadas melhoras no processo de remoção biológica de nitrogênio se compara à operação sem microaeração. Em termos de remoção de matéria orgânica os resultados mostraram eficiências semelhantes a outros autores que desenvolveram sistemas semelhantes ao aqui estudado.

Palavras-chave: Ácidos orgânicos voláteis, Chicanas, Fósforo, Microaeração, Nitrogênio. 


\begin{abstract}
PION DE CARVALHO, A. V. Proposal of modifications in a modified UCT process to evaluate nitrogen and phosphorus removal efficiency. 2016. 177p. Dissertação [Mestrado] Escola Politécnica da Universidade de São Paulo, São Paulo, 2016.

Now a days, nitrogen and phosphorus removal processes have been having a particular importance to Brazil and all the World. Considering the existing processes, Modified UCT is one of the main technologies capable of achieving this taks. This process has the characteristic of having one anaerobic tank aimed at producing volatile fatty acids (VFAs) and two anoxic tanks for denitrification. This paper tried to evaluate possible improvements in this process, operated a pilot plant with a compartmented anaerobic tank and later introduced microaeration to the anoxic tanks. Slugde age was maintained in 10 days and food/microorganisms rate (F/M) was maintained between 0,18 and $0,40 \mathrm{~kg} \mathrm{BOD} / \mathrm{kg}$ VSS d. According to the results, there was no clue of VFAs formation in the anaerobic tank. After the introduction of microaeration to the anoxic tanks it was shown an improvement in nitrogen removal. In terms of organic removal rates the plant had similar efficiency to other authors metioned in this paper.
\end{abstract}

Keywords: Volatile Fatty Acids, chicanes, phosphorus, Microaeration, Nitrogen. 


\section{SUMÁRIO}

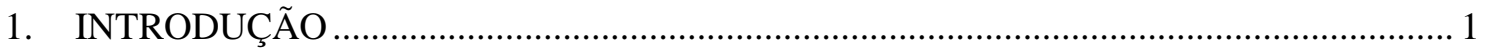

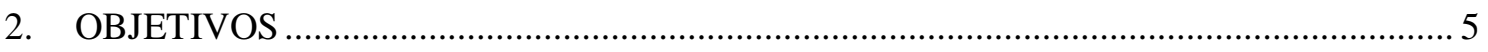

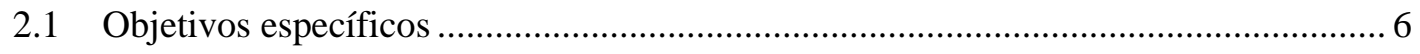

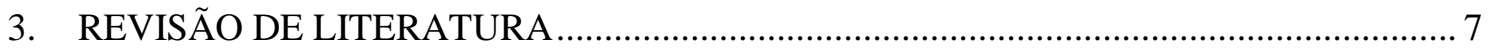

3.1 Sistema de tratamento de esgotos por Lodos Ativados................................................. 7

3.1.1 Matéria Orgânica e suas reações ............................................................................ 7

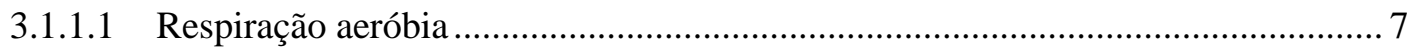

3.1.1.2 Respiração e digestão anaeróbia …………….................................................... 9

3.1.1.3 Matéria Orgânica nas águas residuárias ................................................................... 11

3.1.1.4 Balanço de massa de matéria orgânica ................................................................... 13

3.1.2 Definições e conceitos básicos para um modelo de lodos ativados ......................... 14

3.1.3 Modelo cinético de um sistema de lodos ativados para remoção de matéria orgânica 18

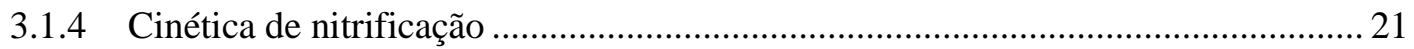

3.1.4.1 Influência da temperatura no processo de nitrificação.......................................... 26

3.1.4.2 Influência do pH e alcalinidade no processo de nitrificação................................. 26

3.1.4.3 Potencial e capacidade de nitrificação .................................................................... 27

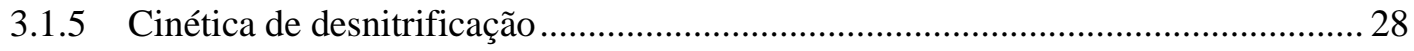

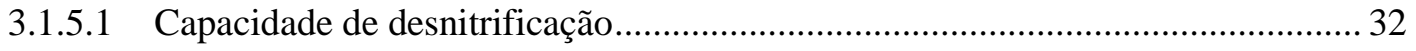

3.1.5.2 Efeito da desnitrificação na demanda de oxigênio.................................................. 33

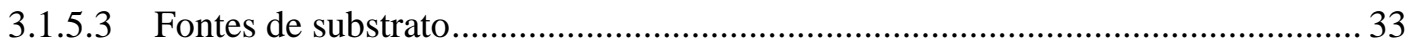

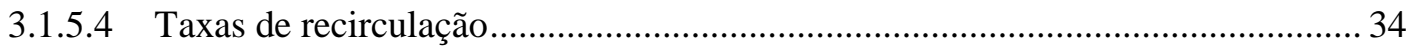

3.1.5.5 Velocidade de desnitrificação ………………................................................... 35

3.1.5.6 Fatores que influenciam a desnitrificação............................................................. 36

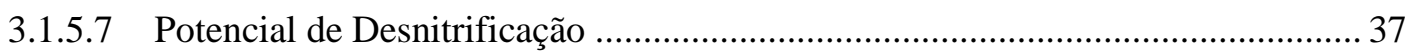

3.2 Remoção biológica de fósforo e processo de tratamento UCT modificado................ 37

3.2.1 Princípio de funcionamento de um processo com remoção biológica de fósforo... 39

3.2.2 Características da zona anaeróbia para remoção de fósforo ................................... 40

3.2.3 Características das zonas anóxicas/aeróbias quando associados a remoção biológica

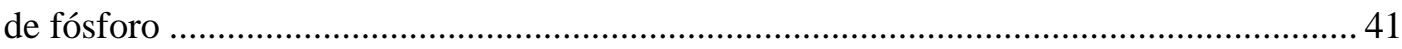

3.2.3.1 Organismos acumuladores de fósforo X Organismos acumuladores de Glicogênio 42 
3.2.4.1 Cinética de transformação de DQO rapidamente biodegradável em AOV (baseado em ALEM SOBRINHO, 1991).

3.2.4.2 Teoria da conversão - Baseado em WENTZEL et al (1990) apud ALEM SOBRINHO (1991).

3.2.4.3 Efeito da fermentação ácida no procedimento de dimensionamento para operação em condição permanente e uniforme (baseado em ALEM SOBRINHO, 1991).................... 51

3.2.4.4 Cálculo da DQO prontamente biodegradável não convertida a AOV .................. 52

3.2.5 Vantagens e desvantagens de emprego de um sistema com remoção biológica de

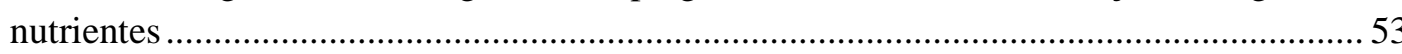

3.2.6 Problemas operacionais de sistemas com remoção biológica de nutrientes ............ 57

3.2.6 Características do lodo gerado por um sistema com remoção biológica de fósforo57

3.2.7 Efeitos da recirculação de nitrato na eficiência de remoção de fósforo.................... 58

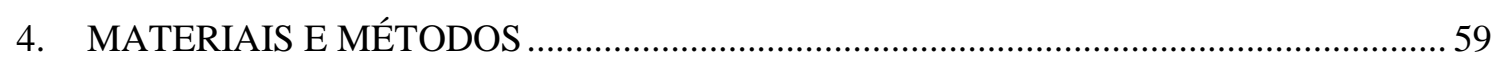

4.1 Localização da planta piloto e condições locais do experimento ............................... 61

4.2 Modelagem dos experimentos de operação da Planta UCT Modificado ..................... 66

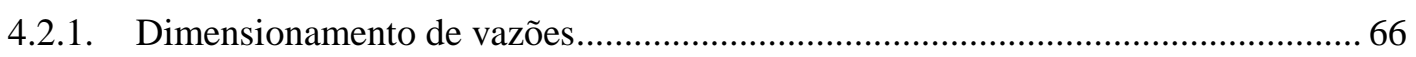

4.2.2. Dimensionamento de Cargas e Parâmetros do processo biológico...........................67 67

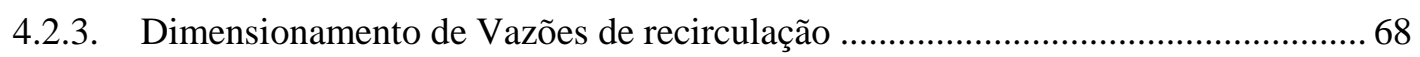

4.3 Metodologia para colocação em operação da planta .................................................. 68

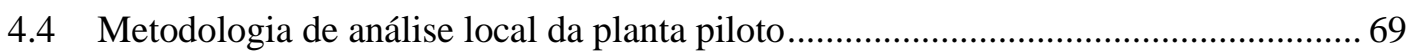

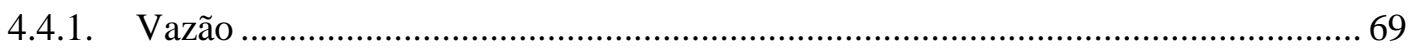

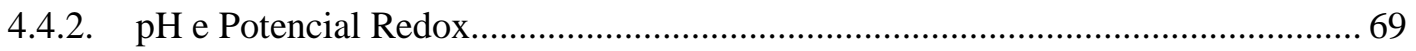

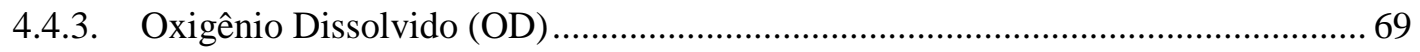

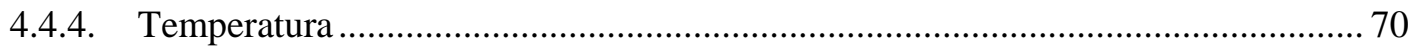

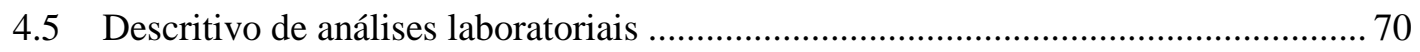

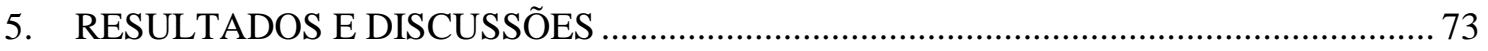

5.1 Vazões e Resultados esperados para um sistema UCT ............................................... 73

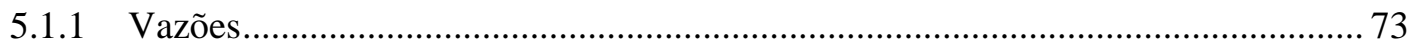

5.1.2 Resultados esperados para um Sistema UCT Modificado ……............................... 80

5.2 Dados de Controle local na planta piloto (pH, Potencial Redox e Oxigênio

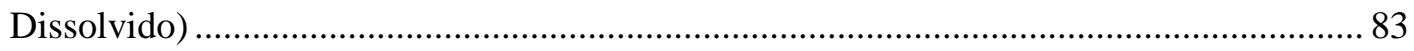

5.3 Resultados para Matéria Orgânica ............................................................................. 97

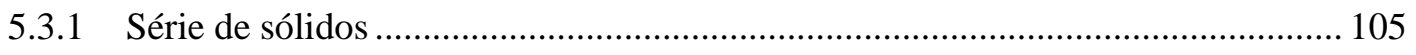

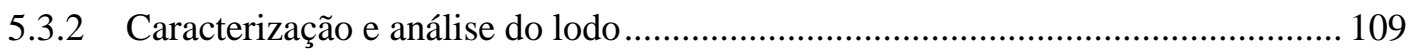

5.3.2.1 Razão entre a concentração de fósforo liberado no meio líquido por DQO capturada por organismos PAO. 
5.3.2.2 Relação entre as taxas de consumo de oxigênio 110

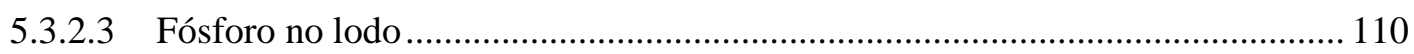

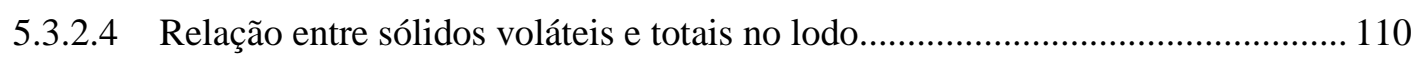

5.3.2.5 Relação entre fósforo liberado e concentração de sólidos no reator anaeróbio . 111

5.3.2.6 Análise dos resultados obtidos para o lodo...................................................... 111

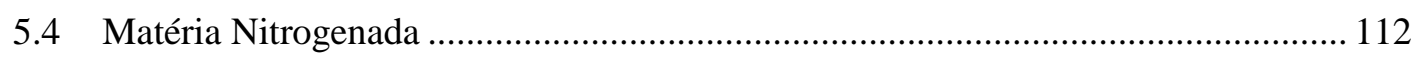

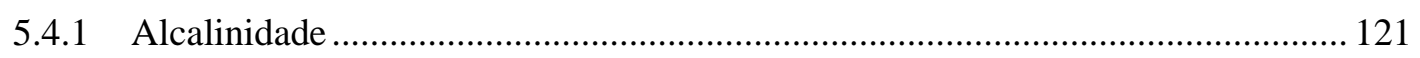

5.4.2 Análise de desempenho do processo de Nitrificação e Desnitrificação.................. 127

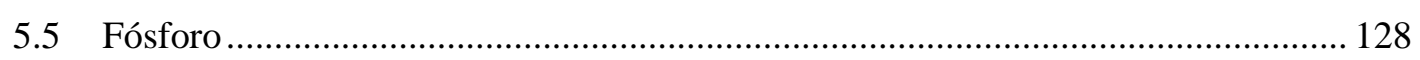

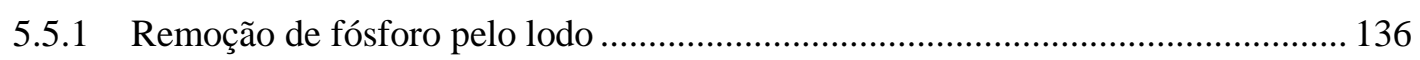

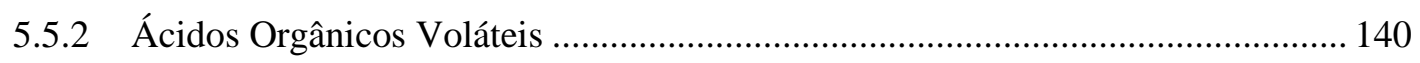

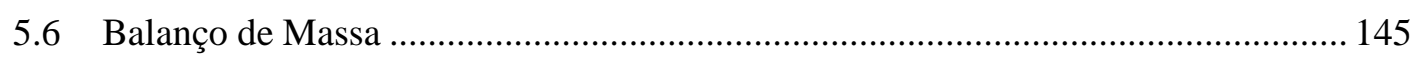

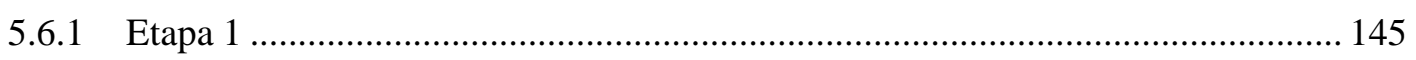

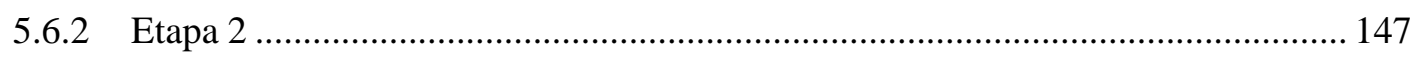

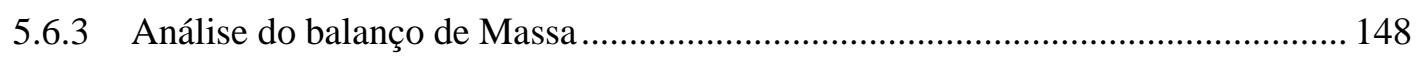

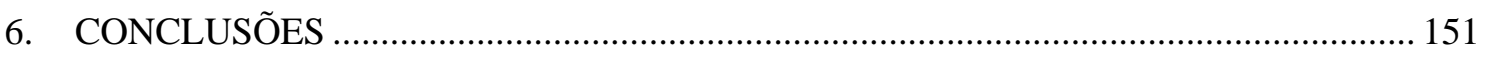

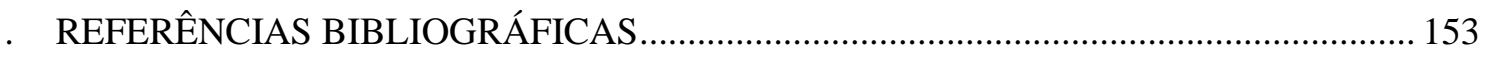

. APÊNDICE 1 - DADOS DAS MEDIÇÕES EM CAMPO E ANÁLISES FÍSICO-

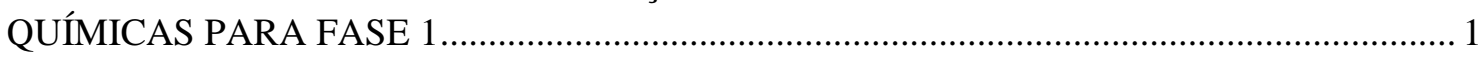

. APÊNDICE 2 - DADOS DAS MEDIÇÕES EM CAMPO E ANÁLISES FÍSICO-

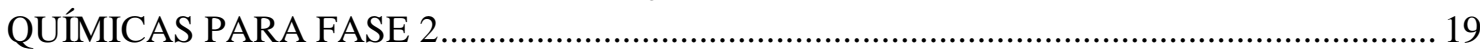




\section{LISTA DE TABELAS}

Tabela 1 - Siglas e nomes das componentes da matéria orgânica.............................................. 11

Tabela 2 - Faixas operacional de sistemas de lodos ativados por aeração prolongada ............... 17

Tabela 3 - Siglas do modelo cinético de nitrificação .............................................................. 22

Tabela 4 - Valores da dependência da temperatura da taxa específica máxima de crescimento de

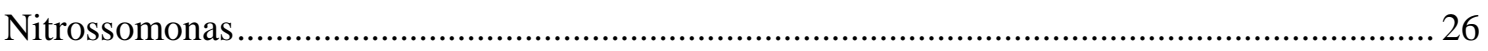

Tabela 5 - Vantangens e desvantagens dos diferentes tipos de sistemas com remoção biológica

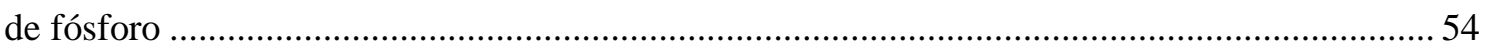

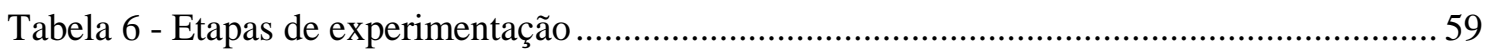

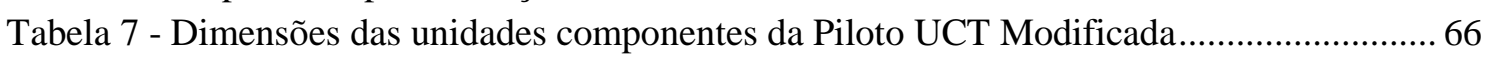

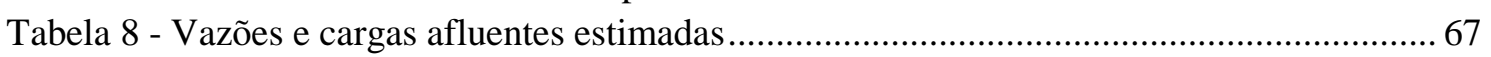

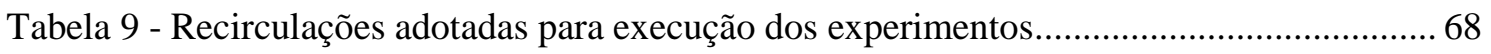

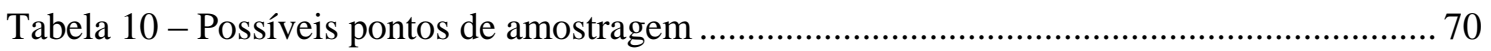

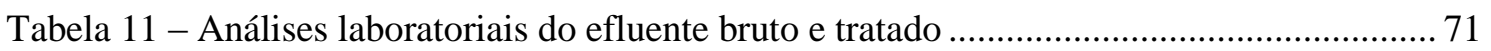

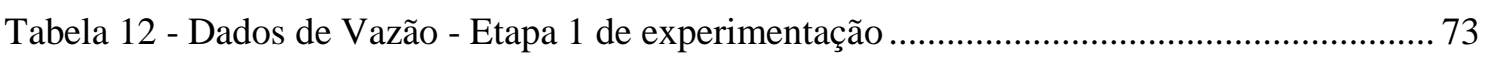

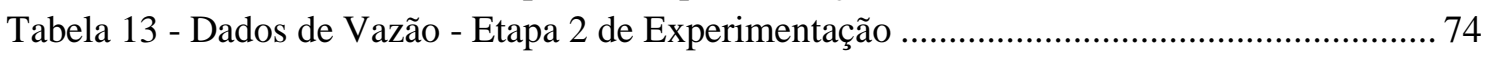

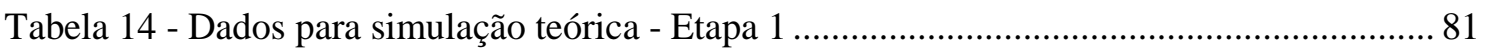

Tabela 15 - Dados para simulação teórica - Etapa 1 .................................................................... 82

Tabela 16 - Estatística Descritiva para os dados de controle local da planta piloto - Etapa 1.... 84

Tabela 17 - Estatística Descritiva dos dados locais de controle da planta piloto - Etapa 2......... 84

Tabela 18 - Estatística Descritiva dos Resultados das Análises Físico-Químicas para DQO -

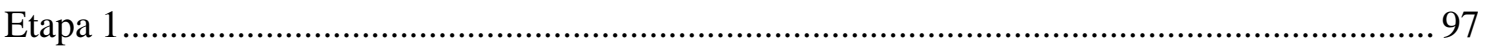

Tabela 19 - Estatística Descritiva dos Resultados das Análises Físico-Químicas para $\mathrm{DBO}_{5,20}$ -

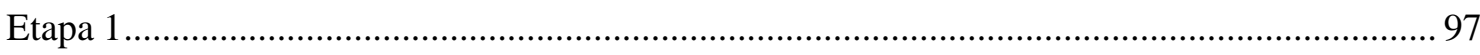

Tabela 20 - Estatística Descritiva dos Resultados das Análises Físico-Químicas para o

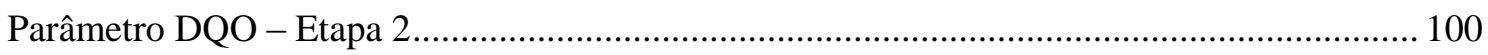

Tabela 21 - Estatística Descritiva dos Resultados das Análises Físico-Químicas para o

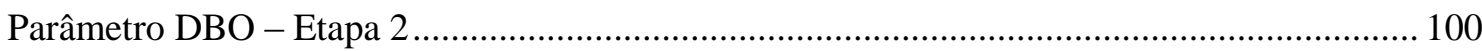

Tabela 22 - Estatística Descritiva dos Resultados das Análises Físico-Químicas para o

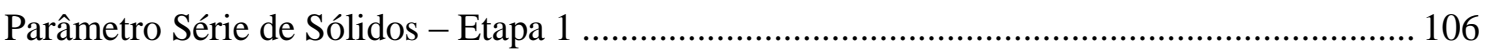

Tabela 23 - Resultados das Análises Físico-Químicas para o Parâmetro Série de Sólidos - Etapa

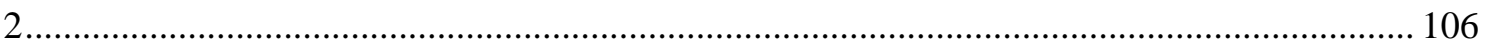

Tabela 24 - Estatística Descritiva dos Resultados das Análises Físico-Químicas para NTK -

Etapa 1.

Tabela 25 - Estatística Descritiva dos Resultados das Análises Físico-Químicas para o parâmetro NTK - Etapa 2

Tabela 26 - Estatística Descritiva dos Resultados das Análises Físico-Químicas para Nitrogênio

Amoniacal - Etapa 1

Tabela 27 - Estatística Descritiva dos Resultados das Análises Físico-Químicas para o

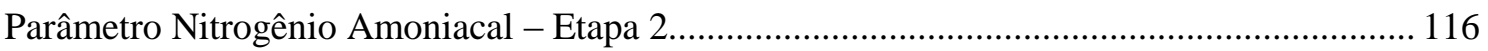

Tabela 28 - Resultados da estatística descritiva para o parâmetro Nitrato - Etapa 1 ................. 119

Tabela 29 - Resultados da estatística descritiva para o parâmetro Nitrato - Etapa 2 ................. 119

Tabela 30 - - Coeficiente de Recuperação de matéria nitrogenada (Bn) para as duas fases de

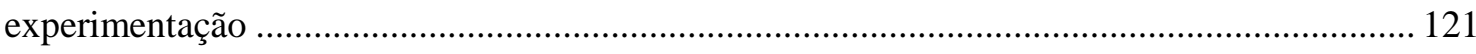

Tabela 31 - Estatística Descritiva dos Resultados das Análises Físico-Químicas para o

Parâmetro Alcalinidade - Etapa 1 . 
Tabela 32 - Resultados das Análises Físico-Químicas para o Parâmetro Alcalinidade - Etapa 2

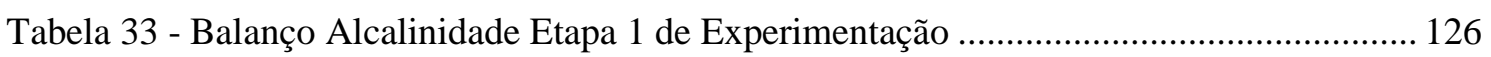

Tabela 34 - Balanço de Alcalinidade Etapa 2 de Experimentação............................................. 126

Tabela 35 - Estatística Descritiva dos Resultados das Análises Físico-Químicas para o

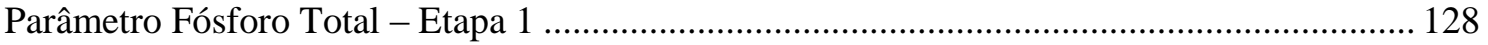

Tabela 36 - Estatística Descritiva dos Resultados das Análises Físico-Químicas para o

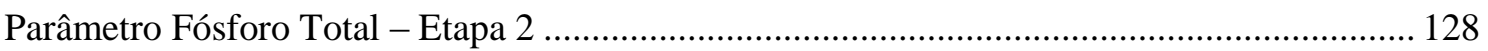

Tabela 37 - Estatística Descritiva dos Resultados das Análises Físico-Químicas para o parâmetro Fósforo solúvel - Etapa 1 .................................................................................... 130

Tabela 38 - Estatística Descritiva dos Resultados das Análises Físico-Químicas para o parâmetro Fósforo Solúvel - Etapa 2

Tabela 39 - índice Volumétrico de Lodo planta UCT Modificado para a fase 1 de

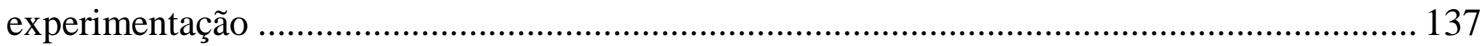

Tabela 40 - Resultados de IVL para a fase 2 de experimentação............................................ 137

Tabela 41 - Estatística Básica descritiva para IVL para a fase 1 de experimentação................. 138

Tabela 42 - Estatística Básica Descritiva para a fase 2 de experimentação ............................... 138

Tabela 43 - Estatística Descritiva dos Resultados das Análises Físico-Químicas para o

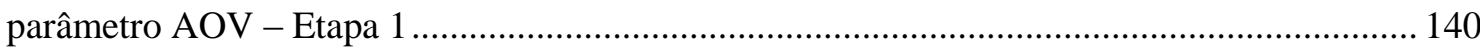

Tabela 44 - Estatística Descritiva dos Resultados para as Análises Físico-Químicas para o

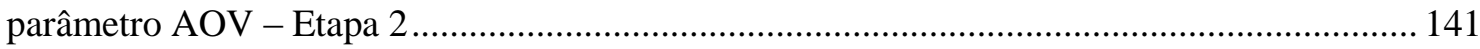

Tabela 45 - Cargas aplicadas nos Reatores para as Etapas de Experimentação......................... 149 


\section{LISTA DE FIGURAS}

Figura 1 - Representação esquemática dos processos metabólicos num ambiente aeróbio ........... 8

Figura 2 - Relações estequiométricas entre oxigênio, nitrato e sulfato ....................................... 9

Figura 3 - Produção de lodo pelo metabolismo aeróbio (esquerda) e anaeróbio (direita) .......... 10

Figura 4 - Frações de matéria orgânica em sistemas aeróbios (esquerda) e anaeróbios (direita) 10

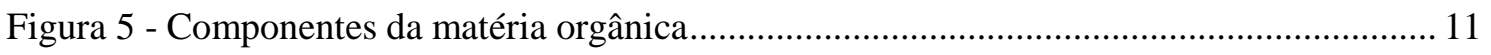

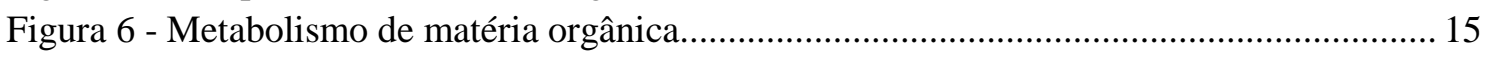

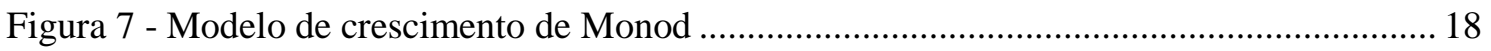

Figura 8 - Esquema de um sistema de lodos ativados e seus pontos de descarte de lodo ............ 19

Figura 9 - Modelo de Monod aplicado a nitrificação ............................................................... 24

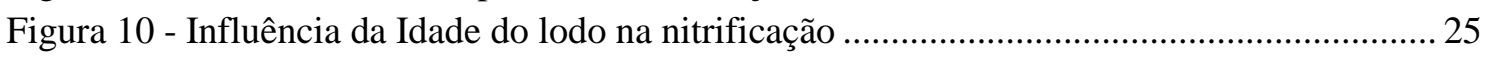

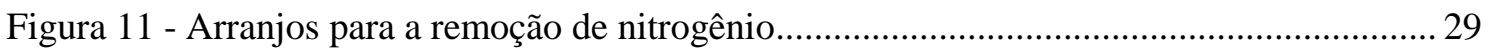

Figura 12 - Relação capacidade de nitrificação x idade do lodo x NTK/DQO ............................ 32

Figura 13 - Relação fração não aerada do lodo x Idade do lodo .................................................. 33

Figura 14 - Configurações possíveis de sistemas com remoção biológica de nitrogênio ............ 34

Figura 15 - Taxa de desnitrificação em reatores pre-D (esquerda) e pós-D (direita) ................... 35

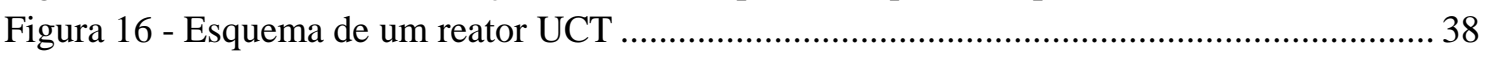

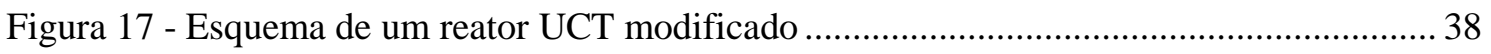

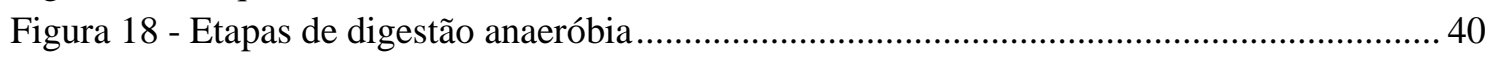

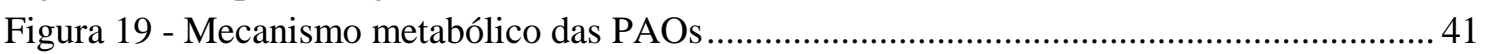

Figura 20 - Mecanismo metabólico de mecanismos acumuladores de fósforo e desnitrificadores

Figura 21 - Métodos de remoção conjunta de nitrogênio e fósforo ............................................. 56

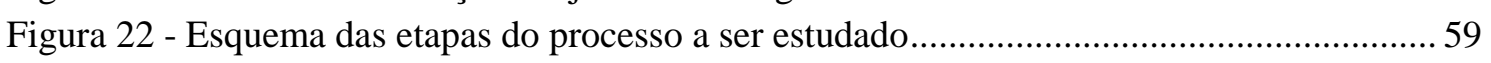

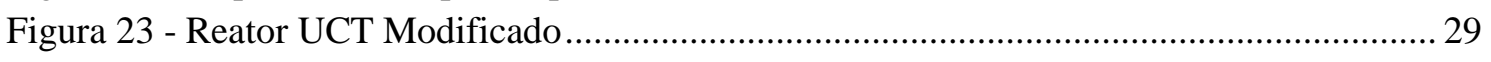

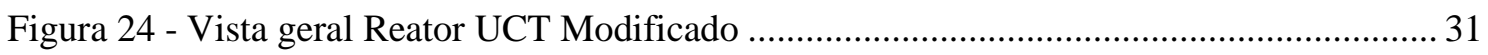

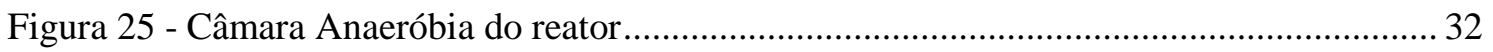

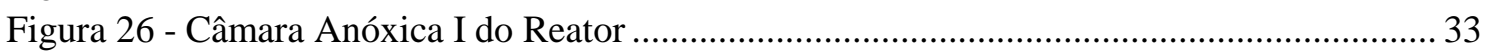

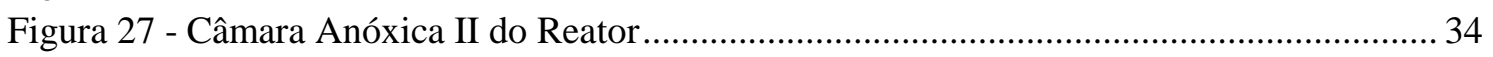

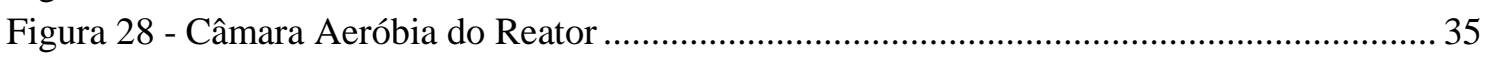

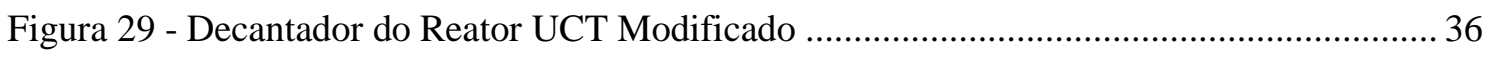

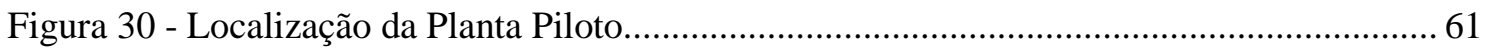

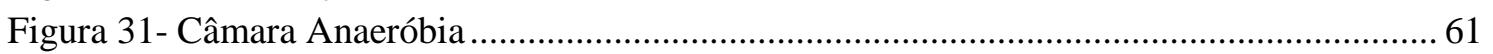

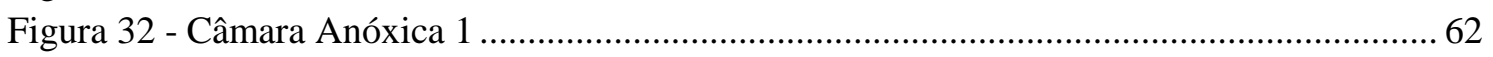

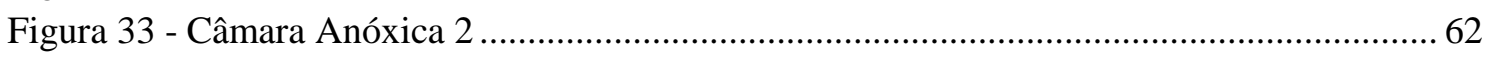

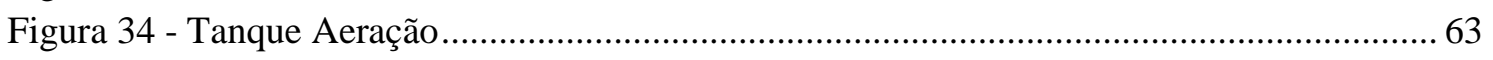

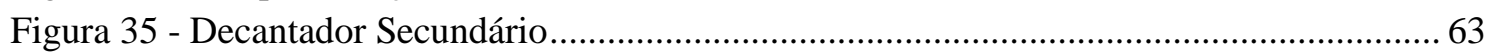

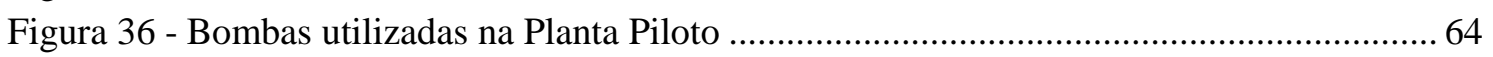

Figura 37 - Equipamentos elétricos de comando da planta piloto..................................................64 64

Figura 38 - Esquema de encaminhamento do esgoto até alimentação da planta piloto ............... 65

Figura 39 - Gráfico da Série Histórica para vazão de alimentação da Planta Piloto ..................... 74

Figura 40 - Gráfico X-Barra para a Vazão de Alimentação da planta piloto ................................. 75

Figura 41 - Gráfico da Série Histórica para o parâmetro Vazão de Retorno de Lodo .................. 76

Figura 42 - Gráfico X-Barra para o parâmetro Vazão de retorno de lodo ..................................... 76

Figura 43 - Gráfico da Série Histórica para o parâmetro Vazão de Recirculação 1..................... 77

Figura 44 - Gráfico X-Barra para o parâmetro Vazão de Reciclo 1 .............................................. 78

Figura 45 - Gráfico da Série Histórica para o parâmetro Vazão de Reciclo 2 .............................. 79 
Figura 46 - Gráfico X-Barra para o parâmetro Vazão de recirculação 2 ……………………...... 79

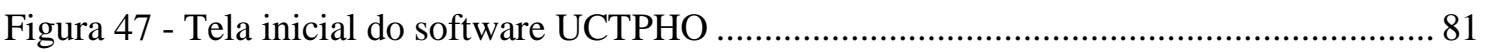

Figura 48 - Tela do software com as constantes heterotróficas utilizadas na modelagem ........... 37

Figura 49 - Tela do Software com as constantes autotróficas utilizadas na modelagem ............. 37

Figura 50 - Tela do Software com as constantes para organismos poli-p utilizadas na

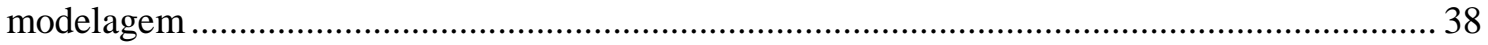

Figura 51 - Tela do software com premissas para nitrogênio e fósforo utilizadas ........................ 38

Figura 52 - Constantes de Arrhenius Utilizadas na modelagem .............................................. 39

Figura 53 - Constantes estequiométricas para microrganismos heterotróficos utilizados na

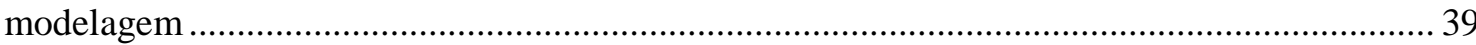

Figura 54 - Parâmetros estequiométricos para microrganismos autotróficos utilizados na modelagem.... 39

Figura 55 - Constantes estequiométricas para organismos poli-p utilizadas na modelagem

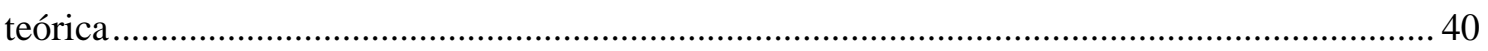

Figura 56 - Resultados teóricos para a Etapa 1 de experimentação ………................................. 40

Figura 57 - Resultados teóricos para a fase 2 de experimentação .............................................. 41

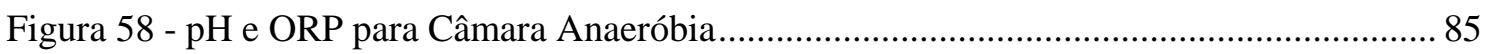

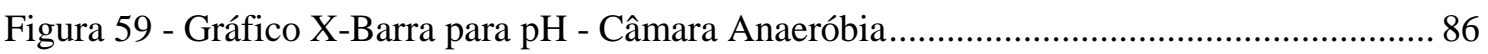

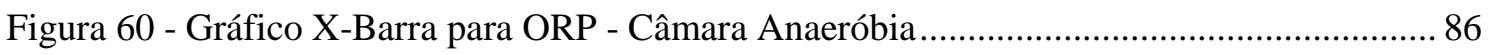

Figura 61 - Gráfico de série histórica para pH e ORP para Câmara Anóxica 1 ........................... 88

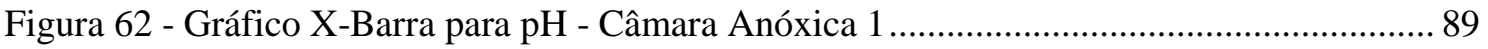

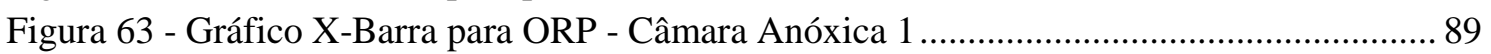

Figura 64 - Gráfico da série histórica para pH e ORP para Câmara Anóxica 2 ........................... 91

Figura 65 - Gráfico X-Barra para pH - Câmara Anóxica 2 ……………………........................ 91

Figura 66 - Gráfico X-Barra para ORP - Câmara Anóxica 2 .................................................. 92

Figura 67 - Gráfico de série histórica para pH, ORP e OD para o Tanque de Aeração ............... 93

Figura 68 - Gráfico X-Barra para o parâmetro pH - Tanque de Aeração...................................... 94

Figura 69 - Gráfico X-Barra para o parâmetro ORP - Tanque de Aeração.................................... 94

Figura 70 - Gráfico X-Barra para o parâmetro OD - Tanque de Aeração..................................... 95

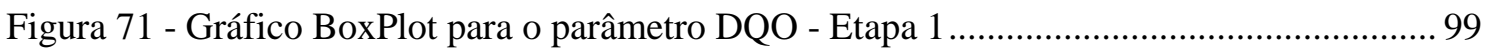

Figura 72 - Gráfico Boxplot para o parâmetro $\mathrm{DBO}_{5,20}$ - Etapa 1 …............................................. 99

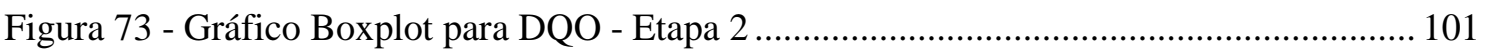

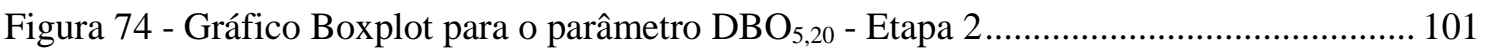

Figura 75 - Gráfico da série histórica para o parâmetro DQO ................................................... 102

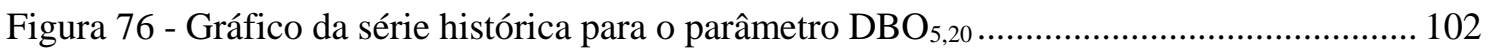

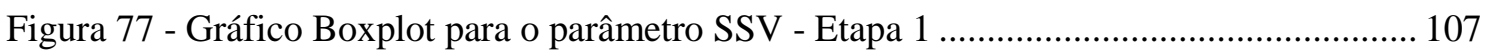

Figura 78 - Gráfico Boxplot para o parâmetro SSV - Etapa 2 .................................................. 107

Figura 79 - Gráfico da série histórica para SSV na entrada e saída da planta UCT Modificada

Figura 80 - Gráfico da série histórica para SSV no tanque de aeração e lodo ........................... 108

Figura 81 - Gráfico Boxplot para o parâmetro NTK - Etapa 1 ............................................................ 113

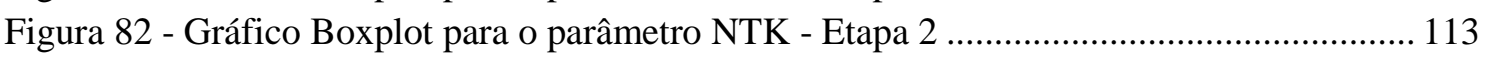

Figura 83 - Gráfico da série histórica para o parâmetro NTK................................................... 114

Figura 84 - Gráfico Boxplot para o parâmetro Nitrogênio Amoniacal - Etapa 1 ........................ 116

Figura 85 - Gráfico Boxplot para o parâmetro Nitrogênio Amoniacal - Etapa 2 ....................... 117

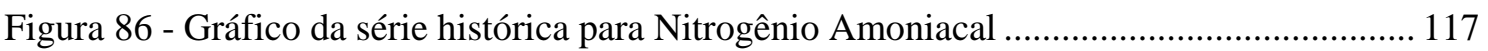

Figura 87 - Gráfico Boxplot para o parâmetro Alcalinidade - Etapa 1 ...................................... 123

Figura 88 - Gráfico Boxplot para o parâmetro Alcalinidade - Etapa 2 ……............................. 123 
Figura 89 - Gráfico da série histórica para alcalinidade.

Figura 90 - Gráfico Boxplot para o parâmetro Fósforo Total - Etapa 1 .................................... 129

Figura 91 - Gráfico Boxplot para o parâmetro Fósforo total - Etapa 2 ……….......................... 129

Figura 92 - Gráfico Boxplot para o parâmetro Fósforo Solúvel - Etapa 1 ................................. 131

Figura 93 - Gráfico Boxplot para o parâmetro Fósforo Solúvel - Etapa 2 ………..................... 131

Figura 94 - Gráfico da série histórica para o parâmetro fósforo total ....................................... 132

Figura 95 - Gráfico da série histórica para o parâmetro fósforo solúvel.................................... 132

Figura 96 - Gráfico Boxplot para o parâmetro AOV - Etapa 1 ……………............................. 141

Figura 97 - Gráfico Boxplot para o parâmetro AOV - Etapa 2 ................................................ 142

Figura 98 - Gráfico da série histórica para o parâmetro AOV ................................................. 142

Figura 99 - Balanço de Massa para a Etapa 1 de experimentação ............................................... 146

Figura 100 - Balanço de Massa para a Etapa 2 de experimentação ............................................ 147 


\section{LISTA DE ABREVIATURAS, SIGLAS E SÍMBOLOS}

$\mu_{\mathrm{m}}$ : Taxa específica de crescimento $\left(\mathrm{d}^{-1}\right)$

$\mu_{\text {máx: }}$ Taxa específica máxima de crescimento $\left(\mathrm{d}^{-1}\right)$

$\mu_{\mathrm{mT}}$ : Taxa de crescimento máximo das bactérias a uma temperatura $\mathrm{T}\left(\mathrm{d}^{-1}\right)$

A/M: Relação alimento microrganismo (kg DBO. $\left.\operatorname{kg~SSVTA}^{-1} \cdot \mathrm{d}^{-1}\right)$

AOV: Ácido orgânico volátil

AT: Amplitude total

$\mathrm{b}_{\mathrm{h}}$ : Decaimento de bactérias heterotróficas $\left(\mathrm{d}^{-1}\right)$

$\mathrm{b}_{\mathrm{n}}$ : Constante de decaimento para as bactérias autotróficas nitrificantes $\left(\mathrm{d}^{-1}\right)$

$\mathrm{B}_{\mathrm{n}}$ : Balanço de massa de material nitrogenado

$\mathrm{B}_{\mathrm{o}}$ : Balanço de massa de material orgânico

Cr: Massa de lodo ativo presente no sistema por unidade de DQO

CRUSP: Conjunto residencial da Universidade de São Paulo

CTH: Centro Tecnológico de Hidráulica - Escola Politécnica da Universidade de São Paulo

CV: Coeficiente de variação

DBO: Demanda Bioquímica de Oxigênio (mg. $\left.\mathrm{L}^{-1}\right)$

DPAO: Organismos assimiladores de fósforo capazes de realizar desnitrificação

$\mathrm{D}_{\text {ec: }}$ : Decantador

$\mathrm{D}_{\mathrm{p}}$ : Capacidade de desnitrificação com material orgânico particulado $\left(\mathrm{mgN} \cdot \mathrm{d}^{-1}\right)$

DP: Desvio Padrão

DBO: Demanda Bioquímica de Oxigênio (mg. $\left.\mathrm{L}^{-1}\right)$

DQO: Demanda Química de Oxigênio (mg.L $\left.\mathrm{L}^{-1}\right)$

$\mathrm{D}_{\mathrm{s}}$ : Capacidade de desnitrificação com material orgânico solúvel $\left(\mathrm{mgN} \cdot \mathrm{d}^{-1}\right)$

$\mathrm{D}_{\mathrm{t}}$ : Capacidade de desnitrificação total de um sistema de lodo ativado

$\mathrm{dX}_{\mathrm{n}} / \mathrm{dtc}$ : Taxa de crescimento das bactérias nitrificantes (mgSSV.L $\left.\mathrm{L}^{-1} \cdot \mathrm{d}^{-1}\right)$

$\mathrm{dX}_{\mathrm{n}} / \mathrm{dtd}$ : Taxa de decaimento das bactérias nitrificantes $\left(\mathrm{mgSSV} \cdot \mathrm{L}^{-1} \cdot \mathrm{d}^{-1}\right)$

$\mathrm{dX}_{\mathrm{n}} / \mathrm{dte}$ : Taxa de descarga de lodo de excesso $\left(\mathrm{mgSSV} \cdot \mathrm{L}^{-1} \cdot \mathrm{d}^{-1}\right)$

Efluente: Esgoto efluente após tratamento no sistema de lodo ativado

ETE: Estação de tratamento de esgoto

f aeróbia: Fração aeróbia dos sistemas de lodo ativado operados

f: Fração de lodo orgânico decaído como resíduo endógeno

$\mathrm{f}_{\mathrm{b}}$ : Fração biodegradável de esgoto

$\mathrm{f}_{\mathrm{bp}}$ : Fração biodegradável particulada de esgoto

$\mathrm{f}_{\mathrm{bs}}$ : Fração biodegradável solúvel de esgoto

$\mathrm{f}_{\mathrm{cv}}$ : Produção de massa bacteriana $\left(\mathrm{gSSV}^{-1} \cdot \mathrm{gDQO}^{-1}\right)$

$\mathrm{f}_{\mathrm{n}}$ : Fração de nitrogênio total Kjeldahl em lodo volátil 
$\mathrm{f}_{\text {up: }}$ Fração de DQO não biodegradável particulada

$\mathrm{f}_{\text {us: }}$ Fração de DQO não biodegradável solúvel

IVL: Índice volumétrico de lodo

$\mathrm{K}_{\mathrm{d}}$ : Constante de desnitrificação

$\mathrm{K}_{\mathrm{la}}$ : Constante de transferência de oxigênio

$\mathrm{K}_{\mathrm{n}}$ : Constante de meia saturação bactérias autotróficas (mgN.L ${ }^{-1}$ )

$\mathrm{K}_{\mathrm{o}}$ : Constante de meia saturação de oxigênio (mg.L-1)

$\mathrm{K}_{\mathrm{H}}$ : Constante de meia saturação bactérias heterotróficas (mgN.L-1)

$\mathrm{K}_{\mathrm{S}}$ : Constante de meia saturação de substrato $\left(\mathrm{mgS} . \mathrm{L}^{-1}\right)$

MMA: Ministério do Meio Ambiente

MNae: Fluxo de nitrogênio amoniacal efluente $\left(\mathrm{mgN} \cdot \mathrm{d}^{-1}\right)$

$\mathrm{MN}_{\mathrm{C}}$ : Fluxo da concentração de amônia nitrificada $\left(\mathrm{gN} \cdot \mathrm{d}^{-1}\right)$

$\mathrm{MN}_{\mathrm{d}}$ : Fluxo de nitrogênio utilizado na desnitrificação $\left(\mathrm{mgN} \cdot \mathrm{d}^{-1}\right)$

$\mathrm{MN}_{1}$ : Fluxo de nitrogênio total Kjeldahl no lodo $\left(\mathrm{mgN}^{-d^{-1}}\right)$

$\mathrm{MN}_{\text {na: }}$ Fluxo de nitrato afluente $\left(\mathrm{mgN} . \mathrm{d}^{-1}\right)$

$\mathrm{MN}_{\mathrm{oe}}$ : Fluxo de nitrogênio orgânico efluente $\left(\mathrm{mgN} \cdot \mathrm{d}^{-1}\right)$

$\mathrm{MN}_{\mathrm{ta}}$ : Fluxo de nitrogênio total Kjeldahl afluente $\left(\mathrm{mgN} \cdot \mathrm{d}^{-1}\right)$

$\mathrm{MN}_{\mathrm{te}}$ : Fluxo de nitrogênio total Kjeldahl efluente $\left(\mathrm{mgN} \cdot \mathrm{d}^{-1}\right)$

MO: Matéria orgânica

$\mathrm{M}_{\mathrm{oc}}$ : Consumo de oxigênio para oxidação de material orgânico $\left(\mathrm{mgO} \cdot \mathrm{d}^{-1}\right)$

$\mathrm{M}_{\text {oeq: }}$ : Oxigênio equivalente recuperado através da desnitrificação ( $\left.m g O \cdot \mathrm{d}^{-1}\right)$

$\mathrm{M}_{\mathrm{on}}$ : Consumo de oxigênio para nitrificação $\left(\mathrm{mgO}^{\mathrm{d}} \mathrm{d}^{-1}\right)$

$\mathrm{M}_{\mathrm{ot}}$ : Consumo total de oxigênio no reator aeróbio $\left(\mathrm{mgO}^{-1} \mathrm{~d}^{-1}\right)$

$\mathrm{mS}_{\mathrm{o}}$ : Fração de DQO afluente oxidada no sistema (mgDQO.d $\left.{ }^{-1}\right)$

$\mathrm{MS}_{\mathrm{ta}}$ : Fluxo de DQO afluente (mgDQO.d $\left.{ }^{-1}\right)$

$\mathrm{mS}_{\mathrm{te}}$ : Fração de DQO detectada no efluente (mgDQO.d $\left.\mathrm{d}^{-1}\right)$

$\mathrm{mS}_{\mathrm{Xv}}$ : Fração de DQO afluente descarregada no lodo de excesso (mgDQO.d $\left.\mathrm{d}^{-1}\right)$

$\mathrm{MX}_{\mathrm{t}}$ : Massa de lodo colocado no cilindro para teste de sedimentabilidade

$\mathrm{mX}_{\mathrm{v}}$ : Produção de lodo $\left(\mathrm{mgSSV}^{-1} \cdot \mathrm{mgDQO}^{-1}\right)$

$\mathrm{N}$ : Nitrogênio

$\mathrm{N}_{\mathrm{a}}$ : Concentração de amônia $\left(\mathrm{mgN} . \mathrm{L}^{-1}\right)$

$\mathrm{N}_{\mathrm{aa}}$ : Concentração de nitrogênio amoniacal afluente $\left(\operatorname{mgN} . \mathrm{L}^{-1}\right)$

$\mathrm{N}_{\mathrm{ae}}$ : Concentração de nitrogênio amoniacal efluente $\left(\mathrm{mgN} . \mathrm{L}^{-1}\right)$

$\mathrm{N}_{\mathrm{C}}$ : Concentração de amônia nitrificada $\left(\mathrm{mgN} . \mathrm{L}^{-1}\right)$

$\mathrm{N}_{\mathrm{D}}$ : Não detectado pelo método padrão utilizado

$\mathrm{NH}_{3}$ : Gás amoníaco $\left(\mathrm{mgN} . \mathrm{L}^{-1}\right)$

$\mathrm{NH}_{4}^{+}$: Íon amônio $\left(\mathrm{mgN} . \mathrm{L}^{-1}\right)$ 
$\mathrm{N}_{\mathrm{l}}$ : Concentração de NTK para a produção de lodo de excesso $\left(\mathrm{mgN} . \mathrm{L}^{-1}\right)$

$\mathrm{N}_{\text {na: }}$ : Concentração de nitrogênio nitrato afluente $\left(\mathrm{mgN} \cdot \mathrm{L}^{-1}\right)$ )

$\mathrm{N}_{\text {ne: }}$ : Concentração de nitrato no efluente $\left(\mathrm{mgN} \cdot \mathrm{L}^{-1}\right)$

$\mathrm{N}-\mathrm{NO}_{2}=$ : Nitrito $\left(\mathrm{mgN} \cdot \mathrm{L}^{-1}\right)$

$\mathrm{N}-\mathrm{NO}_{3}$ : Nitrato $\left(\mathrm{mgN} \cdot \mathrm{L}^{-1}\right)$

$\mathrm{N}_{\mathrm{o}}$ : Material nitrogenado inicial referente a recirculações $\left(\mathrm{mgN} . \mathrm{L}^{-1}\right)$

$\mathrm{N}_{\text {oa: }}$ : Concentração de nitrogênio orgânico afluente $\left(\mathrm{mgN} . \mathrm{L}^{-1}\right)$

$\mathrm{N}_{\mathrm{oe}}$ : Concentração de nitrogênio orgânico efluente $\left(\mathrm{mgN} \cdot \mathrm{L}^{-1}\right)$

N-Orgânico: Nitrogênio Orgânico (mgN.L-1)

$\mathrm{N}_{\mathrm{ta}}$ : Concentração de NTK afluente (mgN.L $\left.\mathrm{L}^{-1}\right)$

$\mathrm{N}_{\mathrm{te}}$ : Concentração de NTK efluente (mgN.L-1)

NTK: Concentração de nitrogênio total Kjeldahl (mgN.L-1)

OD: Concentração de oxigênio dissolvido $\left(\mathrm{mg} . \mathrm{L}^{-1}\right)$

$\mathrm{OD}_{\text {máx }}$ : Valor de oxigênio dissolvido de referência superior (mg.L $\left.\mathrm{L}^{-1}\right)$

$\mathrm{OD}_{\min }$ : Valor de oxigênio dissolvido de referência inferior (mg. $\left.\mathrm{L}^{-1}\right)$

PAO ou OAP ou poli-P: Organismos assimiladores de fósforo

pH: Potencial hidrogeniônico

PHB: Polihidroxidobutiratos.

Q: Vazão afluente $\left({\left.\mathrm{L} . \mathrm{d}^{-1}\right)}^{-1}\right.$

Qe: Vazão efluente $\left(L \cdot d^{-1}\right)$

$\mathrm{r}_{\mathrm{d}}$ : Taxa de desnitrificação

$\mathrm{r}_{\mathrm{dp}}$ : Taxa de desnitrificação para material lentamente biodegradável

$\mathrm{r}_{\mathrm{ds}}$ : Taxa de desnitrificação para material rapidamente biodegradável

$\mathrm{R}_{\mathrm{h}}$ : Tempo de permanência do líquido $\left(\mathrm{d}^{-1}\right)$

$\mathrm{r}_{\text {máx: }}$ Taxa de utilização máxima material carbonáceo (mgDQO.mgX $\left.\mathrm{X}_{\mathrm{a}}^{-1} \cdot \mathrm{d}^{-1}\right)$

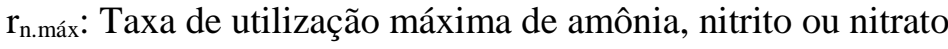

$\mathrm{R}_{\mathrm{s}}$ : Idade de lodo $\left(\mathrm{d}^{-1}\right)$

$\mathrm{R}_{\mathrm{sm}}$ : Idade de lodo mínima para que ocorra nitrificação

$\mathrm{r}_{\text {us: }}$ : Taxa de utilização de material rapidamente biodegradável

S: Concentração de substrato $\left(\mathrm{mg} \cdot \mathrm{L}^{-1}\right)$

$S_{\text {ba: }}$ DQO biodegradável afluente (mg. $\left.\mathrm{L}^{-1}\right)$

$\mathrm{S}_{\text {bpa: }}$ DQO biodegradável particulada afluente $\left(\mathrm{mg} \cdot \mathrm{L}^{-1}\right)$

$\mathrm{S}_{\text {bsa }}$ : DQO biodegradável solúvel afluente $\left(\mathrm{mg} \cdot \mathrm{L}^{-1}\right)$

SS: Sólidos suspensos (mg.L-1)

SSF: Sólidos suspensos fixos (mg.L $\left.\mathrm{L}^{-1}\right)$

SST: Sólidos suspensos totais (mg.L $\left.\mathrm{L}^{-1}\right)$

SSV: Sólidos suspensos voláteis $\left(\mathrm{mg} . \mathrm{L}^{-1}\right)$ 
SSVTA: Sólidos suspensos voláteis no tanque de aeração $\left(m g . L^{-1}\right)$

$\mathrm{S}_{\mathrm{ta}}$ : DQO afluente $\left(\mathrm{mg} \cdot \mathrm{L}^{-1}\right)$

$\mathrm{S}_{\mathrm{te}}$ : DQO efluente (mg. $\left.\mathrm{L}^{-1}\right)$

$\mathrm{S}_{\text {ua: }}$ DQO não biodegradável afluente $\left(\mathrm{mg} \cdot \mathrm{L}^{-1}\right)$

$\mathrm{S}_{\text {upa }}$ : DQO não biodegradável particulada afluente $\left(\mathrm{mg} . \mathrm{L}^{-1}\right)$

$\mathrm{S}_{\text {usa: }}$ DQO não biodegradável solúvel afluente $\left(\mathrm{mg} \cdot \mathrm{L}^{-1}\right)$

T: Temperatura $\left({ }^{\circ} \mathrm{C}\right)$

TCO "in loco": Taxa de consumo de oxigênio real do sistema $\left(\mathrm{mgO}_{2} \cdot \mathrm{L}^{-1} \cdot \mathrm{h}^{-1}\right)$

TCO: Taxa de consumo de oxigênio $\left(\mathrm{mgO}_{2} \cdot \mathrm{L}^{-1} \cdot \mathrm{h}^{-1}\right)$

$\mathrm{TCO}_{\text {end: }}$ Taxa de Consumo de Oxigênio endógena $\left(\mathrm{mgO}_{2} \cdot \mathrm{L}^{-1} \cdot \mathrm{h}^{-1}\right)$

$\mathrm{TCO}_{\mathrm{eq}}$ : Taxa de consumo de oxigênio equivalente $\left(\mathrm{mgO}_{2} \cdot \mathrm{L}^{-1} \cdot \mathrm{h}^{-1}\right)$

$\mathrm{TCO}_{\text {exo }}$ : Taxa de consumo de oxigênio exógena $\left(\mathrm{mgO}_{2} \cdot \mathrm{L}^{-1} \cdot \mathrm{h}^{-1}\right)$

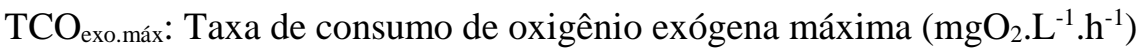

$\mathrm{TCO}_{\mathrm{n}}$ : TCO total devido à nitrificação $\left(\mathrm{mgO}_{2} \cdot \mathrm{L}^{-1} \cdot \mathrm{h}^{-1}\right)$

$\mathrm{TCO}_{\text {n.máxima: }}$ TCO total devido à nitrificação máxima $\left(\mathrm{mgO}_{2} \cdot \mathrm{L}^{-1} \cdot \mathrm{h}^{-1}\right)$

$\mathrm{TCO}_{\text {total: }}$ Taxa de consumo de oxigênio total $\left(\mathrm{mgO}_{2} \cdot \mathrm{L}^{-1} \cdot \mathrm{h}^{-1}\right)$

TDH: Tempo de detenção hidráulica (h)

UCT: University of Cape Town

USP: Universidade de São Paulo

$\mathrm{V}_{\mathrm{r}}$ : Volume do reator $\left(\mathrm{L}^{-1}\right)$

$\mathrm{V}_{\mathrm{T}}$ : Volume total $\left(\mathrm{L}^{-1}\right)$

$\mathrm{V}_{\mathrm{U}}$ : Volume útil $\left(\mathrm{L}^{-1}\right)$

$\mathrm{X}$ : Concentração ativa das bactérias $\left(\mathrm{mgX} . \mathrm{L}^{-1}\right)$

$\mathrm{X}_{\mathrm{a}}$ : Concentração ativa das bactérias heterotróficas $\left(\mathrm{mgX}_{\mathrm{a}} \cdot \mathrm{L}^{-1}\right)$

$\mathrm{X}_{\mathrm{e}}$ : Concentração de resíduo endógeno $\left(\mathrm{mg} \cdot \mathrm{L}^{-1}\right)$

$\mathrm{X}_{\mathrm{F}}$ : Concentração de sólidos fixos (mg. $\left.\mathrm{L}^{-1}\right)$

$\mathrm{X}_{\mathrm{i}}$ : Concentração de resíduo inerte $\left(\mathrm{mg} \cdot \mathrm{L}^{-1}\right)$

$\mathrm{X}_{\mathrm{n}}$ : Concentração ativa de bactérias nitrificantes $\left(\mathrm{mgX}_{\mathrm{n}} \cdot \mathrm{L}^{-1}\right)$

$\mathrm{X}_{\mathrm{t}}$ : Concentração de lodo $\left(\mathrm{gSTS} . \mathrm{L}^{-1}\right)$

$\mathrm{X}_{\mathrm{v}}$ : Concentração de sólidos voláteis $\left(\mathrm{mg} \cdot \mathrm{L}^{-1}\right)$

$\mathrm{Y}_{\mathrm{n}}$ : Coeficiente de rendimento das bactérias autotróficas $\left(\mathrm{mgN} \cdot \mathrm{L}^{-1} \cdot \mathrm{d}^{-1}\right)$

$\theta$ : Coeficiente de dependência da temperatura - Arrehnius 


\section{INTRODUÇÃO}

Atualmente há um movimento mundial de consciência ambiental crescente. Neste contexto muitas pessoas, empresas, administradores públicos entre outros tem dado um foco ao abastecimento de água e tratamento de esgotos sanitários. Em concordância com este movimento foram criadas legislações ambientais em diversos países. Ressaltase principalmente as legislações americanas e europeias que apresentam diversas condicionantes de geração de resíduos sólidos e líquidos. A legislação brasileira por sua vez também está cada vez mais restritiva com relação ao lançamento de efluentes de tratamento de esgotos.

Nesta movimentação nacional pode-se ressaltar as normas CONAMA (Conselho nacional de Meio Ambiente) n $n^{0} 357 / 2005$ e $n^{\circ}$ 430/2011 que estabelecem as diretrizes para lançamento de efluentes em diversas condições. Pode-se observar uma crescente exigência para o lançamento de efluentes e no enquadramento de lançamentos na caracterização do corpo receptor, especialmente em corpos receptores Classe II.

Estas medidas são muito interessante para o melhor aproveitamento dos escassos recursos hídricos disponíveis, uma vez que consideram os diferentes usos dentro da bacia hidrológica e tentam reduzir a poluição destes.

O nitrogênio em esgotos sanitários é normalmente proveniente de excretas de origem humana e alguns tipos de despejos industriais. Seu acumulo no meio ambiente pode gerar eutrofização de rios e lagos. Sua remoção normalmente é feita por via biológica de modo que não há subproduto tóxico da remoção biológica de nitrogênio (o produto é o gás $\mathrm{N}_{2}$ que escapa para o meio ambiente).

Já o fósforo nos esgotos sanitários é principalmente proveniente de excretas de origem humana, despejos industriais e uma pequena parcela de detergentes. Desconsiderando as descargas industriais, devido ao alto grau de variabilidade dos descartes industriais, normalmente devido ao tipo de atividade desenvolvida por cada indústria (por exemplo, em efluentes de laticínios há alta DBO (Demanda Bioquímica de oxigênio) enquanto que indústrias químicas podem descartar grandes quantidades de metais pesados. Nos Estados Unidos e na Europa cerca de $57 \%$ do fósforo presente nos esgotos é proveniente do uso de detergentes. (GRAY, 1981, apud ALEM SOBRINHO, 1991). No Brasil, essa porcentagem situa-se entre 10 e $15 \%$, o que explica a relativa baixa 
concentração desse elemento nos esgotos brasileiros. (JONG, 1977, apud ALEM SOBRINHO, 1991). De acordo com ALEM SOBRINHO (1991), em São Paulo a concentração média de fósforo nos esgotos é de 3 a $4 \mathrm{mg}$ P/L, podendo chegar a $8 \mathrm{mg}$ P/L nas épocas sem chuva. Nos Estados Unidos, a concentração média era de cerca de 10 mg P/L na década de 1990, de acordo com JENKINS et al (1971, apud ALEM SOBRINHO, 1991).

Com este panorama tornou-se imprescindível o desenvolvimento de rotas tecnológicas que permitissem a remoção de fósforo e nitrogênio de esgotos de maneira eficiente confiável, eficaz e economicamente viável.

O fósforo nos esgotos apresenta-se na forma de fosfato, podendo ser inorgânico (ortofosfato e polifosfato) ou orgânico. Porém, a quantidade de fósforo orgânico nos esgotos costuma ser irrisória, predominando as formas inorgânicas. Os ortofosfatos podem ser utilizados diretamente pelos microrganismos em seu metabolismo, enquanto os polifosfatos são moléculas mais complexas, com dois ou mais átomos de carbono, mas que podem ser convertidas a ortofosfatos através do mecanismo de hidrólise. (VON SPERLING, 1997).

O nitrogênio por sua vez apresenta-se predominantemente em sua forma amoniacal $\left(\mathrm{NH}_{4}{ }^{+}\right)$e orgânica. Alguns tipos de microrganismos autotróficos utilizam estes compostos para síntese celular, no entanto, pelas grandes concentrações deste nutriente, torna-se necessário sua retirada de alguma maneira.

Desta forma, os esgotos domésticos contêm uma quantidade de fósforo e nitrogênio superior às necessidades metabólicas normais dos microrganismos presentes nos sistemas biológicos de tratamento de esgoto. Como a sua remoção nestes sistemas é realizada através do crescimento microbiano, a partir da utilização dos elementos nutrientes necessários, geralmente não pode ser realizada com elevada eficiência. Assim, a remoção eficiente de fósforo só era considerada possível através de processos físico-químicos, que levam à produção de elevadas quantidades de lodo (ALEM SOBRINHO, 1991).

Porém, na década de 1960, foi observada em algumas estações de tratamento norteamericanas a peculiar característica de remover biologicamente o fósforo dos esgotos em excesso às necessidades metabólicas normais dos microrganismos. A partir daí, esse 
fenômeno começou a ser estudado em profundidade com o intuito de se compreender os mecanismos envolvidos e, possivelmente, de se projetar sistemas de tratamento que apresentem essa característica. Deste ponto em diante, esse fenômeno será referido como remoção de fósforo em excesso neste trabalho.

Inicialmente, os pesquisadores que se debruçaram sobre o assunto procuraram compreender se a remoção de fósforo em excesso ocorria predominantemente por processos físico-químicos ou biológicos. Os resultados obtidos por diferentes pesquisadores logo deram suporte à teoria de que os mecanismos biológicos eram os predominantes.

Em meados da década de 1970, FUHS \& CHEN (1975, apud ALEM SOBRINHO, 1991) constataram que algumas espécies de bactérias eram capazes de acumular fósforo na forma de grânulos intracelulares. As espécies foram identificadas com pertencentes ao gênero Acinetobacter, e conforme estudos de BUCHAN (1983, apud ALEM SOBRINHO, 1991) a quantidade de fósforo acumulado poderia atingir o valor de $60 \%$ da massa bacteriana. Era o primeiro indício plausível de que o fósforo em excesso poderia ser removido biologicamente. BRODISCH \& JOYNER (1985, apud ALEM SOBRINHO, 1991) identificaram que bactérias dos gêneros Aeromonas e Pseudomonas também eram capazes de acumular fósforo. Os organismos capazes de acumular fósforo serão genericamente denominados OAPs ou PAOs (organismos acumuladores de fósforo) a partir daqui.

Após estas descobertas, as características dessas espécies foram estudadas exaustivamente com o intuito de se compreender as condições que favorecem seu desenvolvimento e a consequente remoção de fósforo em excesso.

Já em 1975, FUHS \& CHEN (1975, apud ALEM SOBRINHO, 1991) sugeriram que o desenvolvimento de Acinetobacter poderia estar ligado à existência da sequência anaeróbia-aeróbia no sistema de tratamento de esgotos e que a captação de fósforo dependia de sua prévia liberação para o líquido, na fase anaeróbia. Baseado em experimentos que confirmavam as sugestões de FUHS \& CHEN, BARNARD (1976, apud ALEM SOBRINHO, 1991) propôs o processo Phoredox, que consiste no processo Bardenpho acrescentado de um reator anaeróbio à montante, que recebe o esgoto afluente e o retorno do lodo do decantador secundário. 
MARAIS et al (1983, apud ALEM SOBRINHO, 1991) desenvolveram equações para estimar a desnitrificação e concluíram que o processo Phoredox pode obter completa desnitrificação apenas se o esgoto afluente apresentar a relação NKT-N/DQO inferior a 0,08. Caso essa relação fosse maior, haveria nitrato no efluente e no lodo de retorno do decantador, que é enviado ao reator anaeróbio. A presença de nitrato neste reator inibe a liberação de fósforo ali e sua posterior remoção na etapa aeróbia. Em decorrência disto, MARAIS et al (1983) propuseram o sistema UCT (Universidade de Cape Town), em que o lodo do decantador secundário é retornado ao reator anóxico primário (ao invés de ser retornado para o reator anaeróbio) e é introduzida uma nova recirculação, do reator anóxico para o anaeróbio (ver Figura 1). Com esta disposição, teoricamente o reator anaeróbio pode receber um reciclo livre de nitrato para esgotos afluente com relação NKT-N/DQO até 0,14 (MARAIS et al, 1983, apud ALEM SOBRINHO, 1991).

Um aspecto fundamental da existência da etapa anaeróbia está relacionado à sua operação como um reator de fermentação. Os OAPs utilizam como substrato para seu crescimento os AOVs (ácidos orgânicos voláteis), que são produtos da fermentação realizada por bactérias fermentadoras. Dessa forma, a entrada de compostos facilmente degradáveis, como carboidratos, (geralmente quantificados na forma de DQO prontamente biodegradável) no reator anaeróbio é de fundamental importância, para que sejam convertidos em produtos da fermentação, como o acetato, fornecendo o substrato requerido pelos OAPs (ALEM SOBRINHO, 1991). Em outras palavras, o reator anaeróbio permite o desenvolvimento de uma microbiota anaeróbia facultativa que, à partir da fermentação de compostos facilmente biodegradáveis, produz AOVs que serão utilizados como substrato pelos OAPs.

Combinando-se os trabalhos de MARAIS et al (1983) e NICHOLLS (1985), podem ser identificados dois fatores que comandam a remoção de fósforo em excesso: a massa de DQO prontamente biodegradável removida do líquido pela biomassa do reator anaeróbio e a "Fração de Massa Anaeróbia", que corresponde à razão entra a massa de lodo no reator anaeróbio e a massa de lodo total no sistema. Se um destes fatores for zero, não haverá remoção em excesso pelo sistema.

Mais recentemente, estão sendo desenvolvidos processos que objetivam a recuperação do fósforo removido do esgoto através da retirada do lodo excedente. Entre estas tecnologias, destaca-se a precipitação do fósforo na forma de fosfato de magnésio e 
amônia hexahidratado $\left(\mathrm{MgNH}_{4} \mathrm{PO}_{4} \cdot 6 \mathrm{H}_{2} \mathrm{O}\right)$, composto conhecido como estruvita. $\mathrm{O}$ fósforo torna-se disponível para o processo de precipitação através da digestão anaeróbia do lodo rico em fósforo, que libera o fosfato acumulado intracelularmente nos OAPs para a fase líquida. De acordo com PASTOR et al (2009) a remoção biológica de fósforo seguida de digestão anaeróbia do lodo de excesso é um dos processos mais adequados para a recuperação do fósforo.

Após a digestão anaeróbia do lodo, este deve ser desidratado, por exemplo, pelo uso de filtro-prensa. O líquido drenado, rico em fosfato solúvel, é então encaminhado para um reator de precipitação de estruvita, onde é adicionado Hidróxido de Magnésio, $\mathrm{Mg}(\mathrm{OH})_{2}$. O processo de precipitação ocorre em dois estágios: nucleação e crescimento dos grãos. Estes mecanismos são governados por uma série de parâmetros físicoquímicos, como o valor do $\mathrm{pH}$ do líquido, temperatura, presença de outros íons, gradiente hidráulico, entre outros, tornando complexa a sua previsão e controle (PASTOR et al, 2009). Os grãos de estruvita formados são retirados do reator de precipitação e passam em seguida por uma etapa de filtração, onde os menores grãos são separados e retornados ao reator de precipitação onde funcionam como semeadura para a formação de novos grãos.

Os grãos de estruvita produzidos neste processo podem ser usados para a produção de fertilizantes para a agricultura ou como insumo para indústrias que utilizam fósforo em suas linhas de produção.

A recuperação de fósforo na forma de estruvita é particularmente interessante em processos em que ocorre remoção biológica de fósforo, uma vez que este componente é retirado no lodo e em situações de digestão anaeróbia há uma tendência de solubilização do fósforo retirado do sistema. Desta forma, a obtenção de estruvita torna-se particularmente interessante se considerada a possibilidade de se reduzir ou barrar potenciais reciclos de fósforo do lodo para o sistema.

\section{OBJETIVOS}

O presente estudo tem como objetivo principal avaliar as condições necessárias e as eficiências que podem ser alcançadas na remoção de nitrogênio e fósforo de esgoto sanitário, em um processo UCT modificado considerando algumas alterações construtivas e de processo nesta metodologia. 
Este estudo terá como finalidade verificar as condições mínimas necessárias para a posterior precipitação do fósforo presente no lodo na forma de estruvita.

\subsection{Objetivos específicos}

- Avaliar os efeitos da compartimentação do reator anaeróbio do processo UCT na produção de ácidos orgânicos voláteis (AOV), no crescimento de bactérias Poli-P e na consequente incorporação de fósforo;

- Avaliar os efeitos da microaeração no reator anóxico e a eficiência de remoção biológica de nitrogênio e fósforo no processo como um todo; 


\section{REVISÃO DE LITERATURA}

\subsection{Sistema de tratamento de esgotos por Lodos Ativados}

Grande parte dos processos de remoção de nutrientes do esgoto tem como principal base o processo de lodos ativados, sistema consagrado para tratamento biológico de águas residuárias. Neste item será feita uma breve apresentação dos principais conceitos relacionados com lodos ativados e a degradação de matéria orgânica por via biológica.

\subsubsection{Matéria Orgânica e suas reações}

Segundo VAN HAANDEL et al (1999) os parâmetros utilizados para quantificar o material orgânico presente no esgoto são DQO (Demanda química de oxigênio, DBO (Demanda Bioquímica de oxigênio) e COT (Carbono orgânico total). Estes parâmetros são comumente utilizados por serem dados provenientes de testes práticos muito difundidos e realizados. Estes testes tem por objetivo definir a atividade microbiológica de um dado líquido amostrado por meio do oxigênio consumido por tais organismos. Ou seja, quantificar indiretamente o metabolismo dos microrganismos presentes no líquido.

Ainda Segundo VAN HAANDEL et al (1999), o termo metabolismo na engenharia sanitária se refere à utilização de substrato pelos microrganismos que é sempre acompanhada de uma transformação química de parte da matéria orgânica em produtos finais ou estáveis, liberando energia também. Esta transformação química é chamada de catabolismo ou dissimilação. Associado ao catabolismo ocorre o processo de assimilação ou síntese de nova matéria celular ou anabolismo.

\subsubsection{Respiração aeróbia}

Em um ambiente aeróbio o catabolismo e anabolismo são interdependentes, uma vez que a oxidação catabólica gera energia que é utilizada no anabolismo celular. 
Catabolismo oxidativo

$$
\text { material orgânico }+\mathrm{O}_{2}-->\mathrm{CO}_{2}+\mathrm{H}_{2} \mathrm{O}+3,3 \mathrm{kCal} / \mathrm{gDQO}
$$

Catabolismo fermentativo

$$
\text { material orgânico }-->\mathrm{CO}_{2}+\mathrm{CH}_{4}+0,3 \mathrm{kCal} / \mathrm{gDQO}
$$

Figura 1 - Representação esquemática dos processos metabólicos num ambiente aeróbio

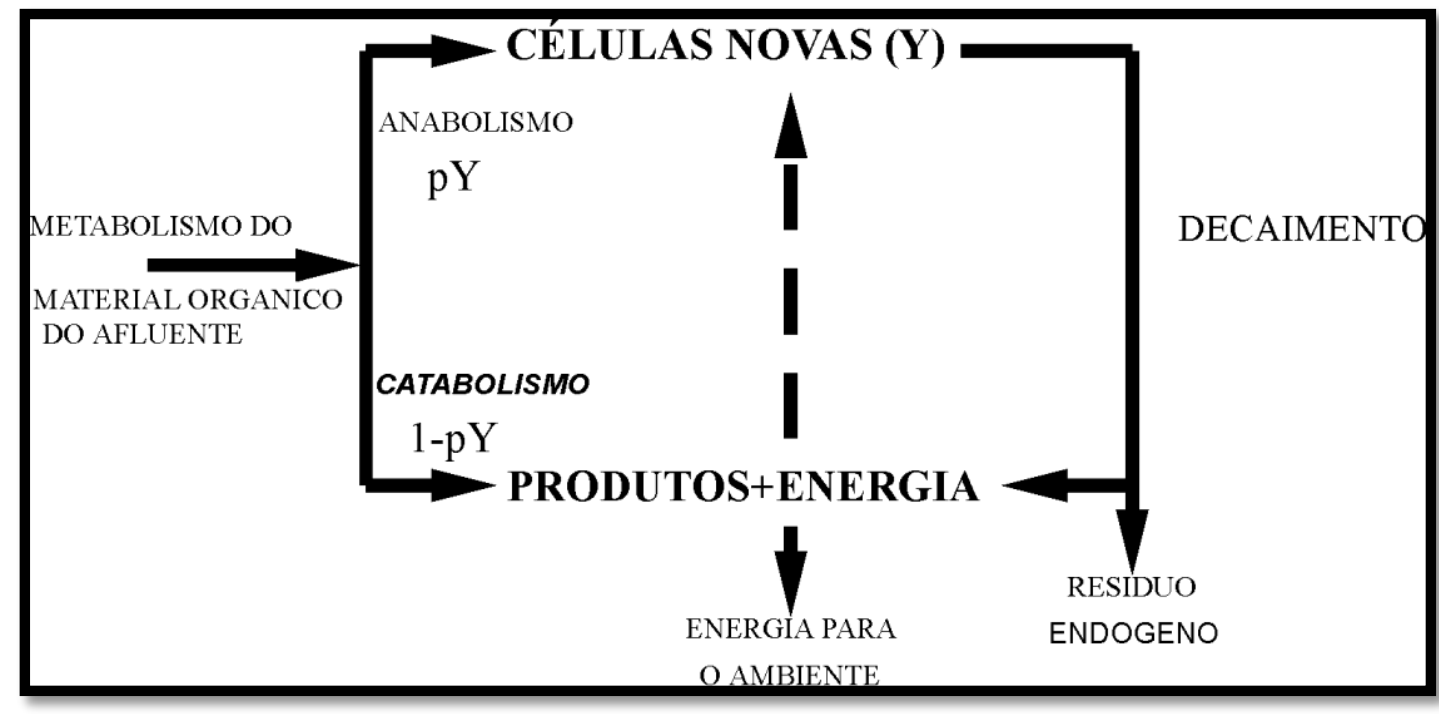

Obs: $\mathrm{p}=$ coeficiente de síntese celular; $\mathrm{Y}=$ Yield Coefficient Fonte: VAN HAANDEL, (1999)

Vale ressaltar que a massa de microrganismos é expressa pelos sólidos voláteis em suspensão (SSV) e indica a quantidade destes organismos num líquido ou sistema. Segundo este mesmo autor a produção de massa bacteriana está na faixa de 0,35 a 0,52 g SSV por g DQO metabolizada.

Outro indicador importante é a proporção entre massa microbiana sintetizada e massa de DQO sintetizada. Esta proporção indica o coeficiente de síntese celular ou coeficiente de crescimento de lodo. É representado pela letra Y (yield coeficiente) e seu valor mais comum é de $0,45 \mathrm{~g} \mathrm{SSV/g} \mathrm{DQO.}$

Segundo MARAIS e EKAMA (1976), deve-se determinar quanto da DQO metabolizada é utilizada para a atividade anabólica dos microrganismos. Desta necessidade surge o conceito da matéria orgânica presente por unidade de SSV $\left(\mathrm{f}_{\mathrm{cv}}\right)$, sendo seu valor típico de 1,48 mg DQO/mg SSV. 
Portanto, em um ambiente aeróbio $2 / 3$ do material orgânico é catabolizado e 1/3 é oxidado, sendo o consumo de oxigênio dissolvido de 0,33 $\mathrm{g} \mathrm{O}_{2} / \mathrm{g}$ DQO metabolizada.

Deve-se ainda ressaltar que a própria massa celular contém material orgânico biodegradável que pode ser oxidada para produtos inorgânicos. Este fenômeno é chamado de respiração endógena e em uma fração $f=0,2$ (MARAIS E EKAMA 1976) da matéria biodegradável não pode ser oxidada. VAN HAANDEL (1999) ainda revela que o decaimento de massa microbiana e a consequente perda de massa de sólidos voláteis e consumo de oxigênio no processo de respiração endógeno ocorre simultaneamente com o metabolismo de material orgânico extracelular, dificultando a determinação experimental da constante $\mathrm{Y}$.

\subsubsection{Respiração e digestão anaeróbia}

Em uma respiração anaeróbia (degradação anaeróbia) não há a presença de oxigênio necessário para as reações de catabolismo. No entanto, alguns outros íons podem fazer o papel de oxidante da matéria orgânica, especialmente o nitrato $\left(\mathrm{NO}_{3}{ }^{-}\right)$e o sulfato $\left(\mathrm{SO}_{4}{ }^{2-}\right.$ ). Muitos microrganismos conseguem realizar a respiração utilizando o nitrato como oxidante ou ainda o sulfato. Segundo VAN HAANDEL (1999), as equações estequiométricas de redução dos agentes oxidantes geram as relações apresentadas na Figura 2.

Figura 2 - Relações estequiométricas entre oxigênio, nitrato e sulfato

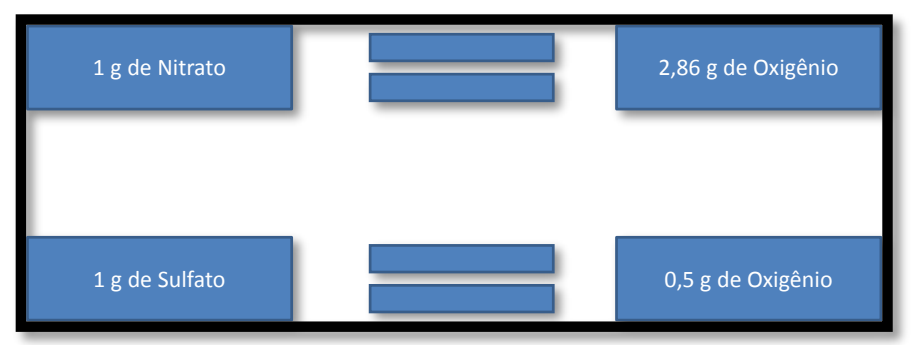

Fonte: VAN HAANDEL (1999)

A lógica de utilização de nitrato em detrimento ao oxigênio será desenvolvida posteriormente na concepção de desnitrificação de sistemas de lodos ativados. 
Figura 3 - Produção de lodo pelo metabolismo aeróbio (esquerda) e anaeróbio (direita)

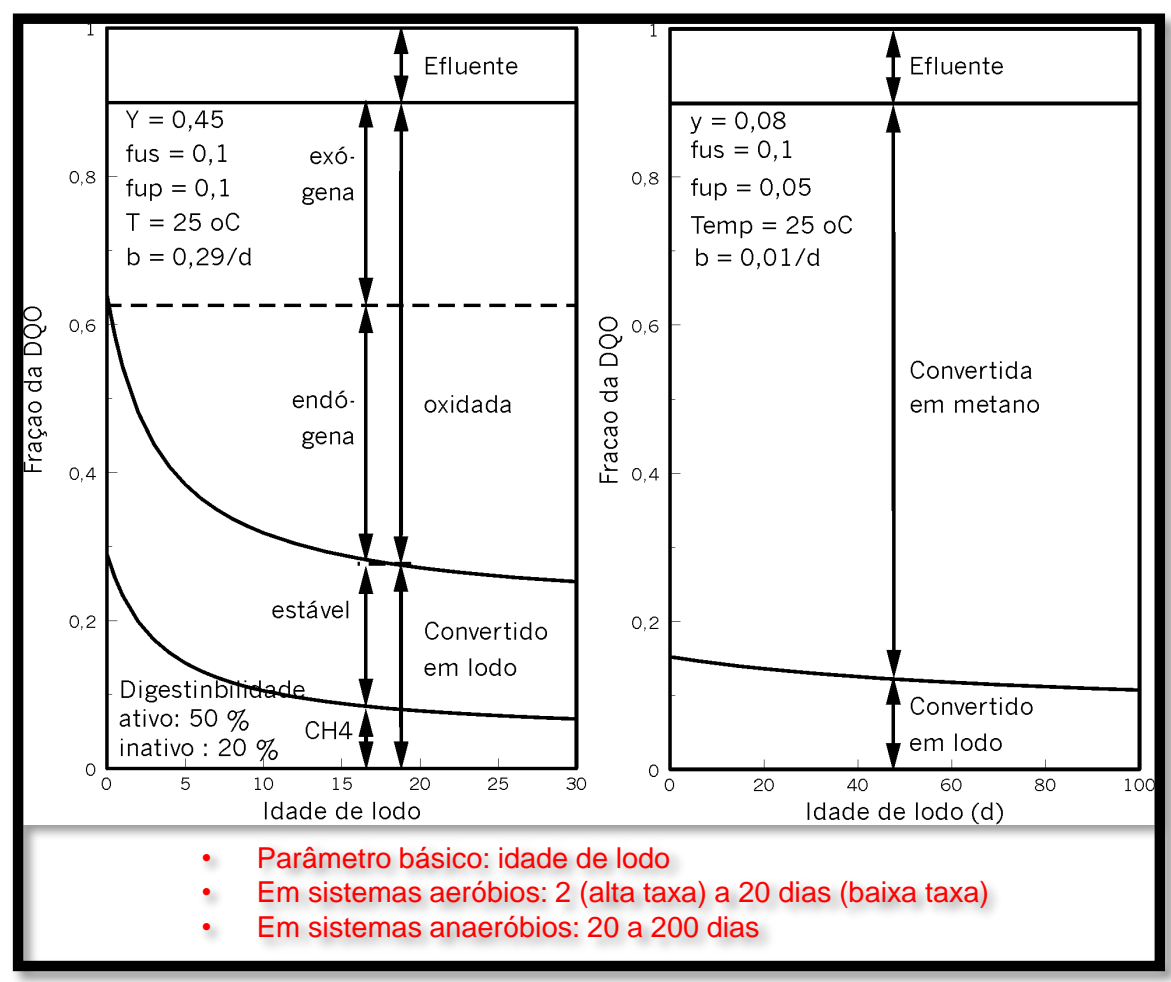

Fonte: Alterado de VAN HAANDEL (1999)

Figura 4 - Frações de matéria orgânica em sistemas aeróbios (esquerda) e anaeróbios (direita)

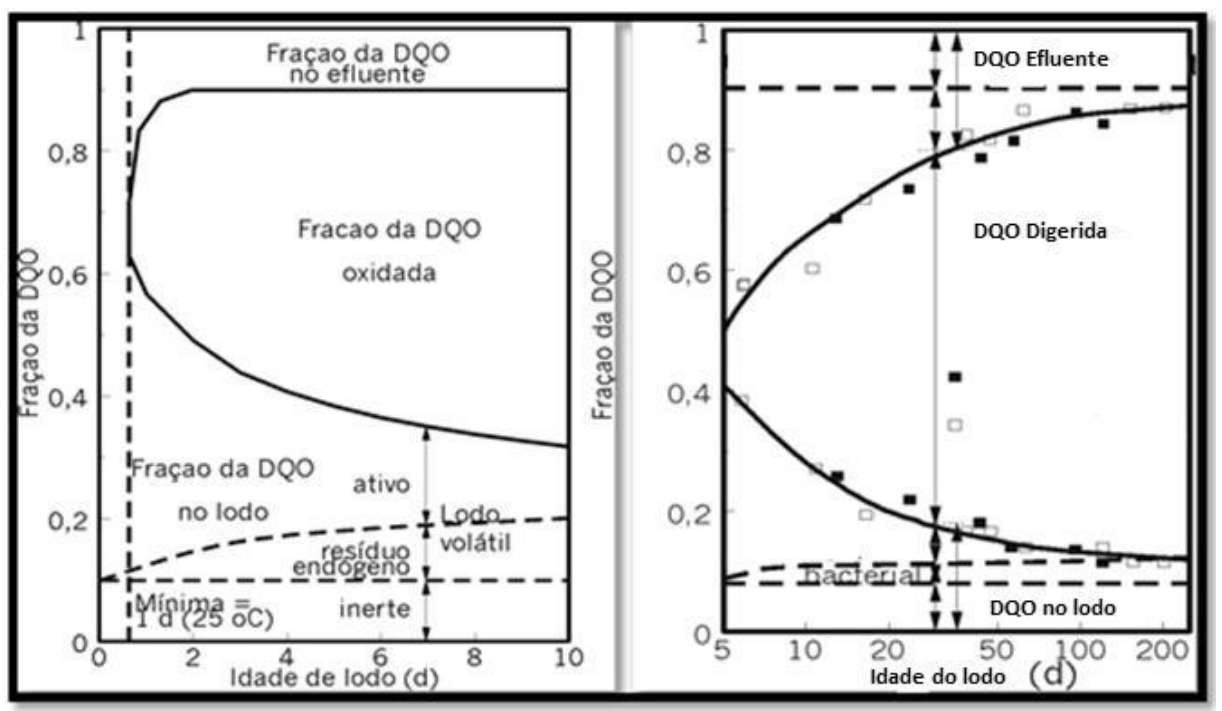

Fonte: Alterado de VAN HAANDEL (1999)

Por outro lado, há microrganismos que metabolizam matéria orgânica sem a presença de um oxidante, o que é normalmente chamado de fermentação. Neste processo não há oxidação, sendo que não há transferência de elétrons entre os íons. Desta forma, para se gerar $1 \mathrm{mg}$ de metano é necessário $4 \mathrm{mg}$ de DQO, sendo que grande parte da energia da reação fica armazenada no metano formado. Outro aspecto importante da fermentação é 
que cerca de $90 \%$ do material metabolizado se transforma em metano e $10 \%$ é sintetizado com massa bacteriana. Adicionalmente a

Figura 3 apresenta um indicativo desta última afirmação, uma vez que a massa de lodo produzida na fermentação é muito menor do que na oxidação aeróbia.

\subsubsection{Matéria Orgânica nas águas residuárias}

Para o desenvolvimento dos modelos cinéticos e teóricos, devem ser destacadas as diversas frações componentes dos esgotos ou águas residuárias afluentes a estação e sua forma de degradação. Para fins de nomenclatura, a matéria orgânica passará a ser chamada de Substrato e representada pela letra "S". Essa nomenclatura posteriormente será útil para a padronização de siglas.

Figura 5 - Componentes da matéria orgânica

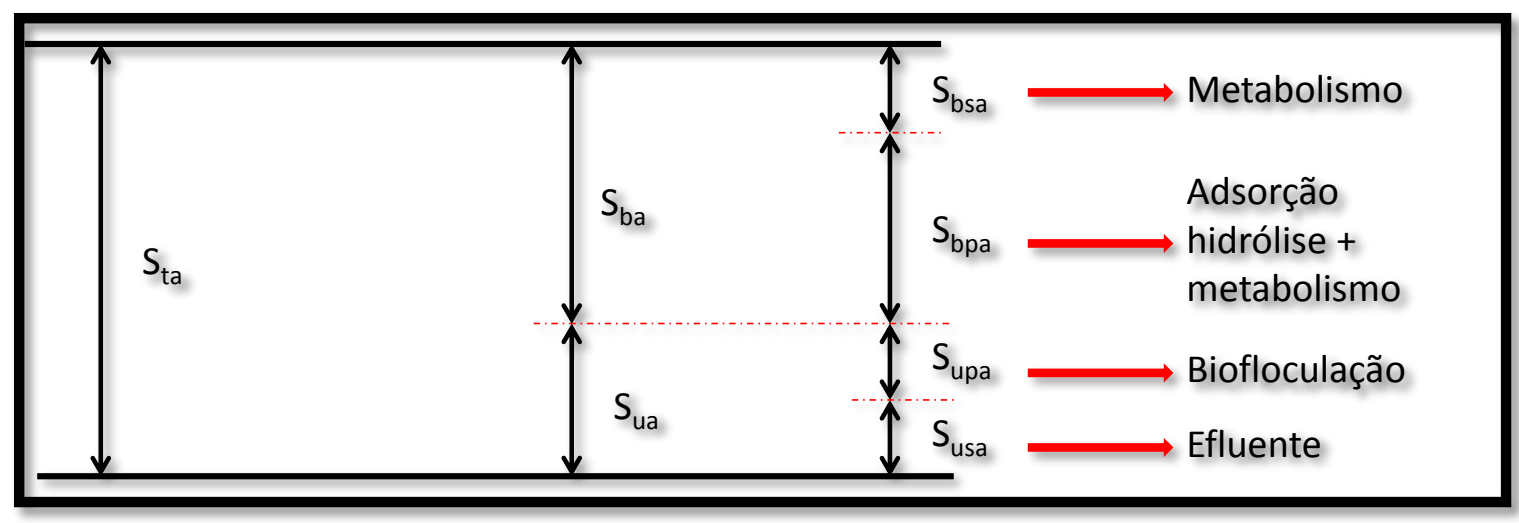

Fonte: Editado de VAN HAANDEL (1999)

Tabela 1 - Siglas e nomes das componentes da matéria orgânica

\begin{tabular}{|c|c|}
\hline Sigla & Nome \\
\hline $\mathrm{S}_{\mathrm{ta}}$ & DQO total afluente \\
\hline $\mathrm{S}_{\mathrm{ba}}$ ou $\mathrm{S}_{\mathrm{b}}$ & DQO biodegradável do afluente \\
\hline $\mathrm{S}_{\text {ua }}$ & DQO não biodegradável do afluente \\
\hline $\mathrm{S}_{\mathrm{bpa}}$ & DQO biodegradável e particulada do afluente \\
\hline
\end{tabular}




\begin{tabular}{|c|c|}
\hline$S_{\text {bsa }}$ & DQO Biodegradável e dissolvida do afluente \\
\hline$S_{\text {upa }}$ & DQO não biodegradável e particulada do afluente \\
\hline$S_{\text {usa }}$ & DQO não biodegradável e dissolvida do afluente \\
\hline
\end{tabular}

Fonte: Editado de VAN HAANDEL (1999)

Aqui é necessário observar que a DQO não biodegradável e dissolvida não consegue ser removida pelo tratamento biológico e, portanto, é a fração que sempre sai no efluente final. A diferença de matéria dissolvida para a particulada consiste no fato de que a fração dissolvida possui moléculas com diâmetro de partícula muito pequeno que permite sua penetração pelas paredes celulares das bactérias e o seu metabolismo direto e a fração particulada só consegue ser metabolizada após uma série de processos para seu processamento.

A seguir serão feitas algumas definições retiradas de VAN HAANDEL (1999) para a composição da DQO.

$$
\begin{gathered}
S_{t a}=S_{b a}+S_{u a} \text { (1) } \\
S_{t a}=S_{b s a}+S_{b p a}+S_{u s a}+S_{u p a} \text { (2) } \\
f_{u s}=\frac{S_{u s a}}{S_{t a}}=\text { fração da DQO afluente não biodegradável e dissolvida } \\
f_{u p}=\frac{S_{u p a}}{S_{t a}}=\text { fração da DQO afluente não biodegradável e particulada } \\
f_{s b}=\frac{S_{s b a}}{S_{b a}}=\text { fração dissolvida da } D Q O \text { biodegradável do afluente } \\
S_{u a}=\left(f_{u s}+f_{u p}\right) S_{t a} \text { (3) } \\
S_{b a}=\left(1-f_{u s}-f_{u p}\right) S_{t a} \text { (4) }
\end{gathered}
$$

Valores normais destes parâmetros para esgotos municipais são na faixa de 0,07 para $f_{u s}, 0,05$ para $f_{u p}$ e 0,25 para $f_{\text {sb. }}$.

Outro conceito importante é o de sólidos suspensos totais (SST) que indica os sólidos no licor misto. Segundo MARAIS e EKAMA (1976) esses sólidos podem ser divididos 
em lodo ativo (que exerce atividade metabólica) e lodo inativo (que não exerce atividade metabólica). O lodo ativo é gerado pela síntese de material orgânico no afluente e o lodo inativo é composto por material orgânico não biodegradável e particulado que pode ser dividido em dois grupos (inerte e resíduo endógeno). Utilizando-se a letra X para as concentrações de lodo, tem-se:

$$
\begin{gathered}
\mathrm{Xa}=\text { Concentração de lodo ativo (mg SSV/L) } \\
\mathrm{Xe}=\text { Concentração de resíduo endógeno }(\mathrm{mg} \mathrm{SSV} / \mathrm{L}) \\
\mathrm{Xi}=\text { Concentração de lodo inerte (mg SSV/L) } \\
\mathrm{Xv}=\text { Concentração de lodo orgânico (mg SSV/L) }
\end{gathered}
$$

Xm = Concentração de lodo inorgânico (mg SSF/L - Sólidos em suspensão fixos)

$$
\mathrm{Xt}=\text { Concentração total de lodo (mg SST/L) }
$$

$$
\begin{gathered}
X_{t}=X_{v}+X_{m}=\frac{X_{v}}{f_{v}}(\mathbf{5}) \\
X_{v}=X_{a}+X_{e}+X_{i}(\mathbf{6})
\end{gathered}
$$

Onde $\mathrm{f}_{\mathrm{v}}$ é a fração volátil de lodo $(0,75)$

\subsubsection{Balanço de massa de matéria orgânica}

Segundo VAN HAANDEL (1999), em um sistema com alimentação constante em regime estacionário, o lodo orgânico é transformado por meio bioquímico ou físico, ou os produtos inorgânicos são oxidados.

$$
\begin{gathered}
\mathrm{MS}_{\mathrm{ta}}=\text { Massa de DQO aplicada diariamente }(\mathrm{kg} \mathrm{DQO} / \mathrm{dia}) \\
\mathrm{MS}_{\mathrm{te}}=\text { Massa de DQO diária no efluente }(\mathrm{kg} \mathrm{DQO} / \mathrm{dia}) \\
\mathrm{MS}_{\mathrm{xv}}=\text { Massa de DQO diária no lodo de excesso }(\mathrm{kg} \mathrm{DQO} / \mathrm{dia}) \\
\mathrm{MS}_{\mathrm{o}}=\text { Massa de DQO Oxidada }(\mathrm{kg} \mathrm{DQO} / \text { dia ou } \mathrm{kg} \mathrm{O} / \mathrm{dia}) \\
M S_{t a}=M S_{t e}+M S_{x v}+M S_{o}
\end{gathered}
$$

Considerando $\mathrm{Q}_{\mathrm{a}}$ a vazão afluente ao sistema e q a vazão de lodo em excesso, todas em litros por dias, tem-se as seguintes equações: 


$$
\begin{gathered}
M S_{t a}=Q_{a} S_{t a}(\mathbf{8}) \\
M S_{t e}=\left(Q_{a}-q\right) S_{t e}(\mathbf{9})
\end{gathered}
$$

O fluxo de material orgânico descarregado no lodo de excesso pode ser determinado através da massa de sólidos voláteis suspensos e da DQO da fase líquida. Sendo $\mathrm{f}_{\mathrm{cv}}=$ 1,5 mg DQO/mg SSV, pode-se concluir:

$$
M S_{x v}=q\left(f_{c v} X_{v}+S_{t e}\right)=q f_{c v} X_{v}+q S_{t e}(\mathbf{1 0})
$$

Para uma futura análise de sistemas de lodos ativados é muito interessante a expressão das frações de DQO que não são processadas e consequentemente são descarregadas com o efluente final.

$$
\begin{gathered}
\frac{S_{t e}}{S_{t a}}+\frac{\left(\frac{q}{Q_{a}}\right) f_{c v} X_{v}}{S_{t a}}+\frac{R_{h} T O C_{c}}{S_{t a}}=B_{o}(\mathbf{1 1 )} \\
T C O_{c}=T C O_{t}-T_{C O}(\mathbf{1 2})
\end{gathered}
$$

Onde $B_{o}$ é o fator de recuperação de matéria orgânica, $R_{h}$ é o tempo de detenção hidráulica no sistema e $\mathrm{TCO}_{c}$ é a taxa de consumo de oxigênio para oxidação da matéria orgânica, $\mathrm{TCO}_{\mathrm{t}}$ é a taxa de consumo de oxigênio total e $\mathrm{TCO}_{\mathrm{n}}$ é a taxa de consumo de oxigênio para nitrificação.

\subsubsection{Definições e conceitos básicos para um modelo de lodos ativados}

Neste item serão apresentadas algumas grandezas essenciais para um sistema de lodos ativados. Novamente, tomou-se como base para este item o modelo apresentado por VAN HAANDEL (1999).

Inicialmente é necessário avaliar os fluxos de matéria orgânica em um sistema de lodos ativados. 
Figura 6 - Metabolismo de matéria orgânica

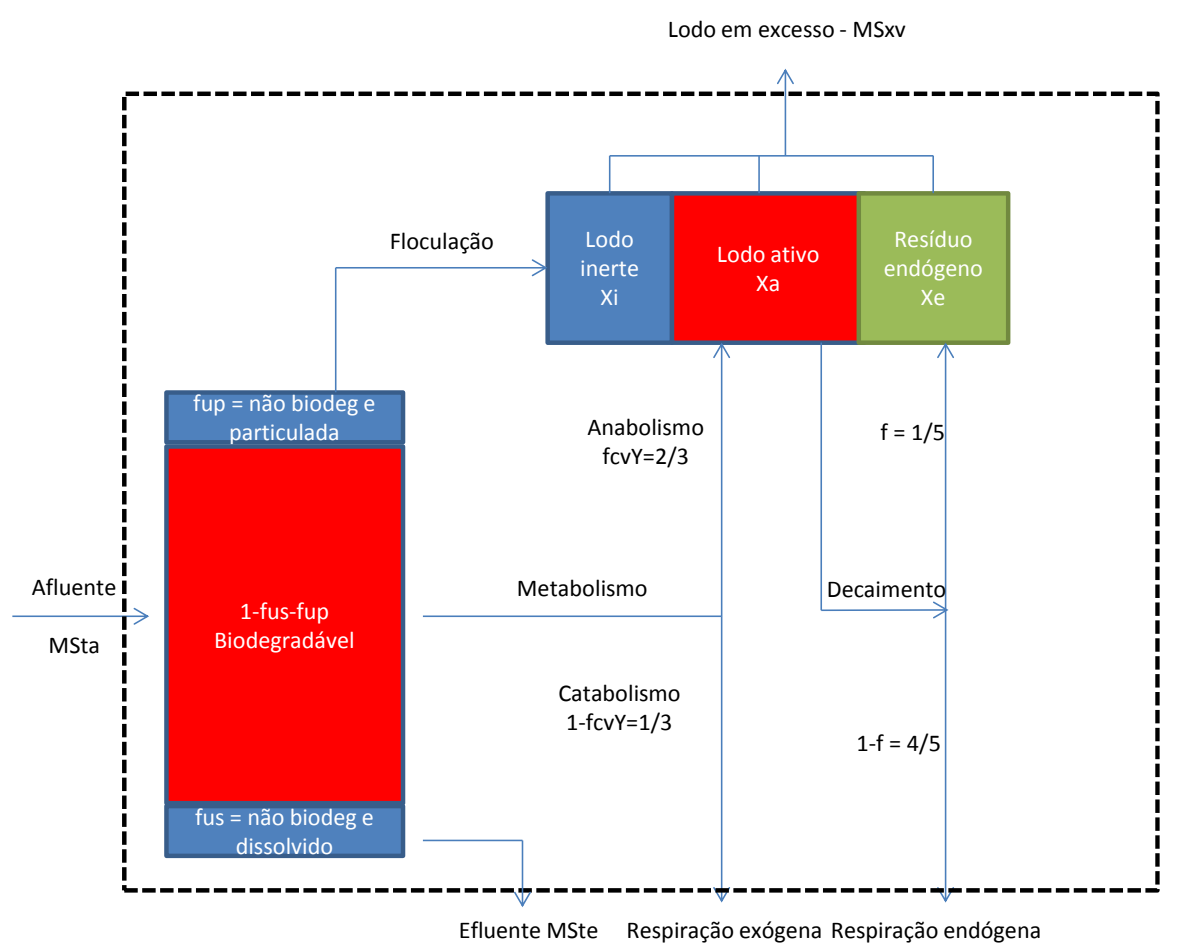

Fonte: VAN HAANDEL (1999)

Outro conceito necessário é o de idade do lodo $\left(\mathrm{R}_{\mathrm{S}}\right)$, pois se trata do parâmetro operacional mais importante de um sistema de lodos ativados. Esta grandeza indica o tempo médio de permanência de lodo no sistema e é definido como a razão entre a massa de lodo presente no sistema e a massa descarregada diariamente.

$$
R_{s}=V_{r} / q(\mathbf{1 3})
$$

Onde $\mathrm{V}_{\mathrm{r}}$ é o volume do reator e q é a vazão de descarte de lodo em excesso do sistema.

Por outro lado é necessário avaliar o tempo de permanência do líquido $\left(\mathrm{R}_{\mathrm{h}}\right)$ que é a razão entre o volume do reator e a vazão afluente a este.

As fórmulas para as concentrações de lodo inerte $\left(\mathrm{X}_{\mathrm{i}}\right)$, ativo $\left(\mathrm{X}_{\mathrm{a}}\right)$, resíduo endógeno $\left(\mathrm{X}_{\mathrm{e}}\right)$ e lodo orgânico $\left(X_{v}\right)$ são:

$$
X_{i}=\left(\frac{f_{u p}}{f_{c v}}\right)\left(\frac{R_{s}}{R_{h}}\right) S_{t a}(\mathbf{1 4})
$$




$$
X_{a}=\frac{\left(1-f_{u p}-f_{u s}\right) c_{r} S_{t a}}{R_{h}}
$$

Onde $\mathrm{C}_{\mathrm{r}}=\mathrm{Y} \mathrm{R} \mathrm{R}_{\mathrm{s}} /\left(1+\mathrm{b}_{\mathrm{h}} \mathrm{R}_{\mathrm{s}}\right)$

$$
\begin{aligned}
& X_{e}=f b_{h} R_{s} X_{a} \text { (16) } \\
& X_{v}=X_{a}+X_{e}+X_{i}
\end{aligned}
$$

Ainda de acordo com o mesmo autor, foram definidos valores teóricos para as principais grandezas de um sistema (fração de DQO no efluente, fração oxidada e fração no lodo em excesso).

Adicionalmente serão apresentadas algumas outras equações de massa para um sistema de lodos ativados que são essenciais.

$$
\begin{gathered}
m S_{b a}=\left(1-f_{u s}-f_{u p}\right)(\mathbf{1 7}) \\
m S_{t e}=f_{u s} \text { (18) } \\
m X_{i}=\frac{f_{u p} R_{s}}{f_{c v}}(\mathbf{1 9}) \\
m X_{a}=\left(1-f_{u s}-f_{u p}\right) C_{r}=X_{a} V \text { (20) } \\
m X_{e}=\left(1-f_{u s}-f_{u p}\right) C_{r} f b_{h} R_{s} \text { (21) } \\
m X_{v}=m X_{i}+m X_{a}+m X_{e}(\mathbf{2 2}) \\
m X_{t}=\frac{m X_{v}}{f_{v}}(\mathbf{2 3}) \\
m S_{o}=\left(1-f_{u s}-f_{u p}\right)\left(1-f_{c v} Y+f_{c v}(1-f) b_{h} C_{r}\right)(\mathbf{2 4})
\end{gathered}
$$

Outro conceito importante é a definição do volume de um reator biológico $\mathrm{V}_{\mathrm{r}}$ é definido de acordo com a concentração de lodo no reator $\left(\mathrm{X}_{\mathrm{v}}\right)$.

$$
V_{r}=\frac{\left(\left(1-f_{u p}-f_{u s}\right)\left(1+f b_{h} R_{S}\right) C_{r}+\frac{f_{u p} R_{s}}{f_{c v}}\right) Q_{a} S_{t a}}{X_{v}}(\mathbf{2 4})
$$

Ainda deve ser apresentado o conceito da relação A/M (alimento/microrganismos) onde são definidas taxas de aplicação de substrato para uma determinada concentração de 
microrganismos. Esta relação é comumente utilizada para determinação do volume do tanque de aeração e são utilizadas 3 faixas de trabalho:

Tabela 2 - Faixas operacional de sistemas de lodos ativados por aeração prolongada

\begin{tabular}{|c|c|c|c|}
\hline $\begin{array}{c}\text { Parâmetro/Faixa de } \\
\text { operação }\end{array}$ & Alta taxa & Convencional & $\begin{array}{c}\text { Aeração } \\
\text { prolongada }\end{array}$ \\
\hline Objetivo & $\begin{array}{c}\text { Somente remoção } \\
\text { de DBO }\end{array}$ & $\begin{array}{c}\text { Remoção de DBO } \\
\text { + Nitrificação }\end{array}$ & $\begin{array}{c}\text { Semelhante ao } \\
\text { convencional + } \\
\text { estabilização do } \\
\text { lodo }\end{array}$ \\
\hline A $/ \mathrm{M}$ (kg & $0,7-1,1$ & $0,2-0,7$ & $<0,15$ \\
\hline Idade do lodo (dias) & 2 a 4 & & Maior do que 18 \\
\hline
\end{tabular}

Fonte: HENZE (2008)

A fórmula para cálculo desta variável é:

$$
\frac{A}{M}=\frac{\text { Carga DBO afluente diária }}{\text { concentração de sólidos no reator }(X v) * \text { Volume do reator }}
$$

Serão apresentadas algumas fórmulas cinéticas utilizadas por VON SPERLING (1997) para as equações cinéticas de lodos ativados.

$$
\begin{gathered}
\Delta X_{a}=-Y_{h} \Delta S_{b} \rightarrow \frac{d X_{a}}{d t}=-Y_{h} \frac{d S_{b}}{d t} \text { (26) } \\
\Delta O_{2}=\Delta S_{b}\left(1-f_{c v} Y_{h}\right)(\mathbf{2 7}) \\
\frac{d O_{2}}{d t}=\text { Taxa de Utilização de oxigênio } \\
\frac{d S_{b}}{d t}-f_{c v} \frac{d X_{a}}{d t}-\frac{d O_{2}}{d t}=0 \text { (28) }
\end{gathered}
$$




\subsubsection{Modelo cinético de um sistema de lodos ativados para remoção de matéria} orgânica

MONOD (1942) fez diversos estudos para avaliar o comportamento microbiano e seu relacionamento com a disponibilidade de substrato no meio. Desta forma, determinaram-se alguns parâmetros para estabelecer o crescimento microbiano de acordo com uma disponibilidade de substrato. Como não é de interesse deste trabalho discutir a fundo a cinética de crescimento, serão apresentados os principais conceitos apenas neste trabalho.

Considerando-se as taxas de crescimento por unidade de massa $\mathrm{X}_{\mathrm{a}}$ para diversos valores de substrato $\left(\mathrm{S}_{\mathrm{b}}\right)$, tem-se:

$$
\frac{d X_{a}}{d t} * \frac{1}{X_{a}}=\mu=\text { Taxa de crescimento específico }\left(\frac{m g S S V}{m g S S V . d i a}\right)
$$

Figura 7 - Modelo de crescimento de Monod

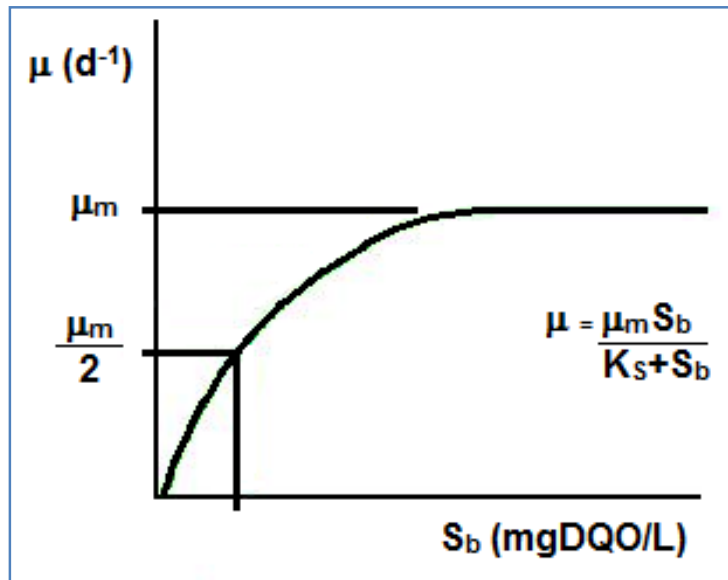

Fonte: VON SPERLING (1997)

Sendo, $\mu_{\mathrm{m}}$ a máxima taxa de crescimento específico e $\mathrm{K}_{\mathrm{s}}$ a constante de meia saturação $\left(\mu_{\mathrm{m}} / 2\right)$, tem-se as seguintes equações cinéticas.

$$
\frac{d S_{b}}{d_{t}}=-\left(\frac{\mu_{m}}{Y_{h}}\right)\left(\frac{S_{b}}{K_{S}+S_{b}}\right) X_{a}=-\left(K_{m} * \frac{S_{b}}{K_{S}+S_{b}}\right) X_{a} \text { (29) }
$$

$\mathrm{K}_{\mathrm{m}}=$ Máxima taxa específica de utilização de substrato $=\mu_{\mathrm{m}} / \mathrm{Y}_{\mathrm{h}}$.

$$
K_{v}=\frac{\mu_{m}}{Y_{h} K_{S}}(\mathbf{3 0})
$$


Esta teoria é aplicada ao caso de tratamento de esgotos, onde deseja-se reduzir ao máximo a quantidade de substrato (matéria orgânica). Utilizando os conceitos apresentados previamente, será discorrido brevemente sobre a idade do lodo na cinética do processo. Vale ressaltar que o $\mathrm{Y}_{\mathrm{h}}$ neste caso refere-se aos microrganismos heterotróficos.

O descarte de lodo do sistema de lodos ativados pode ocorrer de duas formas distintas: Pelo fundo do decantador secundário ou diretamente do reator aerado.

Figura 8 - Esquema de um sistema de lodos ativados e seus pontos de descarte de lodo

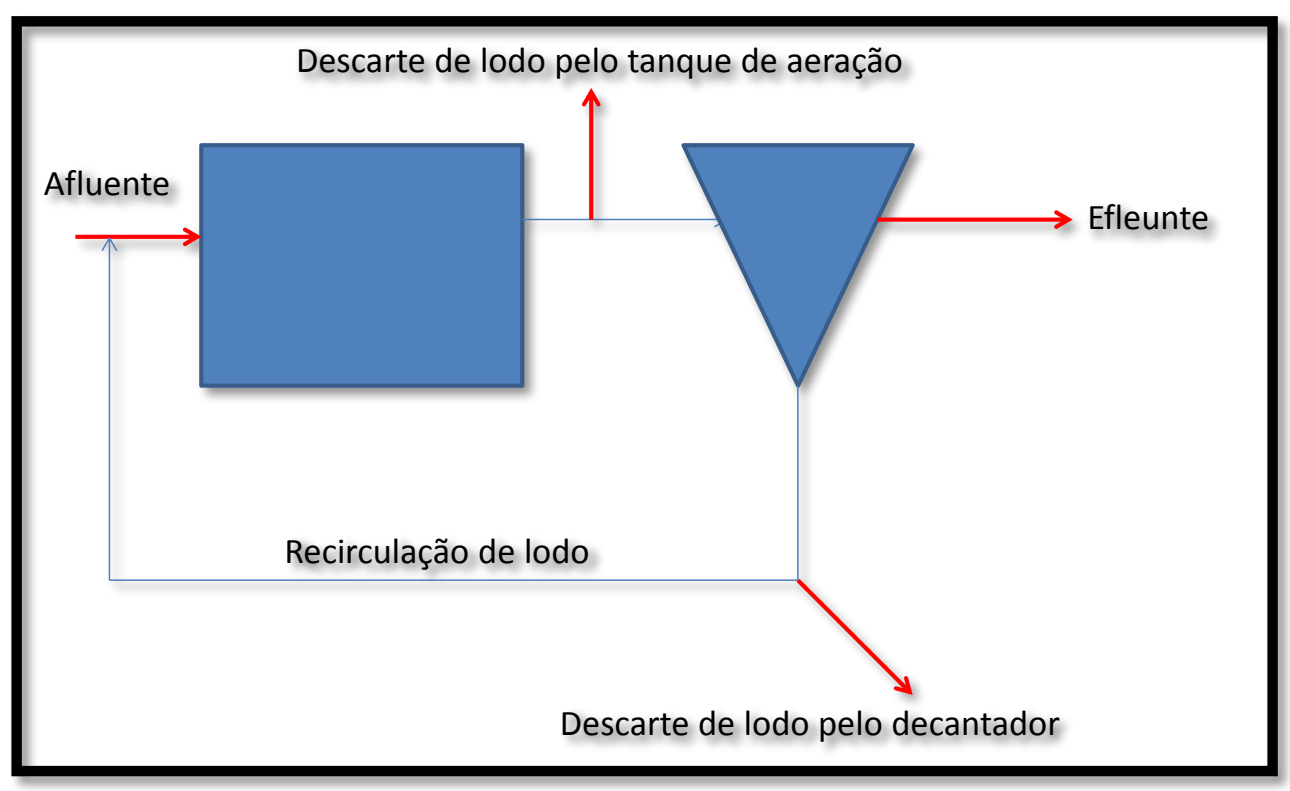

Fonte: Autor

A grande diferença de um descarte de lodo pelo tanque de aeração diretamente consiste no fato de que é possível controlar a idade do lodo neste tanque pela vazão de descarte $\left(\mathrm{Q}_{\mathrm{w}}\right)$, o que é chamado de controle hidráulico da idade do lodo. Já no caso de descarte de lodo pelo fundo do decantador, como a concentração de lodo varia ciclicamente neste, para se controlar a idade do lodo é necessário levar em consideração a concentração de lodo de descarte $\left(\mathrm{X}_{\mathrm{n}}\right)$, do lodo do reator $\left(\mathrm{X}_{\mathrm{o}}\right)$ e da vazão de recirculação $\left(\mathrm{Q}_{\mathrm{r}}\right)$ de modo a se definir o período de descarte.

Desta forma, as equações (31) e (32) expressam as fórmulas para idade do lodo para diferentes opções de descarte de lodo.

$$
\begin{array}{r}
\text { Para descarte do } T A-R_{S}=V / Q_{w}(\mathbf{3 1}) \\
\text { Para descarte do decantador }-R_{s}=\frac{X_{o} V}{X_{r} Q_{r}}
\end{array}
$$


Pode-se notar que a primeira opção é muito mais simples e será adotada como premissa para as modelagens deste trabalho.

Outro fator importante em um sistema de lodos ativados é a vazão de recirculação de lodo que mantém a concentração de sólidos no tanque de aeração em um determinado patamar. Considerando a relação entre vazão de recirculação e vazão afluente (r) e a concentração de sólidos da recirculação de $\left(\mathrm{X}_{\mathrm{r}}\right)$, a concentração de sólidos em suspensão (X) em um sistema é:

$$
X=\frac{r X_{r}}{1+r}(\mathbf{3 3})
$$

Para as equações de balanço de massa, serão apenas apresentadas as principais equações sugeridas por VAN HAANDEL (1999). Para o balanço de massa da concentração de massa ativa $\left(\mathrm{X}_{\mathrm{a}}\right)$, consegue-se eliminar este fator, de modo que a carga de DQO biodegradável fica independente da concentração $X_{\mathrm{a}}$.

$$
S_{b}=\frac{1+b_{h} R_{S}}{Y K_{v} R_{S}}(\mathbf{3 4})
$$

A Concentração de substrato biodegradável pode ser definido também pela concentração de substrato biodegradável afluente $\left(\mathrm{S}_{\mathrm{bi}}\right)$.

$$
S_{b}=\frac{S_{b}}{1+K_{v} X_{a} R_{h}}(\mathbf{3 5})
$$

Desta forma, igualando as fórmulas:

$$
X_{a}=\frac{Y\left(S_{b i}-S_{b}\right) R_{S}}{\left(1+b_{h} R_{S}\right) R_{h}}(\mathbf{3 6})
$$

A massa descartada de lodo $\left(\mathrm{M} \Delta \mathrm{X}_{\mathrm{a}}\right)$ é dada pela seguinte fórmula:

$$
M \Delta X_{a}=X_{a} Q_{w}(\mathbf{3 7})
$$

A massa de $\mathrm{X}_{\mathrm{a}}$ no reator pode ser aproximada pela seguinte fórmula quando a idade do lodo é maior do que 2,5 dias:

$$
M X_{a}=\frac{Y M S_{b i} R_{S}}{1+b R_{s}}(38)
$$


Onde $M S_{b i}$ é a vazão afluente multiplicado pela concentração de substrato na entrada do sistema. Por sua vez a massa de voláteis $\left(\mathrm{MX}_{\mathrm{v}}\right)$ no tanque de aeração é dependente da temperatura do sistema e seu dimensional é dado por:

$$
M X_{v}=\frac{Q S_{t a}\left(\left(1-f_{u s}-f_{u p}\right) Y_{h} R_{s}\right)}{\left(1+b_{h T} R_{S}\right)}\left(1+f b_{h T} R_{S}\right)+R_{s} \frac{f_{u p}}{f_{c v}}(\mathbf{3 9})
$$

Onde $b_{h T}$ é o coeficiente de respiração endógena ajustada para a temperatura de operação do sistema. Para a definição da massa de oxigênio dissolvida necessária para a síntese celular e respiração endógena, pode-se afirmar:

$$
\frac{M O}{d}=\left(1-f_{c v} Y_{h}\right) M S_{b i}+(1-f) b f_{c v} M X_{a}\left(\frac{k g O_{2}}{d i a}\right)
$$

As constantes que dependem da temperatura (em graus Celsius) são:

$$
\begin{aligned}
& K_{v T}=0,071,029^{T-20} \\
& K_{v T}=0,241,029^{T-20}
\end{aligned}
$$

Já $\mathrm{f}_{\mathrm{cv}}$ e $\mathrm{Y}_{\mathrm{h}}$ não dependem de temperatura.

Com relação ao consumo de oxigênio para degradação de matéria orgânica em um sistema para a degradação de matéria orgânica, METCALF \& EDDY (2002) sugere uma taxa de aplicação de 1 a $2 \mathrm{~kg} \mathrm{O} / \mathrm{kg}$ de DBO aplicada ao sistema.

Adicionalmente, ressalta-se que existe uma metodologia para definição de necessidades de oxigênio e meios de transferência (bolhas finas, grossas, aeradores mecânicos), mas como este trabalho não tem por objetivo avaliar condições de aeração, não será apresentada a referida formulação. Para maiores detalhes vide METCALF \& EDDY (2002).

\subsubsection{Cinética de nitrificação}

Em sistemas de lodos ativados também pode ocorrer, dependendo da configuração do sistema, a conversão de nitrogênio em sua forma amoniacal para nitratos em dois passos sequenciais no reator aerado do sistema de lodos ativados.

Estes dois passos são a nitritação e a desnitratação, respectivamente. Vale ressaltar que se a população de bactérias nitrificadoras está bem estabelecida no sistema, a segunda 
etapa do processo em 2 estágios desenvolve-se de maneira muito rápida e para efeitos práticos pode ser considerada como uma reação instantânea.

$$
\mathrm{NH}_{4}^{+} \stackrel{\text { Organismos Autotróficos }}{\longrightarrow} \mathrm{NO}_{3}^{-}
$$

Processo em 2 estágios:

$\mathrm{NH}_{4}^{+}+3 / 2 \mathrm{O}_{2} \stackrel{\text { Org. Nitritantes (Nitrossomonas, etc.) }}{\longrightarrow} \mathrm{NO}_{2}^{-}+\mathrm{H}_{2} \mathrm{O}+2 \mathrm{H}^{+}$

Org. Nitratantes (Nitrobacter, etc.)

$\mathrm{NO}_{2}^{-}+1 / 2 \mathrm{O}_{2} \longrightarrow \mathrm{NO}_{3}^{-}$

De acordo com as reações estequiométricas apresentadas, o consumo de oxigênio para a nitritação é de $3,43 \mathrm{mg} \mathrm{O}_{2} / \mathrm{mg} \mathrm{N}$ e para a nitratação o consumo é de $1,14 \mathrm{mg} \mathrm{O}_{2} / \mathrm{mg} \mathrm{N}$, totalizando 4,57 $\mathrm{mg} \mathrm{O}_{2} / \mathrm{mg} \mathrm{N}^{-\mathrm{NH}_{4}}$ nitrificado. Isto mostra que o consumo de oxigênio por unidade de nitrogênio amoniacal aplicada é muito maior do que o consumo de oxigênio para degradação da DQO.

Como já apresentado previamente, a nitratação é muito rápida, de forma que a primeira etapa da nitritação rege o processo. Desta forma, o modelo teórico considera apenas a primeira etapa do processo. Downing et al (1964) apresentou o crescimento de Nitrosomonas na oxidação de amônia para nitrito de acordo com a equação de Monod.

$$
\begin{gathered}
\frac{d X_{n}}{d t}=\left(\frac{d X_{n}}{d t}\right)_{c}+\left(\frac{d X_{n}}{d t}\right)_{d} \text { (43) } \\
\left(\frac{d X_{n}}{d t}\right)_{c}=\mu X_{n}=\frac{\mu_{m} X_{n} N_{a}}{N_{a}+K_{n}}(44) \\
\left(\frac{d X_{n}}{d t}\right)_{d}=-b_{n} X_{n} \text { (45) }
\end{gathered}
$$

Na qual:

Tabela 3 - Siglas do modelo cinético de nitrificação

\begin{tabular}{|c|c|}
\hline Sigla & Significado \\
\hline$X_{n}$ & Concentração de nitrossomonas \\
\hline
\end{tabular}




\begin{tabular}{|c|c|}
\hline$\left(\mathrm{d} \mathrm{X}_{\mathrm{n}} / \mathrm{dt}\right)$ & $\begin{array}{c}\text { Taxa de variação da concentração de } \\
\text { nitrossomonas - Taxa de crescimento } \\
\text { líquido }\end{array}$ \\
\hline$\left(\mathrm{d} X_{\mathrm{n}} / \mathrm{dt}\right)_{\mathrm{c}}$ & $\begin{array}{c}\text { Taxa de variação da concentração de } \\
\text { nitrossomonas - Taxa de crescimento } \\
\text { bruto }\end{array}$ \\
\hline$\left(\mathrm{d} X_{\mathrm{n}} / \mathrm{dt}\right)_{\mathrm{d}}$ & Taxa de decaimento de nitrossomonas \\
\hline$\mu$ & $\begin{array}{c}\text { Taxa específica de crescimento de } \\
\text { nitrossomonas }\left(\mathrm{d}^{-1}\right)\end{array}$ \\
\hline$\mu_{\mathrm{m}}$ & $\begin{array}{l}\text { Taxa específica máxima de crescimento } \\
\text { de nitrossomonas }\end{array}$ \\
\hline $\mathrm{b}_{\mathrm{n}}$ & $\begin{array}{l}\text { Constante de decaimento de } \\
\text { nitrossomonas }\left(\mathrm{d}^{-1}\right)\end{array}$ \\
\hline $\mathrm{K}_{\mathrm{n}}$ & $\begin{array}{l}\text { Constante de meia saturação de Monod } \\
\qquad(\mathrm{mg} \mathrm{N} / \mathrm{l})\end{array}$ \\
\hline
\end{tabular}

Fonte: VAN HAANDEL (1999) 


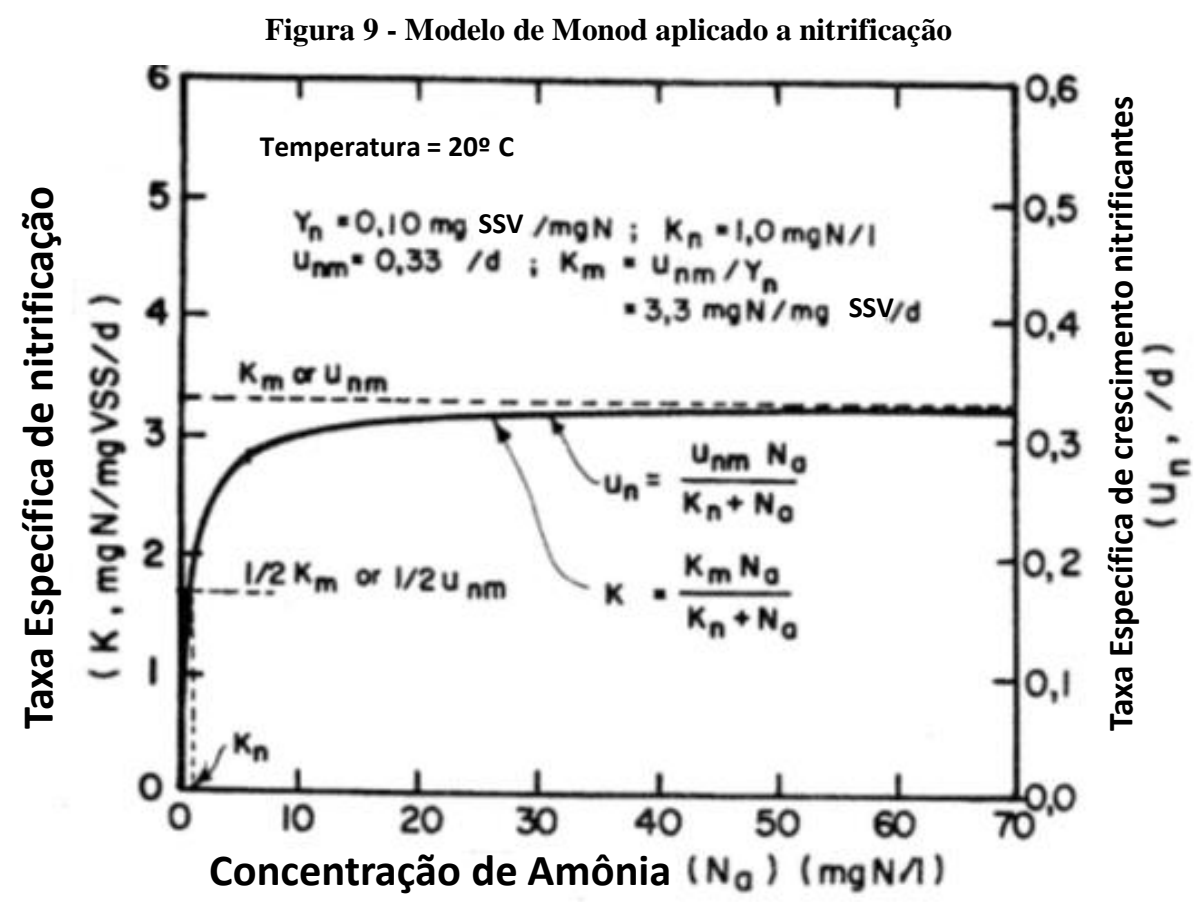

Fonte: Editado de Piveli (2013)

Considerando um sistema em condições estacionárias, considera-se que não há variação de massa de nitrossomonas.

$$
\frac{d X_{n}}{d t}=0={\frac{d X_{n}}{d t}}_{c}+{\frac{d X_{n}}{d t}}_{d}+\frac{d X_{n}}{d t} e
$$

Onde a taxa de variação da concentração de Nitrossomonas devido a descarga de lodo pode ser expressa como a concentração de Nitrossomonas divido pela idade do lodo $\left(\mathrm{R}_{\mathrm{s}}\right)$.

$$
{\frac{d X_{n}}{d t}}_{e}=-\frac{X_{n}}{R_{s}}(47)
$$

Desta forma, a concentração de matéria nitrogenada amoniacal no licor misto e consequentemente no efluente é dado por:

$$
N_{a}=\frac{K_{n}\left(b_{n}+\frac{1}{R_{S}}\right)}{\mu_{m}-\left(b_{n}+\frac{1}{R_{S}}\right)}
$$

Esta equação auxilia na definição da idade mínima do lodo para se gerar uma concentração de nitrogênio no efluente.

$$
N_{a} \leq N_{p}=\frac{K_{n}\left(b_{n}+\frac{1}{R_{S n}}\right)}{\mu_{m}-b_{n}-\frac{1}{R_{S n}}} \text { (49A) }
$$


Ou alternativamente:

$$
R_{\text {sn }}=\left(1+\frac{K_{n}}{N_{p}}\right) /\left(\mu_{m}-b_{n}\left(1+\frac{K_{n}}{N_{p}}\right)\right)(\mathbf{4 9 B})
$$

Onde $\mathrm{N}_{\mathrm{p}}$ é a concentração de nitrogênio disponível para a nitrificação. Considerando águas residuárias municipais, a concentração de amônia disponível para nitrificação é muito maior do que $K_{n}$, de modo que a equação da idade mínima do lodo pode ser pode ser simplificada para:

$$
R_{s n}=\frac{1}{\mu_{m}-b_{n}}(\mathbf{5 0})
$$

Isto indica que a idade do lodo é essencial para nitrificação e em condições operacionais com idade do lodo menor do que as aqui apresentadas não haverá nitrificação.

Figura 10 - Influência da Idade do lodo na nitrificação

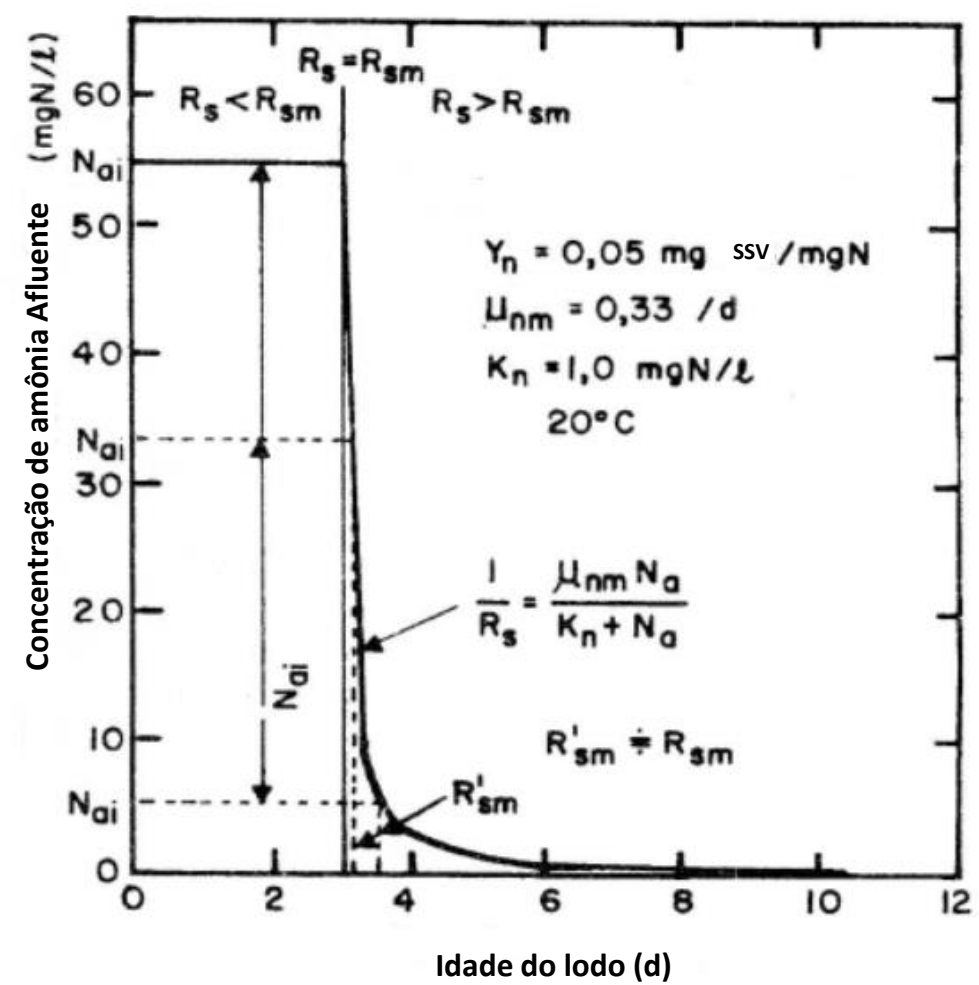

Fonte: Adaptado de Downing et al (1964)

De acordo com VAN HAANDEL (1999), muitas das constantes apresentadas previamente nesta modelagem cinética sofrem grande influência da temperatura. Adicionalmente este mesmo autor afirma que a taxa de crescimento específico máximo das nitrossomonas influência muito mais o desempenho do sistema se comparado com a taxa de decaimento bacteriano $\left(b_{n}\right)$ e a constante de meia saturação de Monod $\left(K_{n}\right)$. 
VAN HAANDEL (1999) afirma que para uma idade do lodo 50\% maior do que a idade mínima do lodo para nitrificação, os efluentes apresentam concentração de amônia muito baixos e a nitrificação será completa.

\subsubsection{Influência da temperatura no processo de nitrificação}

A taxa de crescimento específica máxima $\left(\mu_{\mathrm{m}}\right)$ pode ser definida de acordo com a temperatura, de acordo com a simplificação de Arrehnius.

$$
\mu_{m t}=\mu_{m 20} \theta^{t-20}(\mathbf{5 1})
$$

Onde $\mu_{\mathrm{mt}}$ é uma característica do afluente e $\theta$ é o coeficiente de Arrehnius e seu valor foi determinado por alguns autores.

Tabela 4 - Valores da dependência da temperatura da taxa específica máxima de crescimento de Nitrossomonas

\begin{tabular}{|c|c|c|}
\hline $\boldsymbol{\Theta}$ & Intervalo temperatura $^{\mathbf{0}} \mathbf{C}$ & Referência \\
\hline 1,116 & $19-21$ & Gujer (1977) \\
\hline 1,123 & $15-20$ & Downing et al (1964) \\
\hline
\end{tabular}

Fonte: VAN HAANDEL (1999)

Neste trabalho será utilizado o valor de referência de Ekama e Marais $(1,123)$ para o coeficiente de Arrehnius. Outros fatores que são influenciados pela temperatura são $\mathrm{K}_{\mathrm{n}}$, e $b_{n}$.

$$
\begin{aligned}
& K_{n T}=K_{n 20} 1,123^{t-20} \\
& b_{n T}=b_{n 20} 1,029^{t-20}
\end{aligned}
$$

A idade do lodo deve ser definido pela temperatura mínima de operação do sistema e sugere-se um fator de segurança de $25 \%$ em seu valor mínimo.

$$
R_{s}=1,25 R_{\text {sm (tmin) }}
$$

\subsubsection{Influência do pH e alcalinidade no processo de nitrificação}

De acordo com VAN HAANDEL (1999), o pH exerce grande influência no papel da nitrificação. Para $\mathrm{pH}$ entre 7,2 e 8,5 , os coeficientes cinéticos $\boldsymbol{\mu}_{\mathbf{m}}$ e $\mathrm{K}_{\mathrm{n}}$ se mantém praticamente constantes. Normalmente se adota o valor de $\mathrm{pH} 7,2$ como valor de referência. 
Ainda de acordo com este autor, para $\mathrm{pH}$ entre 5 e 7,2 as fórmulas dos coeficientes cinéticos ficam:

$$
\begin{aligned}
& \mu_{n m, \square H}=\mu_{n m, 7,2} * 2,35^{p H-7,2} \\
& K_{n m, p H}=K_{n m, 7,2} * 2,35^{7,2-p H}
\end{aligned}
$$

Já com relação à alcalinidade, para a nitrificação de $1 \mathrm{mg}$ de $\mathrm{N}-\mathrm{NH}_{4}{ }^{+}$são necessários 7,14 mg de alcalinidade. Adicionalmente ALEM SOBRINHO (1991) constata que se em algum momento da nitrificação a alcalinidade fica abaixo de $40 \mathrm{mg} / \mathrm{L}, \mathrm{o} \mathrm{pH}$ pode ter alguma instabilidade para a nitrificação e isso gerar consequentemente problemas operacionais para a ETE.

Desta forma, ambas as condicionantes ( $\mathrm{pH}$ e alcalinidade) são essenciais para a correta nitrificação.

Como alternativa para o problema da alcalinidade, pode-se mencionar que a desnitrificação conforme será apresentado posteriormente recompõe aproximadamente metade da alcalinidade consumida (METCALF \& EDDY, 2002) o que pode auxiliar na estabilização do processo de desnitrificação.

\subsubsection{Potencial e capacidade de nitrificação}

Segundo VAN HAANDEL (1999), o potencial de nitrificação $\left(\mathrm{N}_{\mathrm{p}}\right)$ pode ser definido como a concentração de nitrogênio que pode ser nitrificada. É representada matematicamente como a concentração total de nitrogênio Kjeldahl afluente (TKN $\mathrm{N}_{\mathrm{ka}}$ ) subtraído pelas concentrações de $\mathrm{TKN}$ utilizados para a produção de lodo em excesso $\left(\mathrm{N}_{1}\right)$ e pelo nitrogênio orgânico no afluente $\left(\mathrm{N}_{\mathrm{oe}}\right)$

$$
N_{p}=N_{k a}-N_{l}-N_{o e}(\mathbf{5 7})
$$

Já a capacidade de nitrificação $\left(\mathrm{N}_{\mathrm{c}}\right)$ é a diferença entre o potencial de nitrificação e a concentração residual de TKN no efluente final ( $\left.\mathrm{N}_{\mathrm{ae}}\right)$ (Equações 58 e 59).

$$
\begin{gathered}
N_{p}=N_{k a}-f_{n}\left(\frac{\left(1-f_{u s}-f_{u p}\right)\left(1+b_{h} R_{s}\right) C_{r}}{R_{s}}+\frac{f_{u p}}{f_{c v}}\right) S_{t a} \\
N_{c}=N_{p}-N_{a e} \text { (59) }
\end{gathered}
$$


Apenas para fins de conceituação, o TKN afluente é composto por nitrogênio amoniacal (utilizado para síntese de microrganismos sendo que parte deve ser nitrificada), nitrogênio orgânico biodegradável e não biodegradável.

$\mathrm{N}_{\mathrm{t}}=$ Nitrogênio total $(\mathrm{mg} \mathrm{N} / \mathrm{L})$

$\mathrm{N}_{\mathrm{a}}=$ Amônia livre (mg N/L)

$\mathrm{N}_{\mathrm{u}}=$ Nitrogênio orgânico solúvel não biodegradável (mg N/L)

$\mathrm{N}_{\mathrm{o}}=$ Nitrogênio orgânico biodegradável (mg N/L)

$$
\begin{gathered}
\text { Resumo: } N_{t}=N_{a}+N_{u}+N_{o} \text { (60) } \\
N_{a}=\frac{K_{n T}\left(b_{n T}+\frac{1}{R_{s}}\right)}{\mu_{n m T}-\left(b_{n T}+\frac{1}{R_{S}}\right)}(\mathbf{6 1}) \\
N_{u}=N_{u i}=f_{n u} N_{t i}(\mathbf{6 2}) \\
N_{o}=\frac{N_{o i}}{1+K_{r} X_{a} R_{h n}}(\mathbf{6 3}) \\
K_{r}=0,0151,029^{T-20}(\mathbf{6 4}) \\
N_{o}=\frac{R_{h n}=\frac{V_{p i}}{Q_{i}}(\mathbf{6 5})}{1+\frac{K_{r} X_{a} V_{p}}{Q_{i}}}=\frac{N_{o i}}{1+\frac{K_{r} M X_{a}}{Q_{i}}}(\mathbf{6 6})
\end{gathered}
$$

\subsubsection{Cinética de desnitrificação}

Após a nitrificação há uma grande quantidade de nitrogênio na forma de nitrato e nitrito que deve ser removida. Neste contexto, existe a etapa de desnitrificação que consiste na transformação de nitrato e nitrito em nitrogênio na forma gasosa. 
Figura 11 - Arranjos para a remoção de nitrogênio

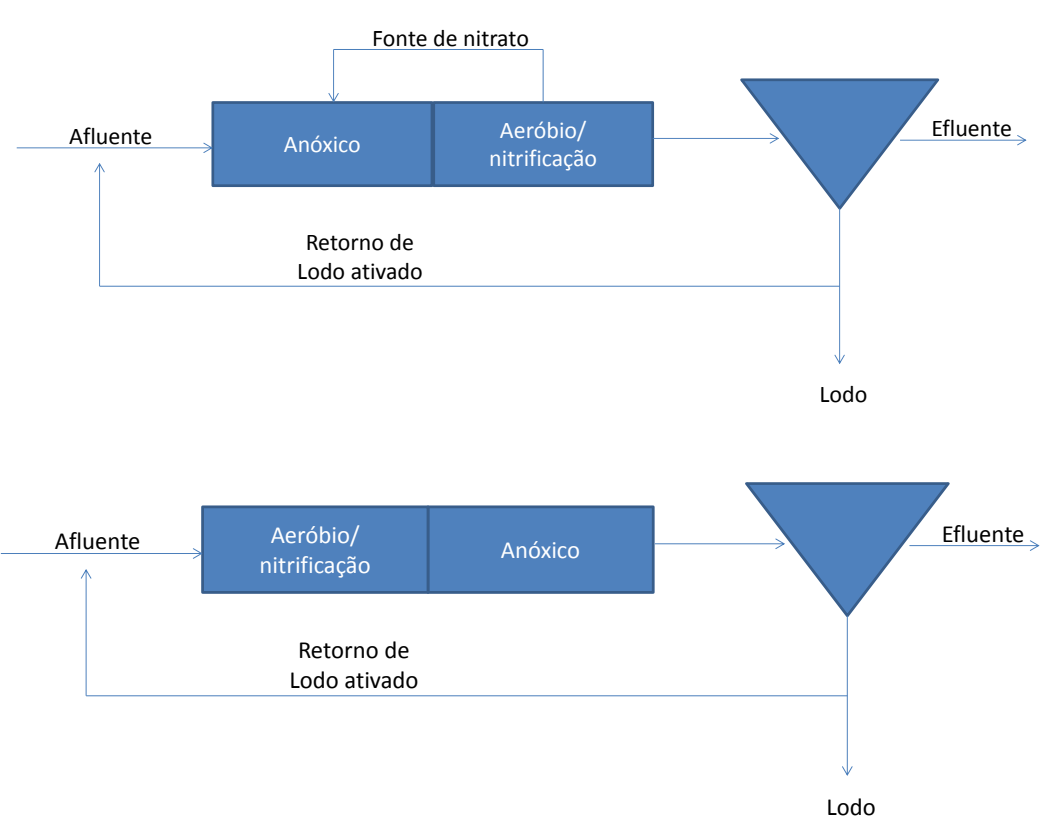

Fonte: Adaptado de Metcalf \& Eddy (2002)

Para a desnitrificação devem ser observadas algumas condições básicas de operação:

1. Ausência de oxigênio dissolvido

2. Presença de matéria orgânica rapidamente biodegradável (fonte de energia)

3. Presença de nitrato ou nitrito

4. Existência de bactérias facultativas

De acordo com METCALF \& EDDY (2002), a desnitrificação requer uma fonte de energia capaz de doar elétrons. Nos reatores aerados o oxigênio faz esse papel, porém como o oxigênio é doador preferencial de elétrons, sua ausência é essencial. Desta forma, para que a desnitrificação ocorra é necessário que haja matéria orgânica rapidamente biodegradável que será decomposta com o intuito de doar elétrons para os íons nitrato e nitrito.

De acordo com VAN HAANDEL (1999), existe a desnitrificação dissimilativa e a desnitrificação assimilativa onde a massa de bactérias facultativas consome o nitrogênio para síntese celular. Segundo PIVELI (2013) a transformação de nitrato em nitrito e posteriormente de nitrito em nitrogênio gasoso se dá da seguinte forma:

$$
\text { Nitrato: } \mathrm{NO}_{3}^{-}+2 \mathrm{H}^{+}+2 e^{-} \rightarrow \mathrm{NO}_{2}^{2-}+\mathrm{H}_{2} \mathrm{O}
$$




$$
\text { Nitrito: } \mathrm{NO}_{2}^{2-}+4 \mathrm{H}^{+}+3 e^{-} \rightarrow \frac{1}{2} \mathrm{~N}_{2}+2 \mathrm{H}_{2} \mathrm{O}
$$

Na ausência de oxigênio e presença de metanol:

$$
\begin{gathered}
\text { Oxidação: } 5 \mathrm{CH}_{3} \mathrm{OH}+5 \mathrm{H}_{2} \mathrm{O} \rightarrow 5 \mathrm{CO}_{2}+30 \mathrm{H}^{+}+30 e^{-} \\
\text {Redução: } 36 \mathrm{H}^{+}+30 e^{-}+6 \mathrm{NO}_{3}^{-} \rightarrow 3 \mathrm{~N}_{2}+18 \mathrm{H}_{2} \mathrm{O} \\
\text { Total: } 5 \mathrm{CH}_{3} \mathrm{OH}+6 \mathrm{NO}_{3}^{-}+6 \mathrm{H}^{+} \rightarrow 5 \mathrm{CO}_{2}+3 \mathrm{~N}_{2}+13 \mathrm{H}_{2} \mathrm{O}
\end{gathered}
$$

Neste segundo caso, pela remoção de íons $\mathrm{H}^{+}$, há um aumento de alcalinidade que foi previamente consumido na nitrificação e o nitrato se torna aceptor de elétrons da matéria orgânica.

A metodologia cinética estudada seguirá VAN HAANDEL (1999) considerando um reator anóxico com escoamento plug flow. A taxa de desnitrificação $\left(\mathrm{r}_{\mathrm{d}}\right)$ é proporcional à concentração de lodo ativado e dependente de uma constante $\left(\mathrm{K}-\mathrm{mg} \mathrm{N} / \mathrm{mgX} \cdot \mathrm{d}^{-1}\right) \mathrm{de}$ desnitrificação.

$$
r_{d}=\frac{d N}{d t}=-K X_{a}(\mathbf{6 7})
$$

Considerando que a nitrificação ocorre em reatores anóxicos pré- $\mathrm{D}$, a taxa $\mathrm{K}$ de desnitrificação ocorre a uma determinada velocidade até certo tempo de permanência no reator e depois há uma redução nesta velocidade (devido à existência apenas de matéria lentamente biodegradável num segundo momento). Desta forma a constante $\mathrm{K}$ deve ser descrita como a soma de duas constantes $\mathrm{K}_{1}$ e $\mathrm{K}_{2}$ para a fase primária e secundária respectivamente.

Desta forma, a taxa de desnitrificação ficaria:

$$
r_{d}=r_{d s}+r_{d p}=\left(K_{1}+K_{2}\right) X_{a}(\mathbf{6 8})
$$

Sendo $r_{d s}$ a taxa de desnitrificação associada à utilização do material rapidamente biodegradável e $r_{d p}$ a taxa de desnitrificação associada à utilização de material lentamente biodegradável.

VAN HAANDEL (1999) ainda menciona uma terceira possível etapa de desnitrificação (pos-D) onde o reator anóxico localiza-se a jusante do reator aerado e sua taxa de desnitrificação está associada a uma terceira constante $\mathrm{K}_{3}$. Este arranjo é muito útil para 
os casos onde se deseja aproveitar parte da matéria orgânica autogerada que pode ser gerada no reator aerado pelas atividades de respiração endógena. Para a faixa de 12 a 22 graus Celsius este mesmo autor apresenta os valores obtidos para as constantes $\mathrm{K}$ para os esgotos brutos da África do Sul.

$$
\begin{gathered}
K_{1}=0,72 * 1,2^{t-20}(\mathbf{6 9}) \\
K_{2}=0,1 * 1,08^{t-20}(\mathbf{7 0}) \\
K_{3}=0,08 * 1,03^{t-20}(\mathbf{7 1})
\end{gathered}
$$

Pode-se observar que a desnitrificação por estes dados se dá de maneira muito mais rápida e adequada quando da presença de matéria orgânica rapidamente biodegradável.

Outro conceito importante é a fração mínima de lodo no reator pré-D. Como a remoção de nitrato (desnitrificação) ocorre com taxas muito mais altas na presença de substrato rapidamente biodegradável, é essencial que durante o tempo de permanência no reator haja tal tipo de substrato para que ocorra a desnitrificação com a maior velocidade possível. A taxa de alimentação de material rapidamente biodegradável pode ser expresso como:

$$
r_{s b s}=\frac{s_{b s a}}{R_{l}}(\mathbf{7 2})
$$

Onde $\mathrm{R}_{1}$ é o tempo de detenção em um reator anóxico. Ressalta-se que a taxa de utilização de material rapidamente biodegradável é proporcional a taxa de desnitrificação associada $\left(\mathrm{r}_{\mathrm{Ds}}=\mathrm{K}_{1} \mathrm{X}_{\mathrm{a}}\right)$.Desta forma, pode-se definir:

$$
r_{D S}=0,12 r_{u s} \mathbf{( 7 3 )}
$$

Onde $r_{u s}$ é a taxa de utilização rapidamente biodegradável.

De acordo com VAN HAANDEL (1999), o tempo de permanência mínima no reator anóxico $\left(\mathrm{R}_{\min }\right)$ é associado a uma fração mínima de massa de lodo no reator pre-D $\left(\mathrm{f}_{\min }\right.$ ou $\left.f_{x t}\right)$.

$$
f_{\min }=\frac{0,12 f_{s b}}{K_{l} C_{r}}(\mathbf{7 4})
$$

Isto mostra a interdependência da nitrificação e desnitrificação com a massa de heterotróficas e com a qualidade do efluente bruto. 


$$
R_{\text {smin }}=\frac{1}{\mu_{n m T}\left(1-f_{x t}\right)-b_{n T}}
$$

Deve-se sempre levar em consideração que a desnitrificação é muito sensível a variações de temperatura e o tempo de detenção hidráulica deve ser sempre definido de acordo com a temperatura mínima para o sistema.

\subsubsection{Capacidade de desnitrificação}

Considerando a fração de lodo em um reator anóxico $\left(\mathrm{f}_{\mathrm{xl}}\right)$ maior do que a fração mínima para nitrificação $\left(f_{\min }\right)$, pode-se definir a capacidade de desnitrificação como sendo todo o nitrato que pode ser convertido a $\mathrm{N}_{2}$ gasoso.

$$
D_{c l}=\left(0,12 f_{s b}+K_{2} C_{r} f_{x l}\right) S_{b a} \text { (76) }
$$

Figura 12 - Relação capacidade de nitrificação $x$ idade do lodo x NTK/DQO
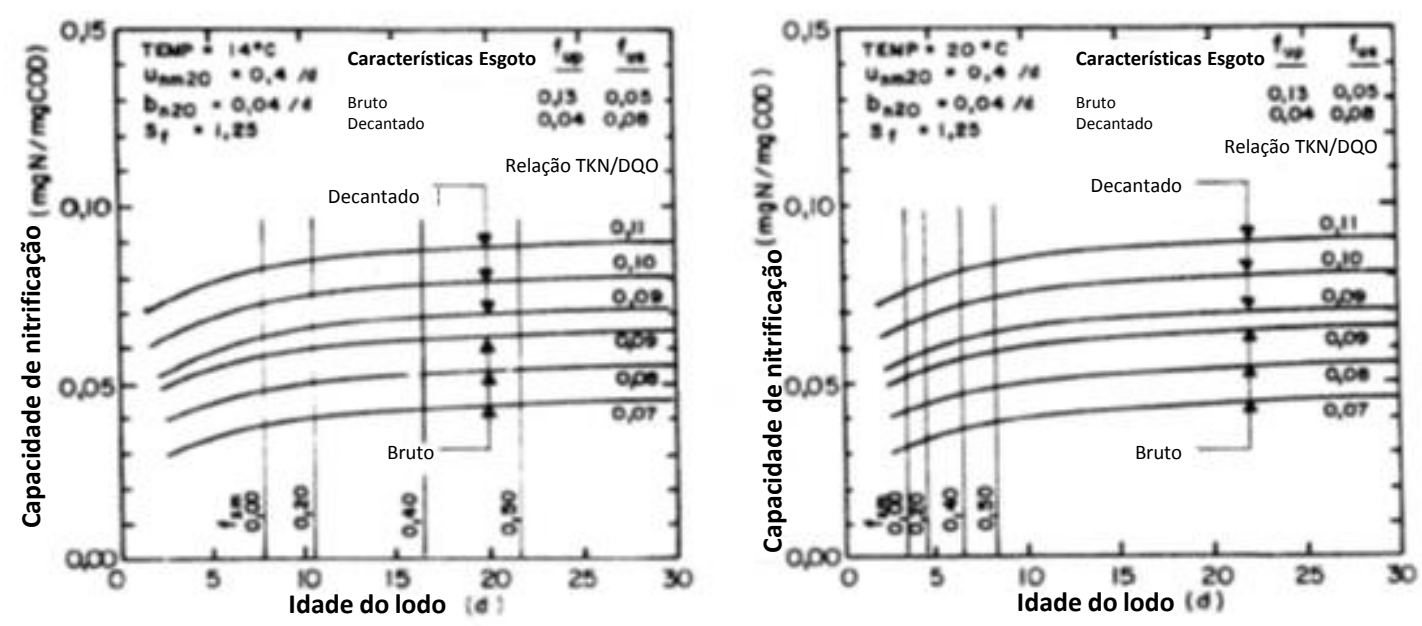

Fonte: Piveli (2013)

De acordo com VAN HAANDEL (1999), o modelo cinético de desnitrificação baseia-se em coeficientes e estes são baseados em observações experimentais muito complexas de serem verificadas na prática. 


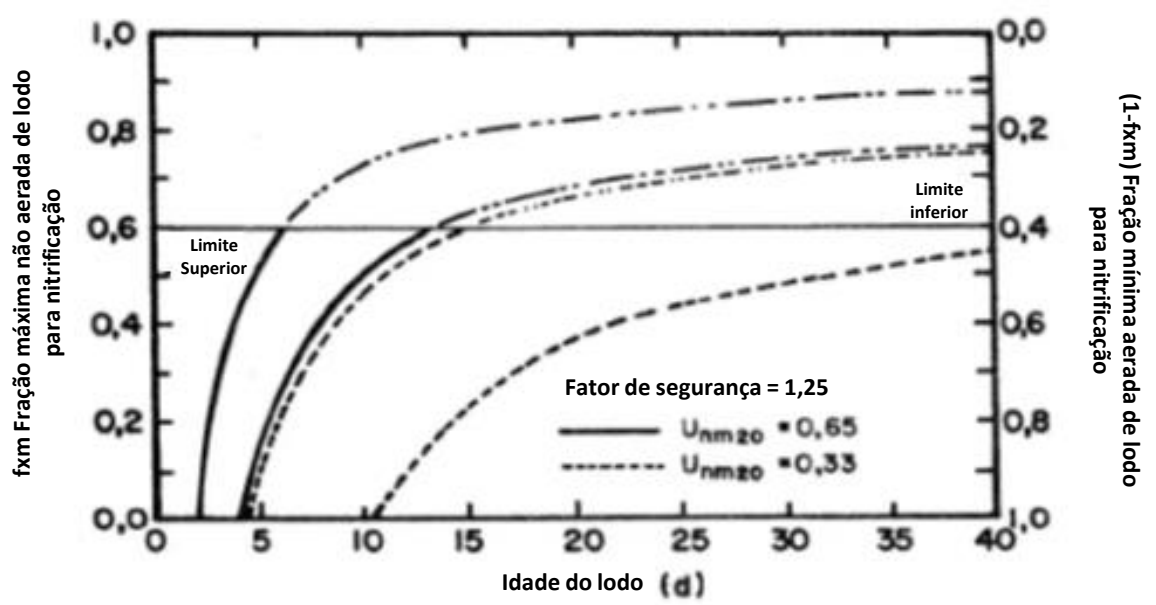

Fonte: Adaptado de ALEM SOBRINHO (1991)

Pela estequiometria, para cada $1 \mathrm{mg}$ de oxigênio utilizado, normalmente se consome 2,994 mg de DQO, assim como $1 \mathrm{mg}$ de nitrato na norma de nitrogênio equivale a 2,86 mg de oxigênio.

\subsubsection{Efeito da desnitrificação na demanda de oxigênio}

Conforme observado por CARLSON (1974) o oxigênio dissolvido é um inibidor da desnitrificação. No entanto, nos reatores anóxicos (pré-D principalmente) pode-se observar em alguns casos uma redução de até $63 \%$ nas demandas de oxigênio em um sistema dotado de reatores anóxicos. Isto representa uma significativa redução de consumo energético em um item que representa quase $50 \%$ dos gastos de uma planta de tratamento de esgotos.

Ressalta-se que em sistemas e/ou etapas onde há oxigênio dissolvido em concentração acima de 0,4 mg/L não ocorre desnitrificação, uma vez que o oxigênio é doador preferencial de elétrons se comparado com o nitrato.

\subsubsection{Fontes de substrato}

Conforme apresentado por VAN HAANDEL (1999), existem 3 tipos de fonte de substrato para um reator anóxico: Externa, interna e auto gerada.

A fonte de substrato externa não é presente na água residuária e normalmente é adicionada em um reator pós-D para que a desnitrificação ocorra. Pode ser pela dosagem de metanol, etanol, etc. (fontes de substrato rapidamente biodegradável). 
Já a fonte interna de substrato está presente na água residuária afluente e é aproveitada pelo seu encaminhamento ao reator anóxico antes de passar por qualquer outro tipo de tratamento biológico (reatores UASB, decantadores primários, etc.). Em esgotos brutos, esta parcela preferencialmente utilizado (DQO rapidamente biodegradável $f_{b s}$ ) é fundamental para o mecanismo de desnitrificação.

Por outro lado os substratos auto gerados são decorrentes da respiração endógena dos microrganismos presentes nos reatores biológicos.

\subsubsection{Taxas de recirculação}

Para uma taxa de desnitrificação constante e um tempo de detenção efetivo $\left(R_{a}\right)$, a remoção efetiva de nitrato é dada por:

$$
\Delta N_{a}=K X_{a} R_{a}(77)
$$

Sendo a vazão total afluente Q, e considerando que haverá desnitrificação de acordo com um reator pre-D, as recirculações possíveis são do reator aerado para o reator anóxico (fonte de nitrato - representado pela letra a) e do decantador secundário para o início do processo ou para o reator aerado (representado pela letra s - para manutenção da concentração de sólidos no reator).

Figura 14 - Configurações possíveis de sistemas com remoção biológica de nitrogênio

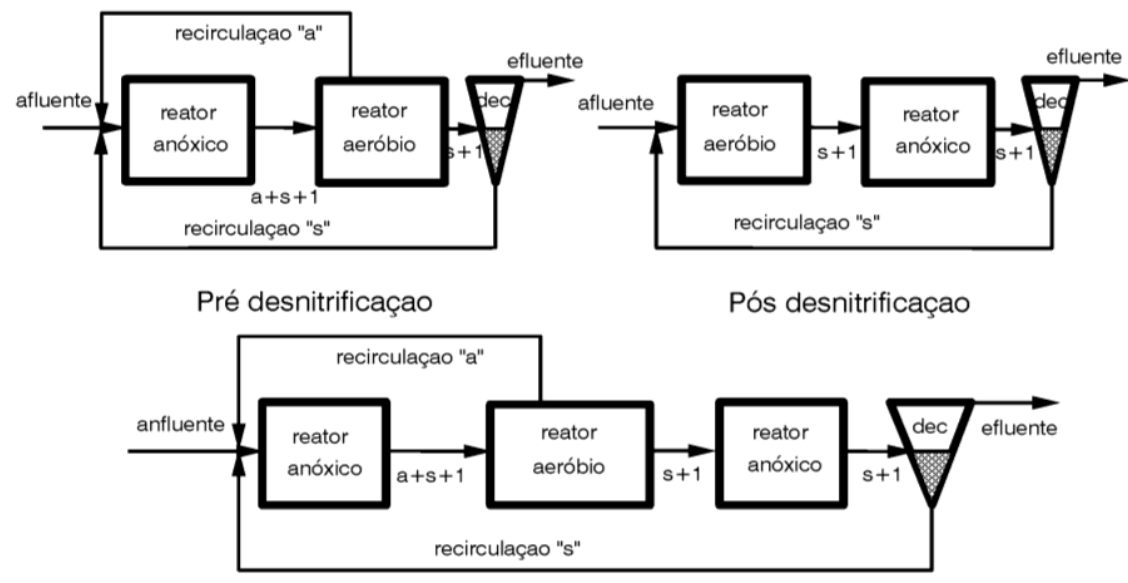

Pré e pós desnitrificaçao: Bardenpho

Fonte: VAN HAANDEL (1999)

Pode-se observar que a vazão de fato afluente ao sistema em estado estacionário é $\mathbf{Q}^{*}(\mathbf{1}+\mathbf{S}+\mathbf{a})$. Desta maneira a taxa efetiva de remoção de nitrato no sistema $\left(\Delta \mathrm{N}_{\mathrm{ns}}\right)$ é dado por: 


$$
\Delta N_{n s}=\Delta N_{a} *(1+s+a) \mathbf{( 7 8 )}
$$

Adicionalmente VAN HAANDEL (1999) apresenta a relação entre o tempo de detenção efetivo $\left(\mathrm{R}_{\mathrm{a}}\right)$ e o tempo de detenção nominal $\left(\mathrm{R}_{\mathrm{n}}\right)$.

$$
R_{n}=R_{a} *(1+s+a)(\mathbf{7 9})
$$

Neste ponto vale ressaltar que as recirculações $\mathbf{s}$ e $\mathbf{a}$ são as razões entre as vazões de recirculação e a vazão afluente. Desta forma, a desnitrificação em reatores anóxicos é regida normalmente pela seguinte curva

Figura 15 - Taxa de desnitrificação em reatores pre-D (esquerda) e pós-D (direita)

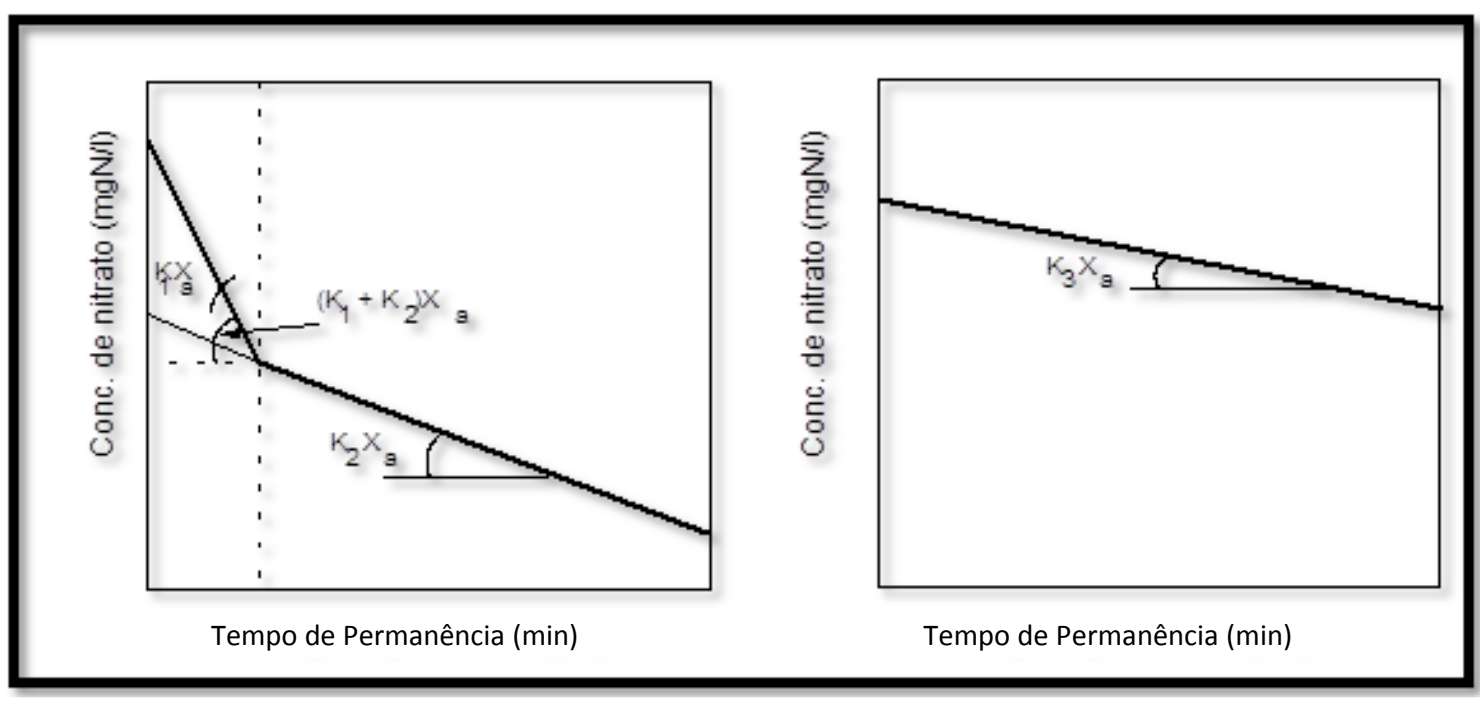

Fonte: Adaptado de VAN HAANDEL (1999)

\subsubsection{Velocidade de desnitrificação}

Para este item, assim como para todo o desenvolvimento da cinética de nitrificação/desnitrificação será empregado o modelo de reator pre-D. Considerando a disponibilidade de nitrato no reator pre-D como $\mathrm{N}_{\mathrm{di}}$, este é definido como:

$$
N_{d i}=\frac{a+s}{a+s+1} N_{c}
$$

Adicionalmente, considerando que a desnitrificação ocorre em duas etapas, conforme Figura 15 , pode-se dividir a remoção de nitrato $\left(\Delta \mathrm{N}_{\mathrm{nps}}\right)$ em duas etapas.

$$
\Delta N_{n s}=\Delta N_{n 1 s}+\Delta N_{n 2 s}
$$

Considerando as taxas de recirculação $(\mathrm{a}+\mathrm{s})$ e $\mathrm{t}_{1} \mathrm{o}$ tempo efetivo de duração da primeira etapa, a equação anterior pode ser expressa como: 


$$
\Delta N_{n s}=K_{1} X_{a} t_{1}(1+s+a)+K_{2} X_{a} R_{n}(\mathbf{8 2})
$$

Desta maneira, pode-se verificar que a primeira fase da remoção de nitrato é proporcional à taxa de crescimento específico das heterotróficas, o que pode variar bastante de acordo com a configuração do sistema, variação diária de vazões e cargas e outros fatores relacionados ao reator aerado.

\subsubsection{Fatores que influenciam a desnitrificação}

De acordo com VAN HAANDEL (1999), existem 7 principais fatores que influenciam a desnitrificação: Composição da matéria orgânica, Constantes cinéticas de desnitrificação $\left(K_{2}\right.$ e $\left.K_{3}\right)$, constantes de nitrificação $\left(\mu_{m}, K_{n}\right.$ e $\left.b_{n}\right)$, Temperatura, concentração de amônia no efluente do sistema, taxas de recirculação (a e s) e idade do lodo $\left(\mathrm{R}_{\mathrm{s}}\right)$.

Conforme mostrado previamente, caso a idade do lodo seja menor do que a idade mínima para nitrificação ocorre uma baixa conversão de nitrogênio amoniacal em nitrato e nitrito o que de fato compromete o desempenho do sistema de remoção de nitrogênio biológico.

METCALF \& EDDY (2002) afirma que o coeficiente de desnitrificação $\mathrm{K}_{1}$ é muito sensível à temperatura, assim como a constante $\mathrm{K}_{3}$ é muito pouco sensível a temperatura.

$$
\begin{gathered}
K_{1, T}=K_{1,20} * 1,2^{T-20} \\
K_{2, T}=K_{2,20} * 1,08^{T-20} \\
K_{3, T}=K_{3,20} * 1,03^{T-20}
\end{gathered}
$$

Com relação à matéria orgânica afluente, pode-se afirmar que a primeira etapa de desnitrificação é diretamente proporcional à concentração de matéria orgânica rapidamente biodegradável, independente de SSVA, idade do lodo, taxas de recirculação e temperatura. Segundo Piveli (2013), esta primeira etapa da desnitrificação é proporcional a uma constante $\alpha\left(0,028 \quad \mathrm{mgN}-\mathrm{NO}_{3}{ }^{-} / \mathrm{mg}\right.$ DQO biodegradável - dados experimentais).

$$
\Delta_{n 1 s}=\alpha S_{b i}(\mathbf{8 6})
$$




$$
\begin{aligned}
t_{1} & =\frac{\alpha S_{b i}}{K_{1} X_{a}(1+s+a)}(\mathbf{8 7}) \\
\alpha & =f_{b s} \frac{1-f_{c v} Y_{h}}{2,86}(\mathbf{8 8})
\end{aligned}
$$

Segundo VAN HAANDEL (1999), pode-se definir o limite de aplicabilidade de um sistema bardenpho pela relação entre a capacidade de nitrificação $\left(\mathrm{N}_{c}\right)$ e a concentração de substrato afluente biodegradável ao sistema.

$$
\left(\frac{N_{c}}{S_{b a}}\right) l=\frac{\left(0,12 f_{b s}+K_{2} C_{r} f_{M}\right)(1+s+a)}{a+s}(\mathbf{8 9})
$$

Caso haja contribuição de águas residuárias industriais, pode-se ter uma redução de $\mu_{\mathrm{m}}$, o que demanda um aumento na idade do lodo para a manutenção do processo.

Outro fator muito importante neste processo é a concentração de nitrogênio amoniacal no efluente, uma vez que com limites mais restritivos será necessárias maiores taxas de recirculação, sendo que há um limite para estas recirculações para o não comprometimento do processo.

\subsubsection{Potencial de Desnitrificação}

Segundo METCALF \& EDDY (2002), o potencial de desnitrificação pode ser definido como sendo todo o nitrato que pode ser realmente convertido em nitrogênio gasoso. Pode ser expresso matematicamente $\left(\mathrm{D}_{\mathrm{pi}}\right)$ como:

$$
D_{p i}=S_{b i}\left(\propto+\frac{K_{2 T} f_{x 1} Y_{h} R_{S}}{1+b_{h T} R_{S}}\right)(\mathbf{9 0})
$$

Ressalta-se que no caso de reator pré-D, o nitrato funciona como doador de elétrons.

\subsection{Remoção biológica de fósforo e processo de tratamento UCT modificado}

Dentre os diversos arranjos para remoção biológica de fósforo e nitrogênio, pode-se destacar conforme apresentado previamente os processos Bardenpho, Phoredox e o processo UCT (University of Cape Town).

O processo UCT foi proposto por Rabinowitz e Marais (1980) sendo uma configuração visando a remoção biológica de fósforo dos esgotos sanitários, de modo a evitar-se a introdução de nitrato na zona anaeróbia por meio de sua introdução em uma câmara anóxica. Adicionalmente segundo VAN HAANDEL (1999), pode-se manter as 
concentrações de nitrato na zona anóxica pelo controle das taxas de recirculação a, de modo a igualar a capacidade de desnitrificação nesta zona com todo o nitrato disponível.

Figura 16 - Esquema de um reator UCT

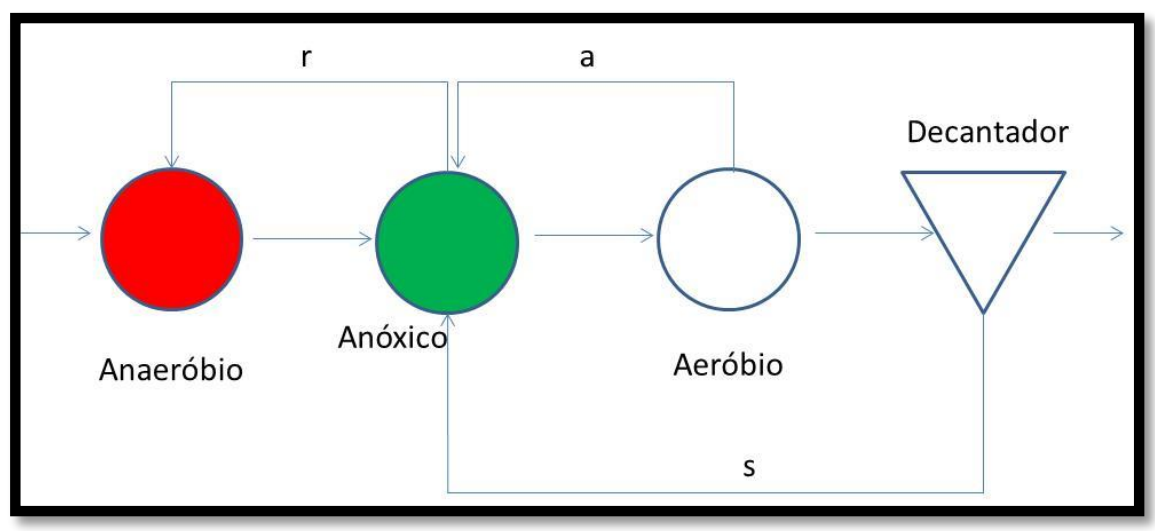

Fonte: Adaptado de VAN HAANDEL (1999)

Esta configuração tem como grande mérito não permitir a introdução de nitrato na zona anaeróbia, mesmo nos casos em que a concentração de nitrato e taxa de desnitrificação variam (com variações de temperatura, concentração de nitrogênio afluente etc).

Segundo VAN HAANDEL (1999) neste processo de tratamento há uma única zona anóxica, descarregando o lodo de retorno (recirculação s) do reator e a recirculação de nitrato na mesma porção reator (recirculação a).

Nesta configuração haverá uma boa remoção de nitrato no reator anóxico. No entanto, caso a desnitrificação não seja completa haverá transferência de nitrato para a zona anaeróbia e consequente comprometimento da remoção de fósforo do sistema como um todo.

De acordo com VAN HAANDEL (1999), o processo UCT modificado tem o mesmo princípio do UCT, no entanto, caracteriza-se pela existência de 2 reatores anóxicos em séria logo após o reator anaeróbio. Neste caso a recirculação de lodo do decantador para o anóxico ocorre na primeira câmara e a recirculação de nitrato ocorre no segundo reator anóxico. Desta forma previne-se que haja recirculação de nitrato para a câmara anaeróbia, potencializando-se a remoção biológica de fósforo.

Figura 17 - Esquema de um reator UCT modificado 


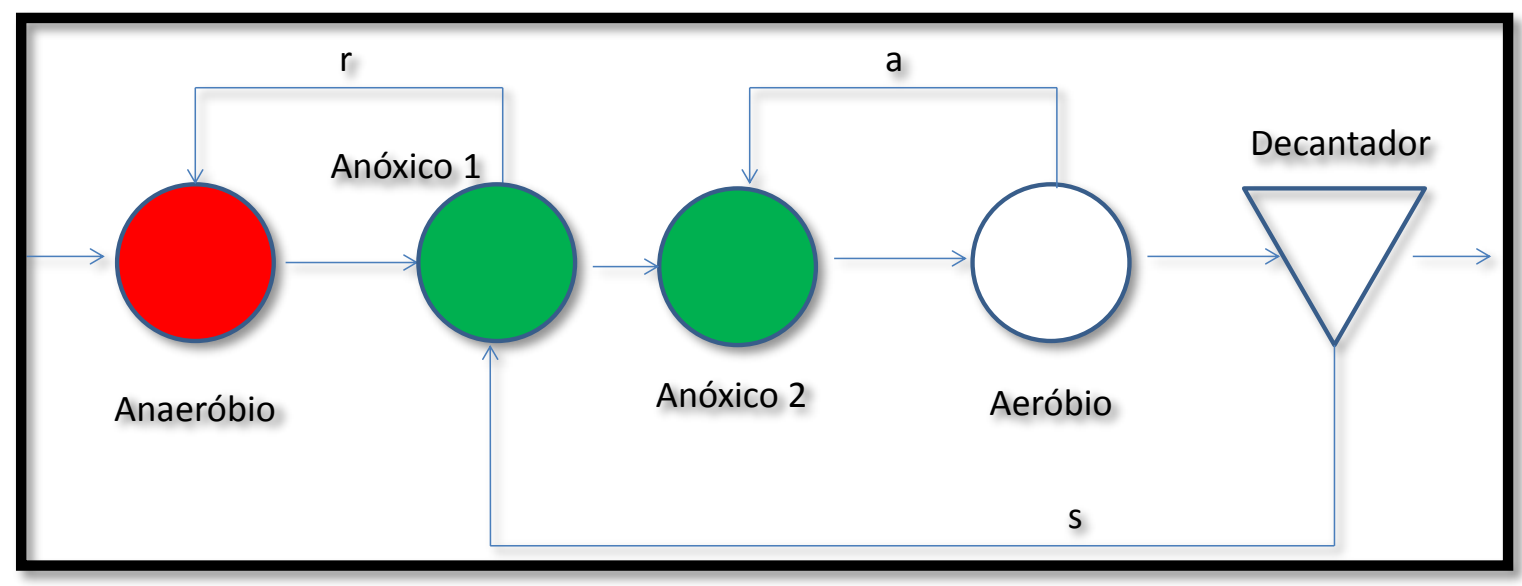

Fonte: Adaptado de VAN HAANDEL (1999)

Como principal desvantagem deste tipo de sistema pode-se destacar que a desnitrificação pode ser incompleta e consequentemente gerar arraste de sólidos no decantador final e subutilização da câmara anóxica.

\subsubsection{Princípio de funcionamento de um processo com remoção biológica de}

\section{fósforo}

Segundo METCALF \& EDDY (2002), num processo de remoção biológica de fósforo, este nutriente é incorporado na biomassa celular que consequentemente é removido no lodo gerado pela unidade de tratamento.

Segundo este mesmo autor, há organismos acumuladores de fósforo (PAO ou OAP) que crescem e consomem o fósforo no sistema. Estes organismos tem grande vantagem competitiva com outras bactérias por esta característica. As principais características apontadas por este autor são:

- Diversas bactérias são capazes de armazenar poli-fosfatos (poli-P) em suas células

- Em condições anaeróbias os PAOs assimilam produtos gerados por fermentação (como ácidos orgânicos voláteis) e liberam fósforo armazenado

- Em condições aeróbias estas PAOs produzem energia (oxidando os produtos de fermentação armazenados) e armazenam poli-P.

Uma característica muito importante dos sistemas para remoção de fósforo é um tanque anaeróbio a montante do restante do processo. Segundo METCALF \& EDDY (2002), este reator deve ter tempo de detenção de 1 a 2 horas. 


\subsubsection{Características da zona anaeróbia para remoção de fósforo}

METCALF \& EDDY (2002) descreve a zona anaeróbia como sendo o local onde ocorre uma degradação parcial da matéria orgânica rapidamente biodegradável na forma de ácidos orgânicos voláteis (principalmente ácido propiônico ou ácido acético). Pode-se observar que o tempo de detenção hidráulica deste reator é menor do que o tempo de detenção hidráulica de um reator anaeróbio tradicional (UASB), uma vez que este último faz a degradação completa da matéria orgânica (tempo de detenção hidráulica de 8 horas para a vazão média) pela hidrólise, acidogênese, acetogênese e metanogênese.

Figura 18 - Etapas de digestão anaeróbia

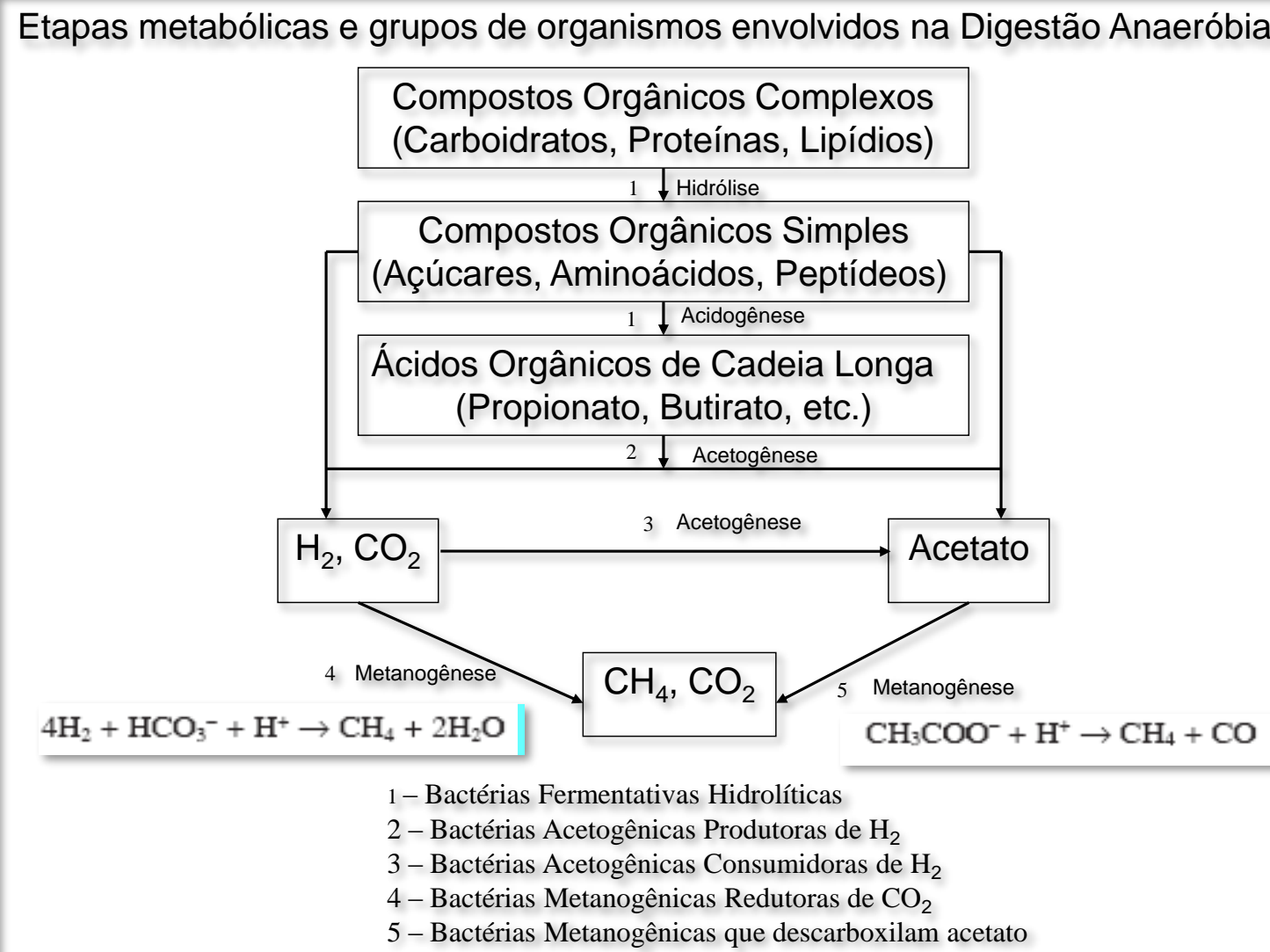

Fonte: CAMPOS (1999)

Segundo METCALF \& EDDY (2002), na fase anaeróbia os organismos PAOs utilizam o fosfato armazenado para a liberação de energia, assim como incorporam os ácidos orgânicos voláteis na forma de PHB (polihidroxidobutiratos). 


\subsubsection{Características das zonas anóxicas/aeróbias quando associados a remoção biológica de fósforo}

Segundo VAN HAANDEL (1999), na zona aeróbia o PHB é usado como energia, assim como para a síntese de poli-P e armazenamento de fósforo como Poli-P internamente. $\mathrm{Na}$ fase anóxica, as heterotróficas facultativas degradam a matéria orgânica rapidamente biodegradável utilizando o nitrato como aceptor de elétrons (ao invés de utilizar o oxigênio como aceptor de elétrons). Ressalta-se que aparentemente há uma contradição na utilização e consequentemente na performance das zonas anaeróbia e anóxica em um mesmo sistema, uma vez que ambas as etapas utilizam a matéria orgânica rapidamente biodegradável para seu funcionamento e caso o esgoto afluente não possua quantidade suficiente de tal tipo de matéria orgânica, pode haver comprometimento do tratamento.

As pesquisas mais modernas sobre a existência de PAOs, GAOs, sugere ainda a existência de PAOs que realizam a desnitrificação. Esse tipo de microrganismo é conhecido por DPAOs. Segundo SANTOS (2014) há inúmeras variedades e diferentes nomenclaturas de bactérias presentes em sistemas de lodo ativado com remoção de fósforo: Acinetobacter, bactérias poli-p, bactérias bioP, bactérias PP, PAO, dentre outros. Os principais constituintes de PAOs segundo este mesmo autor são: Pseudomonas vesicularis, Klebsiella premoniae, Micrococus, Aeromonas hyraphila, Arthrobacter globiformes, Moraxella spp. e Enterobacter spp. Ainda é possível citar um tipo de bactéria detectadas nos ambientes anóxicos de sistemas de lodos ativados: Acumulibacter.

Nas Figuras 19 e 20 são apresentados os mecanismos metabólicos dos diferentes organismos PAO na remoção de fósforo e nitrato (Neste caso DPAO)

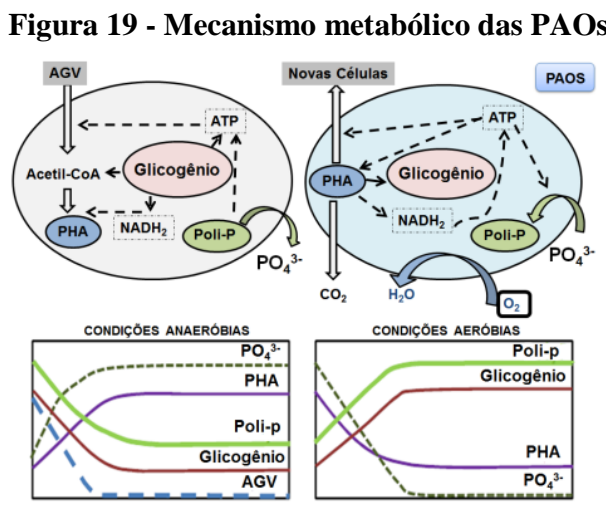

Fonte: SANTOS (2014) 
Figura 20 - Mecanismo metabólico de mecanismos acumuladores de fósforo e desnitrificadores

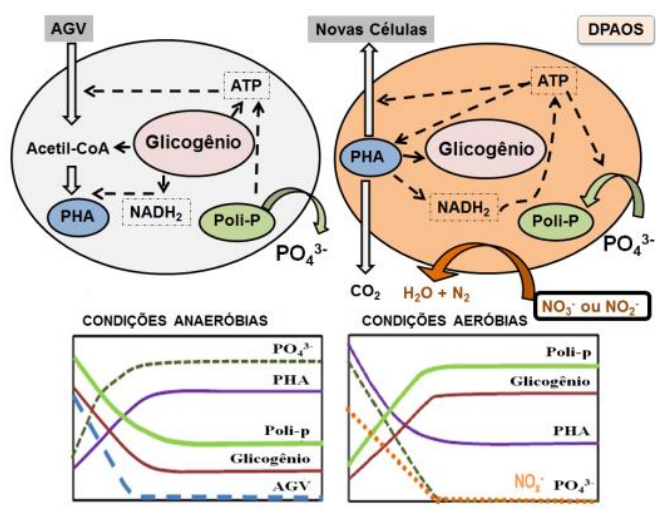

Fonte: SANTOS (2014)

A aeração excessiva, após precipitações ou dias de baixa carga afluente podem diminuir o nível de polímeros intracelulares armazenados, polihidroxialcanoatos (PHA) e glicogênio, afetando o desempenho na remoção de fósforo (BRDJANOVIC et al., 1998b; LOPEZ-VAZQUEZ et al., 2009).

Segundo HENZE et al (1999) há uma melhora no desempenho de remoção de fósforo em sistemas com tempo de detenção hidráulica maiores na etapa anaeróbia. BRDJANOVIC et al., 1998a sugere que a eficiência de remoção de fósforo pode estar muito mais relacionado ao tempo de detenção na etapa anaeróbia do que pela idade do lodo.

Segundo SANTOS (2014), o aparecimento de organismos acumuladores de glicogênio (GAO) competem por AOV com as PAOs, seja a principal causa da deterioração do desempenho do processo de remoção biológica de fósforo (CECH; HARTMAN, 1993; SATOH et al., 2000; LIU et al., 1996; FILIPE; DAIGGER; GRADY, 2001a; THOMAS et al., 2003; OEHMEN, 2004). No entanto, os mecanismos que influenciam a ocorrência de GAOs não foram totalmente elucidados (LOPEZ-VAZQUEZ, 2009).

\subsubsection{Organismos acumuladores de fósforo $X$ Organismos acumuladores de}

\section{Glicogênio}

Os PAOs tem seu crescimento relacionado à etapa anaeróbia do processo de lodos ativados e baixas concentrações de nitrato e nitrito nesta câmara. Segundo SANTOS (2014) foi evidenciado em alguns estudos que a concentração de fósforo influencia na capacidade de absorver em excesso o fosfato na zona aeróbia ou anóxica (WENTZEL et al., 1989b; HENZE et al., 2002; VAN HAANDEL; VAN DER LUBBE, 2012). De acordo com Smolders et al. (1995), o PHA intracelular armazenado por este grupo de 
microrganismos é também usado para: (1) a reposição do conjunto intracelular de glicogênio, (2) crescimento da biomassa e (3), para suprir as necessidades de manutenção aeróbia. Como se sabe, a remoção de fósforo do meio líquido é conseguida através do descarte do lodo de excesso no fim da etapa aeróbia, momento este em que o lodo contém um elevado teor de poli-P.

Já os GAOs também armazenam AOVs na forma de PHB em condições anaeróbias. No entanto, nestes o material intracelular de glicogênio armazenado é usado como energia e fonte de carbono para a captação de AOVs sem realizar a típica liberação de fósforo no ambiente anaeróbio e posteriormente sua captura e absorção no ambiente aeróbio como fazem os PAOs (MINO; VAN LOOSDRECHT; HEIJNEN, 1998; FILIPE; DAIGGER; GRADY, 2001b; ZENG et al., 2003; OEHMEN et al., 2006). Segundo ZENG et al. (2003) na fase aeróbia os GAO utilizam PHA previamente armazenado na fase anaeróbia para reabastecer glicogênio, crescimento da biomassa e suprimento das necessidades de manutenção aeróbia.

Em sistemas em escala de bancada ou plena, diferentes estudos descreveram como a presença e a proliferação de GAO levou a um desempenho abaixo do ideal em termos de remoção biológica de fósforo (SAUNDERS et al., 2003; THOMAS et al., 2003; GU et al., 2005) e, em casos extremos, a falha completa (SATOH et al., 2000; FILIPE; DAIGGER; GRADY, 2001a). Portanto, a partir de uma perspectiva do processo, GAO são vistos como microrganismos indesejáveis porque competem com PAO por substrato solúvel (AOV) e não contribuem para a remoção biológica de fósforo.

Adicionalmente, segundo SANTOS (2014) a importância e os benefícios globais de organismos desnitrificantes e biodesfosfatadores simultâneos (DPAO) em sistemas de lodos ativados, também têm sido amplamente reconhecidos (KUBA; VAN LOOSDRECHT; HEIJNEN, 1996). Os fatores que podem influenciar a ocorrência de DPAOs é definida por diversos autores como uma parcela da atividade aeróbia de PAOs (valores variam de $15 \%$ a $100 \%$ da atividade aeróbia)

\subsubsection{Cinética de remoção biológica de fósforo}

Será utilizado o modelo cinético proposto por ALEM SOBRINHO (1991) baseado na teoria de WENTZEL, EKAMA, DOLD e MARAIS (1990). Foi considerado que o acetato é o único substrato e sua taxa específica de remoção do líquido, como já visto, é 
muito alta e de ordem zero em relação à concentração de acetato. Consequentemente a fração de massa anaeróbia utilizada em sistemas com remoção biológica de fósforo em excesso (superior a 5\%) e todo o acetato será removido do líquido na zona anaeróbia. Assim sendo, não é necessária uma expressão cinética para remoção de substrato líquido, sendo a massa total de acetato removida e estocada como PHB $\left(\mathrm{MS}_{\text {phb }}\right)$ iguala a massa de acetato suprida ( $\left.\mathrm{MS}_{\mathrm{bs}, \mathrm{a}}\right)$ expressos em mg de DQO.

$$
M S_{p h b}=M S_{b s, a}(\mathbf{9 1})
$$

A massa de fósforo liberada $\left(\mathrm{MP}_{\text {lib }}\right)$ é proporcional à massa de acetato removida do líquido.

$$
M P_{l i b}=f_{p . l i b} M S_{b s, a}(m g P)(\mathbf{9 2})
$$

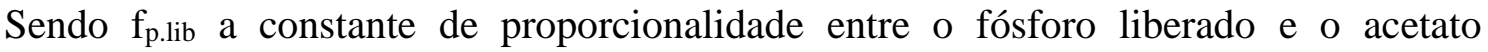
removido e segundo WENTZEL et al (1989) vale $0,5 \mathrm{mg} \mathrm{P} / \mathrm{mg}$ de acetato na forma de DQO.

A utilização de PHB e captação de fósforo em aerobiose ocorre com todo o PHB sendo utilizado na zona aeróbia, então a massa biológica ativa de organismos acumuladores de poli-P sintetizada ( $\mathrm{MX}_{\mathrm{b}, \mathrm{g}}$ sintetizada) é expressa como:

$$
M X_{b, g(\text { sintese })}=Y_{g} M S_{p h b}(m g S S V A)(\mathbf{9 3})
$$

$\mathrm{Y}_{\mathrm{g}}$ é a constante de crescimento específico para organismos acumuladores de poli-P (0,45 mg SSAV/mg DQO) e SSAV são sólidos em suspensão ativos voláteis.

$$
M X_{b, g(\text { síntese })}=Y_{\square} M S_{b s a}(m g S S A V)(\mathbf{9 4})
$$

A perda de massa endógena ocorre na fase anaeróbia e aeróbia e se manifesta como um decréscimo na massa biológica ativa de organismos, resultando no acúmulo de resíduo endógeno particulado.

$$
\frac{d M X_{b, g}}{d t}=-b_{g} M X_{b, g}(\mathbf{9 5})
$$

Onde $b_{\mathrm{g}}$ é a constante da taxa específica de perda de massa endógena para organismos acumuladores de poli-P $\left(0,04 \mathrm{~d}^{-1}\right.$ a $\left.20^{\circ} \mathrm{C}\right)$. Para o aumento da massa endógena por sua vez $\left(\mathrm{MX}_{\mathrm{e}, \mathrm{g}}\right)$ tem-se: 


$$
\frac{d M X_{e, g}}{d t}=+b_{g} f_{E P} M X_{b, \square}\left(m g \frac{S S E V}{d}\right)
$$

Onde f $\mathrm{EP}_{\mathrm{E}}$ é a fração de organismos acumuladores de poli-P que é resíduo particulado não biodegradável (0,25 mg SSV/mg SSAV) e SSEV são os sólidos suspensos endógenos voláteis.

Ainda segundo ALEM SOBRINHO (1991), fazendo-se um balanço da massa biológica ativa através do sistema de lodos ativados, e considerando-se as equações anteriores para um sistema em condições permanentes e uniformes (variação de massa ativa no sistema nula) e massa biológica ativa afluente nula, a massa biológica ativa removida do sistema por dia é a diferença entre a massa biológica sintetizada por dia e a perda endógena de massa biológica ativa por dia.

$$
M X_{b, g(\text { sintese })}-b_{g} M X_{b, g}=\Delta M X_{b, g}(\mathbf{9 7})
$$

A idade do lodo $\left(\mathrm{R}_{\mathrm{s}}\right)$ neste sistema pode ser definido como:

$$
\begin{gathered}
R_{s}=\frac{M X_{b, g}}{\Delta M X_{b, g}}(\mathbf{9 8}) \\
M X_{b, g}=\frac{Y_{g} M S_{b s, a i} R_{s}}{1+b_{g} R_{S}}(\mathbf{9 9})
\end{gathered}
$$

Onde $\mathrm{MS}_{\mathrm{bs}, a \mathrm{i}}$ é a massa de acetato adicionada ao sistema por dia (mg DQO/dia) e é a multiplicação da vazão afluente pela concentração de acetato do afluente (mg DQO/L). Já a vazão de descarte de lodo pode ser definida como:

$$
Q_{w} X_{b, g}=\frac{M X_{b, g}}{R_{S}}\left(m g \frac{S S V}{d}\right)
$$

Já a massa endógena gerada $\left(\mathrm{MX}_{\mathrm{e}, \mathrm{g}}\right.$ é igual a massa endógena removida do sistema

$$
\begin{array}{r}
\Delta M X_{e, g}=f_{E P} b_{g} M X_{e, g} \text { (101) } \\
M X_{e, g}=f_{E P} b_{g} M X_{b, g} R_{s}(m g S S E V)
\end{array}
$$

Em culturas de organismos acumuladores de poli-P alimentada com acetato não há material particulado no afluente e consequentemente a massa total de lodo volátil no sistema $\left(\mathrm{MX}_{\mathrm{G}, \mathrm{t}}\right)$ é dada por:

$$
M X_{G, t}=M X_{b, g}+M X_{e, g}(m g S S V)(\mathbf{1 0 3})
$$




$$
M X_{G, t}=\frac{Y_{g} M S_{b s, a i} R_{S}\left(1+f_{E P} b_{g} R_{S}\right)}{1+b_{g} R_{S}}(\mathbf{1 0 4})
$$

E a massa de lodo removida do sistema por dia $\left(\Delta \mathrm{M}_{\mathrm{G}, \mathrm{t}}\right)$ e massa de fósforo removida por dia ( $\triangle \mathrm{MP})$ são expressas como:

$$
\begin{gathered}
\Delta M_{G, t}=\frac{M X_{G, t}}{R_{S}}\left(m g \frac{S S V}{d i a}\right)(\mathbf{1 0 5}) \\
\Delta M P=f_{x b g, P} \Delta M X_{\square, g}+f_{x e g, p} \Delta M X_{e, g}=f_{x b g, p} \frac{M X_{b, g}}{R_{s}}+f_{x e g, p} \frac{M X_{e, g}}{R_{s}}(\mathbf{1 0 6})
\end{gathered}
$$

Onde $\mathrm{f}_{\mathrm{xbg}, \mathrm{p}}$ é a fração de fósforo contida na massa biológica ativa $(0,41 \mathrm{mg}$ P/mg SSAV - WENTZEL et al, 1989; 0,38 mg P/mg SSAV - Valor mais coerente apresentado por WENTZEL et al, 1989) e $f_{x e g, p}$ é a fração de fósforo contida na massa endógena de organismos acumuladores de poli-P (0,030 mg P/mg SSEV - WENTZEL et al, 1989).

Consequentemente a remoção de fósforo da vazão afluente $(\triangle \mathrm{P})$ é definida por ALEM SOBRINHO (1991) como sendo a vazão de massa de fósforo no sistema dividido pela vazão afluente.

$$
\begin{gathered}
\Delta P=\frac{\Delta M P}{Q}\left(m g \frac{P}{l} \text { afluente }\right)(\mathbf{1 0 7}) \\
f_{x b g, p}=\Delta P \frac{1+b_{g} R_{S}}{S_{b s, a i Y_{g}}}-f_{x e g, p} f_{E P} b_{g} R_{S}\left(\frac{m g P}{m g S S A V}\right)
\end{gathered}
$$

Este modelo inicialmente proposto baseia-se no fato de que não há culturas mistas em regime uniforme e permanente de operação de um sistema de lodos ativados. WENTZEL et al (1989) apud ALEM SOBRINHO (1991) afirma que as populações de organismos acumuladores de poli-P $\left(\mathrm{X}_{\mathrm{b}, \mathrm{g}}\right)$ e os não acumuladores de poli-P atuam aparentemente independentes uma das outras em culturas mistas normais de sistemas de lodos ativados de modo a permitir uma análise independente dos grupos da população em separado. Este mesmo autor afirma que há interação entre as diferentes culturas de microrganismos apenas na zona anaeróbia.

\subsubsection{Cinética de transformação de DQO rapidamente biodegradável em AOV (baseado em ALEM SOBRINHO, 1991)}

ALEM SOBRINHO (1991) afirma que os esgotos afluentes tem muito pouco ou nenhum AOV, sendo que na eventualidade da ocorrência de esgotos com AOVs essa 
fração seria somada ao gerado no reator anaeróbio. A quantidade de AOV gerada no reator anaeróbio por sua vez é governada pela cinética de conversão de DQO rapidamente biodegradável $\left(\mathrm{S}_{\mathrm{bs}}\right)$ em $\mathrm{AOV}$. Esse conversão é intermediada por microrganismos heterotróficos $\left(\mathrm{X}_{\mathrm{b}, \mathrm{Hn}}\right)$. Segundo este mesmo autor a fórmula que expressa esta conversão é:

$$
\frac{d S_{b s}}{d t}=-K X_{b, H n} S_{b s}(\mathbf{1 0 9})
$$

Onde $\mathrm{K}$ é a constante de conversão de primeira ordem $\left(0,06 \mathrm{~d}^{-1}\right.$ segundo WINTZEL et al 1990)

A taxa de liberação de fósforo foi admitida como estequiométrica e relacionada a DQO rapidamente biodegradável removida do líquido.

$$
\frac{d P}{d t}=-C_{s p} \frac{d S_{b s}}{d t}=C_{s p} K X_{b, H n} S_{b s}(\mathbf{1 1 0})
$$

$\mathrm{C}_{\mathrm{sp}}$ é a relação estequiométrica entre fósforo e $\mathrm{DQO}_{\mathrm{sb}}$ e segundo WENTZEL et al (1989) vale $0,5 \mathrm{mg} \mathrm{PO}_{4}-\mathrm{P} / \mathrm{mg}$ DQO convertido.

ALEM SOBRINHO (1991) ainda afirma que o nitrato recirculado inibe a formação de AOV, uma vez que as heterotróficas não acumuladoras de fósforo utilizam o nitrato como aceptor de elétrons de modo a metabolizar os AOVs ao invés de liberá-los. Esse fenômeno pode ser escrito cineticamente como a DQO rapidamente biodegradável disponível para conversão ( $\mathrm{S}_{\text {'bsi }}$ ).

$$
S_{b s i}^{\prime}=S_{b s i}-r 8,6 N O_{3, r}(\mathbf{1 1 1})
$$

Onde $S_{b s i}$ é a concentração de DQO rapidamente biodegradável no afluente e o segundo termo refere-se à quantidade de nitrato recirculado para a zona anaeróbia. Para operação em condição permanente e uniforme, considerando-se volume do reator anaeróbio $\mathbf{V}$ alimentado por vazão $\mathbf{Q}$ e recebendo recirculação $\mathbf{r Q}$, o balanço de massa fica:

Taxa de variação de $S_{b s}$ no reator

= Taxa de entrada de DQO rápidamente biodegradável no reator

- Taxa de saída de DQO rapidamente biodegradável no reator

- Taxa de transformação de $S_{b s}$ em AOV no reator

$$
V \frac{d S_{b s}}{d t}=Q S_{b s \square}^{\prime}-(1+r) Q S_{b s}-K X_{b, H n}-S_{b s} V
$$


Nas condições de operação $\mathrm{d} \mathrm{S}_{\mathrm{bs}} / \mathrm{dt}=0$. Aplicando isso na fórmula anterior, pode-se obter a seguinte expressão simplificada:

$$
S_{b s}=\frac{\frac{S^{\prime} b s}{1+r}}{1+\frac{K X_{b, H n^{R}}}{1+r}}(\mathbf{1 1 3})
$$

Onde $\mathbf{R}$ é o tempo de detenção hidráulica no reator anaeróbio. Para reatores em série anaeróbios consecutivos, a expressão matemática fica:

$$
S_{b s n}=\frac{\frac{S_{b s i}}{1+r}}{\left(1+\frac{K X_{b, H n^{R}}}{(1+r)}\right) n}(\mathbf{1 1 4})
$$

Onde $\mathrm{n}$ é o número de reatores e $\mathrm{R}_{\mathrm{n}}$ é o tempo de detenção hidráulica em um dos reatores anaeróbios. Esta fórmula mostra que se comparando n reatores com volumes somados igual ao volume de um único reator, o reator compartimentado fornecerá mais AOVs na saída da zona anaeróbia quando comparado a um reator unitário. Por sua vez a concentração de organismos heterotróficos não acumuladores de fósforo último reator será:

$$
X_{b, H n}=f_{x a} \frac{M X_{b, h}}{V a t}(\mathbf{1 1 5})
$$

Onde $\mathrm{V}_{\mathrm{at}}$ é o volume total do reator anaeróbio, $\mathrm{f}_{\mathrm{xa}}$ é a fração de massa anaeróbia e $\mathrm{MX}_{\mathrm{b}, \mathrm{h}}$ é a massa ativa de organismos não acumuladores de poli-P (em mg de SSAV).

$$
V \frac{d S_{b s}}{d t}=Q S^{\prime}{ }_{b s i}-(1+r) Q S_{b s}-K X_{b, H n}-S_{b s} V(\mathbf{1 1 6})
$$

Considerando que as vazões dos compartimentos são iguais entre si, pode-se definir:

$$
V_{a t}=N V_{a n} \text { e } R_{N}=\frac{V_{a n}}{Q}(\mathbf{1 1 7})
$$

Desta forma a concentração de AOV na última câmara será:

$$
S_{b s n}=\frac{\frac{S_{b s i}}{1+r}}{1+\frac{K f_{x a} M X_{b, h}}{(1+r) N Q}}(\mathbf{1 1 8})
$$

Deve-se considerar a aplicabilidade deste modelo para reatores em série, segundo WENTZEL et al (1990) só é válida se os valores de K forem iguais para todos os reatores. 
Para a massa de heterotróficas não acumuladoras de fósforo $\mathrm{MX}, \mathrm{b}, \mathrm{h}$, esta se desenvolve $\mathrm{a}$ partir da DQO rapidamente biodegradável subtraído pela massa de DQO rapidamente biodegradável removida pelas poli-P.

Produção de massa ativa de organismos não ac $\square$ muladores de poli $-P$

- Perda de massa endógena de não acumuladores de fósforo

$=$ Retirada de massa ativa de organismos não acumuladores de poli $-P$

$$
\begin{gathered}
Y_{h} Q\left(S_{b i}-\left(S_{b s i}^{\prime}-(1+r) S_{b s n}\right)\right)-b_{h} M X_{b, h} \\
\frac{Y_{h} Q\left(S_{b i}-\left(s_{b s i}^{\prime}-(1+r) S_{b s n}\right)\right)}{M X_{b, h}}-b_{h}=\frac{\Delta M X_{b, h}}{M X_{b, h}}=\frac{1}{R_{s}}(\mathbf{1 1 9})
\end{gathered}
$$

Onde $\mathrm{R}_{\mathrm{s}}$ é a idade do lodo no reator. Reagrupando os termos da expressão pode-se reescrevê-la como:

$$
\frac{M X_{b, h}}{Q}=\frac{\left(S_{b i}-\left(S_{b s i}^{\prime}-(1+r) S_{b s h}\right)\right) Y_{h} R_{S}}{1+b_{h} R_{S}}(\mathbf{1 2 0})
$$

Onde $\mathrm{S}_{\mathrm{bi}}$ é a DQO biodegradável afluente, $\mathrm{Y}_{\mathrm{h}}$ é o coeficiente de síntese celular dos organismos heterotróficos não acumuladores de poli-P (0,45 mg SSAV/mg DQO conforme MARAIS et al, 1976), b é a constante da taxa específica de perda endógena de massa ativa dos organismos heterotróficos não acumuladores de poli-P e $\mathrm{S}_{\mathrm{bsn}}$ é a concentração de DQO prontamente biodegradável à saída do último reator anaeróbio. Por sua vez, a liberação de fósforo no último reator anaeróbio $\left(\mathrm{P}_{\mathrm{n}}\right)$ é definido por ALEM SOBRINHO (1991) como sendo:

$$
P_{n}=C_{s p} S_{b s i}\left(\frac{1}{\left(\frac{\frac{K f_{x a}}{N} M X_{b, h}}{Q}\right)^{n-1}}-\frac{1}{\left(\frac{\frac{K f_{x a}}{N} M X_{b, h}}{Q}\right)^{n}}\right) \text { (121) }
$$

\subsubsection{Teoria da conversão - Baseado em WENTZEL et al (1990) apud ALEM SOBRINHO (1991)}

De acordo com ALEM SOBRINHO (1991), a teoria de conversão apresentada por WINTZEL et al (1990) proporciona uma metodologia para o cálculo de quanto AOV é 
gerado no sistema pelas não acumuladoras de fósforo para ser posteriormente capturada pelas poli-P $\left(\mathrm{MS}_{\mathrm{rem}}\right)$.

$$
M S_{r e m}=\left(S_{b s i}^{\prime}-(1+r) S_{b s n}\right) Q \mathbf{( 1 2 2 )}
$$

Desta forma, a massa de AOV disponível para os heterótrofos não acumuladores de fósforo é a diferença entre DQO afluente biodegradável e massa capturada pelas poli-P.

$$
M S_{b, h}=Q S_{b i}-M S_{r e m}(\mathbf{1 2 3})
$$

Segundo ALEM SOBRINHO (1991), considerando-se a remoção de fósforo pelas poliP mais o conteúdo de fósforo das massas voláteis endógena e inerte e as necessidades de fósforo para o crescimento dos organismos não acumuladores de poli-P permitem a contabilização da remoção total de fósforo do sistema.

O modelo matemático considera as definições utilizadas previamente neste trabalho. Assim, para o cálculo da massa endógena de organismos não acumuladores de poli-P no sistema $\left(\mathrm{MX}_{\mathrm{e}, \mathrm{h}}\right)$ tem-se:

$$
M X_{e, h}=f_{E P} b_{h} M X_{b, h} R_{S}(\mathbf{1 2 4})
$$

Por outro lado a massa volátil inerte no sistema $\left(\mathrm{MX}_{\mathrm{i}}\right)$ pode ser dada por:

$$
M X_{i}=\frac{f_{s, u p} Q S_{t i} R_{S}}{f_{c v}}(\mathbf{1 2 5})
$$

Onde $\mathrm{f}_{\mathrm{s} \text {,up }}$ é a fração de substrato que é particulado e não biodegradável e $\mathrm{f}_{\mathrm{cv}}$ é a relação entre DQO e SSV em lodos de sistemas de lodos ativados com organismos não acumuladores de poli-P

WENTZEL et al (1990) apud ALEM SOBRINHO (1991) determina a massa de fósforo removida do sistema através do descarte de massas voláteis com o excesso de lodos ativados $\left(\mathrm{P}_{\text {hei }}\right)$.

$$
\begin{gathered}
\Delta P_{\text {hei }}=\Delta P_{\text {Heterotróficas }(H)}+\Delta P_{\text {Inerte I }} \text { (126) } \\
\Delta P_{H}=\left(f_{x b h, p} \frac{M X_{b, h}}{R_{S}}+f_{x e h, p} \frac{M X_{e, h}}{R_{S}}\right) \frac{1}{Q}(\mathbf{1 2 7}) \\
\Delta P_{I}=f_{x i, p} \frac{M X_{i}}{R_{S}} \frac{1}{Q} \text { (128) }
\end{gathered}
$$


Onde $\Delta \mathrm{P}_{\mathrm{H}}$ é o fósforo removido pelos organismos heterotróficos não acumuladores de poli-P, $\Delta \mathrm{P}_{\mathrm{I}}$ é o fósforo removido pela massa volátil inerte removida do sistema, $\mathrm{f}_{\mathrm{xbh}, \mathrm{p}}$ é a fração de fósforo na massa ativa de organismos heterotróficos não acumuladores de poli-P (0,03 mg P/mg SSAV), fxeh,p é a fração de fósforo na massa endógena dos organismos heterotróficos não acumuladores de poli-P (0,03 mg P/mg SSEV) e $\mathrm{f}_{\mathrm{xi}, \mathrm{p}}$ é a fração de fósforo na massa inerte volátil ( $0,03 \mathrm{mg}$ P/mg SSIV).

\subsubsection{Efeito da fermentação ácida no procedimento de dimensionamento para operação em condição permanente e uniforme (baseado em ALEM SOBRINHO, 1991)}

Até o presente momento este trabalho discutiu como funciona o mecanismo de remoção biológica de fósforo em um sistema. No entanto, deve-se ainda avaliar o efeito da câmara anaeróbia (onde ocorre fermentação ácida).

Segundo ALEM SOBRINHO (1991) a DQO prontamente biodegradável do afluente $\left(\mathrm{S}_{\mathrm{bsi}}\right)$ pode conter uma fração de AOVs caso haja um decantador primário no qual ocorra a referida fermentação do lodo no fundo do decantador ou ainda em sistemas com digestão de lodo primário ou adensadores, onde o sobrenadante é recirculado para o início do processo e pode conter quantidades significativas de AOVs.

Devido à velocidade de consumo dos AOVs no reator anaeróbio ser muito alta, este mesmo autor sugere que a DQO rapidamente biodegradável seja dividida em duas frações: uma devida aos AOVs no afluente (conforme mostrado anteriormente neste capítulo e que não requer transformação) e outra devido a DQO prontamente biodegradável complexa no afluente (que necessita conversão a AOV antes de ser removida do líquido no reator anaeróbio).

$$
S_{b s i}=S_{b s, a i}+S_{b s, c i}
$$

Onde $\mathrm{S}_{\mathrm{bs} \text {,ai }}$ é a DQO prontamente biodegradável devido aos AOVs no afluente e $\mathrm{S}_{\mathrm{bs}, \mathrm{ci}}$ é a DQO prontamente biodegradável complexa no afluente.

Caso ocorra a entrada de nitrato no reator anaeróbio, ALEM SOBRINHO (1991) afirma não se saber qual parcela da DQO é utilizada preferencialmente como doador de elétrons na câmara anaeróbia. 
No entanto, de acordo com a metodologia descrita por WENTZEL et al (1990), a fração complexa servirá de doador de elétrons para o nitrato neste reator. Ainda de acordo com este autor para se computar a influência do AOV no afluente deve-se rever o modelo apresentado previamente.

Neste caso a equação da DQO prontamente biodegradável disponivel para conversão a AOV (S' bs,ci) seria a DQO complexa menos a parcela consumida pelo nitrato.

$$
\begin{gathered}
S_{b s, c i}^{\prime}=S_{b s, c i}-r 8,6 N O_{3, r}(\mathbf{1 3 0}) \\
S_{b s, c i}^{\prime}=S_{b s i}-S_{b s, a i}-r 8,6 N O_{3, r}(\mathbf{1 3 1})
\end{gathered}
$$

WENTZEL et al (1990) afirma que a DQO prontamente biodegradável complexa na saída do último reator $\left(\mathrm{S}_{\mathrm{bs}, \mathrm{cN}}\right)$ é definida como:

$$
\begin{gathered}
S_{b s, c i}=\frac{\frac{S_{b s, c i}}{1+r}}{\left[1+\frac{f_{x a} M X_{b, h}}{N}\right]^{N}}(\mathbf{1 3 2}) \\
M X_{b, h}=\frac{\left(S_{b i}-\left({S^{\prime}}_{b s, c i}-(1+r) S_{b s, c N}\right)-S_{b s, a i}\right) Y_{h} R_{S}}{1+b_{h} R_{S}}(\mathbf{1 3 3})
\end{gathered}
$$

A massa removida de AOV ( $\left.\mathrm{MS}_{\text {rem}}\right)$ é definida neste caso como sendo o AOV afluente ao reator anaeróbio somado ao AOV formado nesta etapa do processo.

$$
M S_{r e m}=Q S_{b s, a i}+\left(S_{b s, c i}^{\prime}-(1+r) S_{b s, c N}\right) Q(\mathbf{1 3 4})
$$

Já a massa de substrato disponível para os organismos não acumuladores de poli-P por dia $\left(\mathrm{MS}_{\mathrm{b}, \mathrm{h}}\right)$ é definida por ALEM SOBRINHO (1991) como sendo a massa de substrato afluente subtraído da massa de substrato removido.

$$
M S_{b, h}=Q S_{b i}-M S_{r e m}(\mathbf{1 3 5})
$$

\subsubsection{Cálculo da DQO prontamente biodegradável não convertida a AOV}

Observando a metodologia apresentada previamente neste trabalho, pode-se afirmar que devido à finalidade de formação de AOV no reator anaeróbio, não ocorre degradação completa da matéria orgânica rapidamente biodegradável. Desta forma, a concentração de DQO prontamente biodegradável $\left(\mathrm{S}_{\mathrm{bsN}}\right)$ não convertida no último reator anaeróbio é definida por meio de um procedimento apresentado por ALEM SOBRINHO (1991). 
Inicialmente assume-se $\mathrm{S}_{\mathrm{bsN}}$ nula e calcula-se $\mathrm{MX}_{\mathrm{b}, \mathrm{h}} / \mathrm{Q}$. posteriormente calcula-se o valor de $\mathrm{S}_{\mathrm{bsN}}$ e faz-se novamente o cálculo de $\mathrm{MX}_{\mathrm{b}, \mathrm{h}} / \mathrm{Q}$. Este procedimento deve ser executado até se obter valores constantes para $\mathrm{S}_{\mathrm{bsN}}$ e $M \mathrm{XX}_{\mathrm{b}, \mathrm{h}} / \mathrm{Q}$

\subsubsection{Vantagens e desvantagens de emprego de um sistema com remoção biológica de nutrientes}

Atualmente em território brasileiro os processos de tratamento de águas residuárias utilizando sistemas de lodos ativados já estão muito difundidos. No entanto, existe uma limitação muito grande em algumas concessionárias (principalmente autarquias municipais) em relação a sua capacidade de investimentos em projetos de melhoria nos sistemas de abastecimento, coleta e tratamento de esgotos e isto é de certa forma uma barreira para a melhora na qualidade dos serviços prestados. Isso se deve em grande parte às baixas tarifas praticadas em território nacional somado a ineficiência dos prestadores de serviço. De acordo com dados do SNIS (Sistema nacional de informações sobre Saneamento) as tarifas nas regiões norte e nordeste do país não superam $\mathrm{R} \$ 3,00$ por $\mathrm{m}^{3}$ de esgoto coletado e tratado e para as regiões sudeste e sul do país estes valores não superam $\mathrm{R} \$ 3,50$ por $\mathrm{m}^{3}$ de esgoto coletado e tratado.

Pela legislação vigente existem diversos parâmetros que devem ser obedecidos para se fazer um descarte de efluente em um corpo receptor. No entanto, pela fragilidade financeira previamente muitos órgãos ambientais não exigem o lançamento de efluentes com melhor qualidade nos corpos receptores.

Diante deste panorama de escassez de recursos para investimento em tratamento de esgotos, pode-se observar que muitas vezes o emprego de um sistema de remoção biológica de fósforo e nitrogênio é negligenciado em detrimento à manutenção da saúde financeira dos operadores de saneamento. Isso se deve em grande parte aos custos de implantação e operação atrelados a este tipo de tratamento.

Pode-se destacar que um sistema de tratamento de esgotos com remoção biológica de nitrogênio e fósforo geram uma maior quantidade de lodo uma vez que a fração volátil dos organismos poli-P é normalmente menor do que nos organismos não acumuladores de fósforo, além de se ter um consumo de oxigênio elevado se comparado a soluções do tipo anaeróbia ou aeradas naturalmente. 
Ressalta-se, no entanto, que este tipo de solução será cada vez mais empregado, uma vez que os agentes fiscalizadores tendem a cobrar lançamentos com melhor qualidade. Essa filosofia é muito importante, uma vez que isso contribui muito para a despoluição dos corpos d'água e aumento da disponibilidade hídrica.

Este trabalho tem por objetivo trabalhar com uma concepção de tratamento desenvolvida na África do Sul chamada UCT modificada. No entanto segundo VAN HAANDEL (1999) existem diversas configurações possíveis de lodos ativados para a remoção biológica de fósforo. Na Tabela 5 serão apresentadas as principais rotas tecnológicas existentes, suas vantagens e desvantagens.

Tabela 5 - Vantangens e desvantagens dos diferentes tipos de sistemas com remoção biológica de fósforo

\begin{tabular}{|c|c|c|}
\hline Tipo de Sistema & Vantagens & Desvantagens \\
\hline Phoredox & $\begin{array}{c}\text { Sistema pequeno } \\
\text { Simples } \\
\text { Curto tempo de permanência }\end{array}$ & $\begin{array}{c}\text { Não tem nitrificação } \\
\text { Em climas quentes não é } \\
\text { confiável }\end{array}$ \\
\hline $\begin{array}{l}\text { Bardenpho modificado } \\
\text { ( } 3 \text { reatores) }\end{array}$ & $\begin{array}{l}\text { Alta taxa de desnitrificação } \\
\text { Idade de lodo baixa }\end{array}$ & $\begin{array}{l}\text { Pode não funcionar no caso de } \\
\text { ocorrer recirculação de lodo } \\
\text { Desnitrificação incompleta } \\
\text { Tendência de formação de lodo } \\
\text { filamentoso }\end{array}$ \\
\hline $\begin{array}{l}\text { Bardenpho modificado } \\
\text { ( } 5 \text { reatores) }\end{array}$ & Boa remoção de nitrogênio & $\begin{array}{l}\text { Recirculação de nitrato pode } \\
\text { comprometer remoção de } \\
\text { fósforo }\end{array}$ \\
\hline UCT & Promove recirculação de nitrato & $\begin{array}{l}\text { Desnitrificação incompleta } \\
\text { Uso de Capacidade de } \\
\text { desnitrificação é ineficiente }\end{array}$ \\
\hline UCT modificado & $\begin{array}{l}\text { Assegura a melhor condição } \\
\text { anaeróbia }\end{array}$ & Menos Desnitrificação \\
\hline Johannesburgo & $\begin{array}{l}\text { Uso eficiente do reator para remoção } \\
\text { de nitrogênio }\end{array}$ & $\begin{array}{l}\text { Remoção de nitrogênio } \\
\text { incompleta }\end{array}$ \\
\hline
\end{tabular}

Fonte: VAN HAANDEL (1999) 
No sistema UCT, diferentemente dos sistemas Bardenpho e Phoredox, não há reator anóxico secundário nem reator de reaeração, já que a desnitrificação neste reator, por unidade de volume, era muito inferior àquela observada no reator anóxico primário, conforme experimentos realizados por diversos pesquisadores. Sendo assim, estes dois reatores foram eliminados do processo, e o reator anóxico primário teve seu tamanho aumentado. 
Figura 21 - Métodos de remoção conjunta de nitrogênio e fósforo

\section{REMOÇÃO BIOLÓGICA DE NITROGÊNIO E FÓSFORO}

\section{PROCESSO A2/O (PHOREDOX DE 3 ESTÁGIOS)}

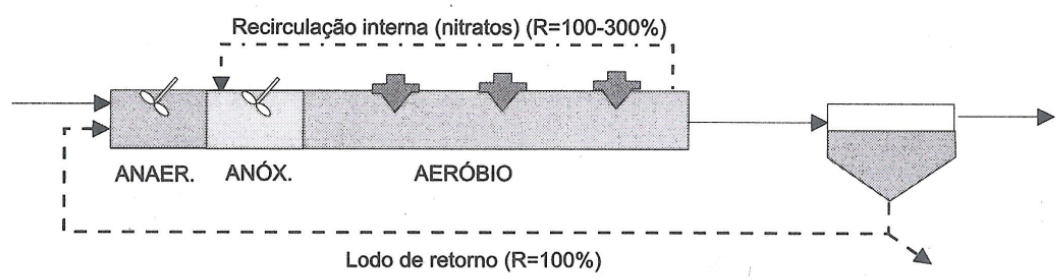

\section{PROCESSO BARDENPHO DE CINCO ESTÁGIOS (PHOREDOX)}
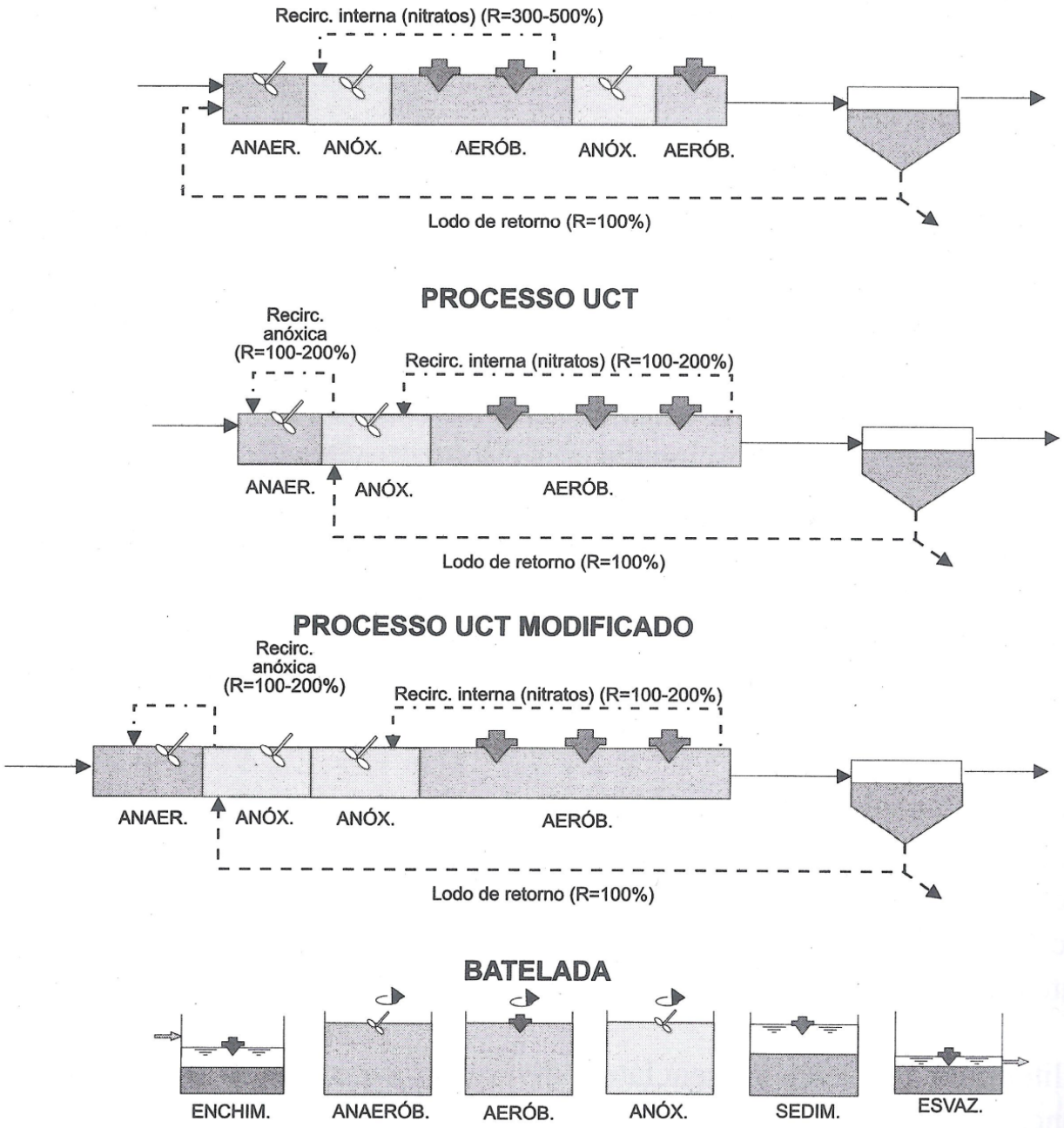

Remoção de N: escape de N2 para a atmosfera Remoção de P: saída em excesso com o lodo secundário

Fonte: VON SPERLING (1997) 


\subsubsection{Problemas operacionais de sistemas com remoção biológica de nutrientes}

De acordo com VAN HAANDEL (1999) existem diversos fatores que podem afetar a correta e eficiente operação de sistemas de lodos ativados.

Este mesmo autor aponta como primeiro e principal fator o lodo carregado de organismos poli-P que é um grande "reservatório" de fósforo que em casos extremos pode ser liberado na fase líquida do tratamento, encaminhando grandes quantidades de nutrientes ao corpo receptor ou ainda recirculando fósforo no sistema. Isso normalmente ocorre quando há uma queda de energia na planta, interrompendo a aeração na zona aeróbia ou ainda quando há a introdução de cargas tóxicas que reduzem a taxa de consumo de oxigênio (TOC) e consequentemente reduz a absorção de fósforo.

Ainda segundo este autor, uma capacidade de aeração insuficiente ou ineficiente pode também gerar um comprometimento da remoção biológica de fósforo pelo fato de que a utilização de PHB na zona aeróbia torna-se incompleta e a energia liberada neste processo será insuficiente para os poli-P regenerarem o polifosfato liberado na zona anaeróbia.

VAN HAANDEL (1999) ainda afirma que caso haja introdução de oxigênio no afluente à estação em etapas previas (como tratamento preliminar ou tratamento primário) pode reduzir a disponibilidade de DQO rapidamente biodegradável e a formação de AOVs na câmara anaeróbia e consequentemente reduzir a população de poli-P para a remoção biológica de fósforo e assim comprometer todo o tratamento previsto. Este mesmo autor cita três possíveis maneiras de corrigir esta deficiência: adição de matéria orgânica externa (ácido acético ou metanol), promover uma fermentação ácida no pré-tratamento, de modo a gerar AOVs a partir do material orgânico afluente ou submeter o lodo em excesso a uma fermentação ácida (degradação anaeróbia incompleta não atingindo a metanogênese).

\subsubsection{Características do lodo gerado por um sistema com remoção biológica de} fósforo

De acordo com KUBA et al (1997) o lodo gerado em sistemas com remoção biológica de fósforo caracterizam-se por uma alta concentração PAOs, de $30 \%$ a $50 \%$ de todo o SSVTA. Segundo este mesmo autor a remoção biológica de fósforo em plantas em larga escala ocorre $50 \%$ em decorrência da existência de PAOs e 50\% aproximadamente é em 
decorrência das atividades de desnitrificação. Desta forma, pode-se observar que o lodo gerado em um sistema UCT tende a ter altas concentrações de fósforo.

De acordo com METCALF \& EDDY (2002), a fração de voláteis no lodo com altas concentrações de PAOs é maior do que em lodos heterotróficos, o que leva a uma tendência de maior geração de lodo no contexto geral de uma planta de tratamento de esgotos.

\subsubsection{Efeitos da recirculação de nitrato na eficiência de remoção de fósforo}

CHEN et al (2011) estudou os efeitos de diversas razões de recirculação de nitrato na eficiência global de remoção de fósforo em sistemas Anaeróbio/Anóxico/Aeróbio/Filtro biológico. De acordo com este autor, quanto maior a taxa de recirculação de nitrato, maior será a remoção de fósforo. Isso se deve pelo fato de que quanto maior a taxa de recirculação maior será a carga de nitrato nos reatores anóxicos.

Este mesmo autor sugere a existência de PAOs relacionadas à desnitrificação ou DPAOs (Denitrification phosphorous accumulating organisms). Estes microrganismos sob determinadas condições tem capacidade de tanto remover fósforo quanto nitrogênio. Estes microrganismos tem condições adequadas de crescimento quando as taxas de recirculação de nitrato são maiores do que o potencial de desnitrificação no reator anóxico.

CHEN et al (2011), no entanto, afirma que existem limites para a razão de recirculação de nitrato para o reator anóxico, uma vez que a partir de razões de recirculação de nitrato de 4 vezes a vazão de entrada na planta as taxas de consumo de DQO na desnitrificação são reduzidas em sistemas similares ao UCT Modificado. 


\section{MATERIAIS E MÉTODOS}

O presente estudo tem por objetivo avaliar algumas modificações no processo UCT modificado conforme Tabela 6.

Tabela 6 - Etapas de experimentação

\begin{tabular}{|l|c|}
\hline \multicolumn{1}{|c|}{ Etapas de avaliação } & Finalidade \\
\hline $\begin{array}{l}\text { Operação normal (chicanas no reator } \\
\text { anaeróbio) }\end{array}$ & $\begin{array}{c}\text { Avaliação da eficiência na remoção } \\
\text { biológica de fósforo desta modificação } \\
\text { no sistema UCT Modificado }\end{array}$ \\
\hline Micro aeração dos reatores anóxicos & $\begin{array}{c}\text { Avaliação da eficiência na remoção de } \\
\text { nitrogênio e fósforo pela introdução de } \\
\text { micro aeração nas câmaras anóxicas }\end{array}$ \\
\hline
\end{tabular}

O sistema UCT foi constituído de um tanque anaeróbio, dois tanques anóxicos, um tanque aerado e um decantador final. $\mathrm{O}$ excesso de lodo foi retirado do sistema pelo tanque de aeração e armazenado para futuras análises (fora do escopo deste projeto). Este estudo não abordará o sistema de tratamento do lodo e recuperação de fósforo na forma de estruvita.

A Figura 22 apresenta um esquema geral da planta piloto UCT estudada neste trabalho.

Ressalta-se que foi utilizada como premissa que o esgoto bruto afluente à planta deveria ter concentração de DQO entre $200 \mathrm{mg} / \mathrm{L}$ a $600 \mathrm{mg} / \mathrm{L}$ para se ter uma comparação mais próxima às águas residuárias afluentes às estações de tratamento de esgotos no Brasil. Desta forma, adotou-se como esgoto bruto o esgoto proveniente de um decantador primário instalado ao lado da planta.

Figura 22 - Esquema das etapas do processo a ser estudado

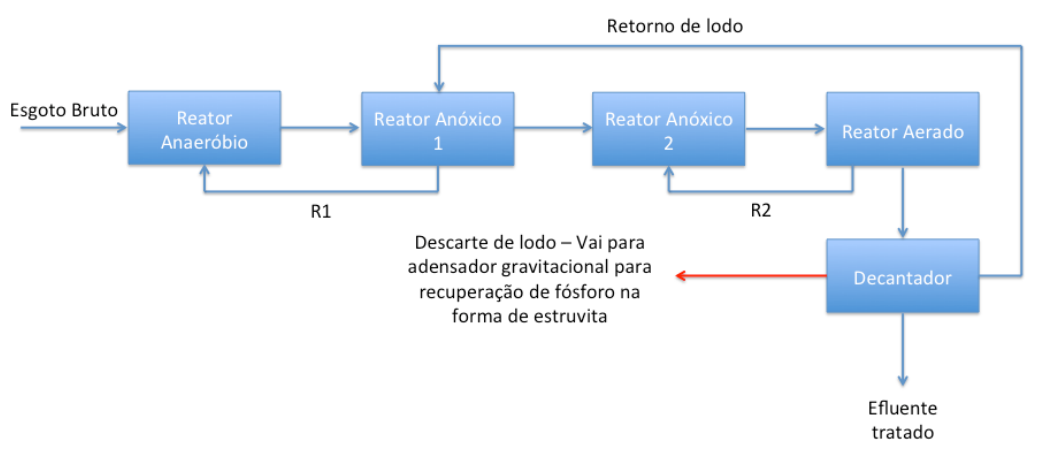

Fonte: Autor 
Os desenhos construtivos da planta piloto (reator UCT modificado e precipitador de estruvita) estão representados nas figuras no Apêndice 3. 


\subsection{Localização da planta piloto e condições locais do experimento}

A planta piloto UCT modificado foi instalada no CTH-USP (Centro de Tecnologia Hidráulica) da Universidade de São Paulo.

Figura 23 - Localização da Planta Piloto

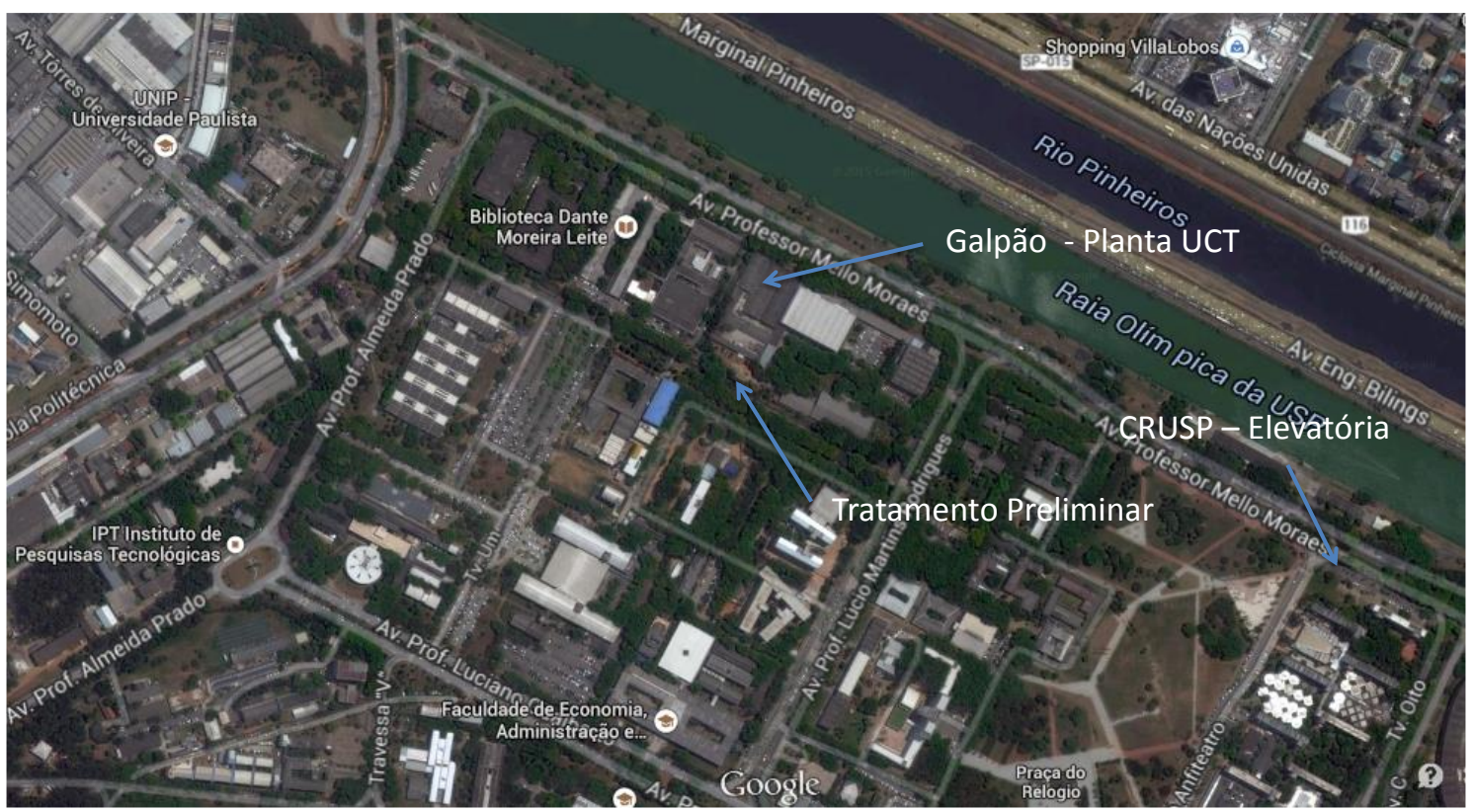

Fonte: Alterado de Google

A planta localiza-se em um galpão coberto sem contato com possíveis precipitações e com elevadas temperaturas (a temperatura média no galpão é de $30^{\circ} \mathrm{C}$ ).

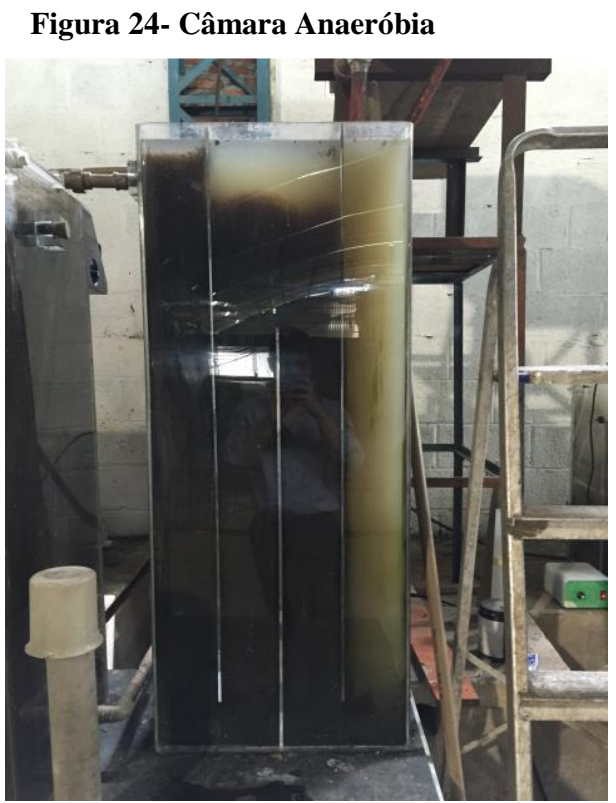

Fonte: Autor 
Figura 25 - Câmara Anóxica 1

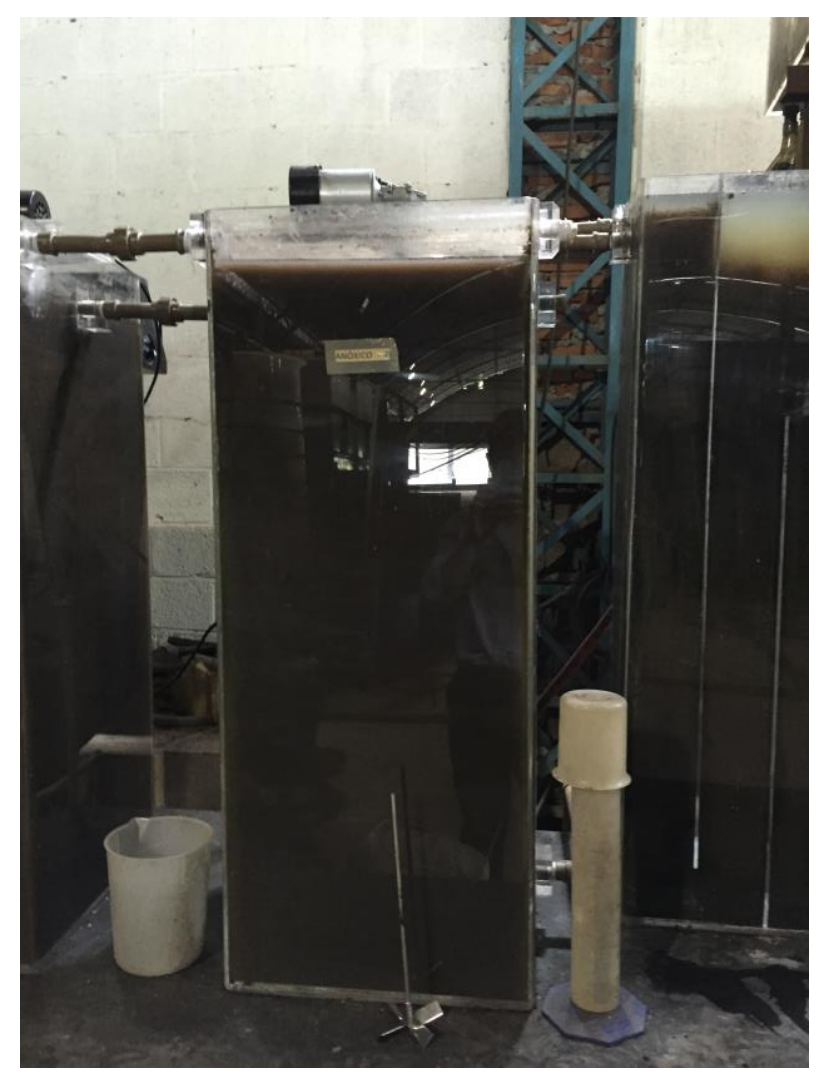

Fonte: Autor

Figura 26 - Câmara Anóxica 2

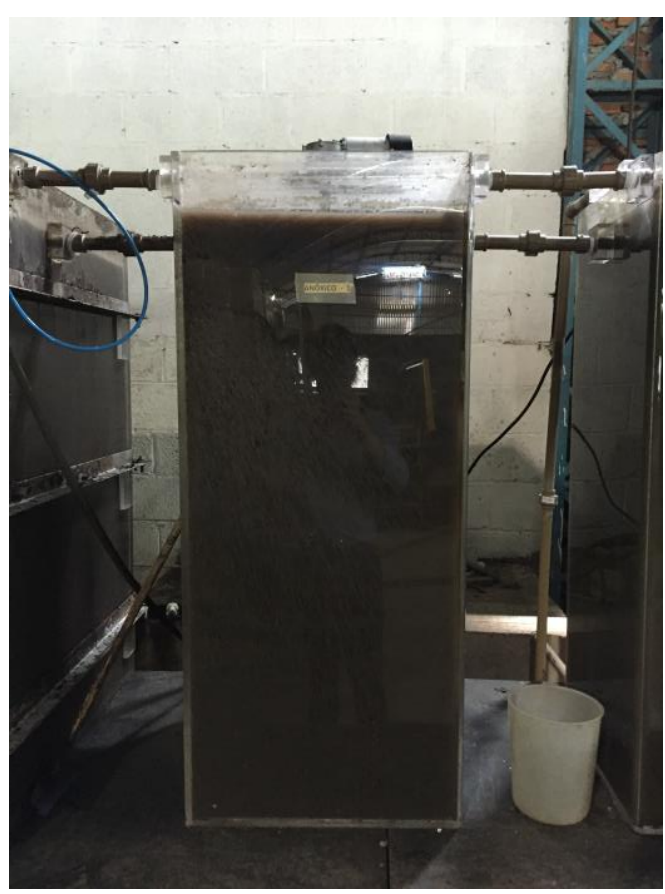

Fonte: Autor 
Figura 27 - Tanque Aeração

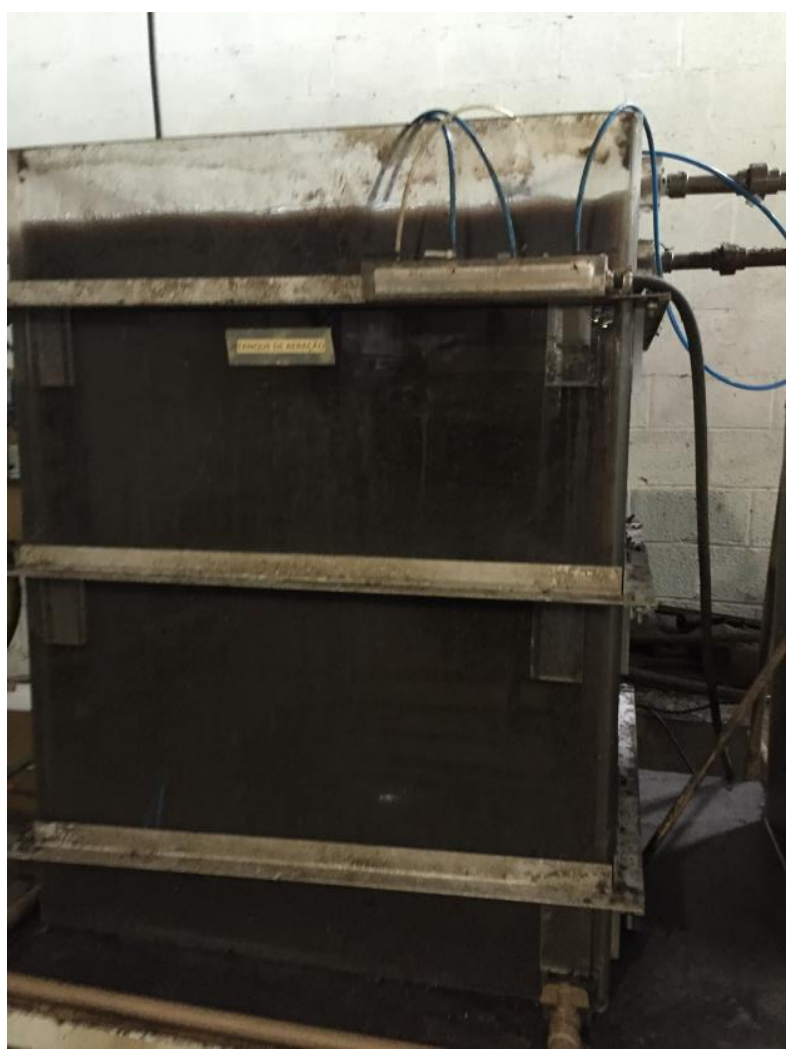

Fonte: Autor

Figura 28 - Decantador Secundário

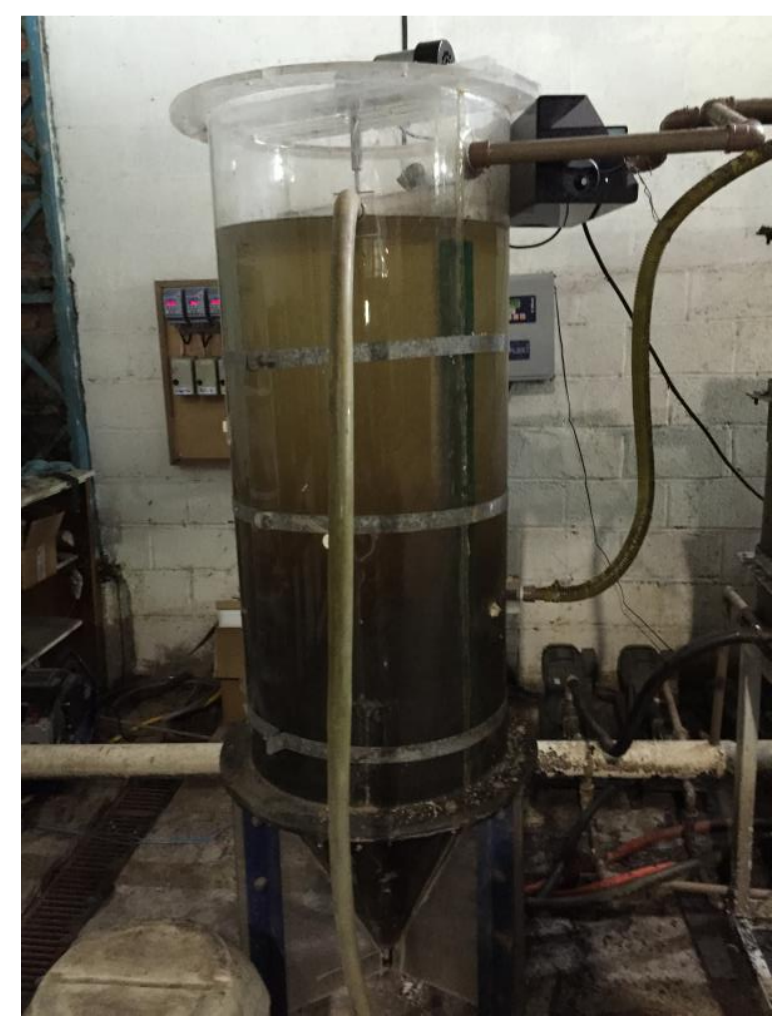

Fonte: Autor 
Figura 29 - Bombas utilizadas na Planta Piloto

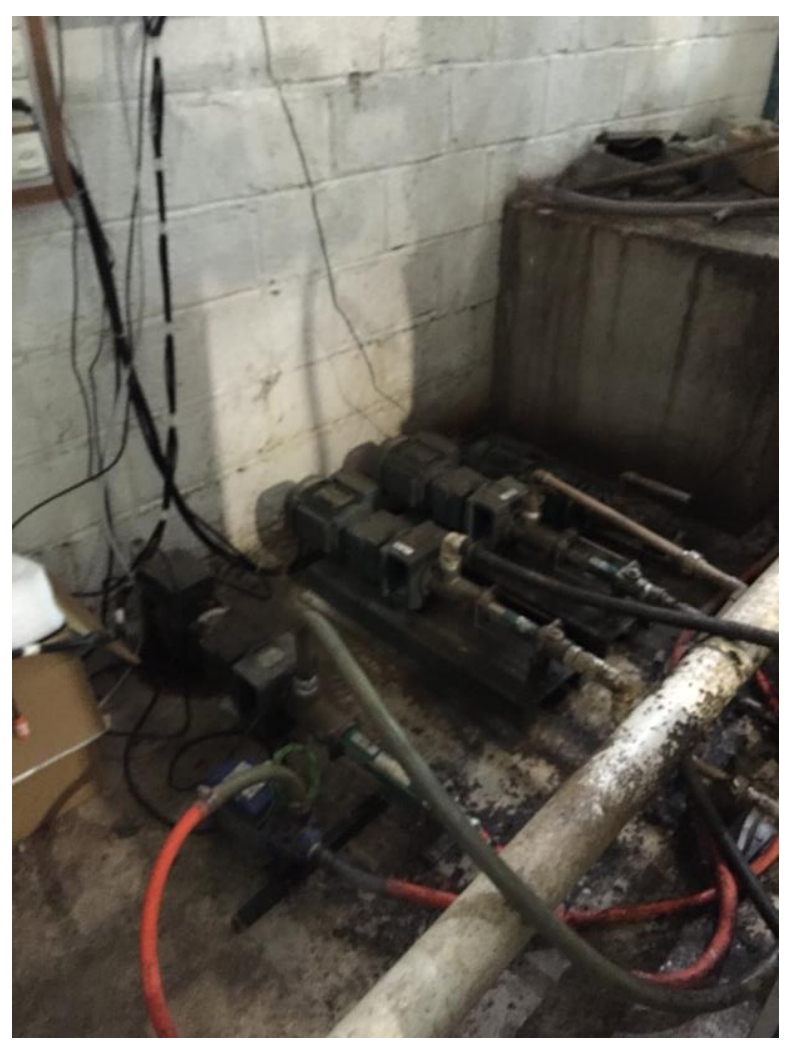

Fonte: Autor

Figura 30 - Equipamentos elétricos de comando da planta piloto

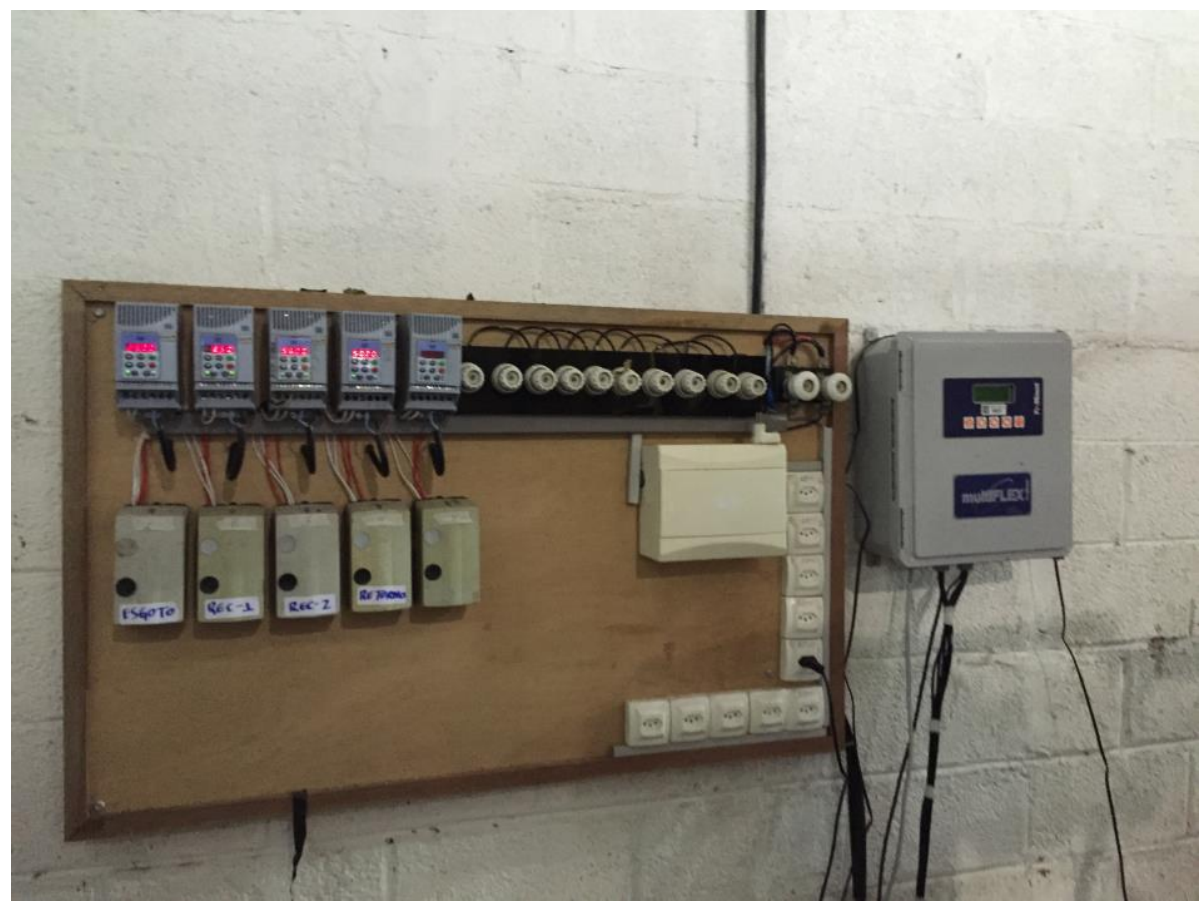

Fonte: Autor 
O esgoto bruto utilizado neste experimento é proveniente do CRUSP (Conjunto Residencial Universitário da USP) e as principais fontes geradoras são os dormitórios dos estudantes que residem nesta localidade e o Restaurante Universitário Central, localizado nas cercanias dos dormitórios. Após reunião em um PV ao lado da Rua da Reitoria, o esgoto é encaminhado parcialmente para a rede coletora da SABESP (operadora de saneamento na cidade de São Paulo) e uma outra parcela é encaminhada via estação elevatória composta por dois conjuntos moto-bomba ( 1 em operação e 1 reserva) para o tratamento preliminar localizado no CTH-USP. A princípio o esgoto passa por um gradeamento fino e por um canal desarenador para remoção de partículas e sólidos com diâmetro acima de $5 \mathrm{~mm}$ e areia. Após passar pelo canal desarenador o esgoto é encaminhado para uma caixa de reunião de vazões que alimenta três conjuntos moto-bomba. Cada um destes conjuntos moto-bomba tem destinos diferentes, sendo que um dos conjuntos moto-bomba alimenta diretamente o galpão no qual a piloto UCT modificado está implantada.

$\mathrm{Na}$ chegada do galpão, há uma caixa de reunião que recebe diretamente o esgoto proveniente da elevatória de esgoto bruto e alimenta por gravidade o decantador primário. A partir da caixa de reunião todo o encaminhamento do esgoto é feito por gravidade.

Tanto a caixa de reunião quanto o decantador primário tem a função de equalizar e manter a vazão afluente o mais constante possível, além de abater parte da carga orgânica para as faixas desejadas.

Após tratamento da planta UCT modificada o esgoto tratado é encaminhado para a rede coletora de esgotos da operadora de saneamento.

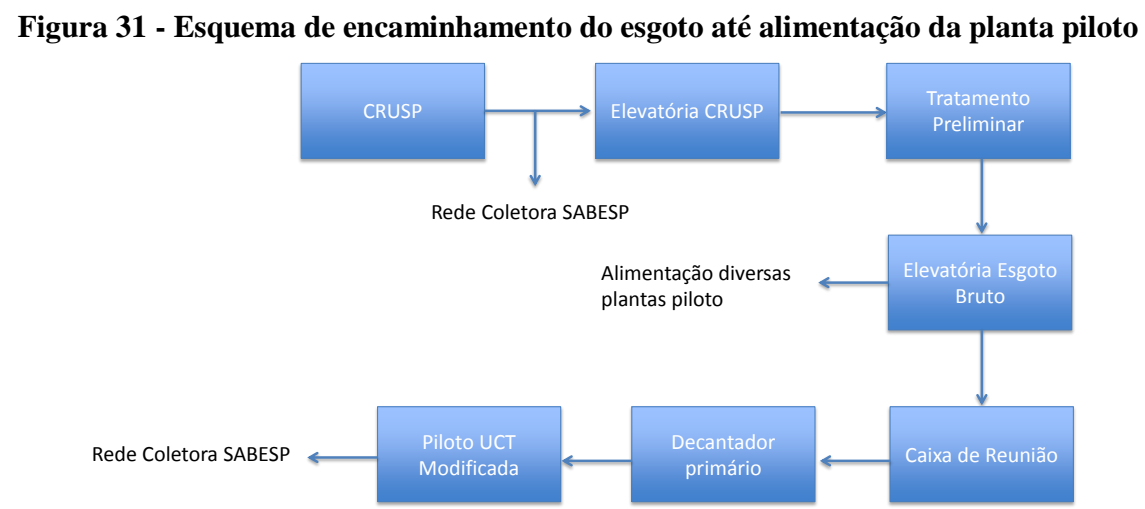

Fonte: Autor 
Desta forma, pode-se inferir que se trata de um esgoto predominantemente doméstico, podendo ser encontrados alguns picos de entrada de nutrientes como nitrogênio e fósforo ao longo do dia devido à atividade do restaurante universitário.

\subsection{Modelagem dos experimentos de operação da Planta UCT Modificado}

Inicialmente este trabalho abordará duas variações no sistema UCT modificado: Operação com uma câmara anaeróbia chicaneada e posteriormente será dotado de microaeração as câmaras anóxicas. Em ambos os casos, foram utilizadas as mesmas condições operacionais que serão descritas nos itens 4.2.1, 4.2.2 e 4.2.3.

\subsubsection{Dimensionamento de vazões}

De acordo com os desenhos de fabricação e checagens de dimensões feitas após a construção, foram levantados os seguintes volumes das câmaras do reator UCT modificado.

Tabela 7 - Dimensões das unidades componentes da Piloto UCT Modificada

\begin{tabular}{|c|c|c|c|c|}
\hline Câmara & Largura (m) & $\begin{array}{c}\text { Comprimento } \\
(\mathbf{m})\end{array}$ & Altura(m) & $\begin{array}{c}\text { Volume } \\
\text { total }\left(\mathbf{m}^{\mathbf{3}}\right)\end{array}$ \\
\hline Anaeróbia & 0,3 & 0,3 & 1,2 & 0,11 \\
\hline Anóxica 1 & 0,4 & 0,4 & 1,1 & 0,18 \\
\hline Anóxica 2 & 0,45 & 0,45 & 1 & 0,20 \\
\hline Aeróbia & 0,8 & 0,8 & 1,1 & 0,70 \\
\hline $\begin{array}{l}\text { Decantador } \\
\text { Secundário }\end{array}$ & \multicolumn{2}{|c|}{ Diâmetro $=0,4$} & 1,0 & 0,13 \\
\hline
\end{tabular}

Fonte: Autor

Considerando volume do tanque de aeração de $0,70 \mathrm{~m}^{3}$ e considerando vazão de alimentação do reator biológico de 84 litros/hora $\left(2 \mathrm{~m}^{3} / \mathrm{dia}\right)$, encontra-se o seguinte tempo de detenção hidráulica no reator aeróbio:

$$
T R H_{\text {aer }}=\frac{0,70 \mathrm{~m}^{3}}{2^{\mathrm{m}^{3} / \text { dia }}}=8,4 \text { horas }(\mathbf{1 3 6})
$$


O volume total da planta UCT modificada é:

$$
\begin{gathered}
\text { Volume }_{\text {total }}=\text { Volume Anaeróbio }+ \text { Volume Anóxico } 1+\text { Volume Anóxico } 2+ \\
\text { Volume Aeróbio }=0,11+0,18+0,20+0,70(\mathbf{1 3 7}) \\
\text { Volume }_{\text {total }}=1,19 \mathrm{~m}^{3}
\end{gathered}
$$

\subsubsection{Dimensionamento de Cargas e Parâmetros do processo biológico}

Esta etapa tem finalidade definir as condições iniciais de operação do sistema a ser operado para que posteriormente possam ser feitos os ajustes necessários para avalições.

A princípio será considerado que o processo de lodos ativados envolvido neste processo será convencional com razão F/M ou A/M de 0,2 kg DBO/kg SSV d. Adotando-se $X_{t}$ de $3,0 \mathrm{~kg} \mathrm{SST} / \mathrm{m}^{3}$ e considerando a relação $X_{\mathrm{v}} / \mathrm{X}_{\mathrm{t}}$ de 0,8 .

Desta forma, considerando-se um afluente doméstico com concentrações de substrato de $0,2 \mathrm{~kg} \mathrm{DBO} / \mathrm{m}^{3}$ a $0,3 \mathrm{~kg} \mathrm{DBO} / \mathrm{m}^{3}$ pela Equação (25) tem-se as seguintes vazões de alimentação de esgoto.

$$
\begin{gathered}
A /_{M}=\frac{Q S_{0}}{V X_{v}}(\mathbf{2 5}) \\
Q=\frac{0,2 * 1,19 * 2,4}{S_{0}}
\end{gathered}
$$

\begin{tabular}{|c|c|c|c|}
\hline $\begin{array}{c}\text { Concentração } \\
\text { DBO } \\
\left(\mathrm{kg} \mathrm{O}_{2} / \mathbf{m}^{3}\right)\end{array}$ & $\begin{array}{c}\text { Vazão de } \\
\text { alimentação } \\
\text { de esgoto } \\
\left(\mathrm{m}^{3} / \text { dia }\right)\end{array}$ & $\begin{array}{c}\text { Vazão de } \\
\text { alimentação de } \\
\text { esgoto (L/hora) }\end{array}$ & $\begin{array}{c}\text { Estimativa de } \\
\text { Carga } \\
\text { Orgânica } \\
\text { Afluente (kg } \\
\text { DBO/dia) }\end{array}$ \\
\hline 0,2 & 2,86 & 119 & 0,57 \\
\hline 0,3 & 1,91 & 79 & 0,57 \\
\hline
\end{tabular}

Desta forma as vazões de esgoto de alimentação estão na faixa de 1,9 a 2,8 $\mathrm{m}^{3} / \mathrm{dia}$.

Tabela 8 - Vazões e cargas afluentes estimadas

Fonte: Autor 


\subsubsection{Dimensionamento de Vazões de recirculação}

Conforme proposto pelo processo UCT modificado existem 3 reciclos internos ao processo: Um reciclo de retorno de lodo do decantador secundário para a primeira câmara anóxica (s), um reciclo do reator aeróbio para a segunda câmara anóxica (a) e um reciclo do primeiro reator anóxico para o reator anaeróbio $(\mathbf{r})$.

VAIOPOULOU et al (2008) indicam fatores de recirculação que foram utilizados no presente trabalho para definição das taxas de recirculação e estão Apresentadas na Tabela 9.

Tabela 9 - Recirculações adotadas para execução dos experimentos

\begin{tabular}{|c|c|c|c|}
\hline Recirculação & $\begin{array}{c}\text { Fator de } \\
\text { recirculação }\end{array}$ & $\begin{array}{c}\text { Vazão adotada } \\
\text { (L/hora) }\end{array}$ & $\begin{array}{r}\text { Vazão } \\
\text { adotada } \\
\left(\mathbf{m}^{\mathbf{3}} / \mathbf{d i a}\right)\end{array}$ \\
\hline $\mathrm{S}$ & 1 & 60 & 1,40 \\
\hline $\mathrm{R}$ & 1 & 60 & 1,40 \\
\hline $\mathrm{A}$ & 1 & 60 & 1,40 \\
\hline
\end{tabular}

Fonte: Autor

Já a idade do lodo a ser considerada inicialmente é de 12 dias $\left(\mathrm{R}_{\mathrm{S}}\right)$. Considerando que a retirada será feita diretamente do reator aeróbio, pode-se definir que a vazão de retirada de lodo $\left(\mathrm{Q}_{\mathrm{w}}\right)$ pela Equação (13) será de aproximadamente $100 \mathrm{~L} /$ dia.

$$
\begin{gathered}
R_{s}=\frac{V}{Q_{w}}(\mathbf{1 3}) \\
Q_{w}=\frac{V}{R_{S}}=100^{\mathrm{Litros}} / \mathrm{dia}
\end{gathered}
$$

\subsection{Metodologia para colocação em operação da planta}

A planta foi colocada em operação no mês de Novembro de 2014 e o período de implantação da planta foi de 6 meses. Para esta atividade inicial de colocação em operação da planta foi utilizado inicialmente lodo biológico aeróbio proveniente da planta de tratamento de esgotos de Barueri (ETE Barueri da SABESP) posteriormente lodo aeróbio proveniente do tanque de aeração do Aquapolo Ambiental. Foi utilizado 
aproximadamente 400 Litros de lodo proveniente da ETE Barueri em Novembro de 2015 e 200L de lodo do Aquapolo Ambiental em Março de 2015.

Durante o período de implantação da planta foram feitas análises pontuais para avaliar a carga afluente, concentração de sólidos, capacidades dos equipamentos instalados e estabilidade da planta. Foram controladas diariamente as vazões do sistema, assim como feitos os devidos ajustes na concentração de sólidos no sistema (SSV e SST). Não serão apresentados no capítulo de discussão de resultados estas análises.

\subsection{Metodologia de análise local da planta piloto}

A análise local da planta consiste na checagem e anotação dos dados de controle para monitoramento dos parâmetros vazão, $\mathrm{pH}$, potencial Redox, Oxigênio dissolvido e temperatura. Esta rotina foi realizada duas vezes por dia pelo período de experimentação. Para a etapa de microaeração das câmaras anóxicas foi realizado controle de oxigênio dissolvido nestas duas câmaras. Nos itens a seguir serão descritas as rotinas de obtenção destes dados.

\subsubsection{Vazão}

Foram feitas análises da vazão afluente à planta piloto e de todas as recirculações existentes. Para tal medição eram armazenadas em recipiente com indicação de volume as alíquotas de 15 segundos de toda a vazão em medição. Após esta etapa eram anotados os valores obtidos para definição da vazão.

\subsection{2. pH e Potencial Redox}

As análises de $\mathrm{pH}$ e potencial redox foram executadas nas câmaras anaeróbia, anóxica 1 e anóxica 2 e tanque de aeração. Foram utilizadas sondas da Marca Prominent para tal medição.

\subsubsection{Oxigênio Dissolvido (OD)}

O Controle de OD foi realizado por meio de um medidor/controlador da marca Prominent com saída 0/4-20 mA e faixa de medição de 0,0 a 10,0 mg/L. O sensor funciona em contato com o licor misto do tanque de aeração. Os registros são mantidos em data logger. Foram mantidos os valores adequados de OD no tanque de aeração de 
acordo com a etapa de experimentação. Para a experimentação foram mantidos níveis de OD entre $0,8 \mathrm{mg} / \mathrm{L}$ a $5 \mathrm{mg} / \mathrm{L}$.

Para a segunda etapa da experimentação foi feito controle de OD nas câmaras anóxicas 1 e 2 por meio de sensores portáteis com a mesma lógica de funcionamento do medidor de OD usado no tanque de aeração.

\subsubsection{Temperatura}

As medições de temperatura foram realizado por meio de termômetro de mercúrio instalado ao lado do tanque de aeração para avaliação da temperatura local.

\subsection{Descritivo de análises laboratoriais}

Para o correto entendimento do sistema e desenvolvimento das análises foram realizadas análises laboratoriais para caracterização do afluente e efluente à planta assim como algumas análises de etapas intermediárias do processo de tratamento proposta para se evidenciar e analisar o comportamento do sistema ao longo da operação da planta piloto. Na Tabela 10 são apresentados os pontos de amostragem possíveis e na Tabela 11 são apresentadas as análises e respectivos pontos de amostragem.

Tabela 10 - Possíveis pontos de amostragem

\begin{tabular}{|c|c|}
\hline Ponto de & Descrição \\
\hline 1 & Efluente do Decantador Primário (Esgoto Bruto) \\
\hline 2 & Efluente do Reator Anaeróbio \\
\hline 3 & Efluente do Reator Anóxico 1 \\
\hline 4 & Efluente do Reator Anóxico 2 \\
\hline 5 & Efluente do Tanque de Aeração \\
\hline 6 & Efluente do Decantador Secundário (Efluente \\
& \\
\hline 7 & Lodinal) \\
\hline
\end{tabular}

Fonte: Autor 
Tabela 11 - Análises laboratoriais do efluente bruto e tratado

\begin{tabular}{|c|c|c|c|}
\hline Tipo de análise & $\begin{array}{c}\text { Pontos de } \\
\text { amostragem }\end{array}$ & $\begin{array}{l}\text { Frequência de } \\
\text { amostragem }\end{array}$ & $\begin{array}{c}\text { Referência Standard } \\
\text { Methods }\end{array}$ \\
\hline Alcalinidade & $1,2,3,4,5,6,7$ & $\begin{array}{c}2 \text { Vezes por } \\
\text { semana }\end{array}$ & Método - 2320-B \\
\hline $\mathrm{DBO}_{5,20}$ Total & 1,6 & $\begin{array}{c}2 \text { Vezes por } \\
\text { semana }\end{array}$ & Método - 5210-B \\
\hline DBO $_{5,20}$ Solúvel & $1,2,3,4,6$ & $\begin{array}{c}2 \text { Vezes por } \\
\text { semana }\end{array}$ & Método - 5210-B \\
\hline DQO Total & 1,6 & $\begin{array}{c}2 \text { Vezes por } \\
\text { semana }\end{array}$ & Método - 5220-B \\
\hline DQO Solúvel & $1,2,3,4,6$ & $\begin{array}{c}2 \text { Vezes por } \\
\text { semana }\end{array}$ & Método - 5220-B \\
\hline $\begin{array}{c}\text { Nitrogênio Total } \\
\text { Kjeldahl }\end{array}$ & $1,5,6$ & $\begin{array}{c}2 \text { Vezes por } \\
\text { semana }\end{array}$ & Método-4500-B \\
\hline $\begin{array}{l}\text { Nitrogênio } \\
\text { Amoniacal }\end{array}$ & $1,5,6$ & $\begin{array}{c}2 \text { Vezes por } \\
\text { semana }\end{array}$ & Método - 4500-B/C \\
\hline Nitrato & $2,3,4,5,6,7$ & $\begin{array}{c}2 \text { Vezes por } \\
\text { semana }\end{array}$ & Método-4110-B \\
\hline Fósforo Total & $1,2,3,4,5,6,7$ & $\begin{array}{c}2 \text { Vezes por } \\
\text { semana }\end{array}$ & Método - 4500-P \\
\hline Fósforo Solúvel & $1,2,3,4,5,6,7$ & $\begin{array}{c}2 \text { Vezes por } \\
\text { semana }\end{array}$ & Método - 4500-P \\
\hline $\begin{array}{c}\text { Série completa de } \\
\text { Sólidos }\end{array}$ & $2,3,4,5,6,7$ & $\begin{array}{c}2 \text { Vezes por } \\
\text { semana }\end{array}$ & Método - 2540 \\
\hline $\begin{array}{c}\text { Ácidos orgânicos } \\
\text { Voláteis }\end{array}$ & $1,2,3,4$ & $\begin{array}{c}2 \text { Vezes por } \\
\text { semana }\end{array}$ & Método - 5560-C \\
\hline
\end{tabular}




\begin{tabular}{|c|c|c|c|}
\hline $\mathrm{pH}$ & $1,2,3,4,5$ & 2 Vezes por dia & $\begin{array}{c}\text { Marca Prominent }- \\
\text { modelo Dulcotes PHE- } \\
112\end{array}$ \\
\hline Temperatura & 5 & 2 Vezes por dia & $\begin{array}{c}\text { Termômetro de } \\
\text { Mercúrio }\end{array}$ \\
\hline Oxigênio & $3,4,5$ & 2 Vezes por dia & $\begin{array}{c}\text { Marca Prominent }- \\
\text { modelo Dulctest DO2 }\end{array}$ \\
\hline
\end{tabular}

Fonte: Autor

Todas as análises químicas realizadas seguem a metodologia determinada por Standard Methods (2012) 


\section{RESULTADOS E DISCUSSÕES}

Neste item serão apresentados os resultados obtidos da operação da planta piloto e serão realizadas as discussões e avaliações dos resultados obtidos. Os dados aqui apresentados serão divididos nas duas etapas de operação, sendo nomeada a etapa 1 como a etapa de operação com as chicanas e a etapa 2 como a etapa de microaeração das câmaras anóxicas.

Todos os resultados obtidos nestas etapa estão tabulados no Apêndice 1 e 2 deste trabalho. Neste item iremos apresentar a estatística básica descritiva para cada um dos parâmetros, realizar as devidas análises estatísticas e discussão.

Adicionalmente será utilizado um conceito estatístico muito relevante na análise de estabilidade de processo: Seis Sigma. Este conceito consiste na avaliação pontual dos resultados em comparação com todos os demais resultados obtidos para um tipo de dado, considerando que se o resultado estiver fora de 3 desvios padrões para mais ou para menos a variável está fora de controle.

Como padrão de resultados utilizado por este trabalho todos os dados e análises estatísticas estão divididos para cada etapa de experimentação. Já os gráficos das séries históricas apresentam todo o período de experimentação devido à sua maior facilidade de comparação visual entre os resultados.

\subsection{Vazões e Resultados esperados para um sistema UCT}

\subsubsection{Vazões}

As tabelas 12 e 13 apresentam os resultados da estatística descritiva básica para os dados de vazão durante as etapas 1 e 2 de experimentação, respectivamente.

Tabela 12 - Dados de Vazão - Etapa 1 de experimentação

\begin{tabular}{|l|r|r|r|r|r|}
\hline \multirow{3}{*}{ Parâmetro } & $\begin{array}{c}\text { Vazão } \\
\text { Alimentação }\end{array}$ & Vazão Retorno & $\begin{array}{c}\text { Vazão } \\
\text { Reciclo 1 }\end{array}$ & $\begin{array}{c}\text { Vazão } \\
\text { Reciclo 2 }\end{array}$ & \multicolumn{1}{c|}{ Temperatura } \\
\cline { 2 - 6 } & \multicolumn{1}{c|}{ L/min } & L/min & L/min & \multicolumn{1}{c|}{ L/min } & oC \\
\hline Média & 1,6 & 1,6 & 1,7 & 1,8 & 22,6 \\
\hline Máximo & 2,4 & 1,96 & 2 & 2,24 & 17 \\
\hline Mínimo & 0,8 & 0,8 & 0,8 & 0,8 & 23 \\
\hline Mediana & 1,6 & 1,64 & 1,64 & 1,8 & 2,2 \\
\hline Desvio padrão & 0,21 & 0,18 & 0,18 & 0,18 & $10 \%$ \\
\hline CV (\%) & $13 \%$ & $11 \%$ & $11 \%$ & $10 \%$ & 11 \\
\hline AT & 1,6 & 1,16 & 1,2 & 1,44 & 248 \\
\hline Número de amostras & 255 & 258 & 206 & 257 & \\
\hline
\end{tabular}

Fonte: Autor 
Pode-se observar que o valor definido na metodologia deste trabalho de vazões de recirculação iguais à vazão de alimentação comparados aos dados obtidos em campo estão nos dois casos aproximadamente iguais. Ressalta-se que durante a fase de partida da planta foram observados alguns episódios de vazões acima das projetadas na metodologia e consequente transbordos nas câmaras da planta devido à não capacidade de escoamento de uma vazão mais elevada.

Tabela 13 - Dados de Vazão - Etapa 2 de Experimentação

\begin{tabular}{|l|r|r|r|r|r}
\hline \multirow{3}{*}{ Parâmetro } & \multicolumn{1}{c|}{$\begin{array}{c}\text { Vazão } \\
\text { Alimentação }\end{array}$} & $\begin{array}{c}\text { Vazão } \\
\text { Retorno }\end{array}$ & $\begin{array}{c}\text { Vazão } \\
\text { Reciclo 1 }\end{array}$ & $\begin{array}{c}\text { Vazão } \\
\text { Reciclo 2 }\end{array}$ & Temperatura \\
\cline { 2 - 6 } & \multicolumn{1}{c|}{ L/min } & L/min & \multicolumn{1}{c}{ L/min } & \multicolumn{1}{c}{ L/min } & oC \\
\hline Média & 1,7 & 1,7 & 1,6 & 1,7 & 25,5 \\
\hline Máximo & 2 & 2 & 2 & 2 & 30 \\
\hline Mínimo & 0 & 1,4 & 0 & 0 & 20 \\
\hline Mediana & 1,78 & 1,76 & 1,6 & 1,72 & 25 \\
\hline Desvio padrão & 0,3 & 0,1 & 0,3 & 0,3 & 2,3 \\
\hline CV (\%) & $17 \%$ & $7 \%$ & $18 \%$ & $15 \%$ & $9 \%$ \\
\hline AT & 2 & 0,6 & 2,04 & 2 & 10 \\
\hline Número de amostras & 64 & 63 & 64 & 64 & 58 \\
\hline
\end{tabular}

Fonte: Autor

A vazão de alimentação consiste no efluente do decantador primário e entrada no reator anaeróbio da planta UCT. O gráfico de série histórica para este parâmetro é apresentado na Figura 32.

Figura 32 - Gráfico da Série Histórica para vazão de alimentação da Planta Piloto

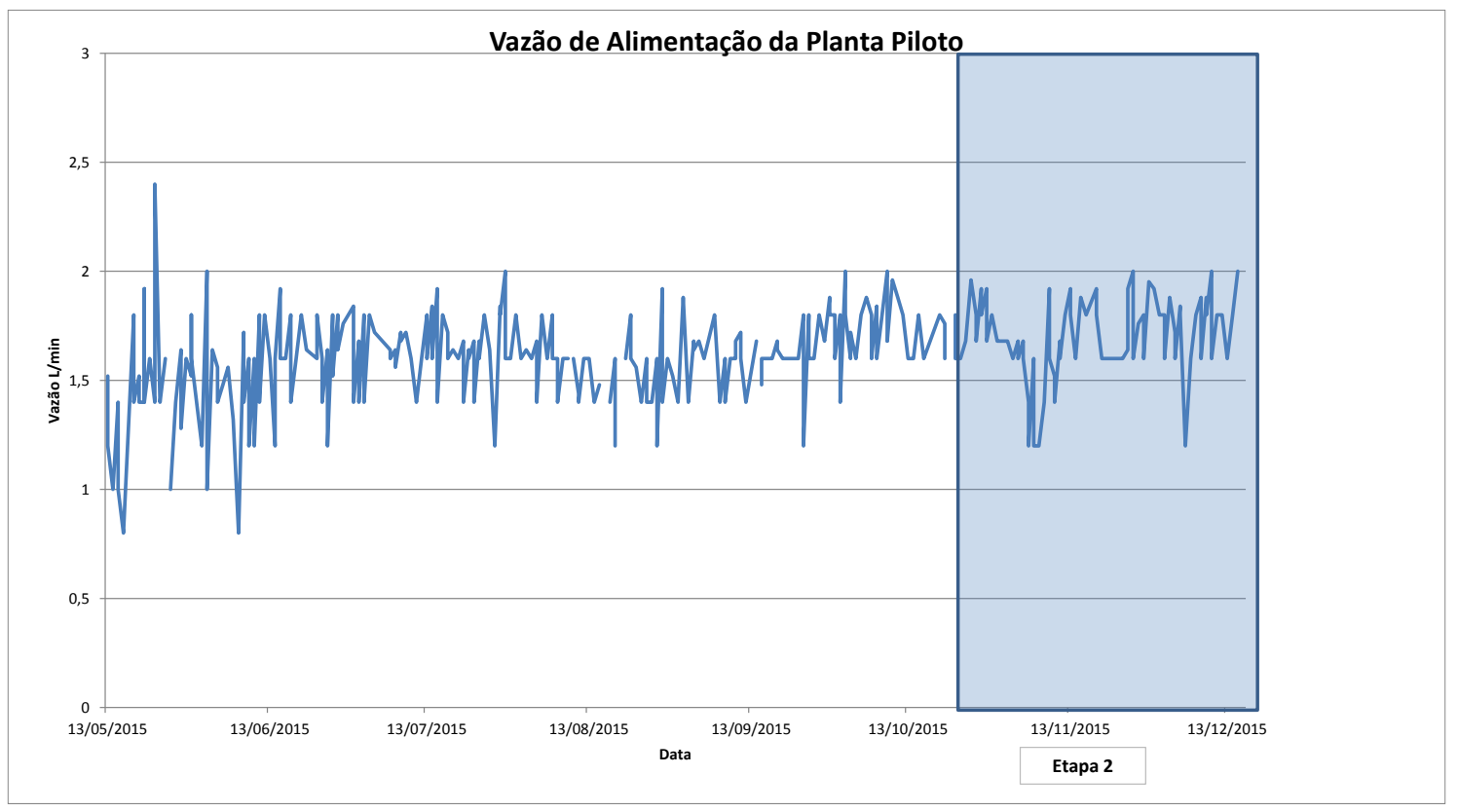

Fonte: Autor 
Adicionalmente será apresentado o gráfico X-barra para os dados de vazão de alimentação da planta piloto UCT modificado. Pode-se observar pela Figura 33 que no primeiro mês de operação foram constatados alguns picos de vazão, sendo que em 5 casos esta variável esteve fora dos intervalos estatísticos de operação.

Isto ocorreu devido problemas operacionais no ajuste do vertedor da caixa de chegada, sendo que em alguns casos ocorreram entupimentos deste vertedor o que de fato comprometeu a alimentação da planta piloto. Este problema foi resolvido com rotinas de limpeza periódicas na caixa de chegada.

Figura 33 - Gráfico X-Barra para a Vazão de Alimentação da planta piloto

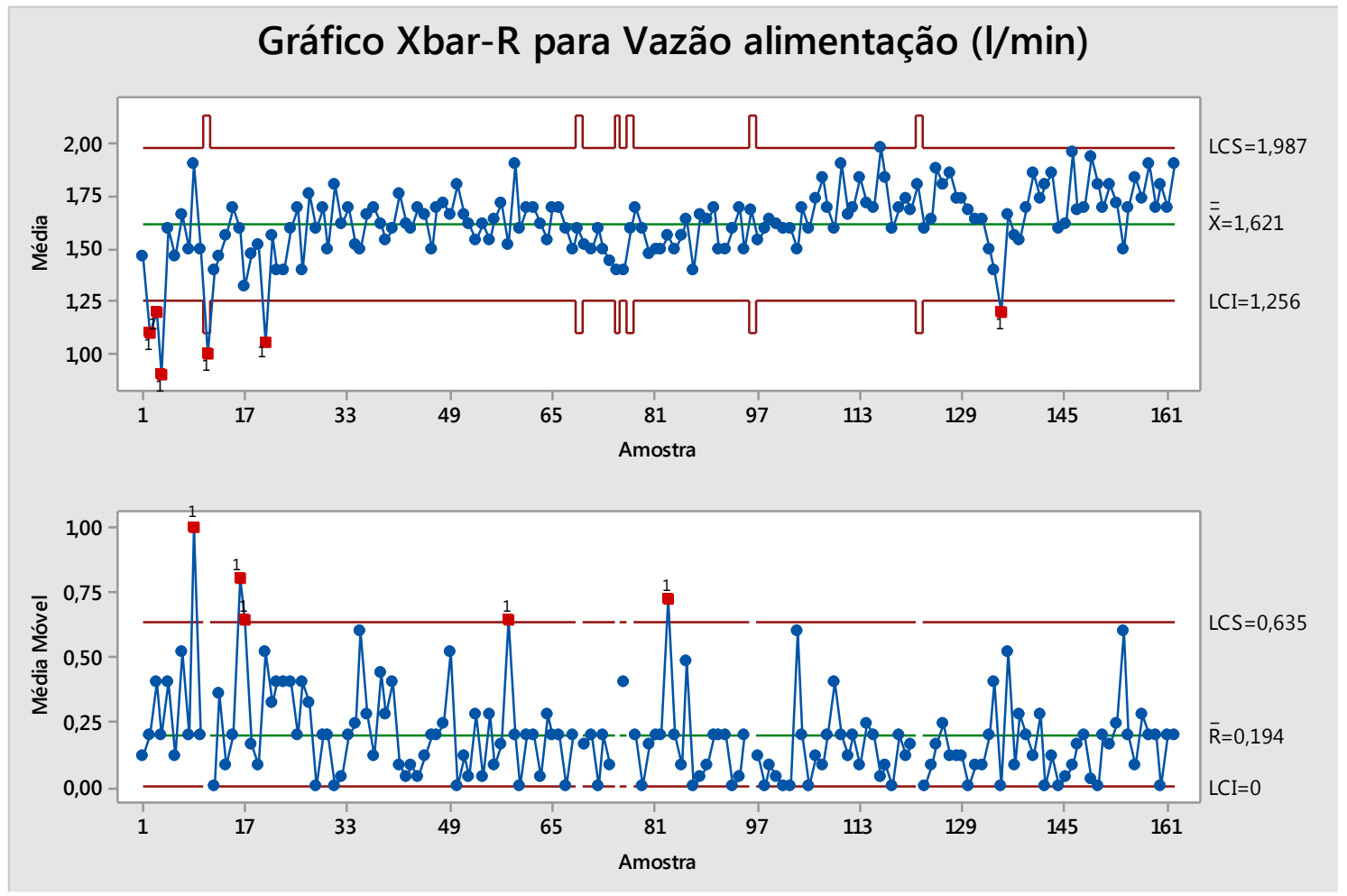

Fonte: Autor

Já o retorno de lodo consiste na alimentação do Reator Anóxico 1 pelo lodo do decantador secundário. Apresenta-se na Figura 34 a série histórica para este parâmetro. 
Figura 34 - Gráfico da Série Histórica para o parâmetro Vazão de Retorno de Lodo

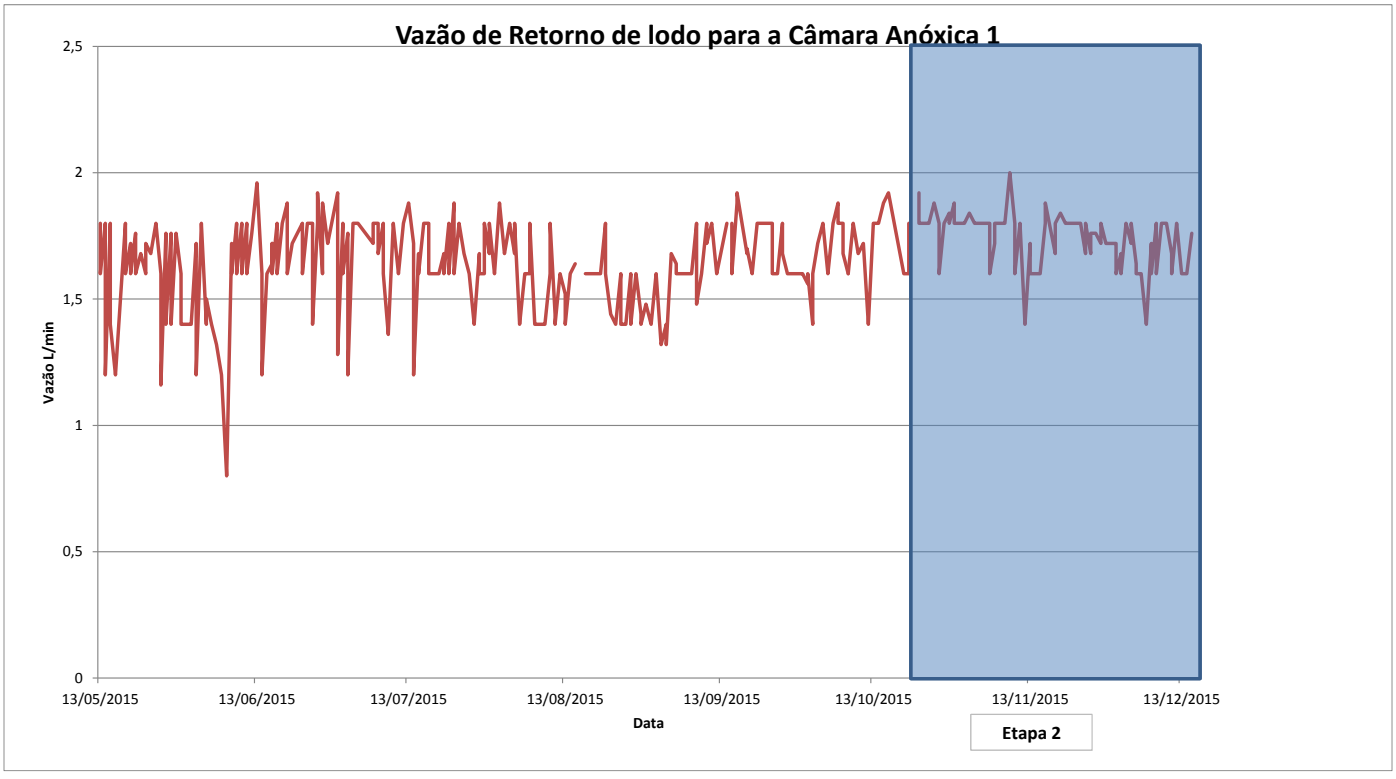

Fonte: Autor

Pode-se observar pela Figura 34 que não foram feitas três anotações para este parâmetro durante os levantamentos em campo devido a dificuldades em se realizar a medição de vazão neste ponto. Pelos dados obtidos foram encontrados 5 momentos nos quais a vazão de retorno de lodo saiu dos limites estatísticos operacionais. Estes 5 momentos podem ser considerados como momentos nos quais ocorreram desequilíbrios. A análise onde são apresentados tais dados estão presentes na Figura 35.

Figura 35 - Gráfico X-Barra para o parâmetro Vazão de retorno de lodo

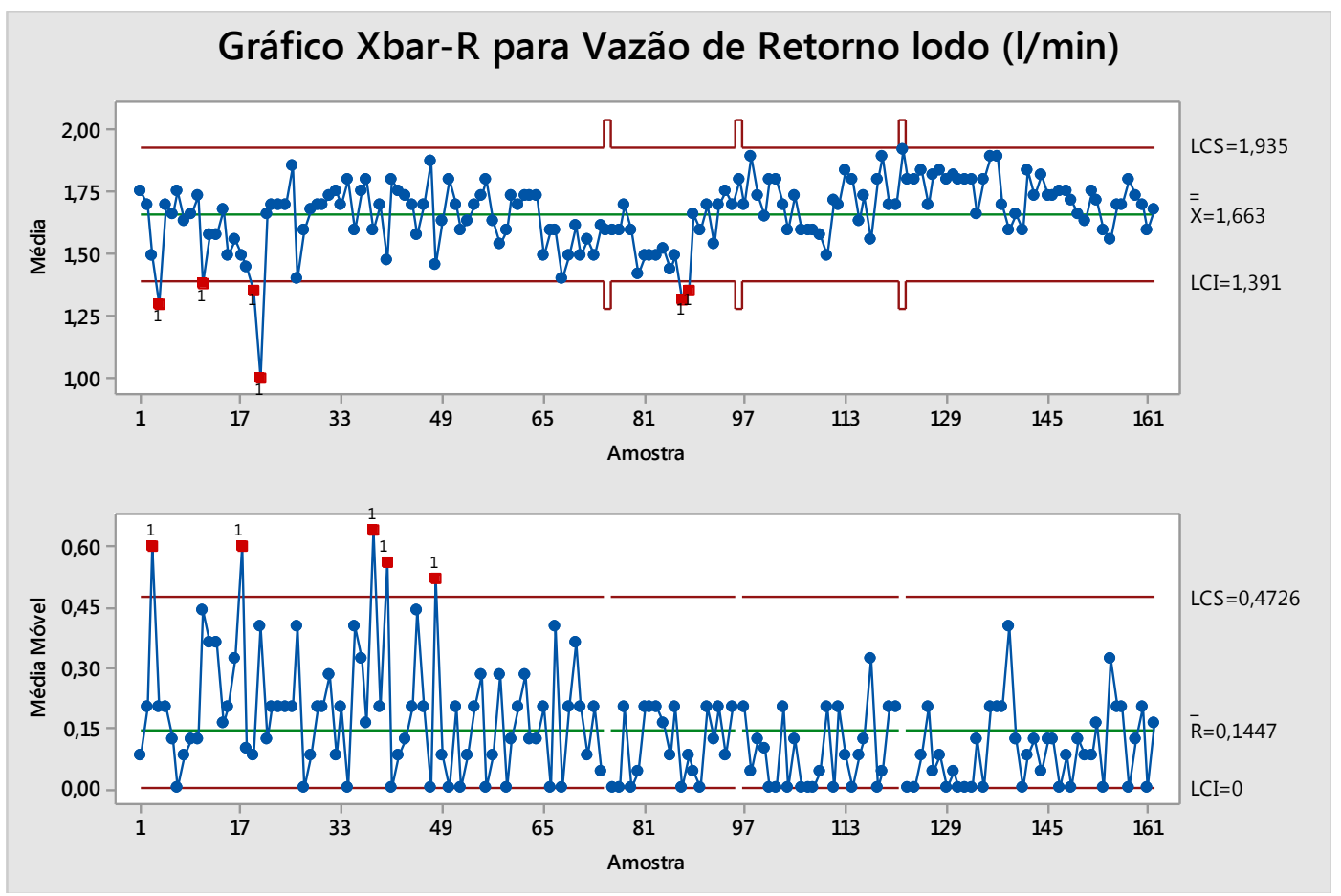

Fonte: Autor 
A Vazão de Reciclo 1 consiste no retorno da câmara Anóxica 1 para a câmara anaeróbia. Os dados para este parâmetros serão apresentados na Figura 36.

Figura 36 - Gráfico da Série Histórica para o parâmetro Vazão de Recirculação 1

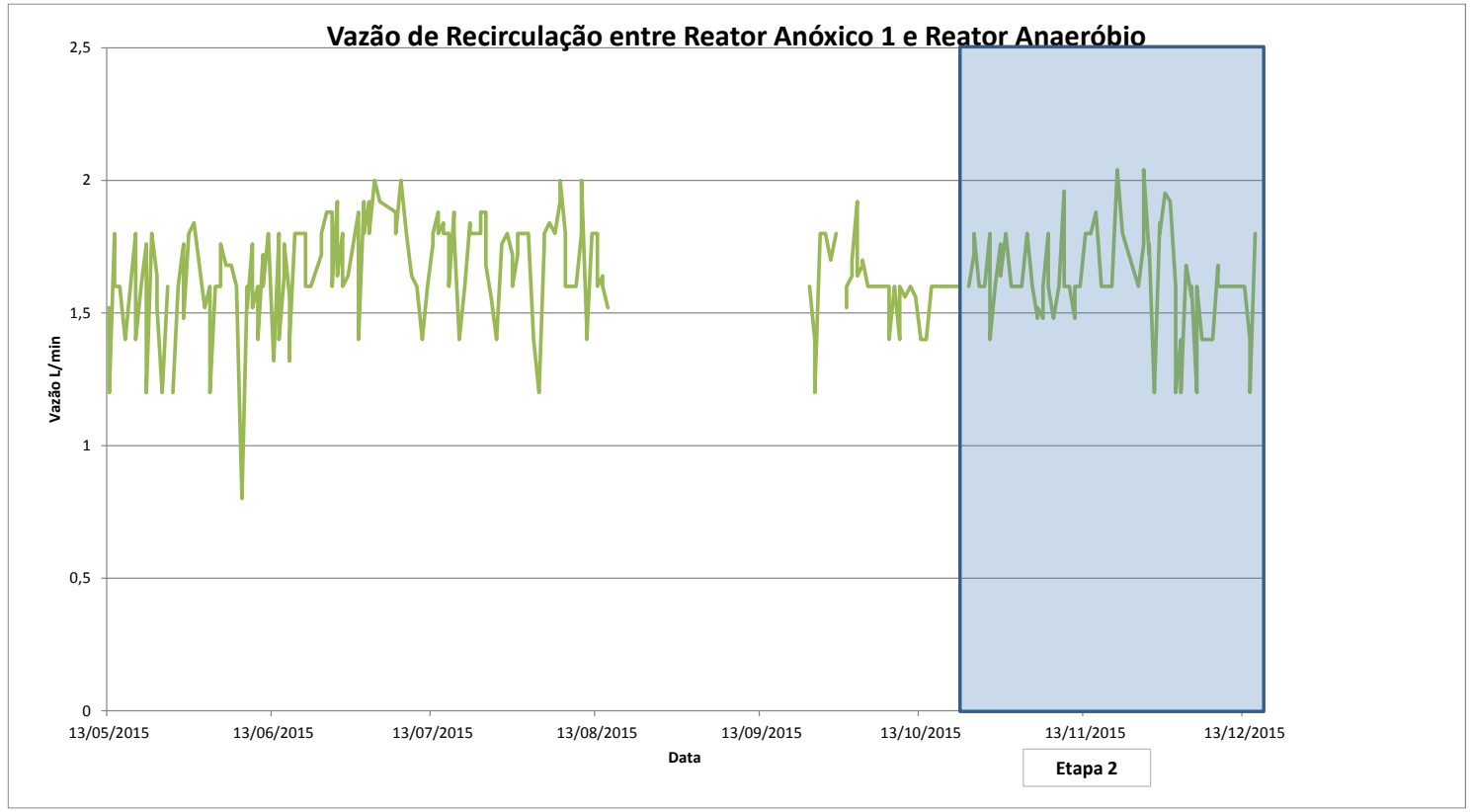

Fonte: Autor

Devido à dificuldades em se obter os dados de vazão para o período de aproximadamente 1 mês não foram registrados os dados desta vazão neste período. Pode-se observar na Figura 37 que para um longo intervalo de tempo não foram obtidas medições de vazão. 
Figura 37 - Gráfico X-Barra para o parâmetro Vazão de Reciclo 1

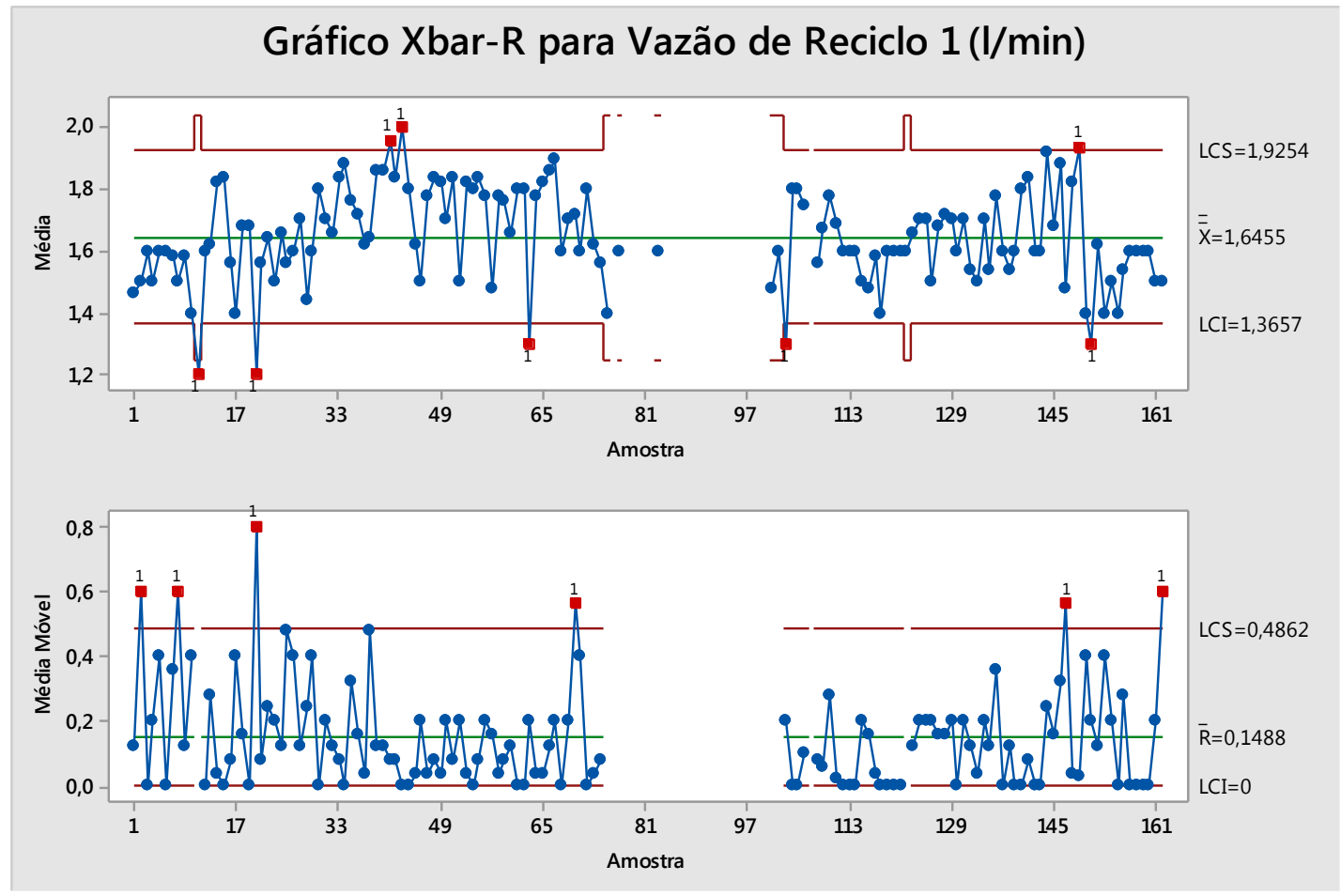

Fonte: Autor

Foram encontrados 5 registros de vazões abaixo dos limites estatísticos de operação e 3 registros acima destes limites. Ressalta-se que construtivamente a câmara anaeróbia é incapaz de receber altas contribuições de reciclo sendo que durante o período de préoperação foram observados alguns transbordamentos gerados por excessos de vazões de recirculação. Devido a este fator foi mantida a razão de reciclo 1 no mínimo operacional da bomba utilizada para tal finalidade.

A vazão de reciclo 2 consiste na alimentação do reator anóxico 2 pelo tanque de aeração. Os dados obtidos serão apresentados na Figura 38. 
Figura 38 - Gráfico da Série Histórica para o parâmetro Vazão de Reciclo 2

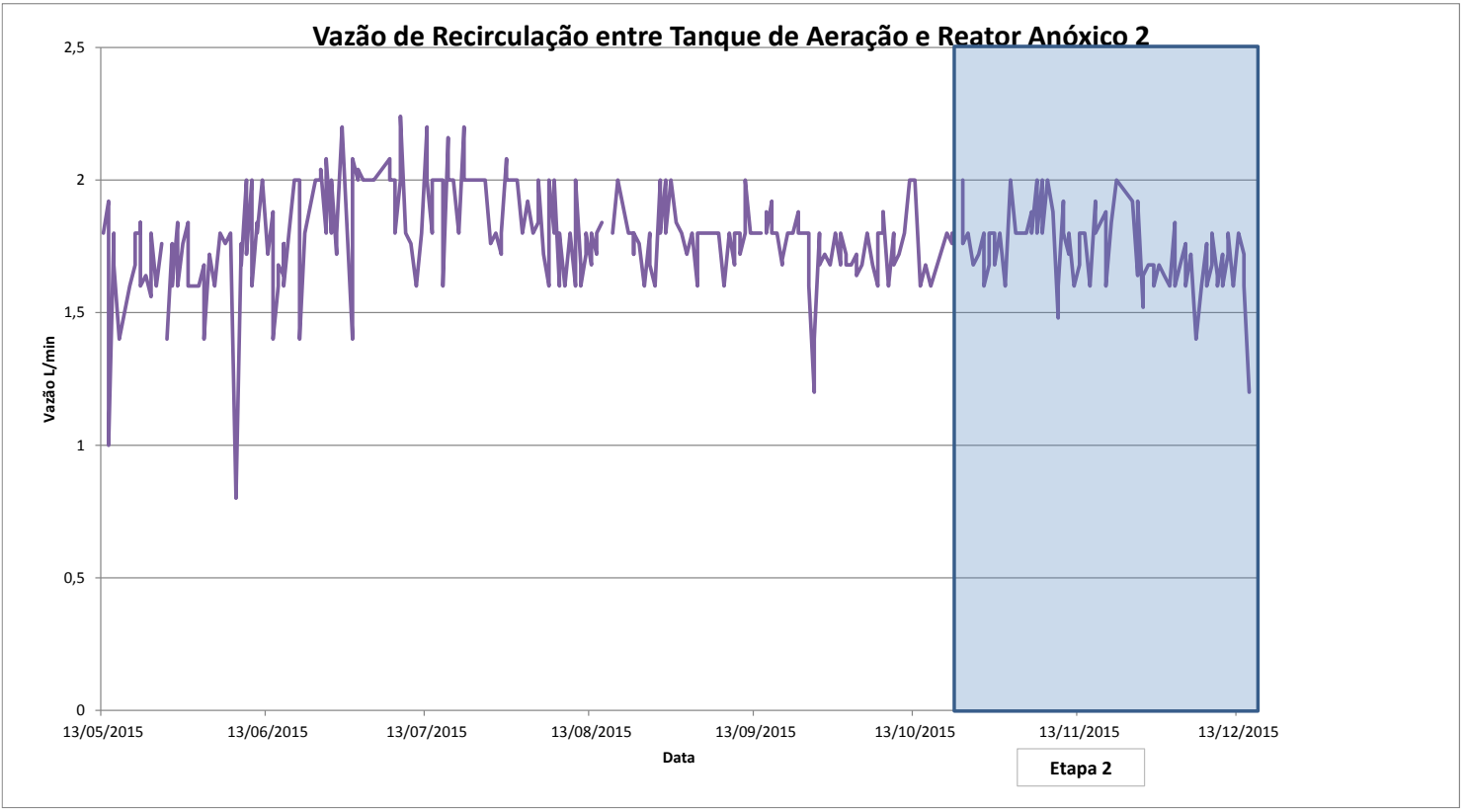

Fonte: Autor

Figura 39 - Gráfico X-Barra para o parâmetro Vazão de recirculação 2

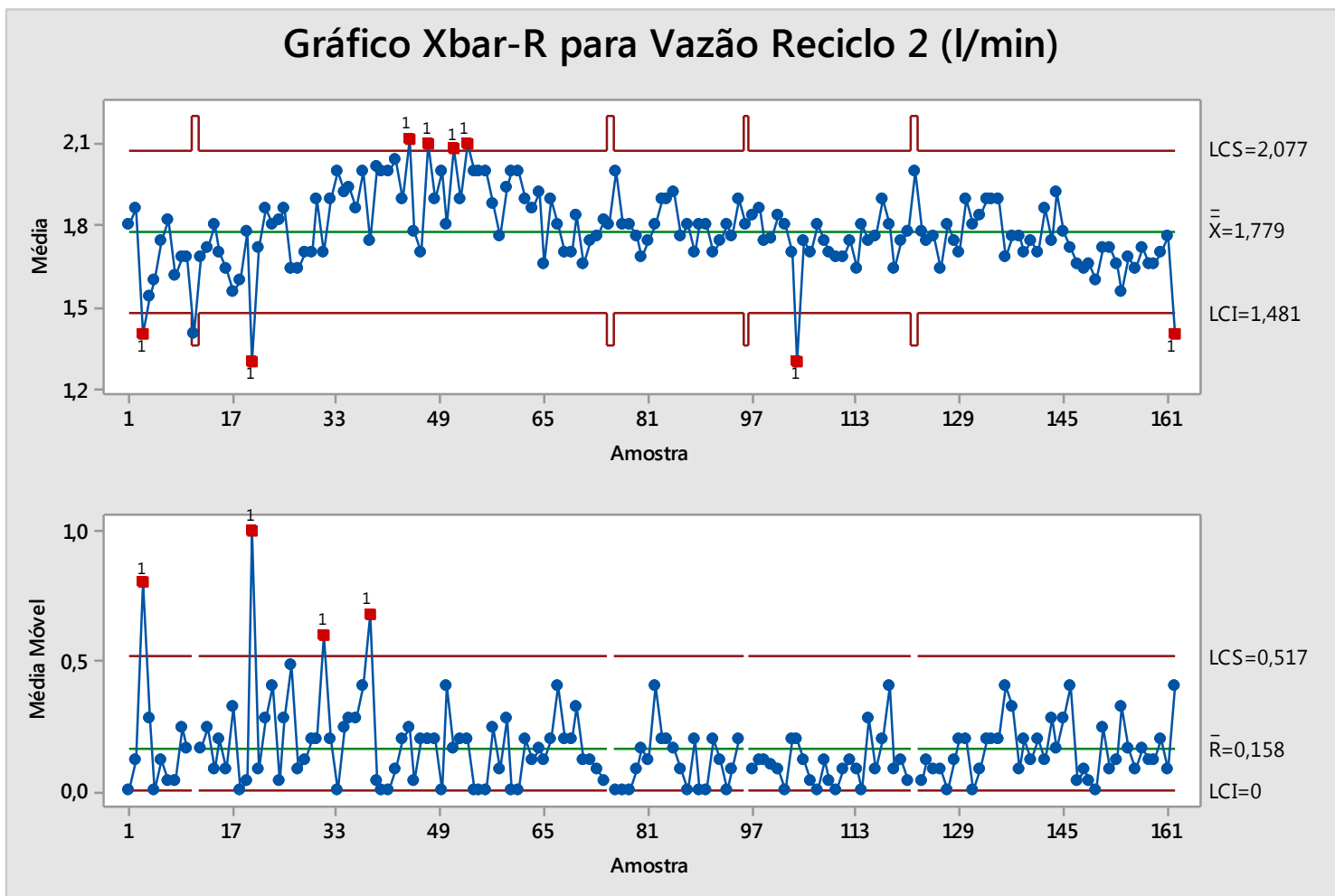

Fonte: Autor

Foram encontrados 8 registros fora dos limites de controle estatísticos para a vazão de reciclo 2 conforme apresentado na Figura 39. 
O sistema de alimentação da planta piloto recebe suas contribuições do conjunto residencial da USP (CRUSP), sendo que a vazão gerada é muito superior à vazão necessária para a operação da planta piloto. Por meio de uma elevatória na área do CRUSP é recalcada parcela do esgoto para o tratamento preliminar do CTH-USP. Após tratamento preliminar as contribuições são encaminhadas via conjunto moto-bomba para a caixa de recebimento da planta UCT modificada.

Pode-se observar durante etapas de experimentação que a vazão afluente à caixa de chegada da planta piloto era muito elevada para as necessidades desta. Como o sistema de recalque de esgoto bruto possui muitas elevatórias em série, sendo que nenhuma delas possui sistema de controle de rotação (e consequentemente de vazão), o sistema fica muito mais sujeito a variações e possíveis desequilíbrios de vazão de alimentação da planta piloto e consequentemente das vazões de retorno e recirculações (ressalta-se que os o recalque do tratamento preliminar para a caixa de chegada e reciclos internos da planta piloto possuem controle de rotação).

Os dados apresentados mostram que a planta operou em grande parte do tempo dentro das condições esperadas e que em alguns momentos foram observados estes desequilíbrios operacionais.

\subsubsection{Resultados esperados para um Sistema UCT Modificado}

Pelo período de experimentação ter sido relativamente curto se comparado com outras pesquisas, é de fundamental importância avaliar os resultados esperados para um sistema UCT modificado em operação em condições semelhantes às condições de projeto deste experimento, porém sem as proposições sugeridas por este estudo. Para tal foi utilizado software da Universidade de Cape Town (UCTPHO) para a realização de uma modelagem teórica. A Figura 40 apresenta a tela inicial do software. 
Figura 40 - Tela inicial do software UCTPHO

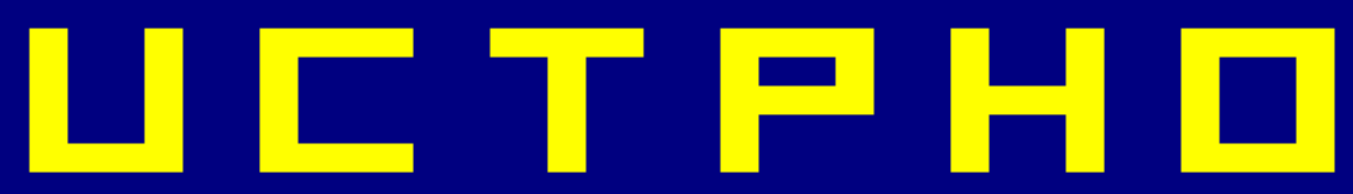

NDBEPR SIMULATION PROGRAM (UCTOLD UERSION) - UERSION 1.0

COPYRIGHT - University of Cape Town - All Rights Reserved Worldwide

Disk may be copied but not offered for lease or sale in part or in full.

\section{Depts Civil/Chemical Eng. \\ University of Cape Town \\ Rondebosch 7pg South Africa}

Program written by Peter Dold in association with

M C Wentzel and G UR Marais

Fonte: Autor

Neste caso foram utilizadas algumas constantes e premissas de modelagem conforme indicados no Apêndice 4 deste trabalho.

Ressalta-se que todas as constantes de modelagem foram definidas pelos autores do software WENTZEL e MARAIS e estão em concordância com a modelagem cinética apresentada neste trabalho.

Todos os dados de dimensões volumétricas e encaminhamento do fluxo foram definidos de acordo com o item metodologia deste trabalho.

Foram feitas duas simulações para avaliar as condições operacionais de entrada e de vazões da etapa 1 e etapa 2 de experimentação. A tabela 14 apresenta os dados de entrada das etapas 1 que foram utilizados no modelo cinético teórico.

Tabela 14 - Dados para simulação teórica - Etapa 1

\begin{tabular}{|l|c|c|}
\hline \multicolumn{1}{|c|}{ Parâmetro } & Valor & Unidade \\
\hline Vazão de Alimentação & 1,6 & $\mathrm{~L} / \mathrm{min}$ \\
\hline Vazão de reciclo 1 & 1,7 & $\mathrm{~L} / \mathrm{min}$ \\
\hline Vazão Reciclo 2 & 1,8 & $\mathrm{~L} / \mathrm{min}$ \\
\hline Vazão de retorno de lodo & 1,6 & $\mathrm{~L} / \mathrm{min}$ \\
\hline DQO afluente & 444 & $\mathrm{mg} / \mathrm{L}$ \\
\hline
\end{tabular}




\begin{tabular}{|l|c|c|}
\hline NTK afluente & 88 & $\mathrm{mg} / \mathrm{L}$ \\
\hline Fósforo Total afluente & 5,5 & $\mathrm{mg} / \mathrm{L}$ \\
\hline OD tanque de aeração & 4,1 & $\mathrm{mg} / \mathrm{L}$ \\
\hline Temperatura & 22,6 & ${ }^{\circ} \mathrm{C}$ \\
\hline Relação SSV/SST afluente & 0,87 & - \\
\hline
\end{tabular}

Fonte: Autor

Já a tabela 15 apresenta os dados referentes ao modelo teórica da etapa 2 de experimentação deste trabalho.

Tabela 15 - Dados para simulação teórica - Etapa 1

\begin{tabular}{|l|c|c|}
\hline \multicolumn{1}{|c|}{ Parâmetro } & Valor & Unidade \\
\hline Vazão de Alimentação & 1,7 & $\mathrm{~L} / \mathrm{min}$ \\
\hline Vazão de reciclo 1 & 1,6 & $\mathrm{~L} / \mathrm{min}$ \\
\hline Vazão Reciclo 2 & 1,7 & $\mathrm{~L} / \mathrm{min}$ \\
\hline Vazão de retorno de lodo & 1,7 & $\mathrm{~L} / \mathrm{min}$ \\
\hline DQO afluente & 540 & $\mathrm{mg} / \mathrm{L}$ \\
\hline NTK afluente & 88 & $\mathrm{mg} / \mathrm{L}$ \\
\hline Fósforo Total afluente & 5,1 & $\mathrm{mg} / \mathrm{L}$ \\
\hline OD tanque de aeração & 4,3 & $\mathrm{mg} / \mathrm{L}$ \\
\hline Temperatura & 25,5 & ${ }^{\circ} \mathrm{C}$ \\
\hline Relação SSV/SST afluente & 0,87 & - \\
\hline
\end{tabular}

Fonte: Autor

Os resultados da simulação teórica serão apresentadas neste item e discutidas posteriormente individualmente para cada parâmetro relevante. 
Os resultados do modelo teórico mostram que o efluente final da etapa 1 de experimentação deve ter 36,3 mg/L de DQO solúvel, 1,6 mg - N/L de amônia, 2,9 mg N/L de NTK, 38 mg/L de Nitrato e $1 \mathrm{mg}-\mathrm{P} / \mathrm{L}$ de fósforo solúvel.

Já para o efluente da etapa 2 de experimentação deveria ter concentrações de 1,3 mgN/L de nitrogênio amoniacal, 2,6 mg-N/L de NTK, 30,5 mg-N/L de nitrato, concentração de DQO de 45,2 mg/L e 0,7 mg/L de fósforo solúvel.

Pode-se observar que no modelo teórico com as características da planta piloto escopo deste trabalho e com a tecnologia de um sistema UCT Modificado tradicional em ambos os casos há uma elevada concentração de nitrato no efluente final (da ordem de 30 $\mathrm{mg} / \mathrm{L}$ ) e concentrações de fósforo solúvel próximo a $1 \mathrm{mg} / \mathrm{L}$. Com relação ao nitrato a atual legislação brasileira não impõe limites para o lançamento deste tipo de nutriente nos corpos receptores, no entanto, com relação ao fósforo há um legislação restritiva

que independentemente de sua aplicabilidade demanda que os efluentes possuam concentrações de fósforo total e solúvel abaixa de $0,1 \mathrm{mg} / \mathrm{L}$.

Adicionalmente pode-se observar que em ambos os casos o efluente esperado para ambas as etapas de experimentação tem concentrações de DQO solúvel mais baixas do que o resultado experimental obtido. Isso se deve em partes ao fato de que a idade real do lodo ter sido muito mais baixa do que a idade do lodo teórica.

\subsection{Dados de Controle local na planta piloto (pH, Potencial Redox e Oxigênio}

\section{Dissolvido)}

Apresenta-se nas Tabelas 16 e 17 os dados para as sondas de controle da planta piloto por etapa de experimentação. Para todos os casos aqui apresentados potencial redox (ORP) está na unidade $\mathrm{mV}$ e oxigênio dissolvido mg/L. 
Tabela 16 - Estatística Descritiva para os dados de controle local da planta piloto - Etapa 1

\begin{tabular}{|c|c|c|c|c|c|c|c|c|c|}
\hline \multirow[t]{2}{*}{ Parâmetro } & \multicolumn{2}{|c|}{ Anaeróbio } & \multicolumn{2}{|c|}{ Anóxico 1} & \multicolumn{2}{|c|}{ Anóxico 2} & \multicolumn{3}{|c|}{ Tanque de Aeração } \\
\hline & $\mathrm{pH}$ & ORP & $\mathrm{pH}$ & ORP & $\mathrm{pH}$ & ORP & $\mathrm{pH}$ & ORP & OD \\
\hline Média & 7,1 & -489 & 7,2 & -504 & 7,1 & -502 & 7,1 & -8 & 4,1 \\
\hline Máximo & 8,2 & -311 & 7,8 & 560 & 7,9 & -248 & 8,33 & 99 & 21 \\
\hline Mínimo & 2,4 & -580 & 5,1 & -590 & 5,9 & -590 & 4,5 & -460 & 0,2 \\
\hline Mediana & 7,1 & -490 & 7,2 & -516 & 7,1 & -509 & 7,1 & 7 & 3,8 \\
\hline Desvio padrão & 0,4 & 38 & 0,4 & 116 & 0,29 & 55 & 0,4 & 97 & 2,199 \\
\hline CV (\%) & $6 \%$ & $8 \%$ & $5 \%$ & $23 \%$ & $4 \%$ & $11 \%$ & $6 \%$ & $1252 \%$ & $54 \%$ \\
\hline AT & 5,8 & 269 & 2,7 & 1150 & 2 & 342 & 3,83 & 559 & 20,8 \\
\hline
\end{tabular}

Fonte: Autor

Tabela 17 - Estatística Descritiva dos dados locais de controle da planta piloto - Etapa 2

\begin{tabular}{|c|c|c|c|c|c|c|c|c|c|c|c|}
\hline \multirow[t]{2}{*}{ Parâmetro } & \multicolumn{2}{|c|}{ Anaeróbio } & \multicolumn{2}{|c|}{ Anóxico 1} & \multicolumn{2}{|c|}{ Anóxico 2} & \multicolumn{3}{|c|}{ Tanque de Aeração } & \multicolumn{2}{|c|}{ OD mg/L } \\
\hline & \begin{tabular}{l|l}
$\mathrm{pH}$ \\
\end{tabular} & ORP & $\mathrm{pH}$ & ORP & \begin{tabular}{l|l}
$\mathrm{pH}$ &
\end{tabular} & ORP & $\mathrm{pH}$ & ORP & OD & Anóxico 1 & Anóxico 2 \\
\hline Média & 6,4419 & $-488,8$ & 6,452 & $-466,9$ & 6,508 & -475 & 7,221 & 28,42 & 4,3 & 0,22 & 0,17 \\
\hline Máximo & 7,4 & -337 & 7,5 & -280 & 7,6 & -317 & 8,3 & 410 & 6,6 & 0,39 & 0,3 \\
\hline Mínimo & 5,6 & -590 & 5,5 & -545 & 5,5 & -550 & 6 & -28 & 2,1 & 0,12 & 0,1 \\
\hline Mediana & 6,4 & -492 & 6,45 & -488 & 6,4 & -493 & 7,3 & 25 & 4,2 & 0,2 & 0,17 \\
\hline Desvio padrão & 0,5 & 37 & 0,5 & 53 & 0,6 & 48 & 0,4 & 53 & 1,1 & 0,05 & 0,05 \\
\hline CV (\%) & $7 \%$ & $-8 \%$ & $8 \%$ & $-11 \%$ & 9\% & $-10 \%$ & $6 \%$ & $187 \%$ & $26 \%$ & $24 \%$ & $26 \%$ \\
\hline AT & 1,8 & 253 & 2 & 265 & 2,1 & 233 & 2,3 & 438 & 4,5 & 0,27 & 0,2 \\
\hline
\end{tabular}

Fonte: Autor 
A série histórica para os dados de $\mathrm{pH}$ e ORP para a câmara anaeróbia estão apresentados na Figura 41.

Figura 41 - pH e ORP para Câmara Anaeróbia

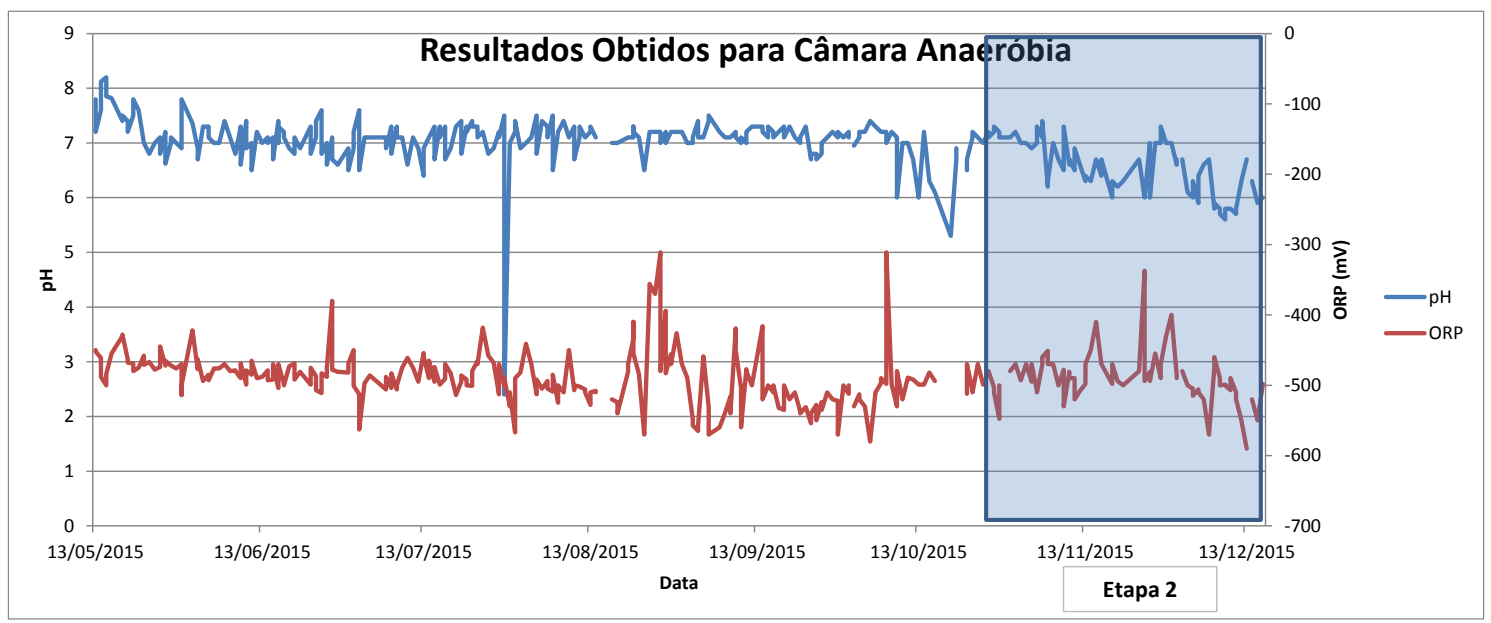

Fonte: Autor

Como a Câmara Anaeróbia é o ponto de recebimento do esgoto (neste caso decantado primariamente) foram observadas durante período de operação efluentes com características visuais diferentes daquelas normalmente encontrados em esgotos domésticos. Isso pode ser observado por momentos nos quais o $\mathrm{pH}$ ficou abaixo de $6 \mathrm{e}$ ORP acima de $-400 \mathrm{mV}$ ou abaixo de $-500 \mathrm{mV}$. A Figura 42 apresenta o Gráfico XBarra para o pH na câmara anaeróbia. 
Figura 42 - Gráfico X-Barra para pH - Câmara Anaeróbia

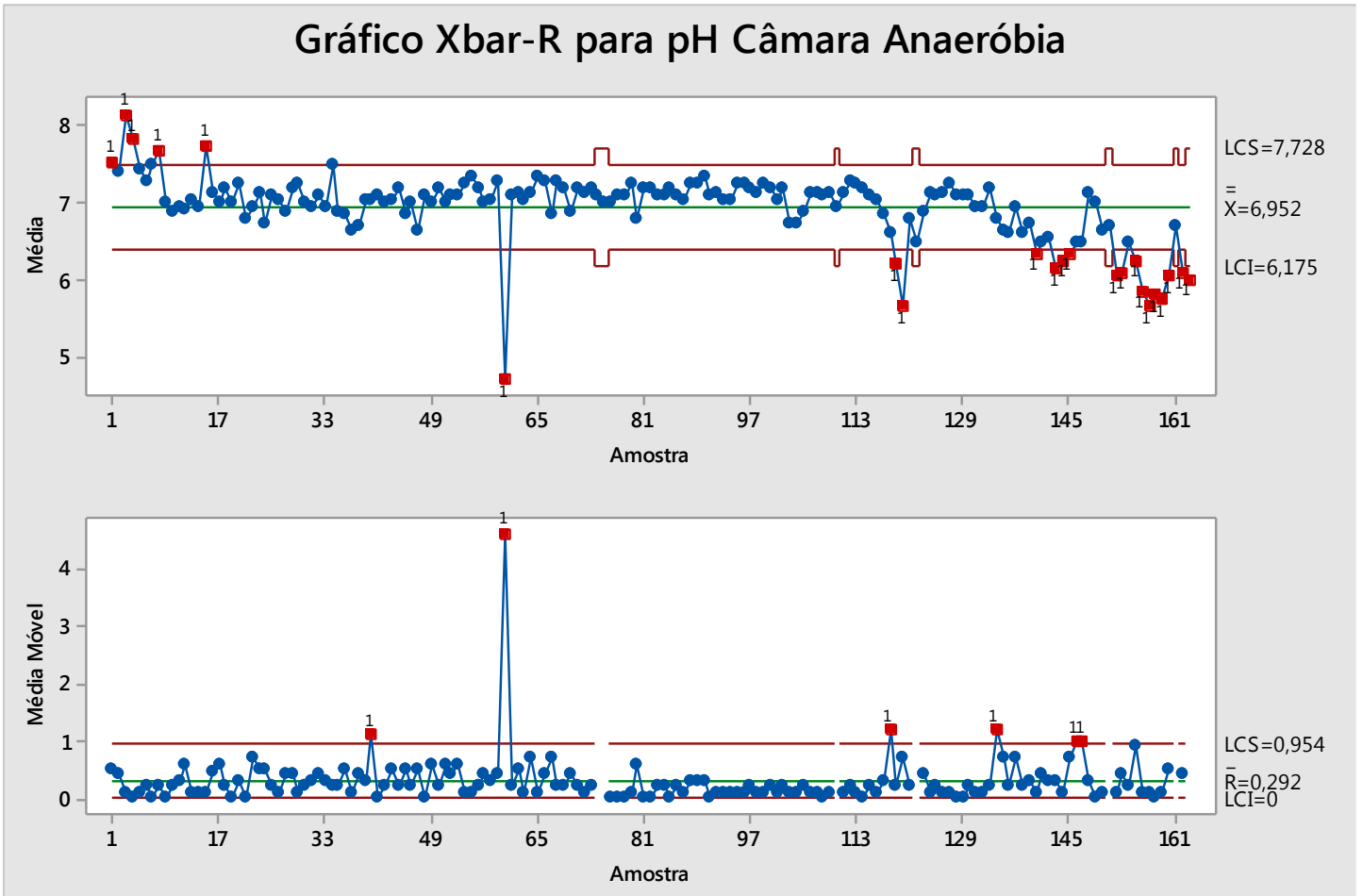

Fonte: Autor

Figura 43 - Gráfico X-Barra para ORP - Câmara Anaeróbia

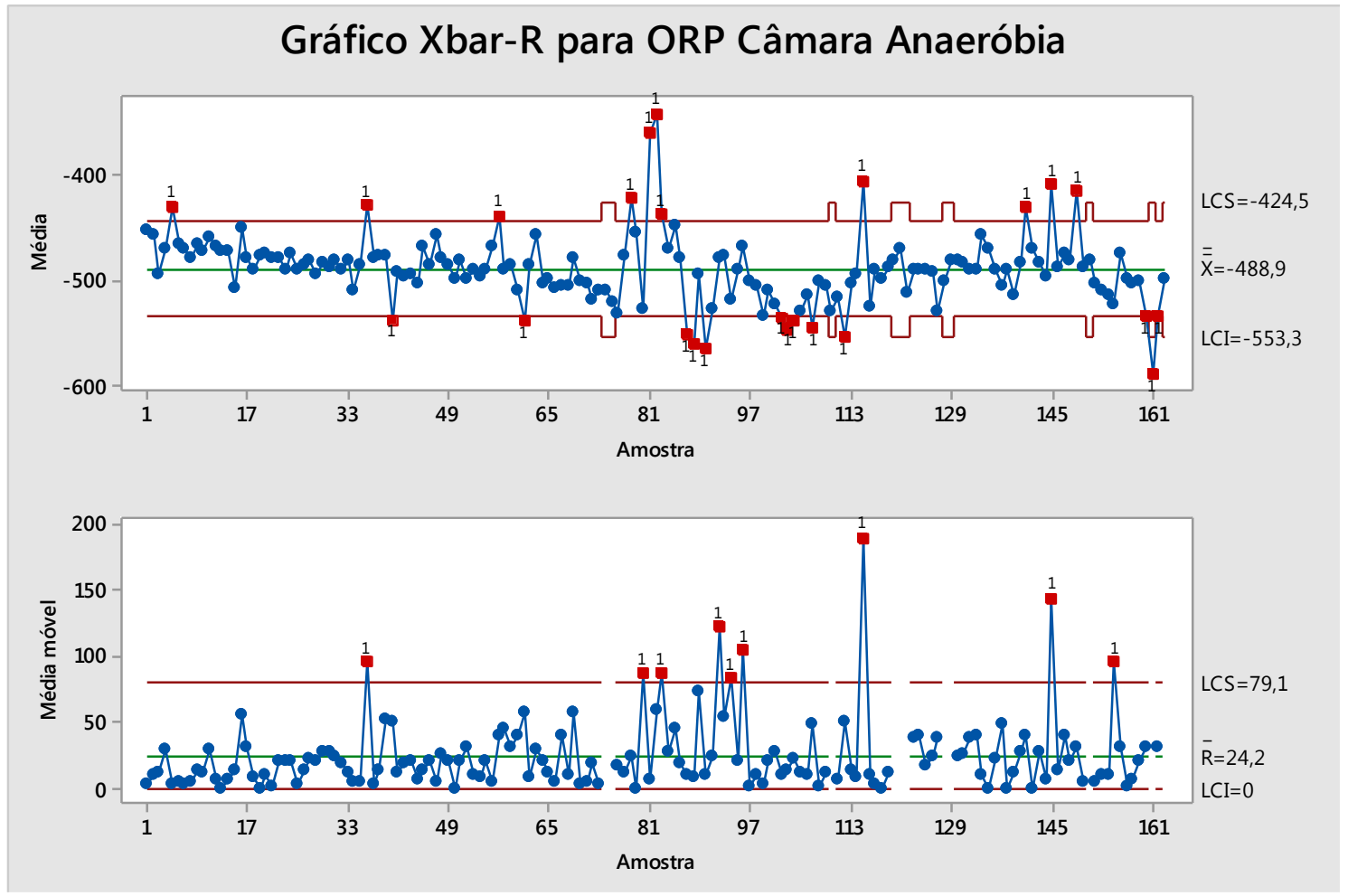

Fonte: Autor

As Figuras 42 e 43 fornecem elementos de análise para verificar a estabilidade do parâmetro ao longo de sua experimentação. Considera-se que até 3 desvios padrão para 
cima ou para baixo o referido parâmetro está dentro da estabilidade de processo. Com relação aos dois parâmetros apresentados foram verificadas menos de 10 ocorrências de possível desequilíbrios nestes parâmetros. Estes desequilíbrios provavelmente foram obtidos em decorrência da alteração da caracterização do afluente da planta.

De maneira geral o comportamento da câmara anaeróbia se manteve constante durante as duas etapas de experimentação, foram procedidos testes de hipóteses considerando como hipótese base que $\mathrm{pH}$ e potencial Redox nas duas etapas de experimentação se comportaram da mesma maneira e hipótese alternativa considerando que um dos dois parâmetros não manteve o mesmo comportamento durante as duas etapas de experimentação.

Considerando-se que uma distribuição T-student e nível de confiança de 95\%, as hipóteses para o parâmetro $\mathrm{pH}$ foram:

$$
\begin{aligned}
& \text { H0: } p H \text { etapa } 1=p H \text { etapa } 2 \text { (136A) } \\
& H 1: p H \text { etapa } 1 \neq p H \text { etapa } 2(\mathbf{1 3 6 B})
\end{aligned}
$$

\begin{tabular}{|c|c|c|}
\hline Valor de T & Graus de liberdade & Valor P \\
\hline 9,57 & 86 & $<0,0001$ \\
\hline
\end{tabular}

Para valores $\mathrm{P}$ acima de 0,05 aceita-se a hipótese $\mathrm{H} 0$ e para valores $\mathrm{P}$ abaixo de 0,05 rejeita-se $\mathrm{H} 0$ e aceita-se $\mathrm{H} 1$.

Desta forma, rejeita-se a hipótese $\mathrm{H} 0$ e houve diferença estatisticamente significante entre o pH da anaeróbia entre as etapas 1 e 2 de experimentação

Já para o potencial Redox (ORP) foi utilizada distribuição T-Student e nível de confiança de $95 \%$ para as seguintes hipóteses:

$$
\begin{aligned}
& \text { H0: ORP etapa } 1=\text { ORP etapa } 2 \text { (137A) } \\
& \text { H1: ORP etapa } 1 \neq \text { ORP etapa } 2(\mathbf{1 3 7 B})
\end{aligned}
$$

\begin{tabular}{|c|c|c|}
\hline Valor de T & Graus de liberdade & Valor P \\
\hline$-0,04$ & 94 & 0,9714 \\
\hline
\end{tabular}


Neste caso aceita-se H0 e pode-se considerar que não houve diferença estatisticamente significante entre os dados de ORP entre a etapa 1 e etapa 2 na câmara anaeróbia.

As Séries Históricas para os parâmetros de controle para a Câmara Anóxica 1 estão apresentados na Figura 44.

Figura 44 - Gráfico de série histórica para pH e ORP para Câmara Anóxica 1

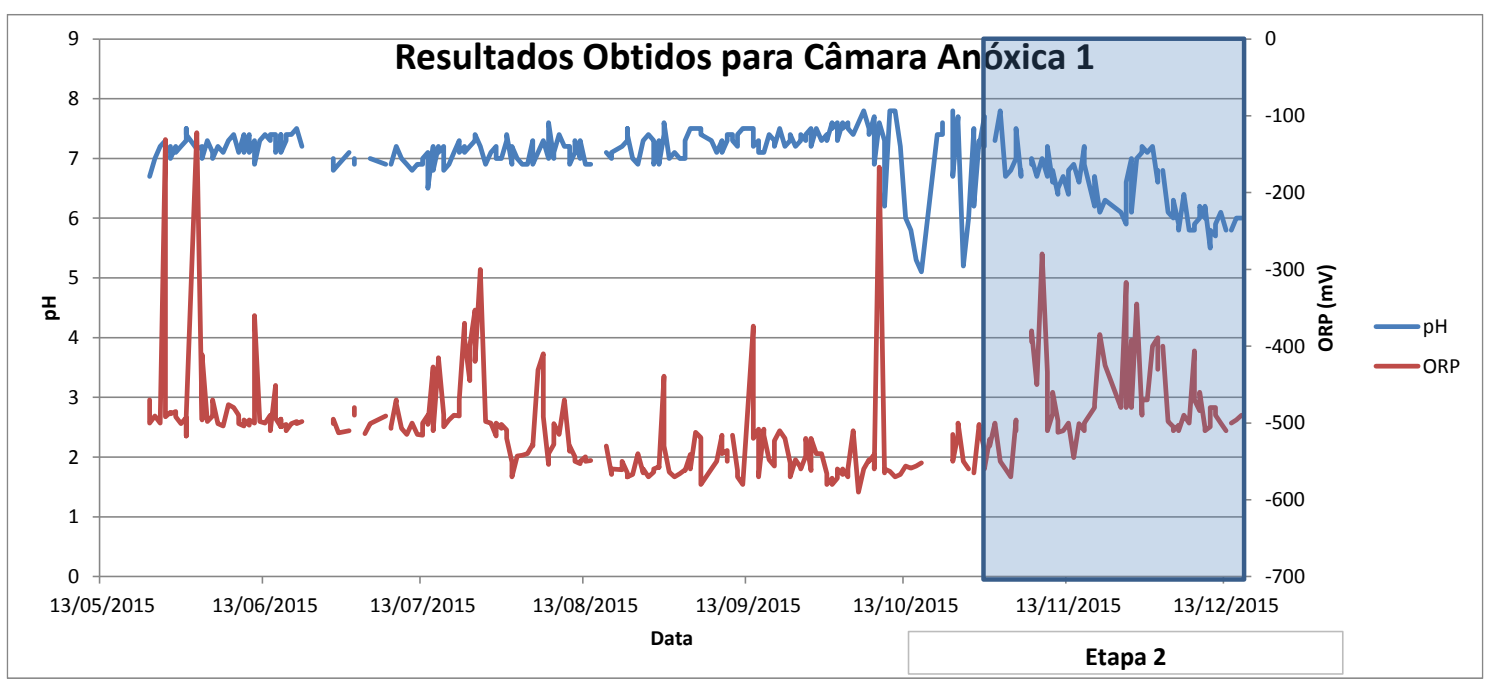

Fonte: Autor

Pode-se observar uma nítida tendência a redução do pH desta câmara na Etapa 2 de experimentação, assim como houve uma nítida elevação do potencial Redox. Os gráficos X-Barra para o parâmetro pH e ORP desta câmara estão apresentados na Figura 45 e 46 respectivamente. 
Figura 45 - Gráfico X-Barra para pH - Câmara Anóxica 1

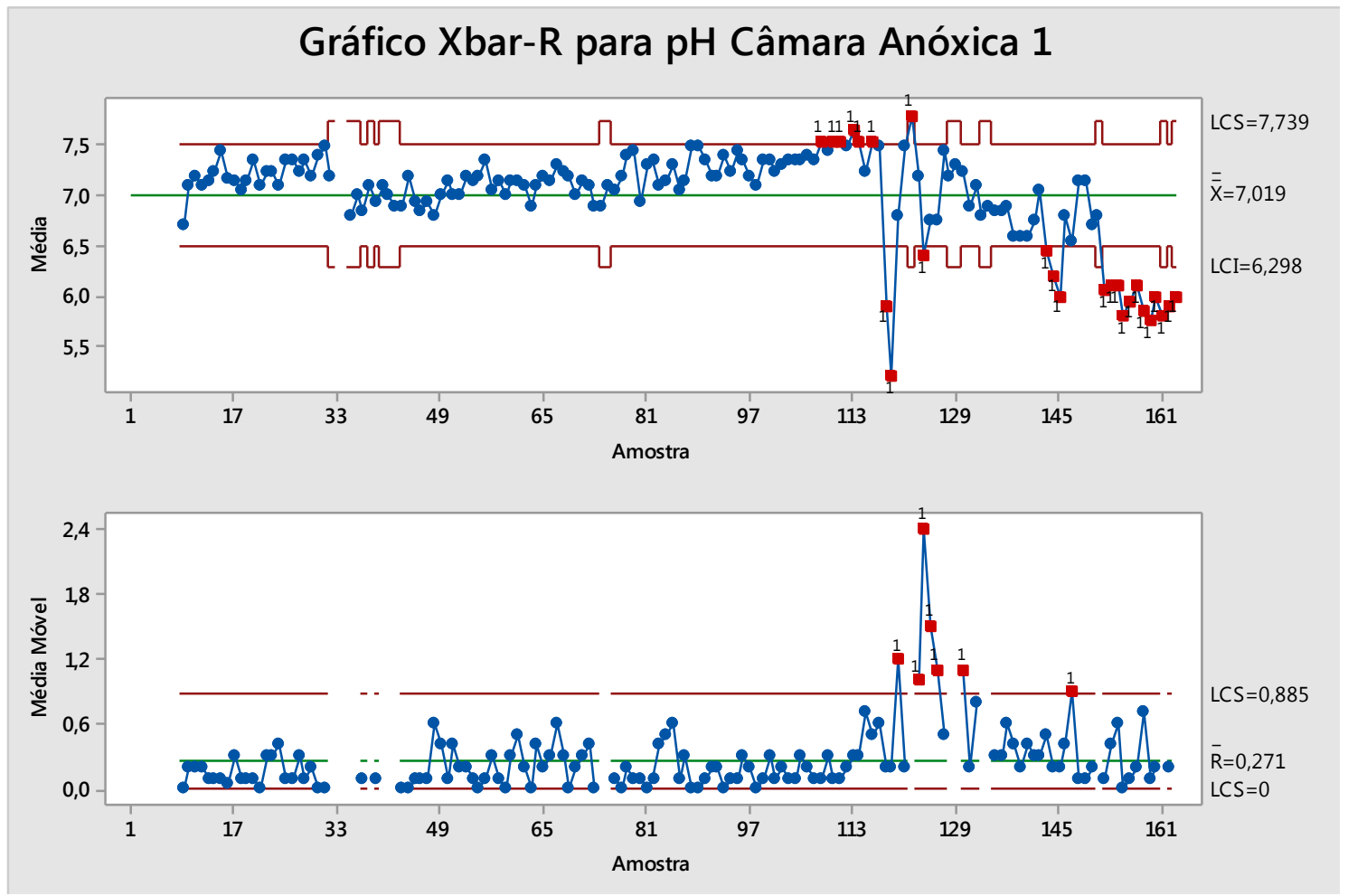

Fonte: Autor

Figura 46 - Gráfico X-Barra para ORP - Câmara Anóxica 1

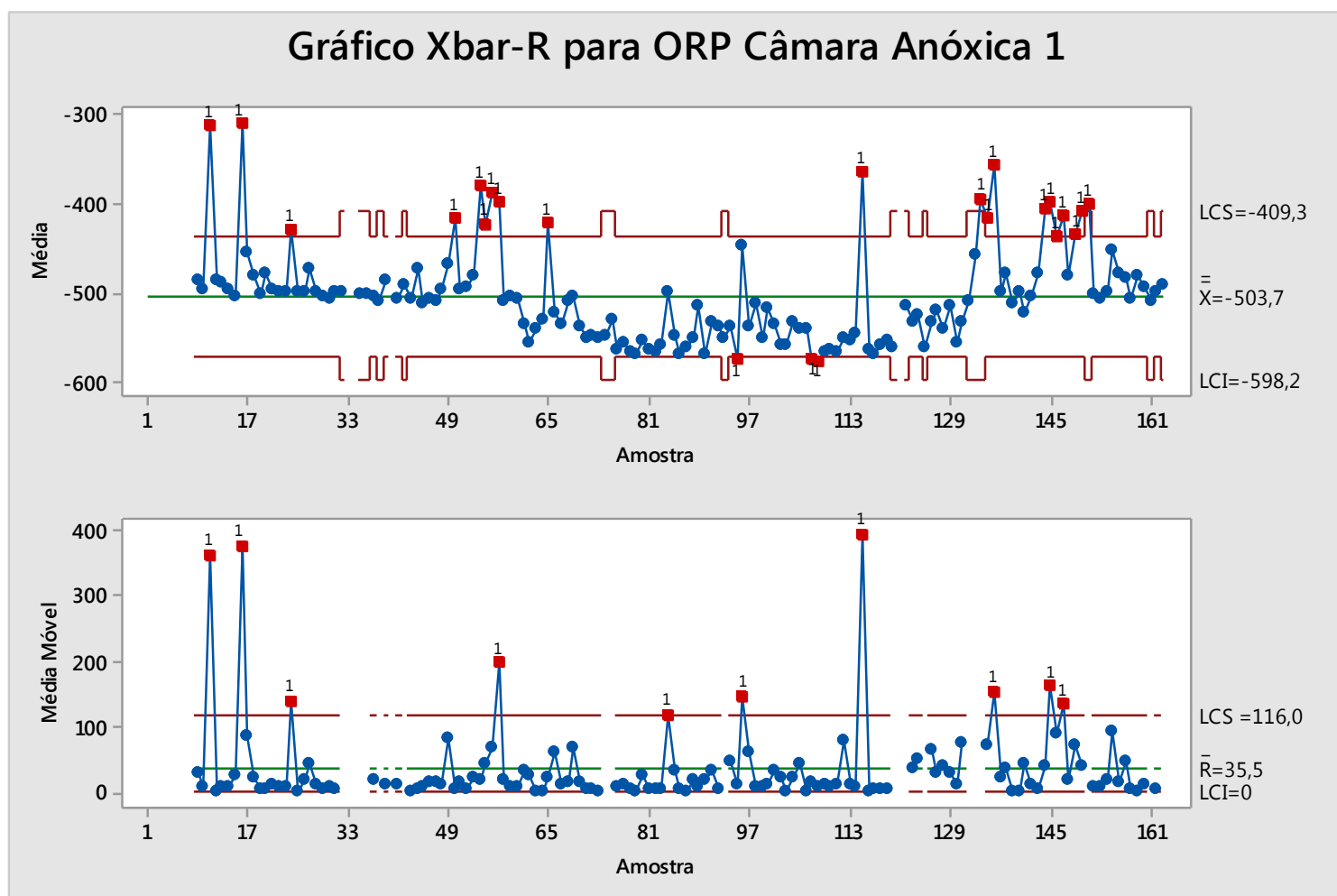

Fonte: Autor 
Executando teste de hipóteses para estas duas variáveis e considerando-se que uma distribuição T-student e nível de confiança de 95\%, as hipóteses para o parâmetro pH foram:

$$
\begin{aligned}
& \text { H0: } p H \text { etapa } 1=p H \text { etapa } 2 \text { (138A) } \\
& H 1: p H \text { etapa } 1 \neq p H \text { etapa } 2 \text { (138B) }
\end{aligned}
$$

\begin{tabular}{|c|c|c|}
\hline Valor de T & Graus de liberdade & Valor P \\
\hline 10,47 & 77 & $<0,0001$ \\
\hline
\end{tabular}

Neste caso pode-se rejeitar $\mathrm{H} 0$ e considerar que houve diferença estatisticamente significante entre o pH na câmara anóxica 1 entre as etapas 1 e 2.

Já para o potencial Redox (ORP) foi utilizada distribuição T-Student e nível de confiança de $95 \%$ para as seguintes hipóteses:

$$
\begin{aligned}
& \text { H0: ORP etapa } 1=\text { ORP etapa } 2 \text { (140A) } \\
& \text { H1: ORP etapa } 1 \neq \text { ORP } e \square \text { apa } 2 \text { (140B) }
\end{aligned}
$$

\begin{tabular}{|c|c|c|}
\hline Valor de $\mathbf{T}$ & Graus de liberdade & Valor P \\
\hline$-3,60$ & 207 & 0,0004 \\
\hline
\end{tabular}

Neste caso rejeita-se $\mathrm{H} 0$ e aceita-se $\mathrm{H} 1$, sendo que há diferença estatisticamente significante entre os dados de ORP entre a etapa 1 e etapa 2 da câmara anóxica 1.

Já para a Câmara Anóxica 2 as séries históricas estão apresentadas na Figura 64. 
Figura 47 - Gráfico da série histórica para pH e ORP para Câmara Anóxica 2

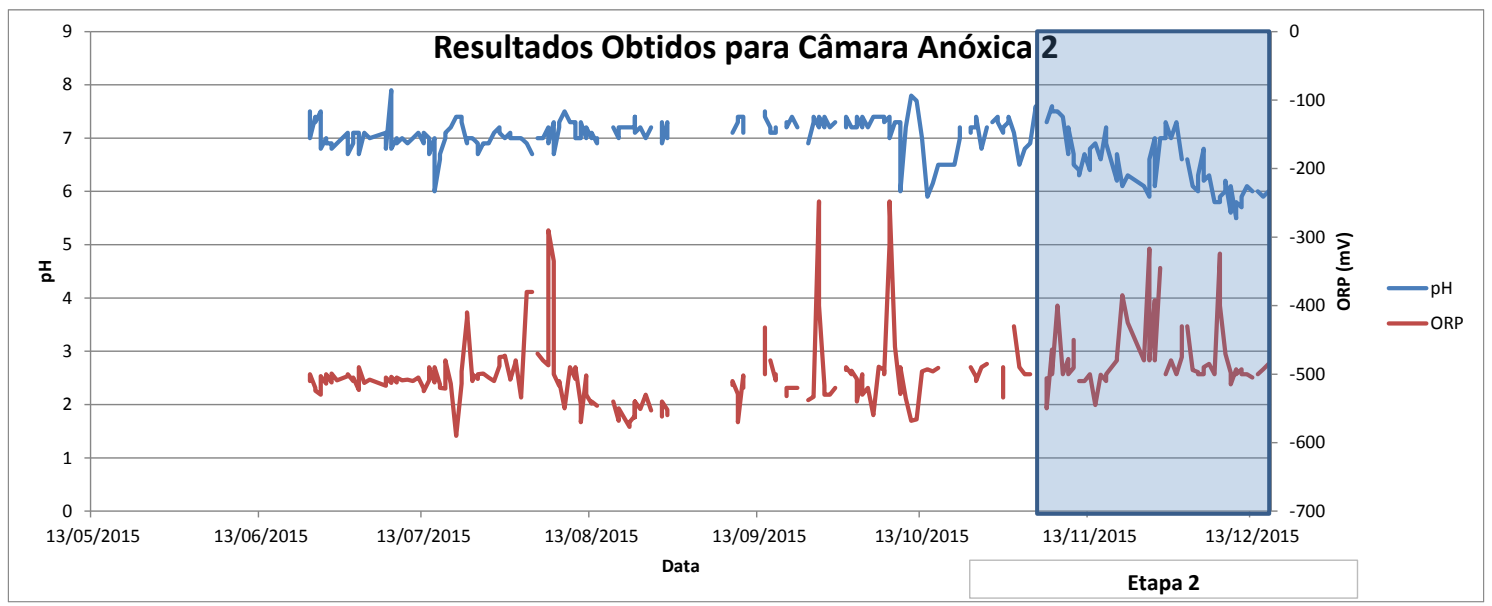

Fonte: Autor

Pode-se observar uma nítida tendência a redução do pH desta câmara na Etapa 2 de experimentação, assim como houve uma nítida elevação do potencial Redox. Os Gráficos de Controle X-Barra para pH e ORP da Câmara Anóxica 2 estão apresentados nas Figuras 65 e 66 respectivamente

Figura 48 - Gráfico X-Barra para pH - Câmara Anóxica 2

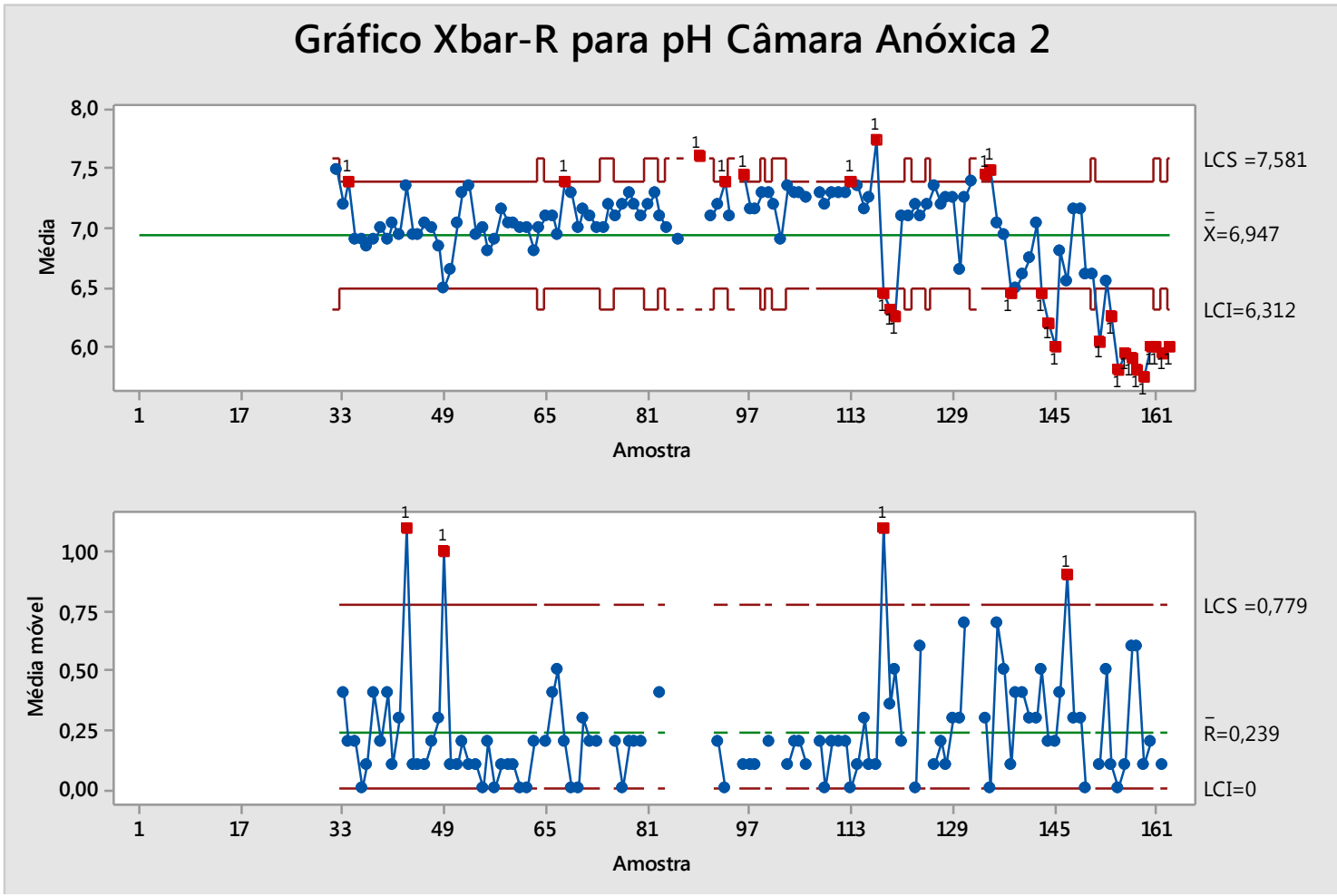

Fonte: Autor 
Figura 49 - Gráfico X-Barra para ORP - Câmara Anóxica 2

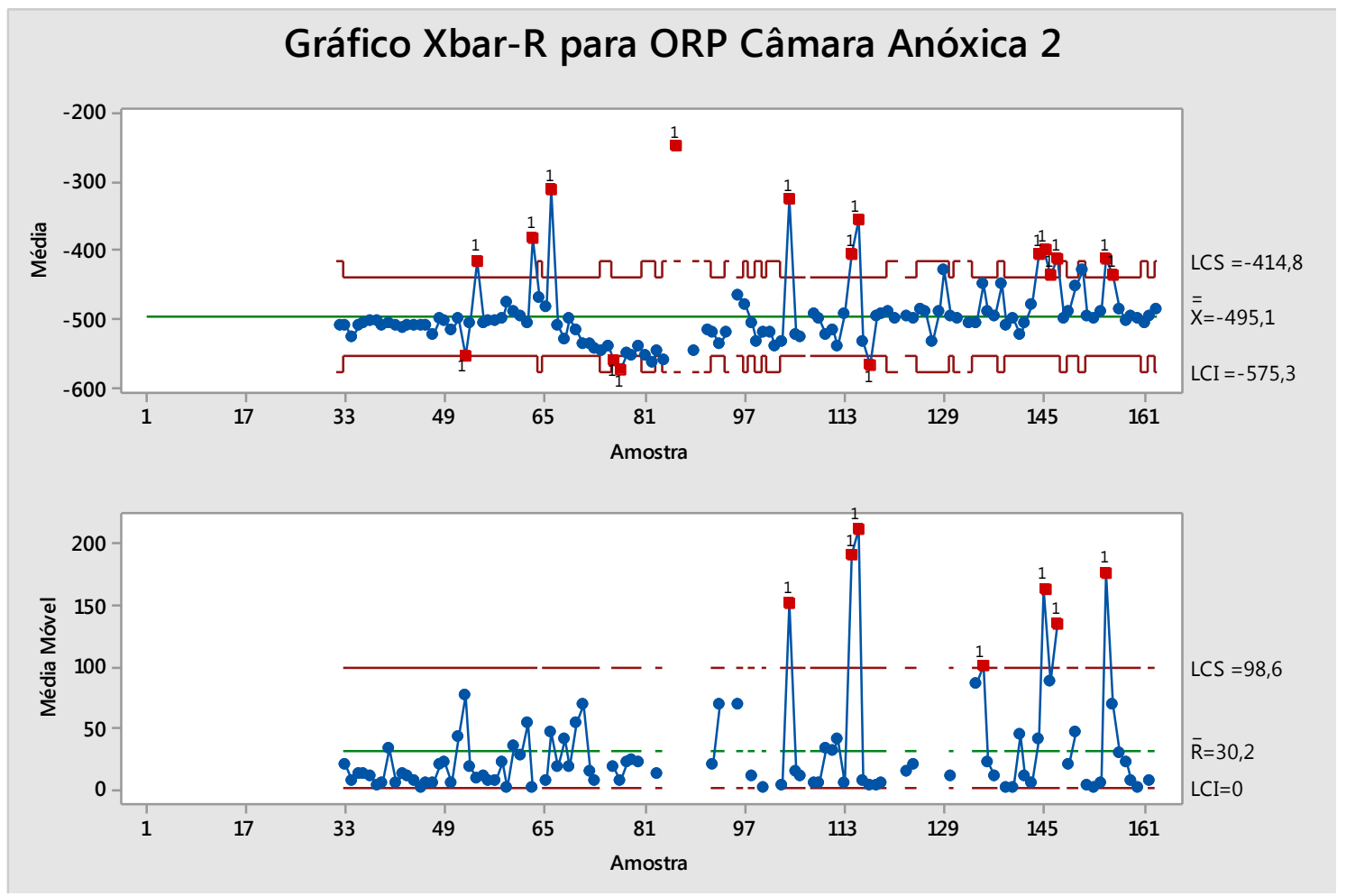

Fonte: Autor

Pode-se observar durante Etapa 1 de experimentação que em alguns momentos tanto pH quanto ORP saíram dos limites estatísticos operacionais para esta Câmara.

Executando teste de hipóteses para estas duas variáveis para comparar seu comportamento durante as duas etapas de experimentação e considerando-se que uma distribuição T-student e nível de confiança de 95\%, as hipóteses para o parâmetro pH foram:

H0: $p H$ etapa $1=p H$ etapa 2 (139A)

H1: $p H$ etapa $1 \neq p H$ etapa 2 (139B)

\begin{tabular}{|c|c|c|}
\hline Valor de $\mathbf{T}$ & Graus de liberdade & Valor P \\
\hline 7,65 & 68 & $<0,0001$ \\
\hline
\end{tabular}

Desta forma, rejeita-se $\mathrm{HO}$ e considera-se que houve diferença estatisticamente significante entre o pH na câmara anóxica 2 entre as etapas 1 e 2 de experimentação.

Já para o potencial Redox (ORP) foi utilizada distribuição T-Student e nível de confiança de $95 \%$ para as seguintes hipóteses: 
H0: ORP etapa $1=$ ORP etapa 2 (140A)

H1: ORP etapa $1 \neq$ ORP etapa $2(\mathbf{1 4 0 B})$

\begin{tabular}{|c|c|c|}
\hline Valor de T & Graus de liberdade & Valor P \\
\hline$-3,47$ & 107 & 0,0008 \\
\hline
\end{tabular}

Desta forma, rejeita-se $\mathrm{HO}$ e considera-se que há diferença estatisticamente significante entre o ORP entre as etapas 1 e 2 de experimentação.

Para o tanque de aeração foram monitoradas três variáveis; $\mathrm{pH}$, ORP e OD. Apresentam-se as séries históricas para estes três parâmetros na Figura 50.

Figura 50 - Gráfico de série histórica para pH, ORP e OD para o Tanque de Aeração

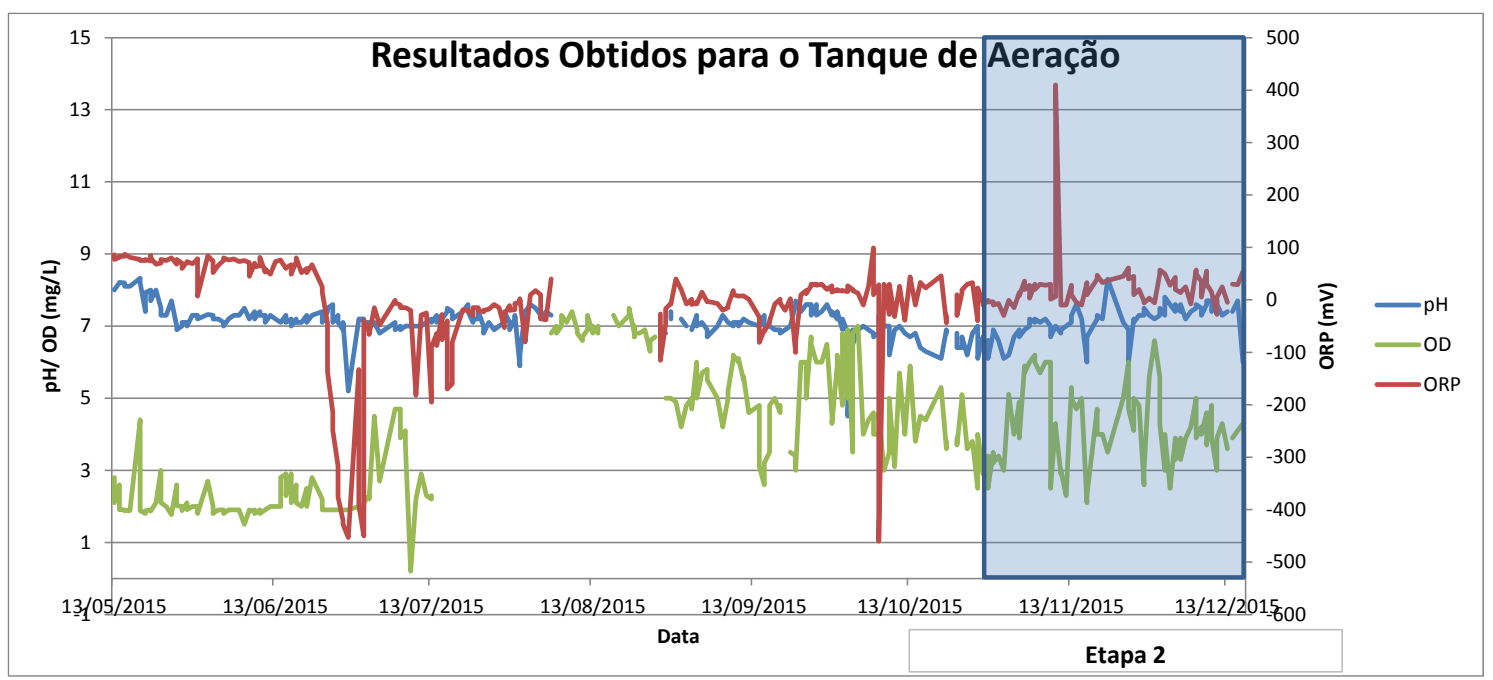

Fonte: Autor

Durante a experimentação, ocorreu a queima dos sensores de OD e ORP/pH o que ocasionaram alguns momentos sem realização de medições dos parâmetros desta câmara. Os Gráficos de controle dos parâmetros OD, pH e ORP para o tanque de aeração estão apresentados nas Figuras 51 a 53, respectivamente. 
Figura 51 - Gráfico X-Barra para o parâmetro pH - Tanque de Aeração

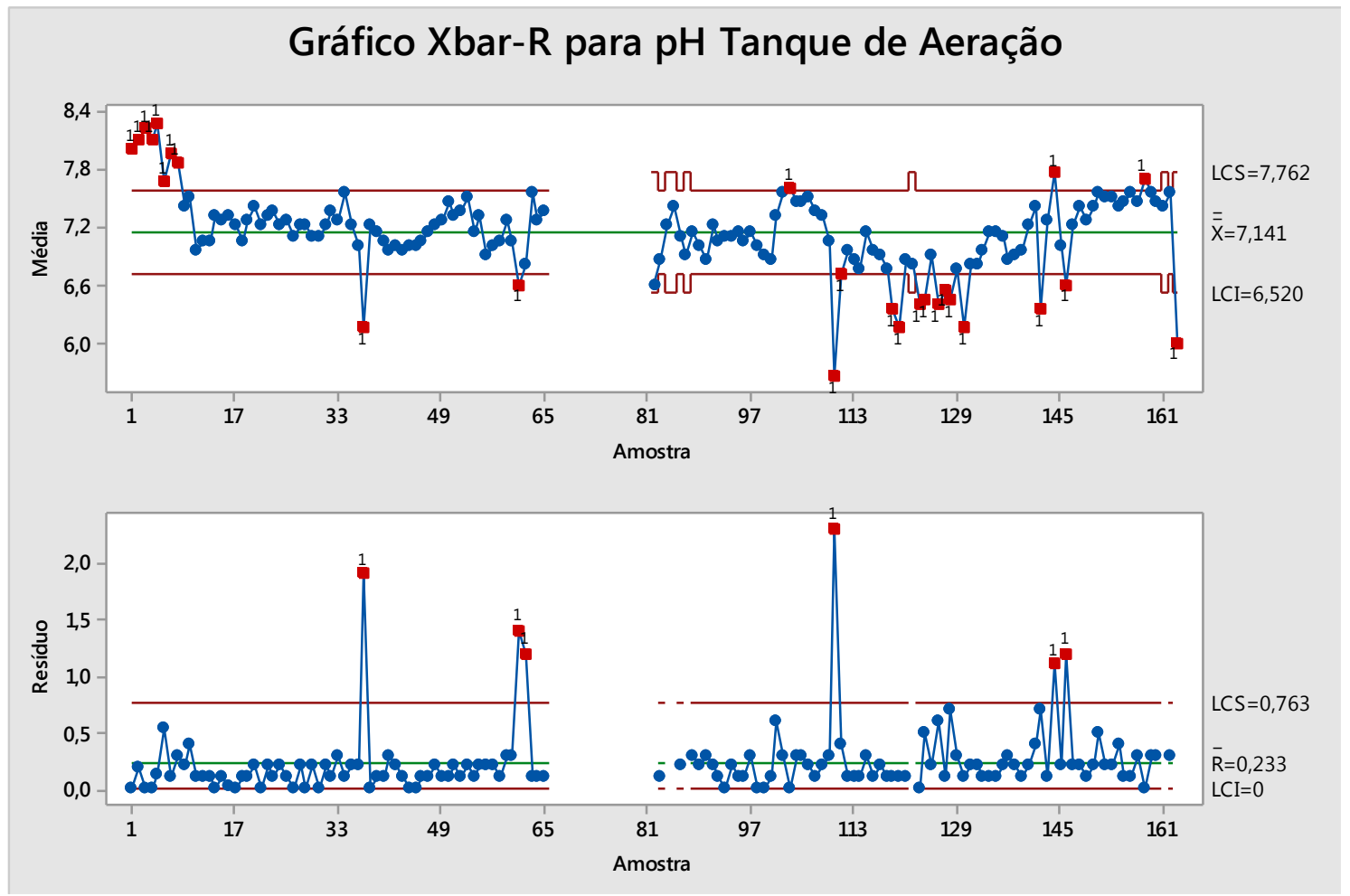

Fonte: Autor

Figura 52 - Gráfico X-Barra para o parâmetro ORP - Tanque de Aeração

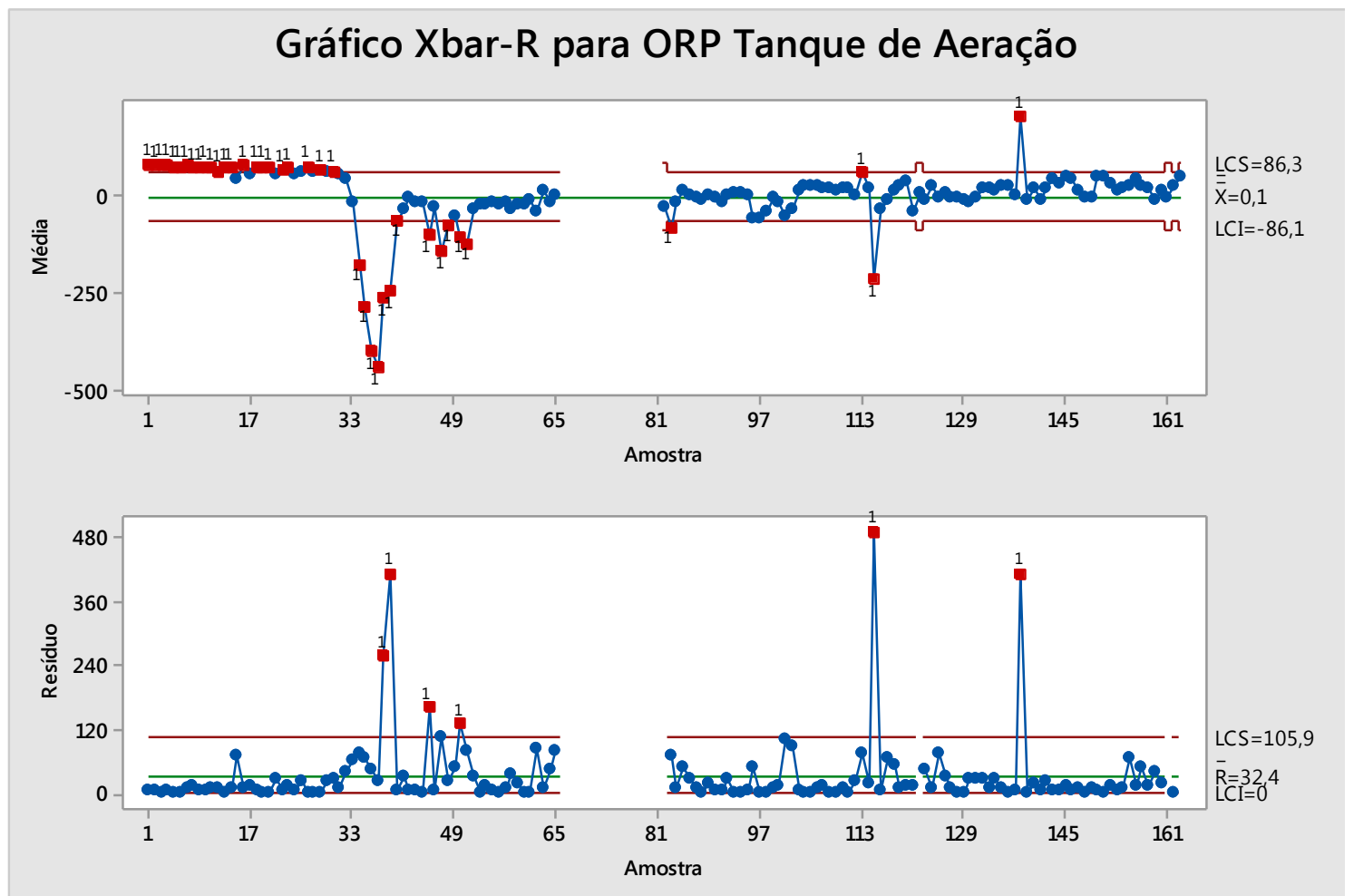

Fonte: Autor 
Figura 53 - Gráfico X-Barra para o parâmetro OD - Tanque de Aeração

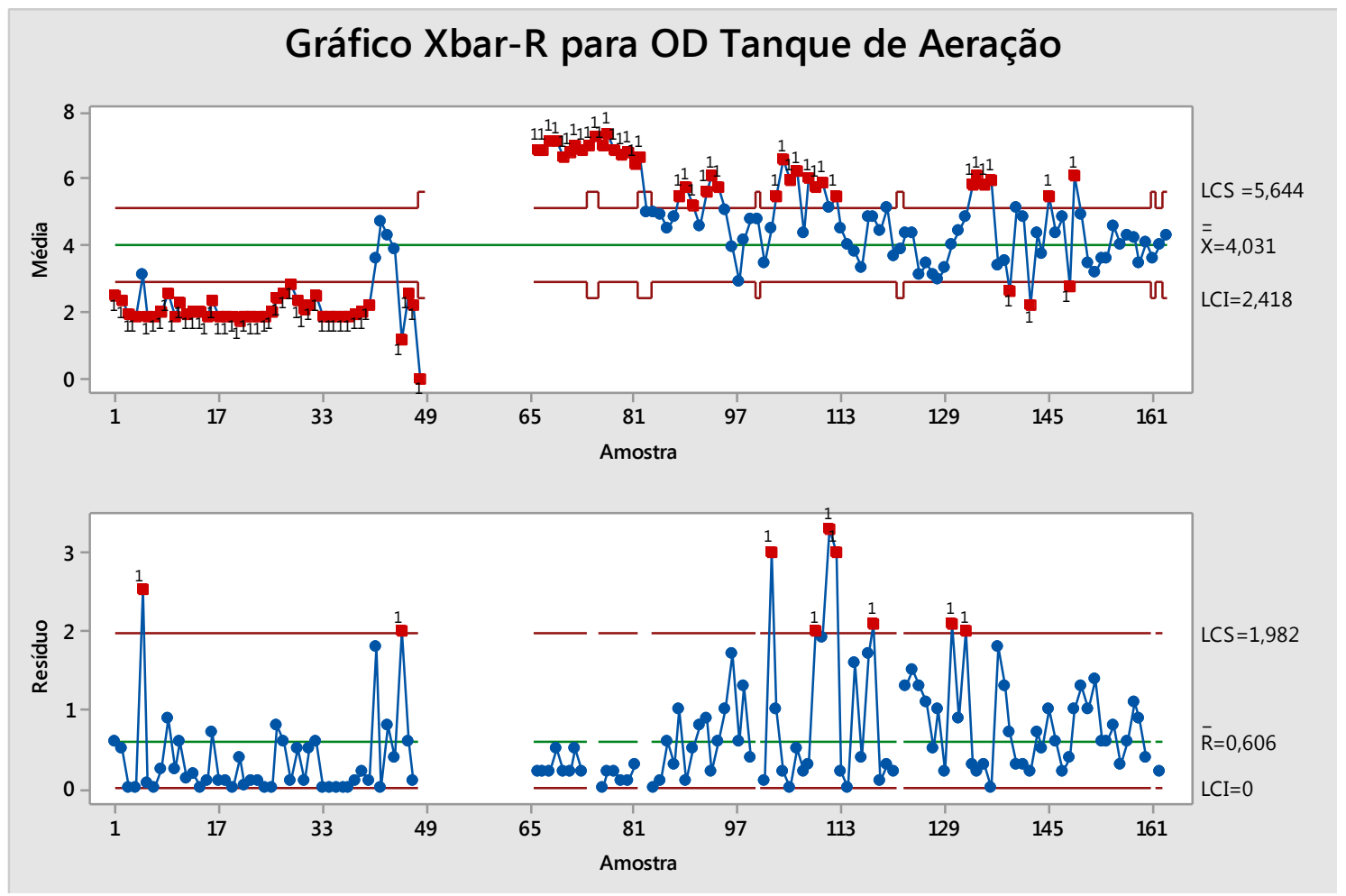

Fonte: Autor

Pelo gráfico 52, pode-se observar que pelo efeito da nitrificação no tanque de aeração em 12 ocasiões o pH ficou abaixo do esperado para a planta, sendo que nestes momentos mesmo não ocorrendo reduções abaixo de $\mathrm{pH} \mathrm{5,0}$ pode-se dizer que este parâmetro teve uma queda fora dos limites de controle.

Durante o período de operação da planta piloto, e resultados obtidos nas análises físicoquímicas realizadas decidiu-se elevar o oxigênio dissolvido de $2 \mathrm{mg} / \mathrm{L}$ para $4-5 \mathrm{mg} / \mathrm{L}$. As Figuras 52 e 53 mostram nitidamente esta variação

Executando teste de hipóteses para estas duas variáveis para comparar seu comportamento durante as duas etapas de experimentação e considerando-se que uma distribuição T-student e nível de confiança de 95\%, as hipóteses para o parâmetro pH foram:

H0: $p H$ etapa $1=p H$ etapa 2 (141A)

H1: $p H$ etapa $1 \neq p H$ etapa 2 (141B)

\begin{tabular}{|l|l|l|}
\hline Valor de $\mathbf{T}$ & Graus de liberdade & Valor P \\
\hline
\end{tabular}




\begin{tabular}{|c|c|c|}
\hline$-1,58$ & 106 & 0,1162 \\
\hline
\end{tabular}

Desta forma, aceita $\mathrm{H} 0$ e pode-se dizer que não foram observadas diferenças estatisticamente significantes entre o pH entre as etapas 1 e 2 de experimentação.

Já para o potencial Redox (ORP) foi utilizada distribuição T-Student e nível de confiança de $95 \%$ para as seguintes hipóteses:

$$
\begin{aligned}
& \text { H0: ORP etapa } 1=\text { ORP etapa } 2(\mathbf{1 4 2 A}) \\
& \text { H1: ORP etapa } 1 \neq \text { ORP etapa } 2(\mathbf{1 4 2 B})
\end{aligned}
$$

\begin{tabular}{|c|c|c|}
\hline Valor de $\mathbf{T}$ & Graus de liberdade & Valor P \\
\hline$-3,90$ & 186 & 0,0001 \\
\hline
\end{tabular}

Neste caso rejeita-se $\mathrm{H} 0$ e considera-se que há diferença estatisticamente significativa entre o ORP entre as etapas 1 e 2.

Para Oxigênio Dissolvido (OD) foi utilizada distribuição T-Student e nível de confiança de $95 \%$ para as seguintes hipóteses:

$$
\begin{aligned}
& \text { H0: OD etapa } 1=\text { OD etapa } 2(\mathbf{1 4 3 A}) \\
& H 1: \text { OD etapa } 1 \neq \text { OD etapa } 2(\mathbf{1 4 3 B})
\end{aligned}
$$

\begin{tabular}{|c|c|c|}
\hline Valor de $\mathbf{T}$ & Graus de liberdade & Valor P \\
\hline$-1,35$ & 205 & 0,1785 \\
\hline
\end{tabular}

Aceita-se $\mathrm{H} 0$ e considera-se que os níveis de OD foram mantidos os mesmos ao longo do experimento.

De acordo com as análises estatísticas obtidas, pode-se observar que os níveis de oxigênio dissolvido foram mantidos iguais durante as etapas de experimentação. Devido à carga orgânica afluente, pode-se observar que os patamares de OD foram maiores do que os normalmente encontrados em sistemas de lodos ativados.

Com relação à pH e ORP observou-se que devido à possíveis melhorias de processo (microaeração das câmaras anóxicas) observaram-se melhores resultados de nitrificação e desnitrificação, sendo que os fatores $\mathrm{pH}$ e ORP estão estritamente relacionados ao 
processo de remoção biológica de nitrogênio. As diferenças predominantes foram observadas nas câmaras anaeróbia, anóxica 1 e anóxica 2.

Durante etapa de análise estatística deste trabalho foi feita análise de Correlação/Regressão entre os parâmetro OD e ORP e Concentração de Nitrogênio Amoniacal no Efluente final. Pelo fato do experimento não ter alterado propositadamente os níveis de OD no tanque de aeração, não obteve-se uma correlação forte com $\mathrm{R}^{2}=0,22$ para OD x Nitrogênio Amoniacal no Efluente e $\mathrm{R}^{2}=0,08$ para ORP $\mathrm{x}$ Nitrogênio Amoniacal no Efluente Final o que mostra um correlação fraca entre os parâmetros.

\subsection{Resultados para Matéria Orgânica}

Apresentam-se nas tabelas 18 e 19 os resultados para a matéria orgânica na fase 1 de experimentação (DQO e DBO, respectivamente).

Tabela 18 - Estatística Descritiva dos Resultados das Análises Físico-Químicas para DQO - Etapa 1

\begin{tabular}{|c|c|c|c|c|c|c|c|}
\hline \multirow{3}{*}{ Parâmetro } & \multicolumn{2}{|c|}{ DQO TOTAL } & \multicolumn{5}{|c|}{ DQO SOLÚVEL } \\
\hline & $\begin{array}{c}\text { Ponto } \\
\text { Amostragem } \\
1 \\
\end{array}$ & \begin{tabular}{|c|} 
Ponto \\
Amostragem \\
6 \\
\end{tabular} & \begin{tabular}{|c|} 
Ponto \\
Amostragem \\
1 \\
\end{tabular} & \begin{tabular}{|c|} 
Ponto \\
Amostragem \\
2 \\
\end{tabular} & \begin{tabular}{|c|} 
Ponto \\
Amostragem \\
3 \\
\end{tabular} & \begin{tabular}{|c|} 
Ponto \\
Amostragem \\
4 \\
\end{tabular} & $\begin{array}{c}\text { Ponto } \\
\text { Amostragem } \\
6 \\
\end{array}$ \\
\hline & $\mathrm{mgO} 2 / \mathrm{L}$ & $\mathrm{mgO} 2 / \mathrm{L}$ & $\mathrm{mgO} 2 / \mathrm{L}$ & $\mathrm{mgO} 2 / \mathrm{L}$ & $\mathrm{mgO} 2 / \mathrm{L}$ & $\mathrm{mgO} 2 / \mathrm{L}$ & $\mathrm{mgO} 2 / \mathrm{L}$ \\
\hline Média & 444 & 188 & 255 & 90 & 87 & 72 & 78 \\
\hline Máximo & 594 & 499 & 364 & 313 & 392 & 250 & 274 \\
\hline Mínimo & 238 & 60 & 160 & 20 & 33 & 16 & 12 \\
\hline Mediana & 412 & 145 & 253 & 76 & 65 & 60 & 37 \\
\hline $\begin{array}{l}\text { Desvio } \\
\text { Padrão }\end{array}$ & 102 & 135 & 57 & 69 & 82 & 60 & 81 \\
\hline $\mathrm{CV}(\%)$ & $23 \%$ & $72 \%$ & $23 \%$ & $76 \%$ & $94 \%$ & $84 \%$ & $105 \%$ \\
\hline AT & 356 & 439 & 204 & 293 & 359 & 233 & 262 \\
\hline
\end{tabular}

Fonte: Autor

Tabela 19 - Estatística Descritiva dos Resultados das Análises Físico-Químicas para DBO5,20 - Etapa 1

\begin{tabular}{|c|c|c|c|c|c|c|c|}
\hline \multirow{3}{*}{ Parâmetro } & \multicolumn{2}{|c|}{ DBO TOTAL } & \multicolumn{5}{|c|}{ DBO SOLÚVEL } \\
\hline & \begin{tabular}{|c|} 
Ponto \\
Amostragem \\
1 \\
\end{tabular} & \begin{tabular}{|c|} 
Ponto \\
Amostragem \\
6
\end{tabular} & \begin{tabular}{|c|} 
Ponto \\
Amostragem \\
1 \\
\end{tabular} & \begin{tabular}{|c|} 
Ponto \\
Amostragem \\
2 \\
\end{tabular} & \begin{tabular}{|c|} 
Ponto \\
Amostragem \\
3 \\
\end{tabular} & \begin{tabular}{|c|} 
Ponto \\
Amostragem \\
4
\end{tabular} & $\begin{array}{c}\text { Ponto } \\
\text { Amostragem } \\
6\end{array}$ \\
\hline & $\mathrm{mgO} 2 / \mathrm{L}$ & $\mathrm{mgO} 2 / \mathrm{L}$ & mgO2/L & $\mathrm{mgO} 2 / \mathrm{L}$ & $\mathrm{mgO} 2 / \mathrm{L}$ & $\mathrm{mgO} 2 / \mathrm{L}$ & $\mathrm{mgO} 2 / \mathrm{L}$ \\
\hline Média & 277 & 94 & 99 & 44 & 36 & 31 & 20 \\
\hline Máximo & 322 & 145 & 154 & 57 & 67 & 58 & 31 \\
\hline Mínimo & 200 & 18 & 50 & 23 & 18 & 14 & 12 \\
\hline Mediana & 286 & 81 & 122 & 41 & 27,5 & 25 & 19 \\
\hline $\begin{array}{l}\text { Desvio } \\
\text { Padrão }\end{array}$ & 35 & 38 & 33 & 11 & 16 & 14 & 6 \\
\hline $\mathrm{CV}(\%)$ & $13 \%$ & $40 \%$ & $33 \%$ & $25 \%$ & $43 \%$ & $45 \%$ & $33 \%$ \\
\hline AT & 122 & 127 & 104 & 34 & 49 & 44 & 19 \\
\hline
\end{tabular}

Fonte: Autor 
Comparando-se os resultados obtidos para o experimento com os resultados obtidos no modelo teórico pode-se verificar que para a matéria orgânica a planta piloto teve desempenho um pouco abaixo do esperado, uma vez que a média para a DQO Solúvel no efluente final foi de $78 \mathrm{mg} / \mathrm{L}$ sendo que esperava-se algo em torno de $35 \mathrm{mg} / \mathrm{L}$ de DQO solúvel.

As Figuras 54 e 55 apresentam os gráficos Boxplot para estas duas variáveis durante fase 1 de experimentação. 
Figura 54 - Gráfico BoxPlot para o parâmetro DQO - Etapa 1

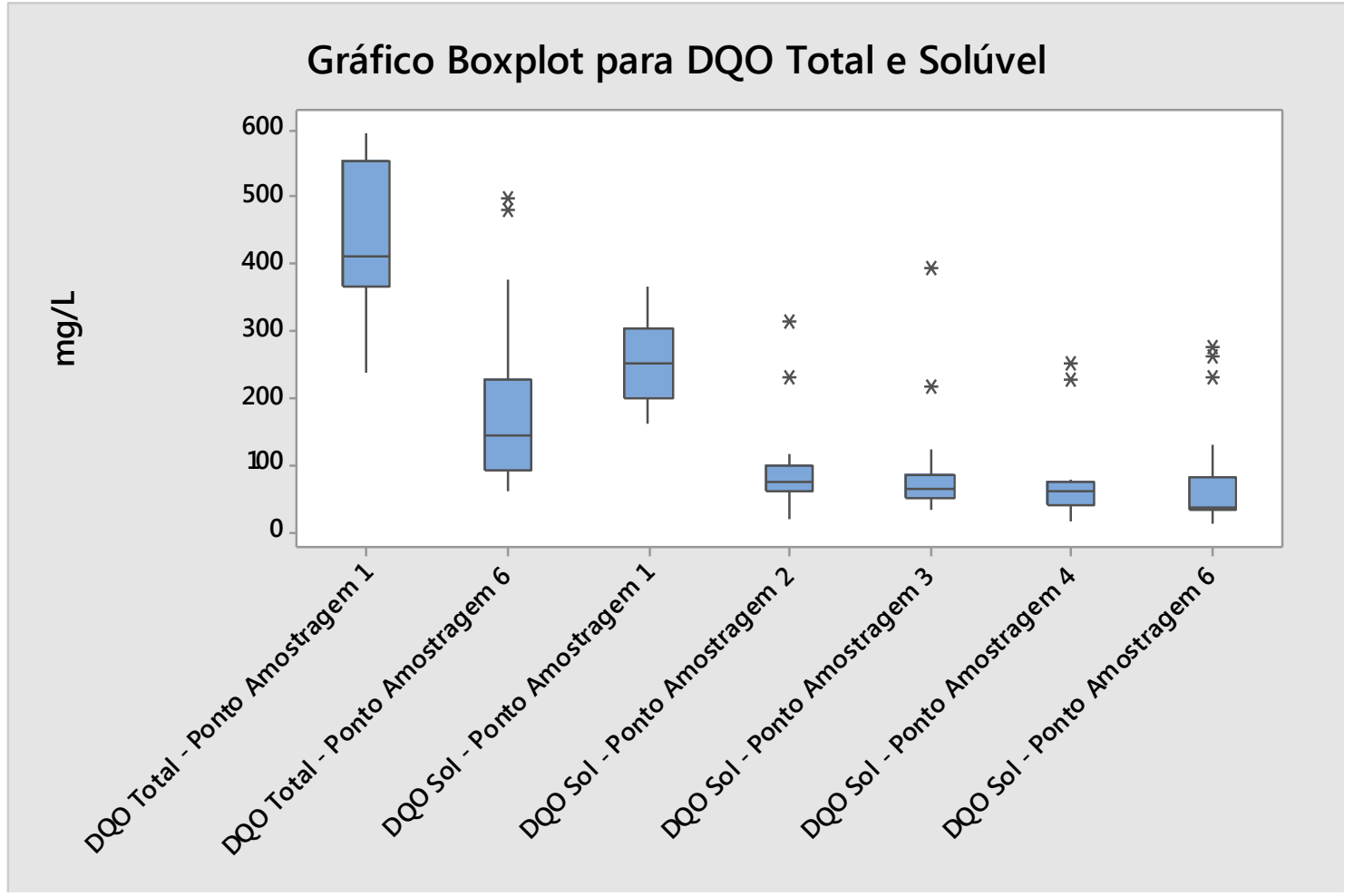

Fonte: Autor

Figura 55 - Gráfico Boxplot para o parâmetro DBO5,20 - Etapa 1

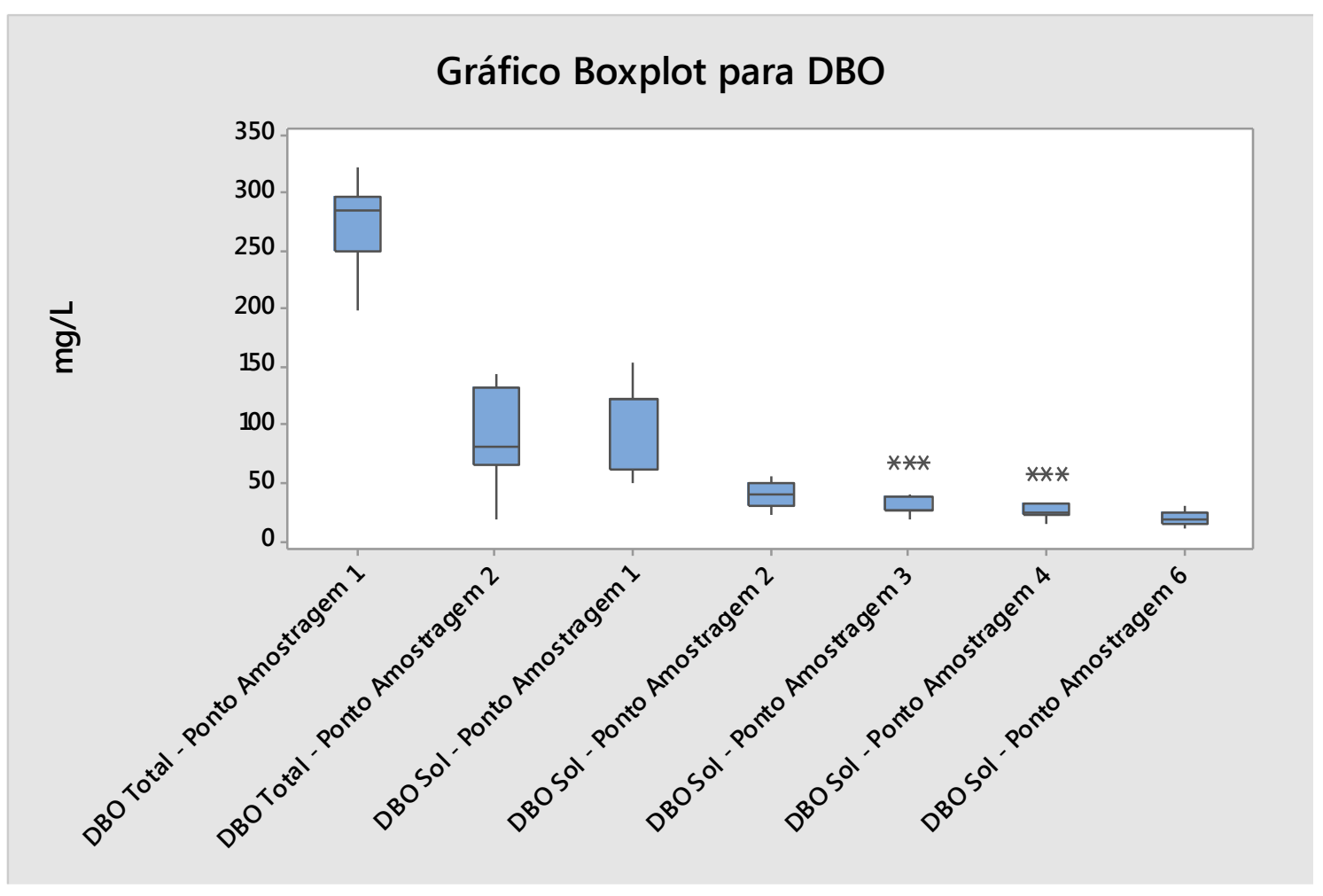

Fonte: Autor 
As tabelas 20 e 21 apresentam as estatísticas descritivas básicas para DBO e DQO para a etapa 2 de experimentação.

Tabela 20 - Estatística Descritiva dos Resultados das Análises Físico-Químicas para o Parâmetro DQO -

Etapa 2

\begin{tabular}{|c|c|c|c|c|c|c|c|}
\hline \multirow{3}{*}{ Parâmetro } & \multicolumn{2}{|c|}{ DQO TOTAL } & \multicolumn{5}{|c|}{ DQO SOLÚVEL } \\
\hline & \begin{tabular}{|c|} 
Ponto \\
Amostragem \\
1 \\
\end{tabular} & \begin{tabular}{|c|} 
Ponto \\
Amostragem \\
6 \\
\end{tabular} & \begin{tabular}{|c|} 
Ponto \\
Amostragem \\
1 \\
\end{tabular} & \begin{tabular}{|c|} 
Ponto \\
Amostragem \\
2 \\
\end{tabular} & \begin{tabular}{|c|} 
Ponto \\
Amostragem \\
3 \\
\end{tabular} & \begin{tabular}{|c|} 
Ponto \\
Amostragem \\
4 \\
\end{tabular} & \begin{tabular}{|c|} 
Ponto \\
Amostragem \\
6 \\
\end{tabular} \\
\hline & $\mathrm{mgO} / \mathrm{L}$ & $\mathrm{mgO} 2 / \mathrm{L}$ & $\mathrm{mgO} 2 / \mathrm{L}$ & $\mathrm{mgO} 2 / \mathrm{L}$ & $\mathrm{mgO} 2 / \mathrm{L}$ & $\mathrm{mgO} / \mathrm{L}$ & $\mathrm{mgO} 2 / \mathrm{L}$ \\
\hline Média & 540 & 72 & 188 & 64 & 54 & 53 & 32 \\
\hline Máximo & 890 & 132 & 339 & 83 & 94 & 92 & 64 \\
\hline Mínimo & 297 & 17 & 117 & 25 & 17 & 10 & 7 \\
\hline Mediana & 500 & 59 & 165 & 70 & 43 & 58 & 35 \\
\hline \begin{tabular}{|l|} 
Desvio \\
Padrão
\end{tabular} & 187 & 44 & 73 & 21 & 28 & 26 & 18 \\
\hline $\mathrm{CV}(\%)$ & $35 \%$ & $62 \%$ & $39 \%$ & $32 \%$ & $52 \%$ & $50 \%$ & $54 \%$ \\
\hline AT & 593 & 115 & 221 & 58 & 77 & 82 & 57 \\
\hline
\end{tabular}

Fonte: Autor

Tabela 21 - Estatística Descritiva dos Resultados das Análises Físico-Químicas para o Parâmetro DBO - Etapa

2

\begin{tabular}{|c|c|c|c|c|c|c|c|}
\hline \multirow{3}{*}{ Parâmetro } & \multicolumn{2}{|c|}{ DBO TOTAL } & \multicolumn{5}{|c|}{ DBO SOLÚVEL } \\
\hline & \begin{tabular}{|c|} 
Ponto \\
Amostragem \\
1 \\
\end{tabular} & \begin{tabular}{|c|} 
Ponto \\
Amostragem \\
6 \\
\end{tabular} & \begin{tabular}{|c|} 
Ponto \\
Amostragem \\
1 \\
\end{tabular} & \begin{tabular}{|c|} 
Ponto \\
Amostragem \\
2 \\
\end{tabular} & \begin{tabular}{|c|} 
Ponto \\
Amostragem \\
3 \\
\end{tabular} & \begin{tabular}{|c|} 
Ponto \\
Amostragem \\
4 \\
\end{tabular} & $\begin{array}{c}\text { Ponto } \\
\text { Amostragem } \\
6 \\
\end{array}$ \\
\hline & $\mathrm{mgO} 2 / \mathrm{L}$ & $\mathrm{mgO} 2 / \mathrm{L}$ & $\mathrm{mgO} 2 / \mathrm{L}$ & $\mathrm{mgO} 2 / \mathrm{L}$ & $\mathrm{mgO} 2 / \mathrm{L}$ & $\mathrm{mgO} 2 / \mathrm{L}$ & $\mathrm{mgO} 2 / \mathrm{L}$ \\
\hline Média & 439 & 100 & 162 & 76 & 46 & 33 & 37 \\
\hline Máximo & 584 & 200 & 250 & 145 & 92 & 52 & 48 \\
\hline Mínimo & 300 & 19 & 58 & 27 & 8 & 12 & 6 \\
\hline Mediana & 386 & 76 & 175 & 72 & 38 & 34 & 42 \\
\hline $\begin{array}{l}\text { Desvio } \\
\text { Padrão }\end{array}$ & 113 & 62 & 77 & 50 & 33 & 15 & 14 \\
\hline $\mathrm{CV}(\%)$ & $26 \%$ & $62 \%$ & $48 \%$ & $66 \%$ & $73 \%$ & $47 \%$ & $38 \%$ \\
\hline AT & 284 & 181 & 192 & 118 & 84 & 40 & 42 \\
\hline
\end{tabular}

Fonte: Autor

Já as figuras 56 e 57 apresentam os gráficos boxplot para os parâmetros de matéria orgânica para a etapa 2 de experimentação. 
Figura 56 - Gráfico Boxplot para DQO - Etapa 2

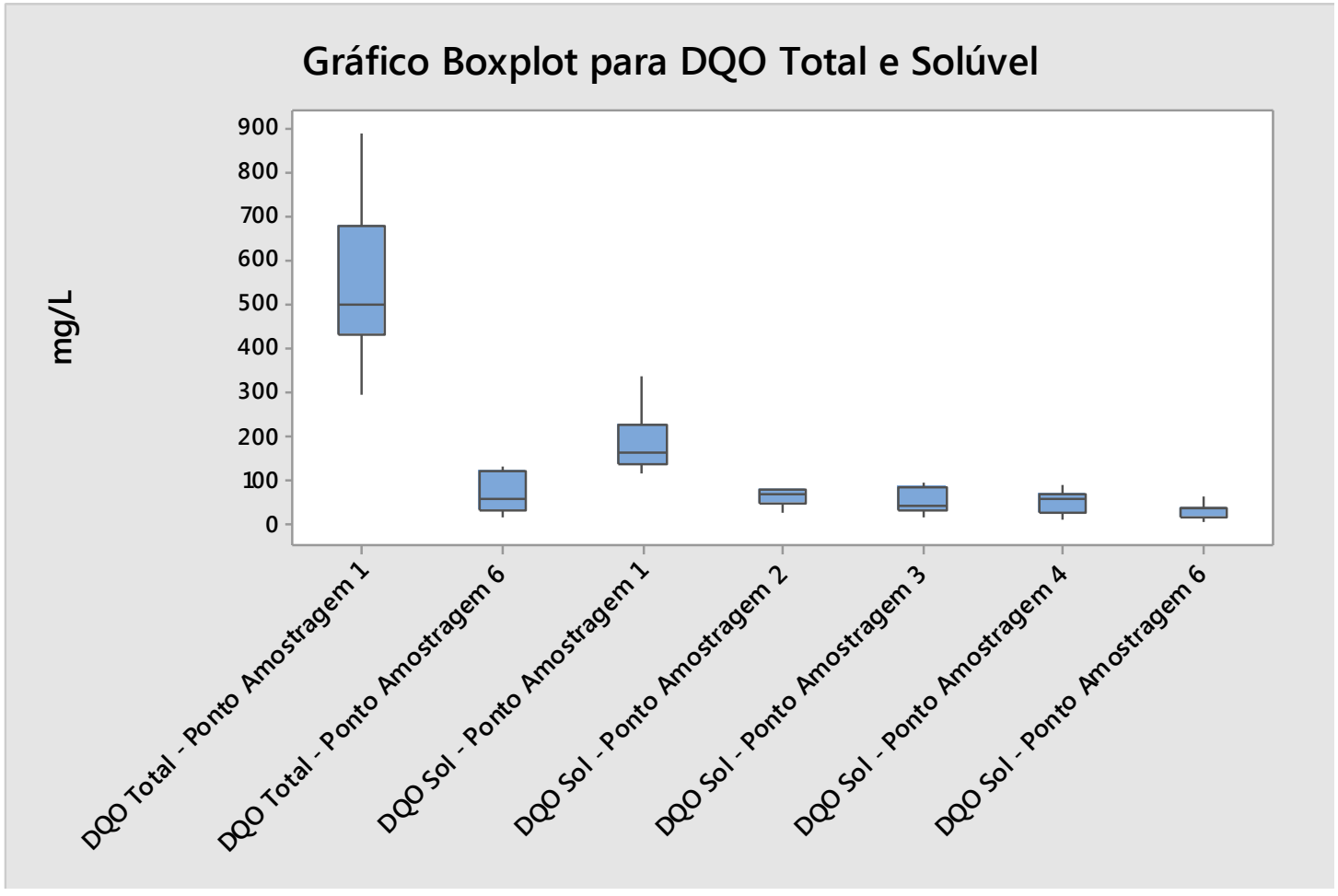

Fonte: Autor

Figura 57 - Gráfico Boxplot para o parâmetro DBO5,20 - Etapa 2

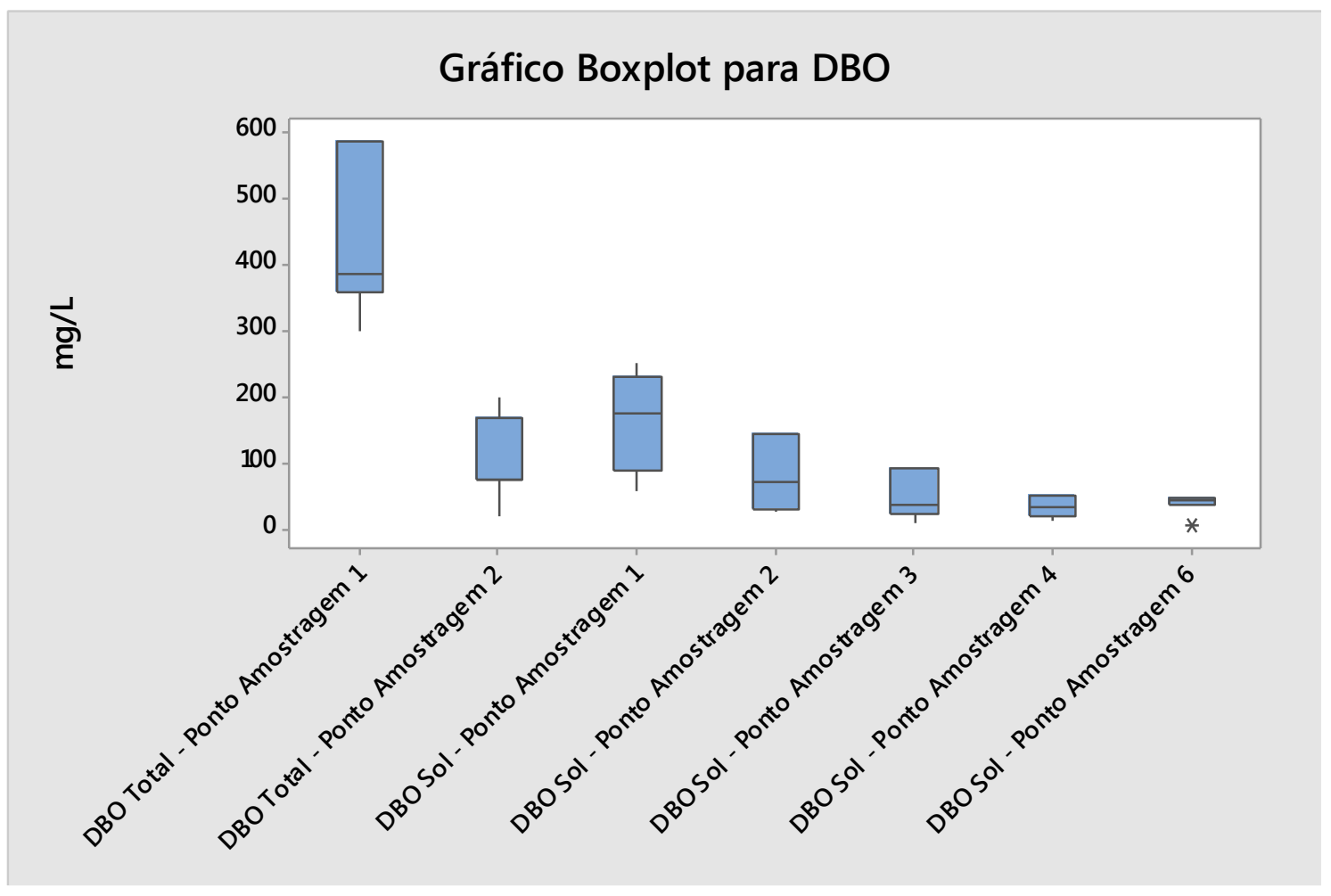

Fonte: Autor 
Apresentam-se nas Figuras 58 e 59 os gráficos das séries históricas para os dois parâmetros utilizados na análise de matéria orgânica. Para os parâmetros analíticos não serão apresentados as análises seis sigma.

Figura 58 - Gráfico da série histórica para o parâmetro DQO

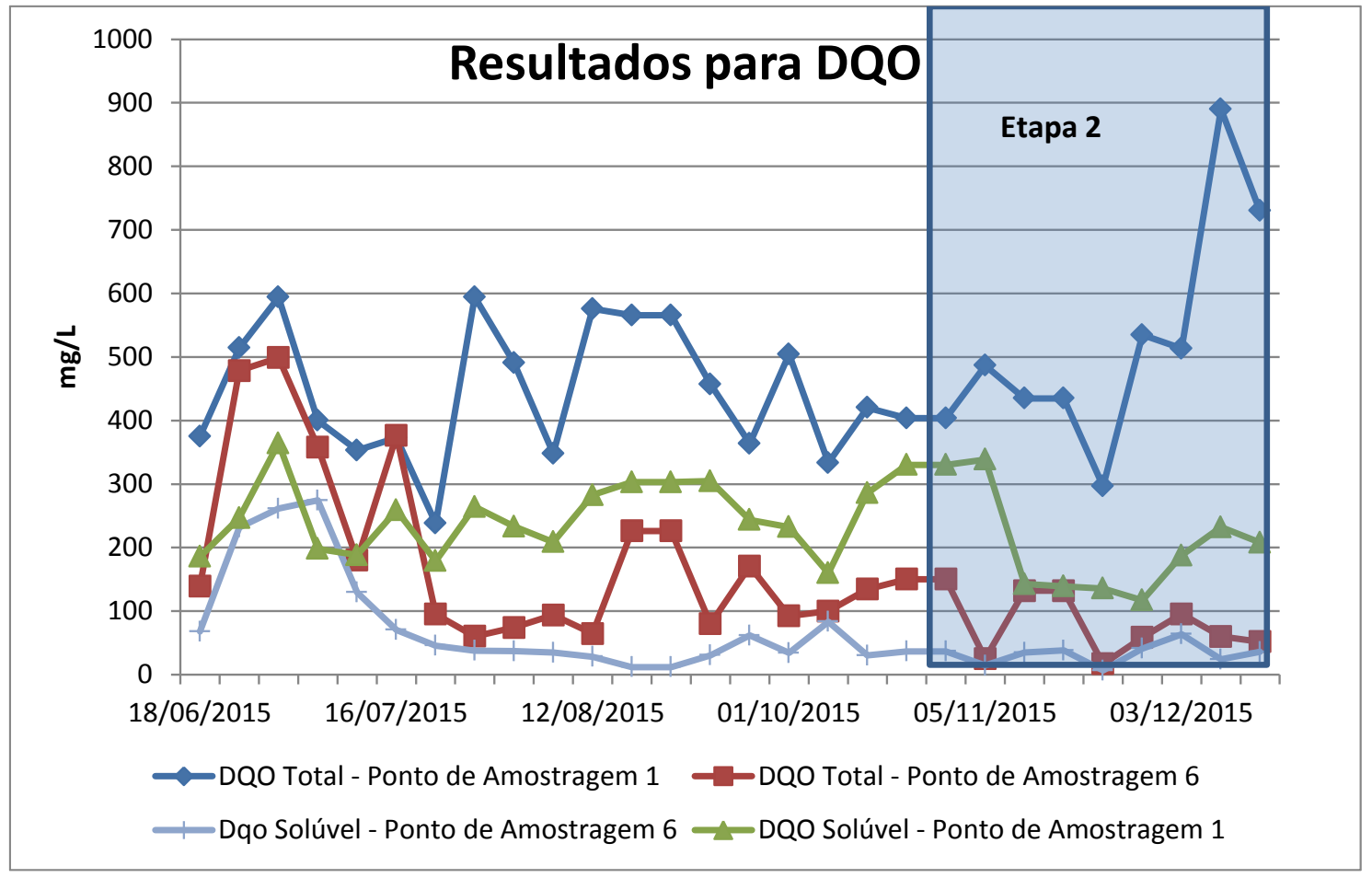

Fonte: Autor

Figura 59 - Gráfico da série histórica para o parâmetro $\mathrm{DBO}_{5,20}$

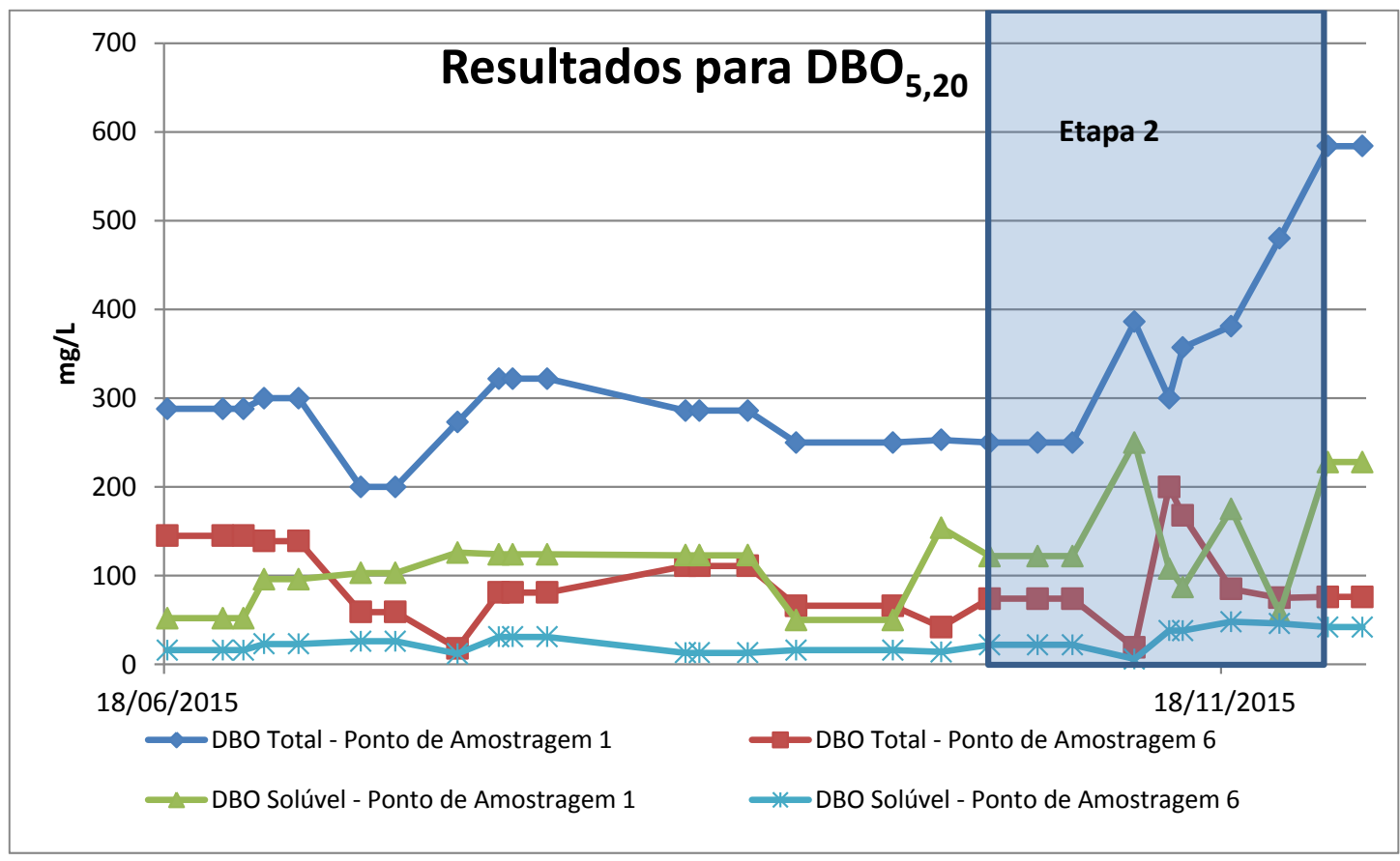

Fonte: Autor 
Pode-se observar que nas últimas duas análises de DQO Total de Entrada foram aferidas quantidades muito elevadas de matéria orgânica. Não é possível definir com exatidão a causa desta elevação, porém observando os valores de DQO solúvel para estas duas amostras pode-se sugerir que este aumento se deu por arraste de sólidos do decantador primário.

A análise comparativa entre as duas etapas se dará pela análise da DQO solúvel de entrada (ponto de amostragem 1) e saída da planta piloto (ponto de amostragem 6) uma vez que para este trabalho há uma relevância maior em se avaliar a remoção da matéria orgânica solúvel sendo que a matéria orgânica particulada deve ser avaliada do ponto de vista da separação líquido-sólido.

Executando teste de hipóteses para as duas variáveis apresentadas para comparar seu comportamento durante as duas etapas de experimentação e considerando-se que uma distribuição T-student e nível de confiança de 95\%, as hipóteses para o parâmetro DQO Solúvel de Entrada foram:

$$
\begin{aligned}
& \text { H0: DQO Sóluvel Ponto Amostragem } 1-\text { etapa } 1= \\
& \text { DQO Sóluvel Ponto Amostragem } 1-\text { etapa } 2(\mathbf{1 4 4 A )} \\
& \text { H1: DQO Sóluvel Ponto Amostragem } 1-\text { etapa } 1 \neq \\
& \text { DQO Sóluvel Ponto Amostragem } 1-\text { etapa } 2(\mathbf{1 4 4 B )}
\end{aligned}
$$

\begin{tabular}{|c|c|c|}
\hline Valor de $\mathbf{T}$ & Graus de liberdade & Valor P \\
\hline 2,34 & 10 & 0,0415 \\
\hline
\end{tabular}

Sendo assim, rejeita-se HO e considera-se que houve diferença estatisticamente significante entre as etapas 1 e 2 de experimentação. Sugere-se que possivelmente esta diferença seja decorrente da sazonalidade ao longo do período de experimentação.

Já para a DQO Solúvel de Saída utilizada distribuição T-Student e nível de confiança de 95\% para as seguintes hipóteses:

$$
\begin{aligned}
& \text { H0: DQO Sóluvel Ponto Amostragem } 6-\text { etapa } 1= \\
& \text { DQO Sóluvel Ponto Amostragem } 6-\text { etapa } 2(\mathbf{1 4 5 A )} \\
& \text { H1: DQO Sóluvel Ponto Amostragem } 6-\text { etapa } 1 \neq \\
& \text { DQO Sóluvel Ponto Amostragem } 6-\text { etapa } 2(\mathbf{1 4 5 B})
\end{aligned}
$$




\begin{tabular}{|c|c|c|}
\hline Valor de $\mathbf{T}$ & Graus de liberdade & Valor P \\
\hline 2,36 & 22 & 0,027 \\
\hline
\end{tabular}

Rejeita-se, portanto, H0 e considera-se que a DQO durante etapa 2 de experimentação teve resultados mais baixos do que os resultados da etapa 1. Isto é muito importante, uma vez que a qualidade do efluente tratado em termos de DQO para a etapa 2 foi melhor do que a etapa 1. Provavelmente contribuiu para este fato a melhor desnitrificação observada e uma possível maior estabilidade do processo como um todo na etapa 2 de experimentação

De acordo com a Figura 58, supõe-se que devido a arreste de sólidos do decantador primário as últimas análises apontam para DBO total de entrada muito elevada se comparada com as concentrações de entrada da etapa 1 de experimentação.

Será avaliado neste trabalho o parâmetro DBO 5,20 solúvel de entrada e saída da planta piloto.

Executando teste de hipóteses para as duas variáveis apresentadas para comparar seu comportamento durante as duas etapas de experimentação e considerando-se que uma distribuição T-student e nível de confiança de 95\%, as hipóteses para o parâmetro $\mathrm{DBO}_{5,20}$ Solúvel de Entrada foram:

$$
\begin{aligned}
& \text { H0: DBO Sóluvel Ponto Amostragem } 1-\text { etapa } 1= \\
& \text { DBO Sóluvel Ponto Amostragem } 1-\text { etapa } 2(\mathbf{1 4 6 A )} \\
& \text { H1: DBO Sóluvel Ponto Amostragem } 1-\text { etapa } 1 \neq \\
& \text { DBO Sóluvel Ponto Amostragem } 1-\text { etapa } 2(\mathbf{1 4 6 B )}
\end{aligned}
$$

\begin{tabular}{|c|c|c|}
\hline Valor de T & Graus de liberdade & Valor P \\
\hline$-1,99$ & 6 & 0,0941 \\
\hline
\end{tabular}

Aceita-se H0 e considera-se que a DBO solúvel de entrada no processo se manteve constante ao longo do período de experimentação.

Já para a $\mathrm{DBO}_{5,20}$ Solúvel de Saída utilizada distribuição T-Student e nível de confiança de $95 \%$ para as seguintes hipóteses: 
H0: DBO Sóluvel Ponto Amostragem $6-$ etapa $1=$

DBO Sóluvel Ponto Amostragem 6 - etapa 2 (147A)

H1:DBO Sóluvel Ponto Amostragem 6 - etapa $1 \neq$

DBO Sóluvel Ponto Amostragem 6 - etapa 2 (147B)

\begin{tabular}{|c|c|c|}
\hline Valor de T & Graus de liberdade & Valor P \\
\hline$-3,06$ & 6 & 0,0222 \\
\hline
\end{tabular}

Desta forma, rejeita-se H0 e considera-se que a DBO do ponto de amostragem 6 para a etapa de experimentação 2 foi maior do que a DBO do ponto de amostragem 6 da etapa 1.

Visualiza-se, assim uma possível incoerência entre os dados de DBO e DQO, uma vez que segundo as análises de DQO, o efluente da etapa 2 de experimentação tem níveis mais baixos de matéria orgânica e as análises de DBO mostram o contrário. No entanto, a metodologia utilizada no presente trabalho para a determinação de DBO é mais suscetível a interferências externas, sendo que pelas análises dos demais parâmetros pode-se inferir que as análises de DBO tenham sofrido algum tipo de interferência que possa ter afetado o resultado aqui apresentado.

Comparando-se os resultados obtidos com os resultados teóricos apresentados no item 5.1 deste trabalho, pode-se observar que a planta piloto UCT modificado obteve resultados um pouco piores do que os resultados teóricos para a DQO solúvel no efluente final na etapa 1 de experimentação, sendo que o resultado teórico para as duas fases ficou em torno de $30 \mathrm{mg} / \mathrm{L}$ (obtido no experimento em média $78 \mathrm{mg} / \mathrm{L}$ ). Já na etapa 2 de experimentação os resultados obtidos estiveram dentro do esperado, uma vez que a DQO solúvel no efluente teórico era da ordem de $35 \mathrm{mg} / \mathrm{L}$ (resultado obtido 28 $\mathrm{mg} / \mathrm{L}$ ). Isto mostra que mesmo com as alterações propostas a planta piloto UCT modificada obteve resultados satisfatórios e dentro do esperado para a remoção da matéria orgânica.

\subsubsection{Série de sólidos}

Parte essencial deste trabalho e de qualquer sistema biológico de tratamento de águas residuárias é a avaliação dos sólidos no sistema. 
As tabelas 22 e 23 apresentam os resultados para os parâmetros básicos estatísticos para SSV. No presente estudo serão feitas as devidas análises referentes à componente volátil da série de sólidos devido à sua fundamental importância para um processo de lodos ativados.

Tabela 22 - Estatística Descritiva dos Resultados das Análises Físico-Químicas para o Parâmetro Série de Sólidos - Etapa 1

\begin{tabular}{|c|c|c|c|c|c|c|c|}
\hline \multirow[b]{2}{*}{ Parâmetro } & \multicolumn{7}{|c|}{ SSV (mg/L) } \\
\hline & $\begin{array}{c}\text { Ponto } \\
\text { Amostragem } \\
1\end{array}$ & \begin{tabular}{|c} 
Ponto \\
Amostragem \\
2
\end{tabular} & \begin{tabular}{|c|} 
Ponto \\
Amostragem \\
3
\end{tabular} & \begin{tabular}{|c|} 
Ponto \\
Amostragem \\
4
\end{tabular} & \begin{tabular}{|c|} 
Ponto \\
Amostragem \\
5
\end{tabular} & \begin{tabular}{|c} 
Ponto \\
Amostragem \\
6
\end{tabular} & $\begin{array}{c}\text { Ponto } \\
\text { Amostragem } \\
7\end{array}$ \\
\hline Média & 126 & 2621 & 3214 & 3317 & 3361 & 74 & 6220 \\
\hline Máximo & 212 & 3920 & 3840 & 4000 & 4920 & 184 & 10620 \\
\hline Mínimo & 62 & 1660 & 1880 & 2600 & 2400 & 22 & 2410 \\
\hline Mediana & 103 & 2560 & 3130 & 3280 & 3250 & 61 & 6060 \\
\hline $\begin{array}{l}\text { Desvio } \\
\text { Padrão }\end{array}$ & 42 & 592 & 452 & 415 & 590 & 46 & 1641 \\
\hline $\mathrm{CV}(\%)$ & $33 \%$ & $23 \%$ & $14 \%$ & $12 \%$ & $18 \%$ & $63 \%$ & $26 \%$ \\
\hline AT & 150 & 2260 & 1960 & 1400 & 2520 & 162 & 8210 \\
\hline
\end{tabular}

Fonte: Autor

Tabela 23 - Resultados das Análises Físico-Químicas para o Parâmetro Série de Sólidos - Etapa 2

\begin{tabular}{|c|c|c|c|c|c|c|c|}
\hline \multirow[b]{2}{*}{ Parâmetro } & \multicolumn{7}{|c|}{ SSV (mg/L) } \\
\hline & $\begin{array}{c}\text { Ponto } \\
\text { Amostragem } \\
1\end{array}$ & \begin{tabular}{|c|} 
Ponto \\
Amostragem \\
2 \\
\end{tabular} & \begin{tabular}{|c} 
Ponto \\
Amostragem \\
3
\end{tabular} & \begin{tabular}{|c|} 
Ponto \\
Amostragem \\
4
\end{tabular} & \begin{tabular}{|c|} 
Ponto \\
Amostragem \\
5
\end{tabular} & \begin{tabular}{|c|} 
Ponto \\
Amostragem \\
6
\end{tabular} & $\begin{array}{c}\text { Ponto } \\
\text { Amostragem } \\
7\end{array}$ \\
\hline Média & 164 & 2830 & 2538 & 2703 & 2603 & 51 & 4850 \\
\hline Máximo & 282 & 6320 & 3680 & 3180 & 3420 & 138 & 7380 \\
\hline Mínimo & 94 & 780 & 1820 & 2280 & 2140 & 9 & 3660 \\
\hline Mediana & 132 & 2550 & 2350 & 2750 & 2550 & 27 & 4680 \\
\hline $\begin{array}{l}\text { Desvio } \\
\text { Padrão } \\
\end{array}$ & 77 & 1787 & 712 & 344 & 414 & 54 & 1122 \\
\hline CV(\%) & $47 \%$ & $63 \%$ & $28 \%$ & $13 \%$ & $16 \%$ & $105 \%$ & $23 \%$ \\
\hline AT & 188 & 5540 & 1860 & 900 & 1280 & 129 & 3720 \\
\hline
\end{tabular}

Fonte: Autor

As Figuras 60 e 61 apresentam os gráficos boxplot para o parâmetro SSV nos diversos pontos de análise para a etapa 1 e 2 , respectivamente. 
Figura 60 - Gráfico Boxplot para o parâmetro SSV - Etapa 1

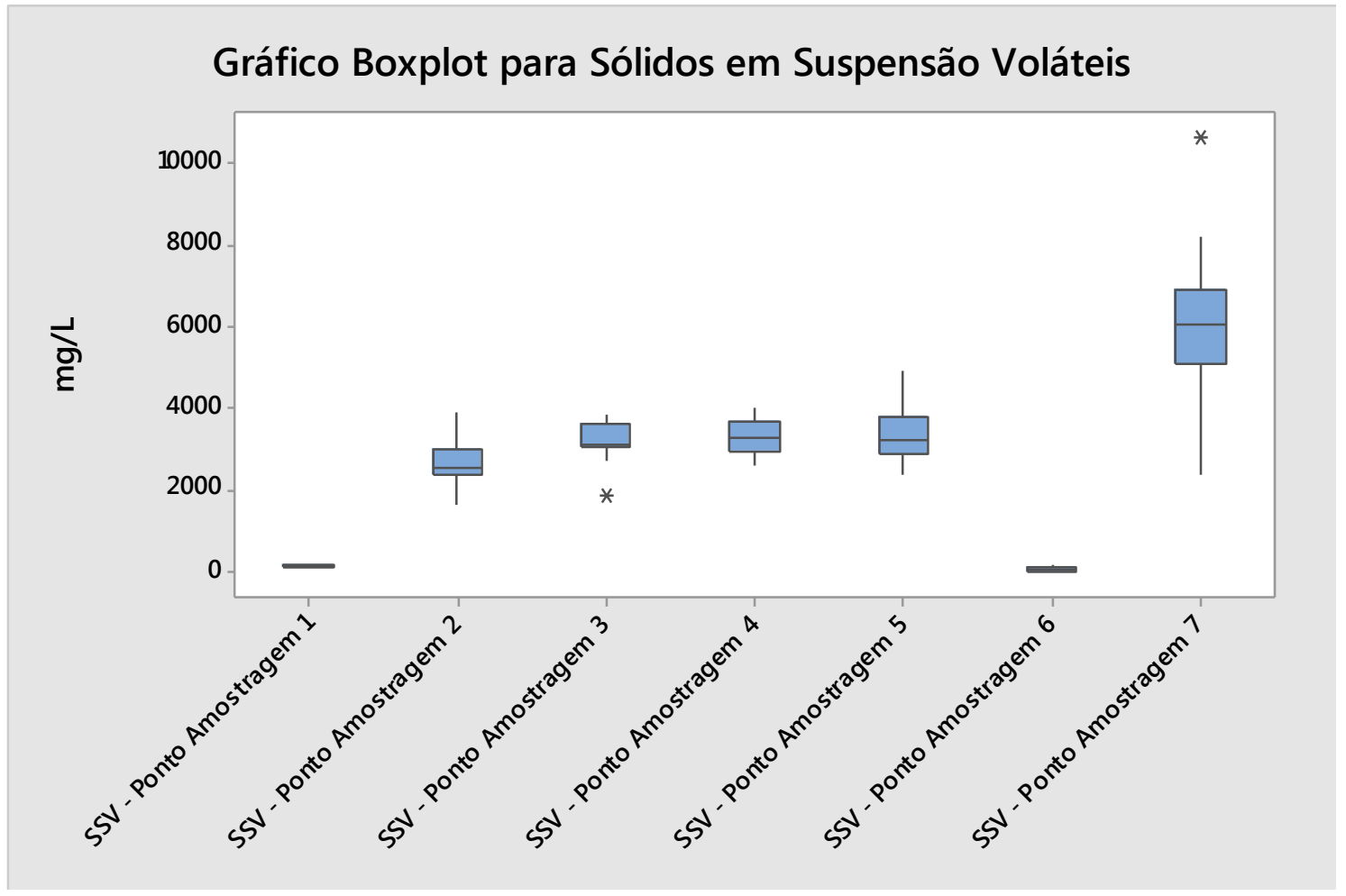

Fonte: Autor

Figura 61 - Gráfico Boxplot para o parâmetro SSV - Etapa 2

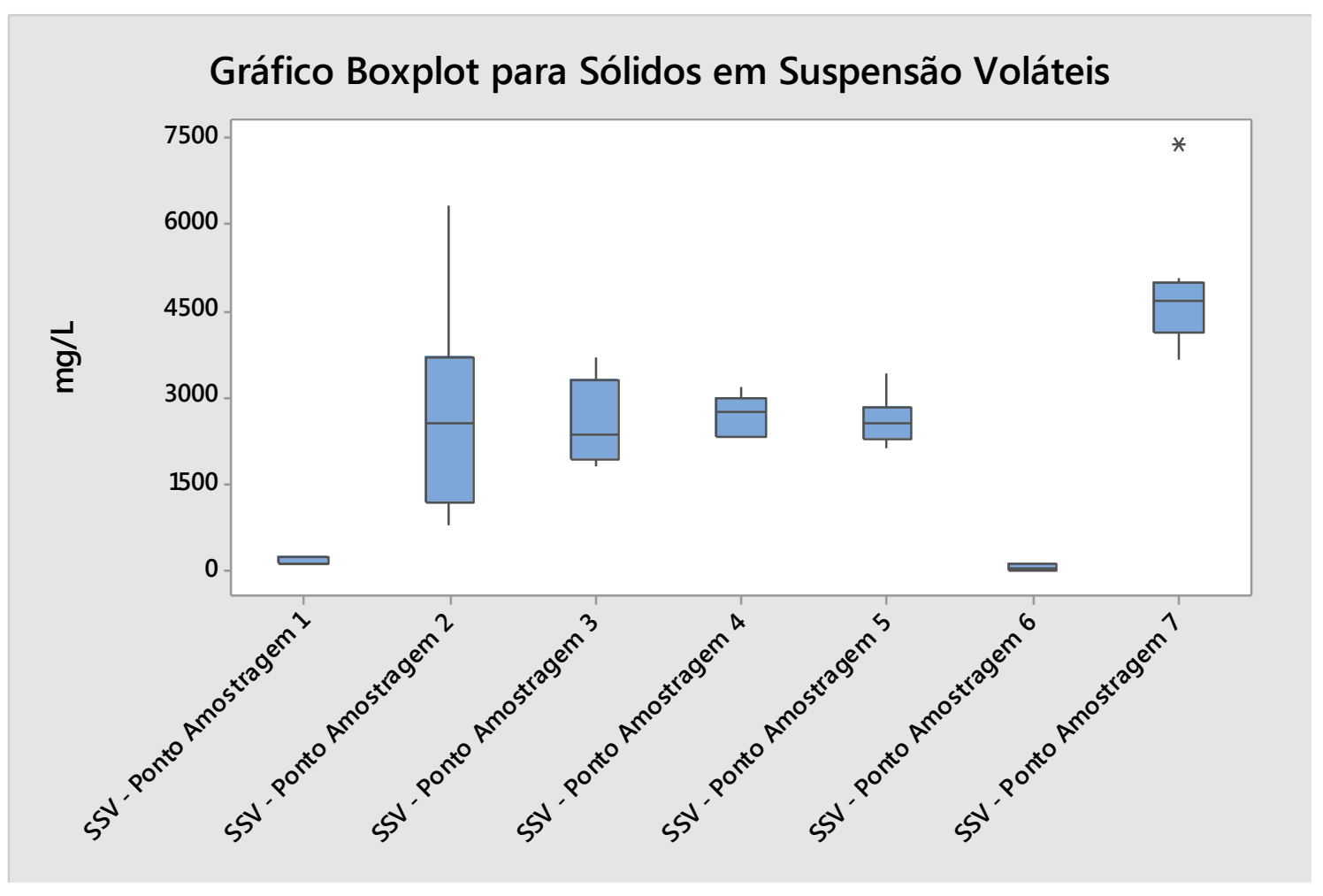

Fonte: Autor 
Os gráficos 62 e 63 apresentam as séries históricas para o SSV na entrada e saída do sistema e para o tanque de aeração e lodo descartado da planta.

Figura 62 - Gráfico da série histórica para SSV na entrada e saída da planta UCT Modificada

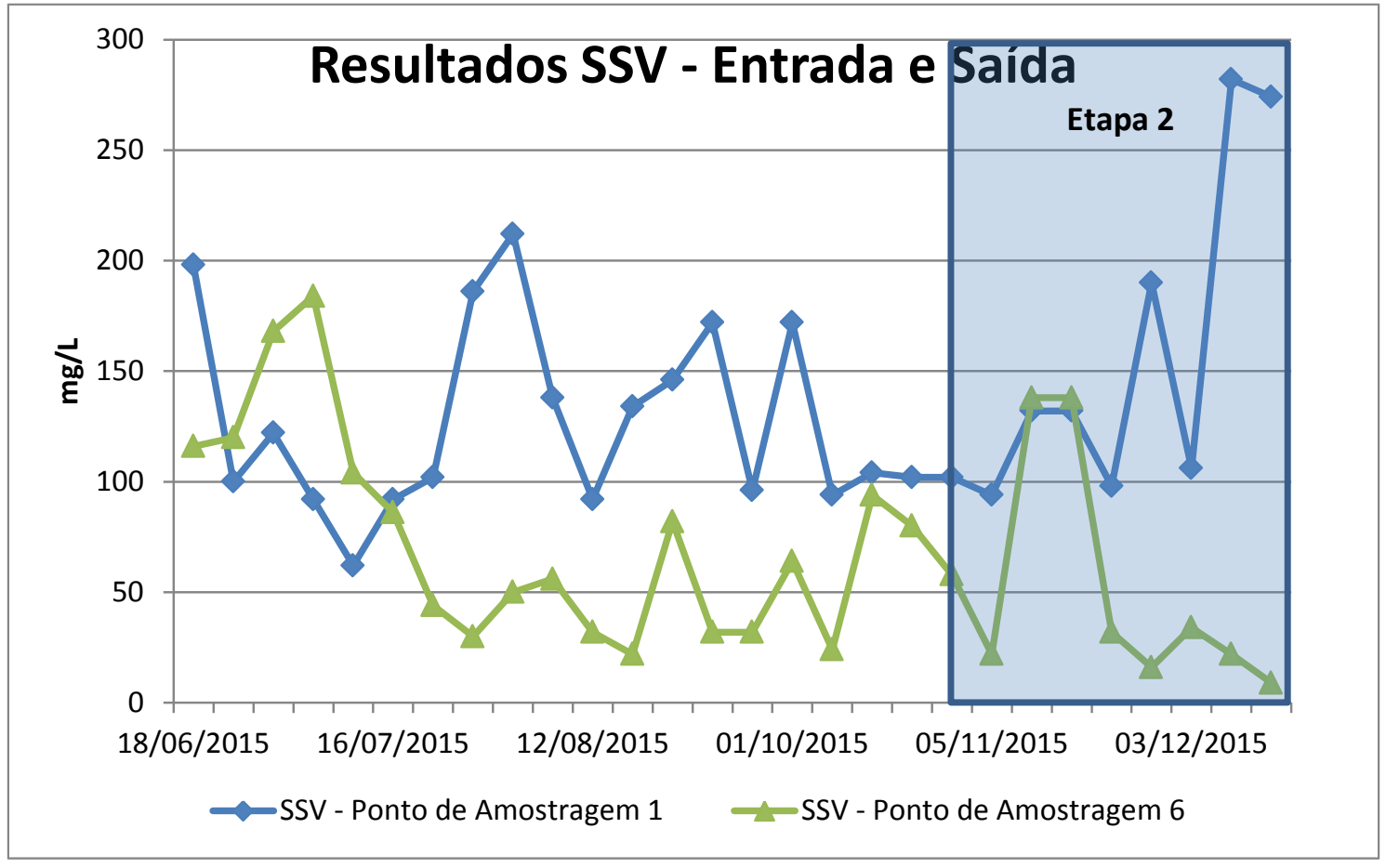

Fonte: Autor

Figura 63 - Gráfico da série histórica para SSV no tanque de aeração e lodo

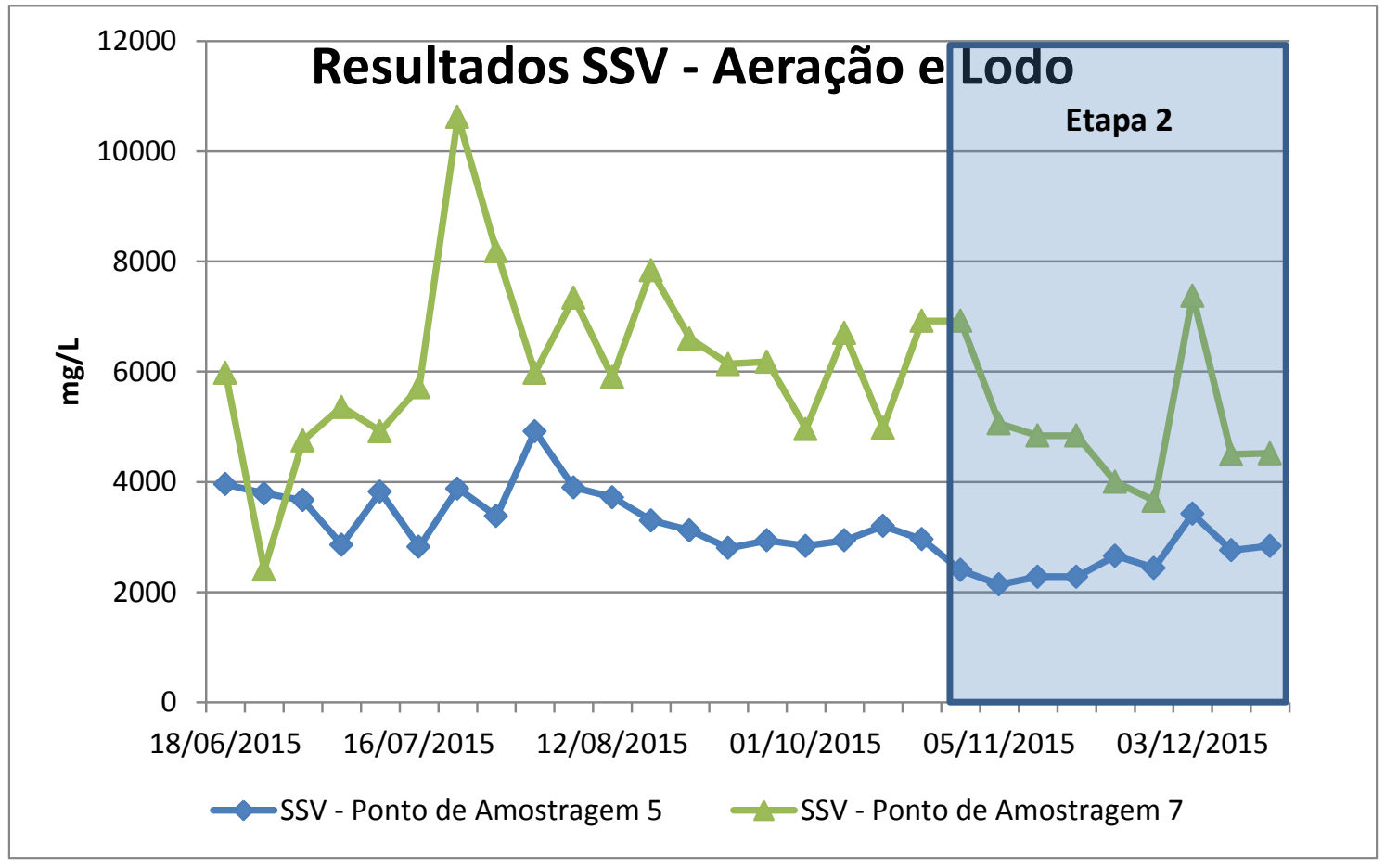

Fonte: Autor 
Durante operação da planta piloto ocorreram diversos problemas com o raspador de lodo do decantador secundário, tanto por questões de quebra quanto de alta velocidade de rotação, o que comprometia a separação sólido líquido nesta fase do processo. Optou-se pela operação manual (duas vezes ao dia) deste raspador de modo a se evitar fugas de sólidos. No entanto, observou-se um constante arraste de sólidos para o efluente final, acredita-se que este arraste possa ter ocorrido pela má funcionalidade deste raspador, ou pela geração de lodo floculento, ou ainda por uma potencial desnitrificação no decantador secundário. Desta forma, para as análises de matéria orgânica serão preferencialmente utilizadas as parcelas solúveis em detrimento às parcelas particuladas.

\subsubsection{Caracterização e análise do lodo}

Qualquer sistema de tratamento de águas residuárias com remoção biológica de fósforo tem por característica básica a remoção de fósforo pelo lodo retirado do sistema. Desta forma, é muito importante para avaliar a presença e formação preferencial de organismos poli-P verificar a composição do lodo gerado pelo sistema.

Segundo SANTOS (2014) existem 5 fatores que podem evidenciar a presença de PAOs (ou poli-P) em um sistema de tratamento de esgotos biológico. Serão apresentados nos itens 5.3.2.1 a 5.3.2.5 estes fatores e seus respectivos valores de referência.

\subsubsection{Razão entre a concentração de fósforo liberado no meio líquido por DQO capturada por organismos PAO}

Para a câmara anaeróbia, onde ocorre a liberação de fósforo, a captura de DQO pelas poli-P diversos autores determinam um parâmetro de referência de $0,5 \mathrm{mg} P$ Liberado/mg DQO Sequestrada (VAN HAANDEL; MARAIS, 1999; VAN HAANDEL; VAN DER LUBBE, 2012; BASSIN, 2012 apud SANTOS, 2014).

Pelo balanço de massa e resultados das análises físico-químicas das Etapas 1 e 2 no reator anaeróbio este parâmetro é de $0,12 \mathrm{mg} \mathrm{P}$ total Liberado/mg DQO Sequestrada para a Etapa 1 e 0,19 mg P liberado/mg DQO Sequestrada para a Etapa 2.

Alguns outros autores (NOBREGA, 2009 e BASSIN, 2012 apud SANTOS, 2014) demonstraram que este coeficiente varia muito em função da temperatura e os 
resultados obtidos por estes são de 0,26 mg P/mg DQO (NOBREGA, 2009) e 0,22 mg P/mg DQO (BASSIN, 2012).

BASSIN (2012) ainda demonstrou que para seu sistema para uma temperatura de $30^{\circ} \mathrm{C}$ obteve um valor de $0,22 \mathrm{mg} \mathrm{P} / \mathrm{mg}$ DQO e $0,37 \mathrm{mg}$ P/mg DQO para uma temperatura de $20^{\circ} \mathrm{C}$

\subsubsection{Relação entre as taxas de consumo de oxigênio}

Trata-se da relação entre as taxas de consumo de oxigênio e quanto mais próxima esta taxa de 1, mais se prevê predominância de PAOs, já que se trata do único grupo que pode utilizar qualquer desses substratos de forma similar (OHEMEN et al., 2005; 2006).

Pelo fato desta pesquisa não ter realizado as análises de respirometria necessárias para avaliação deste fator não será abordado este tema.

\subsubsection{Fósforo no lodo}

SANTOS (2014) determina uma metodologia para avaliação da concentração de fósforo no lodo. Este procedimento consiste na retirada de uma amostra de licor misto no tanque de aeração, centrifugação por $20 \mathrm{~min}$ a $2500 \mathrm{rpm}$ e substituindo o volume sobrenadante por água destilada. Após este tratamento preliminar deve ser realizado o procedimento para avaliação do fósforo total 4500 - P E proposto pela APHA et al (2012). Posteriormente este valor deveria ser dividido pela concentração de sólidos em suspensão voláteis do tanque de aeração o que corresponderia ao fósforo no lodo por unidade de peso do SSV. Segundo VAN HAANDEL; MARAIS (1999) este parâmetro de referência é de 38\%. Neste estudo as amostras de fósforo não seguiram esta metodologia, porém utilizando-se as diferenças entre fósforo total e fósforo solúvel no lodo pode-se ter uma base de comparação com os valores de referência. Para as situações de valores médios e máximos no presente estudo foram obtidos teores de fósforo no lodo entre $0,5 \%$ e $3 \%$ ao longo das duas etapas de experimentação.

\subsubsection{Relação entre sólidos voláteis e totais no lodo}

Segundo SANTOS (2014) a relação entre sólidos voláteis e sólidos totais no lodo indica a concentração de minerais no lodo. Segundo VAN HAANDEL; MARAIS (1999) lodos poli-p tem esta relação em torno de $46 \%$, lodos mistos 70 a $75 \%$ e acima de $80 \%$ para lodos ativados convencionais. 
Para a Etapa 1 de experimentação esta relação foi de $84 \%$ e para a Etapa 2 foi de $76 \%$ o que indica um sistema com lodos mistos.

\subsubsection{Relação entre fósforo liberado e concentração de sólidos no reator anaeróbio}

Para a Etapa 1 de experimentação este coeficiente foi de 0,0076 e para a Etapa 2 de experimentação 0,0080 .

BASSIN (2012) obteve valores de 0,01 para este parâmetro e OHEMEN (2004) obteve valores de 0,05 para este parâmetro. Já SANTOS (2014) obteve valores de 0,014 a 0,052 para sistemas com lodos PAO e 0,008 a 0,017 para lodos mistos.

\subsubsection{Discussão dos resultados obtidos para o lodo}

Pode-se notar que em nenhuma das etapas de experimentação foi observada a presença preferencial de lodo poli-P, sendo que na Etapa 1 de experimentação o lodo apresentou características de lodo misto assim como a Etapa 2 de experimentação. Este tipo de lodo é o mais comum nos sistemas em grandes escalas.

Os diversos autores que foram utilizados como base neste tópico do trabalho obtiveram bons resultados em termos de eficiência de remoção de fósforo, mesmo com lodos com características de lodos mistos e lodos com caracterização diferente das obtidas por VAN HAANDEL; MARAIS (1999). O presente trabalho se enquadra neste caso, uma vez que o efluente final tem concentrações de fósforo em torno de $2 \mathrm{mg} / \mathrm{L}$ e as temperaturas de operação da planta piloto foram em média $25,5{ }^{\circ} \mathrm{C}$ o que pode influenciar em muito a formação preferencial do lodo poli-P, conforme discutido previamente.

Com relação à formação de estruvita, por se tratar de um lodo misto, acredita-se que há um potencial aproveitamento deste lodo para formação de estruvita, uma vez que o lodo apresenta altas concentrações de fósforo tanto em sua forma solúvel quanto particulada. Os resultados em termos de concentrações de fósforo no lodo são semelhantes aos valores obtidos por SANTOS (2014), NÓBREGA (2009) e BASSIN (2012) que obtiveram fósforo total na faixa de $25-30 \mathrm{mg} / \mathrm{L}$ no lodo.

Logicamente, deverão ser procedidas alguns processos de tratamento para a posterior utilização deste lodo para a obtenção de estruvita. 


\subsection{Matéria Nitrogenada}

Para o quesito matéria nitrogenada serão analisados os parâmetros NTK, nitrogênio amoniacal e nitrato.

As tabelas 24 e 25 apresentam a estatística básica descritiva das duas etapas de experimentação para o NTK (nitrogênio total Kjeldahl).

Tabela 24 - Estatística Descritiva dos Resultados das Análises Físico-Químicas para NTK (mg N/L) - Etapa 1

\begin{tabular}{|l|c|c|c}
\hline \multicolumn{4}{|c}{ Nitrogênio Total Kjeldahl } \\
\hline Parâmetro & $\begin{array}{c}\text { Ponto } \\
\text { Amostragem } \\
\mathbf{1}\end{array}$ & $\begin{array}{c}\text { Ponto } \\
\text { Amostragem } \\
\mathbf{5}\end{array}$ & $\begin{array}{c}\text { Ponto } \\
\text { Amostragem } \\
\mathbf{6}\end{array}$ \\
\hline & & & \\
\hline Média & 88 & 380 & 39 \\
\hline Máximo & 116,2 & 557,2 & 96 \\
\hline Mínimo & 70 & 294 & 6 \\
\hline Mediana & 83 & 367 & 25 \\
\hline $\begin{array}{l}\text { Desvio } \\
\text { Padrão }\end{array}$ & 14 & 69 & 28 \\
\hline CV(\%) & $16 \%$ & $18 \%$ & $72 \%$ \\
\hline AT & 46,2 & 263 & 91 \\
\hline
\end{tabular}

Fonte: Autor

Tabela 25 - Estatística Descritiva dos Resultados das Análises Físico-Químicas para o parâmetro NTK - Etapa 2

\begin{tabular}{|c|c|c|c|}
\hline \multicolumn{4}{|c|}{ Nitrogênio Total Kjeldahl } \\
\hline Parâmetro & \begin{tabular}{|c} 
Ponto \\
Amostragem \\
1
\end{tabular} & $\begin{array}{c}\text { Ponto } \\
\text { Amostragem } \\
5\end{array}$ & $\begin{array}{c}\text { Ponto } \\
\text { Amostragem } \\
6\end{array}$ \\
\hline Média & 88 & 287 & 18 \\
\hline Máximo & 99 & 314 & 49 \\
\hline Mínimo & 67 & 241 & 6 \\
\hline Mediana & 94 & 293 & 10 \\
\hline $\begin{array}{l}\text { Desvio } \\
\text { Padrão }\end{array}$ & 12 & 25 & 17 \\
\hline CV(\%) & $14 \%$ & $9 \%$ & $95 \%$ \\
\hline AT & 32,2 & 73 & 43 \\
\hline
\end{tabular}

Fonte: Autor

As Figuras 64 e 65 apresentam os gráficos boxplot para NTK para as duas etapas de experimentação respectivamente. 
Figura 64 - Gráfico Boxplot para o parâmetro NTK - Etapa 1

\section{Gráfico Boxplot para NTK}

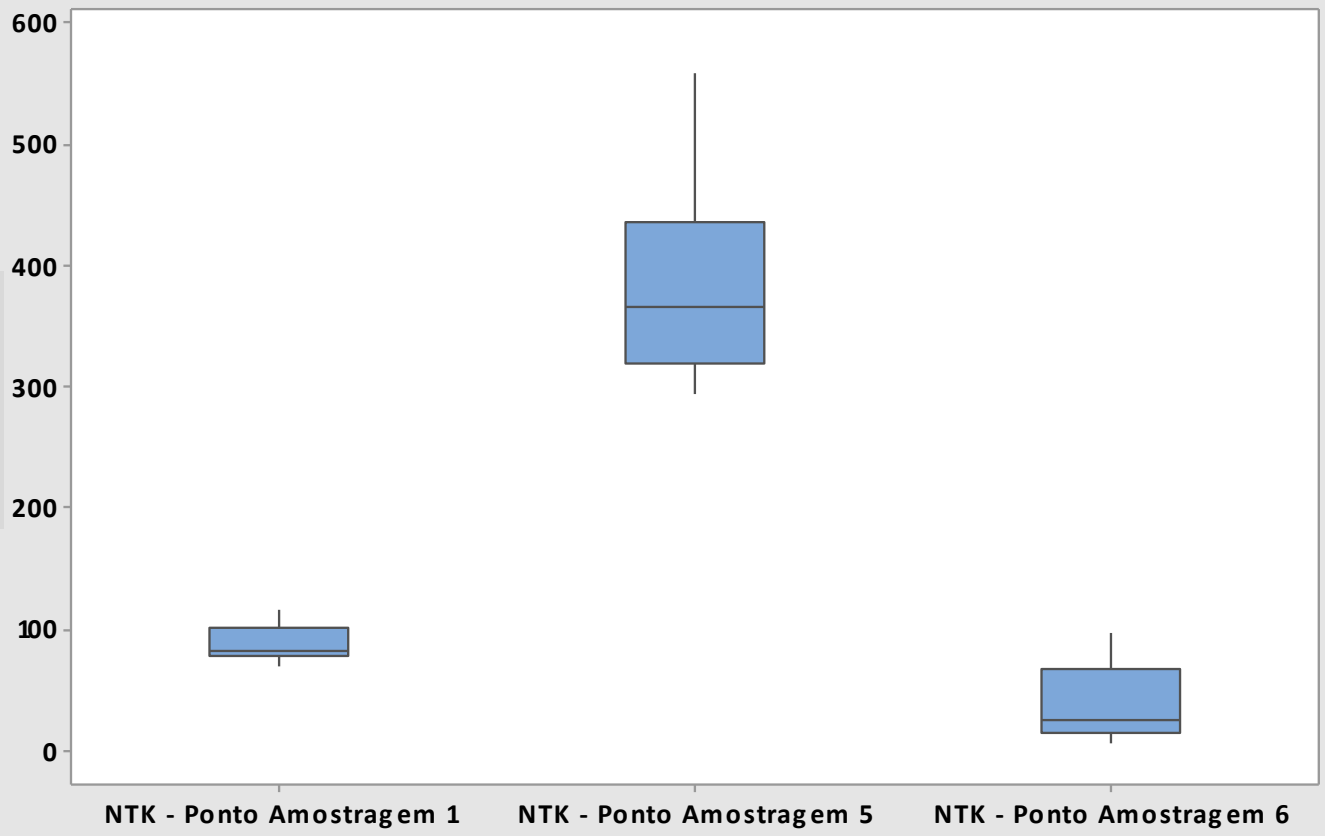

Figura 65 - Gráfico Boxplot para o parâmetro NTK - Etapa 2

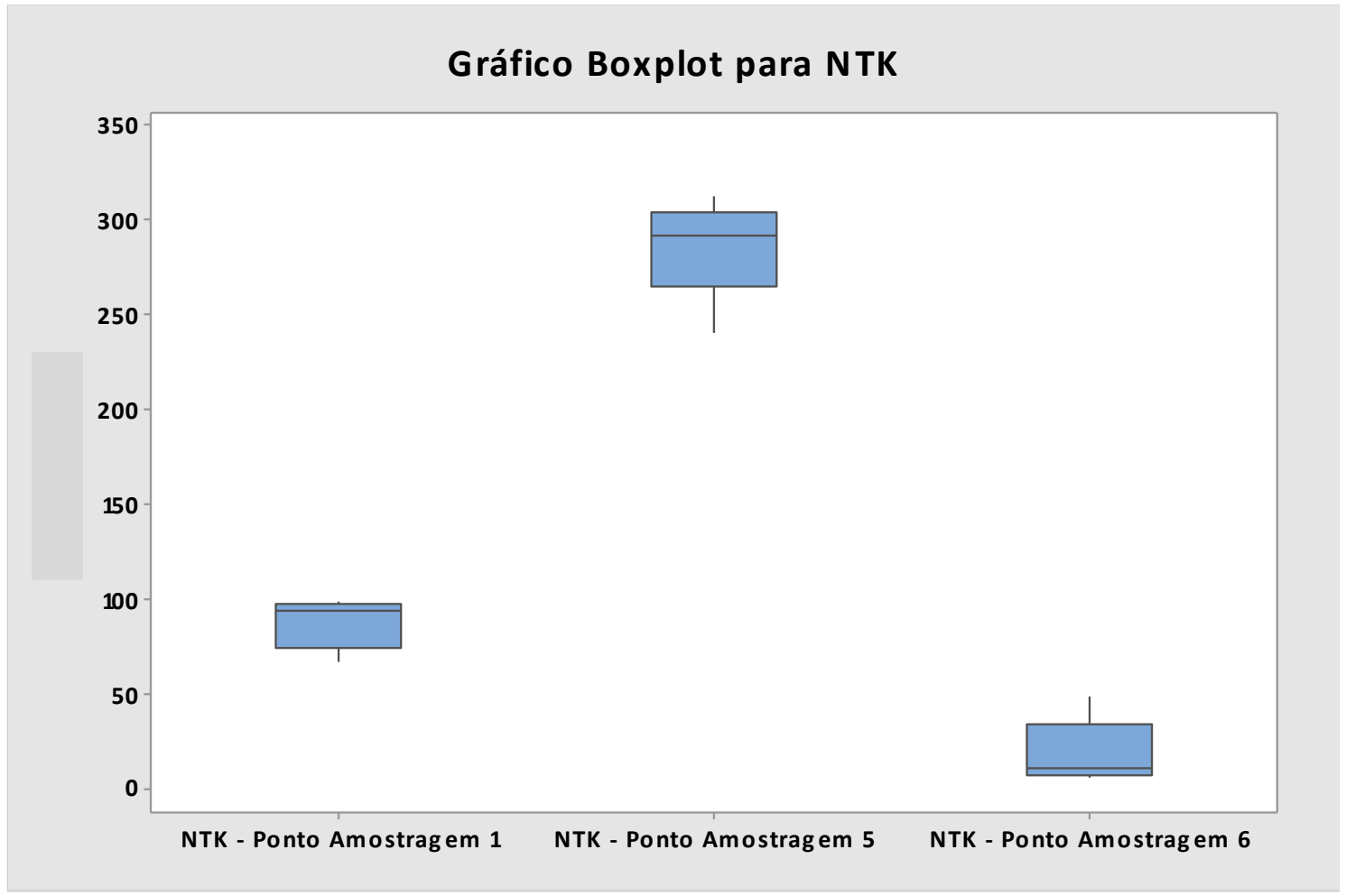

Fonte: Autor

A Figura 66 apresenta a série histórica para o parâmetro NTK. 
Figura 66 - Gráfico da série histórica para o parâmetro NTK

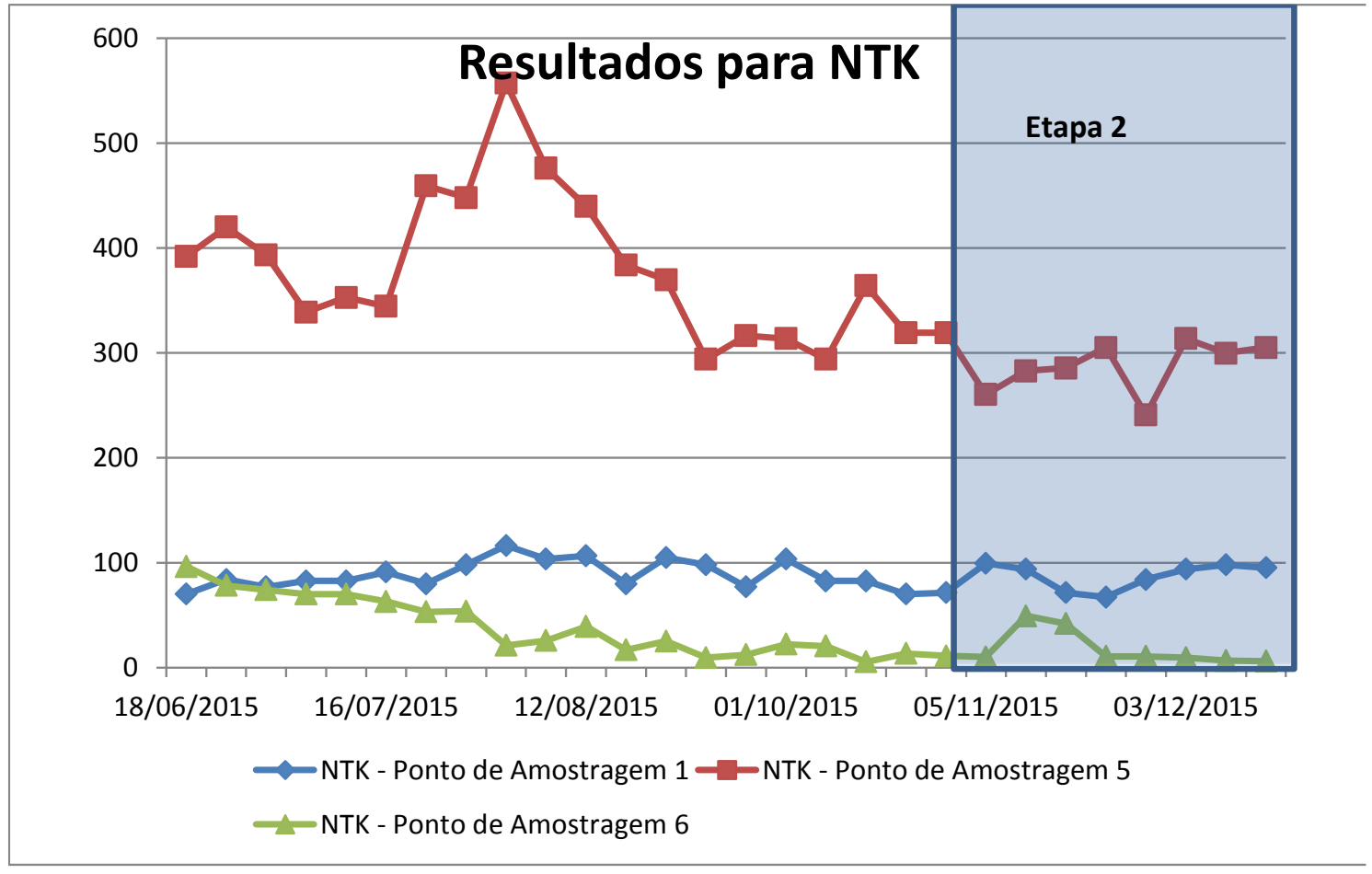

Fonte: Autor

Executando teste de hipóteses para a variável NTK no ponto de amostragem 1 e ponto de amostragem 6 para comparar seu comportamento durante as duas etapas de experimentação e considerando-se que uma distribuição T-student e nível de confiança de $95 \%$, as hipóteses para o parâmetro foram:

\section{H0: NTK Ponto Amostragem 1 - etapa $1=$ NTK Ponto Amostragem $1-$ etapa 2 (148A)}

H1: NTK Ponto Amostragem 1 - etapa 1 = NTK Ponto Amostragem 1 etapa 2 (148B)

\begin{tabular}{|c|c|c|}
\hline Valor de T & Graus de liberdade & Valor P \\
\hline 0,07 & 14 & 0,9416 \\
\hline
\end{tabular}

Aceita-se $\mathrm{H} 0$ e considera-se que as concentrações de entrada na planta piloto UCT modificado de NTK são iguais.

Já para o ponto de amostragem 6 (saída do sistema) os resultados obtidos foram: 
H0: NTK Ponto Amostrage 6 - etapa $1=$ NTK Ponto Amost $\square$ age $6-$ etapa 2 (149A)

H1: NTK Ponto Amostrage 6 - etapa $1 \neq$ NTK Ponto Amostrage 6 - etapa 2 (149B)

\begin{tabular}{|c|c|c|}
\hline Valor de $\mathbf{T}$ & Graus de liberdade & Valor P \\
\hline 2,39 & 21 & 0,2161 \\
\hline
\end{tabular}

Neste caso rejeita-se H0 e considera-se que os nitrogênio NTK de saída do sistema na etapa 2 de experimentação foi menor do que o NTK de saída da etapa 1 de experimentação. Em conjunto com os dados de Nitrito, ORP e pH (que se estabilizaram na etapa 2 de experimentação) do tanque de aeração pode-se inferir que houve uma melhora na nitrificação e desnitrificação na etapa 2 de experimentação.

Para o parâmetro Nitrogênio amoniacal as tabelas 26 e 27 apresentam os resultados da estatística básica descritiva.

Tabela 26 - Estatística Descritiva dos Resultados das Análises Físico-Químicas para Nitrogênio Amoniacal -

Etapa 1

\begin{tabular}{|l|c|c|c|}
\hline \multirow{4}{*}{ Parâmetro } & $\begin{array}{c}\text { Ponto } \\
\text { Amostragemênio Amoniacal }\end{array}$ & $\begin{array}{c}\text { Ponto } \\
\text { Amostragem }\end{array}$ & $\begin{array}{c}\text { Ponto } \\
\text { Amostragem }\end{array}$ \\
& $\mathbf{1}$ & $\mathbf{5}$ & $\mathbf{6}$ \\
\cline { 2 - 4 } & $\mathrm{mgN-NH4+/L}$ & $\mathrm{mgN}-\mathrm{NH} 4+/ \mathrm{L}$ & $\mathrm{mgN}-\mathrm{NH} 4+/ \mathrm{L}$ \\
\hline Média & 68 & 52 & 27 \\
\hline Máximo & 95 & 69 & 66 \\
\hline Mínimo & 27 & 24 & 1 \\
\hline Mediana & 68 & 55 & 19 \\
\hline Desvio & & & \\
Padrão & 15 & 12 & 22 \\
\hline CV(\%) & $21 \%$ & $23 \%$ & $81 \%$ \\
\hline AT & 68 & 45 & 65 \\
\hline
\end{tabular}

Fonte: Autor 
Tabela 27 - Estatística Descritiva dos Resultados das Análises Físico-Químicas para o Parâmetro Nitrogênio Amoniacal - Etapa 2

\begin{tabular}{|l|c|c|}
\hline \multicolumn{3}{|c|}{ Nitrogênio Amoniacal } \\
\hline Parâmetro & $\begin{array}{c}\text { Ponto } \\
\text { Amostragem }\end{array}$ & $\begin{array}{c}\text { Ponto } \\
\text { Amostragem } \\
\mathbf{1}\end{array}$ \\
\hline & mgN-NH4+/L & mgN-NH4+/L \\
\hline Média & 76 & 6 \\
\hline Máximo & 83 & 23 \\
\hline Mínimo & 64 & 0 \\
\hline Mediana & 78 & 1 \\
\hline Desvio & & \\
Padrão & 6 & 10 \\
\hline CV(\%) & $8 \%$ & $163 \%$ \\
\hline AT & 18,2 & 22,68 \\
\hline
\end{tabular}

Fonte: Autor

As Figuras 67 e 68 apresentam os gráficos boxplot para nitrogênio amoniacal nas etapas de experimentação.

Figura 67 - Gráfico Boxplot para o parâmetro Nitrogênio Amoniacal - Etapa 1

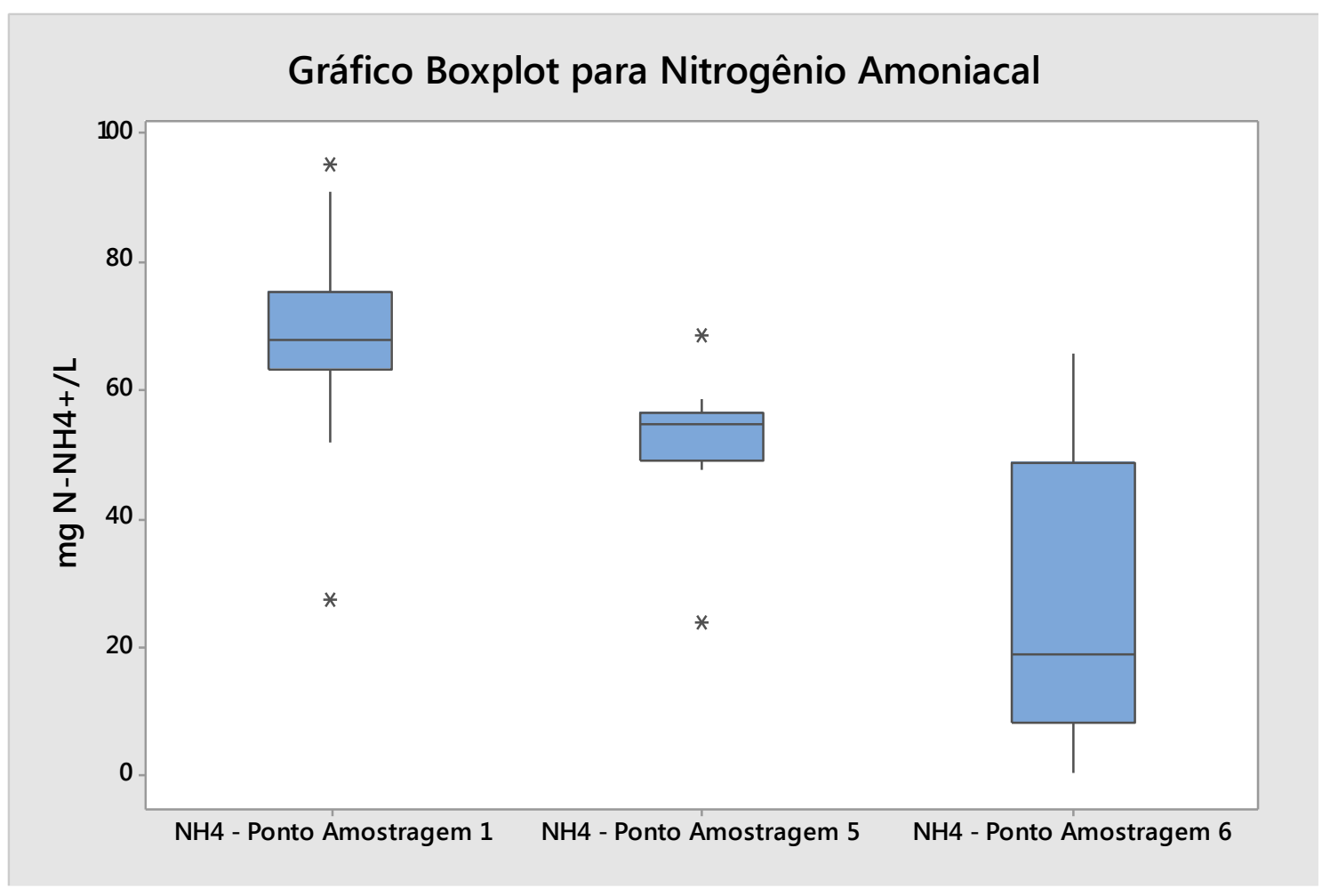

Fonte: Autor 
Figura 68 - Gráfico Boxplot para o parâmetro Nitrogênio Amoniacal - Etapa 2

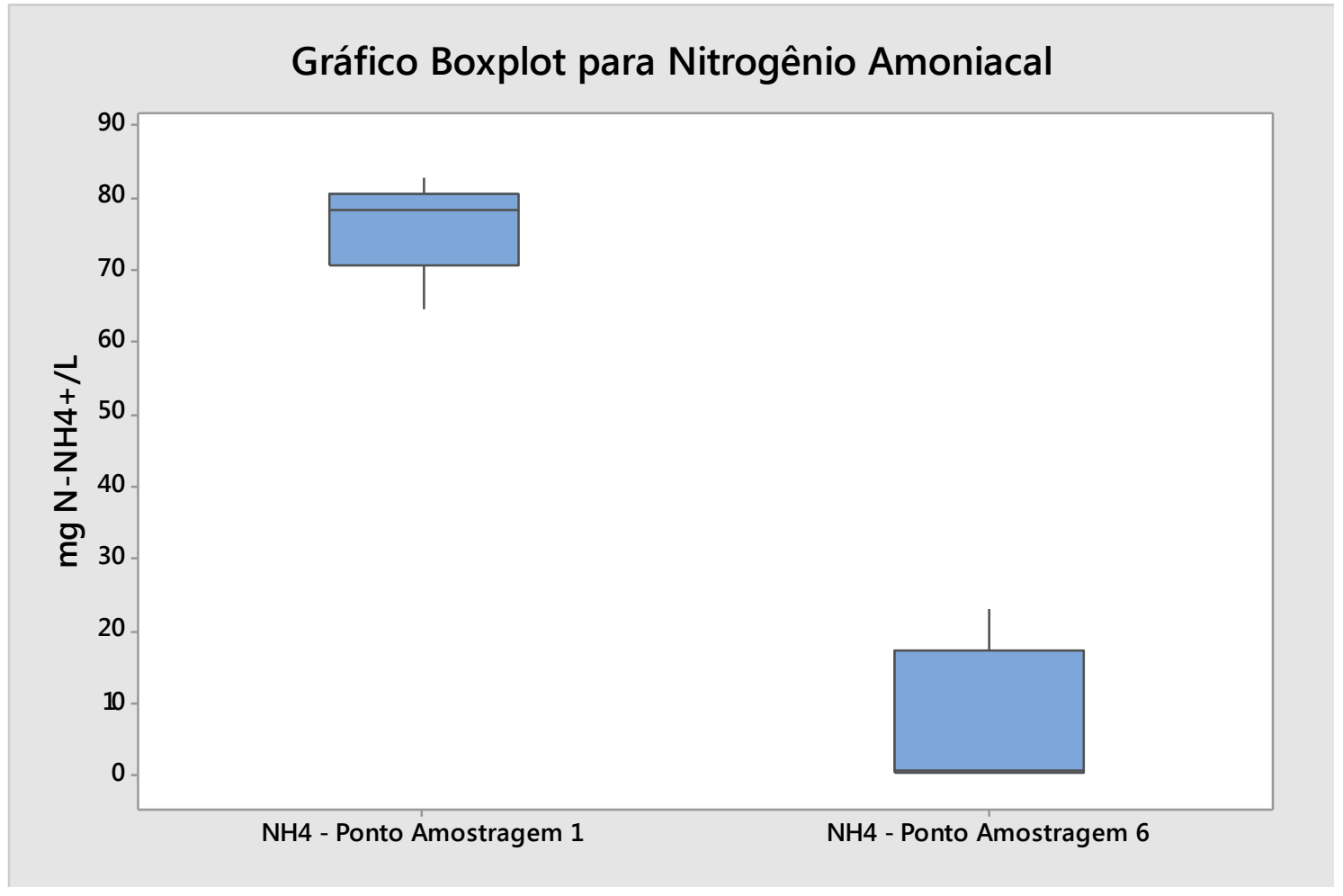

Fonte: Autor

A Figura 69 apresenta a série histórica para este parâmetro. Realizou-se testes de hipóteses para avaliar os resultados deste parâmetro durante as duas etapas de experimentação, considerando-se uma distribuição T-student e nível de confiança de $95 \%$.

Figura 69 - Gráfico da série histórica para Nitrogênio Amoniacal

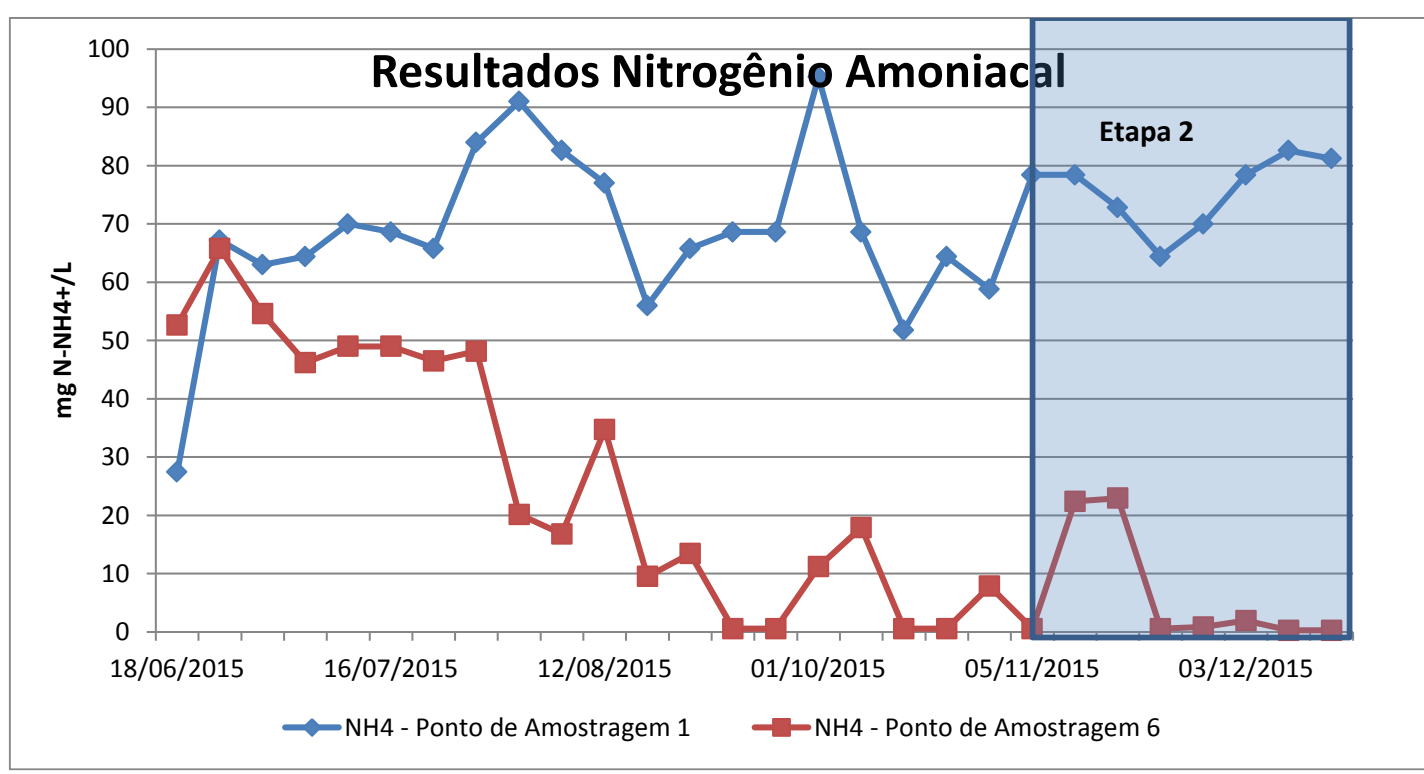

Fonte: Autor 
H0: Nitrogênio Amoniacal Ponto Amostragem 1 - etapa $1=$ Nitrogênio Amoniacal Ponto Amostragem 1 - etapa 2 (150A)

H1: Nitrogênio Amoniacal Ponto Amostragem 1 - etapa $1 \neq$ Nitrogênio Amoniacal Ponto Amostragem 1 - etapa 2 (150B)

\begin{tabular}{|c|c|c|}
\hline Valor de $\mathbf{T}$ & Graus de liberdade & Valor P \\
\hline$-1,93$ & 25 & 0,0647 \\
\hline
\end{tabular}

Neste caso aceita-se H0 e pode-se considerar que o Nitrogênio amoniacal na entrada do sistema teve as mesmas características ao longo do experimento.

H0: Nitrogênio Amoniacal Ponto Amostragem 6 - etapa $1=$ Nitrogênio Amoniacal Ponto Amostragem 6 - etapa 2 (151A)

H1: Nitrogênio Amoniacal Ponto Amostragem 6 - etapa 1 = Nitrogênio Amoniacal Ponto Amostragem 6 - etapa 2 (151B)

\begin{tabular}{|c|c|c|}
\hline Valor de T & Graus de liberdade & Valor P \\
\hline 3,48 & 25 & 0,0019 \\
\hline Neste caso rejeita-se H0 e considera-se que o efluente final na etapa 2 de
\end{tabular}

experimentação teve resultados menores em termos de Nitrogênio amoniacal.

Desta forma, os resultados obtidos mostram que houve uma melhora no resultado do efluente final em termos de Nitrogênio amoniacal e total, o que sugere uma melhora no processo de nitrificação.

Com relação aos resultados de nitrato, ressalta-se que os resultados apresentados neste trabalho para o parâmetro Nitrato foram realizados apenas em laboratório externo (Foi utilizado o laboratório do IPEN - Instituto de Pesquisas Energéticas e Nucleares uma vez que as análises realizadas no cromatógrafo de íons do laboratório de Saneamento do Departamento de Engenharia Civil da Poli-USP apresentou resultados que deixaram dúvidas quanto à precisão do equipamento). As Tabelas 28 e 29 apresentam os resultados da estatística descritiva para Nitrato obtidos para este experimento. 
Tabela 28 - Resultados da estatística descritiva para o parâmetro Nitrato - Etapa 1

\begin{tabular}{|l|c|c|c|c|c|c}
\hline \multirow{2}{*}{ Parâmetro } & \multicolumn{7}{|c}{ Nitrato (mgN/L) } \\
\cline { 2 - 7 } & $\begin{array}{c}\text { Ponto } \\
\text { Amostragem 2 }\end{array}$ & $\begin{array}{c}\text { Ponto } \\
\text { Amostragem 3 }\end{array}$ & $\begin{array}{c}\text { Ponto } \\
\text { Amostragem 4 }\end{array}$ & $\begin{array}{c}\text { Ponto } \\
\text { Amostragem 5 }\end{array}$ & $\begin{array}{c}\text { Ponto } \\
\text { Amostragem 6 }\end{array}$ & $\begin{array}{c}\text { Ponto } \\
\text { Amostragem 7 }\end{array}$ \\
\hline Média & 5 & 8 & 6 & 11 & 19 & 4 \\
\hline Máximo & 18 & 15 & 14 & 21 & 70 & 6 \\
\hline Mínimo & 0 & 0 & 0 & 4 & 6 & 1 \\
\hline Mediana & 4 & 10 & 5 & 10 & 11 & 4 \\
\hline $\begin{array}{l}\text { Desvio } \\
\text { Padrão }\end{array}$ & 7 & 6 & 5 & 5 & 19 & 3 \\
\hline CV(\%) & $137 \%$ & $75 \%$ & $89 \%$ & $47 \%$ & $102 \%$ & $69 \%$ \\
\hline AT & 18 & 15 & 14 & 17 & 64 & 6 \\
\hline
\end{tabular}

Fonte: Autor

Tabela 29 - Resultados da estatística descritiva para o parâmetro Nitrato - Etapa 2

\begin{tabular}{|l|c|c|c|c|c|c}
\hline \multirow{2}{*}{ Parâmetro } & $\begin{array}{c}\text { Nitrato (mgN/L) } \\
\text { Amostrag } \\
\text { em 2 }\end{array}$ & $\begin{array}{c}\text { Ponto } \\
\text { Amostrag } \\
\text { em 3 }\end{array}$ & $\begin{array}{c}\text { Ponto } \\
\text { Amostrag } \\
\text { em 4 }\end{array}$ & $\begin{array}{c}\text { Ponto } \\
\text { Amostrag } \\
\text { em 5 }\end{array}$ & $\begin{array}{c}\text { Ponto } \\
\text { Amostrag } \\
\text { em 6 }\end{array}$ & $\begin{array}{c}\text { Ponto } \\
\text { Amostrag } \\
\text { em 7 }\end{array}$ \\
\hline Média & 0 & 1 & 2 & 9 & 9 & 8 \\
\hline Máximo & 2 & 4 & 4 & 12 & 15 & 17 \\
\hline Mínimo & 0 & 0 & 0 & 6 & 6 & 0 \\
\hline Mediana & 0 & 0 & 1 & 9 & 8 & 8 \\
\hline $\begin{array}{l}\text { Desvio } \\
\text { Padrão }\end{array}$ & 1 & 2 & 2 & 3 & 4 & 7 \\
\hline CV(\%) & $158 \%$ & $160 \%$ & $107 \%$ & $28 \%$ & $43 \%$ & $83 \%$ \\
\hline AT & 2 & 4 & 4 & 6 & 9 & 16 \\
\hline
\end{tabular}

Fonte: Autor

Pelas médias de Nitrato no efluente final, pode-se sugerir que estas tiveram uma tendência a se manter constante durante as duas etapas de experimentação.

De acordo com o modelo teórico apresentado no item 5.1 deste trabalho, estima-se que a concentração de nitrato no efluente em um sistema UCT Modificado com as características operacionais e construtivas da planta piloto deste trabalho seja da ordem de $30 \mathrm{mg} / \mathrm{L}$. No entanto, as análises mostraram que as concentrações de nitrato no efluente seja de aproximadamente $10 \mathrm{mg} / \mathrm{L}$ o que sugere que o processo de desnitrificação na planta piloto estudada tenha tido desempenho superior com a microaeração e com a divisão da câmara anaeróbia com chicanas.

Pelos dados obtidos pelo balanço de massa, as eficiências de remoção de nitrogênio total nas fases 1 e 2 variaram de $55 \%$ para $79 \%$. Adicionalmente segundo teste de hipóteses realizado para comparar diferenças nas concentrações de nitrogênio amoniacal no efluente final mostram que as concentrações para a fase 2 (microaeração das câmaras anóxicas) foram menores do que as concentrações aferidas na fase 1. 
De acordo com SANTOS (2014), em situações onde há um aumento na fonte de substrato (matéria orgânica) do sistema pode-se gerar condições melhores para o desenvolvimento de microrganismos nitrificantes. Isso se deve pelo fato de os microrganismos heterotróficos serem predominantes e aumentos na concentração de substrato podem gerar uma consequente melhor agregação de biomassa nitrificante. Desta forma, a variação nas eficiências de remoção de nitrogênio amoniacal pode ter sido afetada pelo aumento na concentração destes microrganismos.

Durante a fase 1 de experimentação foram observadas formações de microbolhas no decantador secundário, sugestivamente geradas por uma desnitrificação neste compartimento, o que ocasionou problemas de arraste de sólidos junto ao efluente final. Este problema foi minimizado na fase 2 de experimentação, o que pode ser um indicador da melhora no processo de nitrificação e desnitrificação na planta como um todo.

SANTOS (2014) obteve para uma idade de lodo de 20 dias em um reator UCT médias de NTK afluente de 47 a $67 \mathrm{mg}$ N/L e efluentes com 2 a $27 \mathrm{mg}$ N/L (eficiências de processo de $42 \%$ a $96 \%$ ).

Segundo VAN HAANDEL (1999), pode-se calcular o valor da fração recuperada de material nitrogenado como sendo:

$$
\begin{gathered}
B_{n}=(\text { Fluxo de material nitrogenado no lodo }+ \\
\text { Fluxo de material nitrogenado no efluente }+ \\
\text { Fluxo de material Desnitrificado) / } \\
(\text { Fluxo de material nitrogenado no afluente) (152) }
\end{gathered}
$$

Na Tabela 30 são apresentados os dados obtidos para esta variável durante etapas de experimentação. 
Tabela 30 - - Coeficiente de Recuperação de matéria nitrogenada (Bn) para as duas fases de experimentação

\begin{tabular}{|c|c|c|c|c|c}
\hline \multirow{2}{*}{ Data } & MNTa & MNTI & MNd & MNTe & \multirow{2}{*}{ BN } \\
\cline { 2 - 4 } & $\mathrm{mg} / \mathrm{d}$ & $\mathrm{mg} / \mathrm{d}$ & $\mathrm{mg} / \mathrm{d}$ & $\mathrm{mg} / \mathrm{d}$ & \\
\hline $18 / 06 / 15$ & 161280 & 72600 & 39997 & 121283 & $\mathbf{1 , 5}$ \\
\hline $26 / 06 / 15$ & 217728 & 69483 & 47174 & 170554 & $\mathbf{1 , 3}$ \\
\hline $29 / 06 / 15$ & 199584 & 67283 & 58061 & 141523 & $\mathbf{1 , 3}$ \\
\hline $02 / 07 / 15$ & 214099 & 52433 & 94349 & 119750 & $\mathbf{1 , 2}$ \\
\hline $07 / 07 / 15$ & 195068 & 70033 & 79350 & 115718 & $\mathbf{1 , 4}$ \\
\hline $16 / 07 / 15$ & 235872 & 51700 & 108864 & 127008 & $\mathbf{1 , 2}$ \\
\hline $21 / 07 / 15$ & 206842 & 71133 & 86365 & 120476 & $\mathbf{1 , 3}$ \\
\hline $30 / 07 / 15$ & 225792 & 61967 & 114831 & 110961 & $\mathbf{1 , 3}$ \\
\hline $05 / 08 / 15$ & 267725 & 90200 & 221276 & 46449 & $\mathbf{1 , 3}$ \\
\hline $07 / 08 / 15$ & 238694 & 71500 & 199987 & 38707 & $\mathbf{1 , 3}$ \\
\hline $12 / 08 / 15$ & 245146 & 68200 & 165151 & 79995 & $\mathbf{1 , 3}$ \\
\hline $01 / 09 / 15$ & 160877 & 60500 & 141684 & 19192 & $\mathbf{1 , 4}$ \\
\hline $03 / 09 / 15$ & 211680 & 57200 & 184585 & 27095 & $\mathbf{1 , 3}$ \\
\hline $10 / 09 / 15$ & 225792 & 51333 & 175196 & 50596 & $\mathbf{1 , 2}$ \\
\hline $17 / 09 / 15$ & 177408 & 53900 & 125891 & 51517 & $\mathbf{1 , 3}$ \\
\hline $01 / 10 / 15$ & 208858 & 52067 & 174586 & 34272 & $\mathbf{1 , 2}$ \\
\hline $08 / 10 / 15$ & 214099 & 53900 & -13789 & 227889 & $\mathbf{1 , 3}$ \\
\hline $15 / 10 / 15$ & 214099 & 58667 & 196318 & 17781 & $\mathbf{1 , 3}$ \\
\hline $22 / 10 / 15$ & 161280 & 54267 & 134185 & 27095 & $\mathbf{1 , 3}$ \\
\hline $27 / 10 / 15$ & 197407 & 44000 & 145318 & 52089 & $\mathbf{1 , 2}$ \\
\hline $05 / 11 / 15$ & 257645 & 39233 & 228977 & 28668 & $\mathbf{1 , 2}$ \\
\hline $10 / 11 / 15$ & 243130 & 41800 & 185069 & 58061 & $\mathbf{1 , 2}$ \\
\hline $12 / 11 / 15$ & 185069 & 41800 & 108708 & 76360 & $\mathbf{1 , 2}$ \\
\hline $19 / 11 / 15$ & 154829 & 48767 & 138793 & 16036 & $\mathbf{1 , 3}$ \\
\hline $26 / 11 / 15$ & 212890 & 44733 & 185670 & 27219 & $\mathbf{1 , 2}$ \\
\hline $03 / 12 / 15$ & 232324 & 62700 & 190317 & 42007 & $\mathbf{1 , 3}$ \\
\hline $08 / 12 / 15$ & 282240 & 50600 & 281434 & 806 & $\mathbf{1 , 2}$ \\
\hline $10 / 12 / 15$ & 274176 & 52067 & 273370 & 806 & $\mathbf{1 , 2}$ \\
\hline & & & & & \\
\hline
\end{tabular}

Fonte: Autor

Pode-se observar que pelo balanço de matéria nitrogenada os resultados para a etapa 2 de experimentação foram ligeiramente melhores do que os resultados para a Etapa 1 de Experimentação. Pode-se observar ainda um maior fluxo de matéria desnitrificada na Etapa 2 de experimentação o que contribuiu para a melhora em geral deste processo.

\subsubsection{Alcalinidade}

Análise essencial na avaliação da remoção biológica de nitrogênio e estabilidade do processo é a análise da alcalinidade no processo. As tabelas 31 e 32 apresentam os resultados estatísticos para o parâmetro alcalinidade. 
Tabela 31 - Estatística Descritiva dos Resultados das Análises Físico-Químicas para o Parâmetro Alcalinidade - Etapa 1

\begin{tabular}{|c|c|c|c|c|c|c|c|}
\hline \multicolumn{8}{|c|}{ Alcalinidade } \\
\hline \multirow[t]{2}{*}{ Parâmetro } & $\begin{array}{c}\text { Ponto } \\
\text { Amostragem } \\
1\end{array}$ & $\begin{array}{c}\text { Ponto } \\
\text { Amostragem } \\
2\end{array}$ & \begin{tabular}{|c|} 
Ponto \\
Amostragem \\
3
\end{tabular} & \begin{tabular}{|c} 
Ponto \\
Amostragem \\
4
\end{tabular} & $\begin{array}{c}\text { Ponto } \\
\text { Amostragem } \\
5\end{array}$ & $\begin{array}{c}\text { Ponto } \\
\text { Amostragem } \\
6\end{array}$ & \begin{tabular}{|c} 
Ponto \\
Amostragem \\
7
\end{tabular} \\
\hline & $\mathrm{mgCaCO} 3 / \mathrm{L}$ & $\mathrm{mgCaCO} 3 / \mathrm{L}$ & $\mathrm{mgCaCO} 3 / \mathrm{L}$ & $\mathrm{mgCaCO} 3 / \mathrm{L}$ & $\mathrm{mgCaCO} 3 / \mathrm{L}$ & $\mathrm{mgCaCO} 3 / \mathrm{L}$ & $\mathrm{mgCaCO} 3 / \mathrm{L}$ \\
\hline Média & 283 & 33 & 34 & 33 & 31 & 27 & 32 \\
\hline Máximo & 344 & 36 & 35 & 35 & 36 & 30 & 34 \\
\hline Mínimo & 236 & 31 & 33 & 30 & 28 & 24 & 29 \\
\hline Mediana & 273 & 312 & 275 & 241 & 194 & 145 & 226 \\
\hline \begin{tabular}{|l|} 
Desvio \\
Padrão \\
\end{tabular} & 34 & 2 & 1 & 2 & 3 & 2 & 2 \\
\hline CV(\%) & $12 \%$ & $6 \%$ & $4 \%$ & $5 \%$ & $10 \%$ & $8 \%$ & $5 \%$ \\
\hline AT & 108,0 & 5,0 & 2,6 & 5,0 & 8,0 & 6,0 & 5,0 \\
\hline
\end{tabular}

Fonte: Autor

Tabela 32 - Resultados das Análises Físico-Químicas para o Parâmetro Alcalinidade - Etapa 2

\begin{tabular}{|c|c|c|c|c|c|c|c|}
\hline \multicolumn{8}{|c|}{ Alcalinidade } \\
\hline \multirow[t]{2}{*}{ Parâmetro } & $\begin{array}{c}\text { Ponto } \\
\text { Amostragem } \\
1\end{array}$ & \begin{tabular}{|c|} 
Ponto \\
Amostragem \\
2
\end{tabular} & \begin{tabular}{|c|} 
Ponto \\
Amostragem \\
3
\end{tabular} & \begin{tabular}{|c|} 
Ponto \\
Amostragem \\
4
\end{tabular} & \begin{tabular}{|c|} 
Ponto \\
Amostragem \\
5
\end{tabular} & $\begin{array}{c}\text { Ponto } \\
\text { Amostragem } \\
6\end{array}$ & $\begin{array}{c}\text { Ponto } \\
\text { Amostragem } \\
7\end{array}$ \\
\hline & $\mathrm{mgCaCO} 3 / \mathrm{L}$ & $\mathrm{mgCaCO} 3 / \mathrm{L}$ & $\mathrm{mgCaCO} 3 / \mathrm{L}$ & $\mathrm{mgCaCO} / \mathrm{L}$ & $\mathrm{mgCaCO} 3 / \mathrm{L}$ & $\mathrm{mgCaCO} 3 / \mathrm{L}$ & $\mathrm{mgCaCO} / \mathrm{L}$ \\
\hline Média & 275 & 266 & 222 & 197 & 125 & 84 & 173 \\
\hline Máximo & 316 & 392 & 284 & 266 & 200 & 140 & 232 \\
\hline Mínimo & 212 & 132 & 110 & 116 & 82 & 56 & 114 \\
\hline Mediana & 279 & 280 & 232 & 192 & 103 & 70 & 171 \\
\hline $\begin{array}{l}\text { Desvio } \\
\text { Padrão }\end{array}$ & 37,0 & 83,4 & 66,4 & 54,6 & 47,1 & 35,1 & 43,2 \\
\hline $\mathrm{CV}(\%)$ & $13 \%$ & $31 \%$ & $30 \%$ & $28 \%$ & $38 \%$ & $42 \%$ & $25 \%$ \\
\hline AT & 104,0 & 260,0 & 174,0 & 150,4 & 118,0 & 84,0 & 118,0 \\
\hline
\end{tabular}

Fonte: Autor

As figuras 70 e 71 apresentam os gráficos boxplot para alcalinidade das etapas 1 e 2 de experimentação, respectivamente. 
Figura 70 - Gráfico Boxplot para o parâmetro Alcalinidade - Etapa 1

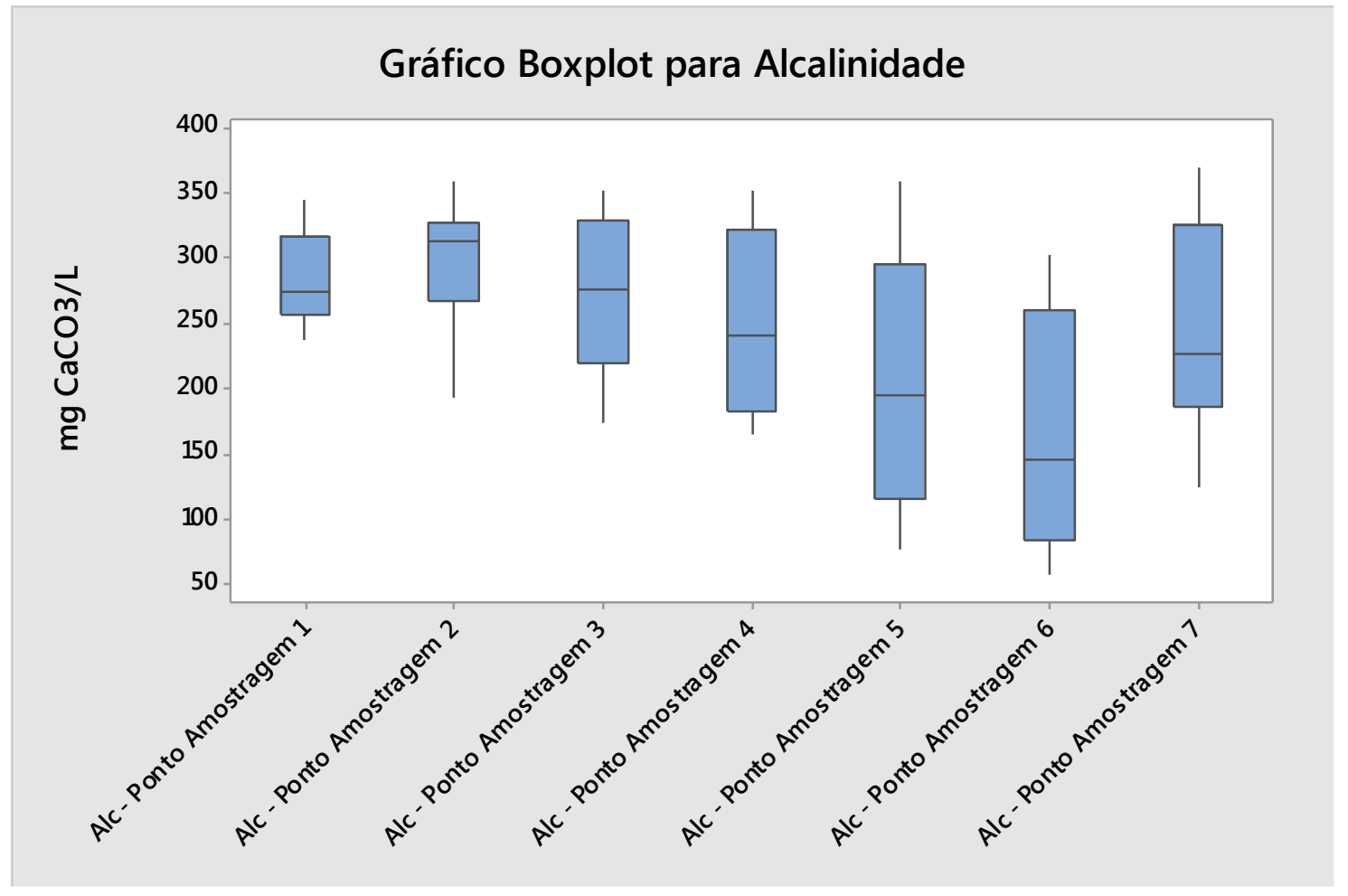

Fonte: Autor

Figura 71 - Gráfico Boxplot para o parâmetro Alcalinidade - Etapa 2

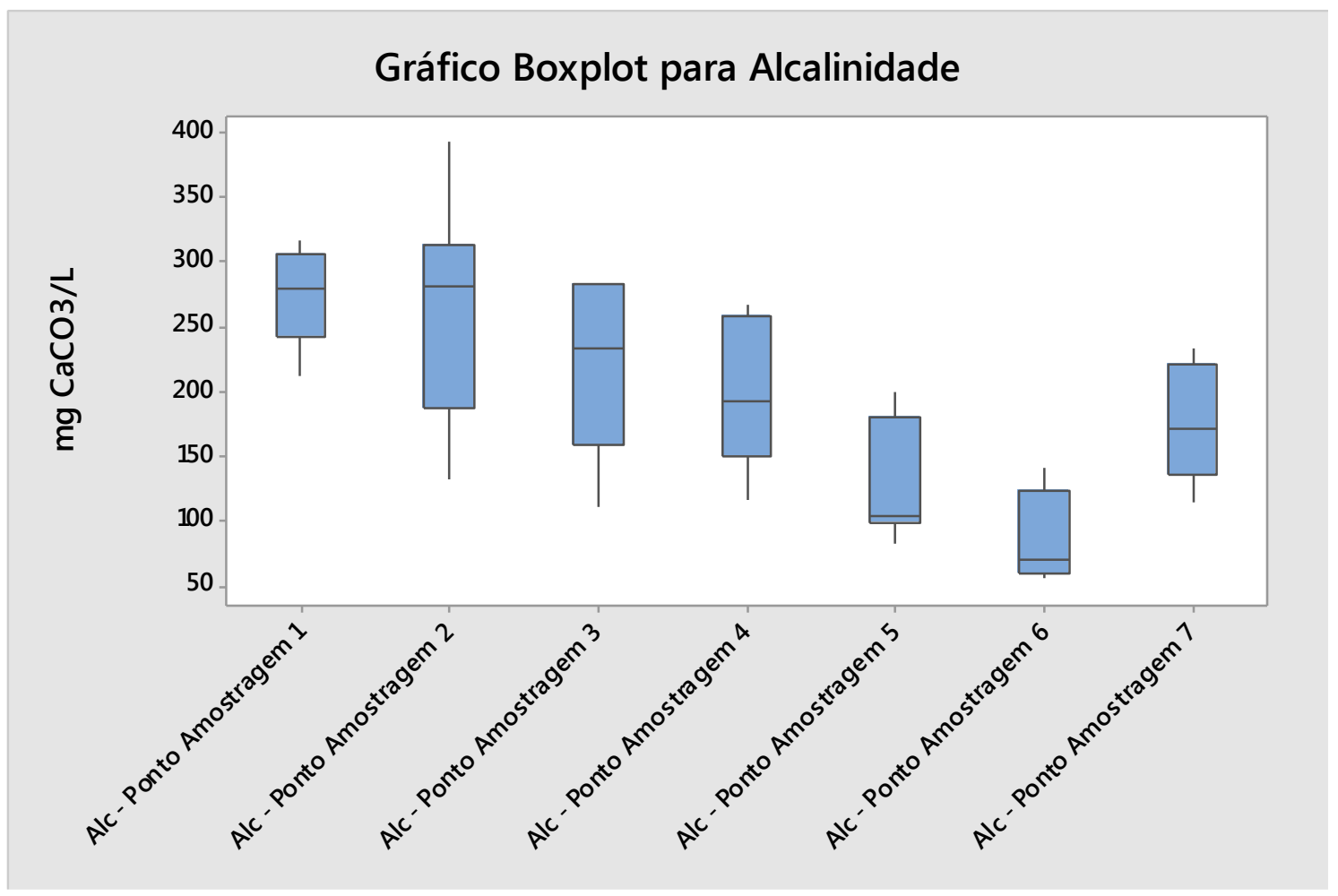

Fonte: Autor 
A Figura 72 apresenta a série histórica para alcalinidade nos diversos pontos de amostragem da planta piloto UCT.

Figura 72 - Gráfico da série histórica para alcalinidade

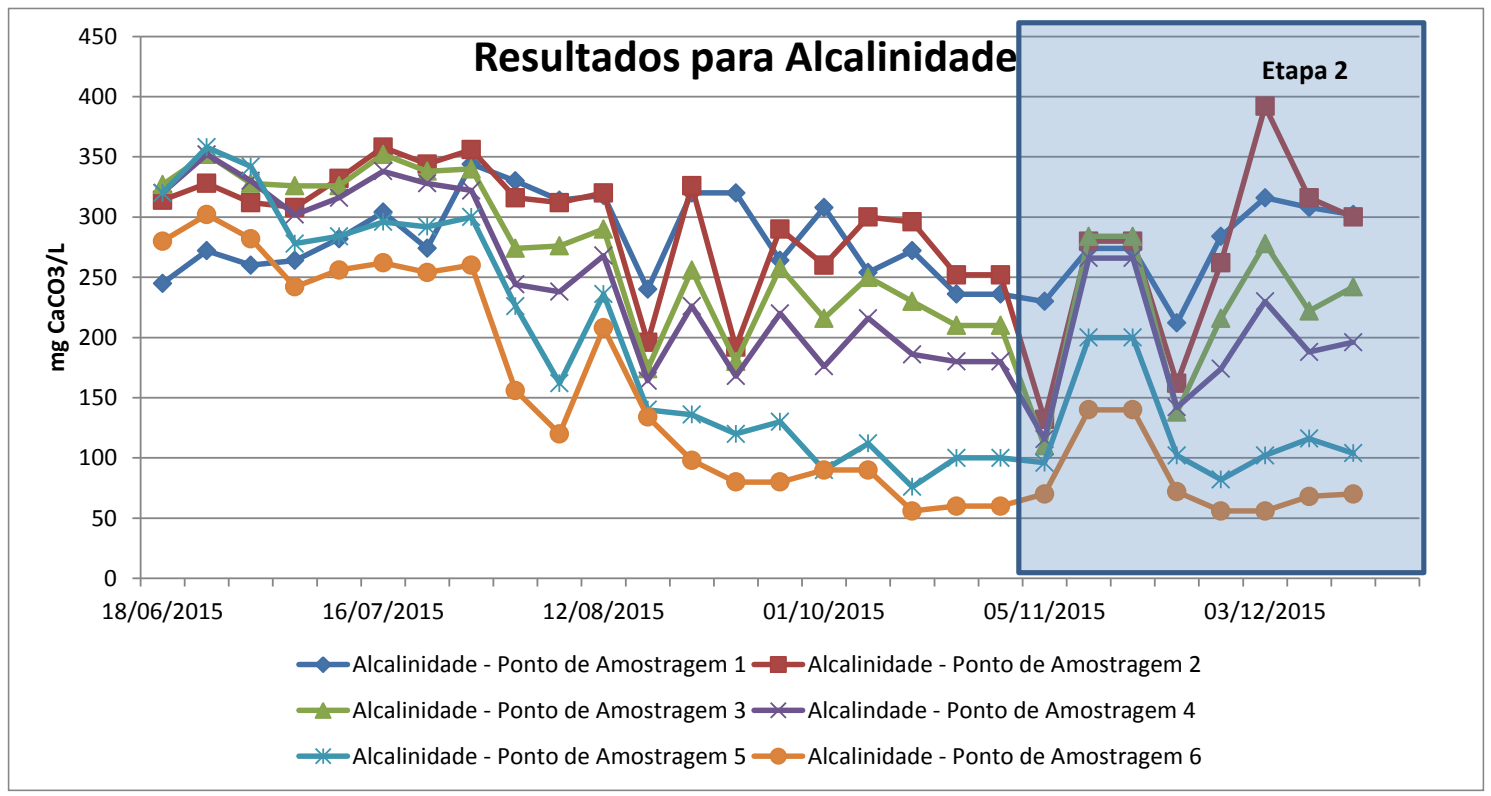

Fonte: Autor

Fato muito importante na análise do processo de remoção biológica de nitrogênio dos esgotos sanitários é a avaliação do consumo e reposição de alcalinidade para avaliação da estabilidade do processo.

Conforme referência bibliográfica, diversos autores como ALEM SOBRINHO (1991) e VAN HAANDEL (1999) apresentam o balanço de alcalinidade para avaliar quanto de matéria nitrogenada foi degradada de acordo com o consumo e reposição de alcalinidade (Vide Equações 59 a 66).

Pode-se notar que em nenhum momento a alcalinidade ficou em valores abaixo de 40 $\mathrm{mg} / \mathrm{L}$, o que poderia indicar uma instabilidade nos resultados de $\mathrm{pH}$.

Adicionalmente, pode-se notar que as taxas de recuperação de alcalinidade foram de aproximadamente $40 \%$ conforme tabelas 33 e 34 . No entanto, pode-se notar que os resultados obtidos pela etapa 2 de experimentação foram mais consistentes, o que corrobora com a tese de que a remoção biológica de nitrogênio na etapa 2 de experimentação teve desempenho melhor.

Comparando-se estes resultados com VAN HAANDEL (1999) pode-se observar que os resultados de recuperação de alcalinidade neste experimento se aproximou dos 
resultados obtidos em sistemas de lodos ativados com remoção biológica de nitrogênio, sendo que os resultados obtidos para a alcalinidade mostram que não correu-se o risco de desequilíbrios pela falta de alcalinidade no sistema.

Os resultados estão apresentados nas Tabelas 33 e 34. 
Tabela 33 - Balanço Alcalinidade Etapa 1 de Experimentação

\begin{tabular}{|c|c|c|c|c|c|c|c|c|c|c|c|c|c|c|c|c|c|c|}
\hline Data & $\begin{array}{l}\text { Amonia } \\
\text { afluente }\end{array}$ & $\begin{array}{l}\text { Amônia } \\
\text { Efluente }\end{array}$ & $\begin{array}{c}\text { TKN } \\
\text { Afluente }\end{array}$ & $\begin{array}{c}\text { TKN } \\
\text { Efluente }\end{array}$ & Noa & Noe & NI & Nam & $\Delta$ alcam & $\mathrm{Nc}$ & $\Delta$ alcn & $\Delta \mathrm{Nd}$ & $\Delta$ alcd & $\Delta$ alct & $\begin{array}{c}\text { Alcalinidade } \\
\text { Afluente }\end{array}$ & $\begin{array}{c}\text { Alcalinidade } \\
\text { Efluente }\end{array}$ & $\Delta$ alct & $\begin{array}{l}\text { Recuperação } \\
\text { Alcalindiade }\end{array}$ \\
\hline $18 / 06 / 15$ & 27 & 53 & 70 & 96 & 43 & 44 & 18 & -19 & -66 & -44 & -313 & -44 & -156 & -536 & 245 & \begin{tabular}{|l|}
280 \\
\end{tabular} & -35 & $7 \%$ \\
\hline $26 / 06 / 15$ & 67 & 66 & 84 & 78 & 17 & 13 & 21 & -17 & -60 & -15 & -110 & -15 & -55 & -225 & 272 & 302 & -30 & $13 \%$ \\
\hline $29 / 06 / 15$ & 63 & 55 & 77 & 74 & 14 & 20 & 19 & -25 & -89 & -16 & -117 & -16 & -59 & -265 & 260 & 282 & -22 & $8 \%$ \\
\hline $02 / 07 / 15$ & 64 & 46 & 83 & 70 & 18 & 24 & 21 & -26 & -94 & -8 & -57 & -8 & -29 & -180 & 264 & 242 & 22 & $-12 \%$ \\
\hline $07 / 07 / 15$ & 70 & 49 & 83 & 70 & 13 & 21 & 21 & -29 & -104 & -8 & -57 & -8 & -29 & -190 & 282 & 256 & 26 & $-14 \%$ \\
\hline $16 / 07 / 15$ & 69 & 49 & 91 & 63 & 22 & 14 & 23 & -14 & -51 & 5 & 37 & 5 & 19 & 5 & 304 & 262 & 42 & $840 \%$ \\
\hline $21 / 07 / 15$ & 66 & 46 & 80 & 53 & 14 & 7 & 20 & -13 & -45 & 7 & 47 & 7 & 24 & 26 & 274 & 254 & 20 & $77 \%$ \\
\hline $30 / 07 / 15$ & 84 & 48 & 98 & 54 & 14 & 6 & 25 & -16 & -57 & 20 & 141 & 20 & 70 & 154 & 344 & 260 & 84 & $55 \%$ \\
\hline $05 / 08 / 15$ & 91 & 20 & 116 & 21 & 25 & 1 & 29 & -5 & -18 & 66 & 470 & 66 & 235 & 688 & 330 & 156 & 174 & $25 \%$ \\
\hline $07 / 08 / 15$ & 83 & 17 & 104 & 26 & 21 & 9 & 26 & -14 & -49 & 52 & 371 & 52 & 185 & 507 & 314 & 120 & 194 & $38 \%$ \\
\hline $12 / 08 / 15$ & 77 & 35 & 106 & 39 & 29 & 4 & 27 & -2 & -6 & 41 & 290 & 41 & 145 & 429 & 318 & 208 & 110 & $26 \%$ \\
\hline $01 / 09 / 15$ & 56 & 10 & 80 & 17 & 24 & 7 & 20 & -3 & -12 & 43 & 307 & 43 & 154 & 449 & 240 & 134 & 106 & $24 \%$ \\
\hline $03 / 09 / 15$ & 66 & 13 & 105 & 25 & 39 & 12 & 26 & 1 & 4 & 54 & 382 & 54 & 191 & 578 & 320 & 98 & 222 & $38 \%$ \\
\hline $10 / 09 / 15$ & 69 & 1 & 98 & 10 & 29 & 9 & 25 & -4 & -14 & 64 & 457 & 64 & 228 & 671 & 320 & 80 & 240 & $36 \%$ \\
\hline $17 / 09 / 15$ & 69 & 1 & 77 & 12 & 8 & 12 & 19 & -23 & -81 & 45 & 324 & 45 & 162 & 406 & 264 & 80 & 184 & $45 \%$ \\
\hline $01 / 10 / 15$ & 95 & 11 & 104 & 22 & 8 & 11 & 26 & -29 & -102 & 55 & 395 & 55 & 197 & 490 & 308 & 90 & 218 & $45 \%$ \\
\hline $08 / 10 / 15$ & 69 & 18 & 83 & 21 & 14 & 3 & 21 & $\begin{array}{l}-9 \\
\end{array}$ & -34 & 41 & 294 & 41 & 147 & 408 & 254 & 90 & 164 & $40 \%$ \\
\hline $15 / 10 / 15$ & 52 & 1 & 83 & 6 & 31 & 5 & 21 & 5 & 18 & 56 & 402 & 56 & 201 & 622 & 272 & 56 & 216 & $35 \%$ \\
\hline $22 / 10 / 15$ & 64 & 1 & 70 & 13 & 6 & 13 & 18 & -25 & -88 & 39 & 279 & 39 & 139 & 330 & 236 & 60 & 176 & $53 \%$ \\
\hline $27 / 10 / 15$ & 59 & 8 & 71 & 11 & 13 & 3 & 18 & -9 & -31 & 42 & 302 & 42 & 151 & 423 & 236 & 60 & 176 & $42 \%$ \\
\hline
\end{tabular}

Fonte: Autor

Tabela 34 - Balanço de Alcalinidade Etapa 2 de Experimentação

\begin{tabular}{|c|c|c|c|c|c|c|c|c|c|c|c|c|c|c|c|c|c|c|}
\hline Data & $\begin{array}{l}\text { Amonia } \\
\text { afluente }\end{array}$ & $\begin{array}{l}\text { Amônia } \\
\text { Efluente }\end{array}$ & $\begin{array}{c}\text { TKN } \\
\text { Afluente }\end{array}$ & $\begin{array}{l}\text { TKN } \\
\text { Efluente }\end{array}$ & Noa & Noe & $\mathrm{NI}$ & Nam & $\Delta$ alcam & $\mathrm{Nc}$ & $\Delta$ alcn & $\Delta \mathrm{Nd}$ & $\Delta$ alcd & $\Delta$ alct & $\begin{array}{l}\text { Alcalinidade } \\
\text { Afluente }\end{array}$ & $\begin{array}{l}\text { Alcalinidade } \\
\text { Efluente }\end{array}$ & $\Delta$ alct & $\begin{array}{l}\text { Recuperação } \\
\text { Alcalindiade }\end{array}$ \\
\hline $05 / 11 / 15$ & 78 & 1 & 99 & 10 & 21 & 10 & 25 & -13 & -48 & 64 & 460 & 64 & 230 & 643 & 230 & 70 & 160 & $25 \%$ \\
\hline $10 / 11 / 15$ & 78 & 22 & 94 & 49 & 15 & 27 & 23 & -35 & -125 & 21 & 150 & 21 & 75 & 101 & 274 & 140 & 134 & $133 \%$ \\
\hline $12 / 11 / 15$ & 73 & 23 & 71 & 42 & -1 & 19 & 18 & -38 & -137 & 12 & 82 & 12 & 41 & -13 & 274 & 140 & 134 & $-1031 \%$ \\
\hline $19 / 11 / 15$ & 64 & 1 & 67 & 11 & 3 & 10 & 17 & -24 & -86 & 40 & 284 & 40 & 142 & 340 & 212 & 72 & 140 & $41 \%$ \\
\hline $26 / 11 / 15$ & 70 & 1 & 84 & 11 & 14 & 10 & 21 & -17 & -60 & 52 & 374 & 52 & 187 & 501 & 284 & 56 & 228 & $46 \%$ \\
\hline $03 / 12 / 15$ & 78 & 2 & 94 & 10 & 15 & 8 & 23 & -16 & -56 & 61 & 434 & 61 & 217 & 596 & 316 & 56 & 260 & $44 \%$ \\
\hline $08 / 12 / 15$ & 83 & 0 & 98 & 7 & 15 & 6 & 25 & -16 & -55 & 67 & 477 & 67 & 238 & 660 & 308 & 68 & 240 & $36 \%$ \\
\hline $10 / 12 / 15$ & 81 & 0 & 95 & 6 & 14 & 6 & 24 & -16 & -56 & 65 & 466 & 65 & 233 & 643 & 302 & 70 & 232 & $36 \%$ \\
\hline
\end{tabular}

Fonte: Autor 


\subsubsection{Análise de desempenho do processo de Nitrificação e Desnitrificação}

Pode-se observar que o processo de nitrificação nas duas etapas de experimentação foi adequado, no entanto, o processo de desnitrificação teve seu pleno funcionamento no final da etapa 1 de experimentação.

Observando que as concentrações de nitrato no tanque de aeração no início do processo indicavam valores acima de $20 \mathrm{mg} / \mathrm{L}$ e as taxas de consumo de alcalinidade indicavam altos consumos, pode-se afirmar que houve nitrificação e consequentemente obteve desempenhos satisfatórios. No entanto, pelas concentrações de nitrato no tanque de aeração e recomposições de alcalinidade pode-se inferir que o processo de desnitrificação na etapa 1 de experimentação teve grande instabilidade e ficou muito prejudicado.

Por outro lado na etapa 2 de experimentação, houve uma estabilização do processo de nitrificação e desnitrificação, uma vez que as concentrações de nitrato no sistema tiveram uma significativa redução, as conversões de nitrogênio amoniacal e nitrato tiveram uma significativa melhora e as recomposições de alcalinidade ficaram na faixa de $40 \%$ o que indica que a desnitrificação passou a ter uma efetiva melhora.

Com relação à idade do lodo nas duas etapas de experimentação foi utilizada o valor de 10 dias, o que é um valor acima da idade mínima para nitrificação de 6 dias neste caso, onde as temperaturas médias foram acima de $25^{\circ} \mathrm{C}$.

VAIOPOLOU (2008) apresentou para diversos sistemas de lodos ativados as concentrações de nitrato propostas variam de 4,4 mg/L a 8 mg/L (SCHLEGEL, 1992; LESOUEF et al, 1992; KAYSER et al, 1992; PAI et al, 2004). No caso do presente experimento as concentrações de nitrato para a etapa 1 de experimentação foi de 18 $\mathrm{mg} / \mathrm{L}$ e de $9,45 \mathrm{mg} / \mathrm{L}$ para a etapa 2 de experimentação.

Durante a operação da planta piloto UCT modificado, foi observado no decantador secundário pequenas bolhas que eram desprendidas do lodo. Este fenômeno teve sua principal ocorrência na etapa 1 de experimentação. Sugere-se que este fenômeno é decorrente da transformação de nitrato em nitrogênio gasoso neste compartimento. $\mathrm{Ou}$ seja, devido a ineficiências de processo, pode ter ocorrido o processo de desnitrificação no decantador secundário, uma vez que as concentrações de nitrato do efluente final 
eram altas e os tempos de detenção hidráulica no decantador secundário também eram altos.

\subsection{Fósforo}

As tabelas 35 e 36 apresentam a estatística descritiva básica para o parâmetro fósforo total para as duas etapas de experimentação.

Tabela 35 - Estatística Descritiva dos Resultados das Análises Físico-Químicas para o Parâmetro Fósforo Total (mg Pt/L) - Etapa 1

\begin{tabular}{|l|c|c|c|c|c|c|c}
\hline \multirow{2}{*}{ Parâmetro } & \multicolumn{7}{|c|}{ Fósforo total I } \\
\cline { 2 - 8 } & $\begin{array}{c}\text { Ponto } \\
\text { Amostragem } \\
\mathbf{1}\end{array}$ & $\begin{array}{c}\text { Ponto } \\
\text { Amostragem } \\
\mathbf{2}\end{array}$ & $\begin{array}{c}\text { Ponto } \\
\text { Amostragem } \\
\mathbf{3}\end{array}$ & $\begin{array}{c}\text { Ponto } \\
\text { Amostragem } \\
\mathbf{4}\end{array}$ & $\begin{array}{c}\text { Ponto } \\
\text { Amostragem } \\
\mathbf{5}\end{array}$ & $\begin{array}{c}\text { Ponto } \\
\text { Amostragem } \\
\mathbf{6}\end{array}$ & $\begin{array}{c}\text { Ponto } \\
\text { Amostragem } \\
\mathbf{7}\end{array}$ \\
\hline Máximo & 5,5 & 25,5 & 28,5 & 27,2 & 27,3 & 2,5 & 32,5 \\
\hline Mínimo & 7,2 & 39,4 & 47,7 & 40,2 & 43,6 & 6,2 & 53,0 \\
\hline Mediana & 5,4 & 8,6 & 4,2 & 10,1 & 7,8 & 0,1 & 10,1 \\
\hline $\begin{array}{l}\text { Desvio } \\
\text { Padrão }\end{array}$ & 1,0 & 33,9 & 37,3 & 35,3 & 35,0 & 2,0 & 42,5 \\
\hline CV(\%) & $18 \%$ & $49 \%$ & $52 \%$ & $46 \%$ & $49 \%$ & $83 \%$ & $49 \%$ \\
\hline AT & 3,3 & 30,8 & 43,5 & 30,1 & 35,8 & 6,1 & 43,0 \\
\hline
\end{tabular}

Fonte: Autor

Tabela 36 - Estatística Descritiva dos Resultados das Análises Físico-Químicas para o Parâmetro Fósforo Total $(\mathbf{P t} / \mathrm{L})$ - Etapa 2

\begin{tabular}{|l|c|c|c|c|c|c|c}
\hline & \multicolumn{7}{|c}{ Fósforo total } \\
\cline { 2 - 8 } Parâmetro & $\begin{array}{c}\text { Ponto } \\
\text { Amostragem }\end{array}$ & $\begin{array}{c}\text { Ponto } \\
\text { Amostragem }\end{array}$ & $\begin{array}{c}\text { Ponto } \\
\text { Amostragem } \\
\mathbf{1}\end{array}$ & $\begin{array}{c}\text { Ponto } \\
\text { Amostragem } \\
\mathbf{3}\end{array}$ & $\begin{array}{c}\text { Ponto } \\
\text { Amostragem } \\
\mathbf{5}\end{array}$ & $\begin{array}{c}\text { Ponto } \\
\text { Amostragem } \\
\mathbf{6}\end{array}$ & $\begin{array}{c}\text { Ponto } \\
\text { Amostragem } \\
\mathbf{7}\end{array}$ \\
\hline Média & 5,1 & 28,7 & 32,5 & 34,2 & 31,5 & 2,1 & 37,7 \\
\hline Máximo & 6,4 & 40,8 & 36,9 & 42,7 & 39,4 & 6,0 & 45,8 \\
\hline Mínimo & 3,5 & 17,8 & 28,3 & 28,3 & 0,3 & 0,2 & 11,1 \\
\hline Mediana & 5,3 & 31,5 & 32,8 & 34,1 & 34,7 & 0,8 & 39,4 \\
\hline Desvio & & & & & & & \\
Padrão & 1,0 & 8,7 & 2,6 & 5,4 & 12,8 & 2,2 & 11,3 \\
\hline CV(\%) & $20 \%$ & $30 \%$ & $8 \%$ & $16 \%$ & $41 \%$ & $104 \%$ & $30 \%$ \\
\hline AT & 2,9 & 23,0 & 8,6 & 14,4 & 39,1 & 5,8 & 34,7 \\
\hline
\end{tabular}

Fonte: Autor

As Figuras 73 e 74 apresentam os gráficos Boxplot para os resultados obtidos para fósforo total. 
Figura 73 - Gráfico Boxplot para o parâmetro Fósforo Total - Etapa 1

\section{Gráfico Boxplot para Fósforo Total}

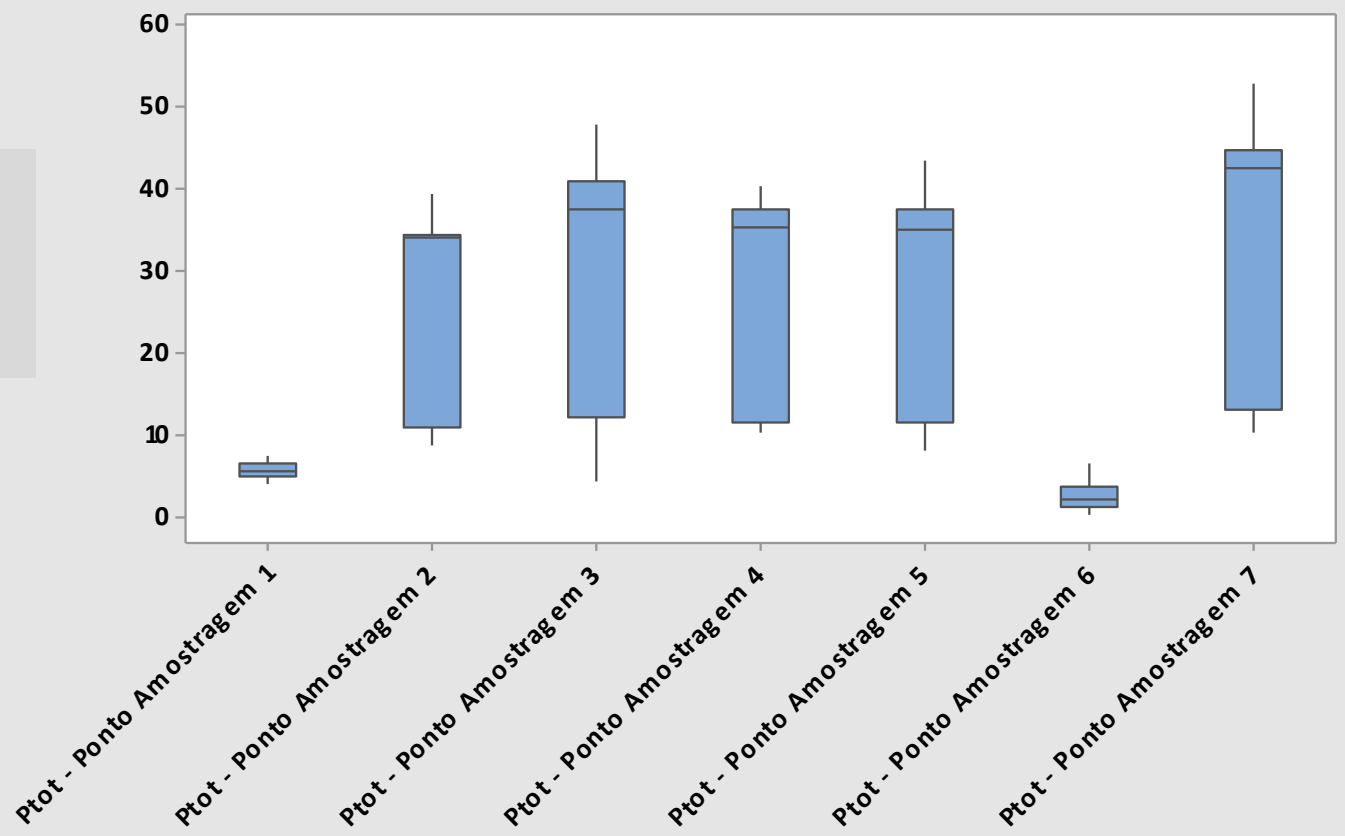

Fonte: Autor

Figura 74 - Gráfico Boxplot para o parâmetro Fósforo total - Etapa 2

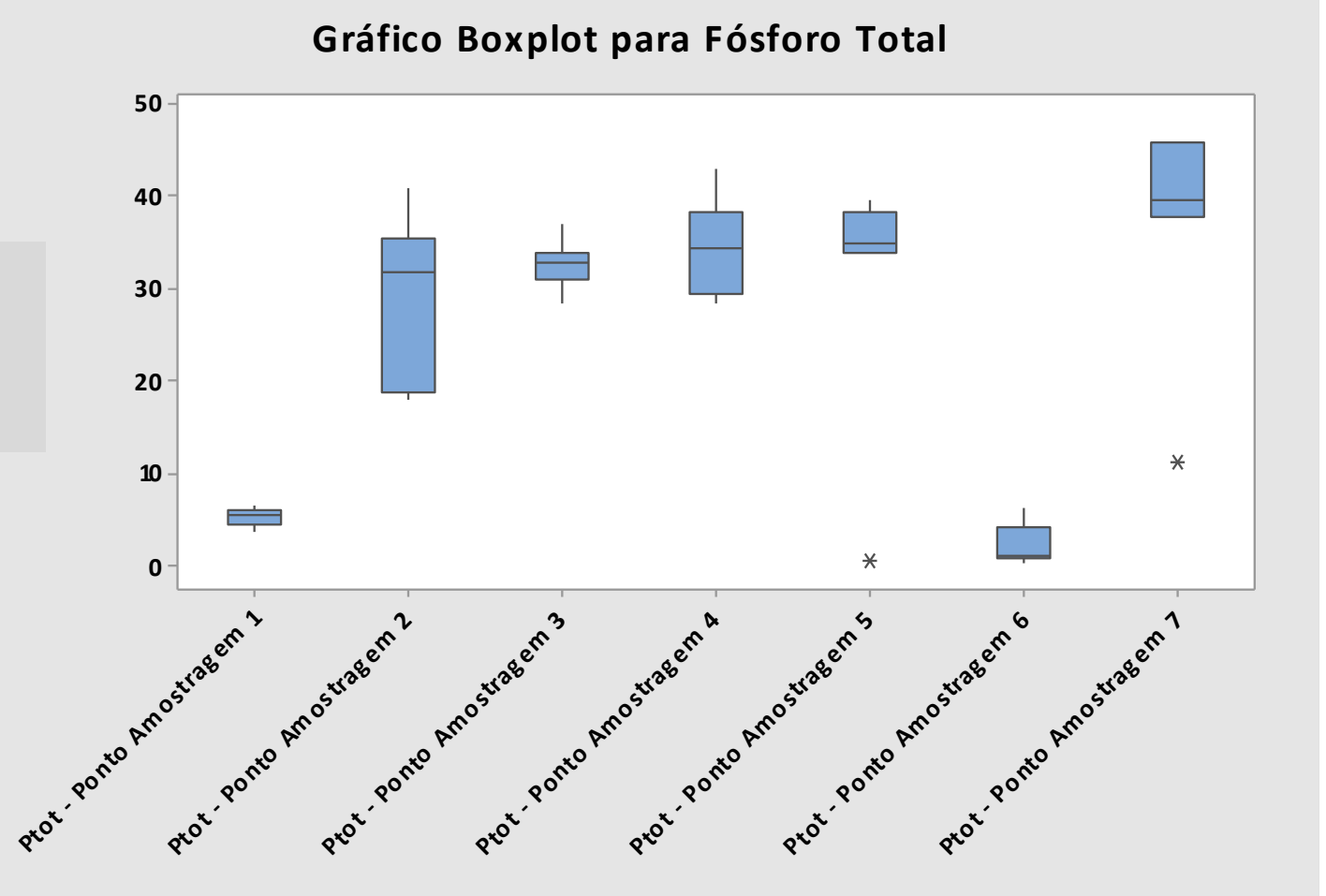

Fonte: Autor 
A estatística básica descritiva para o parâmetro fósforo solúvel está apresentada nas tabelas 37 e 38 .

Tabela 37 - Estatística Descritiva dos Resultados das Análises Físico-Químicas para o parâmetro Fósforo solúvel - Etapa 1

\begin{tabular}{|l|c|c|c|c|c|c|c|}
\hline \multirow{3}{*}{ Parâmetro } & \multicolumn{7}{|c|}{ Fósforo Solúvel (mgP-PO4/L) } \\
\cline { 2 - 8 } & $\begin{array}{c}\text { Ponto } \\
\text { Amostragem }\end{array}$ & $\begin{array}{c}\text { Ponto } \\
\text { Amostragem }\end{array}$ & $\begin{array}{c}\text { Ponto } \\
\text { Amostragem } \\
\mathbf{1}\end{array}$ & $\begin{array}{c}\text { Ponto } \\
\text { Amostragem }\end{array}$ & $\begin{array}{c}\text { Ponto } \\
\text { Amostragem } \\
\mathbf{5}\end{array}$ & $\begin{array}{c}\text { Ponto } \\
\text { Amostragem } \\
\mathbf{6}\end{array}$ & $\begin{array}{c}\text { Ponto } \\
\text { Amostragem } \\
\mathbf{7}\end{array}$ \\
\hline Média & 1,9 & 2,3 & 2,0 & 1,7 & 0,5 & 0,6 & 1,5 \\
\hline Máximo & 2,3 & 2,8 & 2,8 & 2,7 & 2,3 & 2,4 & 2,8 \\
\hline Mínimo & 1,6 & 1,1 & 0,2 & 0,2 & 0,1 & 0,0 & 0,1 \\
\hline Mediana & 1,8 & 2,3 & 2,1 & 1,9 & 0,3 & 0,3 & 1,6 \\
\hline $\begin{array}{l}\text { Desvio } \\
\text { Padrão }\end{array}$ & 0,2 & 0,4 & 0,7 & 0,7 & 0,6 & 0,7 & 0,9 \\
\hline CV(\%) & $12 \%$ & $17 \%$ & $34 \%$ & $40 \%$ & $113 \%$ & $122 \%$ & $58 \%$ \\
\hline AT & 0,7 & 1,7 & 2,6 & 2,5 & 2,3 & 2,3 & 2,7 \\
\hline
\end{tabular}

Fonte: Autor

Tabela 38 - Estatística Descritiva dos Resultados das Análises Físico-Químicas para o parâmetro Fósforo Solúvel - Etapa 2

\begin{tabular}{|c|c|c|c|c|c|c|c|}
\hline \multirow[b]{2}{*}{ Parâmetro } & \multicolumn{7}{|c|}{ Fósforo Solúvel (mgP-PO4/L) } \\
\hline & \begin{tabular}{|c|} 
Ponto \\
Amostragem \\
1 \\
\end{tabular} & \begin{tabular}{|c|} 
Ponto \\
Amostragem \\
2 \\
\end{tabular} & $\begin{array}{c}\text { Ponto } \\
\text { Amostragem } \\
\mathbf{3} \\
\end{array}$ & \begin{tabular}{|c|} 
Ponto \\
Amostragem \\
4 \\
\end{tabular} & \begin{tabular}{|c|} 
Ponto \\
Amostragem \\
5 \\
\end{tabular} & \begin{tabular}{|c|} 
Ponto \\
Amostragem \\
6 \\
\end{tabular} & $\begin{array}{c}\text { Ponto } \\
\text { Amostragem } \\
7 \\
\end{array}$ \\
\hline Média & 1,8 & 2,1 & 1,9 & 1,3 & 0,4 & 0,3 & 0,8 \\
\hline Máximo & 1,9 & 2,6 & 2,6 & 2,6 & 1,1 & 0,6 & 1,8 \\
\hline Mínimo & 1,7 & 0,4 & 0,2 & 0,0 & 0,0 & 0,1 & 0,0 \\
\hline Mediana & 1,8 & 2,6 & 2,3 & 1,3 & 0,2 & 0,3 & 0,3 \\
\hline $\begin{array}{l}\text { Desvio } \\
\text { Padrão }\end{array}$ & 0,1 & 0,8 & 1,1 & 1,1 & 0,5 & 0,2 & 0,9 \\
\hline $\mathrm{CV}(\%)$ & $5 \%$ & $40 \%$ & $56 \%$ & $86 \%$ & $110 \%$ & $57 \%$ & $113 \%$ \\
\hline AT & 0,3 & 2,3 & 2,4 & 2,5 & 1,1 & 0,5 & 1,8 \\
\hline
\end{tabular}

Fonte: Autor

Os gráficos boxplot para este parâmetro nas duas etapas de experimentação estão apresentados nas Figuras 75 e 76. 
Figura 75 - Gráfico Boxplot para o parâmetro Fósforo Solúvel - Etapa 1

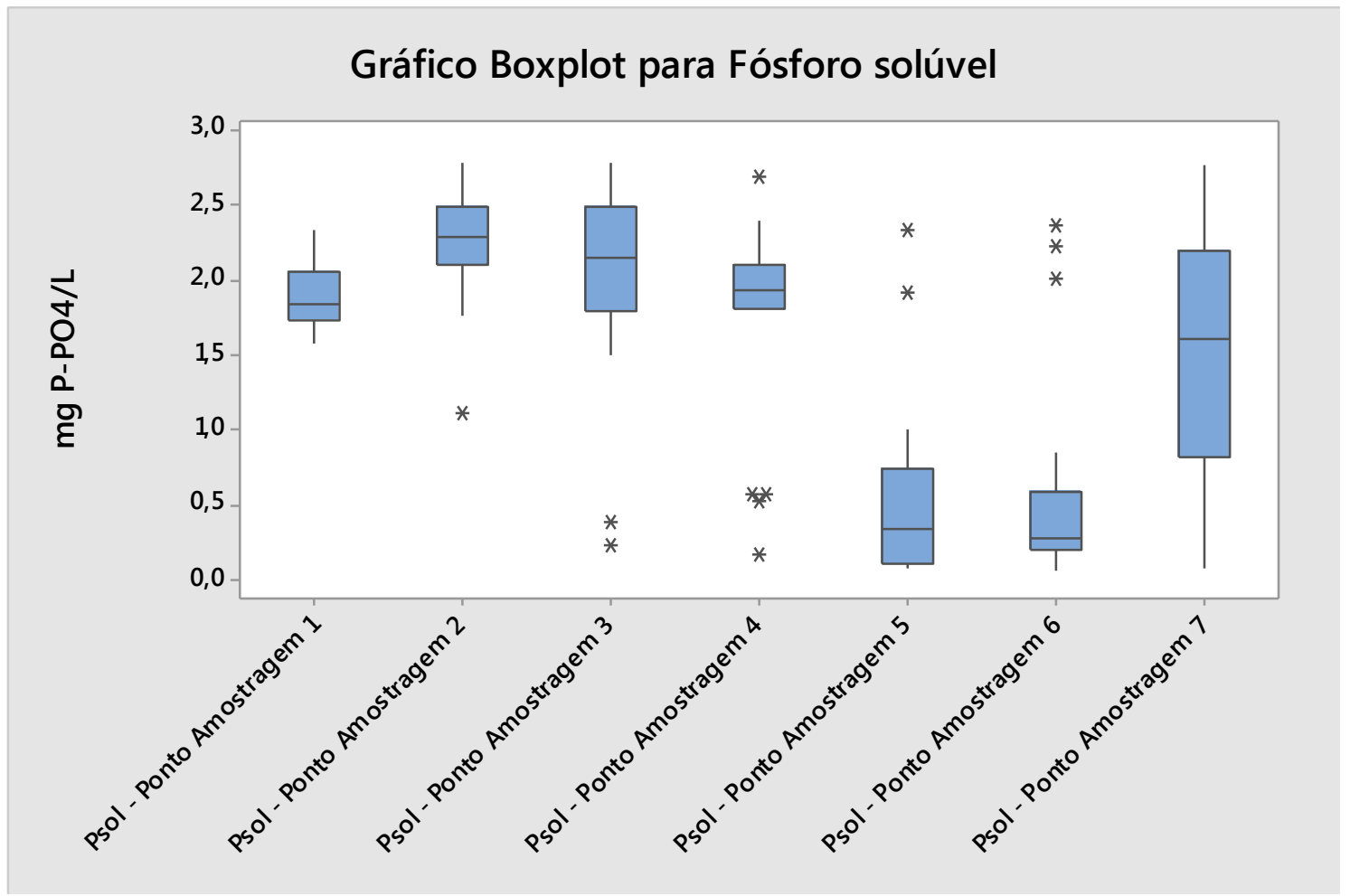

Fonte: Autor

Figura 76 - Gráfico Boxplot para o parâmetro Fósforo Solúvel - Etapa 2

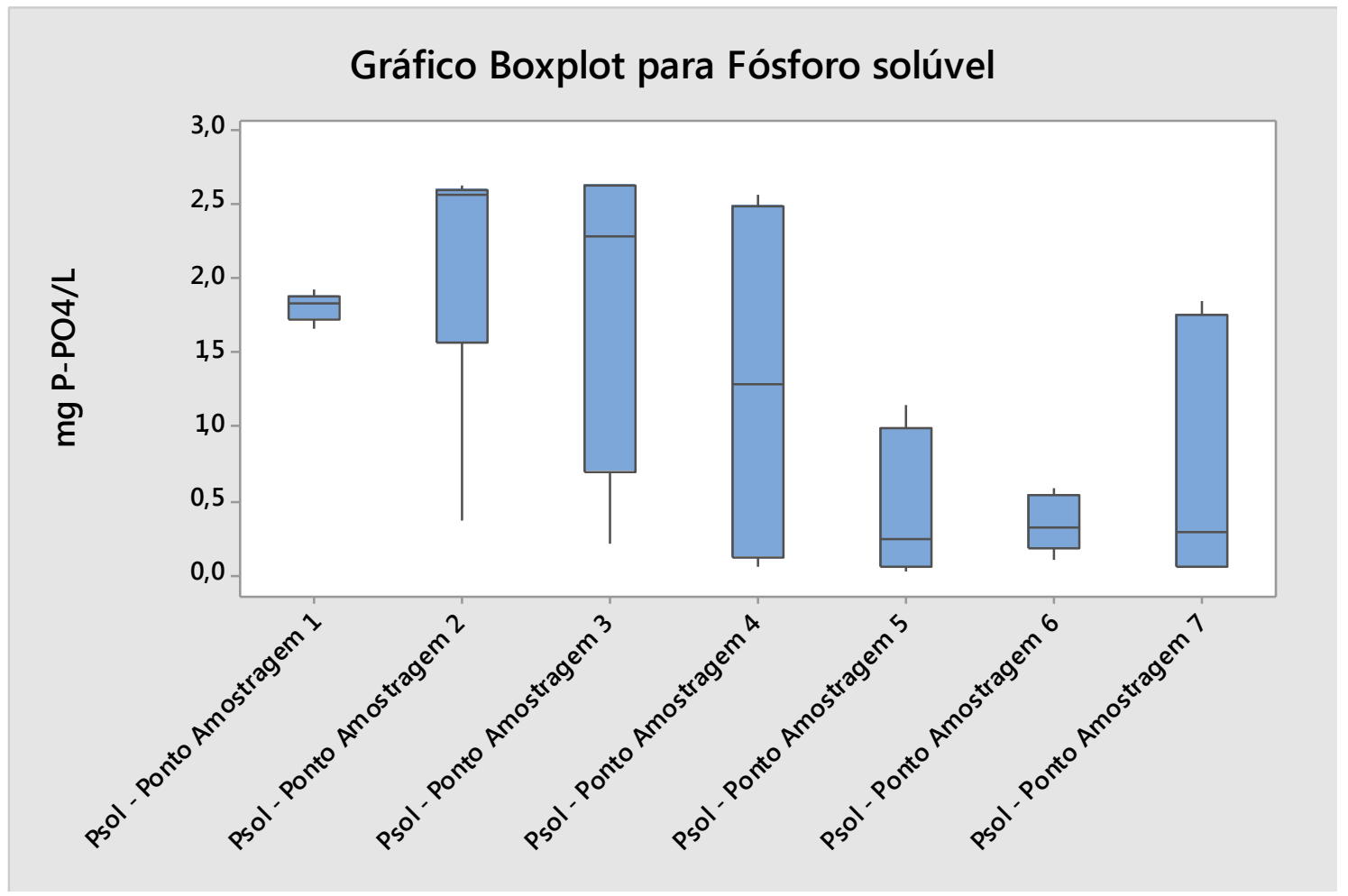

Fonte: Autor 
As Figuras 77 e 78 apresentam as séries históricas para fósforo total e solúvel durante as etapas de experimentação.

Figura 77 - Gráfico da série histórica para o parâmetro fósforo total

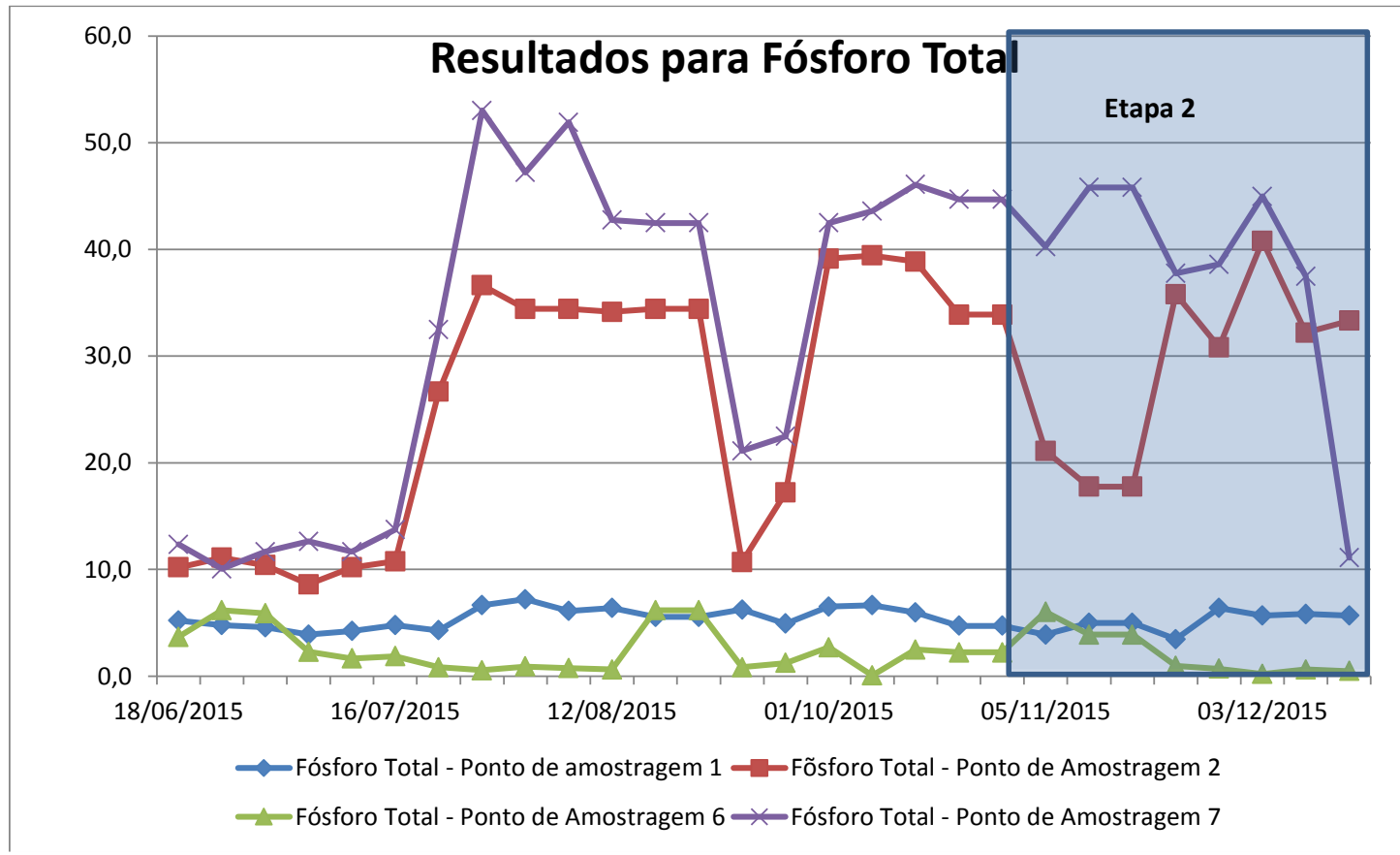

Fonte: Autor

Figura 78 - Gráfico da série histórica para o parâmetro fósforo solúvel

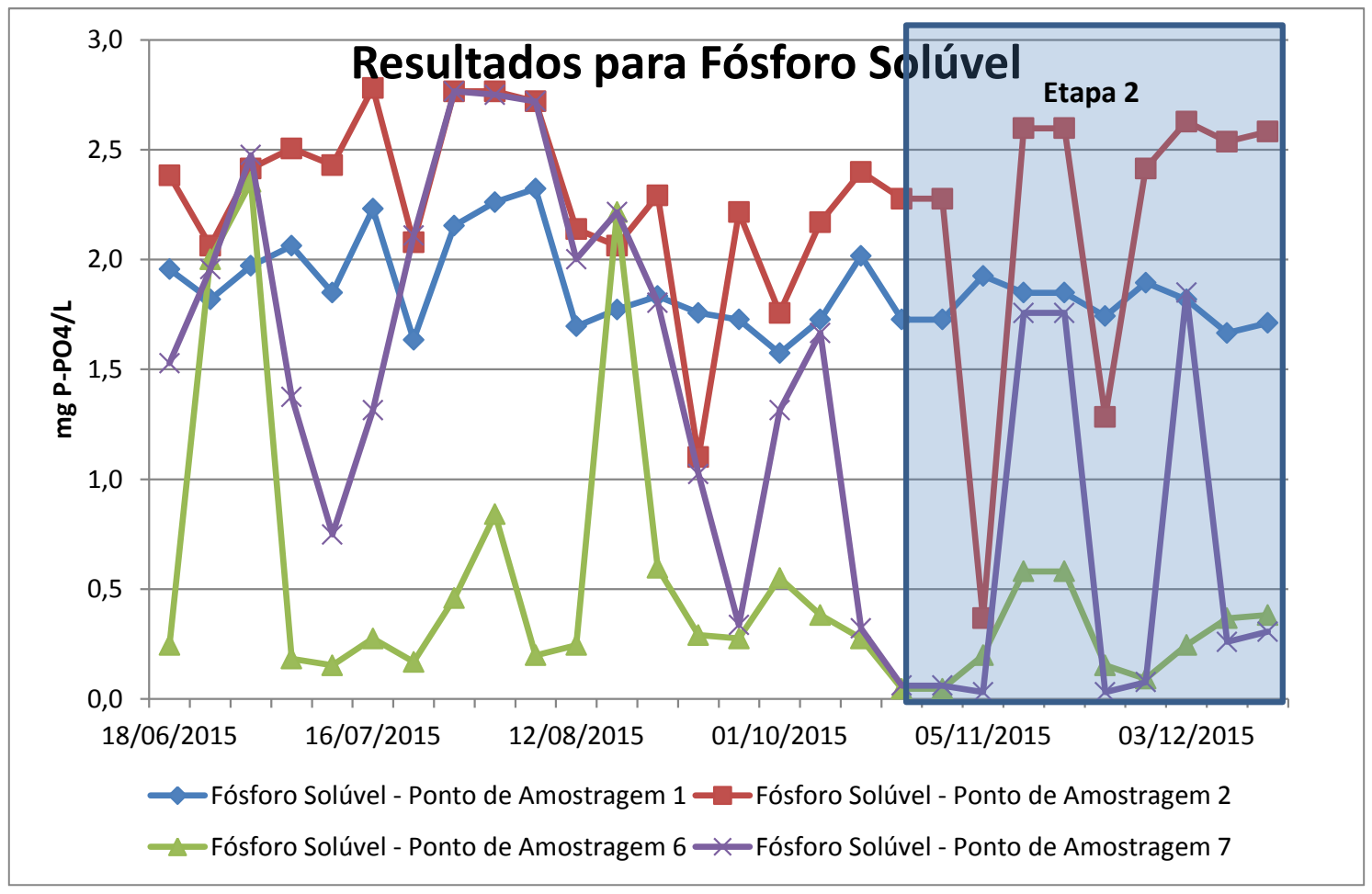

Fonte: Autor 
Pelos dados das séries históricas fica claro que há grande variabilidade de resultados entre as análises pontuais feitas durante período de experimentação. Isto é certamente mais um indício do frágil equilíbrio no processo biológico de remoção de fósforo.

Executando teste de hipóteses para as variáveis Fósforo total e solúvel no ponto de amostragem 6, para comparar seu comportamento durante as duas etapas de experimentação e considerando-se que uma distribuição T-student e nível de confiança de $95 \%$, as hipóteses para o parâmetro foram:

H0: Fósforo Total Ponto Amostragem 1 - etapa $1=$

Fósforo Solúvel Ponto Amostragem 1 - etapa 2 (153A)

H1: Fósforo Total Ponto Amostragem 1 - etapa $1 \neq$

Fósforo Solúvel Ponto Amostragem 1 - etapa 2(153B)

\begin{tabular}{|c|c|c|}
\hline Valor de $\mathbf{T}$ & Graus de liberdade & Valor P \\
\hline 0,80 & 12 & 0,4386 \\
\hline
\end{tabular}

Aceita-se $\mathrm{H} 0$ e considera-se que o fósforo total do afluente à planta piloto UCT se manteve constante ao longo do tempo de experimentação.

H0: Fósforo Total Ponto Amostragem 6 - etapa $1=$

Fósforo Total Ponto Amostragem 6 - etapa 2 (154A)

H1: Fósforo Total Ponto Amostrage 6 - etapa $1 \neq$

Fósforo Total Ponto Amostrage 6 - etapa 2 (154B)

\begin{tabular}{|c|c|c|}
\hline Valor de $\mathbf{T}$ & Graus de liberdade & Valor P \\
\hline 0,40 & 12 & 0,6929 \\
\hline
\end{tabular}

Desta forma, aceita-se H0 e considera-se que o efluente final das duas etapas de experimentação tiveram resultados iguais em termos de fósforo total.

H0: Fósforo Solúvel Ponto Amostragem 6 - etapa $1=$ Fósforo Solúvel Ponto Amostragem 6 - etapa 2 (155A)

H1: Fósforo Solúvel Ponto Amostrage 6 - etapa $1 \neq$ Fósforo Solúvel Ponto Amostrage 6 - etapa 2(155B) 


\begin{tabular}{|c|c|c|}
\hline Valor de $\mathbf{T}$ & Graus de liberdade & Valor P \\
\hline 1,57 & 24 & 0,1297 \\
\hline
\end{tabular}

Neste caso aceita-se H0 e pode-se considerar que os efluentes finais das duas etapas de experimentação tiveram resultados iguais em termos de fósforo solúvel.

H0: Fósforo Total Ponto Amostragem 7 - etapa $1=$ Fósforo Total Ponto Amostragem 7 - etapa 2 (156A)

H1: Fósforo Total Ponto Amostragem 7 - etapa $1 \neq$ Fósforo Total Ponto Amostragem 7 - etapa 2 (156B)

\begin{tabular}{|c|c|c|}
\hline Valor de $\mathbf{T}$ & Graus de liberdade & Valor P \\
\hline$-0,98$ & 18 & 0,3398 \\
\hline
\end{tabular}

Neste caso, aceita-se H0 e considera-se que o lodo nas duas etapas de experimentação possuem as mesmas concentrações de fósforo. Isto de fundamental importância, uma vez que as concentrações de fósforo tem direta influência no aproveitamento de lodo na forma de estruvita.

O presente trabalho tem como principal foco avaliar a remoção biológica de fósforo de um processo UCT modificado com algumas melhorias. Devemos considerar inicialmente que a legislação brasileira segundo resolução 357 do CONAMA impõe um limite de 0,02 mg/L de Fósforo total em ambientes lênticos para corpos receptores classe I.

KUBA (1997) em seus estudos para uma planta piloto em larga escala utilizando a metodologia UCT Modificado um efluente com concentração de fósforo de $0,1 \mathrm{mg} / \mathrm{L}$ sendo que o afluente obteve $5,6 \mathrm{mg} / \mathrm{L}$ de Fósforo total (98\% de remoção). Já VAIOPOULOU (2007) obteve em seus experimentos efluentes com no máximo 0,2 mg/L de Fósforo total (94\% de remoção).

SCHLEGEL (1992) sugere que processos UCT modificados tenham eficiências de remoção de fósforo total da ordem de $70 \%$ a $80 \%$ sendo a concentração no efluente final de $1,8 \mathrm{mg} / \mathrm{L}$. KAYSER et al (1992) obtiveram em seus experimentos concentrações de fósforo de $2,8 \mathrm{mg} / \mathrm{L}$ para o efluente final e $81 \%$ de eficiência de 
remoção deste nutriente. Já PAI et al (2004) obtiveram um efluente com 0,3 mg/L de Fósforo total e 94\% de eficiência de remoção.

Pode-se observar inicialmente que as técnicas de remoção biológica de fósforo tem eficiências que não atingem as exigências legais brasileiras sendo que provavelmente em muitos casos é a necessária uma complementação físico-química.

A planta piloto UCT modificado operada pelo autor obteve uma eficiência na remoção de fósforo total de $55 \%$ para a etapa 1 com média de concentração no efluente final de 2,5 mg/L. Obtiveram-se resultados pontuais muito bons nesta planta, sendo que em alguns momentos foram obtidos efluentes com 0,1 mg/L de Fósforo Total. Em termos de fósforo solúvel obteve-se na etapa 1 de experimentação aproximadamente $70 \%$ de eficiência na remoção de fósforo solúvel, com média de $0,6 \mathrm{mg} / \mathrm{L}$ e em algumas análises pontuais o resultado obtido chegou a ser $0,0 \mathrm{mg} / \mathrm{L}$. Já para a etapa 2 de experimentação foram obtidos efluentes com média de $2,1 \mathrm{mg} / \mathrm{L}$ de fósforo total (eficiência de aproximadamente $60 \%$ ) com resultados pontuais de até $0,2 \mathrm{mg} / \mathrm{L}$ em termos de fósforo total. Já com relação ao fósforo solúvel obteve-se efluentes com média de $82 \%$ de remoção e efluentes com média de $0,3 \mathrm{mg} / \mathrm{L}$ de fósforo solúvel (mínimo obtido para análise pontual de $0,1 \mathrm{mg} / \mathrm{L})$. Observou-se problemas de arraste de sólidos no decantador secundário conforme discutido previamente, sendo que pode-se supor que este fato pode ter tido interferência com os resultados obtidos para fósforo total.

Em termos de fósforo total pode-se observar que ambas as etapas de experimentação tiveram resultados percentuais e de efluente final abaixo dos resultados de outros autores e valores preconizados na literatura. Observa-se que o desvio padrão para o efluente final da etapa 1 de experimentação foi $2,1 \mathrm{mg} / \mathrm{L}$ e de $2,2 \mathrm{mg} / \mathrm{L}$ para a etapa 2 . Isso indica uma grande variabilidade de resultados e uma possível instabilidade de processo.

De acordo com HENZE (2008), um sistema de lodos ativados convencional tem uma remoção de cerca de $15-25 \%$ do fósforo afluente devido ao crescimento e respiração endógena do lodo. Pode-se inferir que $0,75 \mathrm{mg} / \mathrm{L}$ de Fósforo foi utilizado para esta finalidade. 


\subsubsection{Remoção de fósforo pelo lodo}

Conforme discutido previamente neste trabalho, as concentrações de lodo afluente à planta piloto UCT modificada eram baixas se comparadas com os resultados obtidos por autores internacionais. Pode-se inferir que a caracterização do lodo tenha sido definida como lodo misto pelo fato de que as concentrações de fósforo envolvidas neste processo tenham sido relativamente baixas.

Durante fase 1 de experimentação foi obtido na média uma fração volátil do lodo (saída do sistema) de 0,84 e de 0,74 para a fase 2. VAN HAANDEL (1999) sugere que a fração volátil de um lodo poli-P seja 0,6 . Os valores obtidos se aproximam de valores convencionais para lodos ativados sem presença de poli-p. Sugere-se que a concentração de fósforo na entrada possa influenciar a presença preferencial de poli-P e sua concentração no liquor biológico do sistema.

VAIOPOULOU et al(2007) sugerem que lodos que possuam uma predominância de organismos poli-P possam ter problemas de sedimentabilidade de lodo. Estes autores em seus experimentos obtiveram um índice volumétrico de lodo (IVL) entre $226 \mathrm{~mL} / \mathrm{g}$ a $231 \mathrm{~mL} / \mathrm{g}$ para um sistema similar ao utilizado neste trabalho. A Tabela 39 apresenta os resultados para IVL obtidos durante a fase 1 de experimentação deste trabalho e na Tabela 40 para a fase 2 de experimentação. 
Tabela 39 - índice Volumétrico de Lodo $(\mathrm{mL} / \mathrm{g})$ planta UCT Modificado para a fase 1 de experimentação

\begin{tabular}{|c|c|}
\hline \multirow{2}{*}{ Data } & IVL \\
\cline { 2 - 2 } & \\
\hline $18 / 06 / 15$ & 83 \\
\hline $26 / 06 / 15$ & 100 \\
\hline $29 / 06 / 15$ & 73 \\
\hline $02 / 07 / 15$ & 62 \\
\hline $07 / 07 / 15$ & 54 \\
\hline $16 / 07 / 15$ & 79 \\
\hline $21 / 07 / 15$ & 72 \\
\hline $30 / 07 / 15$ & 96 \\
\hline $05 / 08 / 15$ & 64 \\
\hline $07 / 08 / 15$ & 183 \\
\hline $12 / 08 / 15$ & 133 \\
\hline $01 / 09 / 15$ & 194 \\
\hline $03 / 09 / 15$ & 177 \\
\hline $10 / 09 / 15$ & 134 \\
\hline $17 / 09 / 15$ & 153 \\
\hline $01 / 10 / 15$ & 213 \\
\hline $08 / 10 / 15$ & 200 \\
\hline $15 / 10 / 15$ & 192 \\
\hline $22 / 10 / 15$ & 160 \\
\hline $27 / 10 / 15$ & 219 \\
\hline
\end{tabular}

Fonte: Autor

Tabela 40 - Resultados de IVL (mL/g) para a fase 2 de experimentação

\begin{tabular}{|c|c|}
\hline \multirow{2}{*}{ Data } & IVL \\
\cline { 2 - 2 } & Tanque de aeração \\
\hline $05 / 11 / 15$ & 64 \\
\hline $10 / 11 / 15$ & 55 \\
\hline $12 / 11 / 15$ & 58 \\
\hline $19 / 11 / 15$ & 64 \\
\hline $16 / 09 / 00$ & 70 \\
\hline $03 / 12 / 15$ & 60 \\
\hline $08 / 12 / 15$ & 74 \\
\hline $10 / 12 / 15$ & 86 \\
\hline
\end{tabular}

Fonte: Autor

A estatística descritiva básica deste parâmetro está apresentado nas Tabelas 41 e 42. 
Tabela 41 - Estatística Básica descritiva para IVL para a fase 1 de experimentação

\begin{tabular}{|l|c|}
\hline \multicolumn{2}{|c|}{ IVL } \\
\hline Média & 132 \\
\hline Desvio padrão & 57 \\
\hline Máximo & 219 \\
\hline Mínimo & 54 \\
\hline Mediana & 133 \\
\hline
\end{tabular}

Fonte: Autor

Tabela 42 - Estatística Básica Descritiva para a fase 2 de experimentação

\begin{tabular}{|l|r|}
\hline \multicolumn{2}{|c|}{ IVL } \\
\hline Média & 66 \\
\hline Desvio Padrão & 9,904772 \\
\hline Máximo & 86 \\
\hline Mínimo & 55 \\
\hline Mediana & 64 \\
\hline
\end{tabular}

Fonte: Autor

H0: IVL Etapa 1 de experimentação = IVL Etapa 2 de experimentação(157A)

H1: IVL Etapa 1 de experimentação $\neq$ IVL Etapa 2 de experimentação (157B)

\begin{tabular}{|c|c|c|}
\hline Valor de $\mathbf{T}$ & Graus de liberdade & Valor P \\
\hline 4,94 & 21 & $<0,0001$ \\
\hline
\end{tabular}

Neste caso deve-se rejeitar H0 e considerar que houve diferença estatisticamente significante no IVL ao longo das etapas de experimentação, sendo que na etapa 2 a sedimentabilidade foi maior.

Ou seja, Pode-se observar que o lodo da etapa 2 de experimentação tem uma melhor sdeimentabilidade do que o lodo da etapa 1. Adicionalmente comparando com os resultados obtidos por outros autores, o IVL do presente trabalho se mostrou muito menor do que as referências da literatura.

De acordo com METCALF \& EDDY (2002), o IVL de um sistema de lodos ativados convencional deve ficar entre 90 e $150 \mathrm{~mL} / \mathrm{g}$, sendo que caso encontre-se valores abaixo de 90 mL/L há uma boa sedimentabilidade do lodo.

No entanto, avaliando-se o IVL da etapa 1 de experimentação com os resultados apresentados por VAIOPOULOU et al (2007) de $230 \mathrm{~mL} / \mathrm{g}$ pode-se observar que ao se 
executar um teste de hipóteses o valor $\mathrm{T}$ é de -7,95 e desta forma pode-se afirmar que o IVL da etapa 1 de experimentação é menor do que $230 \mathrm{~mL} / \mathrm{g}$, de modo a se inferir que em termos de sedimentabilidade este lodo se aproxima de lodos ativados convencional com lodo heterotrófico.

Este arraste de lodo no efluente final influenciou de maneira significativa os resultados da planta piloto UCT Modificada. Deve-se levar em conta inicialmente que não ocorreram problemas crônicos de sedimentabilidade do lodo. Considerando-se que a concentração de sólidos no tanque de aeração na etapa 1 de experimentação foi de 3361 $\mathrm{mg} / \mathrm{L}$ para etapa 1 e $2603 \mathrm{mg} / \mathrm{L}$ para etapa 2. Sendo o volume desta câmara de $700 \mathrm{~L}$ aproximadamente a massa de lodo nesta câmara era de 2,35 toneladas e 1,82 toneladas para etapa 1 e 2 respectivamente.

Visto que a idade do lodo teórica é de 10 dias, havia um descarte de 100L aproximadamente por dia ou 0,36 toneladas e 0,23 toneladas por dia para etapa 1 e 2 respectivamente. Considerando o arraste de sólidos no efluente final de 74 e $51 \mathrm{mg} / \mathrm{L}$ (respectivamente) e uma vazão de 1,5 L/min, estima-se uma perda de sólidos extra no efluente de 0,16 e 0,11 toneladas paras as etapas de experimentação. Considerando-se este fato, a real idade do lodo na planta piloto foi de 6,02 dias para a etapa 1 de experimentação e 5,35 dias para etapa 2 de experimentação. Pode-se considerar que este fator é o real motivo pelo qual houve este elevado arraste de sólidos no decantador secundário.

Em termos de fósforo solúvel, pode-se observar que o efluente final sempre apresentou baixas concentrações, em torno de $0,2 \mathrm{mg} / \mathrm{L}$.

Pode-se observar que dos cerca de $2,1 \mathrm{mg} / \mathrm{L}$ de fósforo total no efluente final, $1,8 \mathrm{mg} / \mathrm{L}$ refere-se a matéria particulada e apenas $0,2 \mathrm{mg} / \mathrm{L}$ refere-se a fósforo dissolvido. Comparando-se este resultado com os valores sugeridos por VAIOPOULOU et al (2007) para o efluente final de um sistema UCT modificado de 0,2 $\mathrm{mg} / \mathrm{L}$ pode-se notar que os resultados da planta piloto estudada estão próximos aos resultados de outros autores estudados.

Já SCHLEGEL (1992) e KAYSER et al (1992) obtiveram concentrações de fósforo no efluente final de $1,8 \mathrm{mg} / \mathrm{L}$ e $2,8 \mathrm{mg} / \mathrm{L}$ respectivamente. Deve-se levar em conta que estes dois autores obtiveram um afluente à planta com concentrações acima de $10 \mathrm{mg} / \mathrm{L}$. 
Estes resultados são próximos aos valores obtidos para o fósforo total da planta piloto estudada.

Deve-se levar em conta que muitos dos autores utilizados como base para este estudo utilizaram efluentes sintéticos, sendo que o presente estudo utilizou esgoto doméstico, o que pode influenciar a comparação dos resultados. BRDJANOVIC et al (2000) obtiveram para uma estação em larga escala valores de $0,6 \mathrm{mg} / \mathrm{L}$ de fósforo no efluente e VAN VELDHUIZEN et al (1999) 1,8 mg/L para uma outra estação em larga escala. Desta forma, pode-se sugerir que a procedência do esgoto pode ter uma grande influência no resultado final obtido para o fósforo no efluente.

\subsection{2 Ácidos Orgânicos Voláteis}

As tabelas 43 e 44 apresentam os resultados para os parâmetros básicos estatísticos para AOV.

Tabela 43 - Estatística Descritiva dos Resultados das Análises Físico-Químicas para o parâmetro AOV - Etapa

\begin{tabular}{|l|c|c|c|c|}
\hline \multicolumn{5}{|c|}{ Ácidos Orgânicos Voláteis (AOV) } \\
\hline \multirow{3}{*}{ Parâmetro } & $\begin{array}{c}\text { Ponto } \\
\text { Amostragem }\end{array}$ & $\begin{array}{c}\text { Ponto } \\
\text { Amostragem }\end{array}$ & $\begin{array}{c}\text { Ponto } \\
\text { Amostragem }\end{array}$ & $\begin{array}{c}\text { Ponto } \\
\text { Amostragem }\end{array}$ \\
\cline { 2 - 5 } & $\mathbf{1}$ & $\mathbf{2}$ & $\mathbf{3}$ & $\mathbf{4}$ \\
\hline Média & $\mathrm{mg} / \mathrm{L}$ & $\mathrm{mg} / \mathrm{L}$ & $\mathrm{mg} / \mathrm{L}$ & $\mathrm{mg} / \mathrm{L}$ \\
\hline Máximo & 144 & 76 & 61 & 48 \\
\hline Mínimo & 48 & 158 & 154 & 125 \\
\hline Mediana & 86 & 38 & 19 & 14 \\
\hline Desvio & & 72 & 58 & 38 \\
\hline Padrão & 26 & 35 & 35 & 32 \\
\hline CV(\%) & $29 \%$ & $46 \%$ & $58 \%$ & $66 \%$ \\
\hline AT & 96 & 120 & 134 & 110 \\
\hline
\end{tabular}

Fonte: Autor 
Tabela 44 - Estatística Descritiva dos Resultados para as Análises Físico-Químicas para o parâmetro AOV Etapa 2

\begin{tabular}{|l|c|c|c|c|}
\hline \multicolumn{5}{|c|}{ Ácidos Orgânicos Voláteis (AOV) } \\
\hline \multirow{2}{*}{ Parâmetro } & $\begin{array}{c}\text { Ponto } \\
\text { Amostragem 1 }\end{array}$ & $\begin{array}{c}\text { Ponto } \\
\text { Amostragem 2 }\end{array}$ & $\begin{array}{c}\text { Ponto } \\
\text { Amostragem 3 }\end{array}$ & $\begin{array}{c}\text { Ponto } \\
\text { Amostragem 4 }\end{array}$ \\
\cline { 2 - 5 } & $\mathrm{mg} / \mathrm{L}$ & $\mathrm{mg} / \mathrm{L}$ & $\mathrm{mg} / \mathrm{L}$ & $\mathrm{mg} / \mathrm{L}$ \\
\hline Média & 105 & 39 & 34 & 31 \\
\hline Máximo & 125 & 58 & 38 & 34 \\
\hline Mínimo & 72 & 24 & 29 & 24 \\
\hline Mediana & 110 & 36 & 34 & 31 \\
\hline Desvio & & & & \\
Padrão & 22,1 & 16,3 & 3,1 & 3,6 \\
\hline CV(\%) & $21 \%$ & $42 \%$ & $9 \%$ & $12 \%$ \\
\hline AT & 53 & 34 & 10 & 10 \\
\hline
\end{tabular}

Fonte: Autor

As figuras 79 e 80 apresentam os gráficos boxplot para o parâmetro AOV para as duas etapas de experimentação.

Figura 79 - Gráfico Boxplot para o parâmetro AOV - Etapa 1

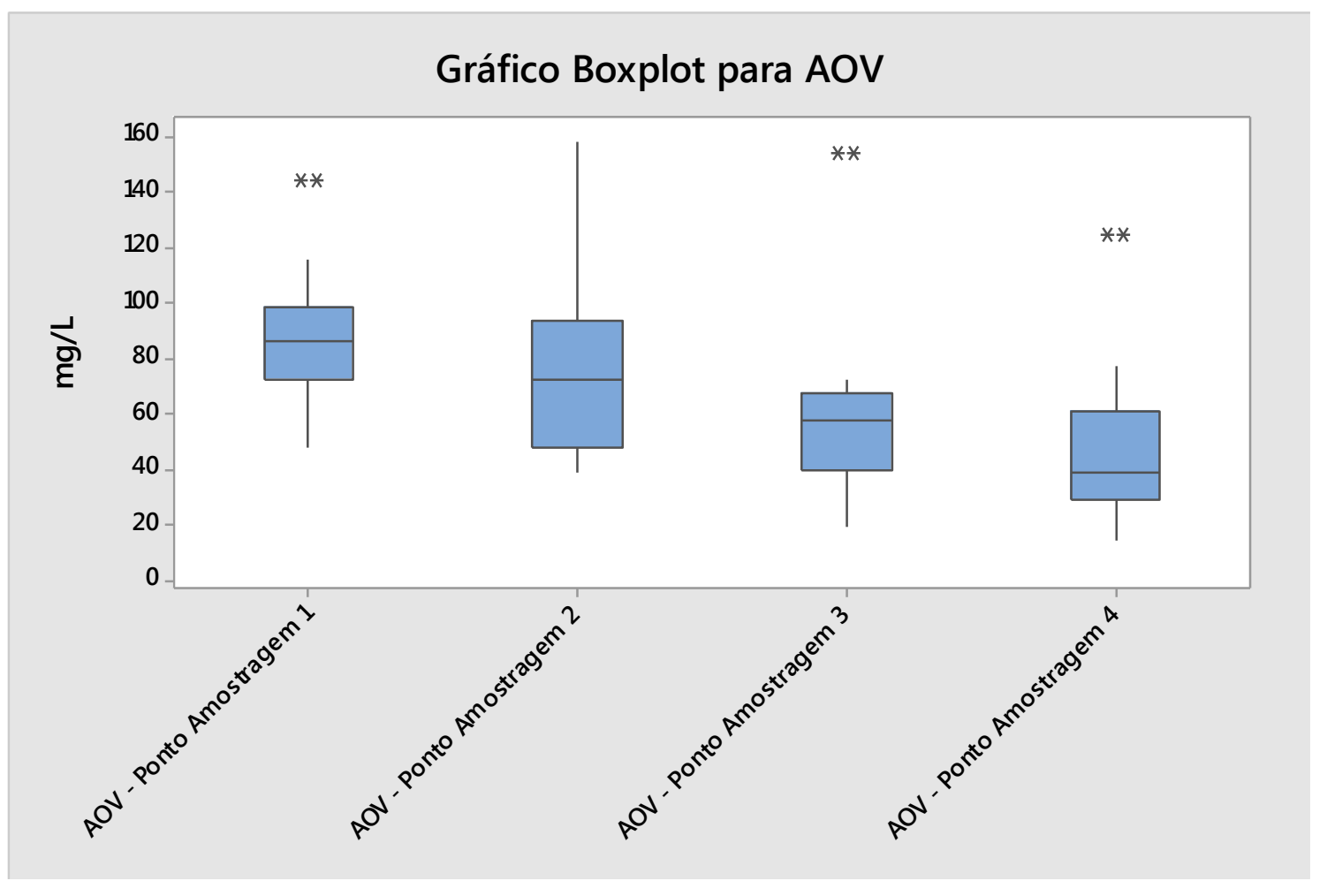

Fonte: Autor 
Figura 80 - Gráfico Boxplot para o parâmetro AOV - Etapa 2

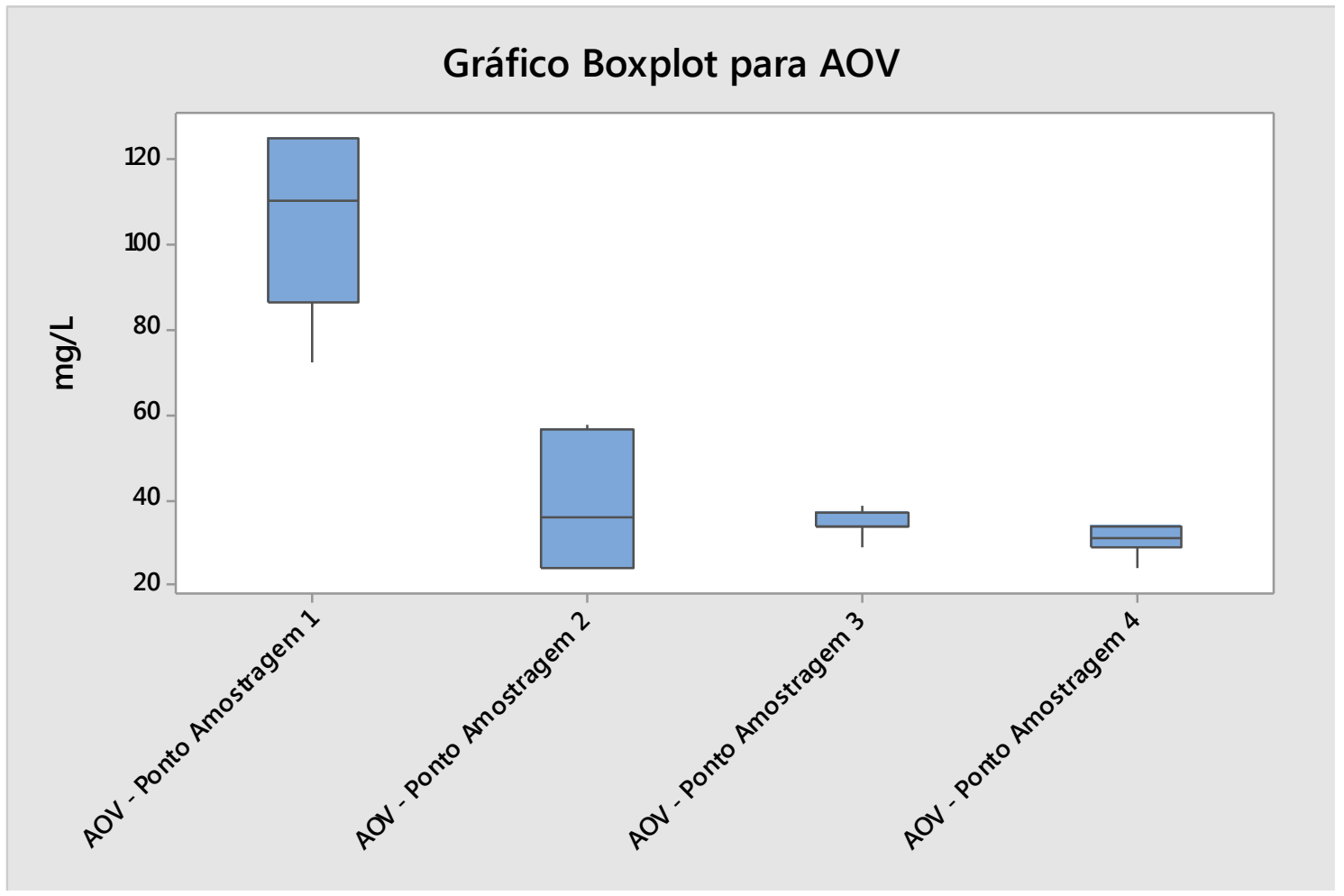

Fonte: Autor

As séries históricas para AOVs estão apresentados no gráfico da Figura 81.

Figura 81 - Gráfico da série histórica para o parâmetro AOV

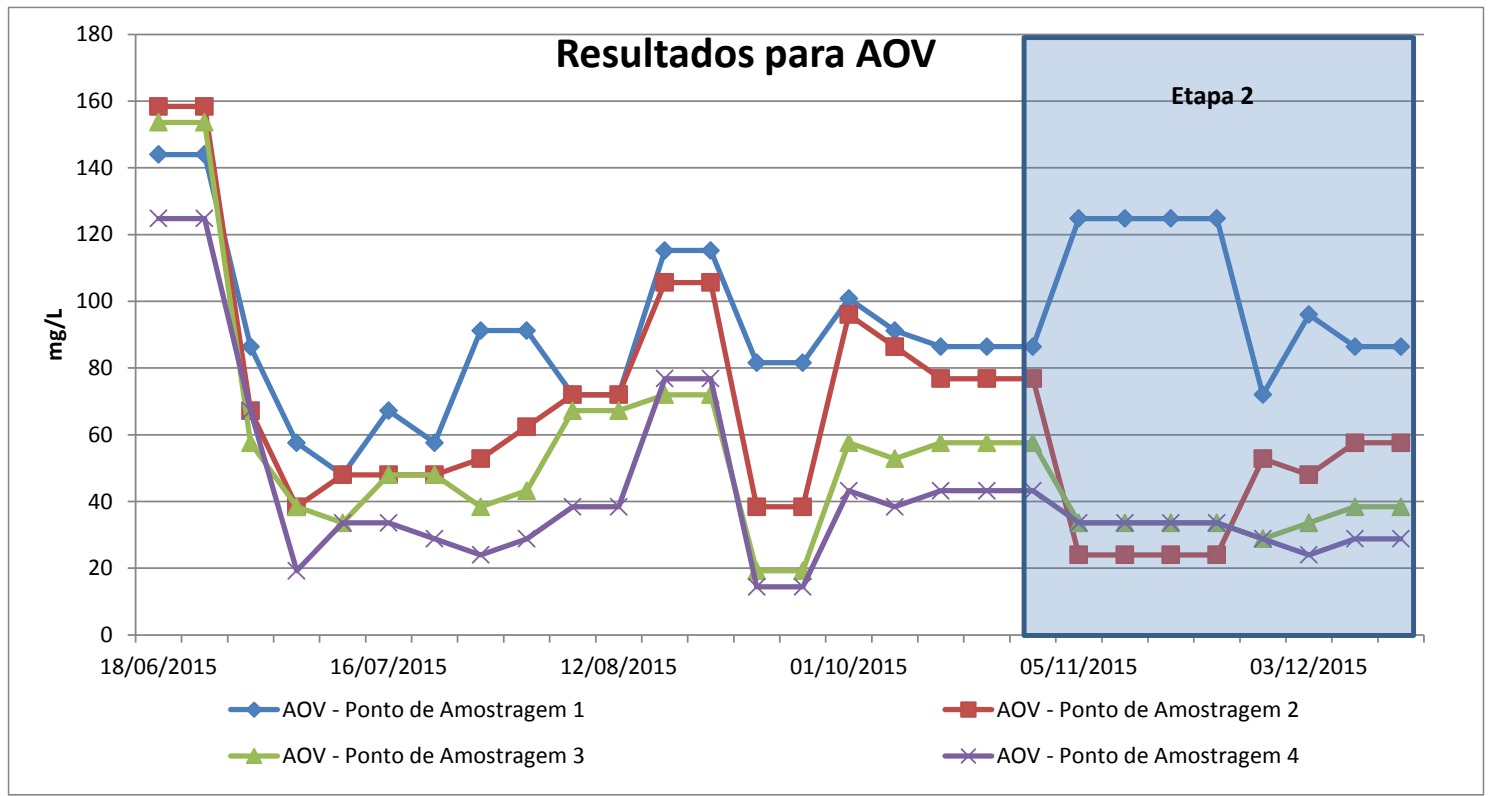

Fonte: Autor

A análise de geração de AOVs devido à câmara anaeróbia chicaneada é um dos objetivos desta pesquisa. Foi realizado teste de hipóteses para avaliar se os valores 
obtidos na saída da camara anaeróbia são superiores à entrada desta câmara (Pontos de Amostragem 1 e 2) considerando as duas etapas de experimentação de modo a avaliar aumentos nas produções de AOVs.

Executando teste de hipóteses no ponto de amostragem 1 e 2 para avaliar a real geração de AOVs na Câmara Anaeróbia e considerando-se que uma distribuição T-student e nível de confiança de 95\%, as hipóteses para o parâmetro foram:

H0: AOVs Ponto de Amostragem 1 - etapa $1=$

AOVs Ponto de Amostragem 1 - etapa 2(158A)

H1: AOVs Ponto de Amostragem 1 - etapa $1 \neq$

AOVs Ponto de Amostragem 1 - etapa 2 (158B)

\begin{tabular}{|c|c|c|}
\hline Valor de $\mathbf{T}$ & Graus de liberdade & Valor P \\
\hline$-1,67$ & 14 & 0,1175 \\
\hline
\end{tabular}

Aceita-se $\mathrm{H} 0$ e considera-se que que o AOV na entrada da camara anaeróbia se manteve com as mesmas características ao longo do período de experimentação.

H0: AOVs Ponto de Amostragem 2 - etapa $1=$

AOVs Ponto de Amostragem 2 - etapa 2(159A)

H1: AOVs Ponto de Amostragem 2 - etapa $1 \neq$

AOVs Ponto de Amostragem 2 - etapa 2 (159B)

\begin{tabular}{|c|c|c|}
\hline Valor de T & Graus de liberdade & Valor P \\
\hline 3,81 & 25 & 0,0008 \\
\hline
\end{tabular}

Os resultados mostram que a hipótese H0 deve ser rejeitada e, portanto, houve variação entre o AOV na saída da câmara anaeróbia entre as 2 etapas de experimentação.

H0: AOVs Ponto de Amostragem 1 - etapa $1=$ AOVs Ponto de Amostragem 2 - etapa 1(160A)

H1: AOVs Ponto de Amostragem 1 - etapa $1 \neq$ AOVs Ponto de Amostragem 2 - etapa 1 (160B) 


\begin{tabular}{|c|c|c|}
\hline Valor de $\mathbf{T}$ & Graus de liberdade & Valor P \\
\hline 1,29 & 34 & 0,2054 \\
\hline
\end{tabular}

Neste caso aceita-se H0 e considera-se que não houve diferença entre as concentrações de AOV na entrada e saída da câmara anaeróbia, o que indica que uma possível não formação de AOVs nesta câmara.

H0: AOVs Ponto de Amostragem 1 - etapa $2=$ AOVs Ponto de Amostragem 2 - etapa 2(161A)

H1: AOVs Ponto de Amostragem 1 - etapa $2 \neq$ AOVs Ponto de Amostragem 2 - etapa 2 (161B)

\begin{tabular}{|c|c|c|}
\hline Valor de $\mathbf{T}$ & Graus de liberdade & Valor P \\
\hline 6,71 & 12 & $<0,0001$ \\
\hline
\end{tabular}

Neste caso rejeita-se H0 e considera-se que houve variação de concentração de AOVs na câmara anaeróbia. No entanto, pelos resultados obtidos pode-se observar que as concentrações de AOVs na entrada da câmara anaeróbia são maiores do que sua saída.

Segundo HENZE (2008), esgotos municipais tem concentrações de AOVs entre 10 e 80 mg/L. Pelos resultados obtidos não há indícios de geração de AOVs na câmara anaeróbia, sendo que pode-se inferir que pelo sistema de bombeamento até a entrada da planta piloto ser composto por dois conjuntos moto-bomba, assim como pelo fato de haver um decantador primário na entrada da planta UCT modificado, o tempo de detenção do esgoto bruto em condições anaeróbias é elevado e o esgoto já chega à câmara anaeróbia com a DQO rapidamente biodegradável convertida em AOVs. Segundo METCALF \& EDDY (2002) para cada 7 a 10 mg/L de AOV há uma remoção de aproximadamente 0,5 a 1,0 mg-P/L de fósforo.

VAN HAANDEL (1999) considera que a liberação de fósforo no reator anaeróbio é proporcional a uma constante ( $f_{\text {pr }} 0,5 \mathrm{mg}$ P/mg DQO) e a concentração de AOV.

$$
\text { Fosfóro liberado na fase líquida }=S_{A O V} f_{p r} \text { (162) }
$$

Para a etapa 1 de experimentação foram sequestrados $41 \mathrm{mg} / \mathrm{L}$ de AOV entre a entrada do sistema e a saída do reator anóxico 2 sendo que utilizando-se a equação 162 
presume-se uma liberação de 20,5 mg/L de Fósforo. Para a etapa 2 de experimentação foram sequestrados $74 \mathrm{mg} / \mathrm{L}$ de AOV sendo que pode-se supor uma liberação de 37 $\mathrm{mg} / \mathrm{L}$ de fósforo no meio líquido.

No experimento, foram liberados $21,7 \mathrm{mg} / \mathrm{L}$ de fósforo total no meio líquido para a etapa 1 de experimentação e 29,1 mg/L para a etapa 2 de experimentação. Desta forma o coeficiente de proporcionalidade obtido para a etapa 1 e 2 de experimentação foram 0,53 e 0,39 respectivamente. Pode-se observar que estas taxas se aproximaram bastante dos valores preconizados por VAN HAANDEL (1999).

No entanto, conforme observado nas análises estatísticas não foram observadas gerações de AOV no reator anaeróbio nas duas fases de experimentação. Pelo fato de ter sido utilizado um decantador primário e o sistema de recalque de esgoto bruto entre a fonte geradora e a entrada da planta piloto possuir algumas etapas sujeitas a anaerobiose pode-se inferir que houve geração de AOV nestas etapas intermediárias, sendo que ao chegar ao reator anaeróbio já havido sido consumida toda a matéria orgânica rapidamente biodegradável para a geração de AOVs.

Ressalta-se que o decantador primário é essencial para a geração de lodo primário para o processo subsequente de geração de estruvita.

Desta forma, pelos resultados obtidos não é possível afirmar que as intervenções sugeridas de dotação de chicanas no reator anaeróbio do sistema UCT modificado surtiram efeito.

\subsection{Balanço de Massa}

Neste item serão apresentados os balanços de massa para os resultados obtidos para cada uma das etapas de experimentação na planta piloto UCT modificada.

\subsubsection{Etapa 1}


Figura 82 - Balanço de Massa para a Etapa 1 de experimentação

\section{HISTÓRICO DE OPERAÇÃO}

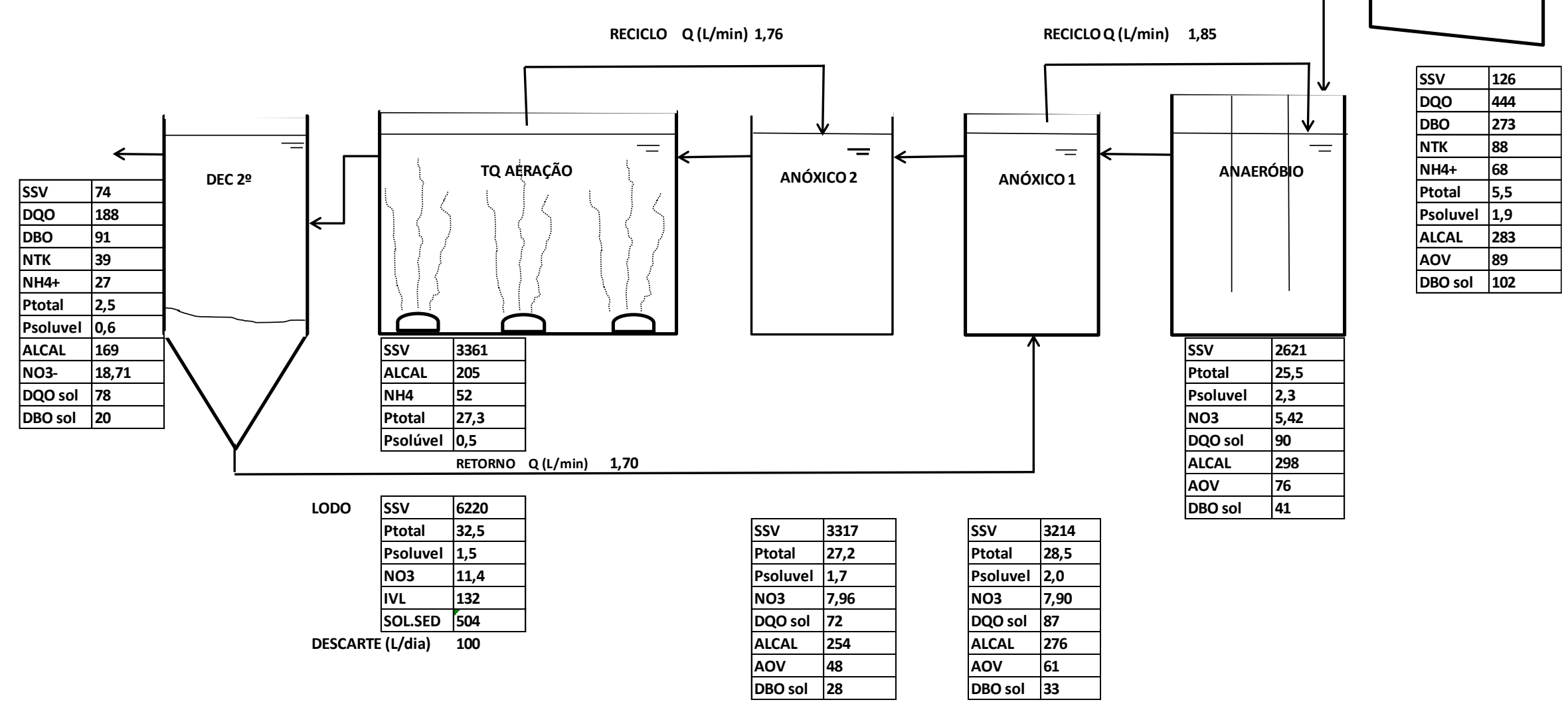

Fonte: Autor 
5.6.2 Etapa 2

Figura 83 - Balanço de Massa para a Etapa 2 de experimentação

UCT IDADE DO LODO: ${ }^{10 \mathrm{~d}}$ HISTÓRICO DE OPERAÇÃO

$\mathrm{A} / \mathrm{M}: \quad 0,40$

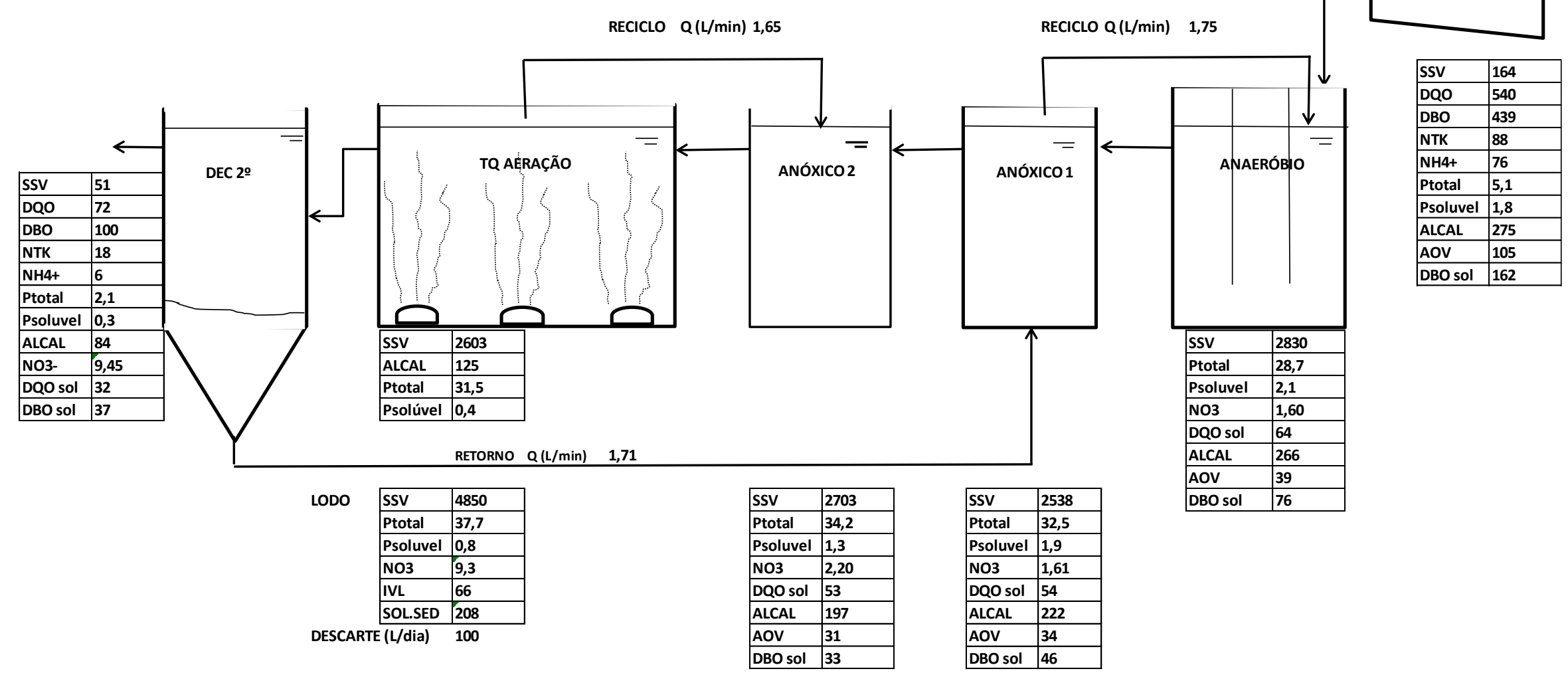

Fonte: Autor 


\subsubsection{Análise do balanço de Massa}

Pelos balanços de massa apresentados durante a primeira etapa de experimentação foram constatados remoções de matéria orgânica em média de $83 \%$ para um tempo de detenção hidráulica de 11 horas na Etapa 1 de experimentação e 86\% em média para um tempo de detenção hidráulica de 10 horas na Etapa 2.

As cargas aplicadas nos reatores são apresentadas na tabela 32.

Em termos de matéria nitrogenada foram observados em média remoções de 55\% para a Etapa 1 e em média $79 \%$ para a Etapa 2.

Em ambas as etapas de experimentação foram constatadas que as concentrações de AOVs na entrada do reator anaeróbio eram maiores do que as concentrações na saída desta unidade, porém as concentrações de fósforo solúvel foram maiores nas saídas do reator anaeróbio do que na entrada.

Em termos de fósforo foram observadas taxas de remoção do processo de aproximadamente $55 \%$ para a Etapa 1 de experimentação e de $60 \%$ para a Etapa 2 de experimentação. De acordo com o teste de hipóteses realizado neste trabalho, o desempenho do sistema UCT modificado foi semelhante para o quesito fósforo tanto solúvel quanto total para as duas etapas. Conforme discutido previamente, a planta piloto teve problemas frequentes de escape de sólidos do decantador secundário devido à velocidade de rotação do raspador de lodo o que pode ter prejudicado os resultados de fósforo total deste experimento.

A tabela 45 apresenta os carregamentos no sistema durante as duas etapas de experimentação. Deve-se levar em conta que houve um aumento no carregamento de matéria orgânica na etapa 2 de experimentação. 
Tabela 45 - Cargas aplicadas nos Reatores para as Etapas de Experimentação

\begin{tabular}{|c|c|c|}
\hline \multirow{2}{*}{ Data } & COV & CNV \\
\cline { 2 - 3 } & kg/m3.d & kg/m3.d \\
\hline $18 / 06 / 2015$ & 0,60 & 0,15 \\
\hline $26 / 06 / 2015$ & 0,68 & 0,20 \\
\hline $29 / 06 / 2015$ & 0,68 & 0,18 \\
\hline $02 / 07 / 2015$ & 0,71 & 0,19 \\
\hline $07 / 07 / 2015$ & 0,64 & 0,18 \\
\hline $16 / 07 / 2015$ & 0,47 & 0,21 \\
\hline $21 / 07 / 2015$ & 0,47 & 0,19 \\
\hline $30 / 07 / 2015$ & 0,57 & 0,21 \\
\hline $05 / 08 / 2015$ & 0,67 & 0,24 \\
\hline $07 / 08 / 2015$ & 0,67 & 0,22 \\
\hline $12 / 08 / 2015$ & 0,67 & 0,22 \\
\hline $01 / 09 / 2015$ & 0,52 & 0,15 \\
\hline $03 / 09 / 2015$ & 0,52 & 0,19 \\
\hline $10 / 09 / 2015$ & 0,60 & 0,21 \\
\hline $17 / 09 / 2015$ & 0,52 & 0,16 \\
\hline $01 / 10 / 2015$ & 0,46 & 0,19 \\
\hline $08 / 10 / 2015$ & 0,60 & 0,19 \\
\hline $15 / 10 / 2015$ & 0,59 & 0,19 \\
\hline $22 / 10 / 2015$ & 0,52 & 0,15 \\
\hline $27 / 10 / 2015$ & 0,63 & 0,18 \\
\hline $05 / 11 / 2015$ & 0,91 & 0,23 \\
\hline $10 / 11 / 2015$ & 0,71 & 0,22 \\
\hline $12 / 11 / 2015$ & 0,84 & 0,17 \\
\hline $19 / 11 / 2015$ & 0,80 & 0,14 \\
\hline $26 / 11 / 2015$ & 1,11 & 0,19 \\
\hline $03 / 12 / 2015$ & 1,32 & 0,21 \\
\hline $08 / 12 / 2015$ & 1,53 & 0,26 \\
\hline $10 / 12 / 2015$ & & 0,25 \\
\hline & & \\
\hline & & \\
\hline & & \\
\hline & & \\
\hline & & \\
\hline & & \\
\hline$y$
\end{tabular}

Fonte: Autor

Pode-se observar que houve um aumento na etapa 2 de experimentação causado por uma elevação da DQO afluente à planta piloto e isso ocasionou um aumento na relação alimento/microrganismo desta etapa.

De acordo com os dados levantados, no sistema houve uma taxa de aplicação de 0,29 kg DQO/kgSSV.d no sistema e de $0,18 \mathrm{~kg}$ DBO/kg SSV.d na etapa 1 de experimentação e de 0,49 kg DQO/kgSSV.d e 0,40 kg DBO/kg SSV.d. Comparando-se os resultados obtidos em relação à matéria orgânica a qualidade do efluente tratado foi semelhante aos resultados obtidos por VAIOPOULOU (2008) que obteve 89\% de remoção de DQO 
e 95\% de remoção de DBO. Já ZHU (2013) obteve resultados que variaram de $85 \%$ para um tempo de detenção de 10 horas e de $95 \%$ para um tempo de detenção de 15 horas. SANTOS (2014) apresentou sob diversas condições operacionais para reatores UCT remoções de DQO que variaram de $70 \%$ a $95 \%$ dependendo das diversas condicionantes do sistema. 


\section{CONCLUSÕES}

Este estudo visou avaliar o comportamento de um sistema UCT Modificado com esgotos não sintéticos considerando potenciais melhorias que possam gerar resultados satisfatórios. As alterações sugeridas nesta pesquisas foram a transformação da câmara anaeróbia em chicaneada para avaliar uma potencial maior geração de ácidos orgânicos voláteis e a microaeração das câmaras anóxicas para avaliar o efeito desta intervenção na nitrificação, desnitrificação e no processo de remoção biológica de fósforo como um todo.

Para as condições operacionais testadas, conclui-se que:

O lodo gerado não foi preferencialmente poli-p, mas um lodo misto, similar aos lodos encontrados em plantas em larga escala. Pode-se verificar que o lodo gerado nesta planta obteve excelente sedimentabilidade, sendo que devido aos escapes de sólidos houve uma redução na idade de lodo real para aproximadamente 6 dias.

Com relação ao processo como um todo pode-se verificar que as eficiências na remoção de matéria orgânica foi satisfatória, cerca de $85 \%$.

Na operação do processo com a câmara anaeróbia chicaneada não foi possível observar melhorias nas gerações de AOV devido ao fato de que o esgoto bruto ter uma encaminhamento longo da geração até a entrada da planta piloto, sendo que em algumas etapas do processo de alimentação da planta pode ter ocorrido geração de AOVs nestas etapas prévias. Ressalta-se que pelos resultados obtidos e comparando-se com a literatura as concentrações de AOV na entrada da planta piloto UCT modificado foram maiores do que as concentrações encontradas na literatura. Desta forma, não foram observados neste caso resultados satisfatórios com a alteração da câmara anaeróbia.

Já com relação à microaeração das câmaras anóxicas foi mantido uma concentração de oxigênio dissolvido entre 0,1 e $0,2 \mathrm{mg} / \mathrm{L}$, o que gerou uma melhora significativa neste caso no processo de remoção biológica de nitrogênio, de 55\% na Etapa 1 para $77 \%$ na Etapa 2.

Com relação à remoção biológica de nitrogênio pode-se observar que a fase 2 de experimentação (microaeração das câmaras anóxicas) obteve resultados 
expressivamente melhores se comparados à fase anterior de experimentação sem o emprego de microaeração com resultados $20 \%$ maiores.

A remoção biológica de fósforo obteve resultados expressivos para a parcela solúvel deste nutriente com resultados pontuais de $0,2 \mathrm{mg}$ P/L. Observou-se uma frágil estabilidade de processo para a remoção deste nutriente. 


\section{- REFERÊNCIAS BIBLIOGRÁFICAS}

ALEM SOBRINHO, P., Contribuição ao estudo de remoção biológica de fósforo em excesso, de esgoto sanitário, por modificação do processo de lodos ativados. Tese apresentada à Escola Politécnica da Universidade de São Paulo como parte dos requisitos para o concurso de livre-docência junto ao Departamento de Engenharia Hidráulica e Sanitária. São Paulo, 1991.

ALI, M.I., Struvite crystallization in fed-batch pilot scale and description of solution chemistry of struvite. In Trans IChemE, Part A Vol. 85 (A3), 2007, Queensland, Australia, p 344-356

ANDREOTTOLA, G., OLIVEIRA E.L., FOLADORI P., DALLAGO L., PETERLINI R., CADONNA M, Método Respirométrico para o monitoramento de processos biológicos. Engenharia Sanitária e Ambiental. Artigo técnico, vol.10, No 1,p.14-23, 2005

APHA; AWWA; WEF. Standard methods for the examination of water and wastewater. Washington, DC, $22^{\text {th }}$ ed. 2012

BASSIN, J. P. Nitrificação de efluentes salinos em reatores de leito móvel com biofilme e biorreatores agitados. Dissertação (Mestrado) - Universidade Federal do Rio de Janeiro, Rio de Janeiro, 189 p. 2008.

BASSIN, J. P. Remoção biológica de nutrientes em sistemas compactos e estudo da diversidade microbiana por técnicas de biologia molecular. Tese (Doutorado) Universidade Federal do Rio de janeiro, UFRJ/COPPE/ Programa de Engenharia Química, 2012. Rio de Janeiro: UFRJ/COPPE, 209 p. 2012.

BASSIN, J. P.; KLEEREBEZEM, R.; DEZOTTI, M. W. C.; VAN LOOSDRECHT, M. C. M. Simultaneous nitrogen and phosphate removal in aerobic granular sludge reactors operated at different temperatures. Water Res. 46, pp. 3805-3816. 2012.

BRDJANOVIC, D., SLAMET, A., VAN LOOSDRECHT, M.C.M., HOOIJMANS, C.M., ALAERTS, G. J., HEIJNEN, J. J., Impact of Excessive Aeration on Biological Phosphorus Removal from Wastewater. Water Research. v. 32, pp. 200-208. 1998a. 
BRDJANOVIC, D., VAN LOOSDRECHT, M.C.M., VERSTEEG, P., HOOIJMANS C. M., AlaerTS, G.J., HEIJNEN, J. J., Modeling COD, $\mathbf{N}$ and $\mathbf{P}$ removal in a fullscale WWTP Haarlem Waarderpolder. Water Research. v. 34, No. 3, pp-846-858, 2000

BUENO, R.F, Nitrificação e desnitrificação simultânea em reator com biomassa em suspensão e fluxo contínuo de esgoto. Tese apresentada ao Programa de PósGraduação em Saúde Pública da Universidade de São Paulo. São Paulo, 2011.

BRASIL, 2005. Ministério do Desenvolvimento Urbano e Meio Ambiente CONAMA. RESOLUÇÃO N $^{\circ} 430$ DE 13 DE MAIO DE 2011. Disponível em: http://www.mma.gov.br/port/conama/legiabre.cfm?codlegi=646;

CAMPOS, J. R. (COORDENADOR), Tratamento de esgotos sanitários por processo anaeróbio e disposição controlada no solo. ABES, Rio de Janeiro, Projeto PROSAB, 1999

CARLSON, C.A. et al, Overland flow Treatment of wastewater. U.S. Army Engineer Waterways Experiment Station, Vicksburg, 1974

CATUNDA, S. Y. C., DEEP, G. S., VAN HAANDEL, A. C., FREIRE, R. C. S., Fast online measurement of the respiration rate in activated sludge systems. IEEE Instrumentation and measurement technology conference Bruxelas, Bélgica, Junho 4-6., 1996

CHEN, Y., PENG, C., WANG, J., YE, L., ZHANG, L., PENG, Y., Effect of nitrate recycling ratio on simultaneous biological nutrient removal in novel anaerobic/anoxic/oxic $\left(\mathrm{A}^{2} / \mathrm{O}\right)$ - biological aerated filter (BAF) system. In: Bioresource Technology, 102, 2011, p 5722-5727.

CHEN, Y., RANDALL, A. A., MCCUE, T., The efficiency of enhanced biological phosphorus removal from real wastewater affected by different ratios of acetic to propionic acid. Water Res. 38 (1): pp. 27-36. 2004.

COStA, A.G., FERREIRA, A.F., VAN HAANDEL, A. C., Monitoramento da atividade bacteriana de um sistema de lodos ativados bardenpho por meio da respirometria. Engenharia Sanitária e Ambiental. Artigo técnico, vol.12, No 1,p.17-23, 2007. 
DOWNING, A L, PAINTER, H A, KNOWLES G, Nitrification in the activated sludge process In J.Proc Inst Sew Purif, 64,2, 1964, p 130-158.

FILIPE, C. D. M., DAIGGER, G. T., GRADY, C. P. L. Jr, A metabolic model for acetate uptake under anaerobic conditions by glycogen accumulating organisms: Stoichiometry, kinetics and the effects of pH. Biotechnol. Bioeng. 76, pp. 17-31. $2001 b$.

FILIPE, C. D. M., DAIGGER, G. T., GRADY, C. P. L. Jr., Stoichiometry and kinetics of acetate uptake under conditions by an enriched culture of phosphorusaccumulating organisms at different pHs. Biotechnol. Bioeng. 76, pp. 32-43. 2001a.

HENZE, M., GUJER, W., MINO, T., MATSUO, T., WENTZEL, M. C., MARAIS, G. V. R., VAN LOOSDRECHT, M. C. M., Activated Sludge Model No. 2, ASM 2 D. Water Science and Technology. 39 (1): pp. 165-182. 1999.

HENZE, M., HARREMOËS, P., LA COUR JANSEN, J., ARVIN, E., Wastewater Treatment: biological and chemical process. $3^{\mathrm{a}}$ ed., Berlin: Springer-Verlag. 2002.

HENZE, M., VAN LOOSDRECHT, M. C. M., EKAMA, G. A., BRDJANOVIC, D., Biological Wastewater Treatment Principles, Modelling and Design. $1^{\mathrm{a}}$ ed., Londres: IWA Publishing. 2008.

HOLMAN, J. B., WAREHAM, D.G., COD, ammonia and dissolved oxygen time profiles in the simultaneous nitrification/denitrification process. Biochemical Engineering Journal , Vol.22, 2005, Christchurch, Nova Zelândia, p 125-133

JÖNSSON, H. Source separation of human urine - separation efficiency and effects on water emissions, crop yield, energy usage and reliability. In: GTZ, editor. First International Conference on Ecological Sanitation, 5-8 November 2001, Nanning, PR China; 2001. p. 39- 45.

KAYSER, R., STOBBE, G., WERNER, M., Operational results of the Wolfsburg wastewater treatment plant, Water Sci. Technol. 25 (6) pp. 203-209, 1992

KUBA, T.,VAN LOOSDRECHT, M.C.M., BRANDSE, F. A., HEIJNEN, J.J., Occurrence of denitrifying phosphorous removing bacteria in modified UCT-type wastewater treatment plants. IN: Wat Res, Vol 31, No 4, 1997, p 777-786 
KUBA, T., VAN loOsdrecht, M. C. M., HeIJNEN, J. J., Phosporus and nitrogen removal with minimal COD requirement by integration of denitrifying dephosfatation and nitrification in a two-sludge system, Water Research. v. 30, n. 7, pp. 1702-1710. 1996.

LeSOUEF A., PAYRAUdeAu M., ROGAlla, F., KlEIBER, B., Optimising nitrogen removal reactor configurations by on-line calibration of the IAWPRC activated sludge model, Water Sci. Technol. 25 (60, pp. 105-123, 1992

LIU, W-T., MINO, T., NAKAMURA, K., MATSUO, T., Glycogen accumulating population and its anaerobic substrate uptake in anaerobic-aerobic activated sludge without biological phosphorus removal. Water Res. 30 (1): pp. 75-82. 1996.

LOPEZ-VAZQUEZ, C. M., The competition between polyphosphate-accumulating organisms and glycogen-accumulating organisms: temperature effects and modelling. Thesis (Ph.D.) - Delft University of Technology. 256 p. 2009.

LOPEZ-VAZQUEZ, C. M.; OEHMEN, A.; HOOIJMANS, C. M.; BRDJANOVIC, D.; GIJZEN, H. J.; YUAN, Z. G.; VAN LOOSDRECHT, M. C. M. Modeling the PAOGAO competition: effects of carbon source, $\mathrm{pH}$ and temperature. Water Research 43 (2): pp. 450-462. IF: 4.655, CN: 65. 2009.

MARTI, N., FERRER, J., SECO, A., BOUZAS, A. Optimisation of sludge line management to enhace phosphorus recovery in WWTP, Water Research, Vol. 42, Valencia, 2008, p 4609-4618

MD. IMTIAJ A., SCHNEIDER, P. A. An approach of estimating struvite growth kinetic incorporating thermodynamic and solution chemistry, Kinect and process description. Chemical Engineering Science, Vol. 63., Brisbane, Austrália, 2008, p 3514-3525

METCALF \& EDDY, Wastewater engineering, treatment and reuse, McGraw-Hill Higher Education, Fourth edition, New York, 2002

MINO, T., VAN LOOSDRECHT, M. C. M., HEIJNEN, J. J., Microbiology and biochemistry of the enhanced biological phosphate removal process. Water Res. 32 (11): pp. 3193-3207. 1998. 
MONOD, J. The growth of bacterial cultures, annual Review of Microbiology. 3, pp. 371-394. 1949.

MOTA, F. S.; VON SPERLING, M. (Coordenadores). Nutrientes de Esgoto Sanitário: Utilização e Remoção. Projeto PROSAB. Edital 5, Tema 2. Rio de Janeiro, RJ. ABES, 2009.

MUNCH, E. V., LANT, P, KELLER, J, Simultaneous nitrification and denitrification in batch reactors, Wat. Res. Vol 30, Número 2, pág 277-284, 1996.

OEHMEN, A., ZENG, R. J., SAUNDERS, M. A., BLACKALL, L. L., KELLER, J., YUAN, Z., Anaerobic and aerobic metabolism of glycogen-accumulating organisms selected with propionate as the sole carbon source. Microbiology. 152, pp. 2767-2778. 2006.

OEHMEN, A., YUAN, Z., BLACKALL, L. L., KELLER, J., Short-term effects of carbon source on the competition of polyphosphate accumulating organisms and glycogen accumulating organisms. Water Sci. Technol. 50, pp. 139-144. 2004.

PAI, T. Y., TSAI, Y.P. CHOU, Y.J., CHANG, H.Y., LEU, H.G. OUYANG, C.F., Microbial kinetic analysis of three different types of EBNR process, Chemosphere 55, pp. 109-118, 2004.

PASTOR, L., MANGIN, D., FERRER, J., SECO, A. Struvite formation from the supernatants of an anaerobic digestion pilot plant. In: Bioresource Technology 101, 2010, p 118-125.

PASTOR, L., MARTI, N., BOUZAS, A., SECO, A. Sewage sludge management for phosphorus recovery as struvite in EBPR wastewater treatment plants. In: Bioresource Technology 99, 2008, p 4817-4824.

PIVELI, R. P, Apresentações da disciplina PHA 5014 -Águas Residuárias I Escola Politécnica da USP, São Paulo, 2013

PROGRAMA DE PESQUISA EM SANEAMENTO BÁSICO (PROSAB). Uso Racional da Água em Edificações. 1. ed. Rio de Janeiro: ABES, 2006. 
RABINOWITZ, B, MARAIS, G v R, Chemical and Biological phosphorus removal in the activated sludge process., Research Report W 32, Dep. Of Civ. Eng. Univ. Cape Town, Rondebosch, África do Sul, 1980.

RICE, E.W., BAIRD, R. B., EATON, A. D., CLOSCERI, L. S., Standard Methods for the Examination of Water and Wastewater. American Water Works Association, 22 ${ }^{\mathrm{a}}$ Edição, Estados Unidos, 2012;

SANTOS, E. V. M. Desnitrificação em sistemas de lodo ativado. Dissertação (Mestrado) - Universidade Federal de Campina Grande (UFCG), Campina Grande, 136 p. 2009

SANTOS, E. V. M, Estratégias para predominância de Organismos acumuladores de fósforo em sistemas de lodo ativado e respirometria aplicada à biodesfosfatação. 267p. Dissertação (Doutorado) - Universidade Federal de Campina Grande (UFCG), Campina Grande, 2014.

SATOH, H., OKUDA, E., MINO, T., MATSUO, T., Calibration of kinetic parameters in the IAWQ activated sludge model: a pilot scale experience. Water Sci. Tech. 42 (3-4): pp. 29-34. 2000.

SAUNDERS, A. M., OEHMEN, A., BLACKALL, L. L., YUAN, Z.; KELLER, J., The effect of GAOs (glycogen accumulating organisms) on anaerobic carbon requirements in full-scale Australian EBPR (enhanced biological phosphorus removal) plants. Water Sci Technol. 47, pp. 37-43. 2003.

SCHLEGEL, S., Operational results of waste water treatment plants with biological n and P elimination, Water Sci. Technol. 25 (4-5), pp. 241-247. 1992

SCHMIDELL, W.; LIMA, U. A.; AQUARONE, E.; BORZANI, W. Biotecnologia Industrial. São Paulo, Edgard Blücher Ltda, v. 2, 2001.

SCHMIDELL, W.; SOARES, H. M.; ETCHEBEHERE, C.; MENES, R. J.; BERTOLA, N. C.; CONTRERAS, E. M. Tratamento biológico de águas residuárias. Florianópolis: Gráfica Paper print, 720 p. 2007. 
SHU, L., SCHNEIDER, P., JEGATHEESAN, V., JOHNSON, J.. An economic evaluation of phosphorus recovery as struvite from digestor supernatant Bioresource Technology, Vol. 97, 2006, Townsville, Australia. p 2211-2216

SISTEMA NACIONAL DE INFORMAÇÕES SOBRE SANEAMENTO, 2013. Diagnóstico dos serviços de Água e Esgoto. Disponível em: http://www.snis.gov.br/diagnostico-agua-e-esgotos/diagnostico-ae-2013;

SLATER, N. Sequencing batch reactor: Cost Effective Wastewater Treatment. 32nd Annual Operators Seminar, Alberta Water \& Wastewater Operators Associaton, Alberta, 2006

SMOLDERS, G. J. F., VAN DER MEIJ, J., VAN LOOSDRECHT, M. C. M., HEIJNEN, J. J., A structured metabolic model for anaerobic and aerobic stoichiometry and kinetics of the biological phosphorus removal process. Biotechnol. Bioeng. 47, pp. 277-287. 1995.

THOMAS, M., WRIGHT, P., BLACKALL, L., URBAIN, V.; KELLER, J., Optimisation of Noosa BNR plant to improve performance and reduce operating costs. Water Sci. Technol. 47 (12): pp. 141-148. 2003.

VAIOUPOUlOU, E., AIVASIDIS, A., A modified UCT method for biological nutrient removal: Configuration and Performance. IN: Chemosphere, Vol. 72, $\mathrm{p}$ 1062-1068, Xanthi, 2008

VAN HAANDEL, A. C., CATUNDA, P. F. C, Determinação da taxa de consumo de oxigênio. In Revista Engenharia Sanitária 21,4, PP 481-488, 1982.

VAN HAANDEL , A, MARAIS G. O Comportamento do sistema de lodo ativado Teoria e aplicações para projetos e operação. Ed. Universidade Federal da Paraíba, Campina Grande, 1999

VAN HAANDEL, A. C. e VAN DER LUBBE, J. Handbook Biological Wastewater Treatment - design and optimization of activate sludge systems, 2007

VAN HAANDEL, A. C., VAN DER LUBBE, J., Handbook biological waste water treatment: design and optimization of activated sludge systems. 2. ed. Londres UK: IWA Publishing of Alliance House, 816 p. 2012. 
VAN VELDHUIZEN, J. M., VAN LOOSDRECHT, M. C. M., HEIJNEN, J. J., Modelling biological phosphorus and nitrogen removal in a full scale activated sludge process. Water Research Vol. 33, No. 16, pp. 3459-3468, 1999.

VON SPERLING, M. Lodos Ativados 2. ed. Belo Horizonte: Departamento de Engenharia Sanitária e Ambiental, Universidade Federal de Minas Gerais, 1997.

UENO,Y., FUJII, M. Three years experience of operating and selling recovered struvite from full-scale plant. In: Environmental Technology, Vol. 22. ed Selper Ltd, 2001, Kyoto, Japão. p 1373-1381

UYSAL, A., DILSAD YILMAZEL, Y., DEMIRER, G. N. The determination of fertilizer quality of the formed struvite from effluent of a sewage sludge anaerobic digestor. In: Journal of Hazardous Materials, Vol. 181. ed Elsevier Ltd, 2010, Turquia. p 248-254

WANG, J., PENG, Y., WANG, S., GAO, Y., Nitrogen Removal by Simultaneous Nitrification and Denitrification via nitrite in sequencial Hybrid Biological, Chinese Journal of Chemical Engineering, 16(5), p 778-784, 2008

WENTZEL, M. C., EKAMA, G.A., DOLD, P.L., MARAIS G.v.R. Biological excess phosphorus removal - Steady state process design, Water SA 16, (1) p 29-47, 1990

WENTZEL, M. C., DOLD, P. L., EKAMA, G. A., MARAIS, G. V. R., Enhanced polyphosphate organism cultures in activated sludge systems. Part III: Kinetic model. Water SA. 15 (2): pp. 89-102. 1989b.

WENTZEL, M. C., LÖTTER, L.H., LOEWNTHAL, R.E., MARAIS, G.v.R. Metabolic behavior of acinetobacter spp in enhanced biological phosphorus removal: a biochemical model. WATER SA, 12, (4) 209-224, 1986

WENTZEL, M. C., EKAMA, G.A., DOLD, P.L., MARAIS G.v.R. Kinetics of biological phosphorus release, Water Science Tech, 17 (11/12), p 57-71, 1985

WENTZEL, M. C., LOEWENTHAL, R.E, EKAMA, G.A., MARAIS G.v.R. Enhanced polyphosphate organism cultures in activated sludge systems: part II Experimental behavior, Water SA,15 (2), p 71-88, 1988 
WENTZEL, EKAMA, G.A., MARAIS G.v.R. Processes and modeling nitrification denitrification biological excess phosphorus removal systems - A review, Water Science Tech,25 (6), p 59-82, 1992

YOO, H., AHN, K., LEE, H., LEE, K., KWAK, Y., SONG, K., Nitrogen removal from synthetic wastewater by simultaneous nitrification and denitrification (SND) via nitrite in an intermittently-aerated reactor, Wat. Res., Vol. 33 Número 1, p 145154,1999

ZENG, R. J., LEMAIRE, R., YUAN, Z., KELLER, J., Simultaneous nitrification, denitrification, and phosphorus removal in a lab-scale sequencing batch reactor. Biotechnol. Bioeng. 84 (2): pp. 170-178. 2003.

ZHU, W., BO, L., YONG-DE, L., FUJUN, W, Evaluation of biological removal efficiency in a UCT process treating municipal wastewater during start-up stage. Journal of Environmental Biology. Vol 34 pp. 459-464. 2013. 


\begin{tabular}{|c|c|c|c|c|c|c|c|c|c|c|c|c|c|c|c|}
\hline \multirow{2}{*}{ Data } & \multicolumn{2}{|c|}{ Anaeróbio } & \multicolumn{2}{|c|}{ Anóxico 1} & \multicolumn{2}{|c|}{ Anóxico 2} & \multicolumn{3}{|c|}{ Tanque de Aeração } & \multirow{2}{*}{$\begin{array}{c}\text { Vazão } \\
\text { Alimentação } \\
\text { L/min }\end{array}$} & \multirow{2}{*}{$\begin{array}{c}\begin{array}{c}\text { Vazão } \\
\text { Retorno }\end{array} \\
\text { L/min }\end{array}$} & \multirow{2}{*}{$\begin{array}{c}\begin{array}{c}\text { Vazão } \\
\text { Reciclo } 1\end{array} \\
\text { L/min }\end{array}$} & \multirow{2}{*}{$\begin{array}{c}\begin{array}{c}\text { Vazão } \\
\text { Reciclo } 2\end{array} \\
\text { L/min }\end{array}$} & \multirow{2}{*}{$\begin{array}{c}\text { Temperatura } \\
\text { oC }\end{array}$} & \multirow[t]{2}{*}{ Horário } \\
\hline & pH & ORP & pH & ORP & pH & ORP & pH & ORP & OD & & & & & & \\
\hline $13 / 05 / 2015$ & 7,8 & -450 & & & & & 8 & 86 & 2,8 & 1,52 & 1,8 & 1,4 & 1,8 & & $8 \mathrm{hs}$ \\
\hline $13 / 05 / 2015$ & 7,3 & -452 & & & & & 8 & 79 & 2,2 & 1,4 & 1,72 & 1,52 & 1,8 & & $15 \mathrm{hs}$ \\
\hline $13 / 05 / 2015$ & 7,2 & -452 & & & & & 8,01 & 77 & 2,1 & 1,2 & 1,6 & 1,2 & 1,8 & & 18hs \\
\hline $14 / 05 / 2015$ & 7,6 & -461 & & & & & 8,2 & 81 & 2,6 & 1 & 1,8 & 1,8 & 1,92 & & $8 \mathrm{hs}$ \\
\hline $14 / 05 / 2015$ & 8,12 & -488 & & & & & 8,21 & 83 & 1,91 & 1 & 1,2 & 1,6 & 1 & & $18 \mathrm{hs}$ \\
\hline $15 / 05 / 2015$ & 8,2 & -500 & & & & & 8,2 & 83 & 1,9 & 1,4 & 1,8 & 1,6 & 1,8 & & 9hs \\
\hline $15 / 05 / 2015$ & 7,85 & -484 & & & & & 8,1 & 87 & 1,88 & 1 & 1,4 & 1,6 & 1,68 & & 14hs \\
\hline $16 / 05 / 2015$ & 7,82 & -455 & & & & & 8,1 & 81 & 1,88 & 0,8 & 1,2 & 1,4 & 1,4 & & 10hs \\
\hline $18 / 05 / 2015$ & 7,4 & -430 & & & & & 8,33 & 77 & 4,4 & 1,8 & 1,8 & 1,8 & 1,6 & & $8 \mathrm{hs}$ \\
\hline $18 / 05 / 2015$ & 7,5 & -428 & & & & & 8,2 & 75 & 1,88 & 1,4 & 1,6 & 1,4 & 1,6 & & $18 \mathrm{hs}$ \\
\hline $19 / 05 / 2015$ & 7,4 & -463 & & & & & 7,4 & 75 & 1,8 & 1,52 & 1,72 & 1,6 & 1,68 & 23 & $8 \mathrm{hs}$ \\
\hline $19 / 05 / 2015$ & 7,2 & -468 & & & & & 7,93 & 77 & 1,88 & 1,4 & 1,6 & 1,6 & 1,8 & 25 & 18hs \\
\hline $20 / 05 / 2015$ & 7,5 & -469 & & & & & 8 & 74 & 1,9 & 1,4 & 1,76 & 1,76 & 1,8 & 22 & $8 \mathrm{hs}$ \\
\hline $20 / 05 / 2015$ & 7,5 & -472 & & & & & 7,9 & 84 & 1,9 & 1,92 & 1,76 & 1,4 & 1,84 & 24 & $15 \mathrm{hs}$ \\
\hline $20 / 05 / 2015$ & 7,8 & -480 & & & & & 7,7 & 80 & 1,87 & 1,4 & 1,6 & 1,2 & 1,6 & 24 & $18 \mathrm{~h}$ \\
\hline $21 / 05 / 2015$ & 7,6 & -475 & & & & & 8 & 68 & 2,1 & 1,6 & 1,68 & 1,8 & 1,64 & 22 & $8 \mathrm{hs}$ \\
\hline $22 / 05 / 2015$ & 7 & -458 & 6,7 & -470 & & & 7,5 & 70 & 3 & 1,4 & 1,6 & 1,64 & 1,56 & 25 & $14 \mathrm{hs}$ \\
\hline $22 / 05 / 2015$ & 7 & -471 & 6,7 & -500 & & & 7,3 & 77 & 21 & 2,4 & 1,72 & 1,52 & 1,8 & 23 & $15 \mathrm{hs}$ \\
\hline $23 / 05 / 2015$ & 6,8 & -467 & 7 & -491 & & & 7,3 & 75 & 2 & 1,4 & 1,68 & 1,2 & 1,6 & 20 & 10hs \\
\hline $24 / 05 / 2015$ & 7 & -478 & 7,2 & -500 & & & 7,7 & 80 & 1,77 & 1,6 & 1,8 & 1,6 & 1,76 & 21 & $8 \mathrm{hs}$ \\
\hline
\end{tabular}




\begin{tabular}{|c|c|c|c|c|c|c|c|c|c|c|c|c|c|}
\hline $25 / 05 / 2015$ & 7,1 & -474 & 7,3 & -131 & 7 & 68 & 2,6 & 0 & 1,6 & 0 & 0 & 22 & 13:30hs \\
\hline $25 / 05 / 2015$ & 6,8 & -445 & 7,1 & -492 & 6,9 & 77 & 2,02 & 1 & 1,16 & 1,2 & 1,4 & 22 & 18hs \\
\hline $26 / 05 / 2015$ & 7,2 & -472 & 7,2 & -486 & 7 & 70 & 2 & 1,4 & 1,76 & 1,6 & 1,76 & 20 & $8 \mathrm{hs}$ \\
\hline $26 / 05 / 2015$ & 6,62 & -465 & 7 & -488 & 7,1 & 60 & 1,88 & 1,4 & 1,4 & 1,6 & 1,6 & 21 & $18 \mathrm{hs}$ \\
\hline $27 / 05 / 2015$ & 7 & -472 & 7,2 & -485 & 7,1 & 72 & 2,1 & 1,64 & 1,76 & 1,76 & 1,84 & 20 & $8 \mathrm{hs}$ \\
\hline $27 / 05 / 2015$ & 7,1 & -472 & 7,1 & -492 & 7 & 73 & 1,91 & 1,28 & 1,4 & 1,48 & 1,6 & 20 & 14hs \\
\hline $28 / 05 / 2015$ & 7 & -476 & 7,2 & -501 & 7,3 & 69 & 2 & 1,6 & 1,76 & 1,8 & 1,76 & 18 & $8 \mathrm{hs}$ \\
\hline $29 / 05 / 2015$ & 6,9 & -470 & 7,3 & -493 & 7,3 & 77 & 2 & 1,52 & 1,6 & 1,84 & 1,84 & 23 & $8 \mathrm{hs}$ \\
\hline $29 / 05 / 2015$ & 7,7 & -514 & 7,5 & -517 & 7,3 & 78 & 1,9 & 1,8 & 1,6 & 1,84 & 1,8 & 23 & $13 \mathrm{hs}$ \\
\hline $29 / 05 / 2015$ & 7,8 & -500 & 7,4 & -490 & 7,2 & 7 & 1,8 & 1,6 & 1,4 & 1,84 & 1,6 & 20 & $18 \mathrm{hs}$ \\
\hline $31 / 05 / 2015$ & 7,36 & -422 & 7,16 & -122 & 7,32 & 84 & 2,7 & 1,2 & 1,4 & 1,52 & 1,6 & 25 & $12 \mathrm{hs}$ \\
\hline $01 / 06 / 2015$ & 6,9 & -477 & 7,2 & -496 & 7,3 & 74 & 2 & 2 & 1,72 & 1,6 & 1,68 & 22 & $8 \mathrm{hs}$ \\
\hline $01 / 06 / 2015$ & 6,7 & -463 & 7 & -411 & 7,2 & 52 & 1,8 & 1 & 1,2 & 1,2 & 1,4 & 20 & $18 \mathrm{hs}$ \\
\hline $02 / 06 / 2015$ & 7,3 & -494 & 7,3 & -498 & 7,2 & 66 & 1,9 & 1,64 & 1,8 & 1,6 & 1,72 & 26 & $8 \mathrm{hs}$ \\
\hline $03 / 06 / 2015$ & 7,3 & -485 & 7,1 & -491 & 7,1 & 75 & 1,9 & 1,56 & 1,4 & 1,6 & 1,6 & 26 & $8 \mathrm{hs}$ \\
\hline $03 / 06 / 2015$ & 7,1 & -493 & 7 & -470 & 7 & 80 & 1,8 & 1,4 & 1,5 & 1,76 & 1,6 & 23 & 14hs \\
\hline $04 / 06 / 2015$ & 7 & -476 & 7,2 & -501 & 7,2 & 76 & 1,9 & 1,48 & 1,4 & 1,68 & 1,8 & 21 & 16hs \\
\hline $05 / 06 / 2015$ & 7 & -476 & 7,1 & -504 & 7,3 & 78 & 1,9 & 1,56 & 1,32 & 1,68 & 1,76 & 21 & $15 \mathrm{hs}$ \\
\hline $06 / 06 / 2015$ & 7,4 & -470 & 7,3 & -476 & 7,3 & 73 & 1,9 & 1,32 & 1,2 & 1,6 & 1,8 & 21 & $11 \mathrm{hs}$ \\
\hline $07 / 06 / 2015$ & 7,1 & -480 & 7,4 & 480 & 7,5 & 75 & 1,5 & 0,8 & 0,8 & 0,8 & 0,8 & 20 & $15 \mathrm{hs}$ \\
\hline $08 / 06 / 2015$ & 6,8 & -479 & 7,1 & -490 & 7,2 & 71 & 1,9 & 1,72 & 1,72 & 1,6 & 1,76 & 21 & 9hs \\
\hline $08 / 06 / 2015$ & 6,8 & -480 & 7,1 & -501 & 7,2 & 45 & 1,87 & 1,4 & 1,6 & 1,52 & 1,68 & 23 & 18hs \\
\hline $09 / 06 / 2015$ & 7,3 & -490 & 7,4 & -504 & 7,4 & 70 & 1,9 & 1,6 & 1,8 & 1,76 & 2 & 27 & $8 \mathrm{hs}$ \\
\hline $09 / 06 / 2015$ & 6,6 & -469 & 7,1 & -496 & 7,2 & 63 & 1,8 & 1,2 & 1,6 & 1,52 & 1,72 & 24 & $18 \mathrm{hs}$ \\
\hline $10 / 06 / 2015$ & 7,4 & -499 & 7,4 & -503 & 7,4 & 65 & 1,9 & 1,6 & 1,8 & 1,6 & 2 & 22 & $8 \mathrm{hs}$ \\
\hline $10 / 06 / 2015$ & 6,9 & -479 & 7,1 & -496 & 7,3 & 81 & 1,8 & 1,2 & 1,6 & 1,4 & 1,6 & 25 & $18 \mathrm{hs}$ \\
\hline $11 / 06 / 2015$ & 7 & -485 & 7,3 & -500 & 7,3 & 53 & 1,9 & 1,8 & 1,8 & 1,72 & 1,84 & 21 & $8 \mathrm{hs}$ \\
\hline
\end{tabular}




\begin{tabular}{|c|c|c|c|c|c|c|c|c|c|c|c|c|c|c|c|}
\hline $11 / 06 / 2015$ & 6,5 & -465 & 6,9 & -360 & & & 7,1 & 59 & 1,9 & 1,4 & 1,6 & 1,6 & 1,8 & 20 & $18 \mathrm{hs}$ \\
\hline $12 / 06 / 2015$ & 7,2 & -490 & 7,3 & -498 & & & 7,3 & 49 & 2 & 1,8 & 1,76 & 1,8 & 2 & 20 & $8 \mathrm{hs}$ \\
\hline $13 / 06 / 2015$ & 7 & -488 & 7,4 & -500 & & & 7,2 & 73 & 2 & 1,6 & 1,96 & 1,32 & 1,72 & 19 & $14 \mathrm{hs}$ \\
\hline $14 / 06 / 2015$ & 7,1 & -479 & 7,3 & -490 & & & 7,1 & 76 & 2 & 1,2 & 1,6 & 1,8 & 1,88 & 20 & 10hs \\
\hline $14 / 06 / 2015$ & 7 & -493 & 7,4 & -510 & & & 7,1 & 75 & 2,8 & 1,6 & 1,2 & 1,4 & 1,4 & 18 & $18 \mathrm{hs}$ \\
\hline $15 / 06 / 2015$ & 7,1 & -492 & 7,4 & -451 & & & 7,3 & 60 & 2,9 & 1,92 & 1,6 & 1,64 & 1,6 & 23 & $8 \mathrm{hs}$ \\
\hline $15 / 06 / 2015$ & 6,7 & -470 & 7,1 & -494 & & & 7,1 & 61 & 2,3 & 1,6 & 1,6 & 1,76 & 1,68 & 24 & $18 \mathrm{hs}$ \\
\hline $16 / 06 / 2015$ & 7,4 & -504 & 7,3 & -505 & & & 7,2 & 67 & 2,9 & 1,6 & 1,64 & 1,56 & 1,64 & 24 & $8 \mathrm{hs}$ \\
\hline $16 / 06 / 2015$ & 7 & -483 & 7,4 & -495 & & & 7,2 & 66 & 2,8 & 1,6 & 1,72 & 1,32 & 1,76 & 25 & $14 \mathrm{hs}$ \\
\hline $16 / 06 / 2015$ & 7,3 & -470 & 7,1 & -505 & & & 7 & 49 & 2,1 & 1,6 & 1,6 & 1,4 & 1,6 & 27 & $18 \mathrm{hs}$ \\
\hline $17 / 06 / 2015$ & 7,2 & -498 & 7,3 & -502 & & & 7,2 & 73 & 2,6 & 1,8 & 1,8 & 1,8 & 1,8 & 25 & $8 \mathrm{hs}$ \\
\hline $17 / 06 / 2015$ & 7,1 & -500 & 7,4 & -510 & & & 7,1 & 80 & 2,1 & 1,4 & 1,6 & 1,8 & 1,8 & 25 & $14 \mathrm{hs}$ \\
\hline $18 / 06 / 2015$ & 6,9 & -473 & 7,4 & -501 & & & 7,1 & 52 & 2 & 1,6 & 1,8 & 1,8 & 2 & 22 & $8 \mathrm{hs}$ \\
\hline $19 / 06 / 2015$ & 6,8 & -469 & 7,5 & -498 & & & 7,3 & 60 & 2,5 & 1,8 & 1,88 & 1,8 & 2 & 24 & $8 \mathrm{hs}$ \\
\hline $19 / 06 / 2015$ & 7,1 & -492 & 7,5 & -501 & & & 7,1 & 52 & 2 & 1,8 & 1,6 & 1,6 & 1,4 & 25 & $17 \mathrm{hs}$ \\
\hline $20 / 06 / 2015$ & 6,9 & -481 & 7,2 & -498 & & & 7,3 & 67 & 2,8 & 1,64 & 1,72 & 1,6 & 1,8 & 21 & $15 \mathrm{hs}$ \\
\hline $22 / 06 / 2015$ & 7,3 & -499 & & & 7,5 & -510 & 7,4 & 25 & 2,2 & 1,6 & 1,8 & 1,72 & 2 & 22 & $8 \mathrm{hs}$ \\
\hline $22 / 06 / 2015$ & 6,8 & -475 & & & 7 & -500 & 7,1 & 15 & 1,9 & 1,8 & 1,6 & 1,8 & 2 & 20 & $18 \mathrm{hs}$ \\
\hline $23 / 06 / 2015$ & 7,1 & -487 & & & 7,4 & -520 & 7,4 & -45 & 1,9 & 1,6 & 1,8 & 1,88 & 2 & 19 & $8 \mathrm{hs}$ \\
\hline $23 / 06 / 2015$ & 7,4 & -507 & & & 7,3 & -524 & 7,5 & -137 & 1,9 & 1,4 & 1,8 & 1,88 & 2,04 & 17 & $18 \mathrm{hs}$ \\
\hline $24 / 06 / 2015$ & 7,6 & -511 & & & 7,5 & -530 & 7,6 & -214 & 1,9 & 1,64 & 1,8 & 1,88 & 1,8 & 17 & $8 \mathrm{hs}$ \\
\hline $24 / 06 / 2015$ & 6,8 & -483 & & & 6,8 & -503 & 7,1 & -249 & 1,9 & 1,2 & 1,4 & 1,6 & 2,08 & 19 & $18 \mathrm{hs}$ \\
\hline $25 / 06 / 2015$ & 7 & -488 & 6,8 & -501 & 7 & -514 & 7,3 & -317 & 1,9 & 1,8 & 1,8 & 1,92 & 1,8 & 21 & $8 \mathrm{hs}$ \\
\hline $25 / 06 / 2015$ & 6,6 & -475 & & & 6,9 & -500 & 7,1 & -376 & 1,9 & 1,52 & 1,92 & 1,64 & 2 & 23 & $17 \mathrm{hs}$ \\
\hline $26 / 06 / 2015$ & 7,1 & -380 & 7 & -501 & 6,9 & -512 & 6,9 & -421 & 1,9 & 1,8 & 1,6 & 1,8 & 1,72 & 23 & $19 \mathrm{hs}$ \\
\hline $26 / 06 / 2015$ & 6,7 & -478 & 6,8 & -495 & 6,8 & -499 & 7,1 & -428 & 1,9 & 1,64 & 1,88 & 1,6 & 1,8 & 24 & $16 \mathrm{hs}$ \\
\hline $27 / 06 / 2015$ & 6,6 & -481 & 6,9 & -513 & 6,9 & -509 & $4,6-5,2$ & -453 & 1,9 & 1,76 & 1,72 & 1,64 & 2,2 & 24 & $8 \mathrm{hs}$ \\
\hline
\end{tabular}




\begin{tabular}{|c|c|c|c|c|c|c|c|c|c|c|c|c|c|c|c|}
\hline $29 / 06 / 2015$ & 6,9 & -482 & 7,1 & -510 & 7,1 & -503 & 7,2 & -133 & 2 & 1,84 & 1,92 & 1,88 & 1,4 & 25 & $18 \mathrm{hs}$ \\
\hline $29 / 06 / 2015$ & 6,5 & -469 & & & 6,7 & -500 & 7,2 & -391 & 1,9 & 1,4 & 1,28 & 1,4 & 2,08 & 24 & $8 \mathrm{hs}$ \\
\hline $30 / 06 / 2015$ & 6,9 & -450 & 6,9 & -480 & 6,9 & -510 & 7,2 & -450 & 1,9 & 1,68 & 1,8 & 1,92 & 2 & 25 & 18hs \\
\hline $30 / 06 / 2015$ & 7,2 & -501 & 7 & -490 & 7,1 & -505 & 7,1 & -39 & 2,1 & 1,4 & 1,6 & 1,8 & 2,04 & 23 & 18hs \\
\hline $01 / 07 / 2015$ & 7,6 & -513 & & & 7,1 & -523 & 7,1 & -61 & 2,3 & 1,8 & 1,76 & 1,92 & 2 & 26 & $8 \mathrm{hs}$ \\
\hline $01 / 07 / 2015$ & 6,5 & -563 & 7,1 & & 6,7 & -490 & 7 & -66 & 2,2 & 1,4 & 1,2 & 1,8 & 2 & 22 & 18hs \\
\hline $02 / 07 / 2015$ & 7,1 & -497 & & -514 & 7,1 & -513 & 7,1 & -15 & 4,5 & 1,8 & 1,8 & 2 & 2 & 24 & $8 \mathrm{hs}$ \\
\hline $03 / 07 / 2015$ & 7,1 & -486 & 7 & -501 & 7 & -508 & 6,8 & -48 & 2,7 & 1,72 & 1,8 & 1,92 & 2 & 25 & $8 \mathrm{hs}$ \\
\hline $06 / 07 / 2015$ & 7,1 & -506 & 6,9 & -491 & 7,1 & -517 & 7,1 & -1 & 4,7 & 1,64 & 1,72 & 1,88 & 2,08 & 22 & $8 \mathrm{hs}$ \\
\hline $06 / 07 / 2015$ & 6,9 & -488 & & & 6,8 & -505 & 6,9 & -6 & 4,7 & 1,6 & 1,8 & 1,8 & 2 & 22 & $18 \mathrm{hs}$ \\
\hline $07 / 07 / 2015$ & 7,3 & -504 & 6,9 & -507 & 7,9 & -513 & 7 & -10 & 4,7 & 1,64 & 1,8 & 2 & 2 & 22 & $8 \mathrm{hs}$ \\
\hline $07 / 07 / 2015$ & 6,8 & -483 & 6,9 & -505 & 6,8 & -504 & 6,9 & -15 & 3,9 & 1,56 & 1,68 & 2 & 1,8 & 21 & 18hs \\
\hline $08 / 07 / 2015$ & 7,3 & -506 & 7,2 & -470 & 7 & -512 & 7 & -15 & 4,1 & 1,72 & 1,8 & 1,8 & 2 & 23 & $8 \mathrm{hs}$ \\
\hline $08 / 07 / 2015$ & 7,1 & -500 & 7,2 & -475 & 6,9 & -505 & 7 & -15 & 3,7 & 1,68 & 1,6 & 1,8 & 2,24 & 26 & $18 \mathrm{hs}$ \\
\hline $09 / 07 / 2015$ & 7,1 & -475 & 7 & -507 & 7 & -509 & 7 & -20 & 0,2 & 1,72 & 1,36 & 1,64 & 1,8 & 23 & $16 \mathrm{hs}$ \\
\hline $10 / 07 / 2015$ & 6,6 & -461 & 6,9 & -515 & 6,9 & -508 & 7 & -182 & 2,2 & 1,6 & 1,8 & 1,6 & 1,76 & 22 & $15 \mathrm{hs}$ \\
\hline $11 / 07 / 2015$ & 7,1 & -475 & 6,8 & -500 & 7 & -510 & 7 & -29 & 2,9 & 1,4 & 1,6 & 1,4 & 1,6 & 21 & $17 \mathrm{hs}$ \\
\hline $12 / 07 / 2015$ & 6,9 & -495 & 6,9 & -515 & 7,1 & -505 & 7,1 & -25 & 2,3 & 1,6 & 1,8 & 1,6 & 1,8 & 20 & $12 \mathrm{hs}$ \\
\hline $13 / 07 / 2015$ & 6,4 & -454 & 6,9 & -516 & 6,9 & -521 & 7,2 & -195 & 2,2 & 1,8 & 1,88 & 1,76 & 2,2 & & \\
\hline $13 / 07 / 2015$ & 6,9 & -459 & 7 & -500 & 7,1 & -525 & 7,1 & -90 & 2,3 & 1,6 & 1,88 & 1,8 & 2 & 19 & $18 \mathrm{hs}$ \\
\hline $14 / 07 / 2015$ & 7,1 & -490 & 7,1 & -490 & 7 & -509 & 7,3 & -64 & & 1,84 & 1,72 & 1,88 & 1,8 & 22 & $13: 30 \mathrm{hs}$ \\
\hline $14 / 07 / 2015$ & 7,1 & -465 & 6,5 & -502 & 6,7 & -490 & 7,1 & -87 & 0,01 & 1,6 & 1,2 & 1,8 & 2 & 24 & $18 \mathrm{hs}$ \\
\hline $15 / 07 / 2015$ & 7,3 & -495 & 7,2 & -427 & 7 & -512 & 7,3 & -28 & & 1,92 & 1,68 & 1,84 & 2 & 25 & $8 \mathrm{hs}$ \\
\hline $15 / 07 / 2015$ & 6,7 & -474 & 6,8 & -510 & 6 & -490 & 7,2 & -76 & & 1,4 & 1,6 & 1,8 & 2 & 23 & \\
\hline $16 / 07 / 2015$ & 7,3 & -499 & 7,2 & -419 & 6,6 & -515 & 7,4 & -40 & & 1,8 & 1,8 & 1,8 & 2 & 23 & \\
\hline $16 / 07 / 2015$ & 7,1 & -499 & 7,1 & -415 & 6,7 & -520 & 7,5 & -170 & & 1,8 & 1,8 & 1,6 & 1,6 & 22 & $18 \mathrm{hs}$ \\
\hline $17 / 07 / 2015$ & 7,3 & -491 & 7,2 & -489 & 7 & -521 & 7,4 & -160 & & 1,72 & 1,8 & 1,88 & 2,16 & 21 & 8hs \\
\hline
\end{tabular}




\begin{tabular}{|c|c|c|c|c|c|c|c|c|c|c|c|c|c|c|}
\hline $17 / 07 / 2015$ & 6,7 & -470 & 6,8 & -505 & 7,1 & -480 & 7,2 & -81 & 1,6 & 1,6 & 1,8 & 2 & 21 & $18 \mathrm{hs}$ \\
\hline $18 / 07 / 2015$ & 6,9 & -483 & 6,9 & -496 & 7,2 & -514 & 7,3 & -50 & 1,64 & 1,6 & 1,4 & 2 & 24 & $12 \mathrm{hs}$ \\
\hline $19 / 07 / 2015$ & 7,3 & -514 & 7,1 & -490 & 7,4 & -590 & 7,4 & -19 & 1,6 & 1,6 & 1,6 & 1,8 & 22 & $12 \mathrm{hs}$ \\
\hline $20 / 07 / 2015$ & 7,4 & -495 & 7,3 & -491 & 7,4 & -514 & 7,6 & -20 & 1,68 & 1,68 & 1,84 & 2,2 & 23 & $8 \mathrm{hs}$ \\
\hline $20 / 07 / 2015$ & 6,8 & -486 & 7,1 & -470 & 7,3 & -496 & 7,4 & -21 & 1,4 & 1,6 & 1,8 & 2 & 26 & $18 \mathrm{hs}$ \\
\hline $21 / 07 / 2015$ & 7,3 & -492 & 7,2 & -370 & 6,9 & -418 & 7,1 & -30 & 1,64 & 1,8 & 1,8 & 2 & 27 & $8 \mathrm{hs}$ \\
\hline $21 / 07 / 2015$ & 7,2 & -500 & 7,1 & -390 & 7 & -410 & 7,2 & -15 & 1,6 & 1,6 & 1,8 & 2 & 27 & $18 \mathrm{hs}$ \\
\hline $22 / 07 / 2015$ & 7,4 & -501 & 7,2 & -445 & 7 & -510 & 7,2 & -15 & 1,68 & 1,88 & 1,8 & 2 & 22 & $8 \mathrm{hs}$ \\
\hline $22 / 07 / 2015$ & 7,3 & -480 & 7,2 & -400 & 7 & -500 & 7,4 & -20 & 1,4 & 1,6 & 1,88 & 2 & 24 & $18 \mathrm{hs}$ \\
\hline $23 / 07 / 2015$ & 7,3 & -466 & 7,3 & -353 & 6,9 & -507 & 7 & -23 & 1,68 & 1,8 & 1,88 & 2 & 22 & $8 \mathrm{hs}$ \\
\hline $23 / 07 / 2015$ & 7,1 & -470 & 7,4 & -420 & 6,7 & -500 & 6,8 & -20 & 1,6 & 1,8 & 1,68 & 2 & 22 & $17 \mathrm{hs}$ \\
\hline $24 / 07 / 2015$ & 7,2 & -418 & 7,2 & -300 & 6,9 & -499 & 7,1 & -18 & 1,8 & 1,68 & 1,56 & 2 & 24 & $8 \mathrm{hs}$ \\
\hline $25 / 07 / 2015$ & 6,8 & -458 & 6,9 & -498 & 6,9 & -505 & 6,9 & -9 & 1,64 & 1,6 & 1,4 & 1,76 & 24 & $15 \mathrm{hs}$ \\
\hline $26 / 07 / 2015$ & 6,9 & -468 & 7,1 & -500 & 7,1 & -510 & 7 & -15 & 1,2 & 1,4 & 1,76 & 1,8 & 22 & $12 \mathrm{hs}$ \\
\hline $27 / 07 / 2015$ & 7,2 & -513 & 7,2 & -517 & 7,2 & -488 & 7,1 & -53 & 1,84 & 1,68 & 1,8 & 1,72 & 23 & $8 \mathrm{hs}$ \\
\hline $27 / 07 / 2015$ & 7,1 & -470 & 7 & -500 & 7,1 & -475 & 7,4 & -28 & 1,8 & 1,6 & 1,8 & 1,8 & 26 & $17 \mathrm{hs}$ \\
\hline $28 / 07 / 2015$ & 7,5 & -501 & 7 & -507 & 7 & -474 & 7,1 & -11 & 2 & 1,6 & 1,72 & 2,08 & 27 & $8 \mathrm{hs}$ \\
\hline $28 / 07 / 2015$ & 2,4 & -490 & 7 & -502 & 7 & -473 & 6,9 & -20 & 1,6 & 1,8 & 1,6 & 2 & 25 & $18 \mathrm{hs}$ \\
\hline $29 / 07 / 2015$ & 7 & -530 & 7,3 & -509 & 7,1 & -507 & 7,2 & -19 & 1,6 & 1,68 & 1,72 & 2 & 23 & $7 \mathrm{hs}$ \\
\hline $29 / 07 / 2015$ & 7 & -510 & 7,4 & -520 & 7 & -508 & 7,3 & -7 & 1,6 & 1,8 & 1,8 & 2 & 25 & $18 \mathrm{hs}$ \\
\hline $30 / 07 / 2015$ & 7,2 & -567 & 6,9 & -551 & 7 & -482 & 5,9 & -5 & 1,8 & 1,6 & 1,8 & 2 & 26 & $8 \mathrm{hs}$ \\
\hline $30 / 07 / 2015$ & 7,4 & -490 & 7,2 & -570 & 7 & -480 & 6,2 & 2 & 1,8 & 1,6 & 1,8 & 2 & 26 & $18 \mathrm{hs}$ \\
\hline $31 / 07 / 2015$ & 6,9 & -482 & 7 & -543 & 7 & -534 & 7,4 & -80 & 1,6 & 1,88 & 1,8 & 1,8 & 23 & $8 \mathrm{hs}$ \\
\hline $01 / 08 / 2015$ & 7 & -441 & 6,9 & -542 & 6,9 & -380 & 7,6 & 10 & 1,64 & 1,68 & 1,4 & 1,92 & 23 & $16 \mathrm{hs}$ \\
\hline $02 / 08 / 2015$ & 7,1 & -470 & 6,9 & -540 & 6,7 & -380 & 7,5 & 18 & 1,6 & 1,8 & 1,2 & 1,8 & 26 & $12 \mathrm{hs}$ \\
\hline $03 / 08 / 2015$ & 7,5 & -513 & 7,3 & -528 & & & 7,3 & 10 & 1,68 & 1,68 & 1,76 & 1,84 & 23 & $8 \mathrm{hs}$ \\
\hline $03 / 08 / 2015$ & 6,8 & -492 & 6,9 & -530 & 7 & -470 & 7,2 & -36 & 1,4 & 1,8 & 1,8 & 2 & 22 & $18 \mathrm{hs}$ \\
\hline
\end{tabular}




\begin{tabular}{|c|c|c|c|c|c|c|c|c|c|c|c|c|c|c|c|}
\hline $04 / 08 / 2015$ & 7,4 & -505 & 7,1 & -431 & 7 & -480 & 7,4 & -38 & & 1,8 & 1,4 & 1,84 & 1,72 & 21 & $8 \mathrm{hs}$ \\
\hline $05 / 08 / 2015$ & 7,3 & -494 & 7,3 & -410 & 7,2 & -487 & 7,3 & 40 & & 1,6 & 1,6 & 1,8 & 1,6 & 20 & $8 \mathrm{hs}$ \\
\hline $05 / 08 / 2015$ & 7,1 & -505 & 7,3 & -492 & 6,9 & -290 & & & 6,8 & 1,6 & 1,6 & 1,8 & 2 & 25 & 18hs \\
\hline $06 / 08 / 2015$ & 7,5 & -509 & 7 & -554 & 7,3 & -335 & & & 7 & 1,8 & 1,6 & 1,92 & 1,8 & 24 & $8 \mathrm{hs}$ \\
\hline $06 / 08 / 2015$ & 6,5 & -485 & 7,6 & -540 & 6,7 & -500 & & & 6,8 & 1,6 & 1,8 & 2 & 2 & 22 & $18 \mathrm{hs}$ \\
\hline $07 / 08 / 2015$ & 7,2 & -525 & 7 & -528 & 7,2 & -517 & & & 7 & 1,6 & 1,4 & 1,8 & 1,6 & 23 & $8 \mathrm{hs}$ \\
\hline $07 / 08 / 2015$ & 7,2 & -500 & 7,1 & -501 & 7,3 & -510 & & & 7,3 & 1,4 & 1,4 & 1,6 & 1,8 & 21 & $18 \mathrm{hs}$ \\
\hline $08 / 08 / 2015$ & 7,4 & -510 & 7,4 & -515 & 7,5 & -550 & & & 7,1 & 1,6 & 1,4 & 1,6 & 1,6 & 22 & $10 \mathrm{hs}$ \\
\hline $09 / 08 / 2015$ & 7,1 & -450 & 7,2 & -470 & 7,3 & -490 & & & 7,4 & 1,6 & 1,4 & 1,6 & 1,8 & 24 & $12 \mathrm{hs}$ \\
\hline $10 / 08 / 2015$ & 7,3 & -507 & 7,2 & -537 & 7,3 & -507 & & & 6,9 & 0 & 1,6 & 1,8 & 1,6 & 22 & $8 \mathrm{hs}$ \\
\hline $10 / 08 / 2015$ & 6,7 & -500 & 6,9 & -530 & 7 & -490 & & & 6,8 & 1,6 & 1,8 & 2 & 2 & 21 & 18hs \\
\hline $11 / 08 / 2015$ & 7,1 & -502 & 7,1 & -544 & 7 & -544 & & & 6,6 & 1,44 & 1,44 & 1,44 & 1,68 & 22 & 8hs \\
\hline $11 / 08 / 2015$ & 7,3 & -502 & 7,3 & -550 & 7,3 & -570 & & & 6,7 & 1,4 & 1,4 & 1,4 & 1,6 & 20 & $18 \mathrm{hs}$ \\
\hline $12 / 08 / 2015$ & 7,1 & -506 & 7 & -553 & 7 & -502 & & & 6,9 & 1,6 & 1,6 & 1,8 & 1,72 & 20 & $8 \mathrm{hs}$ \\
\hline $12 / 08 / 2015$ & 7,1 & -510 & 7,3 & -550 & 7,2 & -530 & & & 7,3 & 1,6 & 1,6 & 1,8 & 1,8 & 20 & $17 \mathrm{hs}$ \\
\hline $13 / 08 / 2015$ & 7,2 & -528 & 6,9 & -544 & 7 & -543 & & & 6,8 & 1,6 & 1,52 & 1,8 & 1,68 & 20 & $8 \mathrm{hs}$ \\
\hline $13 / 08 / 2015$ & 7,3 & -510 & 6,9 & -550 & 7,1 & -540 & & & 7 & 1,6 & 1,4 & 1,6 & 1,8 & 18 & $18 \mathrm{hs}$ \\
\hline $14 / 08 / 2015$ & 7,1 & -508 & 6,9 & -549 & 6,9 & -546 & & & 6,8 & 1,4 & 1,6 & 1,64 & 1,72 & 18 & \\
\hline $14 / 08 / 2015$ & 7,1 & -510 & 6,9 & -549 & 7 & -546 & & & 7 & 1,4 & 1,6 & 1,6 & 1,8 & 19 & $18 \mathrm{hs}$ \\
\hline $15 / 08 / 2015$ & & & & & & & & & & 1,48 & 1,64 & 1,52 & 1,84 & 22 & 16hs \\
\hline $16 / 08 / 2015$ & & & & & & & & & & 0 & 0 & 0 & 0 & 23 & $12 \mathrm{hs}$ \\
\hline $17 / 08 / 2015$ & 7 & -520 & 7,1 & -530 & 7,2 & -540 & & & 7,3 & 1,4 & 1,6 & 1,4 & 1,8 & 23 & 18hs \\
\hline $18 / 08 / 2015$ & 7 & -524 & 7 & -567 & 7 & -568 & & & 7 & 1,6 & 1,6 & 0 & 2 & 21 & $8 \mathrm{hs}$ \\
\hline $18 / 08 / 2015$ & 7 & -540 & 7,1 & -560 & 7,2 & -550 & & & 7 & 1,2 & 1,6 & 0 & 2 & 22 & 18hs \\
\hline $20 / 08 / 2015$ & 7,1 & -481 & 7,2 & -561 & 7,2 & -577 & & & 7,3 & 0 & 1,6 & 0 & 1,8 & 21 & $8 \mathrm{hs}$ \\
\hline $20 / 08 / 2015$ & 7,1 & -470 & 7,2 & -550 & 7,2 & -570 & & & 7,5 & 1,6 & 1,6 & 1,6 & 1,8 & 21 & $18 \mathrm{hs}$ \\
\hline $21 / 08 / 2015$ & 7,1 & -434 & 7,3 & -565 & 7,2 & -561 & & & 6,8 & 1,8 & 1,8 & 0 & 1,8 & 25 & $8 \mathrm{hs}$ \\
\hline
\end{tabular}




\begin{tabular}{|c|c|c|c|c|c|c|c|c|c|c|c|c|c|c|c|}
\hline $21 / 08 / 2015$ & 7,1 & -410 & 7,5 & -570 & 7,4 & -540 & & & 7 & 1,6 & 1,6 & 0 & 1,8 & 25 & $18 \mathrm{hs}$ \\
\hline $21 / 08 / 2015$ & 7,3 & -455 & 7,5 & -568 & 7,3 & -563 & & & 6,7 & 1,6 & 1,6 & 0 & 1,72 & 22 & 18hs \\
\hline $21 / 08 / 2015$ & 7,2 & -455 & 7,4 & -570 & 7,1 & -540 & & & 6,8 & 1,6 & 1,6 & 0 & 1,8 & 22 & $18 \mathrm{hs}$ \\
\hline $22 / 08 / 2015$ & 7,1 & -484 & 7 & -567 & 7,2 & -551 & & & 6,8 & 1,56 & 1,44 & 0 & 1,76 & 23 & 14hs \\
\hline $23 / 08 / 2015$ & 6,5 & -570 & 6,9 & -540 & 7 & -530 & & & 6,9 & 1,4 & 1,4 & 0 & 1,6 & 24 & $12 \mathrm{hs}$ \\
\hline $24 / 08 / 2015$ & 7,2 & -362 & 7,3 & -565 & 7,2 & -553 & & & 6,3 & 1,6 & 1,6 & 0 & 1,8 & 25 & $8 \mathrm{hs}$ \\
\hline $24 / 08 / 2015$ & 7,2 & -356 & 7,3 & -560 & & & & & 6,6 & 1,4 & 1,4 & 0 & 1,68 & 20 & 8hs \\
\hline $25 / 08 / 2015$ & 7,2 & -370 & 7,4 & -570 & & & & & 6,7 & 1,4 & 1,4 & 0 & 1,6 & 21 & $18 \mathrm{hs}$ \\
\hline $26 / 08 / 2015$ & 7,2 & -311 & 7,3 & -564 & 7,3 & -562 & 6,6 & -27 & & 1,6 & 1,6 & 0 & 2 & 22 & $8 \mathrm{hs}$ \\
\hline $26 / 08 / 2015$ & 7 & -480 & 6,9 & -560 & 6,9 & -540 & 6,9 & -115 & & 1,2 & 1,4 & 1,6 & 1,8 & 21 & 18hs \\
\hline $27 / 08 / 2015$ & 7,2 & -394 & 7,3 & -557 & 7,3 & -552 & 6,8 & -46 & 5 & 1,92 & 1,6 & 0 & 2 & 21 & $8 \mathrm{hs}$ \\
\hline $27 / 08 / 2015$ & 7 & -483 & 6,9 & -558 & 7 & -560 & & -17 & 5 & 1,4 & 1,6 & 0 & 1,8 & 25 & 18hs \\
\hline $28 / 08 / 2015$ & 7,2 & -456 & 7,4 & -439 & & & 7,2 & -7 & 5 & 1,6 & 1,44 & 0 & 2 & 23 & $09: 45 \mathrm{hs}$ \\
\hline $28 / 08 / 2015$ & 7,2 & -470 & 7,6 & -530 & & & 7,4 & -8 & 5 & 1,6 & 1,4 & 0 & 2 & 24 & $18 \mathrm{hs}$ \\
\hline $29 / 08 / 2015$ & 7,2 & -426 & 7 & -564 & & & & 40 & 4,9 & 1,52 & 1,48 & 0 & 1,84 & 22 & $15 \mathrm{hs}$ \\
\hline $30 / 08 / 2015$ & 7,2 & -470 & 7,1 & -570 & & & 7,2 & 20 & 4,2 & 1,4 & 1,4 & 0 & 1,8 & 21 & 10hs \\
\hline $31 / 08 / 2015$ & 7 & -489 & 7 & -566 & 6,9 & -248 & 7 & -8 & 4,8 & 1,88 & 1,6 & 0 & 1,72 & 22 & $8 \mathrm{hs}$ \\
\hline $01 / 09 / 2015$ & 7 & -548 & 7 & -561 & & & & 1 & 5 & 1,4 & 1,32 & 0 & 1,8 & 22 & $8 \mathrm{hs}$ \\
\hline $01 / 09 / 2015$ & 7,1 & -557 & 7,3 & -562 & & & 6,9 & -9 & 4,7 & 1,4 & 1,32 & 0 & 1,8 & 23 & $18 \mathrm{hs}$ \\
\hline $02 / 09 / 2015$ & 7,4 & -565 & 7,5 & -541 & & & 7,3 & -5 & 6 & 1,68 & 1,4 & 0 & 1,6 & 21 & $8 \mathrm{hs}$ \\
\hline $02 / 09 / 2015$ & 7,1 & -557 & 7,5 & -560 & & & 7 & -8 & 5 & 1,64 & 1,32 & 0 & 1,8 & 22 & $18 \mathrm{hs}$ \\
\hline $03 / 09 / 2015$ & 7,1 & -459 & 7,5 & -512 & 7,6 & -546 & 7,1 & 15 & 5,7 & 1,68 & 1,68 & 0 & 1,8 & 26 & 8hs \\
\hline $04 / 09 / 2015$ & 7,4 & -531 & 7,5 & -519 & & & 6,9 & -4 & 5,8 & 1,6 & 1,64 & 0 & 1,8 & 25 & $8 \mathrm{hs}$ \\
\hline $04 / 09 / 2015$ & 7,5 & -570 & 7,4 & -580 & & & 6,7 & -3 & 5,5 & 1,6 & 1,6 & 0 & 1,8 & 22 & 18hs \\
\hline $06 / 09 / 2015$ & 7,2 & -560 & 7,3 & -560 & & & 7 & -7 & 5 & 1,8 & 1,6 & 0 & 1,8 & 23 & $12 \mathrm{hs}$ \\
\hline $07 / 09 / 2015$ & 7,1 & -540 & 7,1 & -550 & & & 7,3 & -20 & 4,2 & 1,4 & 1,6 & 0 & 1,6 & 24 & $10 \mathrm{hs}$ \\
\hline $08 / 09 / 2015$ & 7,1 & -516 & 7,3 & -516 & 7,1 & -516 & 7,1 & -15 & 5 & 1,6 & 1,8 & 0 & 1,8 & 25 & 13hs \\
\hline
\end{tabular}




\begin{tabular}{|c|c|c|c|c|c|c|c|c|c|c|c|c|c|c|c|}
\hline $08 / 09 / 2015$ & 7,1 & -540 & 7,1 & -540 & 7,1 & -510 & 7,1 & -11 & 5,2 & 1,4 & 1,48 & 0 & 1,8 & 22 & $18 \mathrm{hs}$ \\
\hline $09 / 09 / 2015$ & 7,2 & -419 & 7,3 & -536 & 7,3 & -529 & 7 & 18 & 6,1 & 1,6 & 1,6 & 0 & 1,68 & 21 & $8 \mathrm{hs}$ \\
\hline $09 / 09 / 2015$ & 7,1 & -450 & 7,4 & -550 & 7,4 & -570 & 7,1 & 10 & 6,2 & 1,6 & 1,6 & 0 & 1,8 & 21 & $18 \mathrm{hs}$ \\
\hline $10 / 09 / 2015$ & 7 & -504 & 7,4 & & 7,4 & -502 & 7,1 & 7 & 6 & 1,6 & 1,8 & 0 & 1,8 & 20 & 8hs \\
\hline $10 / 09 / 2015$ & 7,1 & -560 & 7,3 & -516 & 7,1 & -520 & 7 & 7 & 6,1 & 1,68 & 1,72 & 0 & 1,72 & 22 & $17 \mathrm{hs}$ \\
\hline $11 / 09 / 2015$ & 7 & -477 & 7,2 & -562 & & & 7,2 & 8 & 5,5 & 1,72 & 1,8 & 0 & 1,8 & 23 & $8 \mathrm{hs}$ \\
\hline $11 / 09 / 2015$ & 7,2 & -480 & 7,4 & -570 & & & 7,2 & 8 & 5,6 & 1,6 & 1,8 & 0 & 2 & 21 & $18 \mathrm{hs}$ \\
\hline $12 / 09 / 2015$ & 7,3 & -500 & 7,5 & -580 & & & 7,1 & 1 & 4,6 & 1,4 & 1,6 & 0 & 1,8 & 20 & $12 \mathrm{hs}$ \\
\hline $14 / 09 / 2015$ & 7,3 & -416 & 7,5 & -374 & 7,5 & -432 & 7 & -33 & 4,8 & 1,68 & 1,8 & 0 & 1,8 & 19 & $8 \mathrm{hs}$ \\
\hline $14 / 09 / 2015$ & 7,2 & -520 & 7,2 & -520 & 7,4 & -500 & 7,1 & -81 & 3,1 & 0 & 0 & 0 & 0 & 17 & $18 \mathrm{hs}$ \\
\hline $15 / 09 / 2015$ & 7,1 & -501 & 7,3 & -508 & 7,2 & & 7,3 & -57 & 2,6 & 1,48 & 1,8 & 0 & 1,88 & 18 & 8hs \\
\hline $15 / 09 / 2015$ & 7,3 & -500 & 7,1 & -570 & 7,1 & -480 & 7 & -60 & 3,2 & 1,6 & 1,6 & 0 & 1,8 & 19 & $18 \mathrm{hs}$ \\
\hline $16 / 09 / 2015$ & 7,2 & -510 & 7,1 & -508 & 7,1 & -509 & 7 & -43 & 3,5 & 1,6 & 1,88 & 0 & 1,92 & 21 & $8 \mathrm{hs}$ \\
\hline $16 / 09 / 2015$ & 7,1 & -500 & 7,1 & -516 & 7,2 & -500 & 7 & -40 & 4,8 & 1,6 & 1,92 & 0 & 1,8 & 22 & $18 \mathrm{hs}$ \\
\hline $17 / 09 / 2015$ & 7,2 & -532 & 7,4 & -548 & & & 6,9 & -8 & 5 & 1,6 & 1,8 & 0 & 1,8 & 23 & $8 \mathrm{hs}$ \\
\hline $18 / 09 / 2015$ & 7,3 & -535 & 7,3 & -556 & 7,3 & -532 & 6,9 & 1 & 4,6 & 1,68 & 1,68 & 0 & 1,68 & 24 & $8 \mathrm{hs}$ \\
\hline $18 / 09 / 2015$ & 7,1 & -500 & 7,2 & -523 & 7,2 & -520 & 6,8 & -6 & 4,8 & 1,64 & 1,7 & 0 & 1,7 & 24 & $18 \mathrm{hs}$ \\
\hline $19 / 09 / 2015$ & 7,3 & -520 & 7,5 & -510 & 7,4 & -520 & 6,9 & -20 & & 1,6 & 1,6 & 0 & 1,8 & 20 & 10hs \\
\hline $20 / 09 / 2015$ & 7,1 & -510 & 7,2 & -520 & 7,2 & -520 & 7 & 2 & 3,5 & 1,6 & 1,8 & 0 & 1,8 & 21 & $11 \mathrm{hs}$ \\
\hline $21 / 09 / 2015$ & 7 & -537 & 7,3 & -552 & & & 7,6 & -100 & 3,4 & 1,6 & 1,8 & 1,48 & 1,88 & & \\
\hline $21 / 09 / 2015$ & 7,1 & -540 & 7,4 & -570 & & & 7,7 & -80 & 3 & 1,6 & 1,8 & 0 & 1,8 & & \\
\hline $22 / 09 / 2015$ & 7,3 & -531 & 7,2 & -548 & 6,9 & -538 & 7,4 & 10 & 6 & 1,6 & 1,8 & 1,6 & 1,8 & 21 & 8hs \\
\hline $23 / 09 / 2015$ & 6,7 & -554 & 7,3 & -558 & 7,3 & -533 & 7,6 & 18 & 6 & 1,8 & 1,8 & 1,4 & 1,8 & 23 & $8 \mathrm{hs}$ \\
\hline $23 / 09 / 2015$ & 6,8 & -540 & 7,4 & -560 & 7,4 & -530 & 7,6 & 12 & 5 & 1,2 & 1,6 & 1,2 & 1,6 & 22 & $18 \mathrm{hs}$ \\
\hline $24 / 09 / 2015$ & 6,8 & -528 & 7,3 & -543 & 7,2 & -248 & 7,6 & 27 & 6,7 & 1,8 & 1,6 & 1,8 & 1,2 & 22 & $8 \mathrm{hs}$ \\
\hline $24 / 09 / 2015$ & 6,7 & -550 & 7,4 & -520 & 7,4 & -400 & 7,3 & 30 & 6,5 & 1,6 & 1,6 & 1,8 & 1,4 & 22 & $18 \mathrm{hs}$ \\
\hline $25 / 09 / 2015$ & 6,8 & -524 & 7,5 & -562 & 7,2 & -517 & 7,6 & 30 & 6 & 1,6 & 1,8 & 1,8 & 1,8 & 23 & $8 \mathrm{hs}$ \\
\hline
\end{tabular}




\begin{tabular}{|c|c|c|c|c|c|c|c|c|c|c|c|c|c|c|c|}
\hline $25 / 09 / 2015$ & 7 & -535 & 7,2 & -520 & 7,4 & -530 & 7,3 & 28 & 6 & 1,6 & 1,68 & 1,8 & 1,68 & 21 & $18 \mathrm{hs}$ \\
\hline $26 / 09 / 2015$ & 7,1 & -510 & 7,5 & -540 & 7,2 & -530 & 7,4 & 30 & 6 & 1,8 & 1,6 & 1,7 & 1,72 & 24 & $12 \mathrm{hs}$ \\
\hline $27 / 09 / 2015$ & 7,2 & -520 & 7,3 & -540 & 7,3 & -520 & 7,6 & 20 & 6,5 & 1,68 & 1,6 & 1,8 & 1,68 & 24 & $12 \mathrm{hs}$ \\
\hline $28 / 09 / 2015$ & 7,1 & -522 & 7,4 & -566 & & & 7,3 & 27 & 4,5 & 1,88 & 1,6 & 0 & 1,8 & 24 & $11 \mathrm{hs}$ \\
\hline $28 / 09 / 2015$ & 7,2 & -570 & 7,3 & -580 & & & 7,4 & 15 & 4,3 & 1,8 & 1,6 & 0 & 1,8 & 20 & $19 \mathrm{hs}$ \\
\hline $29 / 09 / 2015$ & 7,1 & -501 & 7,6 & -572 & 7,2 & -494 & 7,2 & 20 & 5,9 & 1,8 & 1,6 & 1,52 & 1,68 & 19 & $8 \mathrm{hs}$ \\
\hline $29 / 09 / 2015$ & 7,1 & -500 & 7,5 & -580 & 7,4 & -490 & 7,4 & 18 & 6,2 & 1,6 & 1,6 & 1,6 & 1,8 & 21 & $18 \mathrm{hs}$ \\
\hline $30 / 09 / 2015$ & 7,2 & -512 & 7,6 & -572 & 7,2 & -500 & 6,9 & 17 & 4,8 & 1,8 & 1,56 & 1,64 & 1,72 & 21 & $8 \mathrm{hs}$ \\
\hline $30 / 09 / 2015$ & 7,1 & -500 & 7,3 & -560 & 7,2 & -495 & 7,2 & 18 & 6,8 & 1,4 & 1,6 & 1,7 & 1,68 & 21 & $18 \mathrm{hs}$ \\
\hline $01 / 10 / 2015$ & & & 7,6 & -567 & 7,2 & -507 & 6,8 & 16 & 5 & 2 & 1,4 & 1,92 & 1,68 & 23 & $8 \mathrm{hs}$ \\
\hline $01 / 10 / 2015$ & 6,95 & -530 & 7,5 & -560 & 7,4 & -540 & 4,5 & 27 & 6,9 & 1,8 & 1,6 & 1,64 & 1,68 & 22 & $18 \mathrm{hs}$ \\
\hline $02 / 10 / 2015$ & 7,1 & -513 & 7,6 & -570 & 7,2 & -500 & 6,9 & 20 & 3,5 & 1,6 & 1,72 & 1,68 & 1,72 & 25 & $8 \mathrm{hs}$ \\
\hline $02 / 10 / 2015$ & 7,2 & -520 & 7,5 & -560 & 7,4 & -530 & 6,5 & 18 & 6,8 & 1,72 & 1,72 & 1,7 & 1,64 & 23 & $18 \mathrm{hs}$ \\
\hline $03 / 10 / 2015$ & 7,2 & -530 & 7,4 & -510 & 7,2 & -520 & 6,9 & 13 & 7 & 1,6 & 1,8 & 1,6 & 1,68 & 22 & $12 \mathrm{hs}$ \\
\hline $04 / 10 / 2015$ & 7,4 & -580 & 7,6 & -590 & 7,4 & -560 & 7 & -10 & 4 & 1,8 & 1,6 & 1,6 & 1,8 & 22 & $12 \mathrm{hs}$ \\
\hline $05 / 10 / 2015$ & 7,3 & -510 & 7,8 & -560 & 7,4 & -489 & 6,9 & 26 & 4,4 & 1,88 & 1,8 & 1,6 & 1,68 & 19 & $8 \mathrm{hs}$ \\
\hline $06 / 10 / 2015$ & 7,2 & -497 & 7,5 & -548 & 7,4 & -494 & 6,8 & 99 & 4,6 & 1,8 & 1,88 & 1,6 & 1,6 & 22 & $8 \mathrm{hs}$ \\
\hline $06 / 10 / 2015$ & 7,2 & -490 & 7,4 & -550 & 7,3 & -500 & 6,7 & 10 & 4 & 1,6 & 1,8 & 1,6 & 1,8 & 23 & $18 \mathrm{hs}$ \\
\hline $07 / 10 / 2015$ & 7,2 & -498 & 7,7 & -541 & 7,4 & -310 & 6,8 & 29 & 4 & 1,84 & 1,8 & 1,6 & 1,8 & 21 & $8 \mathrm{hs}$ \\
\hline $07 / 10 / 2015$ & 7 & -311 & 6,9 & -560 & 7 & -248 & 7,3 & -460 & 4,6 & 1,6 & 1,68 & 1,4 & 1,88 & 24 & $18 \mathrm{hs}$ \\
\hline $08 / 10 / 2015$ & 7,2 & -499 & 7,6 & -167 & 7,3 & -460 & 7 & 30 & 3 & 1,8 & 1,6 & 1,6 & 1,6 & 25 & $8 \mathrm{hs}$ \\
\hline $09 / 10 / 2015$ & 7,1 & -530 & 7,3 & -565 & 7,3 & -529 & 7 & -28 & 3,5 & 2 & 1,8 & 1,4 & 1,8 & 25 & 8hs \\
\hline $10 / 10 / 2015$ & 7 & -520 & 7,8 & -563 & 7,2 & -535 & 6,9 & -32 & 3,1 & 1,96 & 1,68 & 1,56 & 1,72 & 26 & $14 \mathrm{hs}$ \\
\hline $11 / 10 / 2015$ & 7 & -489 & 7,8 & -570 & 7,8 & -568 & 7 & 26 & 5,7 & 1,88 & 1,72 & 1,6 & 1,8 & 25 & $14 \mathrm{hs}$ \\
\hline $12 / 10 / 2015$ & 6,7 & -492 & 7,2 & -567 & 7,7 & -566 & 6,8 & -39 & 4 & 1,8 & 1,4 & 1,56 & 2 & 24 & $14 \mathrm{hs}$ \\
\hline $13 / 10 / 2015$ & 6 & -499 & 6 & -556 & 7 & -496 & 6,7 & 44 & 5,9 & 1,6 & 1,8 & 1,4 & 2 & 24 & $8 \mathrm{hs}$ \\
\hline $14 / 10 / 2015$ & 7,2 & -499 & 5,8 & -559 & 5,9 & -493 & 6,8 & -10 & 3,8 & 1,6 & 1,8 & 1,4 & 1,6 & 25 & $8 \mathrm{hs}$ \\
\hline
\end{tabular}




\begin{tabular}{|c|c|c|c|c|c|c|c|c|c|c|c|c|c|c|c|}
\hline $15 / 10 / 2015$ & 6,3 & -482 & 5,3 & -556 & 6,15 & -496 & 6,4 & 33 & 4,5 & 1,8 & 1,88 & 1,6 & 1,68 & 26 & $8 \mathrm{hs}$ \\
\hline $16 / 10 / 2015$ & 6,1 & -494 & 5,1 & -552 & 6,5 & -491 & 6,3 & 23 & 4,4 & 1,6 & 1,92 & 1,6 & 1,6 & 27 & $8 \mathrm{hs}$ \\
\hline $19 / 10 / 2015$ & 5,3 & & 7,4 & & 6,5 & & 6,1 & 46 & 5,3 & 1,8 & 1,6 & 1,6 & 1,8 & 24 & $8 \mathrm{hs}$ \\
\hline $09 / 10 / 2015$ & 6 & -480 & 6,2 & 560 & 6 & -490 & 6,2 & 30 & 5 & 1,68 & 1,8 & 1,6 & 1,68 & 28 & 18hs \\
\hline $20 / 10 / 2015$ & 6,7 & & 7,4 & & 7 & & 6,9 & -44 & 3,6 & 1,76 & 1,6 & 1,6 & 1,76 & 22 & $8 \mathrm{hs}$ \\
\hline $20 / 10 / 2015$ & 6,9 & -470 & 7,6 & & 7,2 & -500 & 6,8 & -30 & 3,8 & 1,6 & 1,8 & 1,6 & 1,8 & 26 & $17 \mathrm{hs}$ \\
\hline $21 / 10 / 2015$ & & & & & & & & & & 0 & 0 & 0 & 0 & 25 & 10:30hs \\
\hline $22 / 10 / 2015$ & 6,5 & -512 & 7,8 & -515 & 7,1 & & 6,8 & 10 & 3,9 & 1,8 & 1,92 & 1,6 & 2 & 25 & $8 \mathrm{hs}$ \\
\hline $22 / 10 / 2015$ & 6,7 & -470 & 6,7 & -550 & 7,2 & -490 & 6,4 & -30 & 3,7 & 1,6 & 1,8 & 1,6 & 1,76 & 24 & $18 \mathrm{hs}$ \\
\hline $23 / 10 / 2015$ & 7,1 & -508 & 7,7 & -515 & 7,2 & -504 & 6,4 & 13 & 5 & 1,6 & 1,8 & 1,72 & 1,8 & 22 & 8hs \\
\hline $23 / 10 / 2015$ & 7,2 & -510 & 7,6 & -500 & 7,4 & -510 & 6,7 & 19 & 5,1 & 1,6 & 1,8 & 1,8 & 1,8 & 24 & $15 \mathrm{hs}$ \\
\hline $24 / 10 / 2015$ & 7,1 & -470 & 5,2 & -550 & 6,8 & -490 & 6,2 & 30 & 3,6 & 1,68 & 1,8 & 1,6 & 1,68 & 23 & $8 \mathrm{hs}$ \\
\hline $25 / 10 / 2015$ & 7 & -499 & 6 & -560 & 7,2 & -485 & 6,8 & 33 & 3,8 & 1,96 & 1,88 & 1,6 & 1,72 & 26 & $12 \mathrm{hs}$ \\
\hline $26 / 10 / 2015$ & 7,2 & -482 & 7,5 & & & & 7 & -40 & 2,5 & 1,8 & 1,8 & 1,8 & 1,8 & 21 & $8 \mathrm{hs}$ \\
\hline $26 / 10 / 2015$ & 7,1 & -480 & 6,2 & -565 & 7,3 & -490 & 6,1 & 23 & 4 & 1,68 & 1,6 & 1,4 & 1,6 & 24 & $18 \mathrm{hs}$ \\
\hline $27 / 10 / 2015$ & 7,2 & -503 & 7,3 & -502 & 7,4 & & 6,7 & -7 & 2,9 & 1,92 & 1,8 & 1,6 & 1,68 & 21 & $8 \mathrm{hs}$ \\
\hline $27 / 10 / 2015$ & 7,3 & -510 & 7,2 & -505 & 7,3 & & 6,5 & -10 & 2,9 & 1,8 & 1,8 & 1,6 & 1,8 & 24 & $17 \mathrm{hs}$ \\
\hline $28 / 10 / 2015$ & 7,2 & -548 & 7,7 & -534 & 7,1 & -534 & 6,6 & -1 & 3,4 & 1,92 & 1,84 & 1,76 & 1,8 & 24 & $8 \mathrm{hs}$ \\
\hline $28 / 10 / 2015$ & 7,1 & -500 & 7,2 & -560 & 7,2 & -490 & 6,1 & -4 & 2,5 & 1,68 & 1,8 & 1,64 & 1,68 & 25 & $18 \mathrm{hs}$ \\
\hline $29 / 10 / 2015$ & 7,1 & & & -521 & 7,3 & & 6,8 & -4 & 3,5 & 1,8 & 1,88 & 1,8 & 1,8 & 26 & 13hs \\
\hline $29 / 10 / 2015$ & 7,1 & & & -530 & 7,4 & & 6,9 & -10 & 3,2 & 1,8 & 1,8 & 1,8 & 1,8 & 27 & $18 \mathrm{hs}$ \\
\hline $30 / 10 / 2015$ & 7,1 & -480 & 7,3 & -500 & 7,1 & -430 & 6,6 & -7 & 3,4 & 1,68 & 1,8 & 1,6 & 1,6 & 27 & 18hs \\
\hline $31 / 10 / 2015$ & 7,2 & -470 & 7,8 & -550 & 6,5 & -490 & 6,1 & -30 & 3 & 1,68 & 1,8 & 1,6 & 2 & 24 & $12 \mathrm{hs}$ \\
\hline $01 / 11 / 2015$ & 7 & -493 & 6,7 & -560 & 6,8 & -500 & 6,2 & -1 & 5,1 & 1,68 & 1,84 & 1,6 & 1,8 & 23 & $12 \mathrm{hs}$ \\
\hline $02 / 11 / 2015$ & 7 & -470 & 6,8 & -570 & 6,9 & -500 & 6,7 & -15 & 4 & 1,6 & 1,8 & 1,8 & 1,8 & 27 & $12 \mathrm{hs}$ \\
\hline
\end{tabular}




\begin{tabular}{|c|c|c|c|c|c|c|c|}
\hline \multirow{3}{*}{ Data } & \multicolumn{2}{|c|}{ DQO TOTAL } & \multicolumn{5}{|c|}{ DQO SOLÚVEL } \\
\hline & $\begin{array}{c}\text { Ponto } \\
\text { Amostragem } 1\end{array}$ & $\begin{array}{c}\text { Ponto } \\
\text { Amostragem } 6\end{array}$ & $\begin{array}{c}\text { Ponto } \\
\text { Amostragem } \\
1 \\
\end{array}$ & $\begin{array}{c}\text { Ponto } \\
\text { Amostragem } \\
2\end{array}$ & \begin{tabular}{|c|} 
Ponto \\
Amostragem \\
3 \\
\end{tabular} & \begin{tabular}{|c|} 
Ponto \\
Amostragem \\
4 \\
\end{tabular} & \begin{tabular}{|c|} 
Ponto \\
Amostragem \\
6 \\
\end{tabular} \\
\hline & $\mathrm{mgO} / \mathrm{L}$ & $\mathrm{mgO} 2 / \mathrm{L}$ & $\mathrm{mgO} 2 / \mathrm{L}$ & $\mathrm{mgO} / \mathrm{L}$ & $\mathrm{mgO} 2 / \mathrm{L}$ & $\mathrm{mgO} 2 / \mathrm{L}$ & $\mathrm{mgO} 2 / \mathrm{L}$ \\
\hline $18 / 06 / 2015$ & 375 & 139 & 186 & 61 & 50 & 54 & 68 \\
\hline 26/06/2015 & 514 & 479 & 247 & 232 & 217 & 228 & 232 \\
\hline $29 / 06 / 2015$ & 594 & 499 & 364 & 313 & 392 & 250 & 261 \\
\hline $02 / 07 / 2015$ & 400 & 358 & 198 & 114 & 91 & 65 & 274 \\
\hline $07 / 07 / 2015$ & 353 & 180 & 188 & 67 & 82 & 78 & 129 \\
\hline $16 / 07 / 2015$ & 373 & 376 & 259 & 106 & 86 & 75 & 71 \\
\hline $21 / 07 / 2015$ & 238 & 95 & 179 & 69 & 65 & 57 & 46 \\
\hline $30 / 07 / 2015$ & 594 & 60 & 264 & 53 & 125 & 38 & 38 \\
\hline $05 / 08 / 2015$ & 491 & 74 & 233 & 74 & 56 & 63 & 37 \\
\hline $07 / 08 / 2015$ & 348 & 94 & 209 & 94 & 70 & 70 & 35 \\
\hline $12 / 08 / 2015$ & 576 & 65 & 283 & 61 & 40 & 48 & 28 \\
\hline 01/09/2015 & 566 & 226 & 303 & 20 & 53 & 16 & 12 \\
\hline 03/09/2015 & 566 & 226 & 303 & 20 & 53 & 16 & 12 \\
\hline $10 / 09 / 2015$ & 457 & 80 & 305 & 30 & 46 & 42 & 30 \\
\hline $17 / 09 / 2015$ & 364 & 171 & 244 & 84 & 55 & 36 & 62 \\
\hline $01 / 10 / 2015$ & 504 & 92 & 232 & 99 & 72 & 65 & 34 \\
\hline $08 / 10 / 2015$ & 333 & 100 & 160 & 83 & 33 & 57 & 83 \\
\hline $15 / 10 / 2015$ & 420 & 134 & 286 & 71 & 34 & 34 & 30 \\
\hline $22 / 10 / 2015$ & 404 & 150 & 330 & 77 & 66 & 73 & 37 \\
\hline $27 / 10 / 2015$ & 404 & 150 & 330 & 77 & 66 & 73 & 37 \\
\hline
\end{tabular}

\begin{tabular}{|c|c|c|c|c|c|c|c|}
\hline \multirow{3}{*}{ Data } & \multicolumn{2}{|c|}{ DBO TOTAL } & \multicolumn{5}{|c|}{ DBO SOLÚVEL } \\
\hline & \begin{tabular}{|c|} 
Ponto \\
Amostragem \\
1
\end{tabular} & $\begin{array}{c}\text { Ponto } \\
\text { Amostragem } \\
6\end{array}$ & \begin{tabular}{|c|} 
Ponto \\
Amostragem \\
1
\end{tabular} & \begin{tabular}{|c|} 
Ponto \\
Amostragem \\
2 \\
\end{tabular} & \begin{tabular}{|c|} 
Ponto \\
Amostragem \\
3 \\
\end{tabular} & \begin{tabular}{|c|} 
Ponto \\
Amostragem \\
4
\end{tabular} & $\begin{array}{c}\text { Ponto } \\
\text { Amostragem } \\
6\end{array}$ \\
\hline & $\mathrm{mgO} 2 / \mathrm{L}$ & $\mathrm{mgO} / \mathrm{L}$ & $\mathrm{mgO} 2 / \mathrm{L}$ & $\mathrm{mgO} 2 / \mathrm{L}$ & $\mathrm{mgO} 2 / \mathrm{L}$ & $\mathrm{mgO} 2 / \mathrm{L}$ & $\mathrm{mgO} 2 / \mathrm{L}$ \\
\hline $18 / 06 / 2015$ & 288 & 145 & 52 & 31 & 26 & 25 & 16 \\
\hline $26 / 06 / 2015$ & 288 & 145 & 52 & 31 & 26 & 25 & 16 \\
\hline 29/06/2015 & 288 & 145 & 52 & 31 & 26 & 25 & 16 \\
\hline 02/07/2015 & 300 & 139 & 96 & 41 & 31 & 32 & 23 \\
\hline 07/07/2015 & 300 & 139 & 96 & 41 & 31 & 32 & 23 \\
\hline $16 / 07 / 2015$ & 200 & 59 & 103 & 47 & 30 & 25 & 26 \\
\hline $21 / 07 / 2015$ & 200 & 59 & 103 & 47 & 30 & 25 & 26 \\
\hline $30 / 07 / 2015$ & 273 & 18 & 126 & 32 & 29 & 31 & 12 \\
\hline 05/08/2015 & 322 & 81 & 124 & 51 & 67 & 58 & 31 \\
\hline $07 / 08 / 2015$ & 322 & 81 & 124 & 51 & 67 & 58 & 31 \\
\hline $12 / 08 / 2015$ & 322 & 81 & 124 & 51 & 67 & 58 & 31 \\
\hline 01/09/2015 & 286 & 111 & 123 & 41 & 26 & 22 & 13 \\
\hline 03/09/2015 & 286 & 111 & 123 & 41 & 26 & 22 & 13 \\
\hline $10 / 09 / 2015$ & 286 & 111 & 123 & 41 & 26 & 22 & 13 \\
\hline $17 / 09 / 2015$ & 250 & 66 & 50 & 57 & 41 & 23 & 16 \\
\hline $01 / 10 / 2015$ & 250 & 66 & 50 & 57 & 41 & 23 & 16 \\
\hline $08 / 10 / 2015$ & 253 & 42 & 154 & 52 & 24 & 16 & 14 \\
\hline $15 / 10 / 2015$ & 250 & 74 & 122 & 23 & 18 & 14 & 22 \\
\hline $22 / 10 / 2015$ & 250 & 74 & 122 & 23 & 18 & 14 & 22 \\
\hline $27 / 10 / 2015$ & 250 & 74 & 122 & 23 & 18 & 14 & 22 \\
\hline
\end{tabular}




\begin{tabular}{|c|c|c|c|c|c|}
\hline \multicolumn{7}{|c|}{ Data } & $\begin{array}{c}\text { Ponto } \\
\text { Amostragem }\end{array}$ & $\begin{array}{c}\text { Ponto } \\
\text { Amostragem }\end{array}$ & $\begin{array}{c}\text { Ponto } \\
\text { Amostragem }\end{array}$ & & \\
& $\mathbf{1}$ & $\mathbf{5}$ & $\mathbf{6}$ & TAXA DE APLICAÇÃo & TAXA DE NITRIFICAÇÃo \\
\cline { 2 - 5 } & mgN-NH4+/L & mgN-NH4+/L & mgN-NH4+/L & g/m3.d & g/m3.d \\
\hline $18 / 06 / 2015$ & 70 & 392 & 96 & 147 & \#VALOR! \\
\hline $26 / 06 / 2015$ & 84 & 420 & 78 & 198 & -20 \\
\hline $29 / 06 / 2015$ & 77 & 393 & 74 & 181 & -8 \\
\hline $02 / 07 / 2015$ & 83 & 339 & 70 & 195 & 38 \\
\hline $07 / 07 / 2015$ & 83 & 353 & 70 & 177 & 8 \\
\hline $16 / 07 / 2015$ & 91 & 344 & 63 & 214 & 52 \\
\hline $21 / 07 / 2015$ & 80 & 459 & 53 & 188 & 14 \\
\hline $30 / 07 / 2015$ & 98 & 448 & 54 & 205 & 48 \\
\hline $05 / 08 / 2015$ & 116 & 557 & 21 & 243 & 119 \\
\hline $07 / 08 / 2015$ & 104 & 476 & 26 & 217 & 117 \\
\hline $12 / 08 / 2015$ & 106 & 440 & 39 & 223 & 88 \\
\hline $01 / 09 / 2015$ & 80 & 384 & 17 & 146 & 74 \\
\hline $03 / 09 / 2015$ & 105 & 370 & 25 & 192 & 116 \\
\hline $10 / 09 / 2015$ & 98 & 294 & 9,5 & 205 & 113 \\
\hline $17 / 09 / 2015$ & 77 & 316 & 12 & 161 & 65 \\
\hline $01 / 10 / 2015$ & 104 & 314 & 22 & 190 & 111 \\
\hline $08 / 10 / 2015$ & 83 & 294 & 21 & 195 & -62 \\
\hline $15 / 10 / 2015$ & 83 & 364 & 6 & 195 & 125 \\
\hline $22 / 10 / 2015$ & 70 & 319 & 13 & 147 & 73 \\
\hline $27 / 10 / 2015$ & 71 & 319 & 11 & 179 & 92 \\
\hline
\end{tabular}




\begin{tabular}{|c|c|c|c|}
\hline \multicolumn{4}{|c|}{ Nitrogênio Amoniacal } \\
\hline \multirow[t]{2}{*}{ Data } & \begin{tabular}{|c|} 
Ponto \\
Amostragem \\
1 \\
\end{tabular} & \begin{tabular}{|c|} 
Ponto \\
Amostragem \\
5 \\
\end{tabular} & $\begin{array}{c}\text { Ponto } \\
\text { Amostragem } \\
6 \\
\end{array}$ \\
\hline & $\mathrm{mgN}-\mathrm{NH} 4+/ \mathrm{L}$ & $\mathrm{mgN}-\mathrm{NH} 4+/ \mathrm{L}$ & $\mathrm{mgN}-\mathrm{NH} 4+/ \mathrm{L}$ \\
\hline $18 / 06 / 2015$ & 27 & 59 & 53 \\
\hline $26 / 06 / 2015$ & 67 & 69 & 66 \\
\hline $29 / 06 / 2015$ & 63 & 55 & 55 \\
\hline $02 / 07 / 2015$ & 64 & 48 & 46 \\
\hline 07/07/2015 & 70 & 55 & 49 \\
\hline $16 / 07 / 2015$ & 69 & 50 & 49 \\
\hline $21 / 07 / 2015$ & 66 & 52 & 46 \\
\hline $30 / 07 / 2015$ & 84 & 55 & 48 \\
\hline $05 / 08 / 2015$ & 91 & 24 & 20 \\
\hline $07 / 08 / 2015$ & 83 & & 17 \\
\hline $12 / 08 / 2015$ & 77 & & 35 \\
\hline $01 / 09 / 2015$ & 56 & & 10 \\
\hline 03/09/2015 & 66 & & 13 \\
\hline $10 / 09 / 2015$ & 69 & & 1 \\
\hline $17 / 09 / 2015$ & 69 & & 1 \\
\hline $01 / 10 / 2015$ & 95 & & 11 \\
\hline $08 / 10 / 2015$ & 69 & & 18 \\
\hline $15 / 10 / 2015$ & 52 & & 1 \\
\hline $22 / 10 / 2015$ & 64 & & 1 \\
\hline $27 / 10 / 2015$ & 59 & & 8 \\
\hline
\end{tabular}

\begin{tabular}{|c|c|c|c|c|c|c|}
\hline \multicolumn{7}{|c|}{ Nitrato } \\
\hline Data & \begin{tabular}{|c|} 
Ponto \\
Amostrag \\
em 2 \\
\end{tabular} & \begin{tabular}{|c|} 
Ponto \\
Amostrag \\
em 3 \\
\end{tabular} & \begin{tabular}{|c|}
$\begin{array}{c}\text { Ponto } \\
\text { Amostrag } \\
\text { em } 4\end{array}$ \\
\end{tabular} & \begin{tabular}{|c|} 
Ponto \\
Amostrag \\
em 5 \\
\end{tabular} & \begin{tabular}{|c} 
Ponto \\
Amostrag \\
em 6 \\
\end{tabular} & $\begin{array}{c}\text { Ponto } \\
\text { Amostrag } \\
\text { em } 7\end{array}$ \\
\hline $18 / 06 / 2015$ & $\mathrm{mg} / \mathrm{L}$ & $\mathrm{mg} / \mathrm{L}$ & $\mathrm{mg} / \mathrm{L}$ & $\mathrm{mg} / \mathrm{L}$ & $\mathrm{mg} / \mathrm{L}$ & $\mathrm{mg} / \mathrm{L}$ \\
\hline $26 / 06 / 2015$ & & & & & & \\
\hline $29 / 06 / 2015$ & & & & & & \\
\hline $02 / 07 / 2015$ & & & & & & \\
\hline $07 / 07 / 2015$ & & & & & & \\
\hline $16 / 07 / 2015$ & & & & & & \\
\hline $21 / 07 / 2015$ & & & & & & \\
\hline $30 / 07 / 2015$ & & & & & & \\
\hline $05 / 08 / 2015$ & & & & & & \\
\hline 07/08/2015 & & & & & & \\
\hline $12 / 08 / 2015$ & & & & & & \\
\hline $01 / 09 / 2015$ & & & & & & \\
\hline 03/09/2015 & & & & & & \\
\hline $10 / 09 / 2015$ & 18,3 & 11,9 & 8,7 & 8,5 & 21,4 & \\
\hline $17 / 09 / 2015$ & 0,7 & 0,7 & 1,51 & 17,7 & 21,8 & \\
\hline $24 / 09 / 2015$ & 0,2 & 2,9 & 2,7 & 3,93 & 5,8 & \\
\hline $01 / 10 / 2015$ & & 13,1 & 13,6 & 20,9 & 22 & \\
\hline $06 / 10 / 2015$ & & 15 & 1,8 & & 70 & \\
\hline $08 / 10 / 2015$ & & 0,3 & 0,1 & & 6,3 & \\
\hline $15 / 10 / 2015$ & 3,7 & 11,8 & 13 & 11 & 11,2 & 5,8 \\
\hline $22 / 10 / 2015$ & $<0,1$ & $<0,1$ & $<0,1$ & 10,1 & 11 & 0,6 \\
\hline $27 / 10 / 2015$ & $<0,1$ & $<0,1$ & $<0,1$ & 9,9 & 10,5 & 2,8 \\
\hline $29 / 10 / 2015$ & 4,2 & 7,5 & 6,6 & 9,1 & 7,1 & 6,4 \\
\hline
\end{tabular}




\begin{tabular}{|c|c|c|c|c|c|c|c|}
\hline \multicolumn{8}{|c|}{ Alcalinidade } \\
\hline \multirow[t]{2}{*}{ Data } & $\begin{array}{c}\text { Ponto } \\
\text { Amostragem } \\
1 \\
\end{array}$ & \begin{tabular}{|c|} 
Ponto \\
Amostragem \\
2 \\
\end{tabular} & \begin{tabular}{|c|} 
Ponto \\
Amostragem \\
3 \\
\end{tabular} & \begin{tabular}{|c|} 
Ponto \\
Amostragem \\
4 \\
\end{tabular} & \begin{tabular}{|c} 
Ponto \\
Amostragem \\
5 \\
\end{tabular} & \begin{tabular}{|c|} 
Ponto \\
Amostragem \\
6 \\
\end{tabular} & \begin{tabular}{|c} 
Ponto \\
Amostragem \\
7 \\
\end{tabular} \\
\hline & $\mathrm{mgCaCO} 3 / \mathrm{L}$ & $\mathrm{mgCaCO} / \mathrm{L}$ & $\mathrm{mgCaCO} 3 / \mathrm{L}$ & $\mathrm{mgCaCO} 3 / \mathrm{L}$ & $\mathrm{mgCaCO} 3 / \mathrm{L}$ & $\mathrm{mgCaCO} 3 / \mathrm{L}$ & $\mathrm{mgCaCO} 3 / \mathrm{L}$ \\
\hline $18 / 06 / 2015$ & 245 & 314 & 327 & 320 & 320 & 280 & 344 \\
\hline $26 / 06 / 2015$ & 272 & 328 & 352 & 352 & 358 & 302 & 326 \\
\hline $29 / 06 / 2015$ & 260 & 312 & 328 & 330 & 342 & 282 & 334 \\
\hline 02/07/2015 & 264 & 308 & 326 & 302 & 278 & 242 & 312 \\
\hline $07 / 07 / 2015$ & 282 & 332 & 326 & 316 & 284 & 256 & 294 \\
\hline $16 / 07 / 2015$ & 304 & 358 & 352 & 338 & 296 & 262 & 320 \\
\hline $21 / 07 / 2015$ & 274 & 344 & 338 & 328 & 292 & 254 & 370 \\
\hline $30 / 07 / 2015$ & 344 & 356 & 340 & 322 & 300 & 260 & 350 \\
\hline $05 / 08 / 2015$ & 330 & 316 & 274 & 244 & 226 & 156 & 222 \\
\hline 07/08/2015 & 314 & 312 & 276 & 238 & 162 & 120 & 230 \\
\hline $12 / 08 / 2015$ & 318 & 320 & 290 & 268 & 236 & 208 & 254 \\
\hline $01 / 09 / 2015$ & 240 & 196 & 174 & 164 & 140 & 134 & 220 \\
\hline $03 / 09 / 2015$ & 320 & 326 & 256 & 226 & 136 & 98 & 216 \\
\hline $10 / 09 / 2015$ & 320 & 192 & 180 & 168 & 120 & 80 & 184 \\
\hline $17 / 09 / 2015$ & 264 & 290 & 258 & 220 & 130 & 80 & 184 \\
\hline $01 / 10 / 2015$ & 308 & 260 & 216 & 176 & 90 & 90 & 196 \\
\hline $08 / 10 / 2015$ & 254 & 300 & 250 & 216 & 112 & 90 & 190 \\
\hline $15 / 10 / 2015$ & 272 & 296 & 230 & 186 & 76 & 56 & 124 \\
\hline $22 / 10 / 2015$ & 236 & 252 & 210 & 180 & 100 & 60 & 172 \\
\hline $27 / 10 / 2015$ & 236 & 252 & 210 & 180 & 100 & 60 & 172 \\
\hline
\end{tabular}




\begin{tabular}{|c|c|c|c|c|c|c|c|c|c|c|c|c|c|c|}
\hline \multirow[b]{2}{*}{ Data } & \multicolumn{7}{|c|}{$\mathrm{P}$ total (mgP-PO4/L) } & \multicolumn{7}{|c|}{ P solúvel (mgP-PO4/L) } \\
\hline & \begin{tabular}{|c|} 
Ponto \\
Amostragem \\
1
\end{tabular} & $\begin{array}{c}\text { Ponto } \\
\text { Amostragem } \\
2\end{array}$ & \begin{tabular}{|c|} 
Ponto \\
Amostragem \\
3
\end{tabular} & \begin{tabular}{|c|} 
Ponto \\
Amostragem \\
4
\end{tabular} & $\begin{array}{c}\text { Ponto } \\
\text { Amostragem } \\
5\end{array}$ & $\begin{array}{c}\text { Ponto } \\
\text { Amostragem } \\
6\end{array}$ & \begin{tabular}{|c|} 
Ponto \\
Amostragem \\
7
\end{tabular} & $\begin{array}{c}\text { Ponto } \\
\text { Amostragem } \\
1\end{array}$ & \begin{tabular}{|c|} 
Ponto \\
Amostragem \\
2
\end{tabular} & \begin{tabular}{|c|} 
Ponto \\
Amostragem \\
3 \\
\end{tabular} & \begin{tabular}{|c|} 
Ponto \\
Amostragem \\
4 \\
\end{tabular} & \begin{tabular}{|c|} 
Ponto \\
Amostragem \\
5
\end{tabular} & \begin{tabular}{|c|} 
Ponto \\
Amostragem \\
6
\end{tabular} & \begin{tabular}{|c|} 
Ponto \\
Amostragem \\
7 \\
\end{tabular} \\
\hline $18 / 06 / 2015$ & 5,2 & 10,2 & 4,2 & 10,1 & 11,2 & 3,7 & 12,4 & 2,0 & 2,4 & 2,3 & 2,4 & 1,0 & 0,2 & 1,5 \\
\hline $26 / 06 / 2015$ & 4,8 & 11,1 & 11,0 & 10,8 & 10,0 & 6,2 & 10,1 & 1,8 & 2,1 & 2,0 & 1,9 & 1,9 & 2,0 & 2,0 \\
\hline 29/06/2015 & 4,6 & 10,4 & 10,0 & 10,9 & 11,5 & 5,9 & 11,7 & 2,0 & 2,4 & 2,4 & 2,4 & 2,3 & 2,4 & 2,5 \\
\hline $02 / 07 / 2015$ & 3,9 & 8,6 & 11,9 & 11,0 & 11,5 & 2,3 & 12,6 & 2,1 & 2,5 & 2,5 & 1,8 & 0,3 & 0,2 & 1,4 \\
\hline $07 / 07 / 2015$ & 4,2 & 10,2 & 10,9 & 11,1 & 11,2 & 1,7 & 11,7 & 1,8 & 2,4 & 2,3 & 2,3 & 0,5 & 0,2 & 0,7 \\
\hline $16 / 07 / 2015$ & 4,8 & 10,8 & 13,0 & 13,5 & 12,8 & 1,87 & 13,7 & 2,2 & 2,8 & 2,8 & 2,7 & 0,4 & 0,3 & 1,3 \\
\hline $21 / 07 / 2015$ & 4,3 & 26,6 & 28,9 & 30,3 & 29,7 & 0,83 & 32,5 & 1,6 & 2,1 & 2,0 & 1,9 & 0,5 & 0,2 & 2,1 \\
\hline $30 / 07 / 2015$ & 6,7 & 36,6 & 38,6 & 35,3 & 43,6 & 0,56 & 53,0 & 2,2 & 2,8 & 2,7 & 1,8 & 0,6 & 0,5 & 2,8 \\
\hline $05 / 08 / 2015$ & 7,2 & 34,4 & 43,9 & 39,4 & 40,8 & 0,90 & 47,2 & 2,3 & 2,8 & 2,6 & 1,8 & 0,2 & 0,8 & 2,8 \\
\hline $07 / 08 / 2015$ & 6,1 & 34,4 & 39,7 & 40,2 & 41,4 & 0,76 & 51,9 & 2,3 & 2,7 & 2,7 & 2,1 & 0,3 & 0,2 & 2,7 \\
\hline $12 / 08 / 2015$ & 6,4 & 34,1 & 37,2 & 40,0 & 35,5 & 0,62 & 42,7 & 1,7 & 2,14 & 2,11 & 2,05 & 0,34 & 0,24 & 2,0 \\
\hline $01 / 09 / 2015$ & 5,6 & 34,4 & 37,5 & 35,3 & 37,5 & 6,18 & 42,5 & 1,8 & 2,1 & 0,4 & 1,8 & 0,8 & 2,2 & 2,2 \\
\hline $03 / 09 / 2015$ & 5,6 & 34,4 & 37,5 & 35,3 & 37,5 & 6,18 & 42,5 & 1,83 & 2,29 & 2,12 & 1,89 & 0,98 & 0,60 & 1,80 \\
\hline $10 / 09 / 2015$ & 6,2 & 10,7 & 12,2 & 12,5 & 7,8 & 0,8 & 21,1 & 1,76 & 1,10 & 0,23 & 0,15 & 0,06 & 0,29 & 1,02 \\
\hline $17 / 09 / 2015$ & 4,9 & 17,2 & 19,7 & 21,5 & 20,4 & 1,2 & 22,5 & 1,73 & 2,22 & 2,17 & 1,96 & 0,11 & 0,28 & 0,3 \\
\hline $01 / 10 / 2015$ & 6,5 & 39,1 & 42,5 & 38,3 & 34,7 & 2,7 & 42,5 & 1,57 & 1,76 & 1,50 & 0,52 & 0,09 & 0,55 & 1,31 \\
\hline $08 / 10 / 2015$ & 6,7 & 39,4 & 41,4 & 36,6 & 35,3 & 0,06 & 43,6 & 1,73 & 2,17 & 2,11 & 1,99 & 0,28 & 0,38 & 1,67 \\
\hline $15 / 10 / 2015$ & 6,0 & 38,9 & 47,7 & 37,8 & 40,0 & 2,50 & 46,1 & 2,02 & 2,40 & 2,31 & 1,93 & 0,08 & 0,28 & 0,32 \\
\hline $22 / 10 / 2015$ & 4,7 & 33,9 & 41,1 & 36,6 & 36,9 & 2,22 & 44,7 & 1,73 & 2,28 & 1,73 & 0,57 & 0,06 & 0,05 & 0,06 \\
\hline $27 / 10 / 2015$ & 4,7 & 33,9 & 41,1 & 36,6 & 36,9 & 2,22 & 44,7 & 1,73 & 2,28 & 1,73 & 0,57 & 0,06 & 0,05 & 0,06 \\
\hline
\end{tabular}




\begin{tabular}{|c|c|c|c|c|}
\hline \multirow{2}{*}{ Data } & $\begin{array}{c}\text { Ácidos Orgânicos Voláteis (AOV) } \\
\text { Amostragem }\end{array}$ & $\begin{array}{c}\text { Ponto } \\
\text { Amostragem }\end{array}$ & $\begin{array}{c}\text { Ponto } \\
\text { Amostragem }\end{array}$ & $\begin{array}{c}\text { Ponto } \\
\text { Amostragem }\end{array}$ \\
\cline { 2 - 5 } & $\mathbf{1}$ & $\mathbf{2}$ & $\mathbf{3}$ & $\mathbf{4}$ \\
\hline $18 / 06 / 2015$ & 144 & 158 & 154 & 125 \\
\hline $26 / 06 / 2015$ & 144 & 158 & 154 & 125 \\
\hline $29 / 06 / 2015$ & 86 & 67 & 58 & 67 \\
\hline $02 / 07 / 2015$ & 58 & 38 & 38 & 19 \\
\hline $07 / 07 / 2015$ & 48 & 48 & 34 & 34 \\
\hline $16 / 07 / 2015$ & 67 & 48 & 48 & 34 \\
\hline $21 / 07 / 2015$ & 58 & 48 & 48 & 29 \\
\hline $30 / 07 / 2015$ & 91 & 53 & 38 & 24 \\
\hline $05 / 08 / 2015$ & 91 & 62 & 43 & 29 \\
\hline $07 / 08 / 2015$ & 72 & 72 & 67 & 38 \\
\hline $12 / 08 / 2015$ & 72 & 72 & 67 & 38 \\
\hline $01 / 09 / 2015$ & 115 & 106 & 72 & 77 \\
\hline $03 / 09 / 2015$ & 115 & 106 & 72 & 77 \\
\hline $10 / 09 / 2015$ & 82 & 38 & 19 & 14 \\
\hline $17 / 09 / 2015$ & 82 & 38 & 19 & 14 \\
\hline $01 / 10 / 2015$ & 101 & 96 & 58 & 43 \\
\hline $08 / 10 / 2015$ & 91 & 86 & 53 & 38 \\
\hline $15 / 10 / 2015$ & 86 & 77 & 58 & 43 \\
\hline $22 / 10 / 2015$ & 86 & 77 & 58 & 43 \\
\hline $27 / 10 / 2015$ & 86 & 77 & 58 & 43 \\
\hline
\end{tabular}




\begin{tabular}{|c|c|c|c|c|c|c|c|c|c|c|c|c|c|c|c|c|c|c|c|c|c|}
\hline \multicolumn{22}{|c|}{ Série de Sólidos } \\
\hline \multirow[t]{2}{*}{ Data } & \multicolumn{3}{|c|}{$\begin{array}{l}\text { Ponto de Amostragem } 1 \\
\qquad(\mathrm{mg} / \mathrm{L})\end{array}$} & \multicolumn{3}{|c|}{$\begin{array}{c}\text { Ponto de Amostragem } 2 \\
(\mathrm{mg} / \mathrm{L})\end{array}$} & \multicolumn{3}{|c|}{$\begin{array}{l}\text { Ponto de Amostragem } 3 \\
\qquad(\mathrm{mg} / \mathrm{L})\end{array}$} & \multicolumn{3}{|c|}{$\begin{array}{c}\text { Ponto de Amostragem } 4 \\
(\mathrm{mg} / \mathrm{L})\end{array}$} & \multicolumn{3}{|c|}{$\begin{array}{l}\text { Ponto de Amostragem } 5 \\
\text { (mg/L) }\end{array}$} & \multicolumn{3}{|c|}{$\begin{array}{c}\text { Ponto de Amostragem } 6 \\
(\mathrm{mg} / \mathrm{L})\end{array}$} & \multicolumn{3}{|c|}{$\begin{array}{c}\text { Ponto de Amostragem } 7 \\
(\mathrm{mg} / \mathrm{L})\end{array}$} \\
\hline & SST & SSF & SSV & SST & SSF & SSV & SST & SSF & SSV & SST & SSF & SSV & SST & SSF & SSV & SST & SSF & SSV & SST & SSF & SSV \\
\hline $18 / 06 / 2015$ & 206 & 8 & 198 & 2870 & 330 & 2540 & 4180 & 560 & 3620 & 3900 & 500 & 3400 & 4690 & 730 & 3960 & 120 & 4 & 116 & 6880 & 900 & 5980 \\
\hline $26 / 06 / 2015$ & 112 & 12 & 100 & 4310 & 390 & 3920 & 4040 & 350 & 3690 & 4070 & 360 & 3710 & 4190 & 400 & 3790 & 130 & 10 & 120 & 2670 & 260 & 2410 \\
\hline $29 / 06 / 2015$ & 154 & 32 & 122 & 3510 & 350 & 3160 & 3300 & 360 & 2940 & 3650 & 400 & 3250 & 4090 & 420 & 3670 & 194 & 26 & 168 & 5300 & 550 & 4750 \\
\hline $02 / 07 / 2015$ & 104 & 12 & 92 & 1840 & 180 & 1660 & 3400 & 340 & 3060 & 2940 & 340 & 2600 & 3220 & 360 & 2860 & 202 & 18 & 184 & 6100 & 740 & 5360 \\
\hline 07/07/2015 & 68 & 6 & 62 & 2720 & 360 & 2360 & 2480 & 600 & 1880 & 4660 & 660 & 4000 & 4480 & 660 & 3820 & 114 & 10 & 104 & 5780 & 860 & 4920 \\
\hline $16 / 07 / 2015$ & 100 & 8 & 92 & 1920 & 180 & 1740 & 3640 & 420 & 3220 & 3400 & 340 & 3060 & 3280 & 460 & 2820 & 94 & 8 & 86 & 6500 & 780 & 5720 \\
\hline $21 / 07 / 2015$ & 108 & 6 & 102 & 2920 & 340 & 2580 & 3980 & 380 & 3600 & 4440 & 520 & 3920 & 4420 & 540 & 3880 & 46 & 2 & 44 & 12280 & 1660 & 10620 \\
\hline $30 / 07 / 2015$ & 204 & 18 & 186 & 2660 & 260 & 2400 & 4280 & 620 & 3660 & 4140 & 580 & 3560 & 3940 & 560 & 3380 & 32 & 2 & 30 & 9580 & 1400 & 8180 \\
\hline $05 / 08 / 2015$ & 222 & 10 & 212 & 2840 & 180 & 2660 & 4360 & 520 & 3840 & 4520 & 620 & 3900 & 5740 & 820 & 4920 & 52 & 2 & 50 & 6980 & 1000 & 5980 \\
\hline $07 / 08 / 2015$ & 154 & 16 & 138 & 2780 & 400 & 2380 & 4420 & 680 & 3740 & 4500 & 800 & 3700 & 4540 & 640 & 3900 & 64 & 8 & 56 & 8800 & 1460 & 7340 \\
\hline $12 / 08 / 2015$ & 98 & 6 & 92 & 2800 & 360 & 2440 & 4280 & 660 & 3620 & 4440 & 700 & 3740 & 4520 & 800 & 3720 & 38 & 6 & 32 & 7100 & 1200 & 5900 \\
\hline $01 / 09 / 2015$ & 144 & 10 & 134 & 4000 & 560 & 3440 & 3700 & 580 & 3120 & 3820 & 480 & 3340 & 3820 & 520 & 3300 & 24 & 2 & 22 & 9280 & 1440 & 7840 \\
\hline $03 / 09 / 2015$ & 156 & 10 & 146 & 3980 & 440 & 3540 & 3760 & 580 & 3180 & 3700 & 600 & 3100 & 3680 & 560 & 3120 & 88 & 6 & 82 & 8000 & 1400 & 6600 \\
\hline $10 / 09 / 2015$ & 194 & 22 & 172 & 3320 & 580 & 2740 & 3640 & 540 & 3100 & 3480 & 600 & 2880 & 3360 & 560 & 2800 & 40 & 8 & 32 & 7320 & 1180 & 6140 \\
\hline $17 / 09 / 2015$ & 130 & 34 & 96 & 1940 & 160 & 1780 & 3180 & 440 & 2740 & 3280 & 460 & 2820 & 3600 & 660 & 2940 & 52 & 20 & 32 & 7540 & 1360 & 6180 \\
\hline $01 / 10 / 2015$ & 208 & 36 & 172 & 3620 & 520 & 3100 & 3480 & 620 & 2860 & 3440 & 500 & 2940 & 3380 & 540 & 2840 & 70 & 6 & 64 & 6120 & 1160 & 4960 \\
\hline $08 / 10 / 2015$ & 102 & 8 & 94 & 2760 & 240 & 2520 & 3560 & 500 & 3060 & 3340 & 540 & 2800 & 3500 & 560 & 2940 & 26 & 2 & 24 & 8340 & 1640 & 6700 \\
\hline $15 / 10 / 2015$ & 118 & 14 & 104 & 2480 & 380 & 2100 & 3760 & 620 & 3140 & 3720 & 660 & 3060 & 3900 & 700 & 3200 & 118 & 24 & 94 & 6000 & 1020 & 4980 \\
\hline $22 / 10 / 2015$ & 112 & 10 & 102 & 3180 & 500 & 2680 & 3780 & 680 & 3100 & 4040 & 760 & 3280 & 3680 & 720 & 2960 & 94 & 14 & 80 & 8600 & 1680 & 6920 \\
\hline $27 / 10 / 2015$ & 112 & 10 & 102 & 3180 & 500 & 2680 & 3780 & 680 & 3100 & 4040 & 760 & 3280 & 2780 & 380 & 2400 & 60 & 2 & 58 & 8600 & 1680 & 6920 \\
\hline
\end{tabular}


- APÊNDICE 2 - DADOS DAS MEDIÇÕES EM CAMPO E ANÁLISES FÍSICO-QUÍMICAS PARA FASE 2

\begin{tabular}{|c|c|c|c|c|c|c|c|c|c|c|c|c|c|c|c|}
\hline \multirow[t]{2}{*}{ Data } & \multicolumn{2}{|c|}{ Anaeróbio } & \multicolumn{2}{|c|}{ Anóxico 1} & \multicolumn{2}{|c|}{ Anóxico 2} & \multicolumn{3}{|c|}{ Tanque de Aeração } & \multirow{2}{*}{$\begin{array}{c}\text { Vazão } \\
\text { Alimentação } \\
\text { L/min }\end{array}$} & \multirow{2}{*}{$\begin{array}{c}\begin{array}{c}\text { Vazão } \\
\text { Retorno }\end{array} \\
\text { L/min }\end{array}$} & \multirow{2}{*}{$\begin{array}{c}\text { Vazão } \\
\text { Reciclo } 1 \\
\text { L/min } \\
\end{array}$} & \multirow{2}{*}{$\begin{array}{c}\text { Vazão } \\
\text { Reciclo } 2 \\
\text { L/min } \\
\end{array}$} & \multirow{2}{*}{$\begin{array}{c}\text { Temperatura } \\
\mathrm{oC} \\
\end{array}$} & \multirow[t]{2}{*}{ Horário } \\
\hline & $\mathrm{pH}$ & ORP & $\mathrm{pH}$ & ORP & $\mathrm{pH}$ & ORP & $\mathrm{pH}$ & ORP & OD & & & & & & \\
\hline $03 / 11 / 2015$ & 6,9 & -495 & 7 & -496 & 7,6 & & 6,9 & 14 & 4,9 & 1,68 & 1,8 & 1,6 & 1,8 & 24 & $8 \mathrm{hs}$ \\
\hline $03 / 11 / 2015$ & 6,9 & -470 & 7,5 & -510 & 7,4 & & 6,7 & 8 & 3,9 & 1,6 & 1,8 & 1,6 & 1,8 & 25 & $18 \mathrm{hs}$ \\
\hline $04 / 11 / 2015$ & 7 & -508 & 6,7 & & & & 6,9 & 36 & 5,9 & 1,68 & 1,8 & 1,48 & 1,88 & 26 & $8 \mathrm{hs}$ \\
\hline $04 / 11 / 2015$ & 7,3 & -510 & 6,8 & & & & 6,9 & 20 & 5,7 & 1,6 & 1,8 & 1,52 & 1,8 & 26 & $18 \mathrm{hs}$ \\
\hline $05 / 11 / 2015$ & 7,1 & -471 & & -458 & & -506 & 7 & 28 & 6 & 1,4 & 1,8 & 1,48 & 2 & 24 & $8 \mathrm{hs}$ \\
\hline $05 / 11 / 2015$ & 7,4 & -460 & & & 7,3 & -550 & 7,2 & 3 & 6 & 1,2 & 1,6 & 1,6 & 1,8 & & $18 \mathrm{hs}$ \\
\hline $06 / 11 / 2015$ & 6,2 & -451 & 6,9 & -394 & 7,6 & -464 & 7,1 & 30 & 6,2 & 1,6 & 1,72 & 1,8 & 2 & & 8hs \\
\hline $06 / 11 / 2015$ & 6,3 & -470 & 7 & -380 & 7,5 & -500 & 7,2 & 20 & 6 & 1,2 & 1,8 & 1,6 & 1,8 & 20 & $18 \mathrm{hs}$ \\
\hline $07 / 11 / 2015$ & 7 & -470 & 6,7 & -450 & 7,5 & -400 & 7,1 & 30 & 5,7 & 1,2 & 1,8 & 1,48 & 2 & 24 & 8hs \\
\hline $08 / 11 / 2015$ & 6,7 & -500 & 7 & -280 & 7,4 & -500 & 7,2 & 28 & 6 & 1,4 & 1,8 & 1,6 & 1,88 & 25 & $9 \mathrm{hs}$ \\
\hline $09 / 11 / 2015$ & 6,5 & -478 & 6,7 & -434 & 6,7 & -478 & 7 & 30 & 6 & 1,92 & 2 & 1,96 & 1,48 & 22 & $8 \mathrm{hs}$ \\
\hline $09 / 11 / 2015$ & 7,3 & -530 & 7,2 & -510 & 7,2 & -500 & 6,7 & 1,3 & 2,5 & 1,6 & 2 & 1,6 & 1,6 & & 16:30hs \\
\hline $10 / 11 / 2015$ & 6,6 & -481 & 6,6 & -488 & 6,7 & -491 & 7 & 6 & 4,3 & 1,52 & 1,8 & 1,6 & 1,92 & 21 & $8 \mathrm{hs}$ \\
\hline $10 / 11 / 2015$ & 6,7 & -490 & 6,8 & -460 & 6,5 & -450 & 7 & 410 & 4,2 & 1,4 & 1,6 & 1,6 & 1,8 & 22 & $18 \mathrm{hs}$ \\
\hline $11 / 11 / 2015$ & 6,5 & -490 & 6,4 & -497 & 6,4 & & 6,8 & -1 & 2,9 & 1,68 & 1,8 & 1,48 & 1,72 & 21 & $8 \mathrm{hs}$ \\
\hline $11 / 11 / 2015$ & 6,9 & -520 & 6,5 & -512 & 6,3 & -510 & 6,9 & -10 & 3 & 1,6 & 1,8 & 1,6 & 1,8 & 23 & $18 \mathrm{hs}$ \\
\hline $12 / 11 / 2015$ & 6,6 & -508 & 6,7 & -510 & 6,7 & -510 & 7 & -10 & 2,3 & 1,8 & 1,4 & 1,6 & 1,6 & & $8 \mathrm{hs}$ \\
\hline $13 / 11 / 2015$ & 6,3 & -498 & 6,4 & -500 & 6,4 & -500 & 7,1 & 28 & 5,3 & 1,92 & 1,72 & 1,8 & 1,68 & 23 & $8 \mathrm{hs}$ \\
\hline $13 / 11 / 2015$ & 6,4 & -470 & 6,8 & -500 & 6,8 & -500 & 7,3 & 10 & 5 & 1,8 & 1,6 & 1,8 & 1,8 & & $8 \mathrm{hs}$ \\
\hline $14 / 11 / 2015$ & 6,3 & -450 & 6,9 & -545 & 6,9 & -545 & 7,6 & -5 & 4,7 & 1,6 & 1,6 & 1,8 & 1,8 & 25 & $10 \mathrm{hs}$ \\
\hline $15 / 11 / 2015$ & 6,7 & -410 & 6,6 & -501 & 6,6 & -501 & 7,2 & -10 & 5 & 1,88 & 1,6 & 1,88 & 1,6 & 24 & $8 \mathrm{hs}$ \\
\hline
\end{tabular}




\begin{tabular}{|c|c|c|c|c|c|c|c|c|c|c|c|c|c|c|c|}
\hline $16 / 11 / 2015$ & 6,4 & -470 & 7,2 & -510 & 7,2 & -510 & 6 & 33 & 2,1 & 1,8 & 1,8 & 1,6 & 1,92 & 26 & 8hs \\
\hline $16 / 11 / 2015$ & 6,7 & -470 & 6,9 & -500 & 6,9 & -500 & 6,7 & 10 & 2,3 & 1,8 & 1,88 & 1,6 & 1,8 & 25 & $18 \mathrm{hs}$ \\
\hline $18 / 11 / 2015$ & 6 & -498 & 6,2 & -480 & 6,2 & -480 & 7,2 & 40 & 4,7 & 1,92 & 1,68 & 1,6 & 1,88 & 25 & $13 \mathrm{hs}$ \\
\hline $18 / 11 / 2015$ & 6,3 & -470 & 6,7 & -475 & 6,7 & -475 & 7,3 & 47 & 4 & 1,8 & 1,8 & 1,6 & 1,6 & 27 & $18 \mathrm{hs}$ \\
\hline $19 / 11 / 2015$ & 6,2 & -494 & 6,1 & -385 & 6,1 & -385 & 7,2 & 33 & 4 & 1,6 & 1,84 & 2,04 & 1,84 & 23 & $8 \mathrm{hs}$ \\
\hline $20 / 11 / 2015$ & 6,3 & -500 & 6,3 & -425 & 6,3 & -425 & 8,3 & 37 & 3,5 & 1,6 & 1,8 & 1,8 & 2 & 25 & 6hs \\
\hline $23 / 11 / 2015$ & 6,7 & -480 & 6,1 & -480 & 6,1 & -480 & 7,1 & 45 & 5 & 1,6 & 1,8 & 1,6 & 1,92 & & $8 \mathrm{hs}$ \\
\hline $24 / 11 / 2015$ & 6 & -337 & 5,9 & -317 & 5,9 & -317 & 6,9 & 61 & 6 & 1,64 & 1,68 & 1,76 & 1,64 & 30 & $8 \mathrm{hs}$ \\
\hline $24 / 11 / 2015$ & 6 & -494 & 6,6 & -480 & 6,6 & -480 & 6 & 40 & 4,7 & 1,92 & 1,8 & 2,04 & 1,92 & 27 & $18 \mathrm{hs}$ \\
\hline $25 / 11 / 2015$ & 7 & -481 & 7 & -392 & 7 & -392 & 7,2 & 45 & 4,1 & 2 & 1,68 & 1,72 & 1,52 & 28 & $8 \mathrm{hs}$ \\
\hline $25 / 11 / 2015$ & 6 & -494 & 6,1 & -480 & 6,1 & -480 & 7,1 & 10 & 5 & 1,6 & 1,76 & 1,76 & 1,64 & 27 & $18 \mathrm{hs}$ \\
\hline $26 / 11 / 2015$ & 7 & -455 & 7 & -345 & 7 & -345 & 7,3 & 20 & 4,8 & 1,76 & 1,76 & 1,2 & 1,68 & 29 & $8 \mathrm{hs}$ \\
\hline $27 / 11 / 2015$ & 7 & -490 & 7,1 & -490 & 7 & & 7,3 & -3 & 2,6 & 1,8 & 1,72 & 1,84 & 1,68 & 26 & $8 \mathrm{hs}$ \\
\hline $27 / 11 / 2015$ & 7,3 & -470 & 7,2 & -470 & 7,3 & -500 & 7,5 & -6 & 3 & 1,6 & 1,8 & 1,8 & 1,6 & 27 & $18 \mathrm{hs}$ \\
\hline $28 / 11 / 2015$ & 7 & -430 & 7,1 & -470 & 7 & -480 & 7,3 & 3 & 5,6 & 1,952 & 1,72 & 1,952 & 1,68 & 29 & \\
\hline $29 / 11 / 2015$ & 7 & -400 & 7,2 & -400 & 7,3 & -500 & 7,2 & -6 & 6,6 & 1,92 & 1,72 & 1,92 & 1,64 & 26 & \\
\hline $30 / 11 / 2015$ & 6,6 & -485 & 6,6 & -389 & 6,6 & -475 & 7,3 & 50 & 5,6 & 1,8 & 1,72 & 1,6 & 1,6 & 28 & $8 \mathrm{hs}$ \\
\hline $30 / 11 / 2015$ & 6,7 & -490 & 6,8 & -430 & 6,6 & -430 & 7,5 & 57 & 4,3 & 1,8 & 1,6 & 1,2 & 1,6 & 24 & $18 \mathrm{hs}$ \\
\hline $01 / 12 / 2015$ & & & & & & & 7,3 & 50 & 3 & 1,8 & 1,68 & 1,4 & 1,84 & 25 & $8 \mathrm{hs}$ \\
\hline $01 / 12 / 2015$ & 6,7 & -480 & 6,8 & -400 & 6,6 & -430 & 7,8 & 50 & 4 & 1,6 & 1,6 & 1,2 & 1,6 & 29 & $18 \mathrm{hs}$ \\
\hline $02 / 12 / 2015$ & 6,1 & -500 & 6,1 & -498 & 6,1 & -494 & 7,6 & 28 & 2,5 & 1,88 & 1,8 & 1,68 & 1,68 & 27 & $8 \mathrm{hs}$ \\
\hline $03 / 12 / 2015$ & 6 & -505 & 6 & -505 & 6 & -497 & 7,4 & 43 & 3,9 & 1,72 & 1,72 & 1,56 & 1,76 & 28 & $8 \mathrm{hs}$ \\
\hline $03 / 12 / 2015$ & 6,3 & -515 & 6,3 & -510 & 6,3 & -500 & 7,6 & 20 & 3,3 & 1,6 & 1,8 & 1,6 & 1,6 & 25 & $18 \mathrm{hs}$ \\
\hline $04 / 12 / 2015$ & 5,9 & -506 & 5,9 & -503 & 6,8 & -500 & 7,4 & 14 & 3,9 & 1,84 & 1,64 & 1,2 & 1,72 & 25 & $8 \mathrm{hs}$ \\
\hline $04 / 12 / 2015$ & 6,4 & -510 & 5,8 & -510 & 6,2 & -490 & 7,6 & 15 & 3,3 & 1,8 & 1,6 & 1,6 & 1,72 & 30 & $18 \mathrm{hs}$ \\
\hline $05 / 12 / 2015$ & 6,6 & -520 & 6,4 & -490 & 6,3 & -485 & 7,2 & 25 & 3,9 & 1,2 & 1,6 & 1,4 & 1,4 & 29 & $10 \mathrm{hs}$ \\
\hline $06 / 12 / 2015$ & 6,7 & -570 & 5,8 & -500 & 5,8 & -500 & 7,4 & -8 & 4,2 & 1,6 & 1,4 & 1,4 & 1,6 & 26 & $12 \mathrm{hs}$ \\
\hline
\end{tabular}




\begin{tabular}{|c|c|c|c|c|c|c|c|c|c|c|c|c|c|c|c|}
\hline $07 / 12 / 2015$ & 5,8 & -475 & 5,8 & -406 & 5,8 & -324 & 7,5 & 57 & 5 & 1,8 & 1,72 & 1,4 & 1,76 & 27 & $8 \mathrm{hs}$ \\
\hline $07 / 12 / 2015$ & 5,9 & -460 & 5,9 & -470 & 5,9 & -400 & 7,6 & 50 & 3,9 & 1,8 & 1,6 & 1,4 & 1,6 & 28 & $18 \mathrm{hs}$ \\
\hline $08 / 12 / 2015$ & 5,8 & -490 & 6 & -484 & 6 & -469 & 7,5 & 35 & 4,2 & 1,88 & 1,8 & 1,68 & 1,68 & 24 & $8 \mathrm{hs}$ \\
\hline $08 / 12 / 2015$ & 5,7 & -500 & 6,2 & -460 & 6,2 & -470 & 7,3 & 5 & 4 & 1,6 & 1,6 & 1,6 & 1,8 & 26 & $18 \mathrm{hs}$ \\
\hline $09 / 12 / 2015$ & 5,6 & -499 & 6 & -506 & 5,6 & -498 & 7,6 & 55 & 4,6 & 1,88 & 1,8 & 1,6 & 1,64 & 23 & $8 \mathrm{hs}$ \\
\hline $09 / 12 / 2015$ & 5,8 & -500 & 6,2 & -510 & 6,1 & -515 & 7,7 & 30 & 3,7 & 1,8 & 1,8 & 1,6 & 1,6 & 29 & $18 \mathrm{hs}$ \\
\hline $10 / 12 / 2015$ & 5,8 & -507 & 5,5 & -505 & 5,5 & -493 & 7,7 & 15 & 4,8 & 2 & 1,8 & 1,6 & 1,72 & 25 & $8 \mathrm{hs}$ \\
\hline $10 / 12 / 2015$ & 5,8 & -490 & 5,8 & -480 & 5,8 & -500 & 7,4 & 14 & 3,9 & 1,6 & 1,8 & 1,6 & 1,6 & 27 & $18 \mathrm{hs}$ \\
\hline $11 / 12 / 2015$ & 5,7 & -510 & 5,7 & -480 & 5,7 & -493 & 7,7 & -28 & 3 & 1,8 & 1,68 & 1,6 & 1,72 & 23 & $8 \mathrm{hs}$ \\
\hline $11 / 12 / 2015$ & 5,8 & -520 & 5,9 & -490 & 5,9 & -500 & 7,6 & 5 & 3,9 & 1,8 & 1,6 & 1,6 & 1,8 & 24 & $18 \mathrm{hs}$ \\
\hline $12 / 12 / 2015$ & 6,3 & -550 & 6,1 & -500 & 6,1 & -500 & 7,3 & 25 & 4,3 & 1,8 & 1,8 & 1,6 & 1,6 & 24 & $10 \mathrm{hs}$ \\
\hline $13 / 12 / 2015$ & 6,7 & -590 & 5,8 & -510 & 6 & -505 & 7,4 & -5 & 3,6 & 1,6 & 1,6 & 1,6 & 1,8 & 24 & $10 \mathrm{hs}$ \\
\hline $14 / 12 / 2015$ & & & & & & & & & & 1,8 & 1,6 & 1,4 & 1,72 & 26 & $8 \mathrm{hs}$ \\
\hline $14 / 12 / 2015$ & 6,3 & -520 & 5,8 & -500 & 6 & -500 & 7,4 & 30 & 3,9 & 1,8 & 1,6 & 1,2 & 1,6 & 28 & $18 \mathrm{hs}$ \\
\hline $15 / 12 / 2015$ & 5,9 & -550 & 6 & -496 & 5,9 & -493 & 7,7 & 29 & 4,1 & 2 & 1,76 & 1,8 & 1,2 & 24 & $8 \mathrm{hs}$ \\
\hline $16 / 12 / 2015$ & 6 & -498 & 6 & -490 & 6 & -485 & 6 & 54 & 4,3 & 0 & & 0 & 0 & 27 & $8 \mathrm{hs}$ \\
\hline
\end{tabular}




\begin{tabular}{|r|r|r|}
\hline & \multicolumn{2}{|}{} \\
& \multicolumn{2}{|c|}{} \\
& \multicolumn{2}{|c|}{ OD mg/L } \\
\cline { 2 - 3 } Data & Anóxico 1 & Anóxico 2 \\
\hline $03 / 11 / 2015$ & 0,21 & 0,12 \\
\hline $03 / 11 / 2015$ & - & - \\
\hline $04 / 11 / 2015$ & 0,15 & 0,2 \\
\hline $04 / 11 / 2015$ & 0,2 & 0,23 \\
\hline $05 / 11 / 2015$ & 0,26 & 0,1 \\
\hline $05 / 11 / 2015$ & 0,23 & 0,2 \\
\hline $06 / 11 / 2015$ & 0,24 & 0,16 \\
\hline $06 / 11 / 2015$ & 0,23 & 0,2 \\
\hline $07 / 11 / 2015$ & 0,23 & 0,12 \\
\hline $08 / 11 / 2015$ & 0,2 & 0,1 \\
\hline $09 / 11 / 2015$ & 0,3 & 0,2 \\
\hline $09 / 11 / 2015$ & 0,2 & 0,25 \\
\hline $10 / 11 / 2015$ & 0,19 & 0,19 \\
\hline $10 / 11 / 2015$ & 0,12 & 0,15 \\
\hline $11 / 11 / 2015$ & 0,2 & 0,13 \\
\hline $11 / 11 / 2015$ & 0,2 & 0,1 \\
\hline $12 / 11 / 2015$ & 0,2 & 0,1 \\
\hline $13 / 11 / 2015$ & 0,28 & 0,14 \\
\hline $13 / 11 / 2015$ & 0,22 & 0,13 \\
\hline $14 / 11 / 2015$ & 0,15 & 0,12 \\
\hline $15 / 11 / 2015$ & 0,23 & 0,15 \\
\hline $16 / 11 / 2015$ & 0,2 & 0,1 \\
\hline $16 / 11 / 2015$ & 0,23 & 0,17 \\
\hline $18 / 11 / 2015$ & 0,3 & 0,14 \\
\hline $18 / 11 / 2015$ & 0,17 & 0,12 \\
\hline $19 / 11 / 2015$ & 0,27 & 0,11 \\
\hline $20 / 11 / 2015$ & 0,2 & 0,13 \\
\hline $23 / 11 / 2015$ & 0,23 & 0,14 \\
\hline $24 / 11 / 2015$ & 0,3 & 0,15 \\
\hline $24 / 11 / 2015$ & 0,2 & 0,13 \\
\hline $25 / 11 / 2015$ & 0,3 & 0,24 \\
\hline $25 / 11 / 2015$ & 0,3 & 0,14 \\
\hline $26 / 11 / 2015$ & 0,3 & 0,14 \\
\hline $27 / 11 / 2015$ & 0,27 & 0,23 \\
\hline $27 / 11 / 2015$ & 0,23 & 0,21 \\
\hline $28 / 11 / 2015$ & 0,23 & 0,23 \\
\hline $29 / 11 / 2015$ & 0,32 & 0,23 \\
\hline $30 / 11 / 2015$ & 0,24 & 0,25 \\
\hline $30 / 11 / 2015$ & 0,27 & 0,26 \\
\hline $01 / 12 / 2015$ & 0,2 & 0,17 \\
\hline $01 / 12 / 2015$ & 0,2 & 0,2 \\
\hline & & \\
\hline
\end{tabular}




\begin{tabular}{|r|r|r|}
$02 / 12 / 2015$ & 0,39 & 0,16 \\
\hline $03 / 12 / 2015$ & 0,25 & 0,17 \\
\hline $03 / 12 / 2015$ & 0,22 & 0,16 \\
\hline $04 / 12 / 2015$ & 0,18 & 0,16 \\
\hline $04 / 12 / 2015$ & 0,23 & 0,17 \\
\hline $05 / 12 / 2015$ & 0,18 & 0,2 \\
\hline $06 / 12 / 2015$ & 0,19 & 0,3 \\
\hline $07 / 12 / 2015$ & 0,19 & 0,2 \\
\hline $07 / 12 / 2015$ & 0,23 & 0,21 \\
\hline $08 / 12 / 2015$ & 0,16 & 0,18 \\
\hline $08 / 12 / 2015$ & 0,14 & 0,19 \\
\hline $09 / 12 / 2015$ & 0,17 & 0,19 \\
\hline $09 / 12 / 2015$ & 0,19 & 0,17 \\
\hline $10 / 12 / 2015$ & 0,16 & 0,18 \\
\hline $10 / 12 / 2015$ & 0,19 & 0,19 \\
\hline $11 / 12 / 2015$ & 0,17 & 0,2 \\
\hline $11 / 12 / 2015$ & 0,2 & 0,18 \\
\hline $12 / 12 / 2015$ & 0,18 & 0,22 \\
\hline $13 / 12 / 2015$ & 0,16 & 0,19 \\
\hline $14 / 12 / 2015$ & - & - \\
\hline $14 / 12 / 2015$ & 0,16 & 0,19 \\
\hline $15 / 12 / 2015$ & 0,16 & 0,19 \\
\hline $16 / 12 / 2015$ & 0,16 & 0,12 \\
\hline & & \\
\hline
\end{tabular}




\begin{tabular}{|c|c|c|c|c|c|c|c|}
\hline \multirow{3}{*}{ Data } & \multicolumn{2}{|c|}{ DQO TOTAL } & \multicolumn{5}{|c|}{ DQO SOLÚVEL } \\
\hline & $\begin{array}{c}\text { Ponto } \\
\text { Amostragem } \\
1\end{array}$ & $\begin{array}{c}\text { Ponto } \\
\text { Amostragem } \\
6\end{array}$ & \begin{tabular}{|c|} 
Ponto \\
Amostragem \\
1
\end{tabular} & \begin{tabular}{|c|} 
Ponto \\
Amostragem \\
2
\end{tabular} & \begin{tabular}{|c} 
Ponto \\
Amostragem \\
3
\end{tabular} & \begin{tabular}{|c|} 
Ponto \\
Amostragem \\
4
\end{tabular} & $\begin{array}{c}\text { Ponto } \\
\text { Amostragem } \\
6\end{array}$ \\
\hline & $\mathrm{mgO} 2 / \mathrm{L}$ & $\mathrm{mgO} 2 / \mathrm{L}$ & $\mathrm{mgO} 2 / \mathrm{L}$ & $\mathrm{mgO} 2 / \mathrm{L}$ & $\mathrm{mgO} 2 / \mathrm{L}$ & $\mathrm{mgO} 2 / \mathrm{L}$ & $\mathrm{mgO} 2 / \mathrm{L}$ \\
\hline 05/11/2015 & 486 & 25 & 339 & 25 & 32 & 22 & 14 \\
\hline $10 / 11 / 2015$ & 435 & 132 & 143 & 83 & 94 & 70 & 35 \\
\hline $12 / 11 / 2015$ & 435 & 132 & 139 & 77 & 87 & 66 & 38 \\
\hline 19/11/2015 & 297 & 17 & 136 & 41 & 17 & 10 & 7 \\
\hline $26 / 11 / 2015$ & 534 & 59 & 117 & 62 & 41 & 52 & 41 \\
\hline $03 / 12 / 2015$ & 513 & 96 & 188 & 81 & 74 & 92 & 64 \\
\hline 08/12/2015 & 890 & 60 & 232 & 72 & 44 & 52 & 24 \\
\hline 10/12/2015 & 730 & 52 & 208 & 68 & 40 & 64 & 36 \\
\hline
\end{tabular}

\begin{tabular}{|c|c|c|c|c|c|c|c|}
\hline \multirow{3}{*}{ Data } & \multicolumn{2}{|c|}{ DBO TOTAL } & \multicolumn{5}{|c|}{ DBO SOLÚVEL } \\
\hline & \begin{tabular}{|c|} 
Ponto \\
Amostragem \\
1
\end{tabular} & $\begin{array}{c}\text { Ponto } \\
\text { Amostragem } \\
6\end{array}$ & \begin{tabular}{|c|} 
Ponto \\
Amostragem \\
1
\end{tabular} & \begin{tabular}{|c} 
Ponto \\
Amostragem \\
2
\end{tabular} & \begin{tabular}{|c} 
Ponto \\
Amostragem \\
3
\end{tabular} & \begin{tabular}{|c|} 
Ponto \\
Amostragem \\
4
\end{tabular} & $\begin{array}{c}\text { Ponto } \\
\text { Amostragem } \\
6\end{array}$ \\
\hline & $\mathrm{mgO} 2 / \mathrm{L}$ & $\mathrm{mgO} 2 / \mathrm{L}$ & $\mathrm{mgO} 2 / \mathrm{L}$ & $\mathrm{mgO} 2 / \mathrm{L}$ & $\mathrm{mgO} 2 / \mathrm{L}$ & $\mathrm{mgO} 2 / \mathrm{L}$ & $\mathrm{mgO} 2 / \mathrm{L}$ \\
\hline 05/11/2015 & 386 & 19 & 250 & 27 & 8 & 12 & 6 \\
\hline $10 / 11 / 2015$ & 300 & 200 & 108 & 72 & 38 & 34 & 38 \\
\hline $12 / 11 / 2015$ & 357 & 168 & 87 & 72 & 38 & 34 & 38 \\
\hline 19/11/2015 & 381 & 85 & 175 & 31 & 27 & 24 & 48 \\
\hline $26 / 11 / 2015$ & 480 & 75 & 58 & 42 & 24 & 20 & 46 \\
\hline $03 / 12 / 2015$ & 584 & 76 & 228 & 145 & 92 & 52 & 42 \\
\hline $08 / 12 / 2015$ & 584 & 76 & 228 & 145 & 92 & 52 & 42 \\
\hline
\end{tabular}

\begin{tabular}{|c|c|c|c|c|c|}
\hline \multicolumn{7}{|c|}{ Nata } & $\begin{array}{c}\text { Ponto } \\
\text { Amostrage } \\
\mathbf{m} \mathbf{1}\end{array}$ & $\begin{array}{c}\text { Ponto } \\
\text { Amostrage } \\
\mathbf{m} \mathbf{5}\end{array}$ & $\begin{array}{c}\text { Ponto } \\
\text { Amostragem } \\
\mathbf{6}\end{array}$ & TAXA DE APLICAÇÃo & TAXA DE NITRIFICAÇÃo \\
\cline { 2 - 6 } & $\mathrm{mgN-NH4+/L}$ & $\mathrm{mgN-NH4+/L}$ & $\mathrm{mgN-NH4+/L}$ & $\mathrm{g} / \mathrm{m3} . \mathrm{d}$ & $\mathrm{g} / \mathrm{m3} . \mathrm{d}$ \\
\hline $05 / 11 / 2015$ & 99 & 260 & 10 & 234 & 197 \\
\hline $10 / 11 / 2015$ & 94 & 283 & 49 & 221 & 130 \\
\hline $12 / 11 / 2015$ & 71 & 286 & 42 & 168 & 61 \\
\hline $19 / 11 / 2015$ & 67 & 305 & 11 & 141 & 82 \\
\hline $26 / 11 / 2015$ & 84 & 241 & 11 & 194 & 128 \\
\hline $03 / 12 / 2015$ & 94 & 314 & 10 & 211 & 116 \\
\hline $08 / 12 / 2015$ & 98 & 300 & 7 & 257 & 210 \\
\hline $10 / 12 / 2015$ & 95 & 305 & 6 & 249 & 201 \\
\hline
\end{tabular}




\begin{tabular}{|c|c|c|c|}
\hline \multicolumn{4}{|c|}{ Nitrogênio Amoniacal } \\
\hline \multirow{2}{*}{ Data } & $\begin{array}{c}\text { Ponto } \\
\text { Amostragem }\end{array}$ & $\begin{array}{c}\text { Ponto } \\
\text { Amostragem }\end{array}$ & $\begin{array}{c}\text { Ponto } \\
\text { Amostragem }\end{array}$ \\
\cline { 2 - 4 } & $\mathbf{1}$ & $\mathbf{5}$ & $\mathbf{6}$ \\
\hline & mgN-NH4+/L & mgN-NH4+/L & mgN-NH4+/L \\
\hline $05 / 11 / 2015$ & 78 & & 1 \\
\hline $10 / 11 / 2015$ & 78 & & 22 \\
\hline $12 / 11 / 2015$ & 73 & & 23 \\
\hline $19 / 11 / 2015$ & 64 & & 1 \\
\hline $26 / 11 / 2015$ & 70 & & 1 \\
\hline $03 / 12 / 2015$ & 78 & & 2 \\
\hline $08 / 12 / 2015$ & 83 & & 0,3 \\
\hline $10 / 12 / 2015$ & 81 & & 0,3 \\
\hline
\end{tabular}

\begin{tabular}{|c|c|c|c|c|c|c|}
\hline \multicolumn{7}{|c|}{ Nitrato } \\
\hline \multirow[t]{2}{*}{ Data } & \begin{tabular}{|c} 
Ponto \\
Amostragem \\
2 \\
\end{tabular} & \begin{tabular}{|c} 
Ponto \\
Amostragem \\
3 \\
\end{tabular} & \begin{tabular}{|c} 
Ponto \\
Amostragem \\
4 \\
\end{tabular} & \begin{tabular}{|c} 
Ponto \\
Amostragem \\
5 \\
\end{tabular} & \begin{tabular}{|c|} 
Ponto \\
Amostragem \\
6 \\
\end{tabular} & \begin{tabular}{|c} 
Ponto \\
Amostragem \\
7 \\
\end{tabular} \\
\hline & $\mathrm{mg} / \mathrm{L}$ & $\mathrm{mg} / \mathrm{L}$ & $\mathrm{mg} / \mathrm{L}$ & $\mathrm{mg} / \mathrm{L}$ & $\mathrm{mg} / \mathrm{L}$ & $\mathrm{mg} / \mathrm{L}$ \\
\hline \multicolumn{7}{|l|}{$05 / 11 / 2015$} \\
\hline $10 / 11 / 2015$ & $<0,1$ & 0,2 & 0,3 & 10,2 & 6,5 & 7,8 \\
\hline $12 / 11 / 2015$ & $<0,1$ & $<0,1$ & $<0,1$ & 6,2 & 6,4 & 0,2 \\
\hline $19 / 11 / 2015$ & 1,6 & 4,2 & 3,9 & 8,4 & 9,9 & 7,8 \\
\hline $26 / 11 / 2015$ & $<0,1$ & 0,44 & 2,58 & 12,2 & 15 & 16,6 \\
\hline \multicolumn{7}{|l|}{$01 / 12 / 2015$} \\
\hline \multicolumn{7}{|l|}{ 03/12/2015 } \\
\hline \multicolumn{7}{|l|}{$08 / 12 / 2015$} \\
\hline $10 / 12 / 2015$ & & & & & & \\
\hline
\end{tabular}

\begin{tabular}{|c|c|c|c|c|c|c|c|}
\hline \multicolumn{8}{|c|}{ Alcalinidade } \\
\hline \multirow[t]{2}{*}{ Data } & \begin{tabular}{|c} 
Ponto \\
Amostragem \\
1
\end{tabular} & \begin{tabular}{|c} 
Ponto \\
Amostragem \\
2
\end{tabular} & $\begin{array}{c}\text { Ponto } \\
\text { Amostragem } \\
3\end{array}$ & $\begin{array}{c}\text { Ponto } \\
\text { Amostragem } \\
4\end{array}$ & $\begin{array}{c}\text { Ponto } \\
\text { Amostragem } \\
5\end{array}$ & $\begin{array}{c}\text { Ponto } \\
\text { Amostragem } \\
6\end{array}$ & $\begin{array}{c}\text { Ponto } \\
\text { Amostragem } \\
7\end{array}$ \\
\hline & $\mathrm{mgCaCO} 3 / \mathrm{L}$ & $\mathrm{mgCaCO} / \mathrm{L}$ & $\mathrm{mgCaCO} 3 / \mathrm{L}$ & $\mathrm{mgCaCO} / \mathrm{L}$ & $\mathrm{mgCaCO} 3 / \mathrm{L}$ & $\mathrm{mgCaCO} / \mathrm{L}$ & $\mathrm{mgCaCO} 3 / \mathrm{L}$ \\
\hline $05 / 11 / 2015$ & 230 & 132 & 110 & 116 & 96 & 70 & 146 \\
\hline $10 / 11 / 2015$ & 274 & 280 & 284 & 266 & 200 & 140 & 232 \\
\hline $12 / 11 / 2015$ & 274 & 280 & 284 & 266 & 200 & 140 & 232 \\
\hline $19 / 11 / 2015$ & 212 & 162 & 138 & 142 & 102 & 72 & 132 \\
\hline $26 / 11 / 2015$ & 284 & 262 & 216 & 174 & 82 & 56 & 114 \\
\hline $03 / 12 / 2015$ & 316 & 392 & 278 & 230 & 102 & 56 & 184 \\
\hline $08 / 12 / 2015$ & 308 & 316 & 222 & 188 & 116 & 68 & 164 \\
\hline $10 / 12 / 2015$ & 302 & 300 & 242 & 196 & 104 & 70 & 178 \\
\hline
\end{tabular}




\begin{tabular}{|c|c|c|c|c|c|c|c|c|c|c|c|c|c|c|}
\hline \multirow[b]{2}{*}{ Data } & \multicolumn{7}{|c|}{ P total (mgP-PO4/L) } & \multicolumn{7}{|c|}{ P solúvel (mgP-PO4/L) } \\
\hline & $\begin{array}{c}\text { Ponto } \\
\text { Amostragem } \\
1\end{array}$ & \begin{tabular}{|c|} 
Ponto \\
Amostragem \\
2 \\
\end{tabular} & \begin{tabular}{|c|} 
Ponto \\
Amostragem \\
3 \\
\end{tabular} & $\begin{array}{c}\text { Ponto } \\
\text { Amostragem } \\
4\end{array}$ & \begin{tabular}{|c|} 
Ponto \\
Amostragem \\
5 \\
\end{tabular} & \begin{tabular}{|c|} 
Ponto \\
Amostragem \\
6 \\
\end{tabular} & $\begin{array}{c}\text { Ponto } \\
\text { Amostragem } \\
7\end{array}$ & \begin{tabular}{|c|} 
Ponto \\
Amostragem \\
1
\end{tabular} & \begin{tabular}{|c|} 
Ponto \\
Amostragem \\
2 \\
\end{tabular} & $\begin{array}{c}\text { Ponto } \\
\text { Amostragem } \\
3 \\
\end{array}$ & $\begin{array}{c}\text { Ponto } \\
\text { Amostragem } \\
4 \\
\end{array}$ & $\begin{array}{c}\text { Ponto } \\
\text { Amostragem } \\
5\end{array}$ & \begin{tabular}{|c|} 
Ponto \\
Amostragem \\
6 \\
\end{tabular} & $\begin{array}{c}\text { Ponto } \\
\text { Amostragem } \\
7\end{array}$ \\
\hline $05 / 11 / 2015$ & 3,89 & 21,10 & 28,31 & 29,15 & 0,28 & 6,04 & 40,25 & 1,93 & 0,37 & 0,20 & 0,05 & 0,03 & 0,20 & 0,03 \\
\hline $10 / 11 / 2015$ & 5,0 & 17,8 & 33,6 & 37,2 & 34,7 & 3,9 & 45,8 & 1,85 & 2,60 & 2,63 & 2,57 & 1,15 & 0,58 & 1,76 \\
\hline $12 / 11 / 2015$ & 5,0 & 17,8 & 33,6 & 37,2 & 34,7 & 3,9 & 45,8 & 1,85 & 2,60 & 2,63 & 2,57 & 1,15 & 0,58 & 1,76 \\
\hline 19/11/2015 & 3,5 & 35,8 & 33,9 & 29,4 & 38,9 & 1,0 & 37,8 & 1,74 & 1,28 & 0,20 & 0,09 & 0,02 & 0,15 & 0,03 \\
\hline $26 / 11 / 2015$ & 6,4 & 30,8 & 31,4 & 42,7 & 33,6 & 0,7 & 38,6 & 1,89 & 2,41 & 2,18 & 0,15 & 0,50 & 0,09 & 0,08 \\
\hline $03 / 12 / 2015$ & 5,7 & 40,8 & 36,9 & 38,6 & 39,4 & 0,2 & 45,0 & 1,82 & 2,63 & 2,61 & 2,23 & 0,34 & 0,24 & 1,85 \\
\hline $08 / 12 / 2015$ & 5,8 & 32,2 & 30,5 & 28,3 & 33,9 & 0,6 & 37,5 & 1,67 & 2,54 & 2,28 & 1,36 & 0,11 & 0,37 & 0,26 \\
\hline $10 / 12 / 2015$ & 5,7 & 33,3 & 31,9 & 31,1 & 36,4 & 0,5 & 11,1 & 1,71 & 2,58 & 2,31 & 1,21 & 0,14 & 0,38 & 0,31 \\
\hline
\end{tabular}




\begin{tabular}{|c|c|c|c|c|}
\hline \multicolumn{5}{|c|}{ Ácidos Orgânicos Voláteis (AOV) } \\
\hline \multirow[t]{2}{*}{ Data } & $\begin{array}{c}\text { Ponto } \\
\text { Amostragem } \\
1\end{array}$ & \begin{tabular}{|c} 
Ponto \\
Amostragem \\
2 \\
\end{tabular} & $\begin{array}{c}\text { Ponto } \\
\text { Amostragem } \\
3 \\
\end{array}$ & $\begin{array}{c}\text { Ponto } \\
\text { Amostragem } \\
4\end{array}$ \\
\hline & $\mathrm{mg} / \mathrm{L}$ & $\mathrm{mg} / \mathrm{L}$ & $\mathrm{mg} / \mathrm{L}$ & $\mathrm{mg} / \mathrm{L}$ \\
\hline $05 / 11 / 2015$ & 125 & 24 & 34 & 34 \\
\hline $10 / 11 / 2015$ & 125 & 24 & 34 & 34 \\
\hline $12 / 11 / 2015$ & 125 & 24 & 34 & 34 \\
\hline 19/11/2015 & 125 & 24 & 34 & 34 \\
\hline $26 / 11 / 2015$ & 72 & 53 & 29 & 29 \\
\hline $03 / 12 / 2015$ & 96 & 48 & 34 & 24 \\
\hline $08 / 12 / 2015$ & 86 & 58 & 38 & 29 \\
\hline $10 / 12 / 2015$ & 86 & 58 & 38 & 29 \\
\hline
\end{tabular}


Série de Sólidos

\begin{tabular}{|c|c|c|c|c|c|c|c|c|c|c|c|c|c|c|c|c|c|c|c|c|c|}
\hline \multicolumn{22}{|c|}{ Série de Sólidos } \\
\hline \multirow[t]{2}{*}{ Data } & \multicolumn{3}{|c|}{$\begin{array}{l}\text { Ponto de Amostragem } 1 \\
\text { (mg/L) }\end{array}$} & \multicolumn{3}{|c|}{$\begin{array}{l}\text { Ponto de Amostragem } 2 \\
\text { (mg/L) }\end{array}$} & \multicolumn{3}{|c|}{$\begin{array}{l}\text { Ponto de Amostragem } 3 \\
\text { (mg/L) }\end{array}$} & \multicolumn{3}{|c|}{$\begin{array}{l}\text { Ponto de Amostragem } 4 \\
\qquad(\mathrm{mg} / \mathrm{L})\end{array}$} & \multicolumn{3}{|c|}{$\begin{array}{l}\text { Ponto de Amostragem } 5 \\
\text { (mg/L) }\end{array}$} & \multicolumn{3}{|c|}{$\begin{array}{c}\text { Ponto de Amostragem } 6 \\
(\mathrm{mg} / \mathrm{L})\end{array}$} & \multicolumn{3}{|c|}{$\begin{array}{c}\text { Ponto de Amostragem } 7 \\
(\mathrm{mg} / \mathrm{L})\end{array}$} \\
\hline & SST & SSF & SSV & SST & SSF & SSV & SST & SSF & SSV & SST & SSF & SSV & SST & SSF & SSV & SST & SSF & SSV & SST & SSF & SSV \\
\hline $05 / 11 / 2015$ & 108 & 14 & 94 & 2820 & 460 & 2360 & 2940 & 580 & 2360 & 3540 & 600 & 2940 & 2660 & 520 & 2140 & 24 & 2 & 22 & 6320 & 1260 & 5060 \\
\hline $10 / 11 / 2015$ & 144 & 12 & 132 & 800 & 20 & 780 & 2260 & 340 & 1920 & 2660 & 380 & 2280 & 2740 & 460 & 2280 & 168 & 30 & 138 & 6480 & 1640 & 4840 \\
\hline $12 / 11 / 2015$ & 144 & 12 & 132 & 800 & 20 & 780 & 2260 & 340 & 1920 & 2660 & 380 & 2280 & 2740 & 460 & 2280 & 168 & 30 & 138 & 6480 & 1640 & 4840 \\
\hline 19/11/2015 & 104 & 6 & 98 & 3180 & 500 & 2680 & 2200 & 380 & 1820 & 3700 & 680 & 3020 & 3120 & 460 & 2660 & 38 & 6 & 32 & 4980 & 980 & 4000 \\
\hline $26 / 11 / 2015$ & 204 & 14 & 190 & 2840 & 420 & 2420 & 2840 & 500 & 2340 & 2880 & 460 & 2420 & 2980 & 540 & 2440 & 18 & 2 & 16 & 4960 & 1300 & 3660 \\
\hline $03 / 12 / 2015$ & 244 & 138 & 106 & 7340 & 1020 & 6320 & 4900 & 1220 & 3680 & 3960 & 780 & 3180 & 4340 & 920 & 3420 & 57 & 23 & 34 & 9660 & 2280 & 7380 \\
\hline $08 / 12 / 2015$ & 316 & 34 & 282 & 3880 & 160 & 3720 & 3440 & 620 & 2820 & 3380 & 640 & 2740 & 3400 & 640 & 2760 & 25 & 3 & 22 & 5938 & 1440 & 4498 \\
\hline $10 / 12 / 2015$ & 304 & 30 & 274 & 3840 & 260 & 3580 & 3620 & 180 & 3440 & 3380 & 620 & 2760 & 3040 & 200 & 2840 & 29 & 20 & 9 & 6100 & 1580 & 4520 \\
\hline
\end{tabular}


APÊNDICE 3 - DESENHOS CONSTRUTIVOS DA PLANTA PILOTO UCT ESTUDADA 


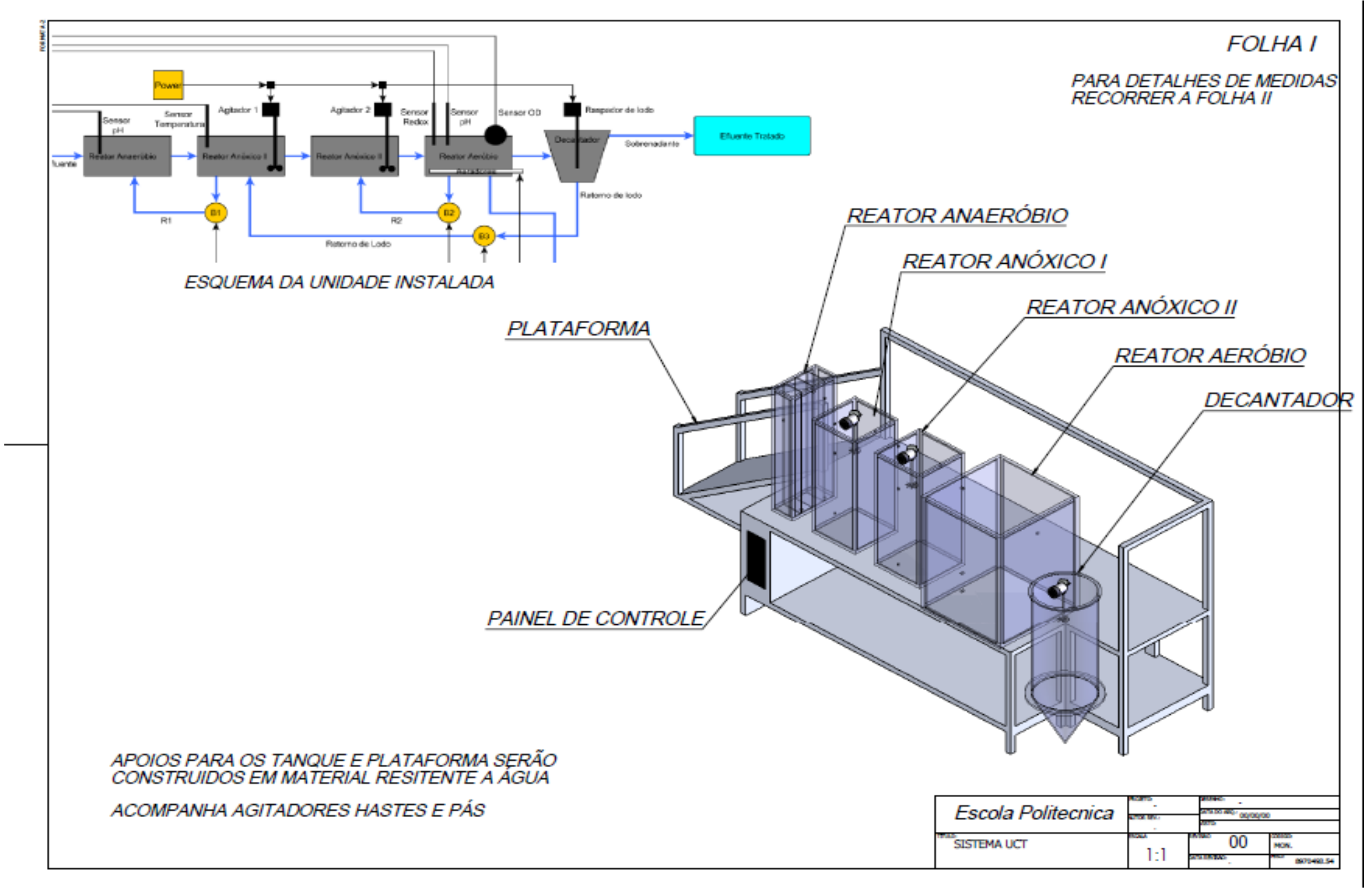




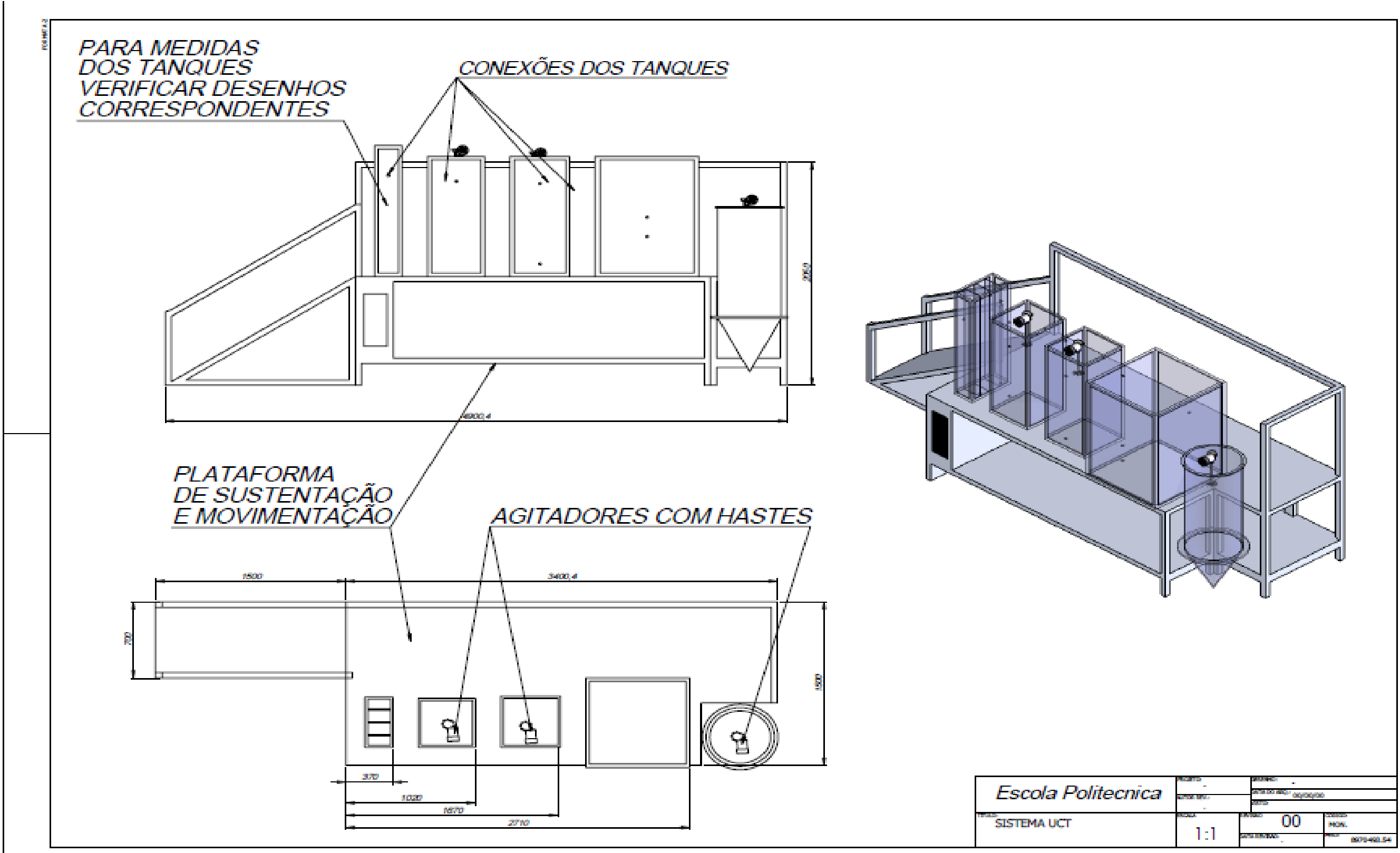




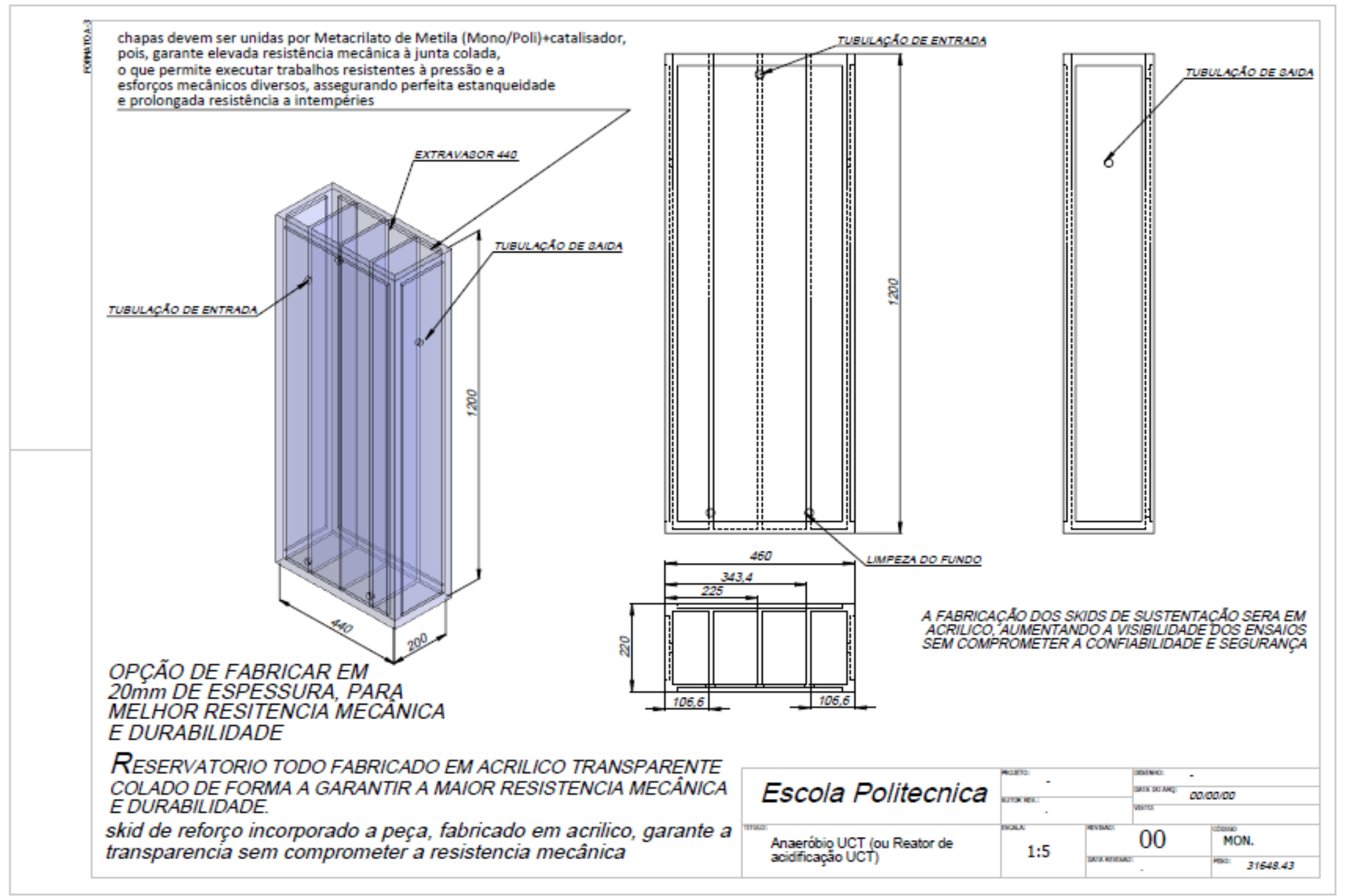


chapas devem ser unidas por Metacrilato de Metila (Mono/Poli)+catalisador, pois, garante elevada resisténcia mecânica à junta colada,

esforcos mecanicos diversos, assegurando perfeita estanqueidade e prolongada resistência a intempéries

e prolon
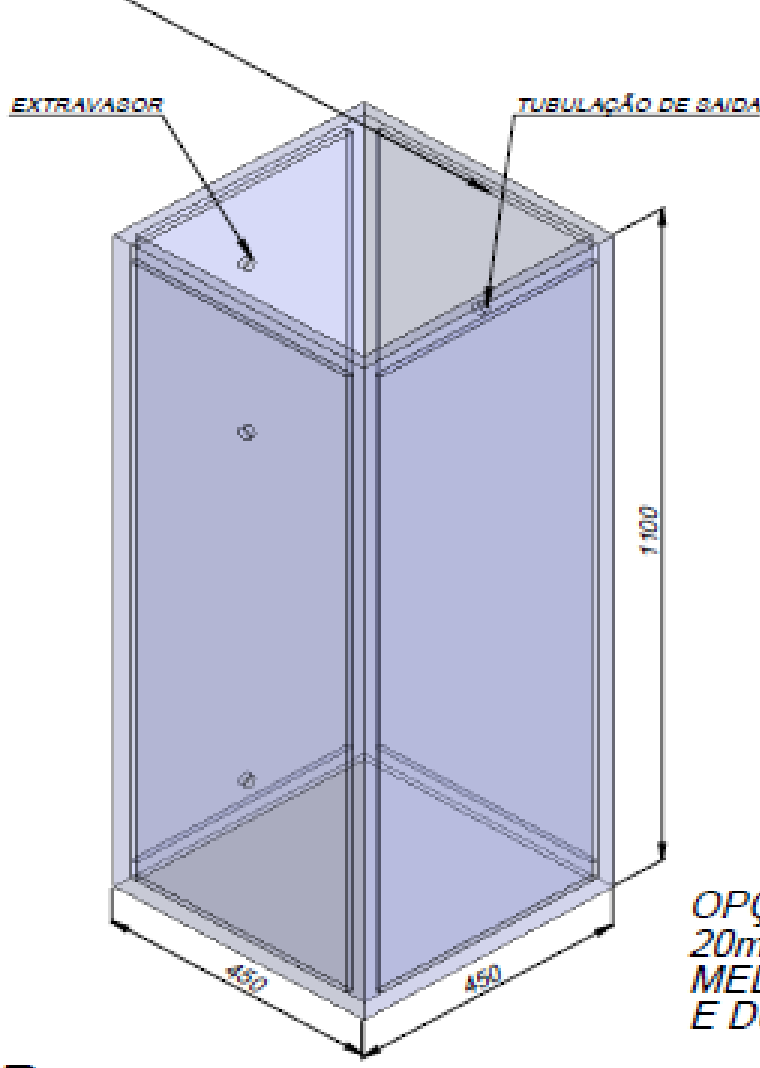

TUEULACAO OE ENTRAOA
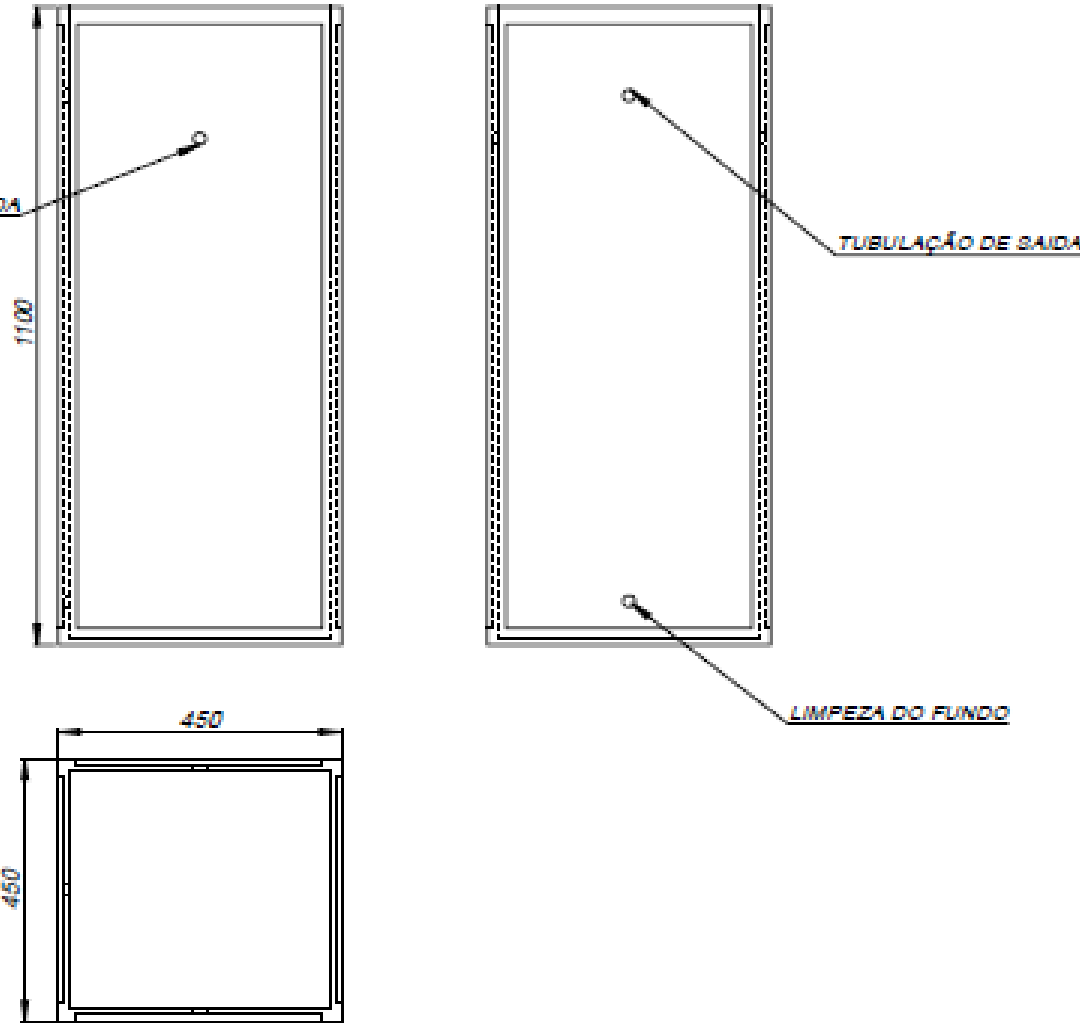

LMPEZA DO FUNDO

RESERVATORIO TODO FABRICADO EM ACRILICO TRANSPARENTE COLADO DE FORMA A GARANTIR A MAIOR RESISTENCIA MECÂNICA E DURABILIDADE.

skid de reforço incorporado a peça, fabricado em acrilico, garante a transparencia sem comprometer a

OPCÃO DE FABRICAR EM $20 \mathrm{~mm}$ DE ESPESSURA, PARA MELHOR RESITENCIA MECANICA MDURABILIDADE

A FABRICACÃO DOS SKIDS DE SUSTENTACÃO SERA EM ACRILICO, AUMENTANDO A VISIBILIDADE DOS ENSAIOS SEM COMPROMETER A CONFIABILIDADE E SEGURANÇA

resistencia mecânica

\begin{tabular}{|l|l|l|l|}
\hline Escola Politecnica & & & \\
\hline Anóxico I & $1: 5$ & 00 & MON. \\
\hline
\end{tabular}


chapas devem ser unidas por Metacrilato de Metila (Mono/Poli)+catalisador, pois, garante elevada resistencia mecanica a junta colada,

o que permite executar trabalhos resistentes a pressáo a

esforços mecânicos diversos, assegurando perfeita estanqueidade

e prolongada resistencia a intempéries
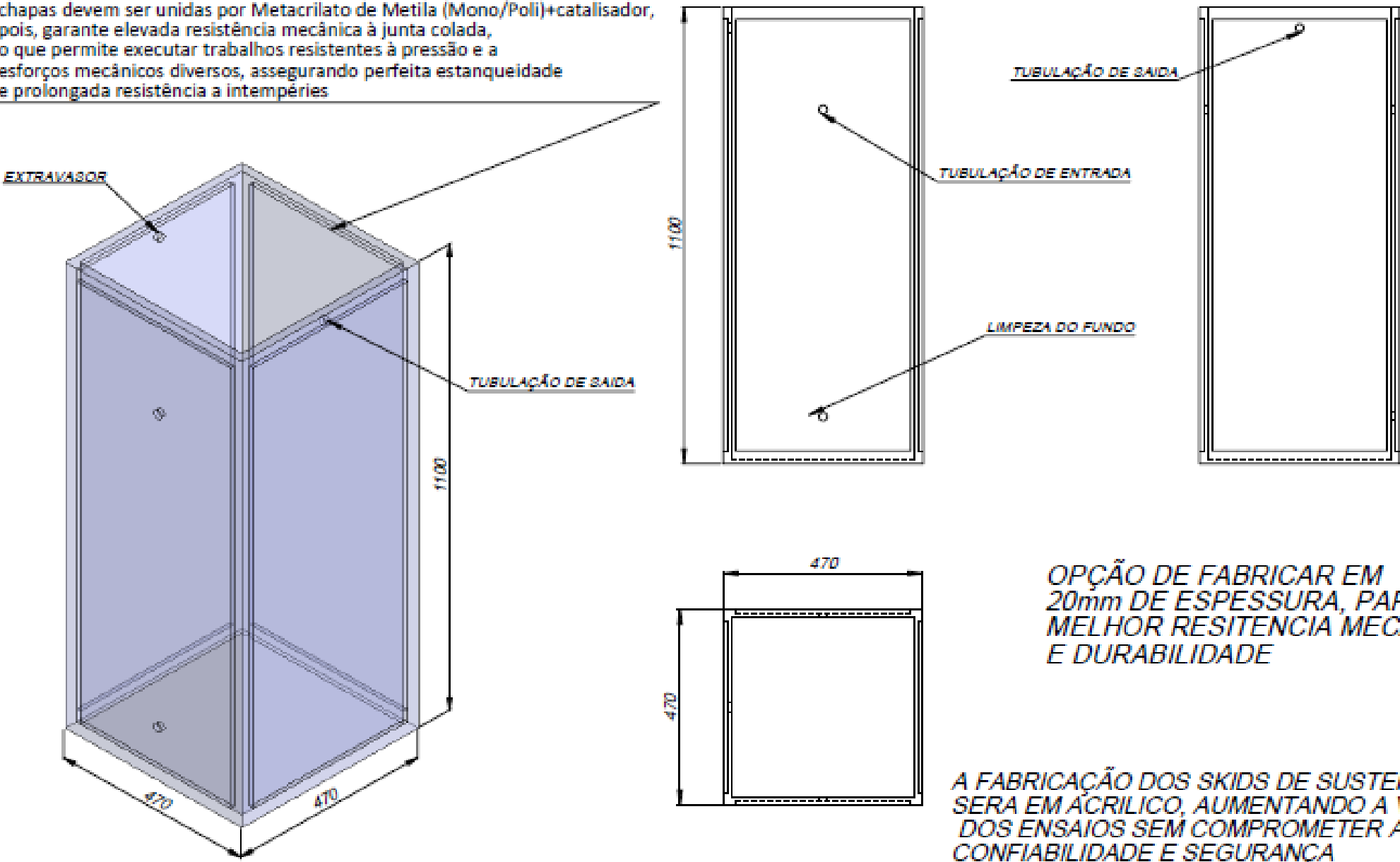

OPÇÃO DE FABRICAR EM $20 \mathrm{~mm}$ DE ESPESSURA, PARA MELHOR RESITENCIA MECANICA E DURABILIDADE

RESERVATORIO TODO FABRICADO EM ACRILICO TRANSPARENTE COLADO DE FORMA A GARANTIR A MAIOR RESISTENCIA MECANICA E DURABILIDADE.

skid de reforço incorporado a peça, fabricado em acrilico, garante a transparencia sem comprometer a resistencia

mecânica

\begin{tabular}{|c|c|c|c|}
\hline Escola Politecnica & & & \\
\hline Anóxico II & $1: 5$ & 00 & MON. \\
\hline
\end{tabular}

A FABRICACÃO DOS SKIDS DE SUSTENTACÃO SERA EM ACRILICO AUMENTANDO A VISIBILIDADE DOS ENSAIOS SEM COMPROMETER A CONFIABILIDADE E SEGURANÇA 

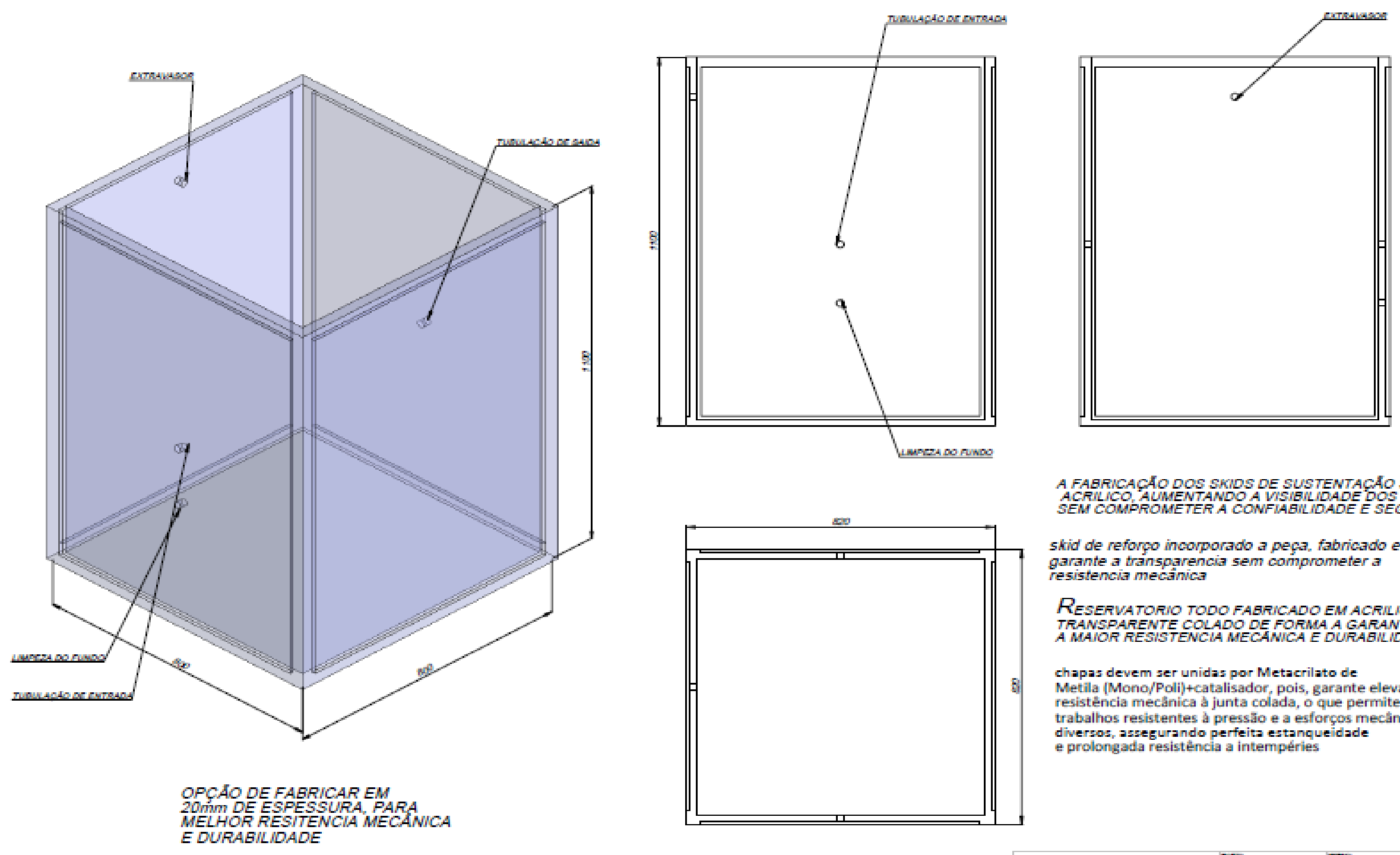

A FABRICACAO DOS SKIDS DE SUSTENTACAO SERA EM ACRILICO AUMENTANOO AVISIBUTLADEDOS ENSAIOS

skid de reforco incorporado a peca, fabricado em acrilico. garante a transparencia sem comprometer a

RESERVATORIO TODO FABRICADO EM ACRILICO TRANSPARENTE COLADO DE FORMA A GARANTIR

chapas devem ser unidas por Metacrilato de

Metila (Mono/Poli)+catalisador, pois, garante elevada resistência mecånica à junta colada, o que permite executar trabalhos resistentes à pressão e a esforços mecânicos diversos, assegurando perfeita estanqueidade MELHOR RESTENCIA MECANICA E DURAB/L/DAD

\begin{tabular}{|c|c|c|}
\hline Escola Politecnica & $\cdots$ & $=-\infty-\infty 0000$ \\
\hline AEROERTO & E- & MoN. \\
\hline
\end{tabular}




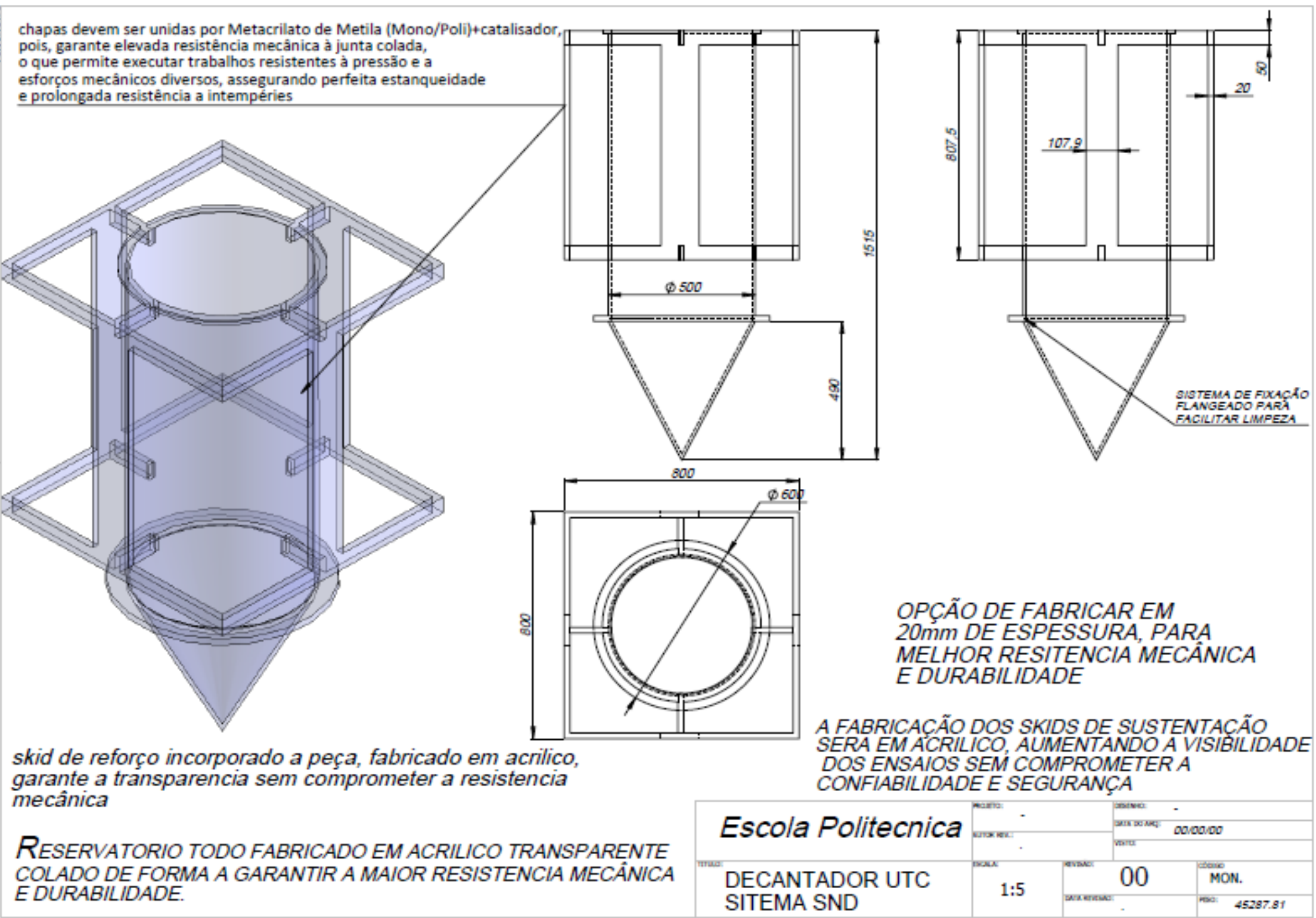




\section{APÊNDICE 4 - TELAS DO SOFTWARE UCTPHO PARA MODELAGEM TEÓRICA DE SISTEMA UCT}

Tela do software com as constantes heterotróficas utilizadas na modelagem

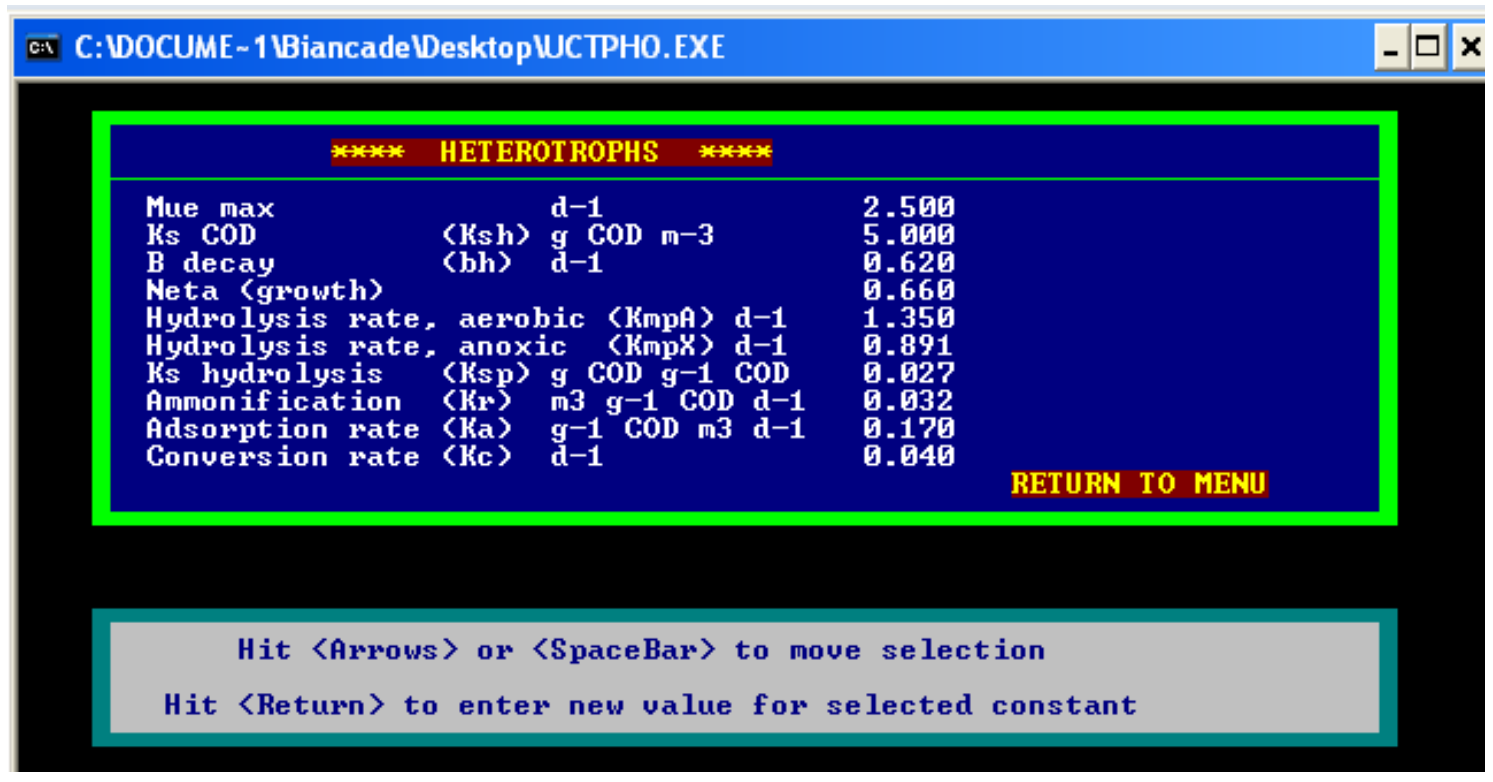

Tela do Software com as constantes autotróficas utilizadas na modelagem

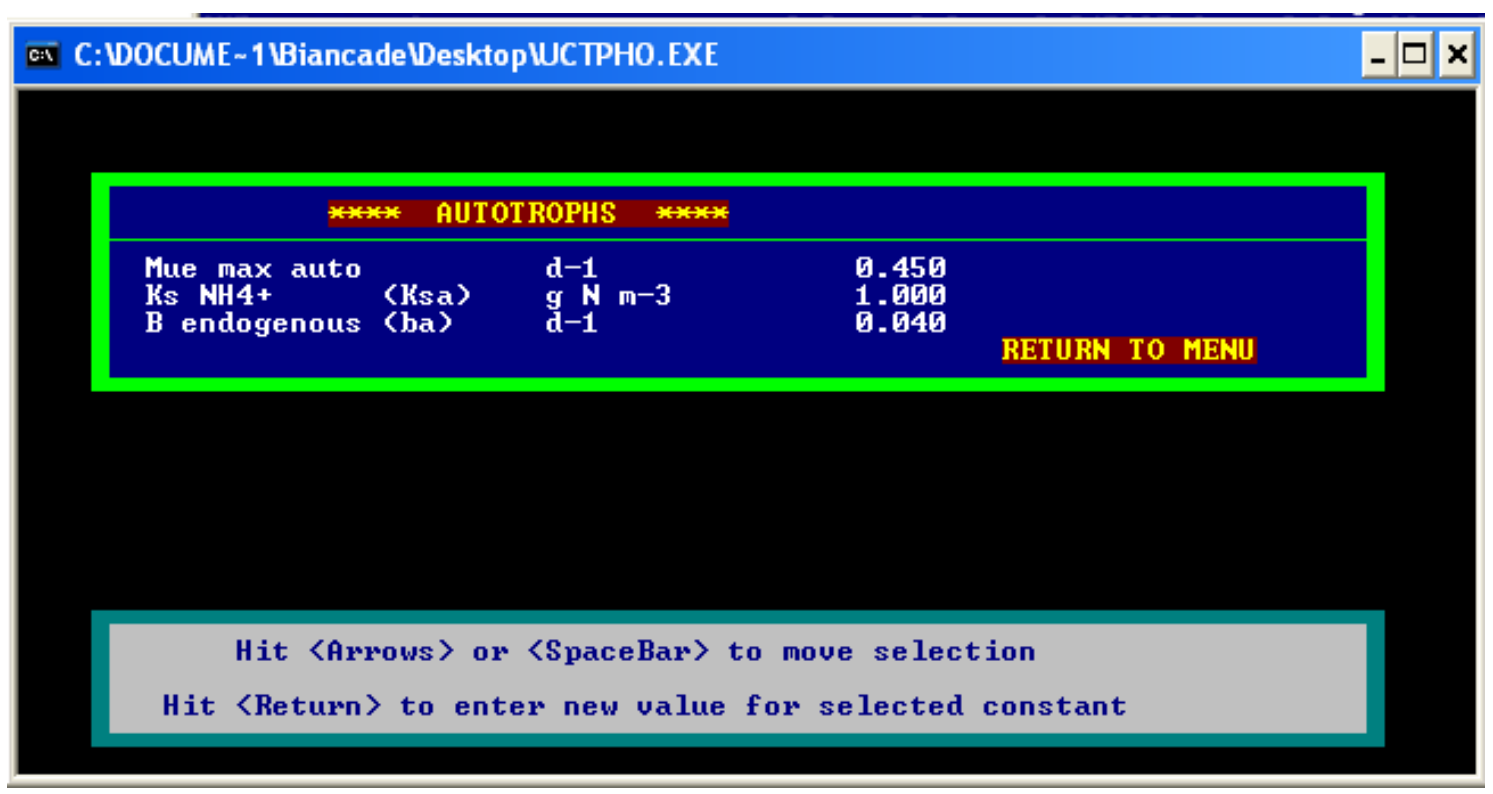


Tela do Software com as constantes para organismos poli-p utilizadas na modelagem

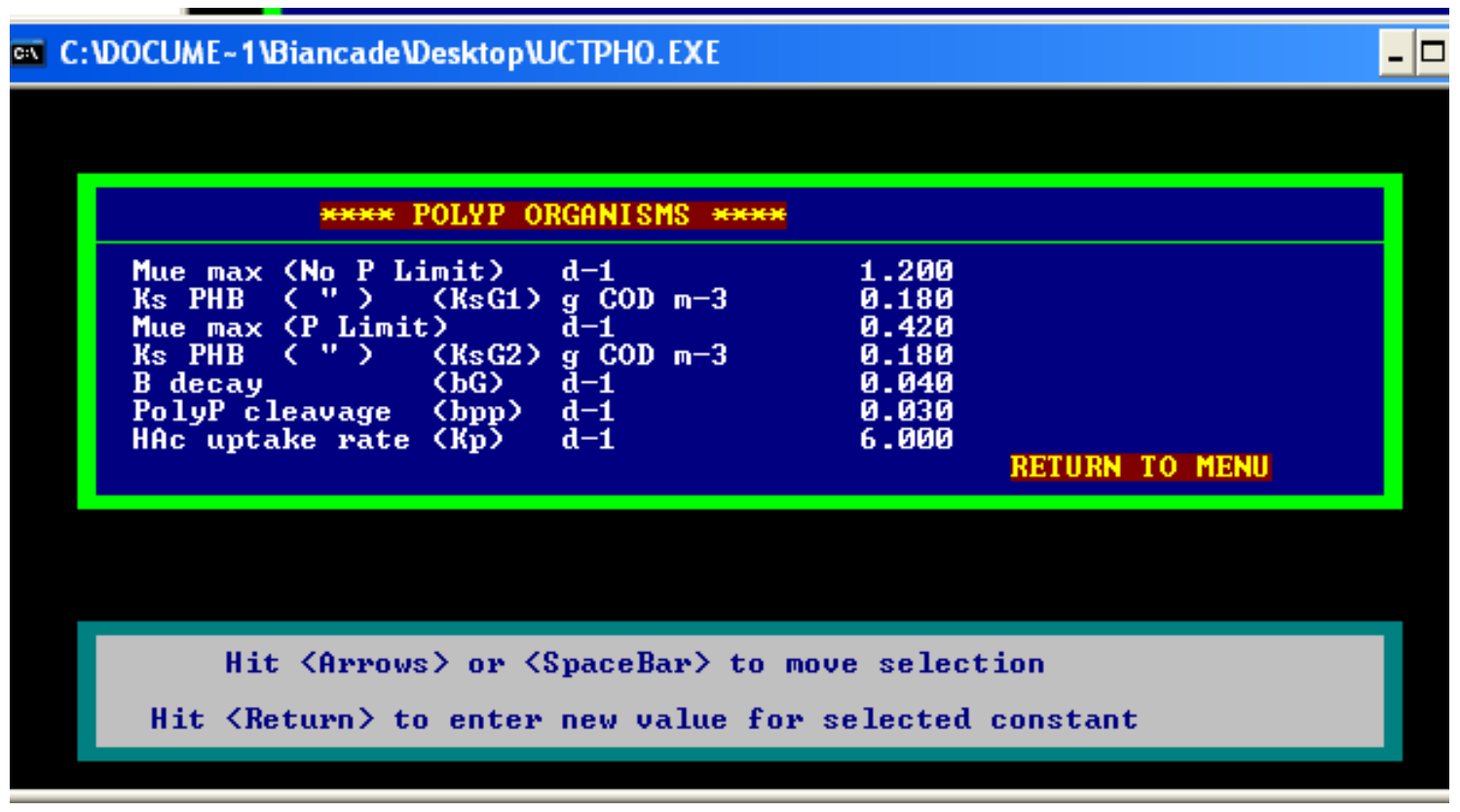

Tela do software com premissas para nitrogênio e fósforo utilizadas

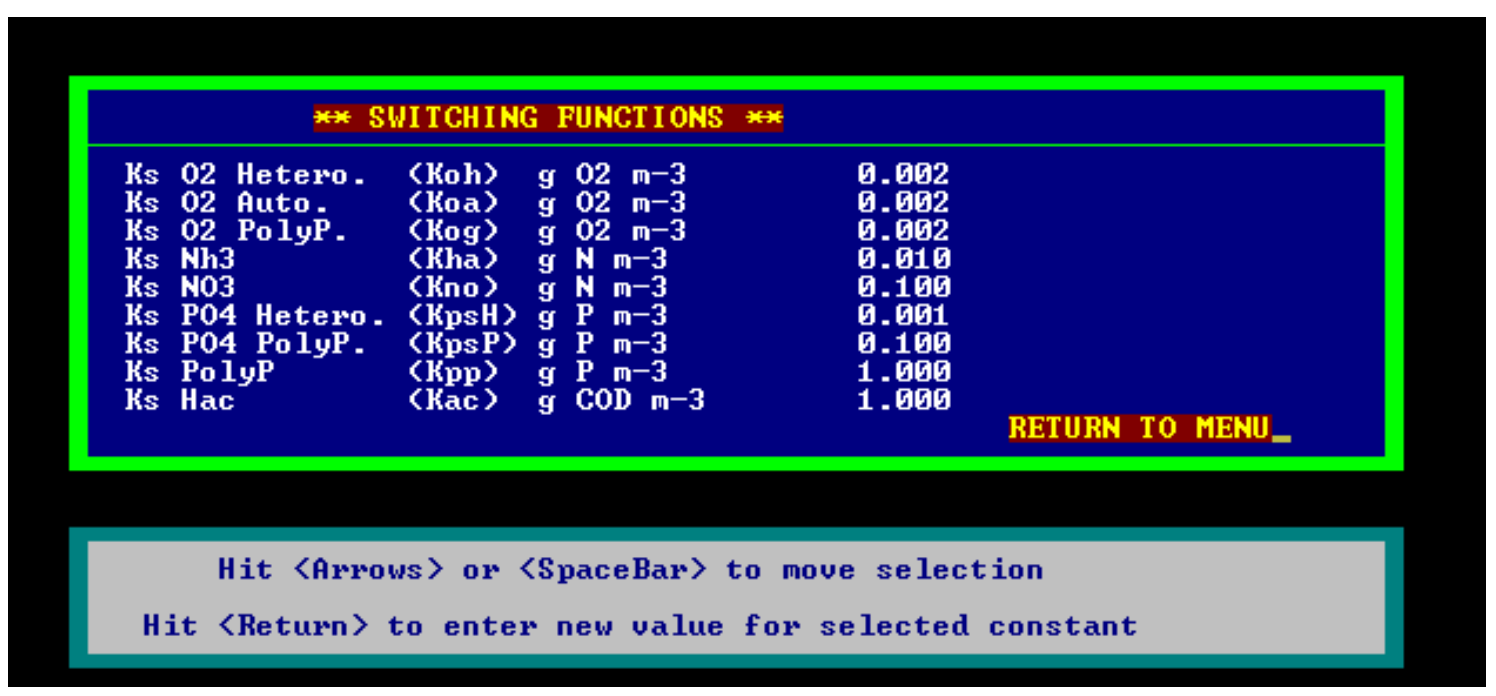


Constantes de Arrhenius Utilizadas na modelagem

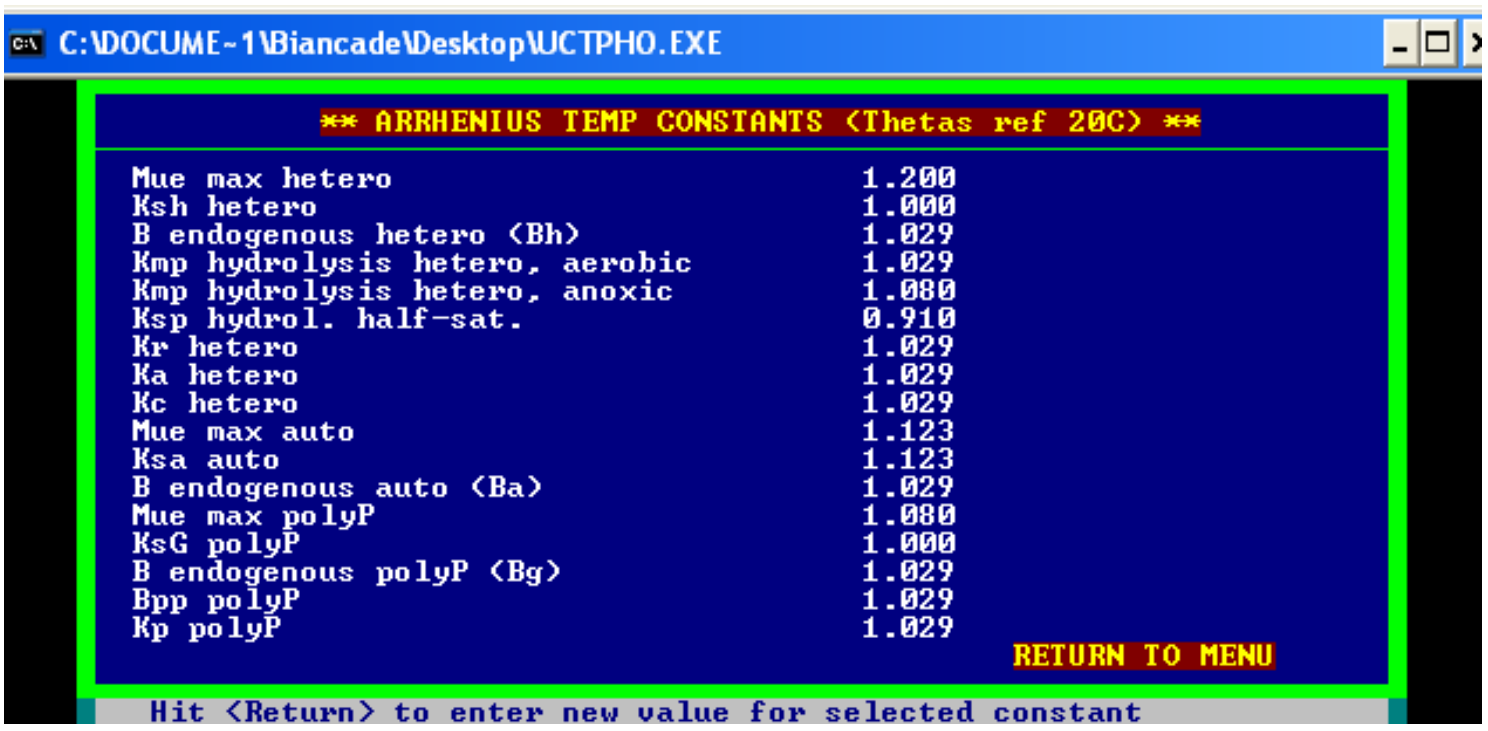

Constantes estequiométricas para microrganismos heterotróficos utilizados na modelagem

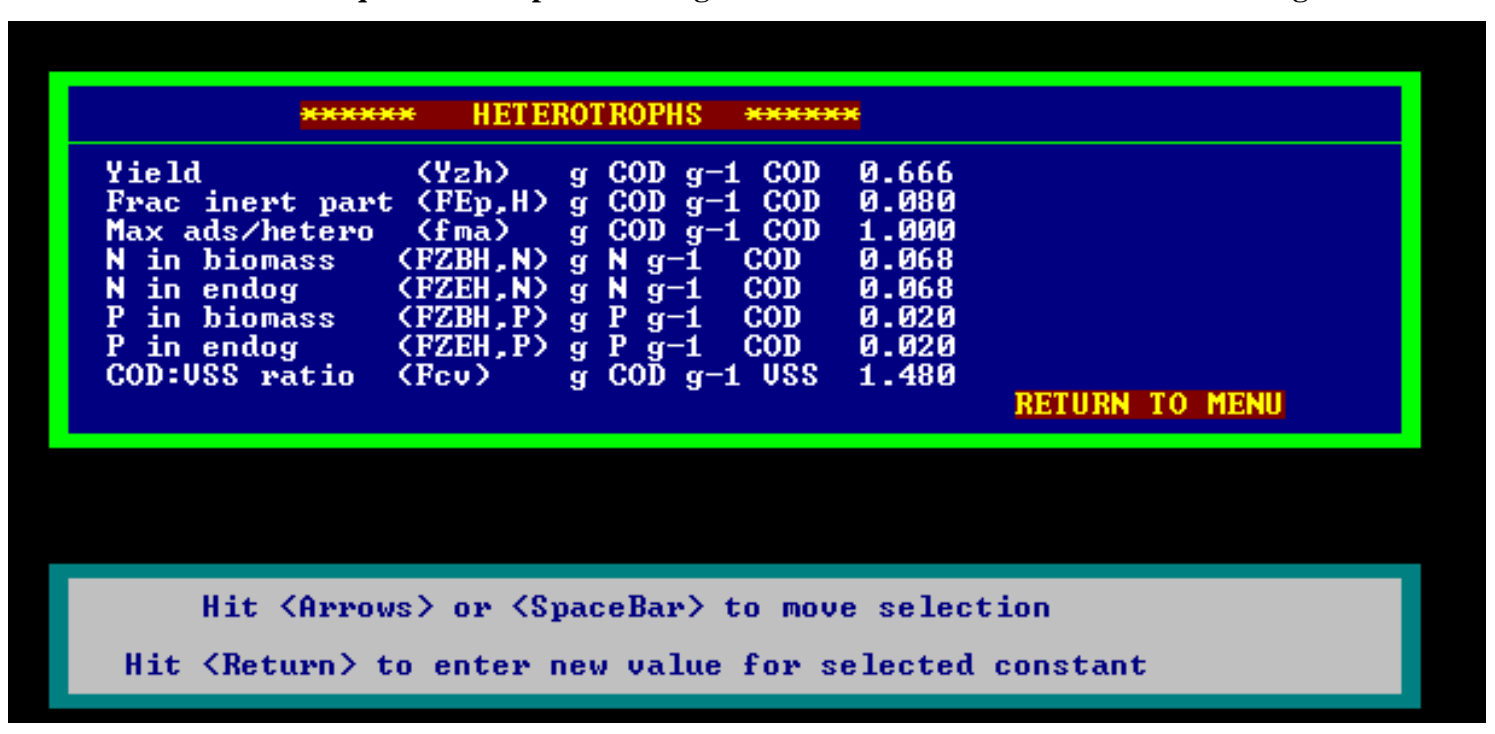

Parâmetros estequiométricos para microrganismos autotróficos utilizados na modelagem

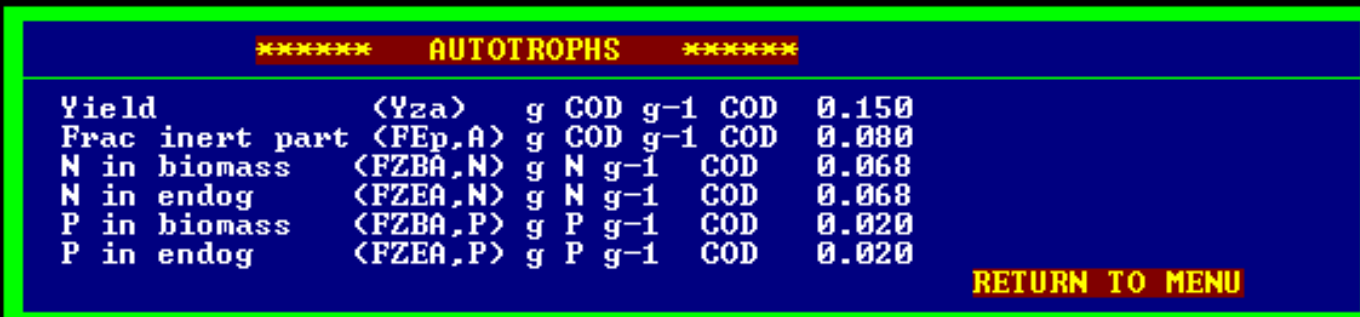

Hit 〈Arrows or 〈SpaceBar〉 to move selection

Hit 〈Return> to enter new value for selected constant 
Constantes estequiométricas para organismos poli-p utilizadas na modelagem teórica

$* * * * * * * *$ POLYP ORGANISMS *********

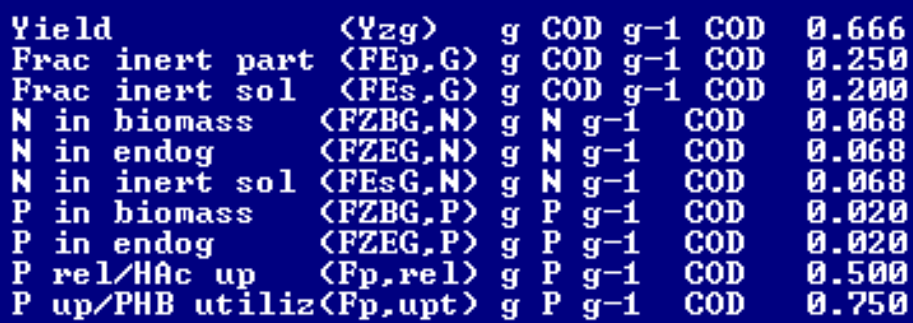

Resultados teóricos para a Etapa 1 de experimentação

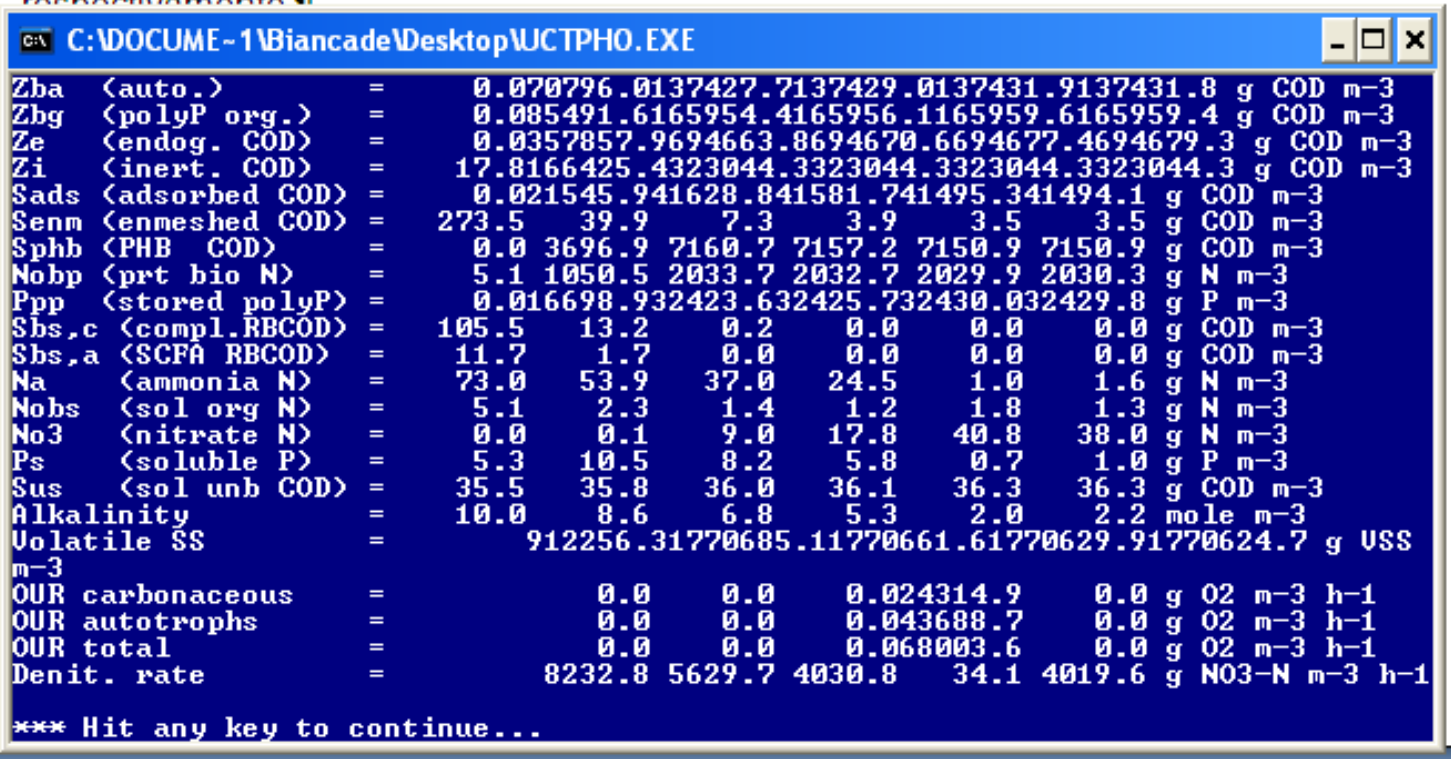


Resultados teóricos para a fase 2 de experimentação

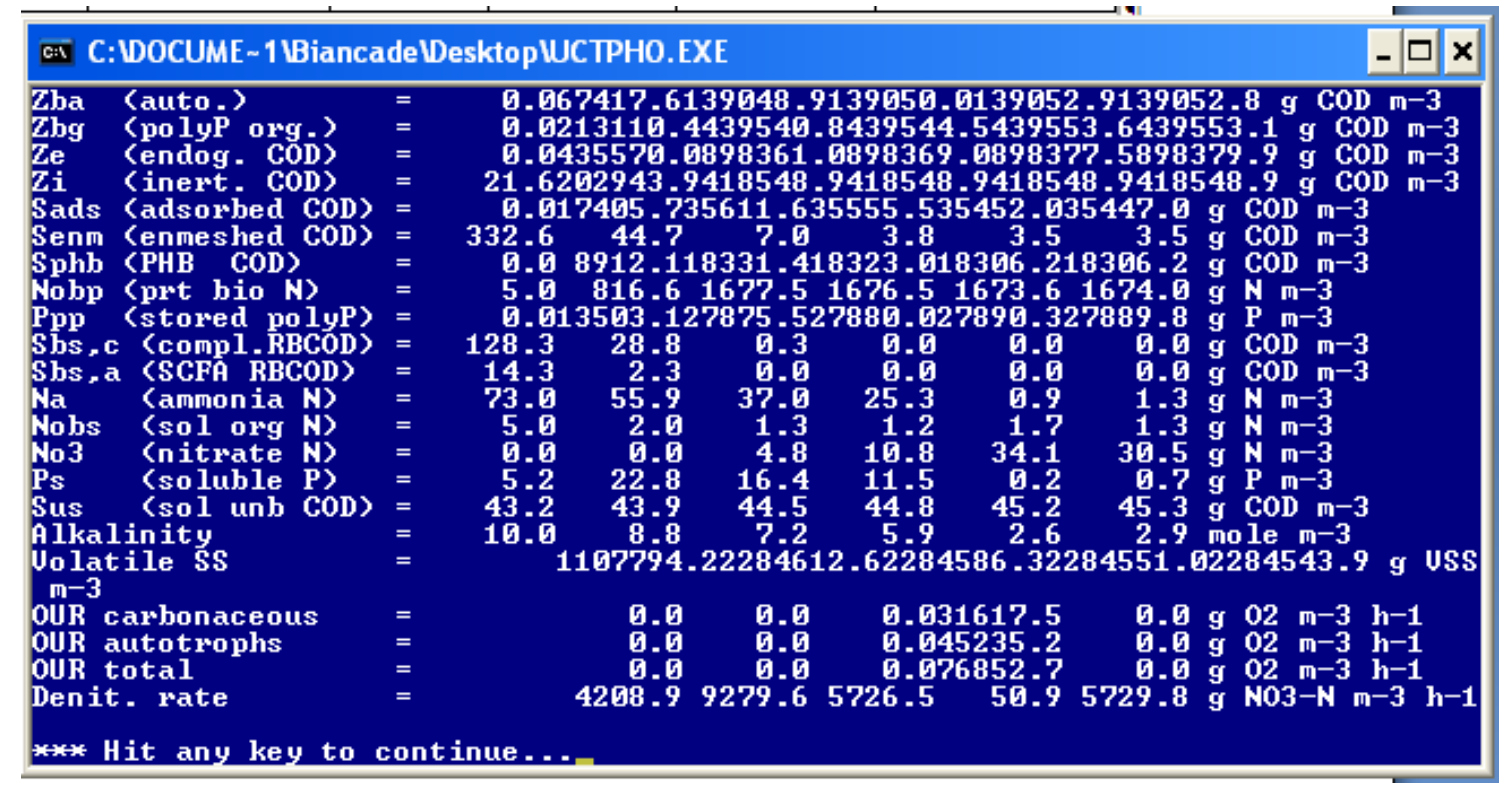

